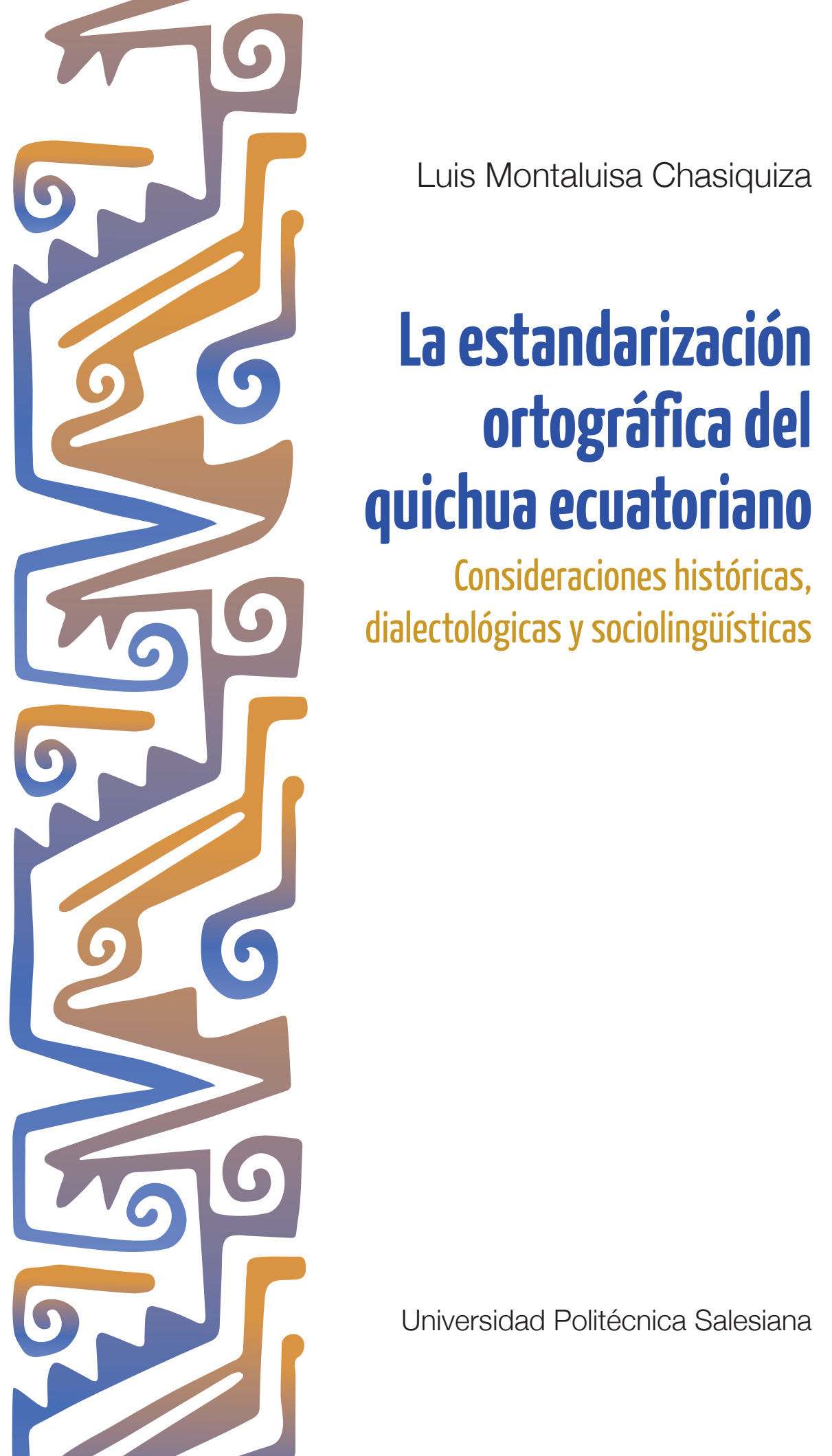




\section{La estandarización ortográfica del quichua ecuatoriano \\ Consideraciones históricas, dialectológicas y sociolingüísticas}





\author{
Luis Montaluisa Chasiquiza
}

\title{
La estandarización ortográfica del quichua ecuatoriano Consideraciones históricas, dialectológicas y sociolingüísticas
}

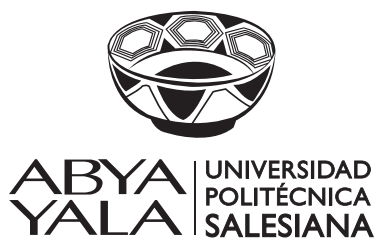

2019 


\section{LA ESTANDARIZACIÓN ORTOGRÁFICA DEL QUICHUA ECUATORIANO Consideraciones históricas, dialectológicas y sociolingüísticas \\ (C) Luis Montaluisa Chasiquiza}

1ra edición:

Universidad Politécnica Salesiana

Av. Turuhuayco 3-69 y Calle Vieja

Cuenca-Ecuador

Casilla: 2074

P.B.X. $(+5937) 2050000$

Fax: (+593 7) 4088958

e-mail: rpublicas@ups.edu.ec

www.ups.edu.ec

CARRERA DE EDUCACIÓN

INTERCULTURAL BILINGÜE

Derechos de autor: $\quad 057487$

Depósito legal: $\quad 006449$

ISBN: $\quad$ 978-9978-10-391-3

Edición, diseño, $\quad$ Editorial Universitaria Abya-Yala

diagramación e impresión Quito-Ecuador

Tiraje: $\quad 300$ ejemplares

Impreso en Quito-Ecuador, octubre de 2019

Publicación arbitrada por la Universidad Politécnica Salesiana 


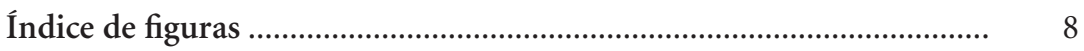

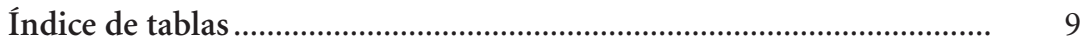

Agradecimientos .................................................................................. 13

Lista de símbolos, abreviaturas y siglas ....................................................... 15

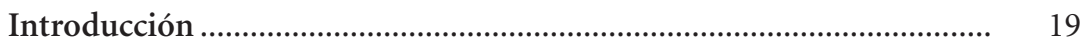

\section{CAPítulo 1}

Lenguas prequichuas del callejón interandino …………………………. 27

Lengua pasto .................................................................................... 34

Lengua cara .......................................................................................... 44

Lengua panzaleo................................................................................. 62

Lengua puruhá/puruguay/purbay................................................................ 88

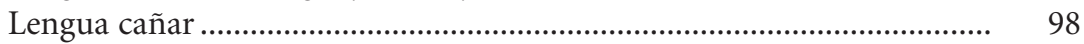

Lengua palta ......................................................................................... 116

A manera de conclusión ............................................................................. 120

Capítulo 2

La presencia del quichua en el Ecuador...................................................... 123

La teoría del origen ecuatoriano ............................................................. 124

Teorías del origen exógeno del quichua ...................................................... 129

Capítulo 3

Rasgos peculiares del quichua ecuatoriano dentro de la familia quechua .. 141 Antecedentes .......................................................................................... 141

El protoquechua........................................................................ 147 


\section{6}

Clasificación de los dialectos quechuas y ubicación

del quichua ecuatoriano dentro de la familia lingüística

Características del quichua ecuatoriano

Capítulo 4

Estado de la cuestión sobre estudios dialectales

del quichua ecuatoriano.

Época colonial

Época republicana.

\section{Capítulo 5}

Variaciones dialectales y zonificación dialectal.

Metodología

Variaciones fonéticas

Variaciones morfofonéticas

Zonas dialectales

A manera de conclusión

Capítulo 6

Políticas lingüísticas incaicas, coloniales y republicanas.

Política incaica

Política colonial del siglo XVI y XVII.

Política colonial del siglo XVIII

Política de comienzos de la República (siglo XIX) .............................. 320

Política republicana ........................................................................ 322

Situación actual............................................................................ 334

\section{Capítulo 7}

El quichua y el proceso de estandarización de su escritura

Aspectos teóricos e históricos sobre la estandarización

de la escritura de lenguas.

Estado del arte de la estandarización de la escritura

del quichua ecuatoriano

Propuesta de estrategias para la revitalización del quichua en el contexto de estandarización de su escritura.

Conclusiones

Capítulo 1

Capítulo 2 
Capítulo 3

Capítulo 4

Capítulo 5 388

Capítulo 6 ...... 389

Capítulo 7. 390

Referencias bibliográficas 393

Sobre el autor. 
Figura 1. Etnias prequichuas de la Sierra ecuatoriana................................ 121

Figura 2. Clasificación dialectal del QA..................................................... 153

Figura 3. Clasificación dialectal del quechua según Torero........................ 154

Figura 4. Ubicación del quichua ecuatoriano

al interior de la familia quechua ................................................................... 155

Figura 5. Zona con sonidos oclusivos aspirados .......................................... 164

Figura 6. Ubicación del quichua ecuatoriano

al interior de la rama QIIB ..................................................................... 181

Figura 7. Mapa de las misiones jesuitas de Maynas ................................... 182

Figura 8. Clasificación dialectal del quichua ecuatoriano ......................... 195

Figura 9. Los cinco subdialectos del quichua de Imbabura ..................... 202

Figura 10. Dialectos ecuatorianos según Carpenter .................................. 204

Figura 11. Dialectos del quichua ecuatoriano según Carpenter .............. 204

Figura 12. Realización de los sonidos /l/ y /r/ según Carpenter............... 206

Figura 13. Realización del fonema $/ \lambda /$ en diferentes lugares ..................... 209

Figura 14. Distribución del quichua en la Sierra y la Amazonía ............. 217

Figura 15. Comunidades de la Sierra y la Amazonía

de donde se tomó la información para el presente estudio

Figura 16. Las seis zonas dialectales en las que se pueden agrupar las hablas del quichua ecuatoriano 


\section{Índice de tablas}

Tabla 1. Fonemas vocálicos y consonánticos del protoquechua (Parker) .. 147

Tabla 2. Fonemas vocálicos y consonánticos del protoquechua (Torero).. 149

Tabla 3. Fonemas vocálicos y consonánticos

del protoquechua (Cerrón-Palomino)

Tabla 4. Cuadro de los fonemas vocálicos y consonánticos

del quichua ecuatoriano ................................................................. 158

Tabla 5. Comunidades donde se realizó las investigaciones lingüísticas. 221

Tabla 6. Cuadro de sonorización de las oclusivas sordas /t/, /č /, / / /

después de nasal

Tabla 7. Variaciones de pronunciación de los términos

$<$ atallpa, wallpa $>$

Tabla 8. Variaciones del fonema $/ \mathrm{k} /$ en el morfema agentivo $\{-\mathrm{k}\}$

y cuando aparece al final de los morfemas $\{$-yuk, -kamak,

-tak, -pak, -rak, -nchik, -nkichik, -ychik\}

Tabla 9. Morfemas que constituyen desarrollos

del quichua ecuatoriano 

A las nacionalidades indígenas del Ecuador en su lucha por hacer respetar sus territorios ancestrales, su cultura, y el derecho a contar con un sistema de educación intercultural bilingüe autónomo, con un currículo propio de cada nacionalidad; y así contribuir a la implementación del Estado plurinacional e intercultural con un modelo de desarrollo sustentable.

A mi entrañable familia: a mi esposa Catalina Álvarez Palomeque, a mi hijo David Efraín y a mi hija María Belén por haberme animado a seguir los estudios.

A mi madre Luz María Chasiquiza, in memoriam; a mi padre David Montaluisa Pilatasig, in memoriam; a mi hermana Rosa Montaluisa Chasiquiza; a mi hermano Francisco Montaluisa Chasiquiza.

A Consuelo Yánez Cossío, gestora del proceso de alfabetización quichua y educación bilingüe intercultural en el Centro de Investigación para la Educación Indígena CIEI de la Pontificia Universidad Católica del Ecuador, mi maestra. 



\section{Agradecimientos}

Dejo constancia de mi agradecimiento imperecedero a las siguientes instituciones: Universidad Politécnica Salesiana del Ecuador, en la persona de su rector el padre Javier Herrán Gómez, por haber estimulado y auspiciado una parte de mis estudios.

Asimismo, va mi gratitud a la Pontificia Universidad Católica del Perú, por haberme abierto las puertas en su posgrado de Estudios Andinos, en la persona de su director, el Dr. Marco Curatola, y en la de su coordinador de Lingüística, mi asesor, el Dr. Rodolfo Cerrón-Palomino, por su tiempo y generosa paciencia dedicada a mi formación, sin cuya ayuda hubiera sido imposible realizar el sueño de ver culminado este trabajo.

Mi agradecimiento va también al personal del posgrado de la universidad por su atención oportuna a mis requerimientos; a los docentes del Programa de Estudios Andinos; a mis compañeros de los seminarios del programa con quienes compartí, tanto en Lima como en el Cuzco, gratos momentos de intercambio de ideas y aprendizaje; a Molly Tun por su apoyo en un seminario en Cuzco.

Agradezco también a las compañeras y compañeros de la Dirección Nacional de Educación Intercultural Bilingüe y a las personas de las veintiséis comunidades indígenas del Ecuador que me facilitaron la información dialectal. 



\section{Lista de símbolos, abreviaturas y siglas}

\section{Símbolos}

[ ] Encierran una representación con los símbolos de la escritura fonética

/ / Encierran una representación con los símbolos de la escritura fonológica

$<>\quad$ Encierran una representación con los símbolos de la escritura ortográfica

\{ \} Encierran un morfema

( ) Encierran formas opcionales

$>\quad$ Indica que lo que precede da lugar a lo que sigue. Por ejemplo: $\{-n k a\}>\{$-na $\}$

$<\quad$ Indica lo contrario del símbolo anterior. Por ejemplo: $\{-n a\}<\{$-nka $\}$

$\sim \quad$ Indica que la forma que precede varía en uso con la que sigue

* Indica que la forma que lo lleva es originaria o reconstruida

- $\quad$ Señala el límite de morfemas. Por ejemplo: re-present-ar

: $\quad$ Los dos puntos junto a una vocal indican un alargamiento de la vocal

' Identifican el significado o la traducción de una palabra

“ $\quad$ Encierran citas textuales o conceptos específicos que requieren ser resaltados Simboliza la africada palatal, como la ch castellana, aunque en los cuadros se

[č puede ubicar entre las oclusiva. En la nomenclatura del AFI usado en Europa, equivale al símbolo: [t $\mathrm{t}]$

[£] Simboliza la africada dental y en la escritura ortográfica se la representa como ts

[c] Simboliza la africada palatal retroflexa, como el sonido que adquiere el grupo consonántico tr pronunciado en el castellano chileno

$[\varphi]$ Simboliza la fricativa bilabial sorda como la $f$ del castellano andino

[x] Simboliza la fricativa velar sorda como la $j$ del castellano

[z] Simboliza a la sibilante dental sonora, correlato de [s]

[š] Simboliza la sibilante palatal sorda, como la sh del inglés. En la nomenclatura del AFI usado en Europa equivale al símbolo: [ $]$ ]

[ž] Simboliza la sibilante palatal sonora. Es correlato de [̌̌]

$[\lambda]$ Simboliza la lateral palatal sonora, equivalente a la $l l$ del castellano hablado en Loja o en el Carchi

[ $\phi]$ Indica "cero" o ausencia total de un elemento 


\title{
16
}

\author{
Abreviaturas y siglas \\ a. \\ ALKI \\ AFI \\ ANE \\ art. \\ BI \\ BCE \\ CCE \\ CHQ \\ CIEI \\ CONACNIE \\ CONADE \\ CONAIE \\ CONESUP \\ CONFENIAE \\ DINACE \\ DINADER \\ DINEIB \\ DINEIIB \\ ECUARUNARI \\ EIB \\ FEI \\ FEINE \\ FENOC \\ FENOCIN \\ Apellido \\ Academia de la Lengua Kichwa ${ }^{1}$ \\ Alfabeto Fonético Internacional \\ Archivo Nacional del Ecuador \\ Artículo \\ Bachillerato Internacional \\ Banco Central del Ecuador \\ Casa de la Cultura Ecuatoriana \\ Central Highland Quichua \\ Centro de Investigación para la Educación Indígena \\ Consejo de Coordinación de Nacionalidades Indígenas del Ecuador \\ Consejo Nacional de Desarrollo \\ Confederación de Nacionalidades Indígenas del Ecuador \\ Consejo Nacional de Educación Superior \\ Confederación de Nacionalidades Indígenas de la Amazonía \\ Dirección Nacional de Construcciones Escolares \\ Dirección Nacional de Deportes y Recreación \\ Dirección Nacional de Educación Intercultural Bilingüe \\ Dirección Nacional de Educación Indígena Intercultural Bilingüe ${ }^{2}$ \\ Ecuador Runacunapac Riccharimuy \\ Educación intercultural bilingüe \\ Federación Ecuatoriana de Indios \\ Federación Ecuatoriana de Indígenas Evangélicos \\ Federación Nacional de Organizaciones Campesinas \\ Federación de Organizaciones Campesina, Indígenas y Negras
}

1 En el presente libro se usa la forma $<$ quichua $>$ y no $<$ kichwa $>$, debido a que el texto está redactado en español y en esta lengua es la forma más común, mientras que $<$ kichwa $>$ se usa cuando el texto está redactado en dicha lengua. Por otra parte, a las variedades dialectales del Ecuador nos referimos como <quichuas $>$, mientras que la expresión <quechua > se usa para referirse a toda la familia lingüistica donde se incluyen las variedades presentes en Perú, Bolivia, Ecuador, Colombia, Argentina, Chile, Paraguay y Brasil.

2 Es el nombre original con el que fue creada la DINEIB en 1988 ( $c f$. nota 138). 
FIA

GONAE

INEFOS

IICSAE

ILL

ILV

LOEI

LOES

MOSEIB

MEC

$\mathrm{n}^{\mathrm{o}}$

OCDE

PISA

prov.

PUCE

PUCP

RAE

SEIB

SERBISH

SHQ

TIC

UCE

UNAE

UNL

UPS

UTPL
Fundación Interamericana de Desarrollo

Gobierno de las Nacionalidades Indígenas de la Amazonía

Instituto Nacional Ecuatoriano de Formación Social

Instituto de Idiomas, Conocimientos y Sabiduría Ancestral del Ecuador

Instituto de Lenguas y Lingüística

Instituto Lingüístico de Verano

Ley Orgánica de Educación Intercultural

Ley Orgánica de Educación Superior

Modelo del Sistema de Educación Intercultural Bilingüe

Ministerio de Educación y Cultura ${ }^{3}$

Numeral

Organización para la Cooperación y el Desarrollo Económico

Programme for International Student Assessment

Provincia

Pontificia Universidad Católica del Ecuador

Pontificia Universidad Católica del Perú

Real Academia de la Lengua Española

Sistema de Educación Intercultural Bilingüe

Sistema Bilingüe Bicultural Shuar

South Highland Quichua

Tecnologías de la información y de la comunicación

Universidad Central del Ecuador

Universidad de Nacional de la Educación

Universidad Nacional de Loja

Universidad Politécnica Salesiana

Universidad Técnica Particular de Loja

3 A partir de 2007, con la creación del Ministerio de Cultura y Patrimonio, pasó a llamarse solamente Ministerio de Educación. Luego, en 2018, el Ministerio de Educación absorbió al ICSAE (N del E). 



\section{Introducción}

En el Ecuador existe una población que se ha definido como perteneciente a la cultura quichua que sobrepasa las setecientas mil personas, según datos del censo de 2010. Este dato no es muy preciso debido a la forma ambigua de la pregunta del censo y a la diglosia existente en la sociedad ecuatoriana. Sin embargo, a nivel oficial es el único dato existente

En el siglo XX, a partir de la década de 1920, casi en forma clandestina, algunas comunidades comenzaron a organizarse bajo la modalidad de sindicatos por el acceso a la tierra. El caso del proceso organizativo de Dolores Cacuango en la zona de Cayambe (prov. Pichincha) incluyó también la implementación de la educación bilingüe propia en cuatro comunidades. ${ }^{4}$ Este proceso educativo se desarrolló entre 1945 y 1963. Es la primera vez que los indígenas comienzan a escribir su len-

4 Dolores Cacuango $(26 / 10 / 1881 \dagger 23 / 04 / 1971)$ fundó cuatro escuelas indígenas en las comunidades de Yana Huaicu (hoy Santa Ana) (octubre de 1945), Pesillo (abril de 1946), La Chimba (octubre de 1946) y Muyu Urcu (posiblemente en 1946). La de Yana Huaicu, regentada por su hijo Luis Catucuamba, funcionó hasta 1963, año en que fue destruida por la dictadura militar de esa época por considerar que era un foco comunista. Rodas $(1989,1998)$ dice que la de Muyu Urcu sobrevivió por haber estado construida fuera de las haciendas de la Asistencia Social, las cuales eran controladas por el Gobierno. Las otras pronto pasaron a la Asistencia Social para protegerlas del Ministerio de Educación, pero allí se perdió la propuesta pedagógica original. Es preocupante constatar que no fueron los patrones ni el cura párroco los que pudieron destruir las escuelas bilingües, sino la burocracia del Ministerio de Educación con el argumento de que los profesores no tenían título. Esto muestra que la educación oficial ha sido y sigue siendo la responsable de la aculturación y de la destrucción de la ciencia ancestral y la educación comunitaria, bajo el pretexto de que el Ministerio de Educación tiene la rectoría de la EIB y esto debe cambiar. 
gua, pues anteriormente solo los religiosos y algunos intelectuales habían escrito en quichua.

Luego surgieron algunos procesos de educación bilingüe donde se empleó el quichua como lengua escrita. En esas circunstancias, la estandarización de su escritura representaba un desafío debido a que en el quichua, al igual que en cualquier lengua, existen variaciones dialectales y las instituciones que promovían la educación en quichua tuvieron políticas distintas frente a la escritura de la lengua. Además, los hablantes de la lengua, durante más de cuatro siglos, habían perdido contactos sostenidos entre sí, con lo cual en cada lugar el habla tuvo su propia evolución.

El 30 de enero de 1953 inició sus actividades en el Ecuador el ILV, previa la firma de un convenio el 1 de septiembre de 1952, el cual duró hasta el 22 de mayo de 1981. Aunque este instituto trabajó en muy pocas comunidades con educación quichua, tuvo mucha influencia en sectores de religión evangélica, debido a su política de traducir la Biblia empleando las hablas locales y la escritura similar a la del castellano. Entre 1960 y 1978 otras instituciones religiosas y de desarrollo organizaron procesos locales de alfabetización en quichua. Pero, las diferentes instituciones que intervinieron en las comunidades indígenas tenían su propia ideología y sus intereses particulares que se exteriorizaron al momento de plantearse el proceso educativo. En un contexto así, podía consolidarse una política de escribir la lengua, o para dividir a la población y dominarla, o para facilitar la unidad de sus hablantes. Estos procesos no son neutros ni solo de técnica lingüística, son hechos políticos que pueden servir para empoderar a los pueblos o ser herramientas al servicio de los grupos de poder. Por otra parte, se tiene que considerar que a nivel de los actores sociales de los mismos pueblos indígenas también había y hay distintos intereses.

Entre 1978 y 1986 desarrolló sus actividades el CIEI de la PUCE, dirigido por Consuelo Yánez. En esta institución se gestó la idea de la estandarización de la escritura de la lengua a nivel nacional, la cual se concretizó en el marco del Subprograma de Alfabetización Quichua, ejecutado en to- 
das las provincias quichuas del país, excepto Chimborazo, por disposición del Ministerio de Educación. Este proceso educativo fue el que permitió el encuentro entre líderes de los diferentes grupos quichuas, tanto de la Sierra como de la Amazonía. Al iniciarse la preparación de textos en quichua y la formación de alfabetizadores para esta actividad a nivel nacional, se pudo constatar una diversidad dialectal aparentemente difusa. Así surgió la idea de realizar una planificación lingüística del quichua.

Sobre el contexto y las ideologías relacionados con la planificación lingüística, diferentes autores han realizado observaciones importantes (Howard, 2007; Ballón, 2009; Junyent et al., 2014). Por otra parte, sobre la norma lingüística se ha dicho que no es un concepto gramatical, sino sociológico (Alonso-Cortés, 2015, pp. 596-597). Por lo tanto, analizar el proceso de estandarización de la escritura del quichua ecuatoriano en el contexto de la educación intercultural bilingüe (EIB) es una tarea compleja, debido a los diferentes factores que intervienen en el mismo, y una situación de diglosia en que sobrevive la lengua, resultado de procesos coloniales de dominación.

Consecuentemente, en este emprendimiento se han presentado problemas lingüísticos y sociolingüísticos, algunos de los cuales se han ido resolviendo en el proceso, pero otros subsisten. Por otra parte, es necesario discutir en profundidad la relación entre revitalización de la lengua y estandarización de la escritura. Al parecer, en el Ecuador, a nivel institucional, se priorizó la estandarización de la lengua y se han descuidado aspectos vitales para su implementación y revitalización. Algo similar ha ocurrido en la política oficial boliviana, según lo describe Garcés, quien señala cuatro presupuestos discutibles de ella en lo referente a la estandarización del quechua:

La política boliviana, con referencia específica al quechua, se está construyendo sobre la base de 4 presupuestos discutibles: 1. pensar que la mantención y revitalización del quechua se construye desde la escrituralidad y la escolaridad; 2 . creer que una unificación panandina del quechua va a promover el empoderamiento y la desestigmatización de los hablantes indígenas del quechua; 3. creer que en la estandarización 
de la forma escrita está la clave de la elaboración y fortalecimiento de la lengua; 4. creer que el criterio histórico es la mejor guía para elaborar un estándar frente a la variación dialectal existente ( $c f$. Luykx 2001). Como bien lo anota Luykx, estos presupuestos muestran como énfasis una política lingüística que a) dirige los esfuerzos a aspectos en los que el quechua se encuentra en desventaja frente al español; b) prioriza las preocupaciones de los planificadores de lengua y educación por sobre las de la mayoría quechuahablante; y, c) vincula la variación dialectal al prestigio y a la jerarquía de una clase, estigmatizando así a las variedades no estandarizadas. Se trata, entonces, de una política lingüística elaborada sobre supuestos de reivindicación lingüística que parte de criterios de escrituralidad, escolaridad, estandarización panandina e historicidad, y a las cuales se responde con una elaboración que tiene como referencialidad el castellano y los intereses de los planificadores. En tal sentido, esta elaboración idiomática se interesa por superar una situación diglósica desde instrumentos de obtención de prestigio tales como la escritura y la escolaridad, y desde la consolidación de un planteamiento academicista, cual es la búsqueda de una unificación escrituraria panandina y la legitimación del criterio de historicidad. Frente a ello, su respuesta también se da mediante el recurso a la obtención de prestigio y la implantación de un modelo normativo de un grupo de élite. No se parte de la realidad lingüística de la mayoría hablante, de sus necesidades e intereses comunicativos concretos. En definitiva, no se parte de lo que tiene la lengua como capital sociocomunicativo, sino de lo que se quisiera tener en términos comparativos con la lengua y el grupo de poder (2004, pp. 23-24). ${ }^{5}$

5 Esta práctica política de intentar revitalizar las lenguas indígenas mediante la normalización elitista de la escritura, señalado en el documento de Garcés (2004), no ha cambiado con el advenimiento del Gobierno de Evo Morales, según se desprende del documento "Conocimiento indígena y prácticas políticas en América Latina” (OREALC/UNESCO, 2019, pp. 43-45). El Gobierno de Evo Morales ha invertido mucho en infraestructura educativa y ha producido textos jurídicos formales favorables a lenguas indígenas. Sin embargo, hace falta un trabajo psicosocial y en los aspectos pedagógico-metodológicos para posicionar los conocimientos ancestrales y las lenguas indígenas en la sociedad y principalmente entre sus hablantes, para así fortalecer la EIB. 
En el caso ecuatoriano, el análisis que se ofrece se realiza luego de un período prudencial tras haber iniciado el proceso de formulación y su aplicación. Se estudió tanto los aspectos estrictamente técnicos como los contextuales. Estos últimos se refieren a los aspectos históricos, psicosociales, políticos, ideológicos, etc., que han sido favorables o no para el propósito perseguido. A nivel educativo se encuentra que más del $80 \%$ de los educadores que se han presentado a rendir la prueba de bilingüismo en la DINEIB en el período 2015-2016, tiene falencias en el manejo de la escritura estandarizada del quichua.

Al observar el panorama, se presentan interrogantes básicas como: ¿Cuál es la realidad dialectal del quichua ecuatoriano y cómo se la representa en la escritura estandarizada? ¿Cuáles son las posibles causas de la fragmentación dialectal del quichua? ¿Qué ocurre con los sustratos, adstratos y superestratos lingüísticos? ¿Cuál es el grado de participación de los líderes comunitarios en el proceso? ¿Cuáles son las dificultades que se han presentado en la estandarización escrita? ¿Cuál es la visión de los actores sociales sobre el proceso? ¿Cuál ha sido la política gubernamental frente al proceso? ¿Qué ajustes se debe realizar al proceso de estandarización del quichua? ¿Cómo ha sido el proceso de la EIB?

Para abordar esta tarea, en cuanto a lo estrictamente lingüístico, fue necesario realizar un estudio sistemático de los dialectos del quichua del Ecuador con el fin de constatar sus diferencias, con una cobertura nacional que facilite la zonificación dialectal de esta lengua. Anteriormente solo se había realizado estudios de campo en partes del territorio nacional donde se habla el quichua. Así, el estudio de Orr (1965/1981) se centró en tres lugares de la Amazonía; Yánez (1974) abarcó las provincias de Chimborazo e Imbabura; Stark y Muysken (1977) cubrieron algunas provincias de la Sierra; Carpenter (1982) investigó el habla en algunas comunidades dispersas de la Sierra y de la Amazonía. De todos ellos, el de Consuelo Yánez, como se verá luego, se destacó tempranamente por realizar los estudios de la fonología y morfología del quichua con la finalidad de sentar las bases para la estandarización de la escri- 
tura de la lengua en el marco de un posible proceso de EIB con carácter nacional. Los otros tuvieron más intereses misioneros o de ilustración académica. Posteriormente, cuando ya se había implementado la alfabetización en quichua y se estuvo utilizando una escritura estandarizada, aparecieron otros estudios de campo de carácter regional como los de Büttner (1993), pero no sobre la realidad dialectal, sino sobre el uso de la lengua en algunas escuelas bilingües.

En el caso del quichua ecuatoriano, además de las consideraciones anteriores, se ha tenido que analizar las dificultades del problema lingüístico en el campo pedagógico y su repercusión en el aspecto organizativo de las comunidades indígenas. Un estudio de esta naturaleza no puede desvincularse del proceso de EIB ni de la reivindicación del ejercicio de los derechos colectivos de las nacionalidades indígenas. Como se puede apreciar, se trata de un caso de lingüística aplicada, de lingüística política, no de lingüística pura.

Se aspira que los resultados de esta investigación sean de interés para las autoridades y planificadores en el diseño y aplicación de las políticas. Igualmente, para los actores sociales de la EIB, de modo que tengan consciencia de la problemática de la estandarización, valoren los logros alcanzados y busquen alternativas de superación a las dificultades existentes. Los proponentes de currículos y de textos tienen un referente para diseñar instrumentos que permitan la consolidación de la estandarización del quichua ecuatoriano. Los docentes de EIB tienen, en este estudio, información lingüística que les permita ser polidialectales a nivel oral y una ayuda para comprender y usar la escritura estandarizada del quichua. Inclusive se podría aspirar, en adelante, a que indígenas ecuatorianos interesados en manejar dialectos provenientes de otros lugares donde se habla el quichua, más allá de las fronteras nacionales, ya sea en forma pasiva (comprensión) o activa (a nivel de habla), tengan en este estudio una ayuda formativa y orientadora. Esto último es una utopía para el largo plazo, pero nada impide que puedan sentarse las primeras ideas para su desarrollo. 


\section{5}

Finalmente, cabe indicar que en el presente libro se ha establecido el siguiente criterio para la representación escrita de la denominación de lengua: cuando el texto está redactado en castellano se escribe quichua, y cuando el texto está redactado en la propia lengua se escribe kichwa, en concordancia con la escritura estandarizada para la misma. Por otra parte, para referirse al conjunto de hablas presentes en el Ecuador, se usa el término quichua o kichwa según se ha señalado; en tanto que, para referirse a toda la familia lingüística que abarca a todas las hablas presentes en los diferentes países se utiliza el término quechua. 



\section{Capítulo 1 Lenguas prequichuas del callejón interandino}

En este capítulo se aborda el estado de la cuestión de las investigaciones en torno a las lenguas prehispánicas que constituyen el sustrato del quichua ecuatoriano. El conocimiento de los sustratos lingüísticos contribuye a preservar aspectos de la identidad de los diferentes pueblos que actualmente integran la nacionalidad quichua del país. Como se verá luego, una parte considerable de topónimos de la Sierra ecuatoriana y también de antropónimos, aunque en menor grado que los anteriores, no pertenecen al quichua sino a lenguas anteriores. Igualmente hay un número importante de fitónimos provenientes de las lenguas de sustrato que están en peligro de perderse para siempre. Esto plantea la necesidad de definir una política coherente para la representación escrita que permita su conservación uniforme en el futuro.

Sobre algunas de las lenguas prequichuas existe diferencias respecto de sus nombres y su ubicación. Sin embargo, para la generalidad de los autores que han realizado estudios sobre las poblaciones preincaicas en la Sierra ecuatoriana, está claro que antes de la presencia del quichua en la Sierra ecuatoriana, hubo varios pueblos, cada uno con su propia lengua y su cultura. Estas lenguas convivieron con el quichua hasta comienzos del siglo XVIII, cuando comenzaron a extinguirse, cediendo ante el quichua. En la Amazonía ecuatoriana ocurrió algo similar, esto es, existieron muchas lenguas antes que el quichua. A diferencia del caso andino, varias de ellas subsisten hasta el presente y esto porque la penetración del quichua en esta región en el período incaico parece haber sido escasa o nula, y solo en el período colonial fue ingresando paulatinamente. 
Como se dijo, las lenguas prequichuas de la Sierra ecuatoriana están extintas y hay poca documentación lingüística sobre ellas, como lo señala, entre otros, Adelaar (2004, p. 172):

The original native languages of the Ecuadorian inter-Andean valley are all extinct. They are virtually undocumented, except for numerous place names and a few lexical items mentioned in Spanish colonial sources. Some more lexical items and possible substratum elements can be found in the modern dialects which together constitute Ecuadorian highland Quechua. For the pre-Quechuan languages of highland Ecuador Barbacoan and Mochica affinities have been proposed (except for Palta and Malacato, which are usually assigned to the jivaroan language family). The language of the Cara in the northern section of the inter-Andean valley has been associated with Barbacoan, those of the Cañar and the Puruhá in its central part to Mochica. It is doubtful if the scanty information on these languages will ever permit us to confirm any such proposals. Much interpretation on these languages will ever permit us to confirm any such proposals. Much interpretation of the available linguistic data (mostly toponymy) is due to the work of Jijón y Caamaño (1940-5) and Paz y Miño (1936-61).

De las lenguas prequichuas han quedado restos lingüísticos en la toponimia, antroponimia, fitonimia y zoonimia. A partir de estos datos y de algunas informaciones proporcionadas por los primeros cronistas, en especial por las "Relaciones geográficas" del siglo XVI y de otros documentos coloniales posteriores, se ha llegado a conocer algo acerca de la existencia de tales lenguas.

Desde comienzos del siglo XX, algunos investigadores se interesaron en realizar compilaciones, principalmente de la toponimia y la antroponimia. Pero debe señalarse que quienes realizaron tales compilaciones no eran lingüistas, sino que tenían formación en etnología, y en algunos casos, como Jijón y Caamaño, en arqueología. Por tanto, el corpus recopilado por ellos requiere ser tamizado a la luz de criterios lingüísticos para evitar conclusiones e interpretaciones distorsionadas. Así, no es de extrañarse que en las listas de palabras atribuidas a estas 
lenguas provenientes de la mayor parte de estos investigadores, se hayan incluido con frecuencia palabras provenientes del quichua.

Por otra parte, varios compiladores de palabras de estas lenguas ensayaron interpretaciones erráticas o gratuitas, sin un criterio lingüístico, cayendo en lo que se conoce como "etimología popular”. Una práctica muy común fue considerar que cada palabra estaba ensamblada de varios morfemas provenientes de diferentes lenguas lejanas, inclusive geográficamente. González Suárez (1892, 1903), Jijón y Caamaño (1941), Pérez (1970), ${ }^{6}$ entre otros, ensayan interpretaciones demasiado arbitrarias, basándose en falsos cognados. Así por ejemplo, el término $<$ quilo $\rangle^{7}$ existe en el idioma panzaleo (Sierra centro del Ecuador), pero también existe en el mapudungun de Chile. En este caso es más plausible pensar que se trata de homófonos, antes que haya un sustrato común entre estas dos lenguas. Pero para esos autores una situación como la señalada habría sido ya una prueba de parentesco lingüístico, sugiriendo que en tiempos remotos, habría existido la presencia de esos pueblos en suelos de la actual Sierra ecuatoriana. También hay que tomar en consideración el contexto de esos años, que era un afán de algunos investigadores de establecer macrofamilias lingüísticas a nivel de Sudamérica, postulando que en el pasado remoto hubo una gran movilidad entre pueblos que hoy en día se hallan en lugares muy distantes.

6 Pérez (1962, p. 32), aun para palabras quichuas muy conocidas para un historiador como él, le da una interpretación suigeneris. Así, el topónimo $<$ Pucará $>$ lo considera como conformado por dos términos provenientes del quichua $<$ puca $>$ 'rojo' y <ra $>$ 'antes'. Pero es más plausible considerar que proviene de $<$ pucara $>$ que es 'fortaleza' en lengua quichua, antes que forzar una división entre $<$ puca $>$ $\mathrm{y}<\mathrm{ra}>$, que juntando sus significados no da ningún sentido apropiado para un topónimo. Además, para ello, arbitrariamente a $<$ ra $>$ le hace provenir del morfema quichua $<-$ raq $>$. Este historiador fue hombre de archivos y de allí su prestigio, pero le faltó conocimiento de la lingüística.

7 En la zona de Cayambe (prov. de Pichincha) existe el apellido Quilo, pero también este término se encuentra en <Quilo-toa $>$, un volcán al occidente de Latacunga, territorio panzaleo. Su significado todavía se desconoce. 
$\mathrm{Al}$ parecer, esta ha sido una práctica muy común no solo en el Ecuador, sino también en otros lados desde la época colonial. Así, Cerrón-Palomino señala, refiriéndose a los estudios toponímicos, que:

Los estudios toponímicos desarrollados en el área andina, y en particular en el Perú, yacen todavía postrados dentro de una práctica desprovista del mínimo rigor científico reclamado por la disciplina. De allí que, ante la ausencia de criterios lingüísticos-filológicos que los respalden, por mencionar solo las disciplinas medulares en las que debe sustentarse toda empresa etimológica, no debe extrañar que continúe en manos de simples aficionados de buena intención. De esta manera, persiste en tales estudios la vieja práctica de la etimología popular, que echa por los suelos toda plausibilidad formal y semántica de los nombres de lugar. Dicha tendencia, que en el área andina se remonta a los tempranos años de la Colonia, como lo prueban, por ejemplo, las disquisiciones toponímicas del cronista Murúa, discutidas en otro lugar por nosotros ( $c f$. Cerrón-Palomino 2008: II-11), puede ilustrarse como las etimologías que suelen darse a nombres como $<$ Rimac $>$, $<$ Apurimac $>$, $<$ Harmey $>$ y $<$ Titicaca $>$. Se dice que el primero significa 'Río hablador', y que estaría aludiendo al río que lleva tal nombre; del segundo se dice que significaría "El señor que habla" [...] el tercero tendría como glosa "Mi mujer"; y finalmente el cuarto equivaldría a "Cerro de cobre". Pues bien, como lo hemos demostrado en otros trabajos, $<$ Rimac $>$ (en verdad $<$ Limac $>$ antes de su quechuización forzada) no aludía al río, sino al oráculo prehispánico que más tarde estaba en la huerta de Jerónimo de Silva [...] < Apurimac>, por su parte, aparte de la mala glosa que se le da (pues en verdad sería 'El hablador principal'), tampoco aludía al río, sino a un oráculo importante que estaba a su orilla [...]; en cuanto a $<$ Huarmey $>$, hay que señalar, en primer lugar, que no se trata de una voz quechua, sino posiblemente quingnam (la antigua lengua yunga de los pescadores con el significado de "Pescadora" [...]; finalmente $<$ Titicaca > es voz híbrida puquina-quechua, en la que <titi $>$ es 'sol' y no 'cobre', de manera que se traduce por 'Peñón del Sol' (2015a, pp. 188-189).

La crítica realizada sobre los estudios de las toponimias también es aplicable a los antropónimos. Para superar el problema de las etimologías populares, relacionadas con los topónimos, Cerrón-Palomino (2015a, pp. 
183-184) propone que estos estudios se realicen de manera interdisciplinaria en donde se incluya la lingüística y la filología como disciplinas nucleares y otras auxiliares como la geografía, la arqueología y la historia.

En lo relacionado al Ecuador, a finales del siglo XX, Caillavet (2000) discute algunos problemas metodológicos relacionados con la toponimia, recurriendo a datos históricos de los cronistas para plantear el significado de algunos términos de la Sierra norte. Aunque ella hace notar también que los documentos de los cronistas deben ser analizados críticamente, pues a veces se prestan a confusión. Sobre lo problemático de la significación de las pocas palabras que los cronistas han dejado, concretamente en cuanto a su interpretación al castellano, ya había advertido también Paz y Miño (1940).

Pero ¿cuáles fueron las lenguas prequichuas y su ubicación en la Sierra ecuatoriana? Existe alguna información de la época colonial al respecto. Así por ejemplo, Cieza de León proporciona datos escuetos sobre la existencia de algunas lenguas que había tanto al norte como al sur del pueblo de Quito, en la Sierra ecuatoriana, sin embargo, al describir a sus pobladores no hace mención a la lengua que se hablaba en la región. Se limita a realizar una discriminación positiva de los mismos. Así, respecto de los habitantes de Quito ${ }^{8}$ señala: "Los naturales de la comarca en general

8 En lengua tsa'fiki, de la nacionalidad tsa'chi, cuyos hablantes viven actualmente en la Costa, al otro lado de la Cordillera, al occidente de Quito, se sigue usando dos palabras terminadas en el morfema $\{$-to $\}$ que significa 'tierra'. Estas palabras son: $<$ Man-to $>$ para referirse al sitio de la actual ciudad de Santo Domingo de los Colorados, y $<$ Te'-to $>$ para referirse a la ciudad de Quito. Según los tsa'chi, Quito en castellano es 'tierra quebradiza', de <te' pa $>$ 'doblado' y $<$ to $>$ 'tierra'. Lo denominan así debido a lo quebradizo del sitio. Esta significación se corresponde con la orografía de Quito, que está asentada sobre unas trescientas quebradas. Por otra parte, en la tradición oral de los $<$ tsa'chi $>$ subsiste la idea de que ellos provienen de la Sierra. Entonces: ¿Los habitantes de Quito hablaban la lengua panzaleo? ¿Esta lengua está emparentada con la lengua tsa'fiki de los tsa'chi que ahora están al occidente de Pichincha y Cotopaxi? Sobre esto se volverá más adelante cuando se hable de los topónimos de esta lengua. 
son más domésticos y bien inclinados y más sin vicio que ningunos de los pasados, ni aun de los que hay en toda la mayor parte del Perú" (Cieza de León, 1553/1973, p. 109). Sin embargo, no dice nada sobre la lengua. Esto ha propiciado los supuestos de que los habitantes de Quito hayan estado más cercanos al habla de los caras (Pérez, 1960), en tanto que otros consideren que desde aquí hacia el sur se hablaba el panzaleo (Reino, 1988).

A pesar de esta problemática, desde finales del siglo XX, algunos investigadores, principalmente geógrafos y etnohistoriadores, basándose en documentos coloniales y en estudios de manejo del espacio físico por parte de los pueblos prehispánicos, vienen contribuyendo a la identificación de la posible ubicación de las “etnias" prequichuas y por ende de sus lenguas (Deler, 1981/2008; Deler et al., 1983; Reino, 1988), del callejón internandino.

Si la identificación y la determinación del territorio ocupado por estas lenguas ya es una tarea compleja, qué decir de los significados de las palabras que se atribuyen a ellas. Los topónimos podrían ayudar en algo, pues según lo han hecho notar autores como Cerrón-Palomino (2015a), parece que entre los pueblos prehispánicos la costumbre era la de nombrar a los lugares a partir de alguna cualidad o característica de los mismos. Además, los topónimos, según lo ha señalado Caillavet (2000, p. 104), han resistido mejor que los antropónimos a las culturas invasoras. En cuanto a los antropónimos, aunque ellos teóricamente podrían contribuir a indicar la procedencia de la persona, debido a los movimientos migratorios que hubo antes y durante la Colonia, han sido más vulnerables que los anteriores. Sin embargo, a futuro, los antropónimos híbridos entre lengua prequichua con quichua pueden ayudar a identificar el sentido de algunos términos prequichuas.

Es así como, aunque todos los términos de las lenguas prehispánicas como son topónimos, antropónimos, fitónimos, zoónimos, etc., son importantes para el conocimiento e identificación de las lenguas prehispánicas, los que más pueden contribuir a este objetivo son los topónimos y los fitónimos, en tanto que los antropónimos pueden contri- 
buir en estudios etnohistóricos, como es el caso de la identificación de las zonas de asentamiento de los mitimaes.

Para estudiar los elementos de las lenguas de sustrato se ha seguido la metodología de agruparlos por las terminaciones de los mismos, aunque en algunos casos también se lo podría hacer tomando como elemento de unidad el componente inicial. Se sospecha que las terminaciones bisilábicas son morfemas libres. En cuyo caso los topónimos compuestos estarían integrados de dos morfemas libres, ya sea provenientes de la misma lengua o a veces se trata de híbridos de lenguas diferentes. Se observa que las raíces por lo general son bisilábicas, sin embargo, no se descartan algunos casos cuando el primer término del ensamblaje sea un monosílabo sujeto a una reducción previa o simplemente existan raíces monosilábicas. En el caso de las terminaciones monosilábicas es más plausible que ellas sean propiamente sufijos.

Sobre la característica de los topónimos compuestos, CerrónPalomino (2015a, p. 183), trae una cita de un texto colonial, que señala que estos topónimos estarían integrados de un nombre y un calificativo. El autor del texto colonial afirma que la siguiente era la costumbre indígena de dar nombres a los lugares:

A los pueblos dan los nombres conforma la calidad o señales del sitio que tienen, como sitio de fortaleza, tierra de sal, provincia de piedras, de agua, de oro, de plata, de corales, tierra cenegoza o anegadiza, sitio de quebradas, lugar riscoso, lugar nuevo, lugar viejo, sitio ahumado, y assi por este modo van todos los más sin etimología que denote más ingenio (Dávalos y Figueroa, 1602, p. 124v).

Para el presente caso se ha tomado en cuenta principalmente los topónimos, una parte de ellos como resultado de nuestro trabajo de campo. En este caso no se indica la fuente. Pero otra parte importante de los términos de sustrato se ha tomado de diversos autores que han hecho compilaciones. En este caso se indica el autor y la página de su obra donde se ha encontrado. Varias expresiones también se han toma- 
do de la revisión de los expedientes de las 177 cajas digitalizadas sobre indígenas que están en el Archivo Nacional del Ecuador.

La investigación de los términos de lenguas prequichuas, además del interés histórico y cultural, contribuye a la toma de decisiones sobre la estandarización de la escritura del quichua. Sobre esto se abordará en el capítulo 7.

Con estos antecedentes, a continuación se señala el posible territorio que ocuparon estas lenguas y algunos ejemplos ${ }^{9}$ con las terminaciones más representativas de las lenguas prequichuas de la Sierra ecuatoriana. Sobre los componentes de las palabras de estas lenguas, en unos pocos casos es posible encontrar en los documentos coloniales algún indicio sobre su significado. Sin embargo, aún esos datos tienen que ser analizados críticamente, como ya se mencionó. Es preciso aclarar que en las fronteras lingüísticas existen zonas en donde se entremezclan los topónimos de las lenguas en contacto.

\section{Lengua pasto}

Sobre esta lengua y su ubicación es preciso diferenciarla de otra denominada quillasinga que estuvo en territorio cercano a la lengua pasto en la actual Colombia. Así, Cieza de León (1553/1973) menciona a pastos y quillasingas como grupos distintos, aunque no informa nada sobre la lengua que hablaban:

Dije que la villa de Pasto está fundada en el valle de Atris, que cae en la tierra de los quillacingas, gentes desvergonzadas, y ellos y los pas-

9 Los ejemplos de la lengua de sustrato se presentan con los símbolos de la escritura empleada por los investigadores de cuyo trabajo se ha tomado. En caso de que no se señale la fuente, significa que ese lugar ha sido visitado por el autor de esta investigación en su trabajo de campo. En esos casos se emplea la escritura ortográfica del castellano que es la que comúnmente se usa en los mapas o en el habla de los actuales pobladores. Las variaciones de pronunciación de los componentes de los términos pueden haber sido influenciadas por factores extralingüísticos, por esa razón, en muchos casos, no es posible establecer una regla fonética precisa. 
tos son muy sucios y tenidos en poca estimación de sus comarcanos [...]. De Ipiales se camina hasta llegar a una provincia pequeña que ha por nombre Guaca, y antes de llegar a ella se ve el camino de los incas, tan famoso en estas partes como el que hizo Aníbal por los Alpes cuando bajó a Italia. Y puede ser tenido este en más estimación, así por los grandes aposentos y depósitos que había en todo él como por ser hecho con mucha dificultad por tan ásperas y fragosas sierras, que pone admiración verlo. También se llega a un río, cerca del cual se va a donde antiguamente los reyes incas tuvieron hecha una fortaleza, de donde daban guerra a los pastos y salían a la conquista de ellos; y está un puente en este río, hecho natural, que parece artificial, el cual es de un peña viva, alta y muy gruesa, y hácese en el medio de ella un ojo por donde pasa la furia del río, y por encima van los caminantes que quieren. Llámase este puente Lumichaca [ahora Rumichaca, actual frontera Ecuador-Colombia], en lengua de los incas, y en la nuestra querrá decir puente de piedra [...]. De la pequeña provincia de Guaca se va hasta llegar a Tuza, que es el último pueblo de los pastos (1553/1973, p. 102).

Según Cieza de León, el territorio de los pastos habría estado entre el río Angasmayo (sur de Colombia) y Tuza (cerca del río Chota, al norte de la prov. de Imbabura, en el Ecuador) ( $c f$. Cieza de León, 1553/1973, caps. XXXIV y XXXVII). Entre los pueblos catalogados como pastos por este autor, en el territorio ecuatoriano actual están: Guaca (Huaca) y Tuza. ${ }^{10}$ Se conoce que los pueblos pastos y quillasingas hablaban lenguas

10 El poblado de $<$ Tuza $>$ inicialmente fue fundado durante el 5 de agosto de 1535, por el capitán Tapia, cumpliendo órdenes de Sebastián de Benalcázar, pero cambió su nombre a San Gabriel en 1884, en honor al expresidente Gabriel García Moreno, quien diseñó su reconstrucción luego del terremoto de 1868. Sin embargo, hay discrepancias entre los estudiosos porque algunos suponen que debió haber existido otro <Tuza $>$ prehispánico más hacia el sur, próximo al río Mira, el cual habría sido la frontera natural entre la lengua pasto y la carangui. Este río nace en las estribaciones de la Cordillera oriental con el nombre de Chota y cruza la Sierra para dirigirse hacia la Costa, ya con el nombre de río Mira. En cuanto a la escritura, en la época colonial la grafía $<\mathrm{z}>$ se usaba para representar al sonido [ts], por lo tanto, la pronunciación pudo haber sido [tutsa]. 


\section{6}

diferentes gracias al documento del segundo Sínodo Quitense de 1594, en cuyo capítulo III se dice: ${ }^{11}$

Por la experiencia Nos consta que en este Obispado hay diversidad de lenguas que no tienen ni hablan la del Cuzco ni la aimará, y que para que no carezca de la doctrina cristiana es necesario hacer traducir el Catecismo y Confisionario en las propias lenguas: por tanto, conformándonos con lo dispuesto en el Concilio Provincial último, habiéndonos informado de las mejores lenguas que podrían hacer esto, Nos ha parecido cometer este trabajo y cuidado á Alonso Núñez de S. Pedro y á Alonso Ruiz para, la lengua de los llanos y tallana; y á Gabriel de Minaya, para la lengua cañar y purguay; y á Fr. Francisco de Jerez y á Fr. Alonso de Jerez, de la Orden de la Merced, para la lengua de los pastos; y á Andrés Moreno de Zúñiga y Diego Bermúdez Presbitero para la lengua quillaisinga; á los cuales encargamos lo hagan con todo cuidado y brevedad, pues de ello será Nuestro Señor servido, y de nuestra parte se lo gratificaremos: $y$ hechos los dichos Catecismos los traigan ó envían ante Nos, para que vistos y aprobados, puedan usar de ellos (las cursivas son mías) (Vargas, 1978, p. 92). ${ }^{12}$

En el presente estudio no se tratará sobre la lengua quillasinga, pues como lo ha señalado Cieza, este pueblo estuvo en la zona de Pasto y actualmente pertenece a la república de Colombia. Algunos estudiosos (Buchwald, 1919/2007, pp. 83-90) relacionan la lengua quillasinga con la lengua viva que está vigente en el valle de Sibundoy/Sebondoy, al este de Pasto, cuyo etnónimo es ahora conocido como $<$ kamëntsá $>$, que según el AFI su representación de la pronunciación es [kamin’tsa]. En la escritura ortográfica lo escriben como: kamënsá, kamsá, camsá, etc.

11 El III Sínodo Quitense se realizó en Loja, en 1596. En esta reunión se confirmaron todas las disposiciones del Sínodo de 1594, excepto las que señalan expresamente que quedan derogadas. Entre esas disposiciones derogadas no consta la relacionada con las lenguas indígenas, por lo que se supone quedaron confirmadas en los términos del anterior Sínodo.

En esta disposición no se menciona la lengua panzaleo. 


\section{7}

El territorio de la lengua pasto, según lo han señalado algunos autores como Martínez (1977, p. 15), habría limitado al norte con el río Guáitara (Colombia), por el sur llegaba hasta el río Chota, límite natural entre las provincias de Carchi e Imbabura. Al este y oeste estaba delimitado por la Cordillera oriental y occidental, respectivamente.

Los topónimos y antropónimos atribuidos al territorio de esta lengua han sido compilados por Grijalva (1923/1988). ${ }^{13}$ Este corpus aparece en orden alfabético y cada uno contiene una referencia. Cuando son topónimos, junto a la palabra se menciona el lugar de su ubicación. Sin embargo, esta referencia no es detallada, pues no señala si el lugar es una parroquia, un caserío, un cantón, etc. En cuanto a los antropónimos, indica la fecha donde aparecen citados en los documentos coloniales que él investigó.

Jijón y Caamaño, por su parte, presenta un corpus de 740 palabras entre topónimos y antropónimos que pertenecerían a la lengua pasto. Su compilación en gran parte está basada en el trabajo de Grijalva. En su estudio presenta los nombres en orden alfabético. En algunas palabras ensaya una interpretación apoyándose en las raíces del idioma, que él siguiendo la tradición de esa época denomina con el nombre exógeno de coayquer $^{14}$ (actualmente awapit). Las interpretaciones propuestas por este autor tienen limitaciones, tanto porque asumió sin más un estrecho parentesco entre el awapit y el pasto como por las dificultades de trans-

13 Cabe anotar que la obra de Grijalva, denominada Cuestiones previas al estudio filológico-etnográfico de las provincias de Imbabura y Carchi, según lo señala en su introducción fechada el 1 de julio de 1923, estuvo terminada en aquel año, pero permaneció inédita hasta 1988 en que fue editada por el BCE. Este autor recopiló 836 palabras de esta lengua. Jijón y Caamaño (1940) indica que conoció la obra inédita de Grijalva y que tomó de allí sus datos para su trabajo de topónimos y antropónimos, aunque señala que usó también datos de unos artículos publicados por el Dr. Coba Robalino en los diarios quiteños El Derecho y El Debate, y también de unos manuscritos del siglo XVIII que tenía en su biblioteca, sobre los cuales no proporciona más información.

14 Coayquer es el nombre de un río en el sur de Colombia. Sus hablantes denominan a su lengua con el nombre de awapit y a su pueblo como Awa, en lugar de Coayquer. 
cripción del vocabulario. Así por ejemplo, la vocal alta central /i/ de este idioma fue representada en forma asistemática con el diptongo $<$ ue $>$ y también $<$ ä $>$. Además, este autor tampoco se libró de la práctica de la etimología popular de la que se habló antes.

A su turno, Luis Paz y Miño hizo una compilación de 230 topónimos de la lengua pasto, y los organizó en 29 grupos. Quince están agrupados por sufijos comunes, trece por prefijos comunes, en tanto que el último grupo consta de un listado alfabético de treinta y cinco términos que no calzan en los grupos anteriores. El agrupamiento por sufijos y prefijos realizado representa un avance metodológico frente a los autores anteriores, que presentan los términos simplemente en orden alfabético. Paz y Miño (1940, p. 163), basándose en Grijalva (1921, p. 173), señala que cinco términos de la lengua pasto estarían identificados con su traducción al castellano. Estos son:

\begin{tabular}{|ll|}
\hline$<$ iscual $>$ & 'lombrices' \\
$<$ quer $>$ & 'pueblo', 'tierra, 'sitio', 'lugar plano' \\
$<$ pas/bas $>$ & 'familia,' 'estirpe' \\
$<$ pue $>$ & 'redondo' \\
$<$ tal $>$ & 'piedra' \\
\hline
\end{tabular}

Señala que los dos primeros términos habrían sido encontrados en un documento del cabildo de Pupiales (Nariño, Colombia) y los dos últimos en uno de Cumbal, del mismo departamento colombiano. De estos documentos no proporciona más detalles por lo que todos ellos deben tomarse con cautela. En cuanto al tercero, simplemente se apoya en una conclusión de Grijalva (1923/1988), quien llegó a esa opinión observando los apellidos indígenas de la zona.

Luego, Eduardo Martínez (1977) realizó un estudio de los documentos anteriores y en su libro Etnohistoria de los pastos compiló 731 palabras de esta lengua, entre topónimos y antropónimos. En cuanto a los topónimos señala los ubicados en Colombia y los que están en 
Ecuador. Sin embargo, aunque se preocupó de identificar la ubicación de cada topónimo, hay problema para manejar su texto como fuente de consulta, pues no los agrupó por terminaciones, sino que los puso en orden alfabético.

A continuación se presentan los topónimos y antropónimos atribuidos a esta lengua, los que están relacionados fundamentalmente con el Ecuador actual. Solo en algunos casos excepcionales se menciona términos que se encuentra en el territorio colombiano. Cuando los términos pertenecen a Carchi no se menciona la provincia, sino solo la comunidad o parroquia y el cantón. Las terminaciones más características de las palabras atribuidas a esta lengua son cuatro: $\{-$-es, -pas/bas, -pud, -quer\}.

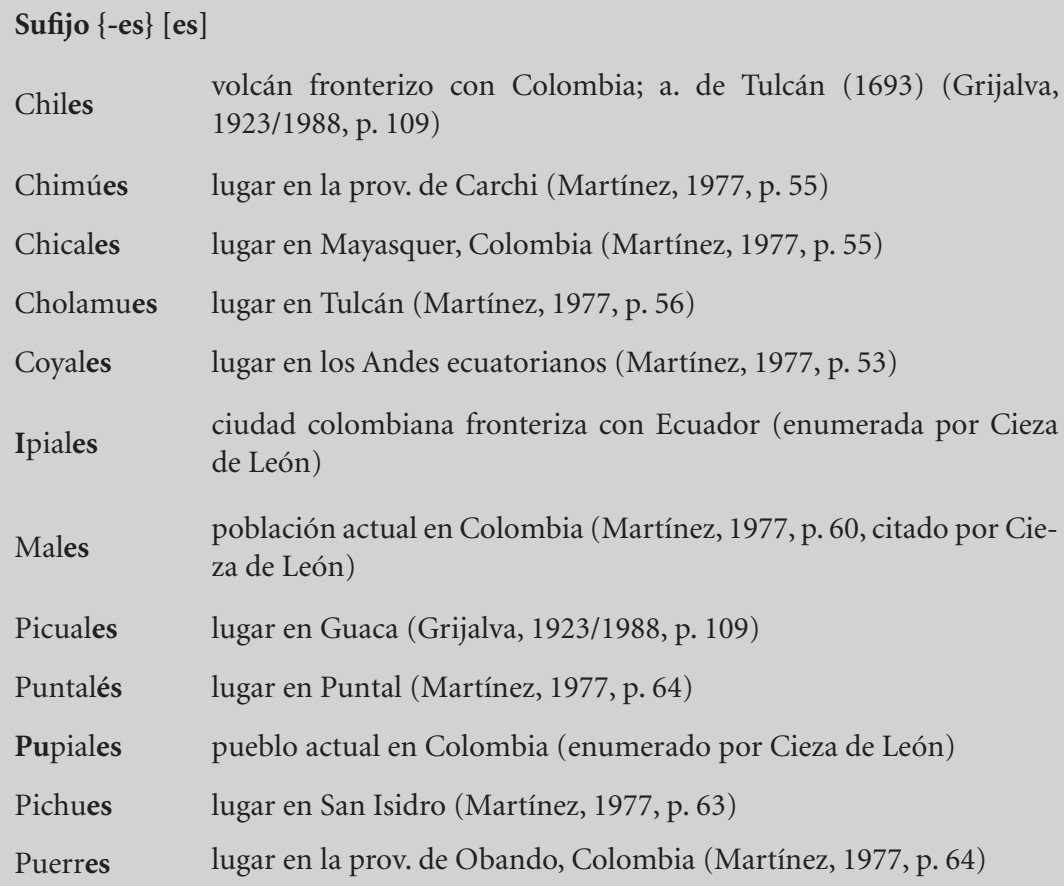


Paz y Miño (1940, pp. 164-165) ubica 46 topónimos terminados en $\{-\mathrm{es}\}$, y es el grupo más numeroso de los 29 que recopila. Este autor discute si dentro de este grupo habría que considerar la terminación $\{$-les $\}$ o \{-es\}. Según él, en contraposición a Jijón y Caamaño, la segunda es la más coherente, aunque no proporciona una razón técnica. Por nuestra parte, se ha constatado que en el lado ecuatoriano existe el pueblo denominado $<$ Chical $>$ y en el lado colombiano existe el lugar denominado <Chicales $>$. Además, si hubiera existido algún parentesco con la lengua awapit, tradicionalmente conocida como coayquer, Paz y Miño tendría razón en considerar que el sufijo es \{-es\} y no $\{$-les $\}$, pues en esa lengua existe el término < pial $>$ que significa 'plata'. Asimismo, existen algunos topónimos terminados en /1/ en el lado ecuatoriano como: <Chigual, Puntal, Quinzhul>, y al otro lado de la frontera colombiana está el cerro $<$ Cumbal $>$, al igual que el topónimo <Chilincal>, que también terminan en /1/. Martínez (1977, p. 59) menciona que <ipial> es un apellido y topónimo en el lado colombiano, pero también un 'árbol'. Estos datos permiten proponer que el sufijo sería $\{$-es\}. Sin embargo, tampoco debería descartarse la posibilidad de que el sufijo sea $\{$-les\}, para los términos $<$ Chiles, Coyales, Ipiales, Puntales, Pupiales, Males $>$. En este caso los términos $<$ Chimues, Cholamues, Pichues, Puerres $>$ no pertenecerían al grupo anterior, sino que podrían ser nombres de grupos étnicos con el plural $\{$-es $\}$ del castellano.

De otro lado, si < pial> 'plata' en lengua awapit estuviera relacionado con la lengua pasto, cabría preguntarse si no existen los prefijos $\{\mathrm{i}-\}$ y $\{$ pu- $\}$ presentes en $<$ Ipiales $>$ y $<$ Pupiales $>$, topónimos en Nariño (Colombia). Esto será tarea de futuras investigaciones. 


\begin{tabular}{|ll|}
\hline $\begin{array}{l}\text { Sufijo }\{\text {-pud }\} \\
\text { Cayalapud }\end{array}$ & lugar en los Andes (Martínez, 1977, p. 51) \\
Cuasapud & a. de Tulcán 1718 (Grijalva, 1923/1988, p. 98) \\
Cuaspud & $\begin{array}{l}\text { lugar en los Andes colombianos, en Cumbal (Grijalva, 1923/1988, p. } \\
\text { 98); hacienda al occidente de Tulcán (Paz y Miño, 1947, p. 77) }\end{array}$ \\
Cualapud & lugar en Guachucal (Grijalva, 1923/1988, p. 97) \\
Chalipud & lugar en los Andes ecuatorianos (Martínez, 1977, p. 54) \\
Guaspud & nombre de una llanura en la prov. de Carchi \\
Ipialpud & a. de Colombia (Martínez, 1977, p. 59) \\
Nispud & lugar en Taques (Martínez, 1977, p. 61) \\
Pialapud & sitio en Colombia (Martínez, 1977, p. 62) \\
Pispud & sitio en la prov. de Carchi (Paz y Miño, 1950b, p. 189); lugar en Car- \\
Tanyalpud & $\begin{array}{l}\text { losama, Colombia (Martínez, 1977, p. 63) } \\
\text { sitio en la prov. de Carchi (Paz y Miño, 1952b, p. 108) }\end{array}$
\end{tabular}

Se podría considerar que <Cuasapud, Cuaspud, Guaspud $>$ son variantes. La mayor parte de estos topónimos son llanuras, pero no se puede todavía proponer una interpretación plausible sobre $\{$-pud\}.

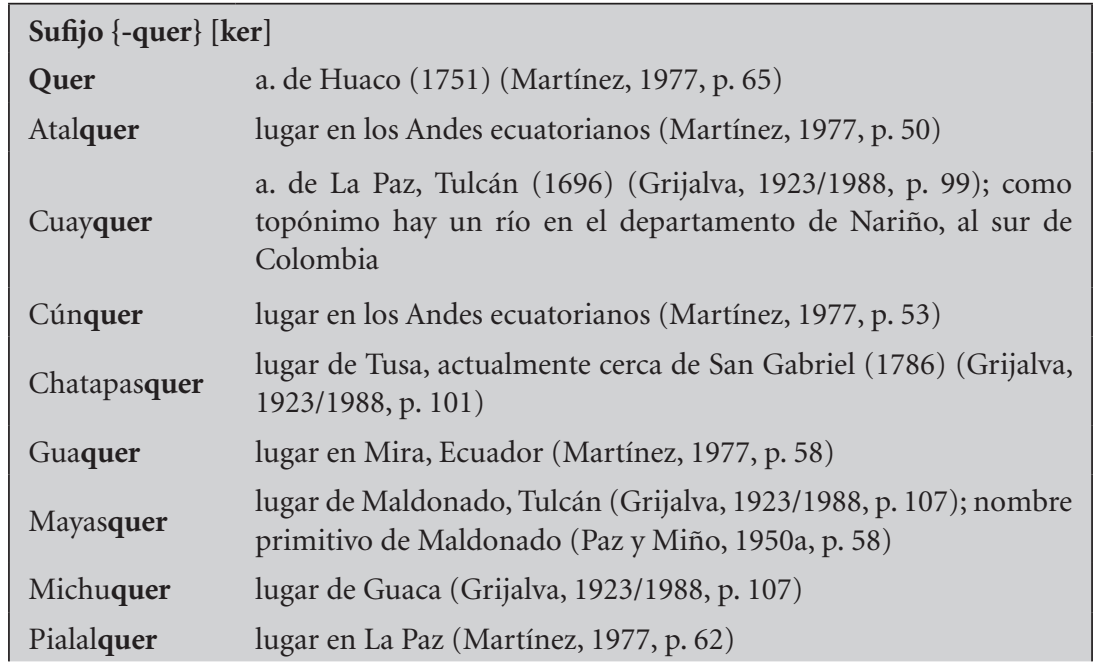




\section{2}

$\begin{array}{ll}\begin{array}{l}\text { Picudquer } \\ \text { Piquer }\end{array} & \begin{array}{l}\text { lugar en Tusa (1592) (Martínez, 1977, p. 62) } \\ \text { orilla derecha del Chota (Martínez, 1977, p. 62) } \\ \text { Pisquer }\end{array} \\ \text { Pueraquer } & \begin{array}{l}\text { lugar en Mira, Ecuador (Martínez, 1977, p. 63) } \\ \text { meseta en la parroquia de Los Andes (Grijalva, 1923/1988, p. 207) }\end{array} \\ \text { Tulcanquer } & \begin{array}{l}\text { antiguo caserío de indios ya desaparecido (Paz y Miño, 1952b, } \\ \text { p. 117) }\end{array} \\ \text { Yagualquer } & \text { sitio en la prov. de Carchi (Paz y Miño, 1952c, p. 213) } \\ \text { Yalquer } & \text { lugar en Guaca (Martínez, 1977, p. 68) }\end{array}$

La palabra <Yagualquer $>$ podría ser un híbrido de <yagual $>$, "arbusto del género Polylepsis y de la familia Rosaceae, conocido como 'árbol de papel', propio de la Cordillera andina”, y de la terminación $<$ quer>, que según el documento colonial antes citado, significaría 'pueblo', 'tierra'. La palabra <Tulcanquer $>$ estaría compuesta de $<$ Tulcán $>$, nombre de la capital de la provincia de Carchi y <quer $>$. Asimismo, podría haber alguna relación entre $<$ pueraquer $>$, el cual por su primer componente a su vez se lo podría relacionar con el nombre $<$ Puerramal $>$, que es el nombre de una comunidad cerca de Chical (cantón Tulcán, prov. de Carchi). Sin embargo, se requiere observar in situ para verificar si la base de las otras palabras mencionadas corresponde a fitónimos o a algún otro elemento conocido.

Entre los antropónimos más característicos de la lengua pasto, pertenecientes a la provincia de Carchi, recopilados de fuentes históricas por Martínez (1977), son los terminados en \{-pas\}. Así, a los citados arriba se añade, entre otros, los siguientes: ${ }^{15}$

15 Entre paréntesis se indica el año en que se ha encontrado la fuente más antigua. Cuando no se señala el año es porque no se sabe si hay alguna fuente escrita antigua. 


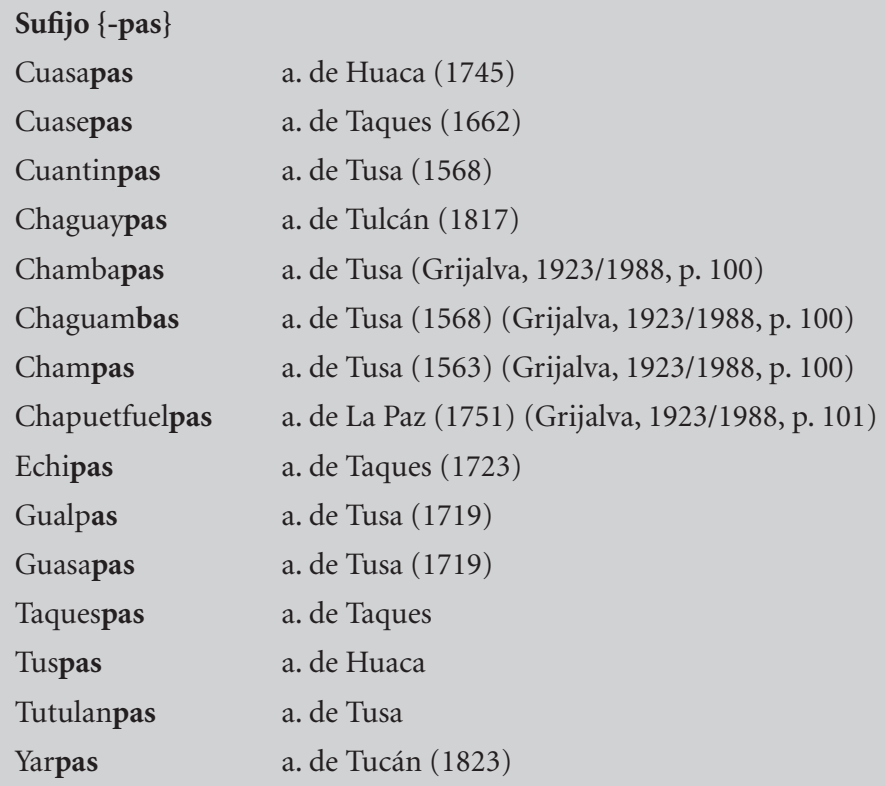

Además de estos, hasta la actualidad existen apellidos terminados en $\{$-paz\}, como Cara-paz, que posiblemente están relacionados con \{-pas\}. Habría que investigar también si el apellido /Paz/ de esta zona está relacionado con $\{$-pas\}. Por otro lado, no hay muchos nombres de lugares con el morfema \{-pas\}, por ejemplo: <Maspas $>$, lugar de Tulcán y apellido de Taques (1730) (Grijalva, 1923/1988, p. 107).

Como la mayoría son apellidos, es prematuro proponer algunas significación para \{-pas/bas\}. Se requiere mayor investigación para verificar si este morfema significa 'familia' como lo sugirió Grijalva. Por otra parte, se puede constatar que después de consonante nasal se ha sonorizado /p/.

Finalmente, se considera conveniente inventariar el nombre de ríos, lomas, montes y valles del territorio de la lengua pasto, para ver si se puede avanzar en la investigación del significado de sus topóni- 
mos. Igualmente, es necesario inventariar los nombres de las plantas de ese territorio para buscar pistas sobre el significado de los topónimos compuestos.

\section{Lengua cara}

Esta lengua habría tenido como frontera norte el río Coangue, llamado también Chota, por el sur al río Guayllabamba, hacia el occidente el río Malbucho, unas 15 leguas al oeste de Lita, por el nororiente el poblado de Chapi, al este de Pimampiro, y por el este a la Cordillera oriental. Esta delimitación está basada en datos coloniales.

Según Cieza de León, los caranquis estaban comprendidos entre el río Chota, ubicado al sur del pueblo de Tuza, y el río Guayllabamba, al norte de Quito. Así pues, las grandes encañonadas de estos dos ríos habrían sido como dos fronteras naturales para los pueblos hablantes de esta lengua. Cieza de León (1553/1973) da a entender que los pueblos de Carangui y Otavalo tenían sus propias lenguas, que eran diferentes al quichua. Así, cuando describe la ruta desde Quito hasta $<$ Tumebamba $>$ (actual ciudad de Cuenca), al referirse a los habitantes del pueblo de Panzaleo, ubicado un poco al sur de Quito, en el valle de Machachi, dice:

Estos y todos los de este reino, en más de mil y doscientas leguas, hablaban la lengua general del Cuzco. Y hablábase esta lengua generalmente porque los señores incas lo mandaban y era ley en todo su reino, y castigaban a los padres si la dejaban de mostrar a sus hijos en la niñez. Mas, no embargante que hablaban la lengua del Cuzco (como digo), todos se tenían sus lenguas, las que usaron sus antepasados. Y así, estos de panzaleo tenían otra lengua que los de Carangue y Otabalo (las cursivas son mías) (1553/1973, p. 111).

Sobre las fronteras noroccidentales y nororientales de esta lengua existe documentación de los siglos XVI y XVII que todavía requiere ser investigada y estudiada. A continuación, se mencionan algunos documentos, principalmente de misioneros mercedarios que, al parecer, 
partían desde Ibarra (prov. de Imbabura) en dirección hacia la Costa y hacia la ceja de selva en la Amazonía.

De los datos coloniales, en una de las "Relaciones Geográficas", ${ }^{16}$ se deduce que la ruta para ir de Ibarra a la Costa era la descrita a fines del siglo XVI por fray Gerónimo de Aguilar, de la Orden de Nuestra Señora de la Merced. Este religioso hace una relación sobre su doctrina en los pueblos de $<$ Caguasquí $>$ y $<$ Quilca $>.{ }^{17}$ Estas dos poblaciones están en el camino hacia la Costa, en la parte occidental de la provincia de Imbabura, un poco antes de la población de Lita. A partir de este último poblado, esta ruta prehispánica seguía la cuenca del río Mira:

La lengua que hablan los indios de este pueblo y Quilca, es la que se trata en esta comarca de Otavalo, particular, aunque la mayor parte de todos estos indios hablan la general del Inga; y puesto caso que algunos no la hablan, entiéndenla muy bien (Gerónimo de Aguilar en Jiménez de la Espada, 1897/1965, vol. III, p. 245).

Sobre la descripción de fray Andrés Rodríguez, doctrinero mercedario de Lita, fechada el 9 de noviembre de $1582,{ }^{18}$ dice: "En lo que toca a la lengua que usan, digo que muy pocos saben la lengua general, porque

16 En adelante se llamarán "Relaciones geográficas" a una serie de textos provenientes de la Colonia que no fueron necesariamente "crónicas", sino más bien datos demográficos y geográficos de carácter estadístico que manejaban ciertas instituciones coloniales, destinados —en parte — para organizar el cobro de tributos. Una parte de estos escritos fueron publicados por Jiménez de la Espada (1881-1887/1965). También existe una publicación ecuatoriana de 1992, de Pilar Ponce Leiva, bajo el título de Relaciones histórico geográficas de la Aundiencia de Quito (siglos XVI-XIX), en la cual constan algunos de los textos publicados antes por Jiménez de la Espada y otros textos rescatados por la autora de los archivos de España.

17 Esta relación es del 12 de noviembre de 1582. Actualmente la población de $<$ Quilca $>$, que estuvo situada al occidente de la provincia de Imbabura, se denomina $<$ Buenos Aires $>$.

18 Según el doctrinero Rodríguez, estos pueblos eran tan pobres que no podían dar ni el "camarico" que eran obligados a dar. 
ellos tienen lengua particular. Es muy obscura" (Rodríguez, 1892/1965, p. 244). Se supone que esta lengua no podía ser otra que la cara.

Sobre esta ruta hacia la Costa, el padre mercedario Joel Monroy trae un cita tomada de un memorial de 1597, del padre fray Gaspar de Torres y cuyo acompañante era don Alonso de Gualpianguo [ sic $],{ }^{19}$ cacique y gobernador de la provincia de Lita. Del relato de este religioso se puede inferir que el último pueblo donde conocían la lengua cara habría estado ubicado a unas 15 leguas hacia el occidente de Lita y a cuatro leguas de un río denominado $<$ Malbucho $>$. Dice que les dio un sermón mediante intérprete, lo cual significa que no conocían la llamada "lengua del inga” que el padre sí sabía conforme se verá más adelante:

Y les hice una plática y sermón de las cosas de Dios nuestro señor, criador del cielo y de la tierra y lo visible e invisible, por lengua de un intérprete y les dí a entender como también habían de dar la obediencia al Rey don Phelipe nuestro señor (Monroy, 1938, p. 324).

El padre Gaspar de Torres pasó de este lugar a territorio del curaca Cayapa. Como se conoce, cayapa es el nombre de la actual nacionalidad chachi, que tiene su propia lengua, que es el cha'palaa, y por lo tanto diferente de la lengua cara.

Desde este día de la madalena, veinte y dos de julio como dicho tengo, estuve en este asiento y pueblo de singobucho hasta veinte de agosto del dicho año de arriba dicho, catequizándolos y rezándoles las oraciones y los mandamientos de la ley de Dios en la lengua de castilla, que por no saber los indios naturales de la tierra la lengua del inga no les rezé en la lengua del inga y ansí comencé a baptizar desde veinte de agosto, al Principal Cayapa y a sus hijos como constará por el libro del santo bap-

19 En los documentos de Gerónimo de Aguilar, en lugar de <Gualapianguo> se escribe $<$ Gualapiango $>$, que debió haber sido un compuesto de \{guala-pi-ango\}, cuya interpretación podría ser 'Señor del río Guala o Gual', si se considera que $<$ ango > significa 'señor, jefe' y < pi> es 'río'. 


\section{7}

tismo que tengo hecho a que me remito, y estuve aquí de asiento hasta veinte y uno de septiembre que fue domingo (las cursivas son mías) (De Torres, 1597 en Monroy, 1938, pp. 325-326).

Por el otro lado, hacia el Oriente, Pimampiro está ubicado al noreste de Ibarra, al pie de la Cordillera oriental. Según su doctrinero, Antonio Borja, a dos leguas al este de este pueblo, cerca de la montaña de Los Quixos, se encontraba otro pueblo llamado Chapi, la mayor parte de cuyos habitantes eran llamados "montañeses", porque tenían sus sementeras en la montaña y hablaban una lengua más difícil que la de los Quixos.

La lengua destos indios de la montaña que digo es muy esquesita, ques muy peor que la de los Quixos, aunque en algunos vocablos se parece la una a la otra, digo de los indios de guerra que se llaman los coronados. Tienen estos indios de la montaña contratación de los indios de guerra y resgatan los unos con los otros (Borja, circa 1591/1965, p. 248).

Chapi parece haber sido frontera lingüística entre la lengua cara y la de la Cordillera oriental, que sería la cofán (actualmente conocida como a'ingae); pues da a entender que allí ya solo una parte minoritaria hablaba la lengua de los de Pimampiro, que a su vez era la de Otavalo.

Los demás indios que hay en Chapi hablan la lengua como estos deste pueblo de Pimampiro, ques lengua esquesita, ques la de Otavalo y Carangue y Cayambe y los demás pueblos desta comarca. Muy pocos indios desta doctrina saben la lengua general del Inga, y casi ningunas mujeres entienden dicha lengua del Inga. No hay en esta doctrina más pueblos que este dicho de Pimampiro, porque el de Chapi se va poblando y reduciendo en este (Borja, circa1591/1965, p. 249).

En cuanto a los términos de esta lengua $<$ cara $>$, algunos autores han recopilado términos de la misma. Así, Grijalva (1923/1988), en la misma obra que recopiló las palabras de los pastos, también trae 382 términos de la lengua cara. Jijón y Caamaño (1940) compiló 610 palabras entre topónimos y antropónimos. Paz y Miño la llama lengua $<$ kara $>$ y juntó 410 palabras y las organizó en 42 grupos, ya sea tomando 
como criterio de agrupación la terminación del vocablo o su parte inicial. Aquiles Pérez, autor de la obra Quitus y caras (1960), con criterio de historiador indica el año donde aparecen mencionados cada uno de los términos de la lengua cara y se pregunta si es lugar o antropónimo, pero a diferencia de Grijalva no indica a qué provincia o parte de ella pertenece el lugar mencionado, lo cual no ayuda mucho en la investigación.

En este estudio, cuando los términos pertenecen a Imbabura no se indica la provincia, sino solo la comunidad o parroquia y el cantón. En cuanto a prefijos, es digno de mención $<$ imba $>$, aunque en las compilaciones se ha prestado más atención al segundo término de los compuestos. Las terminaciones más conspicuas que caracterizan a la lengua $<$ cara > son: <-cachi/gachi, -pi/bi, -puela/buela, -puru/buru, -qui/gui> En cuanto a las variaciones fonéticas de los compuestos, se puede apreciar en los ejemplos la alternancia de las oclusivas sordas /p, t, k/ con sus correlatos [b, d, g]. Los cambios no son sistemáticos. ¿Hubo influencia de la escritura en la fijación de las formas?

Existen algunos términos compuestos con el término <imba> que se combina con otros.

\begin{tabular}{|ll|}
\hline Prefijo $\{$ imba [imba] & \\
Imbabuela & $\begin{array}{l}\text { terreno del cacique de Caranqui, } 1592 \text { (Grijalva, } \\
\text { Imbabura }\end{array}$ \\
& $\begin{array}{l}\text { nombre del volcán que está al noreste de Otavalo } \\
\text { nombre anterior de la laguna que los mestizos la deno- } \\
\text { minan San Pablo (la población indígena de Imbabura, en } \\
\text { Imbacucha }\end{array}$ \\
& gran parte, todavía la conoce con el anterior nombre) \\
\hline
\end{tabular}

En antropónimos, hasta el día de hoy, existen los apellidos $<$ Imba $>$, <Imbaquingo $>$. Es evidente que este último se trata de un híbrido cara-quichua, pues < quingo > está relacionado con <quingu> 'curva en zigzag' como en la expresión <chaguarquingo $>$, sitio en el sur de Quito, compuesto por dos voces quichuas < chaguar $>$ 'penco' y $<$ quingu > 'curva en zigzag'. 


\begin{tabular}{|c|c|}
\hline \multicolumn{2}{|c|}{ Sufijo $\{$-cachi/-gachi\} $[$ kači $\sim$ gači $]$} \\
\hline Cotacachi & lugar y monte en la prov. de Imbabura (Grijalva, 1923/1988, p. 227) \\
\hline Tocachi & $\begin{array}{l}\text { lugar en Cochasquí, Pedro Moncayo, Pichincha (Grijalva, 1923/1988, } \\
\text { p. 227) }\end{array}$ \\
\hline Tupigachi & lugar en Pedro Moncayo, Pichincha (Grijalva, 1923/1988, p. 227) \\
\hline Perugachi & nombre y lugar en Otavalo (Grijalva, 1923/1988, p. 226) \\
\hline Itulcachi & lugar en la prov. de Pichincha, cerca de Pifo \\
\hline Oyacachi & lugar en el noroccidente de la prov. de Napo, al oriente de Pichincha \\
\hline Paragachi & lugar cerca de Pimampiro \\
\hline Perugache & $\begin{array}{l}\text { páramos de Mojanda (Jijón y Caamaño, 1940, p. 253); caserío cerca } \\
\text { de Otavalo; hacienda al noreste de Otón, prov. de Pichincha (Paz y } \\
\text { Miño, 1950b, p. 181) }\end{array}$ \\
\hline Tucalcachi & lugar en Pimampiro (1592) (Jijón y Caamaño, 1940, p. 258) \\
\hline
\end{tabular}

Al parecer no se puede establecer una regla fonética consistente para la variación. Se observa que después de /1/ se mantiene la sorda /k/, pero luego de vocal existen ejemplos donde se ha sonorizado y otros en los cuales no.

Sobre el significado del sufijo \{-cachi/gachi\}, aunque la mayoría son páramos, resulta difícil postular ese significado, pues en el caso de $<$ Cotacachi $>$, se trata de un nevado y no solamente un páramo. Por otra parte, Cerrón-Palomino (2016, comunicación personal) sugiere que podría ser un término inca, donde < cachi> es puquina y significa 'cerco'. De otro lado, se ha encontrado también el topónimo con el componente $<$ cachi $>,{ }^{20}$ en el centro del territorio de la cultura panzaleo, al occidente de Pujilí (prov. de Cotopaxi): <Cachi alto, Cachi San Francisco, Cachi Bajo, Ninin Cachipata>.

20 En la provincia de Salta, al norte de Argentina, zona de antigua presencia quechua, existe también un cerro y un pequeño poblado denominado $<$ Cachi $>$. 


\section{0}

No se puede todavía saber si en este último caso se refiere al término quichua $<$ cachi > 'sal' o si tiene alguna relación $<$ cachi $>$ 'cerco' del territorio de la lengua cara. Habría que ver si estos lugares fueron cercos (chimpu), en cuyo caso la propuesta de Cerrón-Palomino, se confirmaría.

\begin{tabular}{|c|c|}
\hline \multicolumn{2}{|c|}{ Compuestos con <-pi/-vi/-vi $>$ [pi $\sim$ bi] } \\
\hline Ajaví & afluente izquierdo del río Taguando en Ibarra \\
\hline Alámbi & $\begin{array}{l}\text { afluente izquierdo del río Ambi, que a su vez es afluente del río Chota } \\
\text { (Paz y Miño, 1946a, p. 89); afluente del río Nanegal, occidente de la } \\
\text { prov. de Pichincha }\end{array}$ \\
\hline Ambí & río que desciende del Cotacachi y pasa luego cerca de Ibarra \\
\hline Anrabí & nombre de una comunidad en Cotacachi \\
\hline Asabí & río en Íntag (Jijón y Caamaño, 1940, p. 243) \\
\hline Calabí & río en Quitsaya, ${ }^{21}$ actual San José de Minas \\
\hline Cachabí & río en la prov. de Imbabura (Jijón y Caamaño, 1940, p. 245) \\
\hline Cayambi & $\begin{array}{l}\text { nombre antiguo del río Granobles (Paz y Miño, 1947, p. 69) (¿actual } \\
\text { río Blanco?) }\end{array}$ \\
\hline Cuturibí & el nombre de una comunidad en el cantón Pujilí, prov. de Cotopaxi \\
\hline Chinchibí & $\begin{array}{l}\text { hacienda y río en los páramos de Piñán, según Jijón y Caamaño (1940, } \\
\text { vol. I, p. 248) los indígenas pronuncian "ttsinttsipbí" }\end{array}$ \\
\hline Curuví & río en Quitsaya (Jijón y Caamaño, 1940, p. 247) \\
\hline Chapi & población al este de Pimampiro (Borja, 1541) \\
\hline Chorlaví & río encañado y lugar al suroccidente de Ibarra \\
\hline Gualabí & lugar en San Pablo y río en Imantag (Jijón y Caamaño, 1940, p. 249) \\
\hline Guambi & $\begin{array}{l}\text { antiguo nombre de Lita (Jouanen, 1941, p. 327); río en Pimampiro } \\
\text { (Jijón y Caamaño, 1940, p. 247) }\end{array}$ \\
\hline Itambí & riachuelo en San Pablo (Jijón y Caamaño, 1940, p. 250) \\
\hline
\end{tabular}

21 Según la historiadora Lucía Moscoso (2007), Quitsaya fue el nombre prehispánico de San José de Minas, una parroquia desprendida de la parroquia de Perucho, ubicada al noroeste de la actual provincia de Pichincha. El término <quitsaya $>$ en lengua tsa'fiki es muy simbólico, pues significa 'casa en la mitad', de < quitsa > mitad' y <ya $>$ 'vivienda, casa', y este lugar está situado justo en la línea equinoccial. 


$\begin{array}{ll}\text { Mindubí } & \begin{array}{l}\text { puerto ubicado hacia el noroccidente de Lita durante la Colonia } \\ \text { (Jouanen, 1941, p. 327) }\end{array} \\ \text { Pastabí } & \begin{array}{l}\text { río en Otavalo (Jijón y Caamaño, 1940, p. 253) } \\ \text { riachuelo en la Cordillera occidental, entre el Cotacachi y el Yanaures } \\ \text { Pantabí }\end{array} \\ \text { Perlabín y Caamaño, 1940, p. 253) } & \begin{array}{l}\text { río en Quitsaya (Jijón y Caamaño, 1940, p. 253) } \\ \text { río con arena blanca y de recorrido tranquilo, considerado hembra } \\ \text { por los habitantes de la localidad, en Cotacachi, en contraposición con } \\ \text { el río Yanayacu que es el macho, el cual es muy corrientoso y cuando } \\ \text { crece arrasa lo que encuentra a su paso }\end{array} \\ \text { Pichambín }\end{array}$

La pronunciación [pi] solo se da en $<$ Chapi $>$. ¿Será que este no es un compuesto, sino un término simple que no pertenece a este grupo?

Como se puede observar en los ejemplos, todas las palabras terminadas en $\{$-bi/-vi/-pi/\}, son ríos. La primera parte del término provendrían de la lengua $<$ cara $>$ y la segunda $<$ bi/vi/pi $>$ correspondería a las lenguas de los actuales chachi, tsa' chi y awapit, en las cuales la palabra $<$ pi $>$ significa 'río'. Esto se puede probar al observar algunos compuestos presentes en esta zona. Otro es el compuesto $<$ calabi $>$, de $<$ cala $>$ 'plata', en idioma tsa'fiki, y < bi> 'río', con lo cual significaría 'río de plata'. En este caso, la presencia de metales está confirmada porque este río, al igual que el anterior, se encuentra en un antiguo sitio minero que se llamaba <quitsaya $>$, que como se ha mencionado, en lengua tsa'fiki está compuesto de < quitsa> ' mitad' y <ya > 'casa', que sería 'casa en la mitad' (del mundo), debido a que está sobre la línea equinoccial. Actualmente, esta zona se llama San José de Minas debido a la explotación de minas que se realizó durante la Colonia. El caso de $<$ pantabi $>$ provendría de $<$ panta $>$ 'plátano' en idioma cha'palaa, y $<$ bi $>$ proveniente de $<$ pi $>$ 'río'. Entonces, la expresión completa significa 'río de plátanos'. Inclusive existe en la zona el híbrido $<$ perlabi $>$ del castellano $<$ perla $>$, y $<$ bi $>$ 'río' del cha'palaa, cuyo significado es 'río de perlas'.

En estos casos nótese el orden del compuesto es adjetivo-nombre, pero habría que estudiar si en el resto de términos ocurre lo mismo. De 


\section{2}

todas maneras, se puede postular que los topónimos antes señalados son términos compuestos, en algunos casos híbridos pertenecientes a dos lenguas. En consecuencia, es necesario investigar fitónimos y otras características de los lugares para ver si se puede encontrar el significado de la primera parte de estos términos.

Las lenguas awapit, cha'palaa y tsa'fiki actualmente están en la Costa. Sin embargo, el hecho de que la presencia de las terminaciones $<$ bi, vi, pi $>$ sea más frecuente en los topónimos de la parte occidental de las provincias serranas norteñas de Carchi, Imbabura y Pichincha, antes que en los de la parte oriental de las mismas podría ser un indicio de que existió, en época prehispánica, una frontera lingüística entre estas lenguas de la Costa y las de la Sierra norte y centro, como se verá después al tratar el caso de la lengua panzaleo. Por otra parte, en la mitología del pueblo chachi actual existe la creencia de que ellos antiguamente estuvieron en la Sierra, en Imbabura. Con esto queda el interrogante de si la influencia fue desde la Costa hacia la Sierra o viceversa.

\begin{tabular}{|c|c|}
\hline \multicolumn{2}{|c|}{ Terminación <-piro/biro > [piro biro] } \\
\hline Ambubiro & río en San José de Minas, prov. de Pichincha \\
\hline Chachimbiro & lugar en la prov. de Imbabura (Pérez, 1960, p. 19) \\
\hline Pimampiro & $\begin{array}{l}\text { lugar al nororiente de la prov. de Imbabura (1582) (Pérez, 1960, } \\
\text { p. 18) }\end{array}$ \\
\hline Putapiro & $\begin{array}{l}\text { zona de San Pablo (1640-1686), testamento de Rodrigo Anrrango } \\
\text { (Caillavet, 2000, p. 112) }\end{array}$ \\
\hline Tabiro & lugar en Otavalo \\
\hline Tumbabiro & $\begin{array}{l}\text { lugar en la prov. de Imbabura (1570) (Grijalva, 1923/1988, p. 154); } \\
\text { pueblo de Carangui }\end{array}$ \\
\hline Urgachinbiro & lugar en la prov. de Imbabura (1592) (Pérez, 1960, p. 22) \\
\hline
\end{tabular}

En la relación atribuida al padre Antonio Borja, sin fecha precisa (circa 1591) se indica el siguiente significado para <pimampiro $>$ :

El pueblo principal desta doctrina se llama Sant Pedro de Pimampiro; quiere decir este nombre Pimampiro "alaguna grande" [sic]. Pusiéronle 


\section{3}

este nombre los antiguos, por causa de una alaguna [sic] muy grande questá en este asiento, la cual desaguaron los moradores que solían vivir aquí e hicieron en ella sus sementeras; e hoy día los naturales deste pueblo tienen en ella muchas rozas (Jiménez de la Espada, 1881-1887/1965, tomo III, p. 248). ${ }^{22}$

Con este dato y observando las otras palabras terminadas en $<$ piro/biro $>$, se podría suponer que Pimampiro estaría compuesto de dos morfemas \{piman\} y \{piro\}. Esto está argumentado por Caillavet (2000, p. 103) con el siguiente dato: "En un documento de 1609 'Pimampiro' aparece también como 'valle de Piman' Indias (AGI/S Quito 374)". Por su parte, Paz y Miño (1937, p. 23) señala tres lugares, solo en la provincia de Pichincha, que llevan el nombre de Piman.

Por otra parte, en el trabajo de campo realizado en la misma provincia de Imbabura se encontró que existe otro lugar conocido hasta el día de hoy como < valle de piman> junto a la comunidad La Bolsa, frente a Peguche, en Otavalo, en cuyo lugar se puede observar restos de camellones. Esto confirmaría la hipótesis de que < piman> habría significado 'camellón'. Entonces < valle de piman > significaría 'valle de camellones'. Además, Caillavet (2000) ha mostrado que en la Sierra norte, en tiempos prehispánicos, los cultivos se realizaban en camellones construidos en una especie de valles lacustres. Esta técnica permitía asegurar la producción agrícola frente a dos fenómenos naturales temidos por la población indígena y campesina: la sequía y la helada, porque la presencia del agua en torno a los camellones calienta en algunos grados el lugar e impide las heladas.

Se averiguó alguna posible relación de < piman $>$ con las lenguas de la frontera occidental de la lengua cara y se encontró lo siguiente (que requiere investigaciones futuras). En lengua cha'palaa, $<$ piman-

22 Según el diccionario de la RAE (22a edición, 2003, p. 57), “alaguna” es un término en desuso para "laguna". 
ganu> es un verbo en infinitivo, que significa 'bajar el nivel del río', con lo cual queda al descubierto una capa de tierra. En lengua tsa'fiki $<$ piman> significa 'puente' o 'algo sobresalido'. En consecuencia, con los datos señalados, se puede postular que $<$ Pimampiro $>$ podría significar 'laguna con camellones'. En este caso, el término <laguna $>$ habría que entenderlo como una especie de valle lacustre.

\begin{tabular}{|c|c|}
\hline \multicolumn{2}{|c|}{ Terminación $\{$-puela/-buela\} $[$ puela $\sim$ buela] } \\
\hline Ajumbuela & $\begin{array}{l}\text { hacienda al suroccidente del pueblo de Tumbabiro (Paz y Miño, } \\
\text { 1946, p. 86) }\end{array}$ \\
\hline Alobuela & $\begin{array}{l}\text { lugar en parroquia Perucho, prov. de Pichincha (Grijalva, } \\
\text { 1923/1988, p. 206), antiguamente se llamó Curubuela }\end{array}$ \\
\hline Arabuela & valle cerca de la parroquia Atahualpa, al norte de Quito \\
\hline Anrabuela & lugar en Ambuquí (1596) (Jijón y Caamaño, 1940, p. 244) \\
\hline Apuela & lugar en la parroquia Íntag (Grijalva, 1923/1988, p. 206) \\
\hline Carabuela & lugar junto a Ilumán (Grijalva, 1923/1988, p. 285) \\
\hline Caribuela & lugar cerca de Cotacachi \\
\hline Carpuela & $\begin{array}{l}\text { hacienda en la vega izquierda del río Chota (Grijalva, 1923/1988, } \\
\text { p. 207) }\end{array}$ \\
\hline Cubimbuela & sitio en la prov. de Imbabura (Paz y Miño, 1947, p. 77) \\
\hline Colimbuela & $\begin{array}{l}\text { estancia en la prov. de Imbabura, juicio entre Cristina Ango de } \\
\text { Salasar - cacica principal de Otavalo- y las monjas de la Lim- } \\
\text { pia Concepción de Ibarra (Caja 15, Archivo Nacional, } 8 \text { de enero } \\
\text { de 1686); hacienda-obraje de la Colonia (Borchart de Moreno, } \\
\text { 2007, pp. 299-315) }\end{array}$ \\
\hline Congalpuela & $\begin{array}{l}\text { una chacara, testamento de Juan Quibango (1581) (en Caillavet, } \\
\text { 2000, pp. 106-107) }\end{array}$ \\
\hline Culumbuela & $\begin{array}{l}\text { en la zona de Caranqui (1660) (AHBC/I, Juicios, Paquete } 4 \text {, } \\
\text { 1654-1659): "Una quadra nombrada Culumbuela y otro pedaço } \\
\text { de tierra llamada Higosturabuela, y otro pedaço llamado Quin- } \\
\text { rrastudbuela" (en Caillavet, 1983, p. 8) }\end{array}$ \\
\hline Guañubuela & $\begin{array}{l}\text { hacienda en la parroquia de Caguasquí (Grijalva, 1923/1988, } \\
\text { p. 207) }\end{array}$ \\
\hline Imbabuela & $\begin{array}{l}\text { terreno del cacique de Caranqui (1592) (Grijalva, 1923/1988, } \\
\text { p. 207) }\end{array}$ \\
\hline
\end{tabular}




\begin{tabular}{|c|c|}
\hline Itubuela & lugar en Íntag (Jijón y Caamaño, 1940, p. 250) \\
\hline Itugarabuela & $\begin{array}{l}\text { en un testamento (1609), "una chacara nombrada itugarabuela" } \\
\text { (en Caillavet, 1983, p. 7) }\end{array}$ \\
\hline Mollebuela & $\begin{array}{l}\text { terreno en Puenalchi (1592) (Pérez, 1960, p. 20); lugar en Pi- } \\
\text { mampiro (1592) (Jijón y Caamaño, 1940, p. 251) }\end{array}$ \\
\hline Matabuela & sitio en la prov. de Imbabura (Paz y Miño, 1949b, p. 232) \\
\hline Mitababuela & lugar en la prov. de Imbabura (Paz y Miño, 1950a, p. 60) \\
\hline Narchibuela & $\begin{array}{l}\text { lugar en Pimampiro en Imbabura (Grijalva, 1923/1988, p. 226; } \\
\text { Pérez, 1960, p. 20) }\end{array}$ \\
\hline Natabuela & $\begin{array}{l}\text { lugar en Ambuquí; caserío en San Antonio en Imbabura (Grijal- } \\
\text { va, 1923/1988). }\end{array}$ \\
\hline Natabuela & lugar en Ambuquí (Jijón y Caamaño, 1940, p. 251) \\
\hline Paltabuela & $\begin{array}{l}\text { plantación de coca en Pimampiro (1592) (Grijalva, 1923/1988, p. } \\
\text { 207); lugar en San José de Minas (Jijón y Caamaño, 1940, p. 250) }\end{array}$ \\
\hline Peribuela & $\begin{array}{l}\text { comunidad en Imantag, Cotacachi; saliente del nevado Cotaca- } \\
\text { chi (Paz y Miño, 1950b, p. 180) }\end{array}$ \\
\hline Pilchibuela & $\begin{array}{l}\text { lugar en Otavalo (Jijón y Caamaño, 1940, p. 255); nombre primi- } \\
\text { tivo del pueblo de San Rafael (Paz y Miño, 1950b, p. 184) }\end{array}$ \\
\hline Pirugachibuela & $\begin{array}{l}\text { plantación de coca en Pimampiro (1592) (Grijalva, 1923/1988, } \\
\text { p. 207) }\end{array}$ \\
\hline Puchambuela & $\begin{array}{l}\text { en la zona de Cahuasquí (1683), libro de proveimientos, "en el } \\
\text { llano de puchambuela" (en Caillavet, 1983, p. 7) }\end{array}$ \\
\hline Puchimbuela & lugar en Salinas (1592) (Grijalva, 1923/1988, p. 130) \\
\hline Puchinbuela & $\begin{array}{l}\text { hacienda en la parroquia de Salinas (1594) (Grijalva, 1923/1988, } \\
\text { p. 207) }\end{array}$ \\
\hline Quinchibuela & lugar en Puenanche (Jijón y Caamaño, 1940, p. 256) \\
\hline Quitobuela & $\begin{array}{l}\text { lugar en Pimampiro (Grijalva, 1923/1988, p. 207; Jijón y Caama- } \\
\text { ño, 1940, p. 250) }\end{array}$ \\
\hline Tababuela & lugar en Ibarra (Jijón y Caamaño, 1940, p. 257) \\
\hline Tatabuela & Ambuquí, en el valle del Chota, al norte de Ibarra \\
\hline Tilimbuela & $\begin{array}{l}\text { hacienda al noroccidente de Chillogallo, prov. de Pichincha (Paz } \\
\text { y Miño, 1952b, p. 112) }\end{array}$ \\
\hline Tutumbuela & $\begin{array}{l}\text { lugar en Perucho, prov. de Pichincha (Jijón y Caamaño, 1940, } \\
\text { p. 258) }\end{array}$ \\
\hline
\end{tabular}




\section{6}

Utubuela

Yalambuela

Yrubipuela

Ytugarabuela lugar en Pimampiro (1593) (Jijón y Caamaño, 1940, p. 258); nombre primitivo del pueblo de Pimampiro (Paz y Miño, 1952c, p. 209)

lugar en Cotacachi (Jijón y Caamaño, 1940, p. 258)

en la zona de Caranqui (1581) (AHBC/I, Juicios, Paquete 24), testamento de Juan Quibango, "una chacara nombrada Yrubipuela... en el lugar llamado puetac aba tengo una chacara nombrada malchinbuela [...] una chacara nombrada pinguisebuela. Una chacara nombrada carebuela y mas una chacara nombrada Congalpuela" (en Caillavet, 1983, p. 7; 2000, pp. 106-107)

chacara en la zona de Otavalo, en un testamento (1609) (en Caillavet, 1983, p. 7).

En relación a la forma, se realiza como [puela] después de [r, l], pero en los demás contextos ha evolucionado a [buela]. Sin embargo, el caso de $<$ Apuela $>$ no se explica por esta regla.

En cuanto a la estructura, se puede observar que la mayoría de palabras son compuestas de una base más \{-buela/puela\}. En algunos casos la base es una palabra proveniente del quichua y por lo tanto es posible conocer su significado. Tal es el caso de: molle 'una planta'; pilchi 'un tipo de calabaza', yalam > yaran 'sauco' en quechua general.

Según Caillavet, el topónimo de más alta frecuencia de la prov. de Imbabura es el de $\{$-buela\}, y sobre su sentido dice:

Viene asociado con expresiones "tierra, "pedaço de tierra", "chacaras", pero también "loma, llanito, valle”. Por su frecuencia e indeterminación, lo podemos considerar como una terminación genérica que corresponde a la idea de "tierras". El hecho de que aparezca a veces como sufijo suplementario, después de los demás sufijos más precisos (-muet, -cacho) también lleva a darle este sentido general (1983, p. 7).

Caillavet parece tener razón al interpretar que $\{$-buela/puela $\}$ esté asociado con: <chacara, llanito, valle>, pero no parece haber justifica- 


\section{7}

ción para la relación con $<$ loma $>$, pues prácticamente la totalidad de los topónimos observados en el trabajo de campo no se refieren a lomas.

Por otra parte, en el intento de buscar el posible significado de este sufijo se observa que hay unos híbridos en los cuales la primera parte del término tiene un significado conocido. Así, se puede notar la presencia de híbridos como <mollebuela, paltabuela $>$, los cuales podrían a futuro ser el punto de partida para nuevas investigaciones. Efectivamente, los términos $<$ molle, palta $>$ son fitónimos; $<$ molle $>$ es la planta con su fruto que tiene, entre otras, propiedades antiespasmódicas y cicatrizantes; $<$ palta $>$ es el aguacate. Si esto es así, \{-buela/puela $\}$ podría asociarse con 'planicie, tierra de, lugar de', etc. De otra parte, en la comunidad de Churumanga, parroquia El Rosario, del pueblo Salasaca (cantón Pelileo, prov. de Tungurahua), existe un lugar plano denominado [mužipamba] 'pamba de molle, valle de molle’. En este lugar existen árboles de molle hasta el día de hoy. Si se tiene en cuenta esta expresión del quichua, la expresión $<$ mollebuela $>$ se podría asociar con [mužipamba]. Entonces \{-buela\} sería $\{$ pamba\}, es decir, 'planicie’ y por lo tanto $<$ mollebuela $>$ sería 'pampa de molle'. En cuanto a < paltabuela $>$ sería 'pampa de aguacates'. Según Paz y Miño (1950b, p. 173), existen lugares denominados < paltabamba > en las provincias de Pichincha y Bolívar. También hay un lugar y una quebrada afluente del río Pisque en la provincia de Pichincha que se denomina <aguacatepamba>, un híbrido castellano-quichua que equivaldría a $<$ paltabuela $>$, del híbrido quichua-cara. Una ayuda para confirmar estas sospechas sobre la toponimia de la lengua cara, sería estudiar la fitonimia de esta zona, para ver si la primera parte de los otros términos corresponden a nombres de plantas $\mathrm{u}$ algunos otros elementos de la naturaleza.

El caso de $<$ quitobuela $>$ es más complejo, pues se podría asociar con el nombre de $<$ Quito $>$, capital del Ecuador. Pero, por otra parte, en la provincia de Bolívar la población indígena le llama $<$ quitomoso $>$ a un tipo de calabaza que en el resto de la Sierra se llama $<$ zambo $>$. Los salasacas de la provincia de Tungurahua hacen una distinción entre $<$ quito $>$ y $<$ quitomoso >: el primer término es para el fruto cuando está todavía pequeño y 


\section{8}

el segundo cuando ya está grande. ${ }^{23}$ Según Paz y Miño (1951, p. 249), existe una hacienda al sur de Pelileo (prov. de Tungurahua) denominada $<$ Quitocuchu>, que sería un híbrido: la primera parte proveniente de una lengua prequichua y la segunda del quichua; entonces, significaría 'rincón de las calabazas'. Así pues, queda el interrogante de si < quito> fue originalmente un fitónimo que dio lugar a un topónimo o si siempre fue un topónimo. ${ }^{24}$

El caso $<$ Guañubuela $>$, ¿podría asociarse la primera parte de la palabra con el término quichua $<$ wañuy $>$ 'morir, muerte'? Sin embargo de lo dicho anteriormente, en un sitio lejano al territorio de la lengua cara existe el topónimo < pambabuela>, en Salinas de Guaranda (prov. de Bolívar), lo cual podría en duda la propuesta de que \{-buela\} sea el equivalente de <pamba $>$ 'pampa', pues este topónimo resultaría como $<$ pamba-pamba $>$, a menos que se considere el caso de topónimos híbridos redundantes. Efectivamente, según Cerrón-Palomino (2016, comunicación personal), existen abundantes tautologías toponímicas en la región andina como <rio-mayo > 'río-río' o < cachi-pucara $>$ 'fortaleza-fortaleza'.

No se sabe si la planicie del actual aeropuerto de Quito llamada $<$ tababela $>$ se pueda asociar con $<$ tababuela $>$ o si $\{$-bela $\}$ es un sufijo diferente de $\{$-buela\}. Igualmente, en la Sierra centro (prov. de Bolívar) existen nombres de lugares como $<$ Tomabela, Telimbela $>$. ¿Hay relación con $\{$-buela $\}$ del territorio de la lengua cara?, ¿o \{-bela\} es otra terminación diferente? Existe también < puela >, pueblo al este de Riobamba y río afluente derecho del río Chambo (prov. de Chimborazo) (Paz y Miño, 1952b, p. 239).

En cuanto a $<$ alobuela $>$, podría ser un compuesto de $<$ alo $>$ y $<$ buela $>$. En lengua tsa'fiki $<$ alo $>$ es un tipo de árbol denominado 'clavalín', en tanto que en la lengua cha’ palaa <alu > es 'aguacate’. Nótese que

23 Esta información fue proporcionada por Luciana Masaquiza y corroborada por otras personas de la zona.

24 González Holgín (1608/1993, p. 310) trae el significado de Quito como 'paloma, tórtola mediana'. Sin embargo, ni en la investigación de campo ni en la bibliografía de quichuistas ecuatorianos se ha encontrado esta interpretación. 
en esta última lengua no hay la vocal $<\mathrm{o}>$, por lo tanto se asimila $\mathrm{a}<\mathrm{u}>$. Con esto $<$ alobuela $>$ se podría interpretar como 'planicie de aguacates'. En la zona occidental de la provincia de Cotopaxi existe una planicie denominada $<$ alobamba $>$, que confirmaría que este componente $<$ alo $>$ era un término común entre las lenguas prequichua cara, panzaleo y las actuales cha'palaa y tsa'fiki.

Con estos datos se podría postular que la diferencia entre los términos $<$ piro $>$ y $<$ buela $>$, sería que el primero se refiere a un valle lacustre y el segundo es una planicie, es decir un valle no lacustre.

\begin{tabular}{|c|c|}
\hline \multicolumn{2}{|c|}{ Terminación $\{$-puru/-buro $\}$ [puro $\sim$ buru] } \\
\hline Aloburo & $\begin{array}{l}\text { sitio al norte de Tabacundo, prov. de Pichincha (Paz y Miño, 1937, } \\
\text { p. 11) }\end{array}$ \\
\hline Aluburo & monte al norte de Ibarra (Jijón y Caamaño, 1940, p. 243) \\
\hline Anraburo & loma en Imantag, Cotacachi \\
\hline Añaburo & lugar en la parroquia Urcuquí \\
\hline Camburo & lugar en Atuntaqui (1585) (Jijón y Caamaño, 1940, p. 245) \\
\hline Caraburo & montaña al noroeste del actual aeropuerto en Tababela, en Quito \\
\hline Cayamburo & $\begin{array}{l}\text { nevado conocido ahora como Cayambe, prov. de Pichincha (Jijón } \\
\text { y Caamaño, 1940, p. 246) }\end{array}$ \\
\hline Cuniburo & $\begin{array}{l}\text { lugar en Lita; una saliente al sur de Cayambe, prov. de Pichincha } \\
\text { (Paz y Miño, 1947, p. 80) }\end{array}$ \\
\hline Gualinburo & $\begin{array}{l}\text { altura al sureste de Pambamarca, Quito, prov. de Pichincha (Paz y } \\
\text { Miño, 1947, p. 240) }\end{array}$ \\
\hline Gualapuro & comunidad entre Otavalo y Cotacachi, ubicada detrás de una loma \\
\hline Iraburo & monte en Ilí (Jijón y Caamaño, 1940, p. 250) \\
\hline Ninanburo & monte en San José de Minas, prov. de Pichincha \\
\hline Payaburo & altura en Salinas (Jijón y Caamaño, 1940, p. 253) \\
\hline Quitoburo & loma al suroeste de Otavalo, cerca del antiguo Camino Real \\
\hline Tuchinburo & altura al sur de la cordillera de Filocorrales, prov. de Pichincha \\
\hline Yamburo & lugar en Tumbabiro (Jijón y Caamaño, 1940, p. 258) \\
\hline
\end{tabular}




\section{0}

Casi en la totalidad de las terminaciones recopiladas se realizan como [buru], con la excepción en $<$ Gualapuro $>$ que termina en [puro].

Se puede observar que todos los nombres se refieren a montes o lomas. Por otra parte, existe un lugar en la parroquia Cangahua (prov. de Pichincha) denominado Quitoloma, este lugar es una loma de 3780 metros de altura y aquí existe un sitio arqueológico. Se podría suponer que $<$ Quitoloma $>$ sea equivalente en significado al término $<$ Quitoburo $>$, que es un topónimo de Otavalo (prov. de Imbabura) (Grijalva, 1921, p. 37). Grijalva, a partir de un documento de 1594, lo interpreta como 'Quitoloma'. Esta loma <Quitoburo> está cerca de Otavalo. Está cerca del Camino Real que unía Otavalo con Quito, entre una loma denominada Oyagato y el río Calvaquen. ${ }^{25}$ Con estos antecedentes se podría postular que existe la posibilidad plausible de que \{-buro $\}$ haya significado 'loma, cerro'. Por otra parte, en lengua tsa'fiki el término $<$ bu'tu $>$ significa 'cima'. ¿Existe alguna relación entre $<$ buro $>$ y $<$ bu'tu $>$ ?

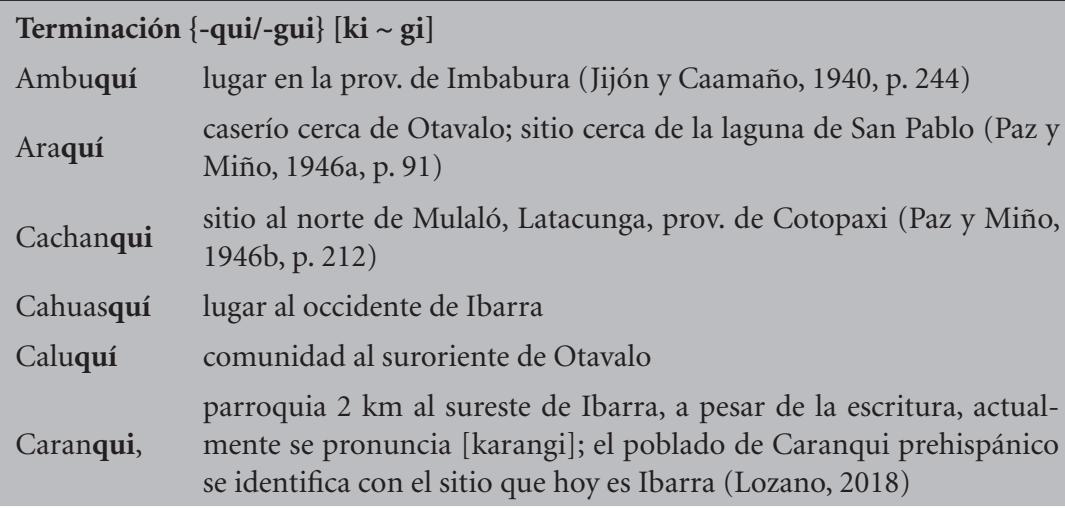

25 En Riobamba existe una loma dentro de la ciudad que se llama $<$ Loma de Quito $>$. En la provincia de Chimborazo y zonas aledañas también existe el apellido $<$ Quito $>$. Esto abre la posibilidad de que el nombre $<$ Quito $>$ no se refiera únicamente a la ciudad de $<$ Quito $>$. 


\section{1}

\begin{tabular}{|c|c|}
\hline Caraqui & $\begin{array}{l}\text { sitio entre Tocachi y Tabacundo, prov. de Pichincha (Paz y Miño, } \\
\text { 1947, p. 66) }\end{array}$ \\
\hline Cochasquí & sitio arqueológico en el cantón Pedro Moncayo, prov. de Pichincha \\
\hline Imbaquí & lugar en Otavalo \\
\hline Inrraquí & $\begin{array}{l}\text { Está en la lista de Paz y Miño (1941a, p. 35), pero no ha podido ser } \\
\text { confirmada en los mapas }\end{array}$ \\
\hline Malchinguí & $\begin{array}{l}\text { población en las faldas meridionales de Mojanda, prov. de Pichincha } \\
\text { (Jijón y Caamaño, 1940, p. 251) }\end{array}$ \\
\hline Picalquí & Lugar en el cantón Pedro Moncayo, prov. de Pichincha \\
\hline Pumaquí & $\begin{array}{l}\text { Está en la lista de Paz y Miño, pero no ha podido ser confirmada en } \\
\text { los mapas }\end{array}$ \\
\hline Pusuquí & lugar en Mitad del Mundo, prov. de Pichincha \\
\hline Quinchuquí & lugar al norte de Otavalo \\
\hline Quisiquí & $\begin{array}{l}\text { Está en la lista de Paz y Miño, pero no ha podido ser confirmada en } \\
\text { los mapas }\end{array}$ \\
\hline Sangolquí & ciudad cerca de Quito, prov. de Pichincha \\
\hline Tontaquí & nombre antiguo de Atuntaqui (Jijón y Caamaño, 1940, p. 257) \\
\hline Yaruquí & lugar y población cercana al Quinche, prov. de Pichincha \\
\hline Urcuquí & lugar al occidente de Ibarra \\
\hline
\end{tabular}

Solo después de nasal /k/ se realiza como [g]. Este monosílabo podría tratarse de un sufijo. No se ha encontrado <qui $>$ en forma aislada ni en un listado de palabras compuestas donde esté como primer miembro, con la excepción de $<$ Quito $>$. Caillavet, sobre algunos sufijos entre los que se encuentra $\{$-qui\}, lo asocia con 'quebrada' y dice lo siguiente: "Los sufijos correspondientes a la idea de 'quebrada' serían -vi/-bi y también -que/-qui o -xe/- xi o -che /-chi, a veces combinados para dar -biche/-pichi. Por tratarse de una zona donde corre agua, podemos encontrar también la palabra 'valle"' (1983, p. 9). Sin embargo, Caillavet señala que también <-que/-qui> significarían 'quebrada'. Los ejemplos tomados de distintas fuentes coloniales, relacionadas con juicios sobre tierras, proveimientos, censos, testamentos, etc. no son muy convincentes sobre este hecho y menos todavía para sostener que podría 


\section{2}

relacionarse con el significado 'valle'. Las palabras $<$ quebrada $>$ y $<$ valle $>$ aparecen en el contexto de las citas, pero los documentos coloniales presentados por la autora no dicen que los topónimos terminados en este sufijo signifiquen 'quebrada' o 'valle'.

En cuanto a los antropónimos, los apellidos terminados en \{-ango $\}$ son característicos del territorio de la lengua cara. Una buena parte de ellos aparecen en los documentos coloniales y eran generalmente caciques. La historiadora Borchart de Moreno (2007, p. 21), siguiendo a Caillavet (2000, pp. 27-28), relaciona el término <ango > con 'señor étnico'.

\begin{tabular}{|l|}
\hline Ango \\
Anrango \\
Andrango \\
Cacuango \\
Farinango \\
Matango \\
Ulcuango \\
\hline
\end{tabular}

El caso de $<$ Ulcuango $>$, se trata de un híbrido quichua-cara de $<$ ulcu $>$, proveniente de $<$ urku $>$ 'cerro' en quichua, y $<$ ango $>$, proveniente de la lengua cara, cuya interpretación sería 'Señor del cerro'. Los demás términos estarían integrados por ambos componentes de la lengua cara.

\section{Lengua panzaleo}

Luego de tratar sobre los pueblos panzaleo ubicados en el actual valle de Machachi (al sur de Quito), Mulahalo (actual Mulaló), Tacunga (actual Latacunga), Mulliambato (actual Salcedo) y Ambato, Cieza de León - al referirse a los de Mocha — da a entender que los habitantes de esta última localidad también hablan la lengua panzaleo: "Hay a la redonda de Mocha algunos pueblos de indios, los cuales todos andan vestidos, y lo mismo sus mujeres, y guardan las costumbres que tienen los de atrás, y 
son de una misma lengua" (Cieza de León, 1553/1973, p. 117). Esto haría suponer que la lengua panzaleo abarcaba un territorio desde el sur de Quito, ${ }^{26}$ las provincias de Cotopaxi y Tungurahua, parte de la provincia de Bolívar y quizá la parte norte de la provincia de Chimborazo. Sin embargo, del dato del susodicho cronista, algunos autores del siglo XX han cuestionado la existencia de esta lengua, como se verá más adelante.

Jijón y Caamaño registra 3398 palabras de topónimos y antropónimos atribuidos al idioma panzaleo. Además de los datos de Cieza de León, uno de los argumentos que este autor tuvo para postular la existencia de los panzaleos como distintos de los caranquis, fue la ausencia de tolas (montículos artificiales de tierra con fines posiblemente funerarios) al sur del río Guayllabamba (cf. Costales, 2002, p. 93).

Asimismo, Luis Paz y Miño (1941) recolectó 562 palabras de la zona panzaleo y los aglutinó en 82 grupos según la terminación o el comienzo de palabra. Sin embargo, como con las demás lenguas, no ensayó interpretaciones ni tampoco ofreció datos históricos.

Más tarde, Aquiles Pérez recopiló 6055 topónimos y antropónimos de la zona de la cultura que él denomina “seudo-panzaleos" (1962). Los llamó así pretendiendo mostrar que esta lengua es una mezcla de varias lenguas con base tsa'fiki. Él supuso que los topónimos y antropónimos de este pueblo estarían vinculados no solamente con las lenguas de los

26 Los datos coloniales no dejan claro qué idioma hablaban los habitantes de Quito, sin embargo, al norte de Quito existe una población denominada <Calacalí $>$. Esta palabra tiene significado en lengua tsa'fiki y está compuesta de $<$ cala $>$ 'plata' $\mathrm{y}<$ calí $>$ que es el nombre con el que los tsa'chi afectivamente conocen a la zona de Santo Domingo de los Colorados. Pero en el pasado pudo haber significado: 'lugar, sitio donde uno vive', algo parecido a $<$ llakta $>$ del quichua La existencia de los topónimos $<$ Calacalí $>$ 'sitio de plata' y $<$ Calabi $>$ 'río de plata' al norte de Quito, permite sugerir que en este lugar se hablaba una variedad de la lengua tsa'fiki y sería un argumento a favor de que el panzaleo tuvo alguna relación lingüística con el actual tsa'fiki. Además, se ratificaría que la zona del actual Quito no era parte de la lengua cara, sino del panzaleo. 


\section{4}

actuales tsa'chila (colorados) y la de los chachilla (cayapas), sino inclusive con lenguas de lugares distantes como son la atacameña, jíbara (shuar), aymara, páez, guaraní, araucana, etc. Estas lenguas, además de la quichua y el castellano, habrían sido las que intervinieron en la conformación de los topónimos y antropónimos de la Sierra centro (Pérez, 1962). ${ }^{27}$

Para explicar esto recurre a fraccionar los términos en dos o tres partes y asignar a cada partícula una supuesta procedencia de cualquiera de las lenguas antes mencionadas, basándose en algún parecido fonético. Con este fin se imagina apócopes, metátesis, etc. Así, para un topónimo dice: "Isimbo, parcialidad, 1763; del cayapa i, ir; y shimbu, mujer" (Pérez, 1962, p. 68), sin embargo, con el trabajo lingüístico se constata que el verbo 'ir' en la lengua cha'palaa (antiguamente denominada cayapa) es $<$ jinu $>$, mas no $<$ i $>$, aunque $<$ shimbu $>$ sí significa 'mujer adulta'. Pérez en este caso, como en la generalidad de sus interpretaciones, no señala el significado que tendrían los términos compuestos, sino solo el significado de cada parte por separado. Pero como se puede apreciar, al juntar las dos palabras no da un significado lógico para denominar a un lugar. En el caso de "Isimbo" es más plausible que el nombre de este lugar, situado al norte de Latacunga, corresponda a un fitónimo, porque, efectivamente, sus hablantes creen que antes allí hubo muchas plantas de una especie denominada [ižimbo].

Siguiendo este mismo estilo, para un antropónimo Pérez dice: "Montaluisa, 1658; del Araucano monta (cu), el que espanta; del Atacameño luisa, arrancar los ojos" (1962, p. 82). Sobra señalar que a la luz de la lingüística y la filología esta interpretación carece de plausibilidad y consistencia, además de seriedad.

27 Como historiador aficionado a la etimología, en 1960 publicó Quitus y caras, libro donde reunió 5375 palabras entre topónimos y antropónimos. A diferencia de Paz y Miño, que los agrupó por terminaciones, él agrupó los nombres por zonas geográficas. Sin embargo, aunque en el campo de la historia colonial recurrió a las "Relaciones geográficas" de Jiménez de la Espada (1897) y a los archivos sobre haciendas, juicios, etc., en el campo lingüístico no tuvo la formación adecuada. 


\section{5}

Por su parte, Alfredo Costales Samaniego y Dolores Costales Peñaherrera (2002, pp. 93-94), apoyándose en Pérez, vuelven a sostener que los antiguos habitantes de las provincias de Imbabura, Pichincha, Cotopaxi y Tungurahua fueron de culturas provenientes de la Costa: cayapas (actuales chachi). Quienes a su vez fueron invadidos por los caras (colorados, actualmente tsa'chila). Ellos insisten en que Jijón y Caamaño se inventó la lengua y cultura panzaleo para atacar la tradición de la existencia del Reino de Quito sostenida por el padre Velasco (1789/1978). Al respecto, señalan:

De este modo queda desvirtuada la presencia de las etnias y lenguas denominadas pantsaleas, primero concebidas por el presbítero José María Coba Robalino, luego por el general Luis Paz y Mino [sic] y finalmente, revestida de una especie de seudo ciencia lingüística por Jacinto Jijón y Caamaño, quien quizo dar una lanzada de muerte al Reino de Quito con su peregrina invención. Inclusive, con mucha audacia, dentro de su cronología prehistórica, creó dos períodos consecutivos, los más antiguos: Panzaleo I y II, y los introdujo en la nomenclatura de la antigüedad ecuatoriana. El Valle de Machachi, donde supuestamente nació aquel nombre de panzaleo, fue siempre parte del grupo de la cara, yumbo o colorado, ligados con Cansacoto, Alluriqum [sic] [en realidad es Alluriquin] y otros pueblos. De esta suerte, en este capítulo en el que vamos a tratar de la lenguas de los yumbos, llamada shillipanu (o también cara o yumba), veremos como tanto los topónimos con los antropónimos proceden, ya sea del shillipanu, ya sea del chapalachi, idiomas emparentados y presentes en la alta sierra, como dijimos ya en otros capítulos de este libro. En este y otros puntos, Jijón elaboró falsas teorías; una de sus notables equivocaciones es el supuesto descubrimiento de una cultura y lengua panzaleas, las cuales deben ser eliminadas de la cronología que elaboró este autor (2002, p. 94).

Entre los argumentos de los Costales para desconocer la existencia de la lengua y cultura panzaleo se puede mencionar:

- Consideran que los tsa'chi (colorados) y chachi (cayapas) estuvieron en la Sierra y serían los quitus y caras, respectivamente; y 


\section{6}

que ellos habrían conformado el Reino de Quito del que habló el padre Juan de Velasco.

- La descomposición suigeneris de los principales topónimos y antropónimos en partes y su asociación con partes de términos supuestamente provenientes de lenguas tsa'fiki y cha'palaa y de las otras lenguas, mencionadas anteriormente; las cuales vinieron, según ellos, más tarde.

Así pues, los topónimos y antropónimos de la Sierra centro, según estos autores, se podrían explicar a partir de segmentos de las lenguas antes señaladas. Así, sobre la lengua de esta zona, los Costales dicen:

Un detenido estudio de la antroponimia (apelativos) y de la toponimia (nombres geográficos), indica que las lenguas de algunos de esos pueblos correspondían a grupos sedentarios; entre ellos figura básicamente los quitus y los cara que hablaban el shillipanu y chafiki o chapalaachi, respectivamente. Las huellas dejadas por estos dos pueblos en toda la geografía del reino comunitario que llegaron a conformar son las más importantes de todas. Después de estas dos lenguas mencionadas, lenguas matrices de nuestros pueblos nativos, otras como la Páez o la atacameña (la primera que se hablaba en el territorio del virreinato de Santa Fe) dejaron poquísimas evidencias. Con la conquista de los cuzqueños que traen al Reino de Quito a sus mitmas o comunidades de trasplante, llegaron tres lenguas: el quichua o runa shimi, propio del Cuzco; el aimara del altiplano boliviano; y el araucano trasplantado de Chile al Perú y luego del Perú a Quito (2002, p. 94).

Por otra parte, desde el lado arqueológico, el padre Porras sostiene que la cultura Panzaleo sería la continuación de la cultura Cosanga, proveniente de la Amazonía (1980, pp. 205-212). Ella pertenecería al período Desarrollo Regional (400 d.C.-700 d.C.), ${ }^{28}$ y se habría originado en los valles de los ríos Quijos y Cosanga, expandiéndose luego a la Sie-

28 Para el Ecuador, los arqueólogos han establecido los siguientes períodos: Precerámico (hasta 4000 a.C.), Formativo (4000 a.C- 500 a.C.), Desarrollo Regional (500 a.C-750 d.C.) e Integración (750 d.C.-1534 d.C.) (Porras, 1980, p. 20). 


\section{7}

rra centro, llegando inclusive hasta Quevedo, en la Costa. A esta cultura la denominó Fase Cosanga-Ṕ́llaro. Las conclusiones de Porras han sido ratificadas por Tamara Lynn Bray (2003). De ser así, lo afirmado por Pérez y los Costales de que la migración hacia la Sierra se dio desde la Costa no tendría sustento. Sin embargo, esta discusión continúa en el campo arqueológico. Así, Bravomalo de Espinosa (2006) considera que los panzaleos son los mismos caras, los cuales desde la Costa habrían invadido anteriormente la Sierra norte y luego la Sierra centro. Su argumento se basa en la existencia de elementos comunes en las piezas arqueológicas entre los de la Costa norte y esta parte de la Sierra.

Así, se han presentado dos visiones diferentes desde el lado arqueológico. Mientras Porras propuso que la migración se produjo desde la Amazonía hacia la Sierra y posteriormente a la Costa, esta última autora propone lo inverso. Ante esta situación, cabe profundizar las investigaciones arqueológicas locales para contar con hipótesis más consistentes sobre estos procesos de migración. Pero desde el lado lingüístico, la afirmación de Pérez, los Costales y Bravomalo, que señala que los panzaleos son los mismos quitus que fueron conquistados por los colorados (tsa' chi), tiene dificultades para explicar la existencia de los topónimos de esta zona terminados en $\{$-wa, -lawa, -aló/haló, -lli,-chi\}, etc. Estas terminaciones no tienen significado en el actual idioma tsa'fiki (colorado) ni en cha'palaa (cayapa), que se supone son la continuación de los idiomas de las poblaciones cara y quitu, respectivamente, según esos autores. Igual cosa ocurre con los principales antropónimos de esta zona como son \{-luisa, monta, -panta, -toa\}; tampoco se ve de dónde los esposos Costales tomaron el nombre de "shillipanu” para designar a la lengua tsa'fiki.

Desde la historia y con formación lingüística, Pedro Reino (1988), apoyándose en las "Relaciones geográficas" del siglo XVI y en otros documentos coloniales escribió: "Los panzaleos: una visión históricolingüística”, cuyo texto fue parte de su tesis de maestría en lingüística, titulada El panzaleo en la frontera sur de la lengua macro-chibcha. Ahí sostiene la existencia de la lengua panzaleo con la presencia de antro- 


\section{8}

pónimos terminados en \{-luisa\}, y apoyándose en un dato de Salazar de Villazante (circa 1562-1572), dice:

Además, luego de nuestro estudio, tampoco diremos que es término de los kitos, sino como se verá más adelante, de todos los compuestos panzaleos que sufijan sus antropónimos en LUISA. Una prueba más de que los kitos son los mismos panzaleos. A esto habría que añadir como parte del bosquejo los nombres terminados en LEO, como panzaleo, chibuleo, mulanleo, etc. que actualmente tienen que ver con poblados (Reino, 1988, p 38).

Con estos antecedentes, a continuación se mencionan las terminaciones más importantes presentes en la zona atribuida a la lengua panzaleo: $\{$-alo/halo, -así, -coa/goa, -chi, -gasi, -gua, -lagua, -lata, -leo, -luisa, -lli, -mala, -mbo, -pi, -po, pulo/bulo, -to, -toa, -tug, -yambo\}.

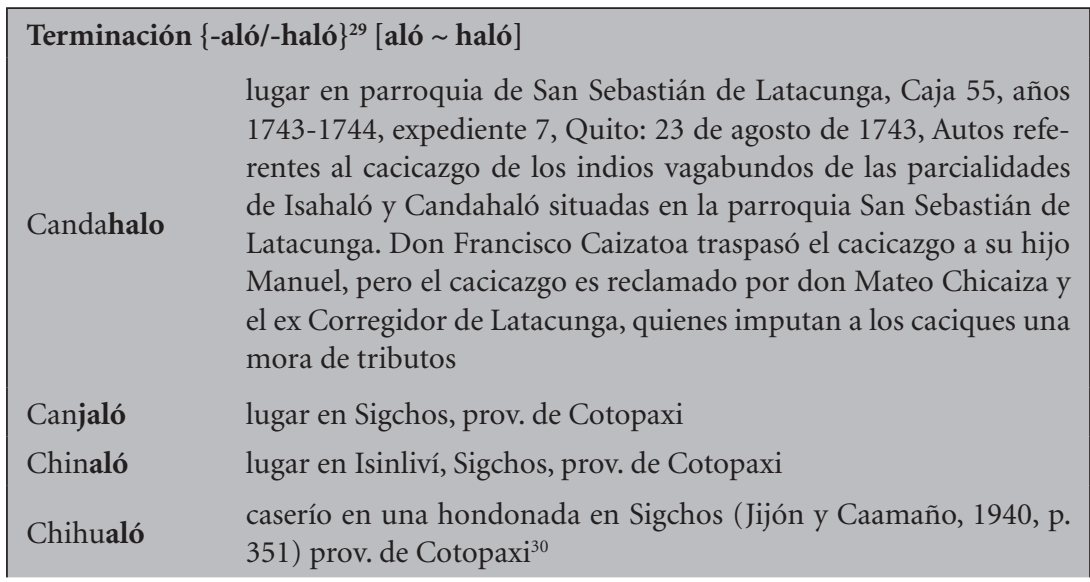

29 Durante los primeros siglos de la Colonia existió vacilación entre $\langle\mathrm{h}\rangle \mathrm{y}\langle\phi\rangle$ en la escritura, ya que se vivía un proceso de evaporación de $<\mathrm{h}>$. En ese contexto se dio la supervivencia escrita de $<\mathrm{h}>$ con $<\mathrm{j}>$ en algunos casos.

30 Jijón y Caamaño la denomina "provincia de León", pues hasta la primera mitad del siglo XX, esta provincia se llamó así en homenaje al filántropo Vicente León (1773-1839), quien antes de fallecer en el Cuzco (Perú), donó en su testamento a su ciudad natal Latacunga sus bienes para la creación de un colegio. 


\begin{tabular}{|c|c|}
\hline Chinaló & lugar al este de Pujilí, prov. de Cotopaxi \\
\hline Chizajaló & $\begin{array}{l}\text { hondón en Toacaso, prov. de Cotopaxi, según auto sobre preten- } \\
\text { dida mudanza de los indios de Chizahaló de Toacazo ( } 23 \text { de mayo } \\
\text { de 1654, Archivo Nacional del Ecuador, Caja 5, 1646-1654, Expe- } \\
\text { diente 18) }\end{array}$ \\
\hline Choaló & $\begin{array}{l}\text { lugar al occidente de Chugchilán, Sigchos, prov. de Cotopaxi (Paz } \\
\text { y Miño, 1948b, p. 227) }\end{array}$ \\
\hline Cotopilaló & lugar al pie del cerro Illiniza, al norte de Saquisilí, prov. de Cotopaxi \\
\hline Cochaló & quebrada en Sigchos, prov. de Cotopaxi \\
\hline Condoaló & comunidad al noreste de Latacunga, prov. de Cotopaxi \\
\hline Cotaló & comunidad al sureste de Pelileo, cerca al volcán Tungurahua \\
\hline Guajaló & $\begin{array}{l}\text { lugar y riachuelo del Machángara, al sur de la ciudad de Quito, } \\
\text { prov. de Pichincha }\end{array}$ \\
\hline Huambaló & lugar al sur de Ambato, prov. de Tungurahua \\
\hline Ilaló & cerro al este de Quito, prov. de Pichincha \\
\hline Isahalo & ver Candahaló \\
\hline Isinaló & sitio al noroccidente de Angamarca (Paz y Miño, 1949b, p. 216) \\
\hline Itualó & afluente del río Pilaló, al oeste de Pujilí, prov. de Cotopaxi \\
\hline Macaló & laderas en Mulalillo, prov. de Cotopaxi \\
\hline Mulaló & $\begin{array}{l}\text { lugar al norte de Latacunga, prov. de Cotopaxi: Jijón y Caamaño es- } \\
\text { cribe "Mulaaló" (1940, p. 385) y Cieza de León escribe "Mulahaló" }\end{array}$ \\
\hline Pichaló & $\begin{array}{l}\text { comunidad al noreste de Latacunga, junto a Condoaló, prov. de } \\
\text { Cotopaxi }\end{array}$ \\
\hline Pilaló & lugar al este de Pujilí, prov. de Cotopaxi \\
\hline Poaló & $\begin{array}{l}\text { lugar al noroccidente de Latacunga, prov. de Cotopaxi; lugar con el } \\
\text { mismo nombre cerca la laguna de Pisayambo, cantón Píllaro, prov. } \\
\text { de Tungurahua }\end{array}$ \\
\hline Putalo & pueblo en la prov. de Tungurahua (Paz y Miño, 1952a, p. 244) \\
\hline Quilaló & comunidad en la parroquia Angamarca, prov. de Cotopaxi \\
\hline Quizaló & otro nombre de Toacazo, prov. de Cotopaxi (Paz y Miño, 1951, p. 249) \\
\hline Saquialó & cerro y promontorio de Angamarca (Jijón y Caamaño, 1940, p. 361) \\
\hline Tagualo & afluente derecho del río Pilaló (Paz y Miño, 1952b, p. 107) \\
\hline
\end{tabular}




$\begin{array}{ll}\text { Tigualó } & \begin{array}{l}\text { quebrada al sur de Salcedo, prov. de Cotopaxi; nombre primitivo } \\ \text { de San Miguel, prov. de Bolívar (Paz y Miño, 1952b, p. 112) }\end{array} \\ \text { Tiguajaló } & \text { un cacicazgo en un expediente de } 1687 \text { escrito como “Tiguahalo" } \\ \text { Tullaló } & \text { sitio al norte de Ambato (Paz y Miño, 1952b, p. 117) } \\ \text { Toaló } & \text { sitio en la prov. de Cotopaxi (Paz y Miño, 1952b, p. 113) } \\ \text { Tusaló } & \text { sitio al este de Quisapincha, prov. de Tungurahua } \\ \text { Yaló } & \text { planicie y caserío en Sigchos (Jijón y Caamaño, 1940, p. 357) } \\ \text { Yajaló } & \begin{array}{l}\text { hondón cultivado en Toacaso, prov. de Cotopaxi (Jijón y Caamaño, } \\ \text { Alopamba }\end{array} \\ \text { Alobamba } & \text { lugar en la prov. de Cotopaxi } \\ \text { Aloasí } & \text { lugar en la parroquia Tisaleo, cantón Tisaleo, prov. de Tungurahua }\end{array}$

La existencia de <Tigualó, Tiguajaló $>$ y también la doble escritura para referirse al mismo lugar $<$ Mulaló y Mulahaló $>$ confirmarían que en [halo] se evaporó la /h/ representada por $<\mathrm{j}>$ y se transformó en [alo] por economía del lenguaje. No se olvide que esto ocurrió con la $<\mathrm{h}>$ en castellano, en el cual esta se ha mantenido en la escritura, pero no en el habla.

Efectivamente, Cieza de León (1553/1973, p. 115) escribe <Mulahalo $>$ para referirse al pueblo que actualmente se conoce como $<$ Mulaló $>$. Estas dos formas de escribir el nombre del mismo pueblo parecen deberse únicamente a una vacilación de escritura del siglo XVI, igual que la representación con $\langle\mathrm{h}>\mathrm{o}$ con $\langle\mathrm{j}\rangle$. Este fenómeno se encuentra en palabras como <Guajaló, Yajaló, Tiguajaló>, etc.; así, en el expediente 15 de la caja 3 de la serie Cacicazgos de la Real Audiencia de Quito del 6 de julio de 1687, se escribe $<$ Tiguahalo $>$ para referirse a $<$ Tiguajalo $>$, que es una parcialidad en San Miguel de Mollehambato (hoy Salcedo). En cuanto al significado no se puede todavía formular una hipótesis consistente.

Por otra parte, la presencia de los híbridos $<$ Alobamba $>$ y $<$ Aloasí $>$ que contienen el prefijo $\{$ alo- $\}$, permite suponer que $\{$-aló $\}$ habría sido un nombre independiente, diferente de $\{$-haló $\}$. Queda pendiente investigar si $\{$-haló $\}$ y $\{$-aló $\}$ eran solo variantes o eran morfemas diferentes. Se tiene que investigar si el prefijo $\{$ alo- $\}$ es el mismo que el sufijo 
$\{$-alo\}. Además, se debe investigar con datos etnohistóricos y de sustrato si la lengua panzaleo estuvo emparentada con las lenguas de la Costa o si fue una lengua diferente de las costeñas cha'palaa y tsa'fiki, aunque por ser lenguas fronterizas hayan compartido algunos grupos de topónimos como los terminados en $<$ calí $>$, $<$ pi $>$ y $<$ to $>$.

El término $<$ Andagualo $>$, nombre de caserío al norte de Píllaro, prov. de Tungurahua (Paz y Miño, 1946a, p. 88), se lo ha separado del grupo anterior debido a que es más plausible que esté integrado por los componentes $<$ Anda + gualo $>$. Efectivamente, al nororiente de Quito, junto a la Nueva Vía Oriental, se halla un lugar denominado simplemente $<$ Gualo $>$.

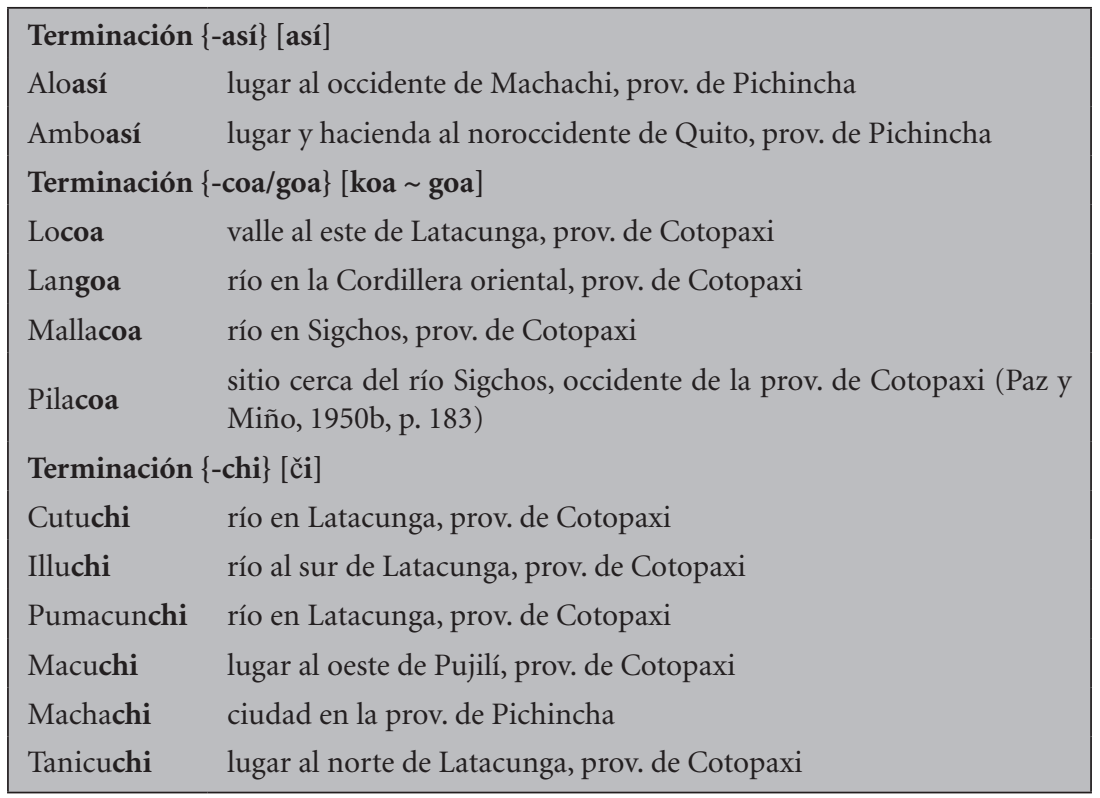

Las palabras terminadas en $\{$ cuchi\} como Tanicuchi, Macuchi, podrían formar un grupo independiente de las terminadas en \{-chi\}. Igualmente, las palabras que tienen el componente $\{$ cunchi\} como $\mathrm{Pu}$ macunchi, Cunchibamba, podría formar otro grupo. El significado de estos componentes tiene que investigarse. 


\section{2}

\begin{tabular}{|c|c|}
\hline Alagasí & $\begin{array}{l}\text { sitio al sureste de Calderón, prov. de Pichincha (Paz y Miño, 1937, p. } \\
\text { 10; 1946, p. 85) }\end{array}$ \\
\hline Alangasí & balneario en el valle de los Chillos, al este de Quito \\
\hline Andagasí & $\begin{array}{l}\text { cacicazgo en Patate, caja 44, años 1731-1732, expediente } 14 \text { del } 1 \text { de } \\
\text { septiembre de } 1731 \text {, auto sobre el cacicazgo de Guambaló, Cotaló, An- } \\
\text { dagasi y Patate que ejerce do Manuel Tubón de los indios guambaloes } \\
\text { de Patate y que reclama para sí don Miguel Zanipatín }\end{array}$ \\
\hline Amagasí & lugar al norte de Quito \\
\hline Caspigasí & lugar y hacienda en la parroquia de Calacalí, al noroccidente de Quito \\
\hline Puengasí & loma al suroriente de Quito \\
\hline Tolagasí & lugar en la parroquia de Tumbaco, al este de Quito \\
\hline
\end{tabular}

En este caso se puede ver que el término $<$ Tolagasí $>$ es un compuesto de $<$ tola $>$ y $<$ gasí $>$; $<$ tola $>$, en términos arqueológicos, es una loma artificial. Igualmente, <caspigasí $>$ es un híbrido entre quichua y panzaleo. Posiblemente otro híbrido sea <andagasi>, proveniente del quichua <anta $>$ 'metal, cobre' y <gasí>. No se sabe el significado de $<$ gasí>, sin embargo, el conocimiento de la primera parte de los términos híbridos podría ser una pista para futuras investigaciones.

\begin{tabular}{|ll|}
\hline $\begin{array}{l}\text { Terminación } \\
\text { Apagua }\end{array}$ & comunidad al oeste de Pujilí, prov. de Cotopaxi \\
Juigua & comunidad al sur de Pujilí, prov. de Cotopaxi \\
Ligua & río afluente del Quitosol (Paz y Miño, 1948b, p. 213) \\
Llangagua & uno de los orígenes del río Ambato, prov. de Tungurahua (Paz y \\
Lligua & quebrod 1948b, p. 226) \\
Malingua & filo de la cordillera de Isinliví, Sigchos, prov. de Cotopaxi \\
Palagua & sitio en la prov. de Tungurahua (Paz y Miño, 1950b, p. 173) \\
Panguigua & quebrada al noreste de Latacunga, cerca de la planta de la luz eléctrica \\
Patagua & quebrada y barrio en Sangolquí, prov. de Pichincha
\end{tabular}




\section{3}

$\begin{array}{ll}\text { Picaigua } & \begin{array}{l}\text { afluente del río Pachanlica; población al este de Ambato, prov. de } \\ \text { Tungurahua } \\ \text { altura y río al occidente de Chucchilan, prov. de Cotopaxi; confluente } \\ \text { Quindigua } \\ \text { derecho del río Pilaló, prov. de Cotopaxi; sitio en la parroquia Gua- } \\ \text { nujo, Guaranda, prov. de Bolívar } \\ \text { Tigua }\end{array} \quad \begin{array}{l}\text { comunidad al oeste de Pujilí, prov. de Cotopaxi } \\ \text { Zumbagua }\end{array} \quad \begin{array}{l}\text { comidad al oeste de Pujilí, prov. de Cotopaxi; altura en el nudo de } \\ \text { Tiopullo, prov. de Cotopaxi (Paz y Miño, 1952c, p. 218) }\end{array}\end{array}$

En varios casos la terminación \{-gua\} está asociada con alturas que al parecer son mesetas, sin embargo, en algunos casos también está ligada a ríos. El término <lligua $>$ está presente también en la provincia de Tungurahua y en ambos casos se refiere a quebradas encañonadas. Por otra parte, existen los siguientes términos que terminan en $<$-gua $>$, pero que el término inicial no es bisilábico, por lo cual no se los incluye en la lista anterior, pues podrían no ser términos compuestos, sino simples.

\begin{tabular}{|ll|}
\hline Terminación $\{$-lagua $\}$ [lawa rawa] \\
Cutuglagua & monte al suroeste de Quito, prov. de Pichincha \\
Gualilagua & lugar al norte de Tambillo, Machachi, prov. de Pichincha \\
Ililagua & monte al este de Nono, prov. de Pichincha \\
Jalilagua & loma al oeste de San Antonio (Paz y Miño, 1949b, p. 217) \\
Lanlagua & parcialidad de Otavalo, prov. de Imbabura \\
Langulagua & sitio al sureste de Amaguaña, prov. de Pichincha \\
Pachalagua & saliente al este de Pifo, prov. de Pichincha \\
Pululagua & volcán destruido al norte de Quito, prov. de Pichincha \\
Putzalagua & cerro al sureste de Latacunga, prov. de Cotopaxi \\
Quindilagua & loma en la prov. de Chimborazo (Paz y Miño, 1952a, p. 248) \\
Sincholahua & cerro al suroriente de Machachi, prov. de Pichincha \\
Tungalahua & loma al norte de Guano, prov. de Chimborazo \\
Tungurahua & volcán al sureste de Ambato, prov. de Tungurahua \\
Uyalagua & loma al este de Guápulo, prov. de Pichincha
\end{tabular}


En este listado se pueden encontrar los siguientes híbridos, donde el primer componente es quichua: $<$ Pachalagua $>$, $<$ Quindilagua $>$, $<$ Pululagua $>$. En estos compuestos, el quichua estaría presente en los términos $<$ pacha $>$ de '¿bajo, de poca altura?', <quindi $>$ de $<$ kinti $>$ 'picaflor', y $<$ pulu $>$ de $<$ puru $>$ 'recipiente de calabaza, respectivamente.

Estos nombres terminados en \{-lagua\} están relacionados con cerros, montes y volcanes. En el caso del término <Tungurahua $>$, para integrarlo en este grupo, habría que demostrar que los sonidos [1] y [r] eran alófonos en esa lengua, caso contrario este término no podría formar parte del mismo. Por otra parte, cabe mencionar que existe el apellido $<$ Lagua $>$ en la provincia de Tungurahua, por lo que se entiende que este era un término independiente con un significado propio, que pudo haber sido 'montaña'. Por otra parte, Paz y Miño (1937, p. 15) trae el topónimo $<$ Cutucloma $>$ sin especificar el sitio ni la provincia de donde lo tomó, esto muestra que el término $<$ Cutuc $>$ podría estar asociado con $<$ Cutuglagua $>$.

Por otra parte, hay palabras terminadas en $\{$-tagua $\}$ y que también son cerros como el volcán $<$ Casitagua $>$, situado al suroeste de $<$ Calacalí $>$, prov. de Pichincha; <Abitagua $>$, cerro y cordillera en Mera, prov. de Pastaza; <Guanguiltagua $>$, cerro al noreste de Quito, prov. de Pichincha, donde está situado el parque Metropolitano y desde el cual se desciende al valle de los Chillos; Chinintagua, cerro en Mocha, prov. de Tungurahua; $<$ Itagua $>$, una de las puntas del Pululagua; Catitagua, loma en Salasaca, prov. de Tunguragua. Entonces, es muy plausible que $\{$-tagua $\}$ y $\{\text {-lagua }\}^{31}$ se refieran a 'alturas'. Esta relación entre $\{$-tagua $\}$ y $\{$-lagua $\}$ se confirmaría con el dato de Cerrón-Palomino (2016, comunicación personal), quien

31 Rodolfo Cerrón-Palomino, en comunicación personal de septiembre de 2016, señala que son interesantes estas variaciones, pues "El puquina presenta variación sistemática entre /t/ y /r/ y la /r/ se hace /l/ en boca de los aimaras. ¿No sería que los hábitos articulatorios de los puquina-collas acompañantes de los incas remodelaron tales términos con sus reglas?". 


\section{5}

sostiene que en el idioma puquina hay una variación sistemática entre /t/ y /r/, y que /r/ a su vez se hace /l/ en boca de los aimaras. En consecuencia, se podría plantear que los hábitos articulatorios de los puquinacollas acompañantes de los incas habrían remodelado tales nombres con sus reglas. De ser así, \{-tagua, -ragua, -lagua\} serían el mismo término y equivaldría al quichua $<$ urku $>$ 'cerro, loma, montaña'.

\begin{tabular}{|ll|}
\hline $\begin{array}{l}\text { Terminación }\{\text {-lata } \text { [lata] } \\
\text { Andiglata }\end{array}$ & caserío al occidente de Ambato (Paz y Miño, 1946a, p. 89) \\
Guasalata & comunidad en Salasaca, prov. de Tungurahua \\
Igualata & $\begin{array}{l}\text { páramo y volcán de } 4300 \text { msnm entre Tungurahua y Chimborazo } \\
\text { tierras en Patate, prov. de Tungurahua, en juicio en litigio de tie- }\end{array}$ \\
Munduglata & $\begin{array}{l}\text { rras, caja 23, años 1697-1699 del Archivo Nacional, expediente 2, } \\
\text { de fecha 21 de agosto de 1697 }\end{array}$ \\
& $\begin{array}{l}\text { un tipo de piedra liviana de origen volcánico; monte al este de Am- } \\
\text { Pishilata }\end{array}$ \\
\end{tabular}

Los híbridos con quichua podrían ser $<$ Guasalata $>$ de $<$ guasha $>$ 'atrás' y $<$ lata $>$; $<$ pishilata $>$ de $<$ pishi $>$ 'liviano, poroso' y $<$ lata $>$.

Estos son nombres de páramos un tanto planos y arenosos, pero hace falta identificar más topónimos con este sufijo. ¿Tiene alguna relación con este componente $\{$-lata\}, el topónimo $<$ Latacunga $>$ ? Existen varios topónimos terminados en $<$ cunga $>$. Así: $<$ Bullacunga $>$ loma al este de Tolontag, prov. de Pichincha; $<$ Caballocunga $>$, sitio al norte de Chaupi, prov. de Pichincha; <Cachicunga $>$, sitio al sur oeste de Cayambe; <Cascacunga $>$, quebrada y sito al sur de Fuvafuya (Paz y Miño, 1937, pp. 12-13). Del último término el autor no menciona a qué provincia pertenece. $<$ Morascunga $>$, lugar al sur de Tolontag, prov. de Pichincha (Paz y Miño, 1937, p. 21); < Sigsicunga >, saliente del cerro Ilaló, prov. de Pichincha (Paz y Miño, 1937, p. 26). En estos ejemplos se puede apreciar que los términos < casca, cachi, sigsi $>$ son quichuas y < cunga $>$ también es quichua, con el significado de 'pasaje, garganta'. Con esto se podría postular que $<$ Latacunga $>$ es un híbrido de $\{$ lata + cunga $\}$ y su 


\section{6}

significado podría ser 'garganta, pasaje entre páramos'. Efectivamente, si se observa la topografía, este lugar está en un valle alargado con las dos cordilleras a los lados.

\begin{tabular}{|c|c|}
\hline \multicolumn{2}{|c|}{ Terminación $\{$-leo $\}$ [leo] } \\
\hline Aluleo & $\begin{array}{l}\text { laguna en el Parque Nacional de los Llanganates, prov. de Cotopaxi, } \\
\text { Tungurahua, Napo y Pastaza }\end{array}$ \\
\hline Chibuleo & comunidad en Ambato, prov. de Tungurahua \\
\hline Lalaleo & lugar cerca de Quero (Paz y Miño, 1948b, p. 221) \\
\hline Mulanleo & comunidad en Pilahuín, Ambato, prov. de Tungurahua \\
\hline Panzaleo & $\begin{array}{l}\text { pueblo al sur de Salcedo, prov. de Cotopaxi; Cieza de León menciona } \\
\text { otro pueblo Panzaleo que habría estado en el valle entre Tambillo y } \\
\text { Machachi, actual prov. de Pichincha; río en el origen del río San Pedro, } \\
\text { prov. de Pichincha (Paz y Miño, 1937, p. 22); loma al sur de Machachi, } \\
\text { prov. de Pichincha (Paz y Miño, 1950b, p. 176) }\end{array}$ \\
\hline Pelileo & $\begin{array}{l}\text { pueblo en la prov. de Tungurahua; quebradilla al norte de Cumbayá, } \\
\text { prov. de Pichincha }\end{array}$ \\
\hline Penileo & lugar en Píllaro, prov. de Tungurahua \\
\hline Salaleo & sitio en Simiatug, Guaranda, prov. de Bolívar \\
\hline Tangaleo & lugar al norte de Ambato, prov. de Tungurahua \\
\hline Tisaleo & pueblo en la prov. de Tungurahua \\
\hline
\end{tabular}

De momento no hay muchas pistas para interpretar el significado de $\{-l e o\}$. Si $<$ Sala $>$, se refiere al arbusto medicinal que menciona en Salamalag y Salayambo, se tendría al menos un componente conocido para proseguir las investigaciones. Se requiere una observación más detenida de cada uno de los lugares para ensayar una interpretación. Igualmente, en la tradición oral está la idea de que <chibu/chipu $>$ es una planta, en consecuencia, $<$ Chibuleo $>$ sería un compuesto con dos términos del idioma panzaleo. 


\section{7}

\section{Terminación \{-luisa\} [luisa]}

Luisa quebrada, pueblo y llanura en Calpi, al noroeste de Riobamba, actualmente conocido como San Pedro de Luisa, a la altura de San Andrés

Nitiluisa comunidad en Calpi, al noroeste de Riobamba

El pueblo de $<$ Luisa $>$ es mencionado en la "Relación geográfica" del licenciado Salazar de Villasante (circa 1562-1572, p. 130) cuando dice: "Desde este pueblo o asiento de Riobamba van a otro pueblo de indios, dos leguas que llaman Luisa". Por otra parte, más abajo se presentará una considerable lista de combinaciones de $<$ luisa $>$ en apellidos típicos de la zona panzaleo. ${ }^{32}$

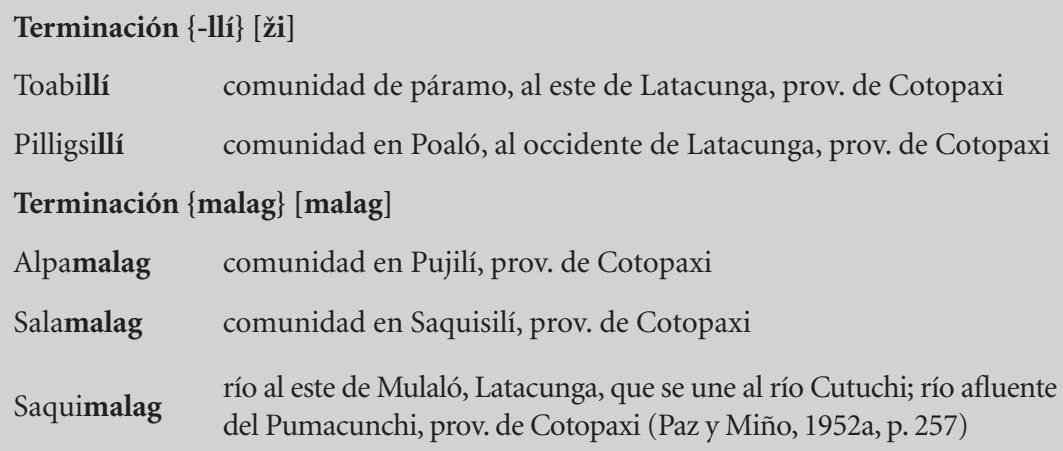

El componente $<$ alpa $>$ podría provenir del quichua $<$ allpa $>$ 'tierra' y <sala $>$ es el nombre de un arbusto medicinal que sirve para el empacho, sus hojas se parece a las del arrayán.

32 La existencia de los poblados Luisa y Nitiluisa haría suponer que el límite sur del territorio de la lengua panzaleo llegaba hasta el norte de la provincia de Chimborazo. 


\section{8}

\begin{tabular}{|c|c|}
\hline Alámbi & $\begin{array}{l}\text { afluente del río Nanegal, occidente de la prov. de Pichicha (Paz y Miño, } \\
\text { 1946a, p. 89) }\end{array}$ \\
\hline Cuturibí & comunidad al occidente de Pujilí, prov. de Cotopaxi \\
\hline Chasupi & río junto a Isinliví, prov. de Cotopaxi (Paz y Miño, 1946a, p. 89) \\
\hline Chespi & antiguo caserío a orillas del río Guaylla \\
\hline Guaspe & río en la prov. de Pichincha \\
\hline Gualipi & afluente del río Peripa, Santo Domingo de los Tsáchilas \\
\hline Isinliví & lugar en cantón Sigchos, prov. de Cotopaxi \\
\hline Lamapi & riachuelo fluente del río Pilaló, prov. de Cotopaxi \\
\hline Matiabí & río en la prov. de Bolívar (Paz y Miño, 1950, p. 57) \\
\hline Piñapí & lugar en Patate, prov. de Tungurahua \\
\hline Pichambi & riachuelo afluente del río Angamarca (Paz y Miño, 1950b, p. 182) \\
\hline Tantapi & río y pueblo al occidente de Alóag \\
\hline Tandaliví & comunidad al norte de Latacunga, prov. de Cotopaxi \\
\hline Tontapí & lugar en Patate, prov. de Tungurahua \\
\hline Tulipi & $\begin{array}{l}\text { sitio cerca de Gualea, Quito, prov. de Pichincha (Paz y Miño, 1952b, } \\
\text { p. 117) }\end{array}$ \\
\hline Tulipe & río y lugar al noreste de Quito, prov. de Pichincha \\
\hline Yallibí & $\begin{array}{l}\text { laderas cultivadas en Angamarca, prov. de Cotopaxi (Jijón y Caamaño, } \\
\text { 1940, p. 357) }\end{array}$ \\
\hline Yanibí & $\begin{array}{l}\text { otro nombre para el río Yanuncay, Cuenca, prov. de Azuay (Paz y Miño, } \\
\text { 1952c, p. 216) }\end{array}$ \\
\hline
\end{tabular}

En los ejemplos que se presentan se puede notar que en la pronunciación, después de nasal se sonoriza /p/. Sin embargo, luego de vocal la sonorización no es regular. La mayor parte de los términos son nombres de ríos, pero para estar seguros de que este sufijo significa 'río' hace falta investigación de campo y de archivo, para verificar si todos los nombres terminados en $\{-$ pi/bi $\}$ inicialmente se referían a ríos. En caso de serlo, estos términos podrían estar relacionados con las lenguas awapit, cha'palaa y tsa'fiki. En algunos compuestos como <Tantapi, Yallibí $>$ se puede suponer que el primer elemento es quichua. Por otra parte, 


\section{9}

términos como $<$ Chespi, Guaspe $>$ podrían no ser parte este grupo, porque las raíces generalmente son bisilábicas y en estas palabras el lexema sería monosilábico.

\begin{tabular}{|c|c|}
\hline \multicolumn{2}{|c|}{ Terminación $\{-$ po/bo $\}[$ po $\sim$ bo] } \\
\hline Alutipo & una planta con espinos largos, prov. de Cotopaxi \\
\hline Laipo & quebrada y lugar al noreste de Latacunga, prov. de Cotopaxi \\
\hline Lambo & $\begin{array}{l}\text { antigua población de la prov. de Pichincha (Jijón y Caamaño, } 1940, \\
\text { p. 307) }\end{array}$ \\
\hline Inchapo & lugar al occidente de Latacunga \\
\hline Isimbo & $\begin{array}{l}\text { comunidad, al noreste de Latacunga, prov. de Cotopaxi; a. del ayllu de } \\
\text { Latacunga (1694) (Jijón y Caamaño, 1940, p. 306) }\end{array}$ \\
\hline Palpo & lugar al este de Latacunga, prov. de Cotopaxi \\
\hline Pueblo & lugar al noreste de Quito, prov. de Pichincha \\
\hline Tipo & $\begin{array}{l}\text { [tipo } \sim \text { tipu } \sim \text { tipu] planta medicinal, prov. de Imbabura, Pichincha, } \\
\text { Cotopaxi, Tungurahua, Chimborazo y Bolívar }\end{array}$ \\
\hline
\end{tabular}

Se constata que luego de nasal se sonoriza la oclusiva. Por otra parte, queda la posibilidad de que $<$ alutipo $>$ esté compuesto de $<$ alu $>$ y $<$ tipo $>$ 'un tipo de planta medicinal', en cuyo caso esta palabra no sería parte de este grupo.

En lengua tsa'fiki $<$ po $>$ es 'espina', en lengua cha'palaa se pronuncia $<$ pu $>$. Lugares como $<$ Poaló $>$ han sido históricamente considerados como sitios de cactus y plantas espinosas. En el caso de $<$ isimbo $>$, este podría provenir de una planta pequeña, una especie de espinos, pronunciada actualmente como [ižimbo]. Estos pocos topónimos podrían abonar la teoría de que los tsa'chi (colorados) estuvieron, en algún momento del pasado, en esta zona panzaleo. Términos como <Laipo, tipo $>$ podrían no ser compuestos, sino raíces simples.

Al norte de la provincia de Chimborazo se ha encontrado algunos topónimos relacionados con lugares secos y espinosos. Así se tiene: 


\section{0}

$\begin{array}{ll}\text { Atapo } & \text { lugar y río en el desierto de Palmira, Guamote } \\ \text { Ilapo } & \text { lugar cerca de Guano, cerca límite con la prov. de Tungurahua } \\ \text { Chipo } & \text { lugar en la llanura de Atapo, Palmira, Guamote }\end{array}$

Si estas palabras tienen relación con la lengua panzaleo, podría postularse que en el pasado ella estuvo presente hasta el norte de la provincia de Chimborazo, lo cual es coherente con la presencia del topónimo $<$ Luisa $>$ que, al parecer, también es de la lengua panzaleo y también está al norte de esta provincia.

\begin{tabular}{|ll}
\hline $\begin{array}{l}\text { Terminación } \\
\text { Amabulú }\end{array}$ & $\begin{array}{l}\text { quebrada al norte de Cumbayá, prov. de Pichincha (Paz y Miño, } \\
\text { 1937, p. 11) }\end{array}$ \\
Atápulo & comunidad en Maca Grande, Latacunga, prov. de Cotopaxi \\
Cullipulo & lugar en Cotacachi, prov. de Imbabura (Paz y Miño, 1947, p. 79) \\
Condabulo & lugar al noreste de Machachi (Paz y Miño, 1937, p. 14) \\
Guápulo & meseta al este de Quito, prov. de Pichincha \\
Tilipulo & valle al noreste de Latacunga, prov. de Cotopaxi \\
Chilibulo & lugar al suroeste de Quito
\end{tabular}

La mayor parte de los nombres terminados en <-pulo/bulo > corresponde a una especie de meseta. $<$ Cullipulo $>$ podría ser un compuesto de $<$ culli $>$ y $<$ pulo $>$. En el caso de $<$ Guápulo $>$ es dudoso de incluir en este grupo por ser su raíz un monosílabo, sin embargo, podría haber la posibilidad de que la sílaba inicial sea parte de una palabra bisilábica reducida.

\footnotetext{
Terminación \{-sagua\} [sawa]

Cachisagua lugar al sureste de Guaranda, prov. de Bolívar

Pisagua sitio al occidente de Quisapincha, prov. de Tungurahua; sitio en la prov. de Bolívar (Paz y Miño, 1950b, p. 188)

Pillasagua antigua parcialidad de Jipijapa hoy desaparecida, prov. de Manabí (Paz y Miño, 1950b, p. 185)
} 


\section{1}

$\begin{array}{ll}\text { Punsagua } & \text { parcialidad indígena de Pasa, prov. de Tungurahua (Paz y Miño, } \\ \text { Tucusagua } & \text { lomi, p. 242) } \\ \text { Tosagua al este del Quinche, Quito, prov. de Pichincha } & \begin{array}{l}\text { lugar al noroeste de la prov. de Manabí, al sureste de Bahía de } \\ \text { Caráquez }\end{array}\end{array}$

No se sabe el significado de este componente, sin embargo, la presencia del mismo en una zona continua que va desde la Cordillera occidental del territorio panzaleo hasta el perfil costanero, podría ser un indicio de que hubo, o un contacto lingüístico sostenido en toda esta zona, o un sustrato común en épocas muy remotas con la Costa. ${ }^{33}$

\begin{tabular}{|c|c|}
\hline \multicolumn{2}{|c|}{ Componente $\{$ to $\}$} \\
\hline Agato & lugar en al prov. de Imbabura \\
\hline Ambato & río en la prov. de Tungurahua (Cieza de León, 1553/1973, p. 116) \\
\hline Añaquito & $\begin{array}{l}\text { lugar al norte de Quito, denominado actualmente Iñaquito, prov. } \\
\text { de Pichincha }\end{array}$ \\
\hline Casanto & $\begin{array}{l}\text { pequeño pico al norte del cerro Ilaló, prov. de Pichincha; nombre } \\
\text { de un tipo de árbol del cual en el pueblo de Alóag hicieron la ima- } \\
\text { gen del Señor de Casanto durante la Colonia }\end{array}$ \\
\hline Leito & hacienda en Patate, prov. de Tungurahua \\
\hline Poato & $\begin{array}{l}\text { lomas al suroccidente de Sucre, Patate, prov. de Tungurahua (Paz } \\
\text { y Miño, 1952a, p. 234) }\end{array}$ \\
\hline Quito $^{33}$ & capital del Ecuador, prov. de Pichincha; loma en Riobamba \\
\hline Quirato & $\begin{array}{l}\text { quebrada al norte de unos restos de un volcán en Pifo, prov. de } \\
\text { Pichincha }\end{array}$ \\
\hline Mulliambato $^{34}$ & sitio en la prov. de Cotopaxi (Cieza de León, 1553/1973, p. 116) \\
\hline Tuntatagto & comunidad en San Andrés, Riobamba, prov. de Chimborazo \\
\hline
\end{tabular}

33 Arriba ya se mencionó que en algunos lugares el término <quito> se usa para denominar al <sampu $>$ [sambo zambo] 'tipo de calabaza' (ver <Quitobuela $>$ en "Lengua cara").

34 ¿Compuesto de molle + ambato? 


\section{2}

El término <to $>$ en idioma tsa'fiki actual significa 'tierra'. Este, junto con $<$ pi $>$ 'río', son de los pocos sufijos que al parecer son comunes en las lenguas panzaleo y tsa'fiki. De tal manera que si hubo en el pasado algún parentesco o contacto entre estas dos lenguas, debió haber sido en una época muy remota, o compartían palabras por ser lenguas fronterizas entre la Sierra y la Costa. Por otra parte, queda en pie la posibilidad de que $<$ Añaquito $>$ sea un compuesto de $<$ Aña $>$ y $<$ quito $>$.

Por otra parte, los actuales hablantes de este idioma tsa'fiki, a la capital de la república no le llaman $<$ Quito $>$, como era de esperarse, sino $<$ Te'to $>$. Marco Aguavil, hablante nativo de tsa'fiki (2016, comunicación personal), dice que lo llaman así debido al terreno quebradizo donde está la ciudad de Quito. < Te'to > provendría de < te'pa > 'doblado' y $\{$ to $\}$ 'tierra', en esta lengua. Por otra parte, tampoco se puede descartar la sospecha de que $<$ Quito $>$ provenga en el pasado del ensamblaje $<$ quitsa $>$ 'mitad' y <to > 'tierra' en la misma lengua con el significado de 'tierra en la mitad' (del mundo). Por otra parte, Ambato podría estar relacionado con $<$ hampatu $>$, una variedad de sapo de color negro, muy simbólico y que se emplea en las curaciones con "limpias".

\begin{tabular}{|c|c|}
\hline \multicolumn{2}{|c|}{ Componente $\{$ toa $\}$ [toa] } \\
\hline Toa & nombre de una hija de un gobernante quiteño preincaico \\
\hline Colatoa & $\begin{array}{l}\text { meseta y nombre de una comuna en el cantón Latacunga, prov. de } \\
\text { Cotopaxi; sitio al norte de Saquisilí, prov. de Cotopaxi }\end{array}$ \\
\hline Cantzatoa & lugar en la prov. de Cotopaxi (Paz y Miño, 1946b, p. 219) \\
\hline Chitoa & $\begin{array}{l}\text { río afluente del Pilatón, oeste de la prov. de Pichincha (Paz y Miño, } \\
\text { 1937, p. 30) }\end{array}$ \\
\hline Patoa & río afluente del Pujilí, prov. de Cotopaxi (Paz y Miño, 1950b, p. 178) \\
\hline Patutoa & sitio en la prov. de Cotopaxi (Paz y Miño, 1950b, p. 179) \\
\hline Pinatoa & sitio en la prov. de Cotopaxi (Paz y Miño, 1950b, p. 185) \\
\hline Pondoa & $\begin{array}{l}\text { sitio al noroeste de Ambato, prov. de Tungurahua (Paz y Miño, 1952a, } \\
\text { p. 235) }\end{array}$ \\
\hline Quilotoa & $\begin{array}{l}\text { nombre de un volcán y su laguna en la parroquia Zumbagua, cantón } \\
\text { Pujilí, prov. de Cotopaxi }\end{array}$ \\
\hline
\end{tabular}




\section{3}

\begin{tabular}{|ll|} 
Quititoa & afluente del río Jatuncama, Isinliví, Sigchos, prov. de Cotopaxi \\
Sagoatoa & $\begin{array}{l}\text { volcán no activo al noroeste de Ambato, fronterizo entre la prov. de } \\
\text { Tungurahua y Cotopaxi }\end{array}$ \\
Saratoa & sitio al occidente del río Isinliví, prov. de Cotopaxi \\
Yahuartoa & nombres de lugares en el cantón Pujilí, prov. de Cotopaxi \\
Toacazo & lugar al noreste de Latacunga, prov. de Cotopaxi \\
Toabilli & lugar al este de Latacunga, prov. de Cotopaxi \\
Toachi & río al sureste de Santo Domingo, prov. de Santo Domingo de los \\
Toaló & Tsáchilas \\
\hline
\end{tabular}

Algunos de los nombres compuestos con \{toa\} son mesetas, pero habría que buscar más topónimos para ver si todos tienen esa característica. También existe un lugar en Sigchos (prov. de Cotopaxi), cercano al $<$ Quilotoa $>$, que se denomina $<$ Quilotuña $>$. Además, existe el apellido Quilo en Cayambe (prov. de Pichincha). Hay también el topónimo denominado $<$ Quilo $>$, que es un río (prov. de Pastaza). Si algún día se identifica el significado de $<$ quilo $>$, se podrá aproximarse al sentido de $<$ Quilotoa $>$. Y, conociendo el sentido de $<$ Quilotoa $>$, se tendría elementos para saber lo que representaba $\{$-toa $\}$. En los híbridos quichuapanzaleo $<$ Yahuartoa $>$ y $<$ Saratoa $>$, el primer componente $<$ yahuar $>$ 'sangre' y <sara > 'maíz' son quichuas, aunque en el caso de <yahuar $>$ podría haber una relación con $<$ jahuar $>$, como lo sugiere Lozano (2018) a propósito del lago de $<$ yahuarcocha $>$ en Imbabura.

El término <toa $>$ también se encuentra en antropónimos como: $<$ Manotoa, Toalombo, Toapanta, Toaquiza $>$, etc. Para Reino (1988, p. 68), el hecho de que <toa $>$ sea claramente un término panzaleo y al mismo tiempo haya sido el nombre de una princesa quiteña, significa que la lengua de Quito debió haber sido el mismo panzaleo. Finalmente si se aplica el criterio de que las raíces generalmente no son monosilábicas, los términos < chitoa, patoa, pondoa $>$ no serían parte de este grupo. 


\section{4}

\begin{tabular}{|c|c|}
\hline \multicolumn{2}{|c|}{ Sufijo $\{$-tug $\}$ [tug] } \\
\hline Catug & lugar en la parroquia de Calpi, Riobamba, prov. de Chimborazo \\
\hline Panyatug & lugar al occidente de la prov. de Cotopaxi \\
\hline Pignetug & sitio en la prov. de Bolívar (Paz y Miño, 1950b, p. 183) \\
\hline Piñanatug & $\begin{array}{l}\text { confluente izquierdo del río Angamarca, prov. de Cotopaxi; nombre pri- } \\
\text { mitivo de Facundo Vela, prov. de Bolívar (Paz y Miño, 1950b, p. 187) }\end{array}$ \\
\hline Simiatug & lugar en la parte norte de la prov. de Bolívar \\
\hline
\end{tabular}

El compuesto <Piñanatug $>$ podría estar compuesto del verbo quichua $<$ piñana $>$ 'enojarse' $+\{$-tug $\}$, pero no se puede todavía ensayar una interpretación de $\{$-tug\}.

Componente $\{$ yambo/yambu $\}$ [yambo yambu]

Yambo laguna cerca de Salcedo, prov. de Cotopaxi

Pisayambo laguna cerca de Píllaro, prov. de Tungurahua

Pucayambo laguna al este de Píllaro, prov. de Tungurahua

Miquiayambu río afluente del Patate, prov. de Tungurahua

Salayambo laguna en los páramos al sureste de Latacunga, prov. de Cotopaxi

La mayoría son lagunas, sin embargo, hay también un río, por lo que se tiene que estudiar si ese río proviene de alguna laguna con el mismo nombre. Se podría también considerar dentro de este grupo los ríos: <Quignayambu, Sindiyambu, Susuyambu, Yutuyambu $>$, los cuales están cerca de Píllaro.

En algunas de las palabras antes citadas, el primer componente es quichua. Así: < puca > 'rojo', <yutu> 'perdiz'. El caso de < sala > podría provenir de <sara $>$ 'maiz', sin embargo, también existe un arbusto medicinal que se llama así. Con estos significados se podría postular que \{yambo/yambú\} tiene cierta relación con 'laguna'. Habría también alguna posibilidad de relacionarse con el término quichua $<$ wampu $>$ 'embarcación', cuya evolución pudo haber sido wampu $>$ wambu $>$ yambu. 


\section{5}

Finalmente, sobre la lengua panzaleo cabe anotar que hay un significativo número de antropónimos terminados en $\{$-luisa $\}$. Su presencia se encuentra en las provincias de la Sierra centro que cubren el territorio panzaleo. Asimismo, ya se mencionó arriba que existen al menos dos topónimos: Luisa y Nitiluisa, al norte de Chimborazo. ${ }^{35}$

\begin{tabular}{|c|c|}
\hline Luisa & $\begin{array}{l}\text { a. de Atocha y Ambato (Jijón y Caamaño, 1940, p. 377); comunidad } \\
\text { al norte de Riobamba, prov. de Chimborazo }\end{array}$ \\
\hline Aluisa & $\begin{array}{l}\text { a. de Pujilí, prov. de Cotopaxi; a. de Machachi, prov. de Pichincha } \\
\text { (Jijón y Caamaño, 1940, p. } 300 \text { ) }\end{array}$ \\
\hline Analuisa & $\begin{array}{l}\text { a. de Saquisilí, Poaló, Sigchos, Toacaso (1720), prov. de Cotopaxi; a. } \\
\text { de Quero, Isamba Guambaló, Quisapincha, prov. de Tungurahua; a. } \\
\text { de Tambillo, prov. de Pichincha (Jijón y Caamaño, 1940, p. 302) }\end{array}$ \\
\hline Anchaluisa & $\begin{array}{l}\text { a. de Poaló, del ayllu de Toacaso de Saquisilí (1720), prov. de Coto- } \\
\text { paxi; a. de Cevallos, prov. de Tungurahua; a. de San Andrés, prov. de } \\
\text { Chimborazo (Jijón y Caamaño, 1940, p. } 302 \text { ) }\end{array}$ \\
\hline Andaluisa & $\begin{array}{l}\text { a. de San Miguelito, prov. de Cotopaxi (Jijón y Caamaño, 1940, } \\
\text { p. 302) }\end{array}$ \\
\hline Caisaluisa $^{35}$ & $\begin{array}{l}\text { a. de Alangasí, Tambillo, Machachi y Alóag, prov. de Pichincha (Ji- } \\
\text { jón y Caamaño, 1940, p. 379) }\end{array}$ \\
\hline Cancaluisa & a. de Toacaso, prov. de Cotopaxi (Jijón y Caamaño, 1940, p. 314) \\
\hline Cañaluisa & a. del Corazón, prov. de Cotopaxi (Jijón y Caamaño, 1940, p. 312) \\
\hline Chasiluisa & $\begin{array}{l}\text { a. de Pujilí, del ayllu de Nascas en Latacunga, prov. de Cotopaxi } \\
\text { (1694) (Jijón y Caamaño, 1940, p. } 346 \text { ) }\end{array}$ \\
\hline Chaluisa & a. de Latacunga \\
\hline Changoluisa & $\begin{array}{l}\text { a. del ayllu de los Hipus y Quillanes de Latacunga (1694), de Sal- } \\
\text { cedo, Aláquez, Poaló, San Felipe y Zumbagua, prov. de Cotopaxi } \\
\text { (Jijón y Caamaño, 1940, p. 351) }\end{array}$ \\
\hline
\end{tabular}

35 Jijón y Caamaño, en su lista de topónimos y antropónimos emplea la grafía $<\mathrm{k}>$ en lugar de $<\mathrm{c}, \mathrm{qu}>$, y a veces $<\mathrm{w}>$ en lugar de $<\mathrm{gu}, \mathrm{hu}>$. En el presente trabajo se transcribe como se suele escribir en el Registro Civil. Así pues, en algunos casos $<$ luisa $>$ aparece como <luiza $>$. Los nombres de las provincias han sido señaladas por el autor, pues Jijón y Caamaño pocas veces las menciona. 


\begin{tabular}{|c|c|}
\hline Guanaluisa & $\begin{array}{l}\text { a. de Santa Rosa, Pilahüín, San Bartolomé, prov. de Tungurahua; a. } \\
\text { San Andrés, prov. de Chimborazo (Jijón y Caamaño, 1940, p. 371) }\end{array}$ \\
\hline Guanoluisa & $\begin{array}{l}\text { a. del ayllu de Ambatos en Latacunga (1694) (Jijón y Caamaño, } \\
\text { 1940, p. 371): en el texto está escrito "Wanoluisa" }\end{array}$ \\
\hline Huiñaluisa & $\begin{array}{l}\text { a. de hombre de la parcialidad de Cabrera de Alangasí, prov. de } \\
\text { Pichincha (Jijón y Caamaño, 1940, p. } 370 \text { ) }\end{array}$ \\
\hline Janchaluisa & $\begin{array}{l}\text { a. de San Miguelito, prov. de Cotopaxi (Jijón y Caamaño, 1940, } \\
\text { p. 355) }\end{array}$ \\
\hline Janchiluisa & $\begin{array}{l}\text { a. de Poaló, Latacunga, prov. de Cotopaxi (Jijón y Caamaño, 1940, } \\
\text { p. 355) }\end{array}$ \\
\hline Jinaluisa & $\begin{array}{l}\text { a. del ayllu de Saquisilí en Latacunga, prov. de Cotopaxi (Jijón y } \\
\text { Caamaño, 1940, p. 356) }\end{array}$ \\
\hline Lasluisa & $\begin{array}{l}\text { a. de Latacunga, Aláquez, Mulaló y Poaló, prov. de Cotopaxi (Jijón } \\
\text { y Caamaño, 1940, p. 376) }\end{array}$ \\
\hline Lumanluisa & $\begin{array}{l}\text { a. de Aláquez, Latacunga, prov. de Cotopaxi (Jijón y Caamaño, } \\
\text { 1940, p. 378) }\end{array}$ \\
\hline Llumiluisa & $\begin{array}{l}\text { a. de hombre de Tilipulito, prov. de Cotopaxi (Jijón y Caamaño, } \\
\text { 1940, p. 375) }\end{array}$ \\
\hline Mangaluisa & a. de Pasa, prov. de Tungurahua (Jijón y Caamaño, 1940, p. 384) \\
\hline Manoluisa & a. de Píllaro, prov. de Tungurahua (Jijón y Caamaño, 1940, p. 383) \\
\hline Mentaluisa & a. de Aláquez, prov. de Cotopaxi (Jijón y Caamaño, 1940, p. 386) \\
\hline Montaluisa $^{36}$ & a. de Latacunga, prov. de Cotopaxi (Jijón y Caamaño, 1940, p. 385) \\
\hline Panaluisa & $\begin{array}{l}\text { a. de Uyumbicho y Machachi, prov. de Pichincha (Jijón y Caamaño, } \\
\text { 1940, p. 336) }\end{array}$ \\
\hline Pasaluisa & $\begin{array}{l}\text { a. de San Felipe, Latacunga, prov. de Cotopaxi (Jijón y Caamaño, } \\
1940 \text {, p. 335) }\end{array}$ \\
\hline
\end{tabular}

36 Existe también el apellido $<$ Monta $>$, lo cual quiere decir que $<$ Montaluisa $>$ es un apellido compuesto de $\{$ Monta + luisa $\}$. Existen también apellidos que comienzan con \{luisa\} como en <Luisaka, Luisapina $>$, etc. El apellido $<$ Chasiluisa $>$ está compuesto de $<$ Chasi + luisa $>$, nótese que el primer elemento de este término compuesto está también en otros apellidos como <Chasiquiza, Chasipanta, Chasillacta $>$, además que existe el apellido $<$ Chasi $>$. 


\begin{tabular}{|c|c|}
\hline Piluluisa & $\begin{array}{l}\text { a. de Cumbijín, Salcedo, prov. de Cotopaxi (Jijón y Caamaño, 1940, } \\
\text { p. } 342 \text { ) }\end{array}$ \\
\hline Pinaluisa & a. de Pujilí, prov. de Cotopaxi (Jijón y Caamaño, 1940, p. 343) \\
\hline Pinluisa & $\begin{array}{l}\text { a. de Guambaló, prov. de Tungurahua (Jijón y Caamaño, 1940, } \\
\text { p. } 343 \text { ) }\end{array}$ \\
\hline Ponluisa & a. de Pelileo, prov. de Tungurahua (Jijón y Caamaño, 1940, p. 339) \\
\hline Quinaluisa & $\begin{array}{l}\text { a. de Machachi, Alóag, prov. de Pichincha; a. de Pelileo, Patate, prov. } \\
\text { de Tungurahua (Jijón y Caamaño, 1940, p. } 323 \text { ) }\end{array}$ \\
\hline Quingaluisa & $\begin{array}{l}\text { a. de Latacunga, San Miguelito, Aláquez, prov. de Cotopaxi; a. de } \\
\text { Pelileo, prov. de Tungurahua }\end{array}$ \\
\hline Quingaluiza & a. de Riobamba, prov. de Chimborazo \\
\hline Quiñaluiza & $\begin{array}{l}\text { a. de Riobamba, prov. de Chimborazo (Jijón y Caamaño, 1940, } \\
\text { p. 407) }\end{array}$ \\
\hline Sangoluisa & $\begin{array}{l}\text { a. de hombre y de mujer de las parcialidades de Angamarcas y } \\
\text { Quimbiaulco, de Alangasí, prov. de Pichincha (Jijón y Caamaño, } \\
\text { 1940, p. } 363 \text { ) }\end{array}$ \\
\hline Sasluisa & a. de Latacunga (Jijón y Caamaño, 1940, p. 361) \\
\hline Sinaluisa & a. de Uyumbicho, prov. de Pichincha (Jijón y Caamaño, 1940, p. 366) \\
\hline Tipanluisa & $\begin{array}{l}\text { a. del ayllu de Toacaso de Latacunga (1720), de Aláquez, Mulalillo, } \\
\text { Poaló, prov. de Cotopaxi; a. de Amaguaña, Sangolquí, prov. de Pi- } \\
\text { chincha (Jijón y Caamaño, 1940, p. } 332 \text { ) }\end{array}$ \\
\hline Toaluisa & $\begin{array}{l}\text { a. del ayllu de Tacunga en Latacunga, prov. de Cotopaxi (1694) (Ji- } \\
\text { jón y Caamaño, 1940, p. 327) }\end{array}$ \\
\hline Yangoluisa & $\begin{array}{l}\text { a. del ayllu de los tanicuchíes, con título de Don de los Chisaetotas en } \\
\text { Latacunga (1694), prov. de Cotopaxi (Jijón y Caamaño, 1940, p. 357) }\end{array}$ \\
\hline Yanchaluisa & $\begin{array}{l}\text { a. de San Miguelito, San Felipe, prov. de Cotopaxi (Jijón y Caamaño, } \\
\text { 1940, p. 358) }\end{array}$ \\
\hline Yanzaluisa & $\begin{array}{l}\text { a. de hombre de las parcialidades de Naupayco y Cóndor, de Alanga- } \\
\text { sí, prov. de Pichincha (Jijón y Caamaño, 1940, p. 358) }\end{array}$ \\
\hline Yunaluisa & a. de Aláquez, prov. de Cotopaxi (Jijón y Caamaño, 1940, p. 359) \\
\hline
\end{tabular}

Entre los antropónimos híbridos con <luisa $>$ en los cuales se puede identificar que el primer componente es quichua, se puede señalar: <Andaluisa, Cancaluisa, Guanoluisa, Huiñaluisa, Mangaluisa, 
Panaluisa, Sangoluisa $>$. El término $<$ mentaluisa $>$ podría ser un híbrido castellano-panzaleo, si $<$ menta $>$ se refiere a la planta medicinal del mismo nombre.

Por otra parte, cabe señalar que existe la hierbaluisa, originaria de Sudamérica, conocida también como cedrón, verbena de las indias, cuyo nombre universal (científico) es Alosia citrodora. ¿Existe alguna relación del término $<$ luisa $>$ con el nombre de esta planta?

En la zona central del territorio de la lengua panzaleo existen muchos apellidos terminados \{-quiza, -quiza\} como: Chasiquiza, Guanoquiza, Izaquisa, Masaquiza, Toaquiza, etc., que podrían ser apellidos de un grupo de mitimaes incrustados en esta zona.

\section{Lengua puruhá/puruguay/purbay}

El territorio de esta lengua abarcaba la parte centro-norte de la actual provincia de Chimborazo y la mayor parte de la actual provincia de Bolívar, sin embargo, existen algunos términos que están muy al sur en Cañar e inclusive Azuay. Además, parece haber existido una franja que pudieron haber compartido entre las lenguas puruhá y cañar. El actual cantón Chunchi (prov. de Chimborazo) estaría en esta zona. Cieza de León dice en relación a este pueblo y su lengua: "Muchos pueblos hay en esta provincia de los Puruaes, que no trato por evitar prolijidad [...]. Fueron conquistados por los señores incas y sus capitanes, y hablan la lengua general del Cuzco, aunque tenían y tienen las suyas particulares" (Cieza de León, 1553/1973, p. 119).

De los datos de Cieza de León se deduce que la tierra de los puruháes estaba comprendida entre el sur de Mocha (prov. de Tungurahua) y Alausí (prov. de Chimborazo).

De la existencia de esta lengua han quedado algunos testimonios coloniales. Así, en la "Relación geográfica” realizada para Francisco Aun- 
cibay, fray Juan de Paz Maldonado — vicario cum voce in capitulo de la casa y convento de Sant-Andrés - dice:

La lengua que hablan es la puruay, ques la suya propia, y todos los más la general del Inga, que tienen por más polida; y los mitima, que son de Condesuyo, questá junto al Cuzco, hablan unos con otros su lengua de aquella su tierra y todos la del Inga (Paz Maldonado, circa 1583/1965, p. 261).

Aquiles Pérez recogió 5280 palabras de la "lengua de los puruhuayes”, como él los denominó, y publicó los libros Purahuayes I y II $(1969,1970)$. Él creyó encontrar en esta lengua raíces del idioma tsa’fiki, cha'palaa, shuar, quichua, aimara, araucano y castellano, e inclusive da porcentajes. Sin embargo, estas afirmaciones no tienen un sustento lingüístico, como ya se ha mencionado, lo cual disminuye el valor de sus trabajos. Lo único que se puede rescatar de sus voluminosas publicaciones es el listado de topónimos y antropónimos, aunque deben ser depurados para futuras investigaciones. Algo similar ocurre con las interpretaciones de Jijón y Caamaño (1940 y 1941) y del general Paz y Miño, aunque este último es más prudente en sus interpretaciones.

Cuando los topónimos no portan indicación de provincia es porque pertenecen a Chimborazo. Sobre las terminaciones de los topónimos, se pueden mencionar las siguientes: $\{$-ag, -ate, -bug, -cahuan, -llin, -ñag, -pala, -shi\}. En cuanto a los antropónimos, las combinaciones con \{-cela\} son características de esta zona.

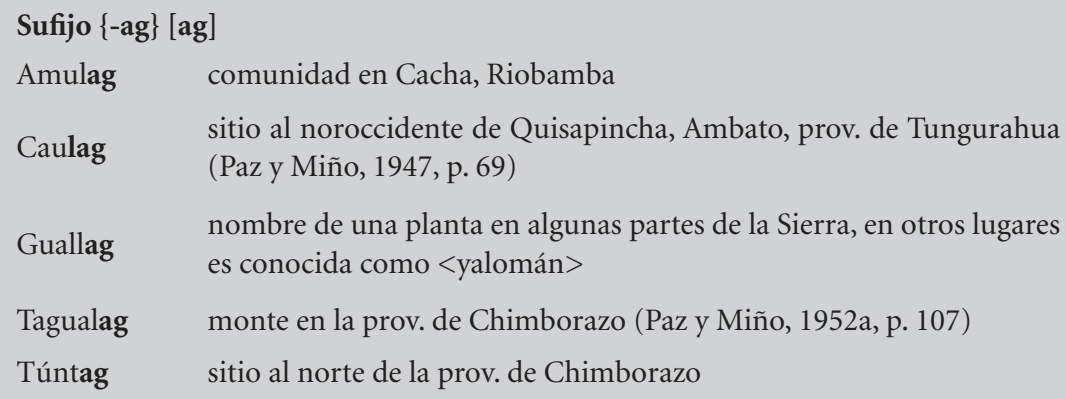




\section{0}

Sufijo $\{$-te $\}$ [te]

Llanganate monte en la Cordillera oriental

Patate río y pueblo en la prov. de Tungurahua

Pucate hacienda en Chambo (Jijón y Caamaño, 1940, p. 501)

Pulucate lugar en Quimiac, prov. de Chimborazo

Usate comunidad en Cubijíes, prov. de Chimborazo

La primera parte de los términos <Llanganate, Patate, Pucate, Usate $>$, al parecer, es quichua.

\begin{tabular}{|ll}
\hline Sufijo $\{$-pug/-bug/-bog $\}$ [pug bug bog] \\
Aichabug & monte al occidente de Punín, Riobamba (Paz y Miño, 1946, p. 84) \\
Aulabug & monte en Sicalpa (Jijón y Caamaño, 1940, p. 445) \\
Baibug & monte al occidente de Riobamba \\
Bulchibug & loma en la prov. de Chimborazo (Paz y Miño, 1946b, p. 211) \\
Bushbug & monte en la prov. de Chimborazo (Paz y Miño, 1946b, p. 211) \\
Calbug & parcialidad de Cubijíes (Jijón y Caamaño, 1940, p. 445) \\
Chaupibug & cerro en el parque Sangay, al este de Riobamba \\
Dolombog & antiguo vértice al oriente de Riobamba (Paz y Miño, 1948b, p. 231) \\
Guabug & comunidad en San Juan, Riobamba \\
Guapug & hacienda en Pallatanga (Jijón y Caamaño, 1940, p. 445) \\
Chillapug & parcialidad de Cubijíes (Jijón y Caamaño, 1940, p. 445) \\
Guillapug & hacienda en Chambo (Jijón y Caamaño, 1940, p. 445) \\
Ishbug & comunidad en parte alta de Cebadas, Guamote \\
Itsubug & monte en Guamote \\
Lambug & sitio en Sigsig, prov. de Azuay \\
Leopug & monte en la prov. de Chimborazo \\
Lutumbug & loma en la prov. de Chimborazo (Paz y Miño, 1948b, p. 225) \\
Llugshibug & comunidad alta en Licto, Riobamba \\
Molobog & hacienda entre Licto y Riobamba \\
Molbog & comunidad en Cañar \\
Naubug & comunidad en Guamote \\
&
\end{tabular}




$\begin{array}{|ll|}\text { Nushibug } & \begin{array}{l}\text { lugar al occidente de Riobamba; monte en la prov. de Chimborazo } \\ \text { (Paz y Miño, 1950a, p. 70) }\end{array} \\ \text { Thungubug } & \text { comunidad en la parte alta de Flores, Riobamba } \\ \text { Tulabug } & \text { colina en la prov. de Chimborazo (Paz y Miño, 1952b, p. 116) } \\ \text { Tulapug } & \text { cerro en la comunidad Bandera Licto, Riobamba } \\ \text { Tulubug } & \text { quebrada de Paccha (Paz y Miño, 1952b, p. 117) } \\ \text { Ubug } & \text { playa a orillas del río Chambo (Jijón y Caamaño, 1940, p. 445) } \\ \text { Yatuibug } & \text { monte en la prov. de Chimborazo (Paz y Miño, 1952c, p. 217) } \\ \text { Yuibug } & \begin{array}{l}\text { monte y una altura al sur del Altar (Paz y Miño, 1952c, p. 218); mon- } \\ \text { te (Jijón y Caamaño, 1940, p. 445) }\end{array} \\ \text { Yulumbug } & \begin{array}{l}\text { loma en la prov. de Chimborazo; una altura entre los ríos Yasipang y } \\ \text { Cebadas (Paz y Miño, 1952c, p. 218) }\end{array}\end{array}$

Nótese que las variaciones de pronunciación son asistemáticas. La mayoría de estos nombres son cerros o lomas, por lo que el significado de \{-bug\} podría estar algo relacionado con estos conceptos. Además, existe el topónimo <tuctibug $>$, el cual es una loma. Ahora bien, como <tucti $>$ es una planta que produce un fruto parecido a un coco pequeño, es una especie de nuez dura de romper para extraer el contenido. Por lo tanto, el significado del topónimo mencionado podría ser 'loma de toctes'.

Entre los nombres híbridos con esta terminación que tienen la raíz quichua están: < aichabug, chaupibug, llugsibug, shungubug $>$.

\begin{tabular}{|ll|}
\hline $\begin{array}{ll}\text { Terminación }\{\text {-cahuan\} [kawán] } \\
\text { Badcahuán }\end{array}$ & río en Penipe \\
Chachacahuán & valle en la prov. de Tungurahua (Paz y Miño, 1948a, p. 84) \\
Leóncahuán & ladera en Penipe \\
Pacahuán & sitio en la prov. de Chimborazo (Paz y Miño, 1950a, p. 73) \\
Paquicahuán & $\begin{array}{l}\text { lugar (Jijón y Caamaño, 1940, p. 420) y hondonada (Paz y Miño, } \\
\text { 1950b, p. 176) }\end{array}$ \\
Pucacahuán & quebrada cerca de Penipe (Paz y Miño, 1951, p. 236) \\
Pucucahuán & quebrada en Penipe (Paz y Miño, 1952a, p. 238)
\end{tabular}




\section{2}

\begin{tabular}{|c|c|}
\hline Sacahuán & quebrada en Guamote \\
\hline Sulucahuán & $\begin{array}{l}\text { tierras del cacicazgo de Tullas y Ocas, Guasuntos (Jijón y Caa- } \\
\text { maño, 1940, p. } 421 \text { ) }\end{array}$ \\
\hline Supaicahuán & arroyo en Penipe \\
\hline Tuncahuán & lugar en Guano; quebrada \\
\hline Tzancahuán & quebrada y afluente del río Guano \\
\hline Tzanancahuán & comunidad en Cebadas, Guamote \\
\hline Yuquiscahuán & quebrada de Quimiag (Paz y Miño, 1952c, p. 219) \\
\hline
\end{tabular}

Varios de ellos son quebradas, por lo que se tiene que investigar tomando esta posibilidad como hipótesis.

Entre los híbridos cuyo primer componente es castellano o quichua se pueden señalar: <Leóncaguán, Paquicaguán, Pucacahuán, Supaicahuán $>$. En opinión de Cerrón-Palomino (2016, comunicación personal), <cahuan> podría estar asociado con el término aimara $<$ q'awa > 'quebrada, barranco'.

\begin{tabular}{|ll|}
\hline \multicolumn{2}{|l|}{ Sufijo $\{-$ llín $\}$ [̌̌́n] } \\
Cubillín & monte en Chambo \\
Chugllín & lugar en Chambo \\
Llinllín & un lugar en la prov. de Chimborazo; a. de Cicalpa, Colta \\
Güillín & cerro en Ludo, Sigsig, prov. de Azuay \\
Sufijo $\{-\tilde{n} a g\}$ & {$[$ ñag] } \\
Apuñag & comunidad en Pungalá \\
Bajañag & cerrito al sureste de Alausí (Paz y Miño, 1946b, p. 208) \\
Barbañag & río al este de Riobamba (Jijón y Caamaño, 1940, p. 454) \\
Chañag & río al este de Riobamba (Jijón y Caamaño, 1940, p. 454) \\
Chulcuñag & lugar en Punín (Jijón y Caamaño, 1940, p. 454) \\
Duñag & lugar en Licto \\
Guagñag & comunidad en Licto, Riobamba \\
Guagñac & río en Achupallas, Alausí (Paz y Miño, 1948b, p. 237) \\
Guaraiñag & lugar en Paute, prov. de Azuay \\
Misñag & río al este de Riobamba \\
Muelañac & loma en la prov. de Chimborazo (Paz y Miño, 1950a, p. 63)
\end{tabular}




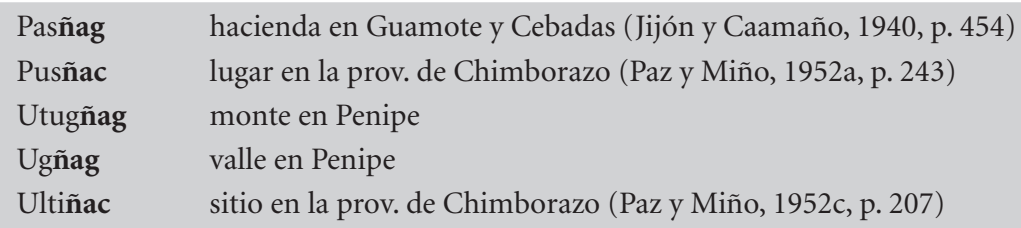

Varios de estos nombres representan ríos, pero se tiene que verificar in situ para asegurarse la hipótesis de que $\{-$ ñag $\}$ esté relacionado con 'río'.

Entre los posibles topónimos híbridos quichua-puruhá se pueden señalar: $<$ Apuñag, chulcuñag, Bajañag $>$. También existe un híbrido castellano-puruhá: $<$ Barbañag $>$.

\begin{tabular}{|ll|}
\hline Componente $\{$ pala $\}$ [palá pála] \\
Cañipala & sitio en la prov. de Chimborazo (Paz y Miño, 1946, p. 219) \\
Colepala & cerro en la prov. de Cañar (Jijón y Caamaño, 1941, p. 12) \\
Gampala & cordillera de Suscal, prov. de Cañar (Jijón y Caamaño, 1941, p. 12) \\
Guachapala & pueblo cerca de Paute, prov. de Azuay \\
Huacapala & cerro y quebrada en San Juan, Riobamba \\
Laipala & lugar en Paute, prov. de Azuay \\
Lampala & sitio y quebrada en Punín \\
Nutbalá & a. de Licán, Riobamba (Jijón y Caamaño, 1940, p. 423) \\
Panchipala & parcialidad de Alausí ya desaparecida (Paz y Miño, 1950b, p. 175) \\
Panupali & riachuelo afluente del río Naranjo (Paz y Miño, 1950b, p. 175) \\
Pipipala & lugar en Quingeo, Cuenca, prov. de Azuay \\
Puculpalá & hacienda en Quimiac, al suroriente de Riobamba \\
Puculpala & comunidad en Chambo \\
Sugpalá & monte en Penipe, Riobamba (Jijón y Caamaño, 1940, p. 423) \\
Shilpalá & comunidad en Cacha, Riobamba \\
Tampalá & cerro en Sidcay, Cuenca, prov. de Azuay \\
Tutupalá & sitio en la prov. de Chimborazo (Paz y Miño, 1952b, p. 121) \\
Ucupalá & arroyo en Penipe, Riobamba (Jijón y Caamaño, 1940, p. 423) \\
\hline
\end{tabular}




\section{4}

No está claro el significado de \{pala\}, pues existen cerros, páramos, arroyos y demás con este componente, sin embargo, se ha encontrado que $<$ Cañi $>$ es un río en San Miguel (prov. de Bolívar) y una quebrada en Ludo (Sigsig, prov. de Azuay). En el supuesto caso de que \{pala\} signifique 'río', 'arroyo' o 'quebreda', entonces el híbrido quichua-puruhá <huacapala $>$ provendría de $<$ huaca $>$ 'sitio ceremonial' y se podría interpretar como 'río del sitio ceremonial'. Entre otros híbridos con el componente \{pala\} se puede señalar: $<$ Cañipala, Colepala, Guachapala, Tutupala, Ucupala $>$.

\begin{tabular}{|ll|}
\hline Sufijo \{-shi\} $\left[\begin{array}{l}\text { ší] } \\
\text { Bacalshi }\end{array}\right.$ & planicie en Calpi, Riobamba \\
Balcashi & monte en la prov. de Chimborazo (Paz y Miño, 1946b, p. 208) \\
Bayushi & planicie en Calpi, Riobamba \\
Billagshi & quebrada cerca de Ingapirca, prov. de Cañar (Paz y Miño, 1946b, \\
Calshi & planicie en Calpi, Riobamba \\
Copshi & planicie en Achupallas, Alausí \\
Gaushi & planicie y comunidad en Calpi, occidente de Riobamba \\
Gulashi & planicie en Columbe, Colta \\
Joyagshi & pueblo al sur de Chunchi, límite con la prov. de Cañar \\
Lanlanshi & lugar en Guano \\
Lluishi & ladera en Retén, Cebadas, Riobamba \\
Monteshi & planicie al noroeste de Riobamba \\
Pachagshi & planicie en Tixán, Alausí; monte en Penipe (Jijón y Caamaño, 1940, \\
Pilligshi & colina en la prov. de Chimborazo (Paz y Miño, 1950b, p. 185) \\
Pishtishi & comunidad en Alausí \\
Pitishi & sitio en la prov. de Chimborazo (Paz y Miño, 1952a, p. 234) \\
Pushi & lugar en Chambo (Jijón y Caamaño, 1940, p. 531) \\
Pulshi & lugar en Licto, Riobamba \\
Relashi & monte cerca de Penipe (Paz y Miño, 1952a, p. 251) \\
Quimshi & lugar en Gualaceo, prov. de Azuay \\
Shaushi & cerro y comunidad en Quero, prov. de Tungurahua \\
&
\end{tabular}




\section{5}

$\begin{array}{|ll|}\text { Shilshi } & \text { colina en Calpi, Riobamba } \\ \text { Shishanshi } & \text { colina en la prov. de Chimborazo (Paz y Miño, 1952b, p. 102) } \\ \text { Shunshi } & \text { nombre primitivo de San Andrés (Paz y Miño, 1952b, p. 104) } \\ \text { Tamshi } & \text { manantial en Penipe (Jijón y Caamaño, 1940, p. 531) } \\ \text { Tocshi } & \text { hacienda en Penipe (Paz y Miño, 1952b, p. 114) } \\ \text { Tunshi } & \text { monte, colina, llanura y hacienda al sureste de Riobamba (Paz y } \\ \text { Tungshi } & \text { lugar al sur de Riobamba (Jijón y Caamaño, 1940, p. 532) } \\ \text { Uchashi } & \text { monte en la prov. de Chimborazo (Paz y Miño, 1952c, p. 206) } \\ \text { Udushi } & \text { cerro en la prov. de Chimborazo } \\ \text { Ulshi } & \text { laderas de Penipe (Jijón y Caamaño, 1940, p. 532) }\end{array}$

La varios nombres terminados en $\{$-shi $\}$ son planicies, pero otros son lomas. Palabras terminados en $\{$-shi\} también existen en territorio de la lengua cañar, en la cual los topónimos con esta terminación son lomas. En la provincia de Maynas (departamento de Loreto, Perú) existe una localidad denominada Tamshiyacu, cuyo primer término es similar al topónimo del territorio puruhá.

Jijón y Caamaño, al observar que existen algunos topónimos comunes en territorio puruhá y en territorio cañar, sostiene que estas dos lenguas están emparentadas y que tienen como base común al mochica, que es una lengua del norte del Perú. Sobre esto último argumenta indicando que tanto en estas dos lenguas de la Sierra ecuatoriana como en el mochica existen terminaciones comunes como $\{$-ate $\}$, entre otras;

37 Sobre el significado de < shunshi $>$ se tiene el siguiente dato de las "Relaciones geográficas" de Paz Maldonado (circa 1580/1965): "Digo queste pueblo se llama Sant Andrés Xunxi. Tomaron los indios esta avocación de Sant Andres cuando lo poblaron, y el otro nombre de Xunxi es que tenía de antes, ques tanto como quien dice 'entremos"'; sin embargo, este significado parece estar dentro de la categoría de etimología popular. 


\section{6}

sin embargo, en esto hay que proceder con más cautela debido a que no contamos con ninguna gramática de las lenguas puruhá y cañar.

A nivel de antropónimos, existe un grupo conformado por la terminación \{-cela\}. Así, Jijón y Caamaño (1940, pp. 424-425) trae el siguiente listado de apellidos de la provincia de Chimborazo, aunque no precisa como en otras ocasiones la fecha del documento en que los encontró.

\begin{tabular}{|ll|}
\hline Aucancela & a. de Guamote, Punín, Tapi y Guasuntos \\
Bacacela & a. de Tapi y Guamote \\
Cayancela & a. de Licán \\
Curicayancela & a. de Licán \\
Duchicela & a. de Punín y Quisapincha \\
Dumacela & a. de Guamote y Guasuntos \\
Guaguacela & a. de Guasuntos \\
Masacela & a.de Licán \\
Mayancela & a. de Licán \\
Quinacela & a. de Punín \\
Quimcela & a. de Punín \\
Quisnacela & a. de Punín \\
Romancela & a. de Licán \\
Saquicela & a. de Licán \\
Salicela & a. de Licán \\
Tenecela & a. de Licán (en Perú hay el a. Tenicela) \\
Yumancela & a. de Licán \\
\hline
\end{tabular}

En el caso de $<$ Guaguacela $>$ se podría proponer que es un híbrido con el quichua $<$ guagua $>$.

Esta terminación se encuentra también en el territorio de la lengua cañar, en la provincia del mismo nombre. Así, Cordero Palacios (1923/1981) señala como parte de la lengua cañar los siguientes: 


\begin{tabular}{|ll|}
\hline Achacela & lugar en Sigsig, prov. de Azuay \\
Belecela & a. de Cañar (Jijón y Caamaño, 1940, p. 425) \\
Bimaicela & a. de Cañar \\
Cochancela & a. de Cañar \\
Cutaicela & a. de Cañar \\
Dumaicela & a. de Cañar \\
Dumancela & a. de Cañar \\
Guaillacela & a. de Cañar \\
Guarcela & a. de Cañar \\
Latacela & a. de Cañar \\
Macancela & a. de Cañar \\
Nibicela & a. de Cañar \\
Saquicela & a. de Cañar \\
Sinancela & a. de Cañar \\
Tenecela & a. de Cañar \\
\hline
\end{tabular}

Según Jijón y Caamaño (1940, p. 426), Jesús Arriaga aportó con el registro de los siguientes antropónimos tomados de la provincia de Azuay:
Biñaicela
a. de Cañaribamba, prov. de Azuay
Chuquicela
a. de Cañaribamba, prov. de Azuay
Sacancela
a. de Cañaribamba, prov. de Azuay

Jijón y Caamaño (1940, p. 426) señala también que Max Uhle le proporcionó la siguiente lista de antropónimos, pero no especifica su procedencia: 

Ayagcela
Arcela
Guabicela
Huacancela
Huacacela
Huayacela
Macacela
Muevecela
Machicela
Namcela

Apellidos terminados en $\{$-cela $\}$ existen en las provincias de Chimborazo, Cañar, Azuay y Loja, es decir, están en territorio de la lengua puruhá y cañar. Por esto no resulta claro si este término fue parte de la lengua puruhá, de la lengua cañar o de las dos. Por otra parte, en Loja existe el topónimo $<$ Cela $>$, que es un monte. No se puede todavía saber si el topónimo $<$ Cela $>$ de la provincia de Loja tenga algo que ver con el segundo componente de los apellidos de las lenguas puruhá y cañar. En Loja existe el apellido <Vacacela $>$, que podría ser una variante del apellido $<$ Huacacela $>$, donde $<$ Huaca $>$ sería en quichua 'sitio sagrado'. Cerrón Palomino (2016, comunicación personal) señala que también en el Perú existe los apellidos < Tenecela, Arcela $>$. Así, es probable que la lengua cañar y llegó al Perú con los mitimaes de Cañar.

\section{Lengua cañar}

Según Cieza de León, la "tierra de los cañares” comenzaría luego de pasar la gran quebrada del Chanchán, al sur de la actual provincia de Chimborazo. Él hace mención a dos aposentos importantes de la "provincia de los cañares", aunque no habla sobre su lengua propia:

Entre los cuales están dos principales, llamado el uno Cañaribamba [actual Oña] y el otro Hatuncañari [actual Ingapirca], de donde tomaron los naturales nombre, y su provincia, de llamarse los cañares como 


\section{9}

hoy se llaman [...]. A la mano diestra y siniestra de este real camino que llevo hay no pocos pueblos y provincias, los cuales no nombro porque los naturales de ellas, como fueron conquistados y señoreados por los reyes incas, guardaban las costumbres de los que voy contando y hablan la lengua general del Cuzco y andan vestidos ellos y sus mujeres (Cieza de León, 1553/1973, p. 120).

Así, el territorio de esta lengua parece haber estado comprendido entre Alausí (prov. de Chimborazo) y Oña (prov. de Azuay), sin embargo, también se encuentran nombres atribuidos a la lengua cañar en la parte norte de la provincia de Loja.

Sobre el nombre de la lengua que se utiliza en esta investigación es el que se señala en el documento del Segundo Sínodo Quitense (1594). No sabemos cómo la denominaban sus hablantes y posiblemente "cañar" sea el gentilicio, como ocurre en muchas lenguas indígenas. Paz y Miño, en su estudio sobre la lengua cañar (1940), propone que el término "lengua cañarí" no cabe ser usado porque hay documentos coloniales donde se la denomina "lengua cañar". Efectivamente, como se puede ver en la cita anterior, Cieza de León menciona que los naturales tomaron el término "cañares", para autodenominarse a partir de los nombres de aquellos dos pueblos mencionados. Además, en este estudio a la lengua y a su población las denominamos “cañar” y no "cañari”, porque al parecer este último término sería la pluralización en esta lengua del etnónimo "cañar", mientras que "cañares" sería la pluralización castellana de "cañar".

En cuanto a las investigaciones sobre esta lengua, Octavio Cordero Palacios, en el libro El quechua y el cañari, terminado en 1923 pero publicado recién en 1970 y reeditado en 1981, incluyó 1873 términos. Por su lado, Paz y Miño (1961) compiló un listado de 2422 términos de la región de Cañar y estableció con ellos 282 grupos. Aquiles Pérez, en su libro Cañaris (1977) compiló 4510 términos de la toponimia y antroponimia del antiguo territorio cañar. En todas estas compilaciones hay muchos términos quichuas, con lo cual el número de términos propios de la lengua cañar se reduce sustancialmente. 


\section{0}

Entre las terminaciones atribuidas a esta lengua están: \{-cay, -copte, cun, -del, -deleg, -pali, -pud, -si, -shi, zhun [žun šun], zhapa [žapa $\sim$ šapa], -zol [sol]\}. En las tres últimas terminaciones, actualmente, hay diferencias de pronunciación entre los hablantes en relación a la forma con la que está escrita en los documentos consultados.

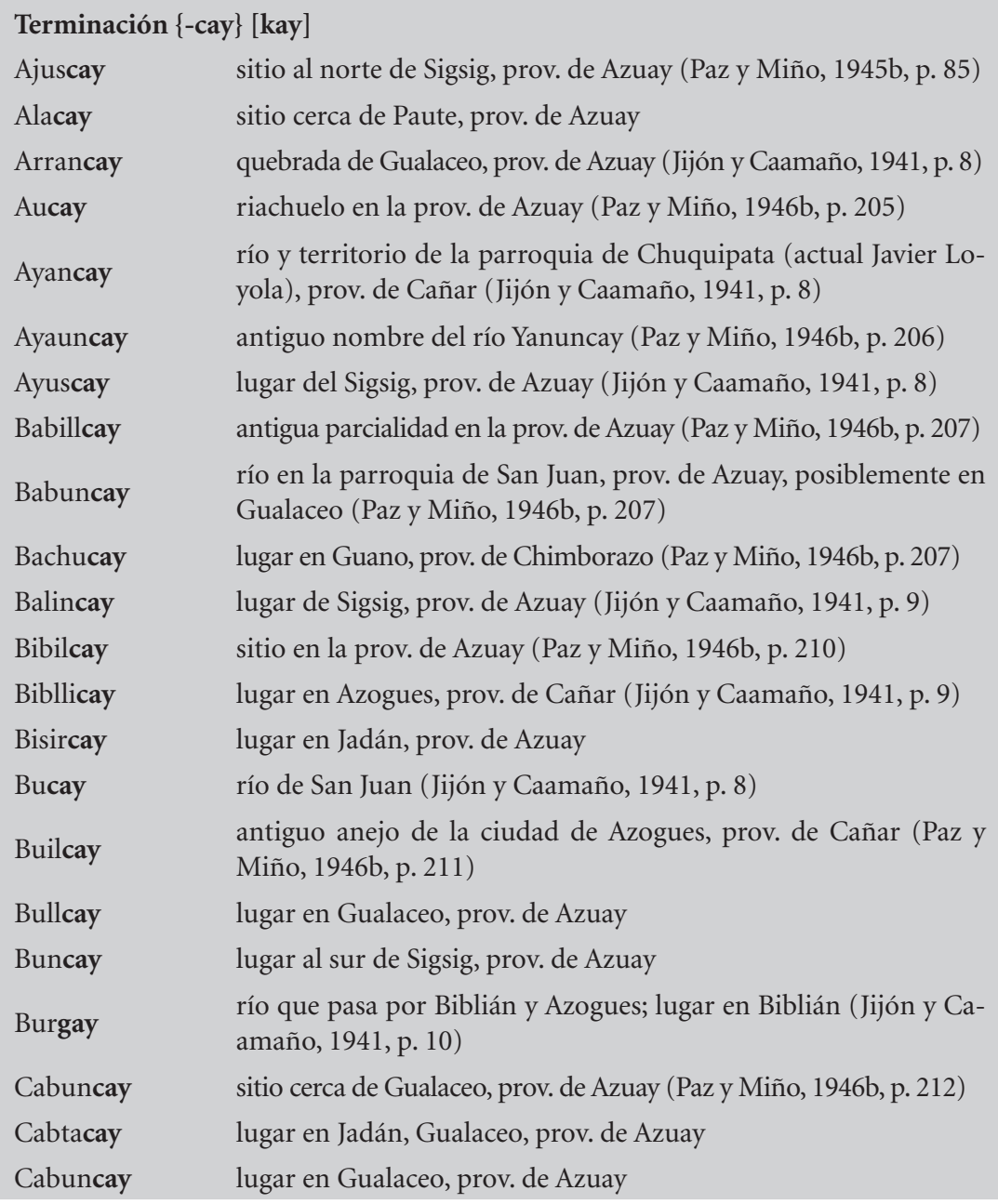




\begin{tabular}{|c|c|}
\hline Camancay & lugar en Paccha, prov. de Azuay \\
\hline Cancay & $\begin{array}{l}\text { lugar en la parroquia de El Oriente (actual Daniel Córdova To- } \\
\text { ral), Gualaceo (Jijón y Caamaño, 1941, p. 11) }\end{array}$ \\
\hline Caucay & $\begin{array}{l}\text { riachuelo en la prov. de Cañar; cordillera al oeste de Cañar, prov. } \\
\text { de Cañar (Paz y Miño, 1947, p. 69) }\end{array}$ \\
\hline Casacay & afluente izquierdo del río Jubones (Paz y Miño, 1947, p. 67) \\
\hline Cashicay & lugar y riachuelo de Biblián, prov. de Cañar \\
\hline Caucay & cerro y río en Cañar, prov. de Cañar \\
\hline Cerracay & lugar en Gualaceo, prov. de Azuay \\
\hline Cililcay & un monte al este de Nabón, prov. de Azuay (Paz y Miño, 1947, p. 70) \\
\hline Cochancay & lugar en La Troncal, Cañar, prov. de Cañar \\
\hline Curquinchicay & lugar en Gualaceo, prov. de Azuay (Jijón y Caamaño, 1941, p. 13) \\
\hline Curuncay & lugar al sur de Sigsig, prov. de Azuay \\
\hline Cusicay & antigua parcialidad de Azogues (Paz y Miño, 1948a, p. 81) \\
\hline Cutilcay & río de Paute, prov. de Azuay (Jijón y Caamaño, 1941, p. 13) \\
\hline Chagualcay & páramo en El Cajas, Cuenca, prov. de Azuay \\
\hline Chalacay & $\begin{array}{l}\text { sitio en la orilla del río Paute, prov. de Azuay; río afluente derecho } \\
\text { del río Collay (Paz y Miño, 1948a, p. 85) }\end{array}$ \\
\hline Chalcay & río de Nabón \\
\hline Chancay & afluente del Santa Bárbara (Paz y Miño, 1948a, p. 86) \\
\hline Charcay & río y lugar en el Cañar, prov. de Cañar \\
\hline Chicticay & río de San Cristóbal, Gualaceo \\
\hline Chilicay & afluente al lado derecho del río Chanchán, prov. de Chimborazo \\
\hline Chullcay & lugar en Déleg, prov. de Cañar; lugar en Chinchero, Perú \\
\hline Churcay & $\begin{array}{l}\text { riachuelo afluente del río Tarqui, Cuenca, prov. de Azuay (Paz y } \\
\text { Miño, 1948b, p. 229) }\end{array}$ \\
\hline Ganacay & $\begin{array}{l}\text { afluente izquierdo del Jubones (Paz y Miño, 1948b, p. 234); lu- } \\
\text { gar en Paute, prov. de Azuay; lugar en Shagalli (Jijón y Caamaño, } \\
\text { 1941, p. 16) }\end{array}$ \\
\hline Guapllincay & lugar en Azogues, prov. de Cañar \\
\hline Guaguacay & río en Molleturo, prov. de Azuay (Paz y Miño, 1949a, p. 238) \\
\hline Gualalcay & lugar en El Valle, Cuenca, prov. de Azuay \\
\hline Gualmincay & afluente derecho del río Gualaceo (Paz y Miño, 1949a, p. 240) \\
\hline
\end{tabular}


102

$\begin{array}{ll}\text { Guallancay } & \text { lugar en Cumbe, Cuenca, prov. de Azuay (Jijón y Caamaño, 1941, } \\ \text { p. 18) } & \begin{array}{l}\text { quebrada en Gualleturo, prov. de Cañar (Jijón y Caamaño, 1941, } \\ \text { Guamuncay }\end{array} \\ \text { p. 17) } \\ \text { Guancay } & \text { lugar en Sigsig, prov. de Azuay (Jijón y Caamaño, 1941, p. 17) } \\ \text { Gullancay } & \text { lugar en Chordeleg (Jijón y Caamaño, 1941, p. 17) } \\ \text { Guncay } & \text { lugar cerca de Azogues } \\ \text { Gupancay } & \text { lugar en El Valle, Cuenca, prov. de Azuay } \\ \text { Güiquicay } & \text { quebrada afluente del río Gualaceo (Paz y Miño, 1949a, p. 56) } \\ \text { Güishcay } & \text { lugar en Oña, prov. de Azuay (Jijón y Caamaño, 1941, p. 18) } \\ \text { Guscay } & \text { quebrada en Gualaceo, prov. de Azuay (Jijón y Caamaño, 1941, } \\ \text { Gussucay } & \text { lugar en Sigsig, prov. de Azuay } \\ \text { Gutacay } & \text { lugar en Sigsig, prov. de Azuay (Jijón y Caamaño, 1941, p. 19) } \\ \text { Iluncay } & \text { loma al sureste de Gualaceo (Paz y Miño, 1949a, p. 56) } \\ \text { Jacay } & \text { lugar en Gualaceo, prov. de Azuay } \\ \text { Jazhacay } & \text { lugar en la prov. de Azuay (Paz y Miño, 1949b, p. 216) } \\ \text { Jidcay } & \text { lugar en Sigsig, prov. de Azuay (Jijón y Caamaño, 1941, p. 19) } \\ \text { Jutracay } & \text { nombre primitivo de Checa, Cuenca, prov. de Azuay (Paz y Miño, } \\ \text { Jublincay } & \text { 1949b, p. 219) } \\ \text { Lacay } & \text { lugar en Déleg, Azogues, prov. de Cañar } \\ \text { Laucay } & \text { lugar en la prov. de Azuay (Paz y Miño, 1949b, p. 219) } \\ \text { Licay } & \text { lugar en Chaguarurcu (actual Santa Isabel), prov. de Azuay } \\ \text { Licacay } & \text { sitio cerca de Sayausí, Cuenca, prov. de Azuay } \\ \text { Lincay } & \text { antigua parcialidad de Guasuntos, prov. de Chimborazo; sitio en } \\ \text { Llamacay } & \text { la prov. de Azuay (Paz y Miño, 1948b, p. 223) } \\ \text { Maguarcay } & \text { lugar en Sigsig, prov. de Azuay (Paz y Miño, 1949b, p. 223) } \\ \text { Masucay } & \text { afluente del río Jubones (Paz y Miño, 1948b, p. 225) } \\ \text { fuente de agua cerca de Azogues, prov. de Cañar (Jijón y Caama- } \\ \text { ño, 1941, p. 22) } \\ \text { afluente izquierdo del río Jubones (Paz y Miño, 1949b, p. 232); río } \\ \text { afluente del Naranjal }\end{array}$




\section{3}

\begin{tabular}{|c|c|}
\hline Morocay & afluente del río Naranjal (Paz y Miño, 1950a, p. 57) \\
\hline Multicay & $\begin{array}{l}\text { lugar en San Bartolomé, Sigsig, prov. de Azuay (Jijón y Caamaño, } \\
\text { 1941, p. 23) }\end{array}$ \\
\hline Muluncay & afluente del río Calera, Pindo (Paz y Miño, 1950a, p. 64) \\
\hline Nachucay & lugar en Guano, prov. de Chimborazo (Paz y Miño, 1950a, p. 66) \\
\hline Nancay & quebrada afluente del río Paute (Paz y Miño, 1950a, p. 67) \\
\hline Narancay & río y lugar al sur de Cuenca, prov. de Azuay \\
\hline Nocay & $\begin{array}{l}\text { lugar en la parroquia El Oriente (actual Daniel Córdova Toral), } \\
\text { Gualaceo (Jijón y Caamaño, 1941, p. 23) }\end{array}$ \\
\hline Norcay & afluente del río Cañar (Paz y Miño, 1950a, p. 70) \\
\hline Nuzhuncay & lugar en Gualaceo, prov. de Azuay \\
\hline Pacalcay & parcialidad de Girón, prov. de Azuay \\
\hline Palcay & río afluente izquierdo del río Cañar \\
\hline Paguancay & río y lugar de Naranjal, prov. de Guayas (Paz y Miño, 1950b, p. 172) \\
\hline Paluncay & sitio cerca del pueblo de Checa (Paz y Miño, 1950b, p. 74) \\
\hline Paucay & sitio en la prov. de Azuay (Paz y Miño, 1950b, p. 179) \\
\hline Pelincay & $\begin{array}{l}\text { lugar de El Pucará (Jijón y Caamaño, 1941, p. 25); afluente dere- } \\
\text { cho del río Jubones (Paz y Miño, 1950b, p. 180) }\end{array}$ \\
\hline Perruncay & quebrada cerca de Azogues (Paz y Miño, 1950b, p. 181) \\
\hline Picay & lugar en Gualaceo, prov. de Azuay \\
\hline Pichacay & lugar en Santa Ana, Cuenca, prov. de Azuay \\
\hline Pincay & antiguo anejo de Azogues (Paz y Miño, 1950b, p. 186) \\
\hline Pirincay & lugar en Paute, prov. de Azuay \\
\hline Piruncay & lugar en Sigsig, prov. de Azuay \\
\hline Pizhucay & río en Suscal, prov. de Cañar \\
\hline Pucay & afluente izquierdo del Naranjal (Paz y Miño, 1952a, p. 238) \\
\hline Puculcay & lugar de El Pucará, prov. de Azuay (Jijón y Caamaño, 1941, p. 26) \\
\hline Puicay-huaicu & $\begin{array}{l}\text { quebrada de Nulti, Cuenca, prov. de Azuay (Paz y Miño, 1952a, } \\
\text { p. 239) }\end{array}$ \\
\hline
\end{tabular}




\section{4}

Purcay

tierras en la prov. de Azuay (Archivo Nacional, caja 64, año 17511751, expediente 10, Quito, p. 19 de octubre de 1751. Juicio posesorio por las tierras de Purcay, las que dice, don Valentín Llivipuglla y Tarcán, cacique de la parcialidad de Tarcán en el pueblo de Paccha en Cuenca, le pertenecen por herencia, pero que fueron tomadas por los hermanos Tarquequica y otros indios aduciendo que eran tierras de comunidad. Actualmente pertenece a la parroquia Borrero de Azogues)

Pirincay sitio cerca de Paute, prov. de Azuay (Paz y Miño, 1950b, p. 188)

Putucay afluente del río Naranjal (Paz y Miño, 1952a, p. 244)

Raucay lugar en Gualaceo, prov. de Azuay (Jijón y Caamaño, 1941, p. 27)

Rircay afluente izquierdo del río Bulubulu; río en Suscal, prov. de Cañar; afluente derecho del río Jubones (Paz y Miño, 1952a, p. 251)

Riscay monte al norte de Zaruma, prov. de Loja (Paz y Miño, 1952a, p. 251)

Rucay

Sacay lugar de Girón, prov. de Azuay (Jijón y Caamaño, 1941, p. 27) lugar en San Sebastián (Paz y Miño, 1952a, p. 254)

Saucay afluente del río Matader; monte de Checa, Cuenca (Paz y Miño, 1952a, p. 258)

lugar en Cuenca (Jijón y Caamaño, 1941, p. 30) (Sid, es un lu-

Sidcay gar San Juan, Galaceo, prov. de Azuay; El Tambo, prov. de Cañar, existe un lugar denominado Sisid; también riachuelo; afluente izquierdo del río Molleturo, prov. de Azuay)

Sinincay río y lugar en Cuenca, prov. de Azuay

Sitincay lugar en Déleg, prov. de Cañar (Jijón y Caamaño, 1941, p. 30)

Suicay lugar en Suscal, prov. de Cañar (Jijón y Caamaño, 1941, p. 30)

Sulcay lugar en Paute, prov. de Azuay (Jijón y Caamaño, 1941, p. 30)

Shanincay quebrada de Chaguarurcu (actual Santa Isabel), prov. de Azuay

Shilicay lugar de Cochapata, Nabón, prov. de Azuay (Jijón y Caamaño, 1941 , p. 28)

Shilincay lugar en Oña, prov. de Azuay (Jijón y Caamaño, 1941, p. 28)

Shirincay quebrada y lugar en Azogues

Shiucay quebrada y lugar en Azogues (Paz y Miño, 1952b, p. 103)

Shucay río y lugar en Baños, Cuenca, prov. de Azuay; afluente izquierdo del río Cañar (Paz y Miño, 1952b, p. 104) 
105

\begin{tabular}{|ll|} 
Shurucay & río en San Fernando; lugar en Pucará, prov. de Azuay \\
Tabacay & orígenes del río de Azogues, prov. de Cañar \\
Tamuscay & río en Achupallas, prov. de Chimborazo \\
Tausacay & riachuelo afluente izquierdo del río Patul (Paz y Miño, 1952b, p. 110) \\
Tilcay & lugar en la prov. de Azuay (Paz y Miño, 1952b, p. 112) \\
Tircay & lugar en Gualleturo, Cañar \\
Tulacay & lugar en Sigsig, prov. de Azuay (Jijón y Caamaño, 1941, p. 33) \\
Tuncay & cordillera de la Asunción; lugar en Paute, prov. de Azuay \\
Uchucay & afluente izquierdo del río Jubones (Paz y Miño, 1952c, p. 206) \\
Vincay & lugar en la prov. de Azuay (Paz y Miño, 1952c, p. 211) \\
Yanacay & lugar en la prov. de Azuay (Paz y Miño, 1952c, p. 14) \\
Yanuncay & río de Cuenca, orígenes del río Paute. Paz y Miño (1952c, p. 216), \\
Yucacay & señala que otro nombre para este río era Yanibí \\
Yumacay & lugarada y lugar en Gualaceo, prov. de Azuay \\
Zhanincay & afluente derecho del río Llauzhari \\
Zhircay & lugar en Suscal, prov. de Cañar (Jijón y Caamaño, 1941, p. 34) \\
Zhucay & afluente izquierdo del río Tarqui \\
\hline
\end{tabular}

Hay un importante número de palabras terminadas en $\{$-cay $\}$ que son nombres de ríos y quebradas. Esto urge a que se investiga si el resto de palabras que no designan ríos también se hayan usado no solamente para designar al lugar, sino a algún río o quebrada del lugar. En algunos híbridos quichua-cañar como $<$ Putucay $>$ es claro que se puede traducir como 'río de algodón'. Igualmente $<$ Cusicay $>$ 'río de la alegría', $<$ Guaguacay $>$ 'río de los niños', $<$ Gullancay $>$, 'quebrada de gullanes' (tacsos), etc.

Por otra parte, $\{$ cay $\}$ también podría plantearse como hipótesis que provenga del aimara <q'aya $>$ con la consiguiente caída de vocal, que según Cerrón-Palomino (2016 comunicación personal) este fenómeno se dio con frecuencia en la historia del quechua, donde se perdió la vocal final de la palabra. Además, se conoce que $<$ q'aya $>$ es variante de $<$ q'awa $>$ y tiene el significado de quebrada. 


\section{6}

\section{Componente $\{$ copte [kopte]}

Casacopte loma al noroccidente de la hacienda Delegzol (Paz y Miño, 1947, p. 67)

Chorocopte lugar en Cañar

Choracopte lugar en Cañar (Jijón y Caamaño, 1941, p. 14)

Cosacopte lugar de San Juan (Jijón y Caamaño, 1941, p. 12)

Componente $\{$-cun $\}$ [kun]

Cuchucun lugar en Cañar

Cuscun lugar en Gualaceo, prov. de Azuay

Cushcun lugar en Cañar (Paz y Miño, 1948a, p. 81)

Cuzcun lugar cerca de Gualaceo, prov. de Azuay (Paz y Miño, 1948a, p. 83)

Podría tener relación con el nombre cultural histórico quechua <cuscuni> 'con Cuzco'.

$\begin{array}{ll}\begin{array}{l}\text { Sufijo }\{\text {-del }\} \text { [del] } \\ \text { Bayandel }\end{array} & \begin{array}{l}\text { lugar en la localidad de Déleg } \\ \text { Bicadel }\end{array} \\ \text { Boladel } & \text { río del Sigsig, prov. de Azuay } \\ \text { Buradel } & \text { sitio cerca de Campanaurco (Paz y Miño, 1946b, p. 211) } \\ \text { Casadel } & \begin{array}{l}\text { lugar y laguna en Nabón, prov. de Azuay (Jijón y Caamaño, } \\ 1941, \text { p. 12) }\end{array} \\ \text { Chigledel } & \begin{array}{l}\text { lugar en Gualleturo prov. de Cañar (Jijón y Caamaño, 1941, } \\ \text { p. 14) }\end{array} \\ \text { Duquirdel } & \begin{array}{l}\text { lugar al este de Nabón, prov. de Azuay (Paz y Miño, 1948b, } \\ \text { p. 232) }\end{array} \\ \text { Gañadel } & \text { lugar en Cumbe; cerro de Cañar (Jijón y Caamaño, 1941, p. 16) } \\ \text { Garudel } & \text { lugar al noreste de Cochapata, Nabón, prov. de Azuay } \\ \text { Gualadel } & \text { lugar y monte en Nabón, prov. de Azuay } \\ \text { Gualdel } & \text { hacienda al occidente de Asunción, prov. de Azuay } \\ \text { Gullandel } & \text { lugar en Suscal, prov. de Cañar }\end{array}$




\section{7}

\begin{tabular}{|ll} 
Labadel & lugar en Gualleturo, prov. de Cañar \\
Nonadel & río cerca de Quingeo (Paz y Miño, 1950a, p. 69) \\
Pambadel & $\begin{array}{l}\text { lugar en Girón, prov. de Azuay (Paz y Miño, 1950b, p. 174); } \\
\text { lugar cerca de Saraguro }\end{array}$ \\
Pucundel & $\begin{array}{l}\text { lugar en Duma, Sigsig, prov. de Azuay (Jijón y Caamaño, 1941, } \\
\text { p. 26) }\end{array}$ \\
Putudel & orígenes del río Chillayacu (Paz y Miño, 1952a, p. 244) \\
Quimandel & $\begin{array}{l}\text { lugar en Sigsig, prov. de Azuay; ladera en Azogues, prov. de } \\
\text { Cañar }\end{array}$ \\
Sabadel & sitio al sureste de Guanazan (Paz y Miño, 1952a, p. 253) \\
Shiñadel & lugar al norte de Oña, prov. de Azuay \\
Tacadel & monte de Cumbe \\
Tardel & cerro de Jima, Sigsig, prov. de Azuay \\
Tordel & lugar en Oña, prov. de Azuay
\end{tabular}

Existe un arbusto denominado < vayan $>$, de hojas grandes, redondas y lisas, de la familia de las Sinantéreas. Además de $<$ bayandel $>$ en Déleg (prov. de Cañar) también existen los topónimos < vayan $>$ en Cochapata, Nabón y Jima, y en Sigsig (prov. de Azuay). Por otra parte, hay el topónimo $<$ bayandel $>$ para referirse a un lugar en Déleg. Entonces, podría sugerirse que $<$ Bayandel $>$ es el lugar donde hay el arbusto de bayan. También en Girón, al sur de Cuenca, existe una altura pequeña denominada $<$ Bayan Loma> 'Loma con bayanes' (Espinosa y Jácome, 1988, p. 88).

Existen algunos híbridos con quichua como en: $<$ Pambadel, Putudel, Tacadel $>$. 
108

\begin{tabular}{|c|c|}
\hline \multicolumn{2}{|c|}{ Componente $\{$ deleg $\}[$ deleg $\sim$ delig $\sim$ dilig $]$} \\
\hline Déleg & $\begin{array}{l}\text { lugar perteneciente a la prov. de Cañar, } 22 \mathrm{~km} \text { al suroeste de Azo- } \\
\text { gues, limítrofe con la prov. de Azuay }\end{array}$ \\
\hline Bayandéleg & $\begin{array}{l}\text { quebrada de San Fernando, prov. de Azuay (Jijón y Caamaño, } \\
\text { 1941, p. 9) }\end{array}$ \\
\hline Candéleg & lugar en San Bartolomé, Sigsig, prov. de Azuay \\
\hline Chordeleg & cantón en la prov. de Azuay \\
\hline Gondeleg & lugar en San Bartolomé, Sigsig, prov. de Azuay \\
\hline Gordeleg & lugar en Jadán, Gualaceo, prov. de Azuay \\
\hline Gualadeleg & lugar en Sigsig, prov. de Azuay (Jijón y Caamaño, 1941, p. 17) \\
\hline Gualdeleg & $\begin{array}{l}\text { lugar en la parroquia El Oriente (actual Daniel Córdova Toral) } \\
\text { (Jijón y Caamaño, 1941, p. 17) }\end{array}$ \\
\hline Guapdondelig & $\begin{array}{l}\text { llanura desde Baños hasta el río Machángara, Cuenca, prov. de } \\
\text { Azuay (Jijón y Caamaño, 1941, p. 17) }\end{array}$ \\
\hline Guerdeleg & $\begin{array}{l}\text { lugar en San Bartolomé, Sigsig, prov. de Azuay (Jijón y Caamaño, } \\
\text { 1941, p. 17) }\end{array}$ \\
\hline Pindilig & lugar en la prov. de Cañar \\
\hline Sondeleg & lugar en Sigsig, prov. de Azuay \\
\hline Shindéleg & lugar en San Bartolomé, Sigsig, prov. de Azuay \\
\hline Shindilig & lugar en Azogues, prov. de Cañar \\
\hline Zhondéleg & lugar en Chordeleg, prov. de Azuay \\
\hline
\end{tabular}

Por otra parte, existe un lugar en Chordeleg denominado $<$ Delegsol>. Esto muestra que también podía ocurrir en posición inicial y que varios de los términos de la lista pueden ser formas compuestas.

En las “Relaciones geográficas”, Hernando Pablos señala:

Primeramente, se llama este asiento de la ciudad de Cuenca y todo el valle que se extiende desde Los Baños hasta la ribera de Machángara, en lengua de los naturales destos cañares, Guapdondelic, y cuando los conquistó la primera vez Inga Yupanque, les preguntó que cómo se llamaba todo este valle, respondieron los señores dél que se llamaba Guapdondelic [así], que quiere decir "llano grande como el cielo", luego 
le puso el Inga Yupangue el mesmo nombre en su lengua, mamándole Tomebamba, que quiere decir lo propio (1582/1965, p. 265).

Se puede observar que <Guapdondelic $>$ es un compuesto de $<$ guapdon + delic/deleg $>$. Sobre el primer componente no se puede saber su significado, pues hay que estudiar el significado simbólico de $<$ tumi>, pero no parece referirse al concepto de "cielo" que hoy se tiene (seguramente se trata de una metáfora). El segundo significado de "llanura" parece ser plausible, pues los lugares compuestos con el término $<$ deleg, delig $>$ son llanuras, es decir, pampa [pamba bamba].

\section{Componente \{pali\} [pali]}

Carapali lugar de Chaguarurcu (actual Santa Isabel), prov. de Azuay, nombre primitivo de Santa Isabel (Paz y Miño, 1947, p. 65)

Toctapali sitio en Chaguarurcu (actual Santa Isabel) (Paz y Miño, 1952b, p. 114)

Tortapali sitio en Chaguarurcu (actual Santa Isabel) (Jijón y Caamaño, 1941, p. 32)

Tutupali afluente izquierdo del río Tarqui, cerca de Cuenca, prov. de Azuay

Zhinpali lugar en Las Nieves, Nabón, prov. de Azuay

Estos términos al parecer son compuestos. Así, $<$ Tutupali $>$ estaría integrado por $<$ tutu + pali $>$, el primero sería de origen quichua y el segundo cañar.

\begin{tabular}{|c|c|}
\hline \multicolumn{2}{|c|}{ Posible sufijo $\{$-pud $\}$ [pud] } \\
\hline Ashapud & $\begin{array}{l}\text { planta lorantácea Lorantus Nitidus; lugar en la parroquia de Sidcay (Ji- } \\
\text { jón y Caamaño, 1941, p. 8) }\end{array}$ \\
\hline Aypud & lugar en la parroquia Alausí, prov. de Chimborazo \\
\hline Chalapud & lugar en Molleturo, prov. de Azuay (Jijón y Caamaño, 1941, p. 13) \\
\hline Chalpud & lugar en Chunchi, prov. de Chimborazo (Jijón y Caamaño, 1941, p. 13) \\
\hline Jazhapud & lugar en Sigsig, prov. de Azuay (Paz y Miño, 1949b, p. 219) \\
\hline Larapud & $\begin{array}{l}\text { lugar en San Bartolomé, Sigsig, Prov. de Azuay (Jijón y Caamaño, 1941, } \\
\text { p. 20) }\end{array}$ \\
\hline Naspud & lugar en la prov. de Azuay (Paz y Miño, 1950a, p. 68) \\
\hline Nucpud & lugar en la prov. de Azuay (Paz y Miño, 1950a, p. 70) \\
\hline
\end{tabular}




\section{0}

$\begin{array}{|ll|}\text { Nudpud } & \begin{array}{l}\text { lugar en Azogues (Jijón y Caamaño, 1941, p. 23); origen del río Tabacay } \\ \text { (Paz y Miño, 1950a, p. 70) }\end{array} \\ \text { Nunpud } & \text { lugar en la prov. de Azuay (Paz y Miño, 1950a, p. 70) } \\ \text { Perpud } & \text { lugar en Sigsig, prov. de Azuay } \\ \text { Pichipud } & \text { lugar cerca de Punín (Paz y Miño, 1950b, p. 183) } \\ \text { Rirpud } & \text { lugar en Suscal, prov. de Cañar (Paz y Miño, 1952a, p. 251) } \\ \text { Sarpud } & \text { lugar en Sigsig, prov. de Azuay } \\ \text { Sasapud } & \text { lugar en la prov. de Chimborazo (Paz y Miño, 1952a, p. 258) } \\ \text { Tegapud } & \begin{array}{l}\text { hacienda en Girón, prov. de Azuay; lugar al sureste de San Fernando, } \\ \text { prov. de Azuay (Paz y Miño, 1952b, p. 111) }\end{array} \\ \text { Uzhupud } & \text { lugar en Paute, prov. de Azuay } \\ \text { Zhirpud } & \text { nombre antiguo de Suscal }\end{array}$

Existen algunos híbridos como: <chalapud, larapud, sasapud, uzhupud $>$.

\begin{tabular}{|ll|}
\hline \multicolumn{2}{l}{ Sufijo $\{$-sí\} $[$ si] } \\
Alausí & ciudad en la prov. de Chimborazo \\
Chalagsí & lugar en Shaglli, Santa Isabel, prov. de Azuay \\
Chocarsí & lugar en Nulti, Cuenca \\
Doctasi & lugar al oriente de Gualaceo (Paz y Miño, 1948b, p. 231) \\
Ganasi & $\begin{array}{l}\text { cordillera de San Bartolomé, Sigsig, prov. de Azuay (Paz y Miño, } \\
\text { Peleusí }\end{array}$ \\
Pulusí & nombre prehispánico de la ciudad de Azogues \\
Sayausí & lugar en Cuenca \\
Togtesí & lugar en Gualaceo, prov. de Azuay \\
Udusí & antigua parcialidad de Nabón (Paz y Miño, 1952c, p. 207)
\end{tabular}

En la relación Sant Francisco Pueleusi del Azogue, fray Gaspar de Gallegos dice lo siguiente sobre el nombre < peleusi>: 
Llámase Peleusi (asi) este pueblo en la lengua de los indios, porque parece ser que en este pueblo, más que en otra parte alguna, hay los campos llenos de unas matas que dan unas flores amarillas, las cuales, por su tiempo, ques por mayo y junio, cubren todo el campo; que quiere decir "campo amarillo". Llámase la lengua destos naturales cañare, porque así se llama toda esta provincia y términos de la ciudad de Cuenca (circa 1582/1965, vol. II, p. 274).

Según este texto, el nombre de la tierra de Azogues es Pueleusi o Peleusi. La interpretación dada parece ser de etimología popular, a menos que con más investigación se demuestre que \{peleu\} haga referencia a las flores amarillas de la planta conocida con el nombre de $<$ ñachak $>$, que abunda hasta hoy en esa zona, y además que el término <-si $>$ esté relacionado con meseta, campo, etc.

\begin{tabular}{|c|c|}
\hline \multicolumn{2}{|c|}{ Sufijo $\{-s h i\}[$ ši $]$} \\
\hline Billagshi & quebrada en Ingapirca, prov. de Cañar \\
\hline Bormashi & lugar en la prov. de Azuay (Paz y Miño, 1946b, p. 211) \\
\hline Chobshi & laguna en Sigsig, prov. de Azuay (Jijón y Caamaño, 1941, p. 14) \\
\hline Ganshi & $\begin{array}{l}\text { cerro en Cañar (Jijón y Caamaño, 1941, p. 16); lugar al este de Rio- } \\
\text { bamba, prov. de Chimborazo (Jijón y Caamaño, 1940, p. 530) }\end{array}$ \\
\hline Gashi & río en Penipe, prov. de Chimborazo \\
\hline Garaoshi & lugar en Quingeo, prov. de Azuay (Jijón y Caamaño, 1941, p. 16) \\
\hline Golashi & loma de Cumbe, Cuenca, prov. de Azuay \\
\hline Gulashi & cerro en Jima, Sigsig, prov. de Azuay (Paz y Miño, 1948b, p. 236) \\
\hline Gurshi & lugar en Sigsig, prov. de Azuay \\
\hline Jalshi & cerro en Paccha, Cuenca \\
\hline Joyacshi & lugar en Suscal (Jijón y Caamaño, 1941, p. 20) \\
\hline Llamagshi & lugar en Gualleturo, prov. de Cañar (Jijón y Caamaño, 1941, p. 21) \\
\hline Llipshi & $\begin{array}{l}\text { quebrada en Chaguarurcu (actual Santa Isabel), prov. de Azuay (Ji- } \\
\text { jón y Caamaño, 1941, p. 21) }\end{array}$ \\
\hline Paullushi & quebrada en Jima, prov. de Azuay (Paz y Miño, 1950b, p. 179) \\
\hline Pupashi & loma cerca de Azogues, prov. de Cañar (Paz y Miño, 1952a, p. 242) \\
\hline
\end{tabular}




\section{2}

Rishi

monte cerca de San Bartolomé, Sigsig, prov. de Azuay (Paz y Miño, 1952a, p. 252)

Runshi monte en la prov. de Chimborazo (Paz y Miño, 1952a, p. 253)

Shalashi lugar en Jima, Sigsig, prov. de Azuay

Shaushi lugar en Jima, Sigsig, prov. de Azuay

Shirishi lugar en Jima, Sigsig, prov. de Azuay

Shuishi lugar en Jima, Sigsig, prov. de Azuay

Shullashi lugar cerca de Jima, prov. de Azuay (Paz y Miño, 1952b, p. 104)

Tarabshi lugar en Jima, Sigsig, prov. de Azuay

Tarushi loma al occidente del pueblo de Jima, prov. de Azuay (Paz y Miño, 1952b, p. 110)

Tocteshí sitio cerca de Gualaceo, prov. de Azuay (Paz y Miño, 1952b, p. 114)

Tushi lugar en Sigsig, prov. de Azuay

Zhatashi sitio cerca de Girón, prov. de Azuay (Paz y Miño, 1952c, p. 224)

Zhaurinshi colina cerca de Chordeleg, prov. de Azuay (Paz y Miño, 1952c, p. 224)

La existencia de $\{$-shi $\}$ como un término con significado propio se comprueba por la existencia del fitónimo <garao $>$ como término independiente, el cual, según Jijón y Caamaño (1941, p. 16), es una planta proteácea Lomatia Obliqua, así como un páramo de Checa, en Gualleturo (prov. de Azuay). Por otra parte, existe el topónimo <Garaoshi> que es un lugar en Quingeo (prov. de Azuay). Además, existe el topónimo $<$ tocteshi $>$ que podría plausiblemente interpretarse como 'sitio o lugar con toctes', equivalente al término <tocti-ucu $>$, una loma situada al lado occidental de Quito. En los ejemplos presentados existen los híbridos con quichua: $<$ Pupashi, Shullashi $>$.
Sufijo $\{$-shun/zhun/sun $\}$ [šun žun]]
Bayanzhun
cerro en Sigsig, prov. de Azuay
Bayozhun
cerro en Tixán, prov. de Chimborazo
Bulzhun
lugar en Gualaceo, prov. de Azuay
Burashun
lugar Jadán, Gualaceo, prov. de Azuay 


\begin{tabular}{|c|c|}
\hline Buyzhun & lugar en El Tambo, prov. de Cañar \\
\hline Cagnazhun & lugar en Gualaceo, prov. de Azuay (Paz y Miño, 1946b, p. 214) \\
\hline Cahuashun & lugar en Gualaceo, prov. de Azuay \\
\hline Capagzhun & lugar en Gualaceo, prov. de Azuay \\
\hline Chubzhun & antiguo anejo de Azogues (Paz y Miño, 1948b, p. 227) \\
\hline Ganzhun & lugar al sur de Chordeleg, (Paz y Miño, 1948b, p. 234) \\
\hline Guaizhun & cerro en Azogues \\
\hline Guanzhun & lugar San Bartolomé, Sigsig, prov. de Azuay \\
\hline Güizhun & quebrada en Gualaceo (Jijón y Caamaño, 1941, p. 18) \\
\hline Llagshun & lugar en Paute, prov. de Azuay \\
\hline Manzhun & lugar en Gualaceo, prov. de Azuay (Jijón y Caamaño, 1941, p. 22) \\
\hline Nauzhún & $\begin{array}{l}\text { lugar en San Bartolomé, Sigsig, prov. de Azuay (Jijón y Caamaño, } \\
\text { 1941, p. 23) }\end{array}$ \\
\hline Pilzhún & $\begin{array}{l}\text { cerro argentífero en Azogues, prov. de Cañar (Jijón y Caamaño, } \\
\text { 1941, p. 25) }\end{array}$ \\
\hline Pinazhún & $\begin{array}{l}\text { una de las minas auríferas en Sigsig, prov. de Azuay (Jijón y Ca- } \\
\text { amaño, 1941, p. 25) }\end{array}$ \\
\hline Quinashún & lugar en Sigsig, prov. de Azuay \\
\hline Shalashún & lugar en Sigsig, prov. de Azuay \\
\hline \multicolumn{2}{|c|}{ Componente $\{$-tarqui\} [tarki] } \\
\hline Tarqui & $\begin{array}{l}\text { lugar al sur de Cuenca, prov. de Azuay; afluente del río Paute, } \\
\text { Cuenca; afluente izquierdo del río Guaranda, prov. de Bolívar } \\
\text { (Paz y Miño, 1952b, p. 109) }\end{array}$ \\
\hline Guapatarqui & $\begin{array}{l}\text { lugar en Columbe, Colta, prov. de Chimborazo; lugar en Cumbe, } \\
\text { Cuenca, prov. de Azuay }\end{array}$ \\
\hline Guaguatarqui & $\begin{array}{l}\text { vallecito al sur de Cuenca, prov. de Azuay (Paz y Miño, 1948b, } \\
\text { p. 238). }\end{array}$ \\
\hline Portete Tarqui & sitio al sur de Tarqui, al norte de Girón \\
\hline \multicolumn{2}{|c|}{ Posible sufijo $\{$-zol $\}[$ sol $]$} \\
\hline Canazol & hacienda en Chordeleg, prov. de Azuay (Paz y Miño, 1946b, p. 18) \\
\hline Capzol & lugar en Chunchi, prov. de Chimborazo \\
\hline Charasol & lugar en Azogues, prov. de Cañar \\
\hline Delegsol & lugar en Chordeleg, prov. de Azuay (Jijón y Caamaño, 1941, p. 15) \\
\hline
\end{tabular}




\section{4}

$\begin{array}{|ll|}\text { Gananzol } & \text { caserío al este de San Juan, Gualaceo, prov. de Azuay } \\ \text { Gonzol } & \text { comunidad, cerro y río en Chunchi, prov. de Chimborazo (Paz y } \\ \text { Moisol } & \text { Miño, 1948b, p. 237) } \\ \text { Pimonsol } & \text { lugar en Girón, prov. de Azuay } \\ \text { Pucarsol } & \text { lugar en Cañar (Paz y Miño, 1952a, p. 236) } \\ \text { Soransol } & \text { lugar en Chordeleg, prov. de Azuay } \\ \text { Toctezol } & \text { Pazy Miño no menciona el lugar donde se encuentra este topónimo } \\ \text { Viezol } & \text { parcialidad de Sigsig, prov. de Azuay (Paz y Miño, 1952c, p. 210) }\end{array}$

Existen híbridos con quichua como en: $<$ Pucarsol, Toctezol, Yaguarzol $>$. Por otra parte, $<$ Pucarsol $>$ parece provenir de $<$ Pucarasol $>$.

\begin{tabular}{|c|c|}
\hline \multicolumn{2}{|c|}{ Componente $\{$ zhapa/shapa $\}$ [žapa šapa] } \\
\hline Aroczhapa & $\begin{array}{l}\text { nombre antiguo del pueblo San Bartolomé, Sigsig, prov. de Azuay } \\
\text { (no se conoce cómo se pronunciaba }<\mathrm{zh}>\text { ) }\end{array}$ \\
\hline Gullanzhapa & lugar al sur de Cuenca \\
\hline Lluzhapa & lugar hacia el occidente de Oña \\
\hline Raquishapa & cerro de Jima, Sigsig, prov. de Azuay (Jijón y Caamaño, 1941, p. 27) \\
\hline Shaishapa & $\begin{array}{l}\text { cerro en Chaguarurcu (actual Santa Isabel) (Jijón y Caamaño, } \\
1941 \text {, p. 28) }\end{array}$ \\
\hline Tacalzhapa & lugar en Santa Ana, Cuenca \\
\hline Uduzhapa & $\begin{array}{l}\text { lugar y río en Cochapata, Nabón, prov. de Azuay (también escrito } \\
<\text { Udushapa }>\text { ) }\end{array}$ \\
\hline
\end{tabular}

Se constata que las palabras con esta terminación están solo en la provincia de Azuay. Por otra parte, fray Domingo de los Ángeles señala lo siguiente sobre el término < aroczhapa >, al referirse al pueblo de San Bartolomé de Aroczhapa: "Llámase arocxapa el asiento de este pueblo, porque hay en el mucha cantidad de unas flores que se llaman en su lengua cañar aroc" (circa 1582/1965, p. 271). Esto permitiría postular que el término <zhapa> significaría, 'planicie, rincón de'. Si esto fuera así, el término $<$ Gullanzhapa $>$ significaría 'planicie de gullan'. En estructura quichua, <gullanzhapa $>$ equivaldría a <gullanpampa $>$. Igualmente, 


\section{5}

$<$ aroczhapa $>$ sería $<$ arocpamba $>$. El término < gullan $>$, en la Sierra sur designa una planta y su fruto a los cuales en la Sierra norte y centro se llama $<$ tacso $>$, que es la Passiflora tripartita var. Mollissima. Podría también interpretarse como una variación del plural $<$ llapa $>$, del quechua del norte del Perú, del aumentativo <sapa $>$.

\begin{tabular}{|c|c|}
\hline \multicolumn{2}{|c|}{ Nombres con base $\{$ gullan- $\}$ [gu $\lambda$ an] o con final $\{$-gullan $\}$ [gu $\lambda$ an] } \\
\hline Gullan & planta Passiflora tripartita, var. Mollissima $<$ tacso $>$ \\
\hline Gullancay & $\begin{array}{l}\text { lugar en Cojitambo, Azogues, prov. de Cañar (Jijón y Caamaño, } \\
1941 \text {, p. 18) }\end{array}$ \\
\hline Gullandel & lugar en Suscal, prov. de Cañar (Jijón y Caamaño, 1941, p. 18) \\
\hline Gullanshapa & cerro en El Valle, Cuenca, prov. de Azuay \\
\hline Pirigullan & $\begin{array}{l}\text { planta Passiflora tripartita, var. Mollissima <tacso }>\text { (Jijón y Caama- } \\
\text { ño, 1941, p. 25) }\end{array}$ \\
\hline
\end{tabular}

Adicionalmente, se tiene otros nombres de la onomástica actual con /ž/ que sobreviven hasta hoy en el territorio de la lengua cañar. Entre las personas que han recopilado términos de la lengua cañar están: Luis Cordero (1892/1989), Octavio Cordero (1923/1981) y Rosaleen Howard (2010). Algunos de los términos todavía vigentes son:

\begin{tabular}{|c|c|c|}
\hline Chinzhi & [činži] & 'desayuno' \\
\hline Zhadan & [žadan] & 'un tipo de planta' \\
\hline Zharpa & [žarpa] & 'áspero, escabroso’ \\
\hline Zharpi & [žarpi] & una comida de maíz molido grueso como arroz \\
\hline Zhima & [žima] & $\begin{array}{l}\text { una variedad de maíz muy apreciada que es de } \\
\text { color perla }\end{array}$ \\
\hline Zhin & [žin] & lugar en Taday, al este de Azogues \\
\hline Zhirbi, zhirbu & [žirbi, žirbu] & 'crespo, ensortijado' \\
\hline Zhiripi & [žiripi] & 'arbusto de buena madera' \\
\hline Zhiru & [žiru] & 'color gris' \\
\hline Zhizhi & [žiži $]$ & 'broza seca para hacer fuego' \\
\hline Zhuru & [žuru] & 'cicatrices, principalmente en la cara' \\
\hline Zhuta & [žuta] & 'pájaro, en general' \\
\hline
\end{tabular}




\section{6}

En el quichua actual de Cañar se mantiene un par mínimo entre estos dos fonemas $\lambda / \check{z}<1 \mathrm{l} / \mathrm{zh}>$. Esto confirma la necesidad de introducir la grafia $<\mathrm{zh}>$ en la escritura quichua de Cañar.

\begin{tabular}{|ll|}
\hline $\begin{array}{l}\text { killu } \\
\text { kizhu }\end{array}$ & 'amarillo' \\
\hline
\end{tabular}

También existen palabras con $<\mathrm{z}>$ fricativa dental sonora. Entre los términos que siguen vigentes con este sonido están:

\begin{tabular}{|lll|}
\hline Hizi & {$[$ xizi $]$} & 'risueño/a' \\
Tuzu & {$[$ tuzu $]$} & 'decaído' \\
Zipi & {$[$ zipi $]$} & 'agrietado' \\
Zula & {$[$ zula $]$} & 'grano' \\
\hline
\end{tabular}

Existen algunos otros términos como [kuzu] el cual designa un 'tipo de gusano grande', que algunos de los autores mencionados, lo consideran como pertenecientes a la lengua cañar, pero esto no puede ser, pues este término es conocido en toda la Sierra, y se pronuncia como [kusu $\sim \mathrm{kuzu}$ ]. Esto es así porque existen varios topónimos en la Sierra norte y centro que llevan el nombre de Cusubamba de /kusupampa/, 'planicie de este tipo de gusanos'. Cabe anotar que también hay el término /kuru/, pero este es diferente de /kusu/, pues se refiere a gusano en general. En consecuencia, se requiere inventariar con precaución algunos de los términos del corpus atribuible a la lengua cañar. Esto es importante para ser consistentes en la representación escritura de los términos de sustrato en la estandarización del quichua.

\section{Lengua palta}

El territorio palta ocupaba la actual provincia de Loja y parte de El Oro y Zamora Chinchipe. Sobre la lengua o lenguas que se hablaban en este territorio existen diferentes opiniones entre los estudiosos. En el numeral 151 de la relación atribuida a Juan de Salinas se menciona lo siguiente: 


\section{7}

En términos de dicha ciudad hay tres diferentes gentes, naciones o lenguas. La una lengua se dice cañar, y la otra palta, y la otra Malacatas [así], questas dos últimas, aunque difieren algo, se entienden \{así]; y así son diferentes en hábitos y en trajes, y aun en condiciones, porque la gente cañar es gente más doméstica y de más razón que no la palta (circa 1573/1965, p. 301).

Más adelante, en el numeral 160, dice:

Los naturales dichos son muy bien agestados y los de la nación palta más bien dispuestos, aunque no de tanta razón y policía como los cañares, ni de tanta habilidad y ingenios para cualquier cosa; aunque los unos y los otros a cualquier oficio que se ponen lo toman bien; aunque los cañares en todo hacen ventaja. Todos ellos viven sanos, y así hay muchos muy vejísimos (circa 1573/1965, p. 302).

Un autor anónimo (circa 1582/1965, pp. 139-140) que escribió la Relación de la doctrina de Nambija y Yahuar Songo, menciona tres lenguas: rabona, palta y bolona. Uno de los autores que ha investigado sobre estos datos es Torero (2002). Por otra parte, otro autor anónimo en la Relación de la tierra de Jaén, al referirse a la provincia de Xoroca, dice:

Desta provincia de Chirinos a la de Xoroca hay seis lenguas. Es tierra de montaña poblados en ella (así). Tiene diferente lengua de los Chirinos, porque hablan la lengua palta. Llaman al maíz xemé, y al agua yumé, y la leña let, y el fuego capal. Son indios de behetría; no tienen Señor que los gobierne (Anónimo, circa 1571/1965, p. 143).

Varios autores han relacionado la lengua palta con las lenguas amazónicas de la denominada familia jibaroana. Así, un escritor actual sobre los topónimos de Loja dice:

Se conoce con el nombre lenguas jíbaras o jibaroanas, a cierta familia de lenguas que hablaban y hablan los llamados jíbaros en la época precolombina y colonial. Dentro de estas lenguas jíbaras están el shuar, achuar, wambisa, awajum o aguaruna, dentro de las cuales se incluye las extintas lenguas palta, el guayacundo-calvas, y la malacatos; dichas de otra manera (patagón, xiroa y rabona) (García, 2013, p. 14). 


\section{8}

Aquiles Pérez recopiló 1918 palabras de la zona de esta cultura y publicó la obra Paltas (1984). Según él, esta lengua es una combinación de varias lenguas como el shuar, cañar, cara, panzaleo, etc. Las terminaciones más frecuentes en el territorio de la lengua palta son: \{-nama, -nga, -numa, -piro\}.

\begin{tabular}{|c|c|}
\hline \multicolumn{2}{|c|}{ Componente $\{$ nama $\}$ [namá] } \\
\hline Bucanama & $\begin{array}{l}\text { hacienda cerca de Malacatos, prov. de Loja (Paz y Miño, 1946b, } \\
\text { p. 211) }\end{array}$ \\
\hline Cumbinama & región del Alto Chinchipe \\
\hline Cangonama & pueblo al sur del monte Cango, al sur de Zaruma \\
\hline Cumbinama & $\begin{array}{l}\text { lugar en el Alto Chinchipe, prov. de Zamora Chinchipe (Paz y } \\
\text { Miño, p. 1947, p. 80) }\end{array}$ \\
\hline Chupanama & sitio en la región del río Zamora (Paz y Miño, 1948b, p. 229) \\
\hline Gonzanama & pueblo en Loja \\
\hline Guachanama & $\begin{array}{l}\text { pueblo y monte cerca de Celica, prov. de Loja (Paz y Miño, 1948b, } \\
\text { p. 237) }\end{array}$ \\
\hline Guancanama & $\begin{array}{l}\text { nombre antiguo del río que pasa junto a Loja (Paz y Miño, 1949a, } \\
\text { p. 49) }\end{array}$ \\
\hline Yangonama & $\begin{array}{l}\text { parcialidad de Zamora Chinchipe ya desaparecida (Paz y Miño, } \\
\text { 1952c, p. 2015) }\end{array}$ \\
\hline
\end{tabular}

En Loja existe el apellido <Gonza $>$, por lo tanto, $<$ Gonzanamá $>$ podría ser un término compuesto.

\begin{tabular}{|ll|}
\hline $\begin{array}{l}\text { Componente }\{\text {-numa } \text { [numá] } \\
\text { Agannuma }\end{array}$ & cerro cerca de Vilcabamba \\
Cajanuma & nudo entre Loja y Malacatos \\
Caronoma & $\begin{array}{l}\text { parcialidad en Yaguarzongo ya desaparecida (Paz y Miño, 1947, } \\
\text { p. 66) }\end{array}$ \\
Guallashinuma & quebrada al sur de Vilcabamba \\
Guayanuma & lugar al pie del río Colambo (Jijón y Caamaño, 1941, p. 53) \\
Jerinuma & afluente izquierdo del río Catamayo (Paz y Miño, 1949b, p. 219) \\
Larinuma & cerro \\
Lambunuma & cerro al occidente de Vilcabamba, prov. de Loja
\end{tabular}




$\begin{array}{ll}\begin{array}{l}\text { Lujinuma } \\ \text { Mamanuma }\end{array} & \begin{array}{l}\text { lugar al pie de Gonzanamá, prov. de Loja } \\ \text { quebrada en el valle de Loja (Jijón y Caamaño, 1941, p. 53) } \\ \text { Palanuma }\end{array} \\ \text { Purunnuma } & \begin{array}{l}\text { afluente derecho del río Chinchipe (Paz y Miño, 1950b, p. 173) } \\ \text { cerro de Gonzanamá }\end{array} \\ \text { Tumianuma } & \begin{array}{l}\text { hacienda al pie del río Lambunuma (Jijón y Caamaño, 1941, } \\ \text { Turanuma }\end{array} \\ \text { Turunuma } & \text { quebrada entre Loja y Chinguilanchi } \\ \end{array}$

Se observa que la mayor parte de estas palabras son cerros, lo que haría presumir que el significado de \{-numa\} pudo haber sido 'cerro'.

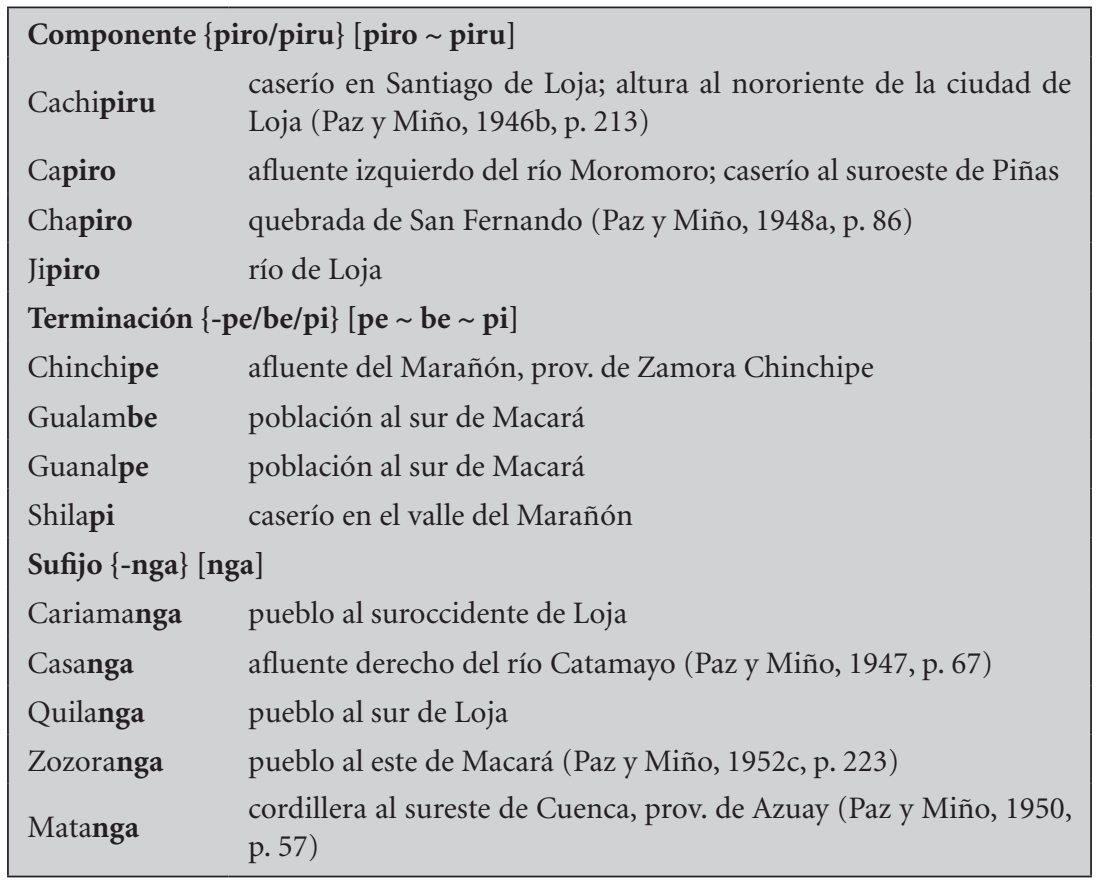

En el caso de que $\{$-nga\} esté relacionado con el quichua, se tendría híbridos con quichua como: <Casanga, Matanga $>$. 
120

\section{A manera de conclusión}

Con la documentación existente hasta cerca de fines del siglo XX, Taylor (1988, p. 37), basado en (Deler, 1981, p. 19), presenta un mapa con las por él denominadas "etnias" de la zona andina: pasto, cara, panzaleo, puruhá, cañar y palta. Torero (2002, p. 373), a partir de esta distribución étnica, las relaciona con lenguas de sustrato, aunque él dice que prefiere designar a la lengua cara con el nombre de "otavalo".

En las fronteras de estas lenguas hay que tomar en consideración una franja bastante ancha en donde existen topónimos de una y otra lengua fronteriza. Este podría ser tomado como un signo de interacción dinámica entre los hablantes de las diferentes lenguas fronterizas, como las señaladas por las fuentes que se han mencionado. Por lo tanto, lo señalado en la Figura 1 son solo aproximaciones idealizadas.

Por otra parte, las lenguas preincaicas de la Sierra ecuatoriana pueden contener, a su vez, sustrato de lenguas anteriores. Eso explicaría la presencia de varios sufijos para referirse a un mismo significado como: montaña, sementera, etc. Para obtener más datos de estas lenguas, se requiere desarrollar y aplicar un modelo de estudio interdisciplinario de lingüística, etnohistoria, antropología y arqueología, como lo señala Cerrón-Palomino (2015).

Los términos compuestos híbridos, donde hay una parte en lengua conocida y otra en lengua no conocida, pueden ser una pista para nuevas investigaciones sobre el significado de los nombres de las lenguas prequichuas.

La representación escrita de términos provenientes de lenguas prequichuas plantea un reto para la estandarización de la escritura del quichua, pues contienen algunos sonidos que no existen en esta lengua. 


\section{1}

Figura 1

Etnias prequichuas de la Sierra ecuatoriana

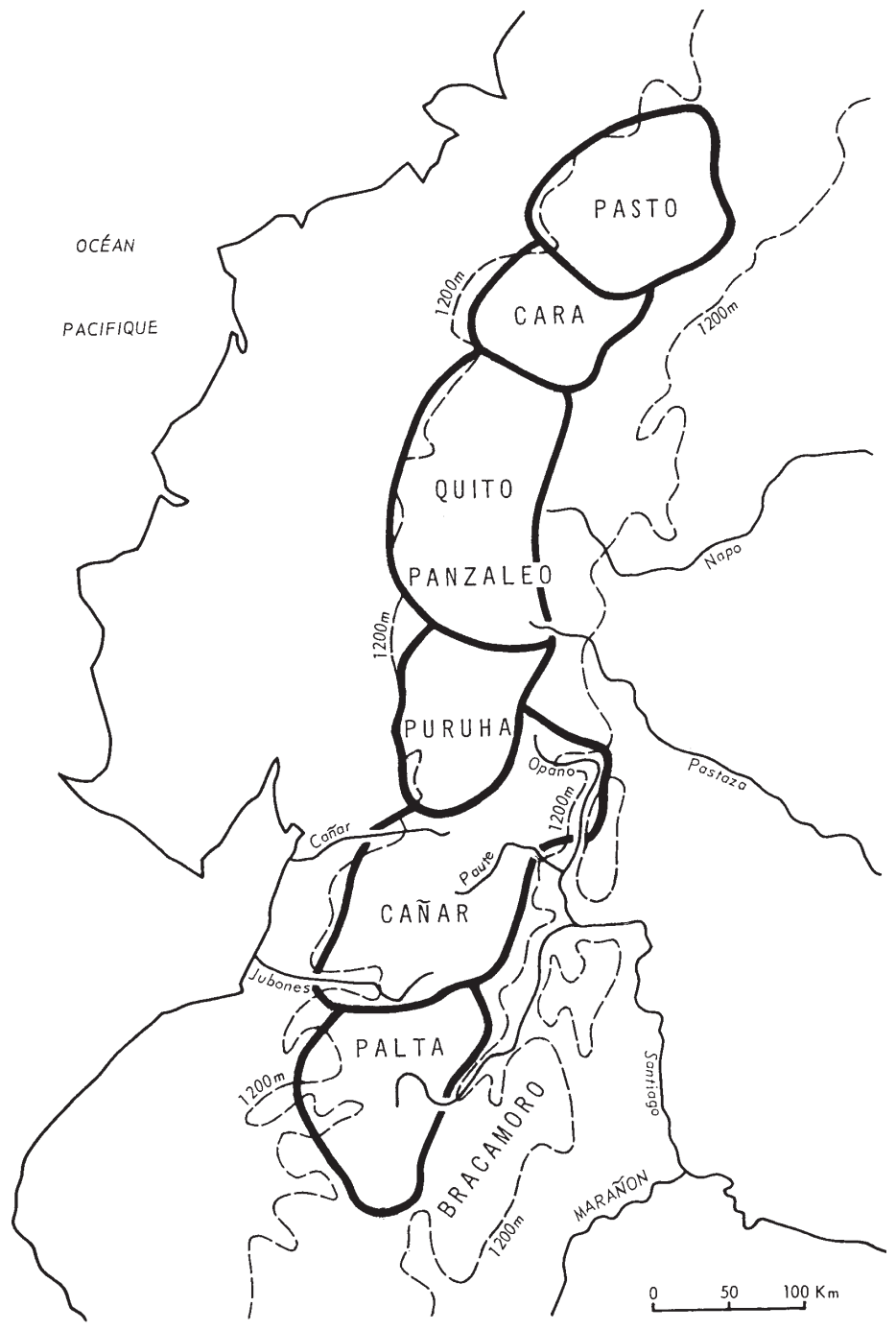

Fuente: Taylor, 1988 adaptado de Deler, 1981, p. 19 

Capítulo 2 La presencia del quichua en el Ecuador

Sobre la presencia del quichua en el Ecuador se han formulado varios planteamientos. ¿Es preincaico, como dicen unos, o llegó con los incas como sostienen otros? ¿Antes de la invasión española ya estuvo muy extendido en el país o su difusión se produjo principalmente con la evangelización, durante la Colonia? La discusión continúa. Algunos autores, a lo largo de la historia, han propuesto diferentes hipótesis acerca de la presencia del quichua en suelo ecuatoriano apoyándose en criterios de orden lingüístico, arqueológico y etnohistórico, fundamentalmente. $\mathrm{Al}$ presente no es posible llegar a una posición cerrada sobre el tema.

Una vez que se ha presentado el estado del arte sobre las lenguas prequichuas que constituyen el sustrato del quichua de la Sierra ecuatoriana, se pasa a tratar las teorías acerca de la presencia del quichua en el Ecuador. ${ }^{38} \mathrm{Al}$ respecto, los autores se han alineado en torno a dos posiciones: la una postula que esta lengua es originaria del Ecuador y la otra considera que el quichua es de origen exógeno. La segunda posición se subdivide a su vez en torno a dos hipótesis: la una sostiene que esta lengua llegó a estos lugares antes de la presencia de los incas por factores comerciales y religiosos, y la otra señala que el quichua arribó al Ecuador con los incas. A continuación, presentamos una síntesis crítica de las propuestas.

38 En este punto no se involucran las teorías que se han propuesto sobre el origen del quichua en el Perú. Para esto remitimos a los estudios de Torero (1974, 2007), CerrónPalomino (1987), Heggarty y Beresford-Jones (2012), Itier (2013), entre otros. 


\section{La teoría del origen ecuatoriano}

Luisa Stark, basándose en argumentos de lingüística interna —la reconstrucción interna de seis sufijos, la diversidad dialectal del quichua de la Sierra centro- y también en algunos datos arqueológicos del padre Porras (1980), postula la teoría del origen ecuatoriano del quichua. Esta hipótesis surgió en la década de 1970, no ha tenido muchos seguidores, pero es conveniente revisar sus argumentos como un complemento al conocimiento de las lenguas de sustrato del quichua.

En el campo arqueológico, el padre Porras, por los mismos años que Stark elaboraba su propuesta sobre el origen del quichua, encuentra similitudes en la cerámica de la cultura panzaleo de la Sierra centro con la de la fase Cosanga ubicada en la actual provincia amazónica de Napo. Partiendo de esto, este autor sugiere que la cultura cosanga se habría expandido desde la Amazonía hacia Píllaro, en la zona central de la serranía, luego se habría extendido hacia la Costa y de allí a otros lugares más distantes. Esta cultura habría surgido por el año 400 a.C., en los valles situados entre el río Quijos y el río Cosanga, en las estribaciones amazónicas de la Cordillera oriental; desde allí, hacia 700 d.C., habría salido hacia la Sierra, posiblemente acosados por hordas de cazadores y recolectores amazónicos. Esta cultura habría estado vigente en la Sierra hasta la invasión de los incas ( $c f$. Porras, 1980, pp. 205-285). Apoyándose en estos datos arqueológicos - y en los de lingüística interna que se verán más adelante-, Stark identifica a la lengua quichua como idioma de este pueblo amazónico. Sin embargo, aun suponiendo que la propuesta de expansión de la cultura cosanga sea comprobada, no hay manera de concluir que el idioma que hablaban los migrantes cosanga en épocas preincaicas era el quichua, por el contrario, se conoce que la zona originaria de esta cultura, al momento de la invasión española, estuvo ocupada por la lengua quijo. De ahí que el argumento de que haya ocurrido el fenómeno de una expansión del quichua desde Cosanga hacia la Sierra centro del Ecuador hace unos mil años es un argumento muy 


\section{5}

deleznable para aplicar al origen y difusión de esta lengua, tomando como base la Amazonía ecuatoriana.

En cuanto a la argumentación lingüística, según Hartmann (1979, p. 286), Stark en 1973 había propuesto la clasificación del quichua de la Sierra ecuatoriana en dos grupos: el ecuatoriano A y el ecuatoriano B.

Hace pocos años Stark (1973: 5-10, 17), “dejando aparte los testimonios de los historiadores", ha tratado de analizar evidencias lingüísticas a favor de la existencia preincaica del quechua en el Ecuador. A raíz de determinadas diferencias morfológicas entre los dialectos quechuas de la Sierra establece dos agrupamientos: el primero denominado "ecuatoriano A" incluye los dialectos hablados en las provincias de Pichincha, Cotopaxi y Tungurahua, el segundo, "ecuatoriano B", comprende los de las provincias de Imbabura, Chimborazo, Cañar, Azuay y Loja. Esta clasificación se basó en seis sufijos: el de posesión, dos locativos (direccional y separativo respectivamente), dos sufijos independientes (énfasis y 'todavía') y, finalmente, el de gerundio, o sea el sufijo subordinador cuando no hay cambio de actor en la cláusula principal y la subordinada, de los cuales, en rigor, según mi opinión, solo se pueden tomarse en consideración los cinco primeros. Estos morfemas en el grupo B tienen una 'a' (vocal baja) antes de una fricativa velar o de una nasal mientras que los del grupo A ostentan ' $u$ ' o 'i' (vocales altas) respectivamente. En base de esto Stark formula la hipótesis de que las formas que se encuentran en los dialectos que componen el grupo A representan las formas más antiguas que las del grupo B, y no solamente más parecidas a las formas originales del proto-quechua sino incluso más tempranas que las formas reconstruidas por Parker.

Con estos datos se puede observar morfemas que en el ecuatoriano B tienen la vocal [a], en tanto que en el ecuatoriano A se realizan como [u] o [i]. Los morfemas involucrados fueron el genitivo-benefactivo $\{-$ pak $\}$, el direccional $\{$-man $\}$, el ablativo $\{$-manta $\}$, el independiente contrastivo $\{$-tak $\}$ y el independiente estativo $\{$-rak\}. Como la autora supone que la realización de estos morfemas en el ecuatoriano A son los más antiguos que los del B, los reconstruye como ${ }^{\star}\{$-puk, -mun, -munta, 
-tik, -rik\}, respectivamente. Así pues, según Stark, los cambios vocálicos se habrían operado en la siguiente dirección: $[u>a], y[i>a]$.

Sobre esta propuesta, Hartmann realiza un análisis crítico de la teoría mencionada. Basándose en la documentación de varios autores de inicios de la Colonia, en los datos de las "Relaciones geográficas" y en datos de otros autores posteriores, descarta la posibilidad de que el quichua tenga un origen en la Amazonía ecuatoriana en los siguientes términos:

La ponencia pronunciada por Louisa Stark, Universidad de Wisconsin, Madison, con motivo del "Primer seminario Nacional de Educación Bilingüe en el Ecuador", celebrado en Quito el mes de octubre de 1973, y las hipótesis formuladas por ella, a raíz de evidencias lingüísticas en combinación con resultados de la investigación arqueológica, acerca de la procedencia del quechua ecuatoriano y de su ubicación temporal han estimulado a la autora de este artículo a revisar, una vez más, los testimonios históricos a disposición a favor o en contra de una posible existencia preincaica del quechua en el Ecuador. Se descarta la posibilidad de que el quechua originase en el Oriente ecuatoriano para seguir difundiéndose a la Sierra y a continuación en dirección sur al Perú (Hartmann, 1979, p. 293).

A pesar de estas críticas, la autora ( $c f$. Stark, 1985, pp. 453-454) continuó proponiendo el origen del quichua en la Amazonía ecuatoriana y su posterior expansión hacia la Sierra centro y la Costa. Luego habría llegado a la Costa central del Perú y finalmente al Cuzco. Posteriormente, los incas — mediante los mitimaes — habrían expandido el quichua cuzqueño — que se distinguía por las series oclusivas aspiradas y glotalizadas - a las provincias de Loja, Azuay, Cañar e Imbabura, donde no se habló el quichua antes de los incas. Menciona que las glotalizadas no se mantuvieron en el Ecuador, sino solo las aspiradas. Stark señala, además, que la hipótesis de que el quichua haya entrado desde el sur con los incas solo está basada en un argumento de etnohistoria de Cieza de León y Garcilazo de la Vega, el primero de paso por el Ecuador 
y el segundo que quizá nunca estuvo en el Ecuador. En tanto que ella pretendió basarse en un argumento arqueológico y en otros de lingüística interna. Asimismo, dice que el quichua anteriormente no fue una lengua aglutinante, sino analítica. En otra publicación, Stark (1985, p. 453) señaló lo siguiente:

Furthermore, there are enough similarities between Panzaleo and Cosanga ceramics from the Oriente (400 B. C.-600 A. D.) to presume that the two are related, with the Cosanga pottery of a period somewhat earlier than the Panzaleo ceramics (Porras 1975). If this is the case then perhaps we can assume, as did von Tschudi that early speakers of Quichua entered Ecuador from the East, and after settling there a group split off and traveled south. This group probably traveled along the coast, settling on the north central coast of Peru sometime before the $9^{\text {th }}$ century (Torero 1972: 82). In fact, the Quechua of this area shares certain phonological characteristics with the Quichua of Ecuador which are not found in other Quechua speaking areas. These include the lack of post-velar stops, lack of aspiration and glotalization in the stop series, and the vocing of stops after nasals (Parker, 1970, p. 167).

La argumentación lingüística de la autora la resume Cerrón-Palomino en los siguientes términos:

El carácter arcaico de las formas con vocal alta estaría refrendado, según la autora (cf. Sobre todo Stark 1974, 1985b), por el hecho de que, de acuerdo a una tendencia generalizada del quechua en virtud de la cual muchos — si no la mayoría - de los sufijos fueron formas libres originariamente, aquellas parecen haber sido raíces verbales en un principio: así, ${ }^{\star}$-puq derivaría de una raíz ${ }^{\star}$ pu $\left(c f .{ }^{*}\right.$ pu-ri- 'caminar'. Donde ${ }^{*}$-ri sería, a su vez, el mismo verbo ri- 'ir'); ${ }^{\star}$-mun ${ }^{\star}{ }^{\star}$ mun-ta, por su parte, provendrían de la raíz ${ }^{\star} \mathbf{m u}-\left(c f .{ }^{\star} \mathbf{m u}\right.$-na- 'querer'), que indicaría algo como 'realizar una acción en dirección del hablante'; finalmente ${ }^{\star}$-tiq $\mathrm{y}^{*}$ riq estarían relacionados con los verbos originarios ${ }^{\star}$ ti- 'existir' (cf. tiya-) y ${ }^{\star}$ ri- 'ir, respectivamente. Como se ve, mediante una ingeniosa aplicación del método de reconstrucción interna, Stark se permite un buceo mucho más profundo en lo que pudo haber sido la protohistoria del quechua (1987, p. 339). 
Otro argumento lingüístico de Stark ( $c f .1985$, p. 452) dice que el habla de la Sierra centro del Ecuador, es decir, el denominado quichua ecuatoriano A, presenta mucha diversidad dialectal, lo cual es signo de ser más antiguo que los que conforman el quichua ecuatoriano B, y esto constituye una evidencia para ella de que el quichua fue hablado en esta zona antes de la conquista de los incas.

De la revisión de los argumentos de lingüística interna de Stark, se puede colegir que la autora no presenta el criterio con el cual seleccionó los morfemas antes señalados para fundamentar su hipótesis, cuando hay otros morfemas que tienen esta misma característica: el oscilativo \{-ykacha\} que, en esta zona, se realiza como [ykača $\sim$ yxiča], el aditivo independiente $\{$-pash\} que se pronuncia como [paš $\sim$ piš $]$. Tampoco tomó en cuenta los cambios vocálicos en el léxico como en [yuyak > yuyik] 'el que sabe, anciano'; [kuyay > kuyiy], 'amar', usado en la Sierra; [ñukančik > ñukunčik] 'nosotros'; [yawar > yawur] 'sangre'; [munay > munuy], etc., que también se dan en la Sierra centro, en donde el cambio habría sido de $[\mathrm{a}>\mathrm{i}$ ] y de [a $>\mathrm{u}$ ], respectivamente, los cuales muestran la tendencia contraria a lo propuesto por Stark. El cambio lingüístico operado en la morfofonémica, según la propuesta de Stark, choca contra el principio de plausibilidad. Es más factible el cambio de [a] > $[\mathrm{i} \sim \mathrm{u}]$ que la inversa, como esta autora propuso. Sobre la inviabilidad de la hipótesis han opinado Hartmann (1979, pp. 287-289) y CerrónPalomino (1987, pp. 338-341) desde el punto de vista lingüístico.

En la formulación de su propuesta, Stark tampoco la contrastó con datos de los documentos coloniales como: crónicas, "Relaciones geográficas", etc. Ahora se tiene a disposición más documentación acerca de las misiones coloniales, tanto de los jesuitas en Maynas como de los dominicos en Canelos; ellas tuvieron su base en Quito y fueron las encargadas de evangelizar a pueblos amazónicos de distintas lenguas. Al parecer estos misioneros tomaron como lengua de transición las propias de esos pueblos, pero se apoyaron mucho en el quichua. Los pocos escritos que se conocen sobre la doctrina cristiana que utilizaban, generalmente van 
acompañados de la versión quichua. Así, por ejemplo, en el catecismo anónimo de 1753 de una lengua de la familia tucano (secoya), el texto castellano aparece seguido del secoya y luego del quichua. Además, los misioneros en sus recorridos iniciales generalmente se hacían acompañar de quichuas, inicialmente de la Sierra y luego de los "quichuizados" de la ceja de montaña. Esto muestra un ingreso paulatino del quichua en la Amazonía durante la época colonial, lo cual constituye un contraargumento a la hipótesis formulada por Stark de que el quichua surgió en la Amazonía ecuatoriana y de allí se expandió a la Sierra centro del Ecuador.

Por otra parte, Stark tampoco tomó en consideración la presencia de un significativo número de topónimos, fitónimos y antropónimos presentes en la Sierra centro que no pertenecen al quichua, sino a lenguas anteriores. Si el quichua hubiera sido muy antiguo en la Sierra centro del Ecuador, los topónimos, antropónimos y fitónimos prequichuas serían muy escasos. Por otra parte, la diversidad dialectal de esta zona podría explicarse acaso por la presencia de mitimaes de diversos lugares que fueron colocados en la zona durante el incario y no porque la gran fragmentación se deba a su antigüedad, como lo sugiere Stark.

Así pues, los avances en las investigaciones, tanto a nivel de lingüística interna como de lingüística externa, le han dejado huérfana de respaldo científico a esta propuesta.

\section{Teorías del origen exógeno del quichua}

La mayor parte de autores que han estudiado la presencia del quichua en el Ecuador considera que vino del sur. Sin embargo, existen discrepancias tanto en la época de su llegada como en la forma de su expansión.

\section{Las teorías del arribo preincaico del quichua}

Durante la época colonial, Juan de Velasco, al hablar del idioma del Reino de Quito, señala que era un dialecto del mismo de los incas, 
130

que estuvo ya presente en estas tierras desde antes de la venida de los cuzqueños. Al respecto dice:

El de los Scyris, que era el dominante, no era otra cosa, según he significado otras veces, que un dialecto del mismo idioma de los Incas del Perú, o más bien, el mismo mezclado con otros, y diversamente pronunciado. Esta circunstancia, la cual no se había observado entre tantos países intermedios, causó a Huayna Cápac tanta maravilla en Quito que conoció y confesó (según es fama constante) el que ambas monarquías habían tenido un mismo origen (Velasco, 1789/1978, vol. II, pp. 170-171).

Sobre la hipótesis de Velasco no se han encontrado datos en otras fuentes que la corroboren. Por otra parte, ella es de fines del siglo XVIII, por ende, resulta bastante tardía.

Posteriormente, ya en la época republicana, el suizo Tschudi (1873), postuló también que el quichua arribó al Ecuador en tiempos preincaicos. De la posición de este autor, Hartmann trae una cita, traducida por ella, cuyo texto es el siguiente:

La opinión generalmente compartida de que solo con las conquistas incaicas el quechua haya sido difundido al norte, hasta Quito y más allá, porque largo tiempo antes de que existiera una dinastía de los incas, se hablaba quechua en la parte septentrional de la América del Sur, en la actual República del Ecuador [...]. Prescindiendo de algunas excepciones locales insignificantes [continúa escribiendo] cabe aceptar como un hecho de que en todas aquellas regiones, en las que está en uso aún hoy día, el idioma quechua se ha hablado también ya miles de año antes de la dinastía incaica [...] a raíz de formas antiguas que, pese a la influencia del dialecto cuzqueño modernizante ejercida durante el inca Atawal'pa se han conservado en Quito, considero al dialecto de Quito como más antiguo que el del Cuzco, lo mismo que el dialecto Tsintčay (1979, pp. 267-268).

A fines del siglo XIX varios autores también sostienen el carácter preincaico del quichua ecuatoriano, por ejemplo, Grimm (1986, pp. 
V-VI) — siguiendo el modo de pensar de aquella época- argumenta que el dialecto ecuatoriano es más primitivo por tener solo tres vocales y formas gramaticales menos variadas que el del Cuzco. Otros autores que sostienen la presencia preincaica del quichua son: Middendorf (1890, p. 3) y Cordero (1892/1955, pp. VII-VIII).

Luego, Torero, basándose en un documento publicado por Rostworowski (1970, pp. 135-178), asume que el quichua se expandió desde el Perú y que llegó a tierras lejanas como el actual Ecuador cuando dice:

Como resultado de largos siglos de relación socioeconómica multiregional en los Andes, las variedades Chinchay del Quechua - y tal vez algunas variedades Yúngay todavía no tan distantes de aquellas- se habían convertido en el vehículo de comunicación más importante que cualquier otro: la "lengua verdaderamente general" la llamarían los cronistas. Hacia 1530 (año cero preconquista), se empleaba desde el centro de Chile y el noroeste argentino hasta Ecuador y quizá el sur de Colombia y hasta a orillas del río Amazonas (donde Orellana, el descubridor del gran río se entendió pocos años después por medio del quechua con algunos pueblos ribereños) (Torero, 1974/2007, p. 104).

Hartmann revisa las teorías de Velasco, Tschudi y Torero, y sin descartar que haya habido posibles infiltraciones o penetraciones quechuas en tiempos preincaicos, sostiene que una difusión masiva de esta lengua se dio con los incas:

Por lo demás opino, en base de las fuentes a disposición, que la quechuización de amplias partes de la actual República del Ecuador no se ha iniciado antes de la llegada de los Incas, empeño que ha sido continuado con pleno y duradero efecto en la época colonial, reflejando las variantes dialectales existentes, por lo menos en parte y en mayor o menor grado, efectos obrados por el sustrato respectivo en el superestrato quechua (Hartmann, 1979, p. 293).

Posteriormente, Torero matiza la presencia preincaica del quechua en el Ecuador y ya no se refiere a todo el quichua ecuatoriano, sino al de la Sierra septentrional como parte del QIIB (cf. “Antecedentes”, cap. 3): 
Ahora bien, de lo dicho hasta aquí queda claro que no se dieron durante la conquista y la ocupación incaicas del Ecuador (ni tampoco, naturalmente, en la época hispánica) los factores y condiciones requeridos para la introducción y la extensión consistente de un dialecto quechua del tipo IIB, cuyas formas son, sin embargo, las que han predominado sustantivamente en la constitución de las hablas ecuatorianas modernas. Se deriva de esto que la presencia del proto IIB ecuatoriano en el área septentrional debe fijarse en términos preincaicos. En respaldo de esta conclusión, si fuera necesario, y como de contragolpe, se hace evidente que solo con una presencia preincaica ya suficientemente avanzada pudo este IIB contrarrestar los masivos y múltiples aportes "sureños" llegados con el imperio y salir finalmente victorioso - aunque no indemne- de la contienda lingüística (1984/2011, p. 103).

Posteriormente, Hartmann (1997), al referirse a las "fuentes quechuas de la época colonial con referencia al Ecuador", ratifica que la primera fase de "quichuización" del Ecuador en tiempos preincaicos debió limitarse a una elite, pero que la extensión del quichua a toda la Sierra ocurrió solamente a partir de los siglos XV y XVI, con la imposición de la lengua por los incas.

Torero, para sostener que el quichua ya estuvo bastante difundido en el Ecuador al momento de la llegada de los españoles retoma el dato de Cieza de León (1553/1973) de que en la Sierra ecuatoriana, además de las lenguas propias en los diversos pueblos, estaba presente la lengua general de los incas (Torero, 2002, pp. 98-105). Sin embargo, este último dato no necesariamente es garantía de que el quichua haya penetrado ampliamente en el Ecuador antes de la venida de los incas. No se conoce con precisión el grado de contacto con la mayoría de la población y el paso del cronista fue breve por estas tierras.

A pesar de ello, esta teoría de la presencia del quichua en el Ecuador desde antes de la llegada de los incas pareció muy aceptable para varios estudiosos durante la segunda mitad del siglo XX. Ella buscaba integrar aspectos lingüísticos, históricos, económicos, geográficos e inclusive religiosos, como es el caso de las peregrinaciones al santuario de 
Pachacámac en la actual Lima. Esta teoría inclusive era muy útil para contrarrestar la animadversión de algunos sectores que estigmatizaban al quichua señalándolo como el idioma de los invasores incas, pues presentaba la expansión del quichua como algo casi neutro y pacífico. Sin embargo, ya desde la misma década de 1970 comenzó a ser cuestionada académicamente.

Por su parte, Hocquenghem (2012) considera que los argumentos de Torero, según los cuales concluye que el quichua llegó al Ecuador desde el período Intermedio Tardío ${ }^{39}$ mediante el comercio — principalmente del mullu— antes de la presencia de los incas, son cuestionables. Con datos históricos, etnohistóricos y arqueológicos Hocquenghem intenta demostrar que la propuesta de Torero fue construida omitiendo algunos factores contextuales. Así, señala que en las tumbas de Chincha se ha encontrado un escaso número de mullus, además, según los diseños mochicas encontrados en el Intermedio Temprano, no usaban canoas con balsas, sino solo de totora.

In our view, Torero accepted acritically a highly dubious reding of the 'Report' made by Rostworowsky, and founded the better part of his thesis upon this reading and upon its questionable interpretation and conclusions as to the possible existence of a pre-Hispanic maritime trade route along the length of the central and northern Andean coast between Chincha and Puerto Viejo. For this reason, it becomes very difficult to

39 Para facilitar la comprensión de los lectores ecuatorianos, señalamos la clasificación de la arqueología del Perú: Precerámico Temprano 12000 a.C.-5000 a.C.; Precerámico Medio 5000 a.C-3000 a.C.; Precerámico Tardío 3000 a.C-1800 a.C.; Inicial 1800 a.C.-1200 a.C.; Horizonte Temprano 1200 a.C.-200 a.C.; Intermedio Temprano 200 a.C.-600 d.C.; Horizonte Medio 600 d.C.-900 d.C.; Intermedio Tardío 900 d.C.-1450 d.C.; Horizonte Tardío 1450 d.C.-1532 d.C. En cambio, la arqueología del Ecuador se clasifica en: Precerámico 11000 a.C.-4000 a.C.; Formativo 4000 a.C.-300 d.C.; Desarrollo Regional 300 d.C.-800 d.C.; Integración 800 d.C.-1480 d.C.; Inca 1480 d.C.-1533 d.C. (Los datos del Ecuador están basados en Porras [1980] y Bravomalo [2006]). 
134

accept his theory regarding the spread of the Quechua he calls Chinchay during the Late Intermediate Period, which we must challenge in the light of fresh information (Hocquenghem, 2012, p. 354).

Esta posición de Hocquenghem refuta la teoría de Torero, que por más de cuarenta años había sostenido que el quichua se había extendido al Ecuador en tiempos preincaicos a partir de la Costa central del Perú.

Cabe también señalar que Torero no parece haber dado mucho valor en su análisis al papel de la política evangelizadora colonial en la difusión del quichua. Actualmente existen varios autores que han trabajado sobre este aspecto de la Colonia (Estenssoro, 2003; Durston, 2007). Así, el establecimiento de lenguas generales durante la Colonia explicaría la presencia del quichua en la Sierra ecuatoriana y la no presencia del quechua en la Costa norte peruana.

Por su parte, Itier (2013) trae otra hipótesis según la cual el quichua no habría surgido en la Costa central del Perú (como había propuesto Torero y que había permanecido como plausible por más de treinta años hasta fines del siglo XX). Itier, luego de analizar datos históricos, plantea que pudo haber un quechua antiguo en el Cuzco. Este autor argumenta que, aunque los nombres de los primeros incas no son quechuas, los principales conceptos cuzqueños de poder sí son quechuas: wiraqucha, illapa, chuqi-illa, inti, punchaw, pacha-yachachik, así como también la mayor parte de la toponimia local. Entre sus conclusiones señala:

Pero sobre todo, el proceso por el cual los habitantes de la región del Cuzco adquirieron el quechua puede entreverse a través del resultado de la evolución local de la lengua. Si bien el cuzqueño antiguo parece haber tenido una mayor influencia particular de los incas y del aimara que la que se observa en el cuzqueño moderno, la impronta de estos sustratos en el léxico y la morfosintaxis del quechua cuzqueño no deja de ser relativamente débil. Aun en campos semánticos como los de la fauna, flora y las herramientas, es decir aquellos en que más suele manifestarse la influencia léxica de los sustratos, el dialecto cuzqueño contiene pocos términos que no sean de origen quechua (Itier, 2013, p. 254). 
Ahora bien, si el quichua hubiese llegado a la Costa ecuatoriana proveniente de la Costa central peruana, este debería haberse mantenido en las regiones de la Costa hasta hoy o por lo menos hasta la Colonia, pero los datos históricos no van en esa dirección. La toponimia y las "Relaciones geográficas" muestran que mientras más se aleja de la Sierra en dirección hacia la Costa, es más escasa la presencia del quichua, en tanto que la presencia de las lenguas prequichuas en la Costa es más visible. Podría también pensarse que el quichua habría provenido de la Costa norte peruana, pero eso tampoco es plausible, pues en esa zona norteña del Perú no ha sido el quichua el predominante en los inicios de la Colonia, sino otras lenguas. De tal suerte que el arribo del quichua proveniente del Perú por mar y por la Costa tiene dificultades en el sustento histórico. Resta, entonces, considerar la posibilidad de su ingreso por la Sierra en tiempos preincaicos, pero sobre esto no existen datos.

\section{La teoría de la introducción del quichua con la presencia inca}

Varios autores, en cambio, han señalado que el quichua fue introducido por los incas. Entre ellos están: González Suárez (1891/2007), Jijón y Caamaño (1952/1997, pp. 67-68), Caillavet (2000), Gonzalo Ortiz (2001), entre otros. Este último, religioso de la Congregación Redentorista, al comentar distintos pasajes del padre Juan de Velasco, concluye que el quichua fue introducido por los incas:

La tesis del P. Velasco de un idioma común entre el Imperio de los Incas y del Reino de Quito es sencillamente imposible. Y eso por una razón, esta sí verdadera, que es la aducida por el mismo P. Velasco: el idioma difundido por los Incas, el quichua, era un idioma muy limitado, de la región del Cuzco, elevado a la categoría de idioma general y de lengua oficial del Imperio solo por los Incas a partir del siglo XII. Al norte del Perú y sur del Ecuador no llegó el quichua sino en la segunda mitad del siglo XV. Por tanto, no podía haberse difundido en el Norte antes de que lo impusieran los Incas como idioma general (Ortiz, 2001, p. 18). 
El padre Ortiz, para argumentar su propuesta, se pregunta: ¿Quiénes hablaban el quichua a la llegada de los españoles? Y esboza la siguiente respuesta:

-Los miembros de la familia imperial: hijos y viudas de Atahualpa y el resto de la familia imperial, muy numerosos por cierto, dada la poligamia generalizada entre los príncipes y señores importantes (de Huaina Cápac se afirma que tuvo más de cien hijos);

-Los generales y oficiales que pertenecían a la familia imperial, tales como Rumiñahui;

-Los miembros de las clases dirigentes venidos del Perú para participar en la administración. No pocos de ellos —imitando a su señor Huaina Cápachabían formado su hogar en las acogedoras tierras del "reino" de Quito. A la clase dirigente pertenecían los "orejones" o militares escogidos, y eran de sangre inca pura ("rinriyoc auquicuna", tales como el General Kiskis); -Los "mitimaes", ubicados estratégicamente por los Incas para asegurar el dominio imperial; los más de estos mitimaes procedían de la región del Cuzco, por ejemplo los de San Andrés Xunxi (Provincia de Chimborazo) que, según Paz Maldonado, "son de Condesuyo que está junto al Cusco, y hablan unos con otros su lengua de aquellla tierra"; -Las tropas peruanas, que en su mayor parte eran de habla quichua; -La clase dirigente local, que habían entrado a formar parte de la élite gobernante: caciques, o curacas, que habían hecho propia la cultura y la lengua de los amos cuzqueños. (En este hecho se basa la atribución a un cacique de Alangasí de la composición poética "Atahualpa Huañui", de la que se hablará después). Los españoles conservaron la estructura de gobierno implantada por los Incas, que tenía como eje la autoridad de los caciques;

-No pocos indígenas de las clases populares, que aprendieron el quichua para poder relacionarse con las autoridades y gente importante, especialmente en sus transacciones comerciales (2001, p. 14).

Lamentablemente, el padre Ortiz no propone nuevos argumentos para sostener sus afirmaciones, solo queda en el anuncio. Tampoco aborda sobre la presencia de las lenguas de sustrato que son un argumento en favor del arribo tardío del quichua al Ecuador. Sin embargo, la versión de que el quechua cuzqueño llegó con los incas tiene sus 
bemoles, pues existe otra versión según la cual desde Guamanga hasta Quito no se hablaba el quechua imperial "congruo" del Cuzco, sino el "corrupto" ( $c f$. Huerta, 1616/1993). Esto llevaría a pensar que si el quichua llegó con los incas al Ecuador no pudo haber sido el cuzqueño, sino otro denominado por los primeros quechuistas coloniales como "lengua general", como se verá más adelante.

Hocquenghem (2012), con estudios que diferentes autores han realizado sobre las rutas de navegación, principalmente del Intermedio Tardío y del Horizonte Tardío, ha llegado a la conclusión de que la navegación por mar desde Chincha (ubicada al sur de la actual Lima) hasta Pueblo Viejo (en Portoviejo del actual Ecuador) era difícil. Igualmente, señala que el comercio del mullu desde las costas ecuatoriales no era con Chincha, sino con la parte norte del Perú. En consecuencia, postula que fue con la expansión del imperio de los incas que el quichua llegó al Ecuador.

It seems credible that it was only once the northern frontier of the Inca Empire reached the cost of the Tumbes Valley and the highlands north of Quito - that is to say, during the second half of the fifteenth century - that the spread of Quechua into the northern Andes began (Hocquenghem, 2012, p. 365).

Aunque Hocquenghem hace cuestionamientos válidos a las dificultades de un contacto masivo prehispánico entre Chincha en el Perú y la Costa ecuatoriana, Itier liga al quechua con los incas, lo cual favorece la hipótesis de que este idioma llegó con ellos, sin embargo, quedan en pie otras preguntas irresueltas sobre la presencia del quichua en Ecuador. Así por ejemplo, ¿por qué en suelo ecuatoriano está presente el QIIB, cercano al habla extinta del costeño central peruano, descrito por Domingo Santo Tomás, y no el QIIC que actualmente es hablado en la capital de los incas? Igualmente, ¿por qué en el Ecuador se usa vocablos de elementos importantes que provienen del QI y no del QIIC, que debieron hablar los incas? Así, en Ecuador se usa <yaku $>$ 'agua', $<$ tamya $>$ 'lluvia', <chusku> 'cuatro', proveniente del QI, en vez de $<$ unu $>$, $<$ para $>$, $<$ tawa $>$, respectivamente, que corresponden al cuzqueño. 
Varios de estos interrogantes han comenzado a ser aclarados con los estudios de algunos autores que sospechan sobre la existencia de dos realidades quechuas diferentes a las cuales se las ha denominado lengua general en épocas diferentes. La una habría sido la variedad de Chincha descrita por el primer gramático, Domingo de Santo Tomás; esta habría sido la que hablaban los incas; Betanzos (1551/2015) y Cieza de León (1553/1973) han dejado algunas expresiones quichuas pronunciadas por los soberanos cuzqueños. La otra sería la señalada tardíamente, a fines del siglo XVI, a partir del III Concilio, y que corresponde al "cuzqueño aimarizado moderno", es decir, con sonidos laringalizados. Igualmente a las hablas de la Sierra central peruana, arbitrariamente se las denominaría "chinchaysuyas", cuando la auténtica chinchaysuya habría sido la de Chincha, ubicada en la Costa sur peruana. Sobre la existencia de esta confusión en la denominación de lengua general entre los autores de mediados del siglo XVI y los de fines de ese siglo y posteriores, Cerrón-Palomino dice:

Sin embargo, como lo han venido señalando César Itier (2011) y quien escribe (cf. Cerrón-Palomino 2013b), el referente de "lengua general" no ha sido el mismo entre los autores mencionados, habiendo devenido en una designación ambigua. En efecto, lo que los primeros cronistas registran y ponen en boca de los incas no es el mismo quechua al que se refieren más tarde Blas Valera o Garcilaso ni tampoco Gonçález Holguín, Acosta o Cobo. Se trata, en verdad, de variedades claramente distintas, aun cuando, juzgadas a partir de la información histórica y dialectal de que disponesmos en la actualidad, formaran parte de la llamada rama sureña (en oposición a la central). Y no obstante que el material probatorio con que contamos para sostenerlo señalado resulta fragmentario, por no decir precario, de todos modos es suficientemente importante y decisivo para evitar caer en el error tradicional de asignar a los incas una variedad quechua que, ahora lo sabemos, se configura y codifica con posterioridad a la caída del Imperio y consiguiente ordenamiento colonial $\left(2017\right.$, p. 85). ${ }^{40}$

40 Sobre este asunto se volverá en el cap. 3, a propósito de las características del quichua ecuatoriano. 
Por otra parte, de las palabras consideradas propias del "nuevo chinchaisuyu” por Figueredo (1700/1991, pp. 113-121), apenas 45 de las 170 palabras traídas en la obra, son conocidas en todo el Ecuador. Adicionalmente, hay tres conocidas únicamente en Cañar, Azuay y Loja: $<$ mashay, ruru, parkuy $>$ 'calentar en el sol, huevo, regar agua', respectivamente, y una <musiyay $>$ 'presentir, conjeturar' que es usada en la Amazonía y en la provincia de Bolívar en la Sierra.

Quizá la respuesta parcial a esta complejidad esté en lo proponía Hartman (1994): que hubo dos momentos de llegada del quichua al Ecuador. El primero pudo haber sido a manera de pequeños enclaves que se fueron conformando por comerciantes al estilo de los mindalaes estudiados por Salomón (1980/2011). El segundo pudo ser en forma masiva a través de los incas. En esto habrían contribuido los mitimaes como también lo señala Hartman en el mismo artículo. Sobre la presencia de los mitimaes traídos de distintos lugares del imperio, todavía es un campo abierto la investigación.

Visto así, la teoría de la presencia preincaica del quichua en el Ecuador y la otra que sostiene que esta lengua fue introducida por los incas, resultarían más complementarias antes que excluyentes. Pero adicionalmente, la generalización del quichua en el Ecuador parece haberse debido, en una tercera etapa, a la labor de los misioneros. El padre Ortiz hace una síntesis de esta tarea de los religiosos de las diferentes órdenes:

Fueron los MERCEDARIOS, los primeros en aprender el quichua. El P. Martín de Victoria, capellán de Benalcázar, redactó la primera gramática quichua, lastimosamente extraviada. De él dice González Suárez: "En muy breve tiempo llegó a hablar expeditamente la lengua del Inca, y fue el primero que ejercitaba en ella, en su convento, a varios clérigos y a los religiosos de su orden". No se quedaron atrás los hijos de San Francisco. Tan pronto como llegó a Quito (6 de diciembre de 1535), fray Jodoco Rique se dedicó a aprender el quichua y a prestar asistencia y enseñanza principalmente a los miembros de la familia real y de la nobleza local. Llegó a dominar a la perfección el idioma de los Incas y 
redactó varias obras lamentablemente perdidas, entre ellas: "Catecismo y Devocionario en Quichua", "Sermones varios en lengua quichua y española" (2001, pp. 33-34).

Ortiz menciona que también los agustinos tuvieron una cátedra de quichua. Por su parte, los dominicos tuvieron la cátedra "oficial" de quichua asignada por la Corona española en 1581. El primero en ejercerla fue fray Hilario Pacheco, el segundo fue el criollo fray Pedro Bedón, de quien se dice se había formado en Lima. Los jesuitas llegaron a Quito en 1586 y contaban con cuatro maestros en idioma quichua, entre los que estaba Diego González de Holgín, quien permaneció en Quito hasta el año de 1600. Según Ortiz (2001, p. 34), interpretando datos del historiador jesuita padre Jouanen (1941, p. 187), ellos se hicieron cargo del Seminario Mayor de San Luis y de la cátedra de quichua en 1594 y la ejercieron hasta su expulsión en 1767.

Luego de la revisión de estas teorías, se puede concluir que las dos propuestas del origen exógeno del quichua cuentan con mayores argumentos que la endógena. Sin embargo, estas tampoco resuelven todas las interrogantes que se plantean al estudiar la diversidad dialectal del quichua ecuatoriano, como es el hecho de que el quichua de la Sierra centro es más fragmentario que las hablas de la Sierra norte y sur. La propuesta de Hartman (1994), de que hubo dos momentos de llegada del quichua al Ecuador, el primero bastante reducido en tiempos preincaicos y el segundo con mayor intensidad ya con la presencia de los gobernantes cuzqueños, hasta el momento aparece como muy plausible; si se toma en consideración la presencia abundante de elementos de sustrato de las lenguas prequichuas. Efectivamente, la masificación tardía del quichua en el Ecuador explicaría la alta presencia de topónimos de las lenguas de sustrato.

Queda pendiente la explicación del porqué existe mayor fragmentación dialectal en la Sierra centro que en las otras regiones. Esto quizá se deba a la presencia de numerosos grupos de mitimaes que fueron asentados por los incas y que cada uno, posteriormente, tuvo su propia evolución. 
Capítulo 3 Rasgos peculiares del quichua ecuatoriano
dentro de la familia quechua

El quichua ecuatoriano forma parte de la familia quechua presente en Colombia, Ecuador, Perú, Bolivia, Argentina y Chile. Pero, ¿con cuáles hablas quechua de esta familia, el ecuatoriano está más relacionado?, ¿cuáles son sus particularidades? Sus características pueden apreciarse mejor con el conocimiento de la evolución de los estudios dialectales realizados, principalmente, a partir del siglo XX..$^{41}$

\section{Antecedentes}

En la segunda mitad del siglo XX, Paul Rivet y Georges CréquiMontefort publicaron cuatro volúmenes (1951-1956) con la bibliografía del quechua y el aimara producida hasta entonces en los diferentes países, y sugirieron la elaboración de una gramática comparada de estas lenguas.

Posteriormente, como lo señala Cerrón-Palomino (1987, p. 94), "Rowe $[\ldots]$ abría un campo totalmente nuevo en la investigación de la lingüística histórica quechua" al concluir que el dialecto cuzqueño no era el más arcaico del quechua, ya que había experimentado más cambios que el ayacuchano. Esta visión revolucionó el pensamiento tradicional.

41 Un compendio de los intentos previos de clasificación dialectal desde la época Colonial hasta los trabajos relacionados con este tema realizados por Parker y Torero puede verse en Cerrón-Palomino (1987, 2003). 
Por su parte, Ferrario ( $c f$. Cerrón-Palomino, 1987, p. 94), basándose en indicios históricos y algunas simples inferencias lógicas, sostiene que no todas las variedades modernas están en "absoluta paridad glotológica" respecto de un protoidioma. Él observaba que las investigaciones lingüísticas de las hablas contemporáneas debían considerar como un lineamiento básico la reconstrucción de un "protorunasimi”.

A su criterio, de este "protoidioma" se habrían derivado dos ramas: el "inca clásico", del cual a su vez —en una segunda derivaciónhabrían surgido el ecuatoriano y el argentino, entre otros; y el "Chinchaisuyo”, que estaría integrado por diferentes dialectos (ayacucho, junín, huánuco, etc.) y a los cuales Ferrario considera como "neoquechuas".

Luego vino la etapa comparativa de los dialectos que comprendían el quechua con los trabajos de dos lingüistas: el norteamericano Parker (1963/2013) y el peruano Torero (1964/2003). Estos autores, además de investigar las diferencias dialectales contemporáneas de la familia idiomática mediante trabajo de campo, realizaron estudios de lingüística histórica. Así surgió el interés por estudiar las características de los distintos dialectos con la finalidad de realizar una clasificación de las hablas existentes actualmente en varios países.

Tales investigadores clasificaron de manera independiente, las diversas hablas en dos grandes grupos con sus respectivas particularidades. Parker (1963/2013) las clasificó en Quechua B (QB), que comprende las hablas de la Sierra central peruana, y Quechua A (QA), integrado por las restantes. Por su parte, Torero (1964/2003) las dividió en Quechua I (QI) y Quechua II (QII), ${ }^{42}$ y al QII lo subdividió a su vez en: QIIA (que abarca las hablas de la Sierra norte peruana), QIIB (que comprende las hablas de la Selva norte peruana, las ecuatorianas y las colombianas) y QIIC (que cubre las hablas del sur peruano, Bolivia, Argentina y Chile).

42 El QI de Torero corresponde al QB de Parker, y el QII al QA de Parker. 
Posteriormente, Torero ratificó la posición del quichua ecuatoriano en el grupo QIIB en los siguientes términos:

Lingüísticamente, el complejo dialectal ecuatoriano-colombiano (que se designará aquí simplemente como ecuatoriano) es una rama del quechua IIB, cercano a los dialectos de Chachapoyas (Amazonas) y Lamas (San Martín) del nororiente peruano, y afiliable con el habla costeño central peruana descrita en 1560 por Fray Domingo de Santo Tomás y con la de Huarochirí (serranías del departamento de Lima) recogida en un amplio conjunto de textos en los primeros años del siglo XVII (véase trascripción paleográfica y versión en francés de estos textos en Taylor, 1980) (2002, p. 98).

Sin embargo, esta clasificación no está exenta de objeciones, pues existen, por ejemplo, hablas del QIIA que comparten características con el QI. Además, hay otras hablas intermedias entre las dos grandes ramas. Así, el quechua de Pacaraos tiene características del grupo que integra el QI, pero también algunas exclusivas de él, al interior de la rama, y tiene otras que son propias del QII. Esto ha dado asidero a algunas discusiones en las últimas décadas. Se ha llegado inclusive a proponer el abandono de la división QI-QII en favor de un continuum dialectal quechua. Según esto, las diferencias dialectales no se explicarían por la cronología de la expansión, sino por el grado de coherencia en la amplia comunidad hablante debido, fundamentalmente, a la distancia geográfica. Así:

For Quechua too, the initial family-tree classification has fallen increasingly into disarray as our knowledge of the geographical diversity across the family has grown over recent decades, especially with the documentation of dialects intermediate between the supposed two main branches, or others that classify well with neither (Adelaar 1977, 1987; Taylor 1984a, 1984b). As early as Landerman (1991) it was demonstrated that the two-way QI-QII split is untenable; but because he still kept faith with the tree idealization in principle, he remained unable to offer any alternative. [...] In short Heggarty (2005) calls for the traditional family tree classification of a deep two way QI-QII split to be abandoned, in favor of a more continuum-like model instead. It 


\section{4}

thus remains to set this new view of Quechua's origins in a real-world context that might explain how and why the family diverged into such a pattern, if not by Torero's sequence of migrations (Beresford-Jones y Heggarty, 2010, p. 74).

Sin embargo, esta presunción ha sido observada recientemente por Adelaar con datos actuales de la dialectología. Este autor, para argumentar la validez de la división arbórea, emplea criterios de carácter lexical, morfológico y fonológico. Señala que de ellos, el morfológico es el más importante en la distinción de las dos ramas. En defensa de la división QI-QII, al referirse a las críticas que se han realizado a esta clasificación, indica que "por contraste, ni uno de los argumentos de índole lingüística aducidos por la literatura de las últimas dos décadas en contra de la división original del quechua en dos ramas primarias se muestra resistente al escrutinio científico" (Adelaar, 2013, p. 62).

Frente a estas discusiones cabe anotar que la clasificación dialectal de una lengua, como cualquier fenómeno social, es una abstracción y una idealización. En la operación clasificatoria de las ciencias, con frecuencia, aparecen las excepciones, aun en las ciencias naturales, ${ }^{43} \mathrm{y}$ ni qué decir en las ciencias sociales como es la lingüística. Así pues, la clasificación en dos ramas solo es un instrumento analítico que permite hacer una hermenéutica de la diversidad lingüística quechua. Además, la propuesta del continuum, aunque parece útil para explicar la presencia de algunas variantes fonológicas del QI como [ča:šaq] 'llegaré', del verbo /ĉa:/ < ĉaya-> 'llegar', y que en el QII se realiza como [čayasaq $\sim$ čayašaq čayašak čayaša], igualmente variantes morfofonémicas como el continuativo $\{$-ra: $\}$ del QI, $\{$-raya- $\}$ del QII, tampoco explica satisfactoriamente la totalidad de los fenómenos lingüísticos del que-

43 Basta recordar lo que ocurrió cuando descubrieron el ornitorrinco en el siglo XVIII, a propósito de la caracterización del grupo de animales ovíparos y vivíparos. Umberto Eco, para explicar esta complejidad tituló a una aparecida obra semiótica suya, en 1997, como Kant y el ornitorrinco. 
chua. Por eso consideramos que tanto la clasificación arbórea como la del continuum no necesariamente deben ser vistas como modelos alternativos excluyentes, sino como puntos de vista diferentes y quizás hasta contradictorios.

Por otra parte, vale recordar que desde las opiniones históricas y etnohistóricas, así como del análisis filológico-lingüístico del corpus quechua extraído de los documentos de los cronistas tempranos, existe la sospecha de que en el siglo XVI existieron dos realidades lingüísticas distintas a las cuales se las ha referido con el mismo nombre de lengua general (cf. cap. 2).

Así pues, al parecer, para los primeros cronistas y quichuistas como el religioso dominico fray Domingo de Santo Tomás (1560/1995), por "lengua general" o "lengua del inga" se entendía la variedad que se hablaba en la costa centro-sureña peruana, identificada con el antiguo señorío de Chincha. Esta variedad habría desaparecido a fines del siglo XVI. Según Adelaar (2013, p. 43) y otros autores, esta lengua general estaría identificada con el QIIB, sin embargo, más tarde, a partir del Tercer Concilio Limense (1582-1583), propugnado por los jesuitas, se identificó con el nombre de lengua general a la variedad cuzqueña (actual QIIC). Como consecuencia de esta reinterpretación antojadiza tardía, desde fines del siglo XVI y principalmente del siglo XVII, al QI se lo identificó como quechua chinchaisuyo ${ }^{44}$ (cf. Huerta, 1616/1993, p. 18) sin que hubiera razón para ello; pues este, incluso geográficamente, está distante de Chincha, que está en la Costa al sur de Lima.

Esta confusión sobre la lengua general ha sido precisada, con argumentación sólida basada en el análisis lingüístico de los textos quechuas que constan en los primeros cronistas, por Cerrón-Palomino (2015b, pp. 36-37) cuando dice:

44 Huerta (1616/1993) escribe "chinchaysuyo", en tanto que Figeiredo (1700) escribe "chinchaisuyo". 
Ahora bien, esta lengua general ha sido designada también como chinchaisuya, y a ella parece referirse, sin advertirlo, el Inca Garcilaso de la Vega, cuando trata de oponerla a su "lengua general", que no es sino el quechua que será promovido más tarde por el Tercer Concilio Limense (1582-1583). No otra cosa se desprende del pasaje de su Historia general, en el que busca explicar el imaginado desencuentro comunicativo que habrían tenido el intérprete Felipillo y el inca Atahualpa en Cajamarca, y que según el autor se habría debido, entre otros factores, al hecho de que el faraute no manejaba la lengua "del Cozco" sino la de Chinchaisuyo, y lo hacía "bárbaramente", de manera que el inca se habría visto obligado a aproximar su habla al del dialecto del lenguaraz de Poechos. Sobra señalar que la oposición dialectal insinuada por el Inca resulta arbitraria, desde el momento en que está asumiendo que Atahualpa hablaba en quechua conciliar, cuando sabemos que, aparte del anacronismo implícito, todo conduce a pensar que tanto Felipillo como el último soberano inca hablaban variedades muy afines: la lengua general llamada también chinchaisuya (CerrónPalomino, 2017, p. 89).

Asimismo, otro referente para la comprensión de las características del quichua ecuatoriano son los trabajos de reconstrucción relacionados con el protoquechua. La reconstrucción de la protolengua permite la formulación de criterios para la zonificación dialectal del quichua ecuatoriano $y$, a partir de ella, es posible analizar el proceso de estandarización de la escritura quichua (como se verá en los capítulos siguientes).

Con tales antecedentes, a pesar de las divergencias resultantes de la complejidad de toda zonificación del quechua, en el presente trabajo se presenta como referencia la ubicación del quichua ecuatoriano en las clasificaciones formuladas por los investigadores que han trabajado en lingüística histórica, a partir de las propuestas iniciales de Parker (1963) y Torero (1964). Los gráficos, que algunos de tales autores han venido postulando sobre la clasificación dialectal, permiten tener una visión panorámica de las diferentes hablas que conforman la familia lingüística. 


\section{El protoquechua}

Parker y Torero, a partir de los datos de mediados del siglo XX, rastrearon la evolución de la lengua en forma retrospectiva. El objetivo de esto fue realizar la reconstrucción del protoidioma en sus niveles fonológico, morfológico y léxico. Esta tarea ha sido continuada por algunos investigadores como Cerrón-Palomino (1987, 2003), y Adelaar con Muysken (2004). En lo que sigue se pasa revista a tales reconstrucciones para luego esbozar las características del quichua ecuatoriano.

\section{Fonemas del protoquechua según Parker}

Parker reconstruyó tres vocales más un fonema de intensidad vocálica y dieciocho consonantes, tal como puede verse en la siguiente tabla:

\section{Tabla 1}

Fonemas vocálicos y consonánticos del protoquechua (Parker) ${ }^{45}$

\begin{tabular}{|l|l|l|l|}
\hline Vocales & & \\
\hline $\begin{array}{r}\text { Anterioridad } \\
\text { Aposterioridad }\end{array}$ & Anterior & Central & Posterior \\
\hline Cerradas & $\star_{\mathrm{i}}$ & & \\
\hline Abierta & & ${ }^{* a}$ & \\
\hline
\end{tabular}

45 Se conoce que Parker publicó los trabajos de fonología y morfología en inglés entre 1969 y 1970, pero en este estudio se sigue la edición realizada por el discípulo de Parker, Rodolfo Cerrón-Palomino, quien en 2013 publicó un compendio de seis trabajos de Parker realizados entre 1963 y 1971, lo que al final resultó ser un homenaje póstumo, pues el profesor Parker había fallecido en Nuevo México el 6 de noviembre de 2010. 


\begin{tabular}{|c|c|c|c|c|c|c|}
\hline \multicolumn{7}{|l|}{ Consonantes } \\
\hline $\begin{array}{l}\text { Modo } \\
\text { articulación }\end{array}$ articulación & Bilabial & Dental & Palatal & $\begin{array}{l}\text { Retrofle- } \\
\mathrm{ja}^{46}\end{array}$ & Velar & Postvelar \\
\hline Oclusivas & ${ }^{*} \mathrm{p}$ & ${ }^{*} t$ & $*^{\prime c}$ & ${ }^{*} \hat{\mathrm{c}}$ & ${ }^{\star} \mathrm{k}$ & ${ }^{*} \mathrm{q}$ \\
\hline Fricativas & & ${ }^{*} \mathrm{~s}$ & *气̌s & & ${ }^{*} \mathrm{~h}$ & \\
\hline Nasales & ${ }^{*} \mathrm{~m}$ & ${ }^{*} \mathrm{n}$ & ${ }^{*} \tilde{\mathrm{n}}$ & & & \\
\hline Laterales & & ${ }^{\star} 1$ & $\star \lambda$ & & & \\
\hline Vibrantes & & ${ }^{{ } \mathrm{r}}$ & & & & \\
\hline Espirante retrofleja & & $\star_{\check{r}}$ & & & & \\
\hline Semiconsonantes & ${ }^{*} \mathrm{~W}$ & & ${ }^{*} \mathrm{y}$ & & & \\
\hline$* /+$ intensidad $/{ }^{47}$ & & & & & & \\
\hline
\end{tabular}

Fuente: Parker, 2013, p. 71

\section{Fonemas del protoquechua según Torero}

Torero propuso seis vocales (tres cortas y tres largas) y dieciséis consonantes, según puede apreciarse en la tabla que sigue:

46 En 1963, Parker propuso la existencia de la alveolar / ф / y la palatal /č/ en el sistema protoquechua, pero en 1969 se rectificó, postulando la existencia de las palatales /č/ y /ĉ/, simple y retrofleja, respectivamente, con lo cual coincidía con la propuesta de Torero en este punto. Los fonemas / $\hat{c} / \mathrm{y} / \check{c} /$ son en verdad africados, pero se ha hecho usual en la nomenclatura quechua/quichua ubicarlos entre los oclusivos.

47 Posteriormente, Parker reformuló su interpretación en favor de la cantidad vocálica, siguiendo en esto la propuesta de Torero. 
Tabla 2

Fonemas vocálicos y consonánticos del protoquechua (Torero)

\begin{tabular}{|c|c|c|c|c|c|c|c|}
\hline \multicolumn{8}{|l|}{ Vocales } \\
\hline $\begin{array}{l}\text { Anterioridad } \\
\text {-posterioridad } \\
\text { Apertura }\end{array}$ & \multicolumn{2}{|l|}{ Anterior } & \multicolumn{3}{|c|}{ Central } & \multicolumn{2}{|c|}{ Posterior } \\
\hline Cerradas & \multicolumn{3}{|l|}{$*_{\mathrm{i},}{ }^{*} \mathrm{i}:$} & & & \multicolumn{2}{|r|}{${ }^{*} \mathrm{u},{ }^{*} \mathrm{u}:$} \\
\hline Abiertas & & & \multicolumn{3}{|c|}{${ }^{*} \mathrm{a},{ }^{*} \mathrm{a}:$} & & \\
\hline \multicolumn{8}{|l|}{ Consonantes } \\
\hline $\begin{array}{r}\begin{array}{r}\text { Punto } \\
\text { aticulación }\end{array} \\
\text { Modo } \\
\text { articulación }\end{array}$ & Bilabial & Dental & Palatal & Retrofleja & Velar & Postvelar & Glotal \\
\hline Oclusivas & ${ }^{*} \mathrm{p}$ & $*_{t}$ & $*_{\mathrm{c}}$ & ${ }^{*} \hat{\mathrm{c}}$ & ${ }^{\star} \mathrm{k}$ & ${ }^{*} \mathrm{q}$ & \\
\hline Fricativas & & ${ }^{*} \mathrm{~s}$ & $\star_{\mathrm{s}}$ & & & & ${ }^{\star} \mathrm{h}$ \\
\hline Nasales & ${ }^{*} \mathrm{~m}$ & ${ }^{*} \mathrm{n}$ & ${ }^{*} \tilde{\mathrm{n}}$ & & & & \\
\hline Laterales & & & $\star \lambda$ & & & & \\
\hline Vibrantes & & ${ }^{*} \mathrm{r}$ & & & & & \\
\hline Semiconsonantes & ${ }^{*} \mathrm{~W}$ & & ${ }^{*} \mathrm{y}$ & & & & \\
\hline
\end{tabular}

Fuente: Torero, 1964/2003

Como puede apreciarse en los cuadros vocálicos, Parker consideró, inicialmente, tres vocales cortas más un fonema de intensidad vocálica, en tanto que Torero siempre consideró tres vocales orales cortas con su correlato de tres vocales largas. Las tres vocales largas solo existen en los dialectos que conforman el QB de Parker, equivalente del QI de Torero, y están restringidas a la primera persona posesora y actora, pero también a algunos morfemas verbales compartidos por ambas ramas de la familia.

En los dialectos del quichua ecuatoriano no existen vocales largas, excepto en la Amazonía central, donde se da el alargamiento de la vocal /i/ cuando se añade el morfema locativo $\{$-pi $\}$ a una palabra que termina en /i/. Los gramáticos del siglo XIX, que elaboraron textos de la variedad 
ecuatoriana, no reportaron este fenómeno, sea porque no existía entonces o porque no le prestaron atención. En todo caso, se trata de un fenómeno puramente fonético, marginal, que se puede ver, por ejemplo, en:

[wasi: kawsani] > /wasipi kawsani/ 'vivo en casa'

Ahora bien, como se puede observar en la Tabla 1, en ambos casos estaban incluidas las semiconsonantes. La diferencia de la reconstrucción de Parker frente a la de Torero está en que el primero admite la existencia de dos laterales: una alveodental ${ }^{\star} / 1 /$ y otra palatal ${ }^{\star} / \lambda /$, en tanto que el segundo solo admite la palatal. Parker incluía, además de una vibrante ${ }^{\star} / \mathrm{r} /$, una espirante retrofleja ${ }^{\star} / \check{\mathrm{r}} /$. La /1/ era tratada por Parker como aimarismo, pero reconstruible, mientras que Torero la rechazaba. Otra diferencia era que Torero consideraba que la fricativa velar ${ }^{\star} / \mathrm{x} /$ postulada por Parker habría sido una glotal ${ }^{*} / \mathrm{h} /{ }^{48}$

En cuanto a las vocales, Torero postuló el alargamiento vocálico en tanto que Parker interpretó este fenómeno como acento de intensidad. Finalmente, Parker aceptó la propuesta de Torero y descartó la presencia de vocales largas (cf. Cerrón-Palomino, 1987).

\section{Fonemas del protequechua según Cerrón-Palomino}

Este autor, reconstruyó tres vocales y dieciséis consonante. Luego de su análisis no incluyó en su reconstrucción las vocales largas propuestas por Torero; tampoco los segmentos /řl ni /l/ propuestos por Parker. Los protofonemas ofrecidos aparecen seguidamente en los cuadros respectivos.

48 Se conoce que la diferencia entre estos dos autores en el uso de $<\mathrm{x}>\mathrm{y}<\mathrm{h}>$ era más de notación que de estructura. 


\section{1}

Tabla 3

Fonemas vocálicos y consonánticos

del protoquechua (Cerrón-Palomino)

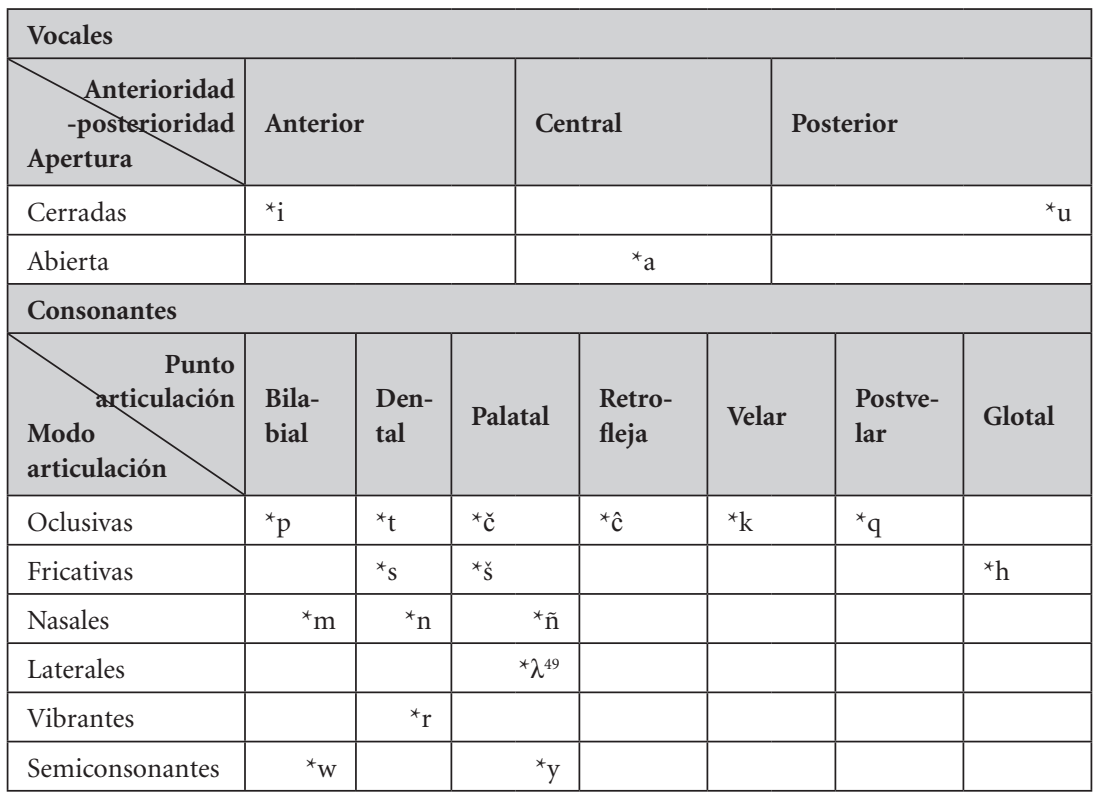

Fuente: Cerrón-Palomino, 1987, p. 128

Al comparar los elementos del sistema consonántico del quichua ecuatoriano actual, cuyo cuadro se expone más abajo, se observa que este se explica naturalmente a partir del sistema del protoquechua, dejando de lado las particularidades provenientes del sustrato, y de su propia evolución. Sin embargo, como se verá en el capítulo 5, la gran variedad del ecuatoriano, está en la realización de los fonemas, y los morfemas, es decir en el nivel de la concretización fonética. A nivel morfológico es donde existen más diferencias respecto de la protolengua, pues no

49 En el original $/ \lambda /$ se halla representado por el símbolo /Ĩ/. 
152

solamente ha habido cambios morfofonéticos, sino también una reducción cuantitativa importante de morfemas, y además de innovaciones no menos interesantes.

\section{Clasificación de los dialectos quechuas y ubicación del quichua ecuatoriano dentro de la familia lingüística}

Diversos autores han ensayado propuestas de clasificación dialectal y la ubicación del ecuatoriano al interior de lo que algunos consideran como una familia de lenguas antes que meramente grupo de dialectos perteneciente a una misma lengua.

\section{Ubicación del quichua ecuatoriano en el diagrama de Parker (1969)}

En la clasificación de 1963, Parker, ubicó al quichua ecuatoriano junto a las variedades dialectales de la Amazonía peruana, cuando señaló: "Aunque claramente derivado del dialecto del Cuzco, el de EcuadorUcayali, a menudo llamado quichua y no quechua, muestra muchas características divergentes" (1963-1972/2013, p. 39). ${ }^{50}$

Años más tarde, como se puede ver en el esquema de abajo, Parker (1969b/2013, p. 63) ubicó al dialecto ecuatoriano junto al sureño del Cuzco y de Ayacucho, y no junto al de Amazonas del Perú. ${ }^{51}$ El argumento fue que, si bien el ecuatoriano comparte varias características comunes con este último, no ha conservado el fonema palatal retroflejo /ĉ/. Por otra parte, señaló que las dos innovaciones compartidas: sonorización de oclusivas después de nasal y fusión de /k/ y /q/, integraban

50 Se presenta solo la clasificación de las hablas del QA de Parker (equivalente al QII de Torero) y no el QB (QI de Torero), porque en este se encuentra el ecuatoriano.

51 Al parecer, al referirse en 1969 al habla Amazonas, Parker no incluyó en ella las hablas del departamento amazónico de Loreto. 


\section{3}

cambios que definían un "grupo areal” y no de evolución interna de las hablas.

\section{Figura 2}

\section{Clasificación dialectal del QA}

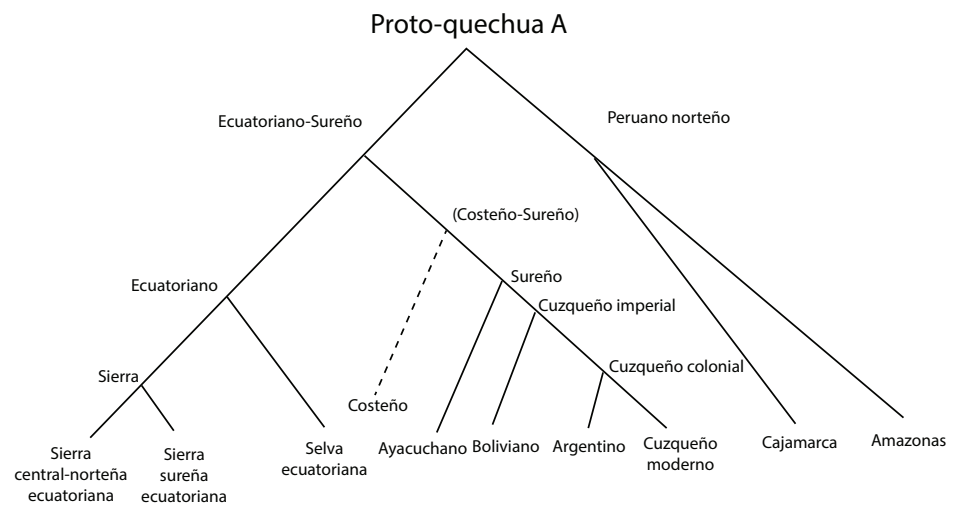

Fuente: Parker, 1963-1972/ 2013, p. 63

Actualmente, con los datos de Mercier (1983), Taylor (1979) y Landerman (1973), se puede concluir que el quichua ecuatoriano tiene más en común con las hablas de los ríos Napo, Tigre y Pastaza peruanos, del departamento de Loreto, que con el de Chachapoyas, del departamento Amazonas.

\section{Ubicación del quichua ecuatoriano en la clasificación de Torero (1974)}

Como se observa en la figura, Torero (1974/2007, p. 154) ubicó al quichua ecuatoriano junto con las hablas amazónicas del Perú y de Colombia, las cuales constituyen el grupo QIIB establecido en 1964. 


\section{4}

\section{Figura 3}

\section{Clasificación dialectal del quechua según Torero}

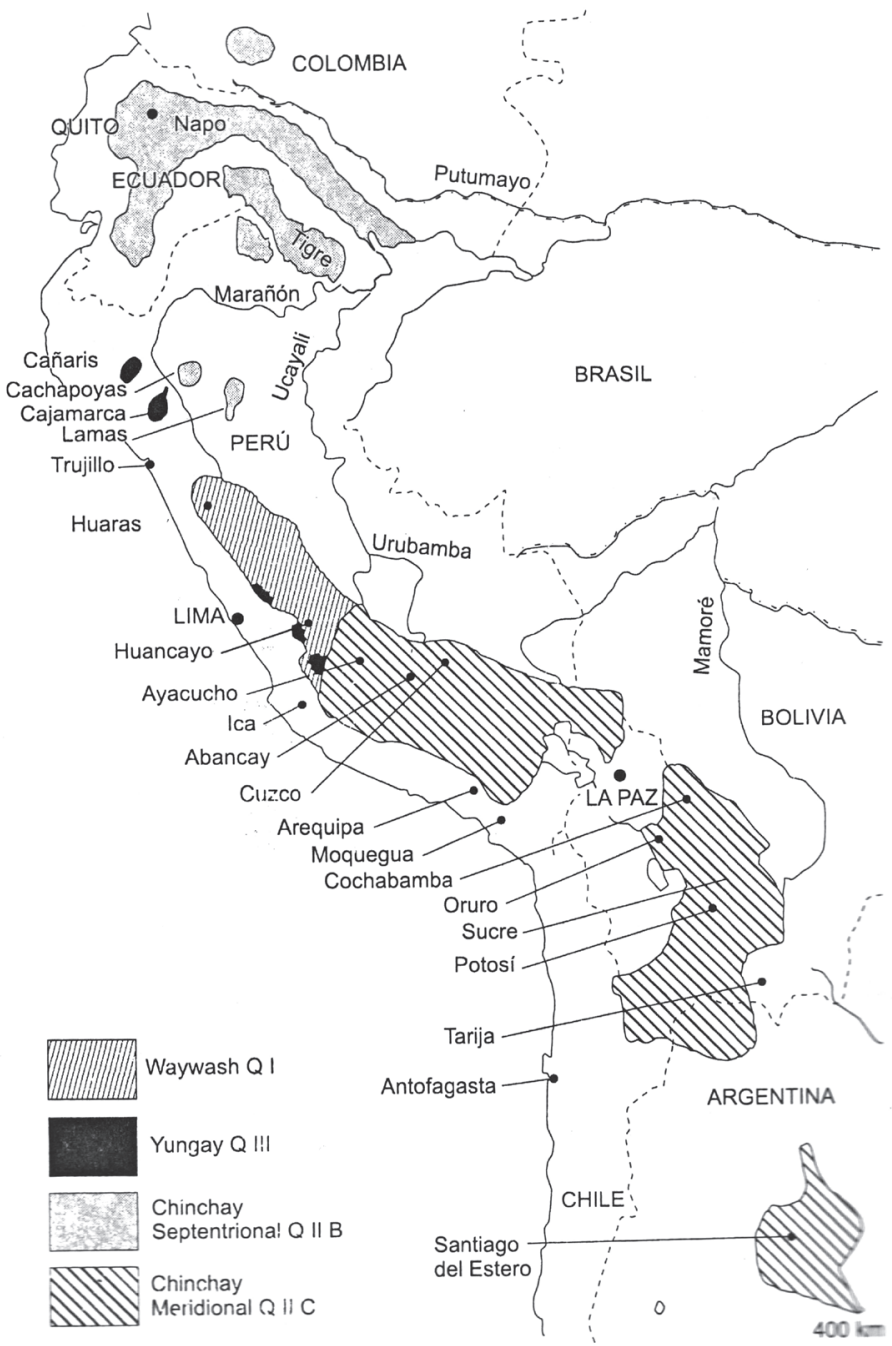

Fuente: Torero, 1974/2007, p. 154. 
155

\section{Ubicación del quichua ecuatoriano en el diagrama de Cerrón-Palomino (1987)}

En la figura siguiente, Cerrón-Palomino (1987, p. 247) sitúa al quichua ecuatoriano como parte del QIIB junto con las hablas de los departamentos peruanos de San Martín, Amazonas y Loreto, a las cuales añade las de Colombia. Sin embargo, nótese que en el quichua de las hablas de Chachapoyas, provincia del departamento de Amazonas, así como en el ecuatoriano, existe una diferencia importante. Según Taylor (2000, p. 48), en Chachapoyas existe la distinción entre /č/ y / ĉl, en tanto que en las hablas ecuatorianas este último fonema no existe.

Figura 4

Ubicación del quichua ecuatoriano al interior de la familia quechua

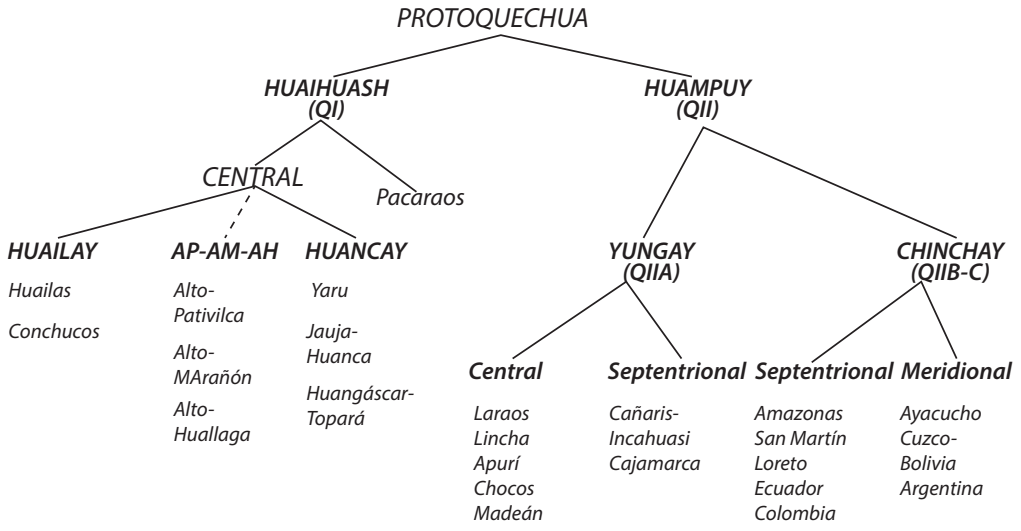

Fuente: Cerrón-Palomino, 1987, p. 247

A las hablas que integran el QIIB señaladas por los autores citados y que están relacionadas con las ecuatorianas, se tendría que agregar la del grupo denominado "santarrosino" del departamento Madre de Dios en Perú, señalada como integrante de la "napeña” por Marcos Mercier: 
156

Actualmente en su variedad NAPEÑA es el principal, y a veces único idioma de comunicación de unos 45 mil nativos de la cuenca del Napo, desde Mazán en el Perú hasta las cabeceras en el Ecuador. Hablantes del kichwa del Napo se encuentran también en comunidades de Alamas de los ríos Tigre y Pastaza, y aún en la lejana Madre de Dios, por el río Tahuamanú, a donde caucheros se llevaron un grupo de Santorrosinos (1983, p. 29). ${ }^{52}$

\section{Características del quichua ecuatoriano}

Al hablar de las características del quichua ecuatoriano se debe señalar que es imposible circunscribir las características de un dialecto al territorio de un país, pues algunas de ellas sobrepasan las fronteras nacionales, y otras, por el contrario, solo cubren una parte del territorio nacional.

Como se ha visto en los diagramas presentados, los autores que han formulado las clasificaciones del quechua desde la segunda mitad del siglo XX, señalan que las hablas que constituyen el quichua de Ecua-

52 Con "santarrosino" se refiere a los quichuas de la población de Santa Rosa, ubicada en el río Napo (Tena, Ecuador), los cuales fueron llevados por un cauchero al departamento Madre de Dios (Perú), en la Selva, a la altura del Cuzco. Luis Canelos Macochoa — de aproximadamente cuarenta años en 1984- decía sobre los padres de su generación: "Fueron traídos un centenar de ellos por el cauchero Arturo Reátegui, en 1911, y llegaron a la boca del tío Tacuatimanu un 30 de Agosto de dicho año, motivo de su denominación. Vivieron regados a través del río Tacuatimanu durante unos cuatro años, trabajando como peones para diversos caucheros y siringueros quienes abandonaron Madre de Dios alrededor de 1915 y no les pagaron el pasaje de retorno" (Pozzi-Escot, 1998, p. 298). Por otra parte, en la memoria de los hablantes de Tena está que en tiempos de sus abuelos solían viajar por el Napo hasta el río Huallaga (Perú) para proveerse de sal; cuentan que se demoraban seis meses en ese periplo, pues para los quichuas ecuatorianos de la Amazonía era más factible ir al Perú por río, que cruzar la Cordillera oriental y salir a Quito o a la Costa. Contactos como estos pudieron haber sido un factor importante para la unidad dialectal de toda esta zona. 
dor están relacionadas actualmente con las variedades quechuas de la Selva noreste peruana, que se encuentran en los departamentos de Loreto, San Martín y Amazonas, así como en Colombia. Sin embargo, cabe anotar que la variedad quechua de Amazonas tiene una diferencia importante, pues mantiene la distinción entre los fonemas /č/ y /ĉc/, de la cual carece el ecuatoriano.

La razón para que confluyan características comunes entre las hablas que constituyen el QIIB, se debe posiblemente a que en el siglo $\mathrm{XVI}^{53}$ ellas habían sido difundidas por misiones del Obispado de Quito. Además, los jesuitas atendieron gran parte de la Amazonía ecuatoriana, y también Maynas, hasta su expulsión en 1767. El padre Ortiz, al referirse al papel de los jesuitas y a los textos empleados en la evangelización de los indios del Ecuador, dice:

En Quito y en Perú se utilizaron los mismos textos gramaticales y doctrinales [...]. Cuando se hace referencia al Ecuador o al Quito de esa época, hay que tener presente que el territorio de la Real Audiencia de Quito y del Obispado de Quito se extendía bastante más que el Ecuador de hoy día. El Obispado de Quito llegaba hasta Cajamarca y Trujillo y comprendía la inmensa región de la Misión de los Maynas. Esta Misión abarcaba las cuencas de los afluentes del Marañón por parte del Perú: Huallaga, Ucayale, Panapura: colindaba con el territorio del obispado de Charcas (Bolivia) y por el oriente con el Brasil. El quichua "quiteño" se habló en todas las comarcas a donde llegaban los jesuitas con sus misiones. Por esto la Gramática o Arte del Quichua que edita en 1753 el jesuita Nieto Polo del Águila es para la Provincia de Quito y para las misiones de Maynas (2001, p. 36).

Según los estudios comparativos, las particularidades de los dialectos del quichua ecuatoriano se pueden encontrar en el campo fonético-fonológico, morfológico y léxico. A nivel sintáctico la diferencia

53 A partir del siglo XVII la zona de Chachapoyas pasó a conformar el Obispado de Trujillo, cuando éste fue organizado separándose del de Quito. 
158

entre los dialectos es menor y no solo dentro del quichua ecuatoriano, sino al interior de toda la familia lingüística. Al respecto, Parker dice: "Los textos disponibles para diversos dialectos muestran un alto grado de homogeneidad sintáctica, a excepción de lo relativo a la reestructuración que ha resultado del prestamo de preposiciones y conjunciones del castellano en ciertos dialectos" (1969c/2013, p. 77).

A continuación se presentan cinco particularidades del quichua ecuatoriano en al campo fonológico y varias en el nivel morfológico, desagregadas en la morfología nominal y en la verbal.

\section{Nivel fonológico}

El sistema fonológico fundamental del quichua ecuatoriano actual no es muy distinto de los propuestos para el protoquechua por Parker, Torero y Cerrón-Palomino que han sido señalados. A continuación se presentan los cuadros vocálico y consonántico del quichua ecuatoriano actual. En tales cuadros se tendría que incluir los fonemas provenientes de las lenguas de sustrato, de los cuales se hablará en el capítulo 7 que trata sobre la estandarización de la escritura del quichua.

Tabla 4

Cuadro de los fonemas vocálicos

y consonánticos del quichua ecuatoriano

\begin{tabular}{|l|l|l|l|}
\hline Vocales $^{54}$ & \multicolumn{2}{|l|}{} \\
\hline $\begin{array}{r}\text { Anterioridad } \\
\text { Aposterioridad }\end{array}$ & Anterior & Central & Posterior \\
\hline Cerradas & i & & \\
\hline Abierta & & a & \\
\hline
\end{tabular}

54 En Ecuador no se ha dado el problema por el número de vocales como ha ocurrido en el Cuzco, pues todos están de acuerdo en la existencia de tres vocales. La discusión se ha dado en torno a las consonantes. 
159

\begin{tabular}{|c|c|c|c|c|c|c|}
\hline \multicolumn{7}{|l|}{ Consonantes $^{55}$} \\
\hline $\begin{array}{l}\text { Modo } \\
\text { articulación }\end{array}$ & Bilabial & Dental & Palatal & $\begin{array}{l}\text { Palatal } \\
\text { retrofleja }\end{array}$ & Velar & Postvelar \\
\hline Oclusivas & $\mathrm{p}$ & $\mathrm{t}$ & $\check{\mathrm{c}}$ & & $\mathrm{k}$ & \\
\hline Fricativas & & s & š & & $\mathrm{x}$ & \\
\hline Nasales & $\mathrm{m}$ & $\mathrm{n}$ & $\tilde{\mathrm{n}}$ & & & \\
\hline Laterales & & 1 & $\lambda$ & & & \\
\hline Vibrantes & & r & & & & \\
\hline Semiconsonantes & $\mathrm{w}$ & & $y$ & & & \\
\hline
\end{tabular}

Fuente: Álvarez y Montaluisa, 2017

Las diferencias más importantes se deben a los efectos de los fenómenos de evolución que han tenido en el tiempo y en el espacio las diferentes hablas del quechua/quichua, y a la presencia de algunos sonidos provenientes de las lenguas de sustrato. Así por ejemplo, en el caso del quichua de Cañar y Azuay, pervive hasta el día de hoy un importante léxico de la lengua Cañar ( $c f$. cap. 1), en el cual existe la presencia del fonema /ž/ que se transcribe como $<\mathrm{zh}>$. En el siguiente ejemplo se puede apreciar la necesidad de incluir esta grafía para diferenciarla de la grafía del fonema $/ \lambda /$ :

\begin{tabular}{|ll|}
\hline Zhadan & 'una planta' \\
Llatan & 'desnudo, pelado' \\
\hline
\end{tabular}

55 En los dialectos de la Sierra centro y parte de la Sierra sur del Ecuador, existe un reducido número de palabras con sonidos aspirados $\left[\mathrm{p}^{\mathrm{h}}, \mathrm{t}^{\mathrm{h}}, \mathrm{ch}^{\mathrm{h}}, \mathrm{k}^{\mathrm{h}}\right]$, que podrían provenir de un superestrato de origen cuzqueño. Adicionalmente, hay la presencia de los fonos [e, o, $\varnothing, \check{z}, \mathrm{z}, \mathrm{b}, \mathrm{d}, \mathrm{g}, \mathrm{f}]$ en el léxico, provenientes de las lenguas de sustrato. Actualmente existe la presencia del fono [h] proveniente del fonema /q/ en el quichua de Tungurahua y Chimborazo, posiblemente como superestrato también del Cuzco. Por otra parte, hay que señalar que en el cuadro fonológico, siguiendo la tradición de la lingüística quechua, el fonema africado /č/ se representa en la fila de las oclusivas y no aparte, como podría ser. 
160

Inclusive se tendría un par mínimo en el quichua actual de la provincia de Cañar entre estos dos fonemas que se representan con las grafías /ll, zh/.

\begin{tabular}{|ll|}
\hline Killu & 'amarillo' \\
Kizhu & 'vagina' \\
\hline
\end{tabular}

A continuación veremos las diferencias principales del quichua ecuatoriano con relación al sistema de los otros dialectos.

La no presencia del fonema /q/

En los dialectos del quichua ecuatoriano no se da el fonema /q/, debido a que este elemento se ha velarizado $y$, consecuentemente, fusionado con $/ \mathrm{k} /$. Esta característica parece ser de larga data, pues desde los documentos del siglo XVIII, que son los primeros que se conoce del ecuatoriano, no se registra representaciones de este fonema. La no distinción de / $/$ con /q/ se da, actualmente, tanto en el Ecuador, en el ingano de Colombia como en la Amazonía peruana. Podría tratarse de un fenómeno de innovación compartida. Ejemplos:

\begin{tabular}{|llll|}
\hline Protoquechua & $\begin{array}{l}\text { Ecuatoriano- } \\
\text { ingano }\end{array}$ & $\begin{array}{l}\text { Amazonía } \\
\text { peruana }\end{array}$ & Glosa \\
/ñqa/ & $/$ ñuka/ & /nuka/ & 'yo' \\
/qam/ & $/ \mathrm{kan} /$ & $/ \mathrm{kan} /$ & 'tu' \\
/puriq/ & $/$ purik/ & $/$ purik/ & 'caminante' \\
\hline
\end{tabular}

Sonorización de las consonantes oclusivas

Las oclusivas sordas /p, t, č, k/ se sonorizan después de nasal y en algunos casos en posición intervocálica. Sin embargo, en el trabajo de campo se encontró que la sonorización no es regular ni se da por igual en el léxico de todas las zonas dialectales ( $c f$. cap. 5). Además, en algunos 
casos, las reglas de sonorización son diferentes en un contexto morfológico, a diferencia de lo que ocurre en el nivel lexical.

El fenómeno de la sonorización de las oclusivas sonoras después de nasal, lo comparten el ingano de Colombia, toda la Amazonía peruana y parte del QIIA. Inclusive habría participado de este el quechua costeño-central, según los datos proporcionados por el Lexicón de Domingo de Santo Tomás (1560/1995). Parker llega a sostener que la sonorización de las oclusivas después de nasales sería una "característica areal” (1969b/2013, p. 63), es decir, no sería una innovación compartida.

\section{La presencia restringida de aspiradas}

Existen algunos autores que han visto en el quichua ecuatoriano más relación con el cuzqueño que con el tardíamente denominado chinchaysuyano. Así, Grimm dice que "Aunque el dialecto del Chinchaysuyo se habla al norte del Cuzco, el de Quito tiene más semejanza con la lengua del Cuzco sobre todo en las formas gramaticales" (1896, p. v). Sin embargo, en el caso de la presencia de las aspiradas que es un fenómeno característico del quechua cuzqueño actual, en Ecuador, de las seis zonas dialectales en que se han dividido los dialectos del Ecuador, según los resultados de la investigación que se presentan en el capítulo 5, la única zona donde existe un limitado número de palabras con aspiración es la zona de la Sierra centro. Las provincias donde existe más presencia de aspiradas son: Cotopaxi, Tungurahua, Chimborazo y Bolívar.

Este fenómeno es reducido en relación al cuzqueño actual, no solo en cuanto al léxico, sino también a nivel posicional, pues solo se da en posición inicial de palabra. En el habla del Cuzco se da también en otras posiciones. $\mathrm{Al}$ respecto, Muysken dice:

Parker (1969) ha mostrado que la relación léxica entre los aspirados y glotalizados cusqueños [sic] y los ecuatorianos es muy confusa y asistemática. Parece ser del mismo [sic] índole que la relación entre globalización y aspiración en aymara y en el quechua cusqueño, tal como 
descrito por Stark (1975). La semejanza parece tan superficial que es más probable que se debe a influencia posterior que a una $[$ sic $]$ origen común (1977, p. 6).

Por otra parte, cabe anotar que los términos que portan aspiración en la Sierra centro del Ecuador no necesariamente coinciden con los del Cuzco. Es ilustrativo de esta asimetría el cotejo realizado por Torero (2002). Este autor, basándose en el diccionario de Stark y Muysken (1977) y Cusihuaman (1976), dice:

A) Solamente 32 glotalizadas o aspiradas cuzqueñas corresponden a aspiradas o a /ts/ (cinco casos, todos relacionados con /ch'/ cuzqueña). En cambio 43 glotalizadas y aspiradas del Cuzco —un número mayor- se presentan sin aspiración en Ecuador; esto, únicamente $42,6 \%$ de glotalizadas y aspiradas cuzqueñas hallan correspondencia en aspiradas o /ts/ ecuatorianas. Por otro lado, las hablas interandinas exhiben con aspiradas 25 raíces que solo tienen consonantes llanas en cuzqueño o en los demás dialectos peruanos. La cifra de casos en común se reduce así a $32 \%$. Se ha incluido a /ts/ inicial de palabra porque, aparte de aparecer en vocablos no evidentemente quechuas o de corresponder en tres ocurrencias a /tR/ de raíces quechuas, muestra en los cinco casos ya aludidos correspondencia con /ch'/ de Cuzco. B) Los porcentajes de ocurrencia de oclusivas aspiradas (o de fricativas) dentro de los totales con sus correlatos no aspirados son, en las raíces quechuas del ecuatoriano interandino, muy inferiores a los índices que arroja la correlación glotalizadas y aspiradas/llanas en el habla cuzqueña: orden labial 11, 7\% (Cuzco 31,4\%); dental 5,1\% (Cuzco 38,8\%); velar 12,7\% (Cuzco - velar y uvular- 46,2\%). Incluso, en el orden palatal africado, donde Cuzco ostenta la alta cifra de 59, 5\% de glotalizadas y aspiradas (haciendo las glotalizadas por sí solas el 48,9\% del total), el ecuatoriano no presenta sino la africada palatal llana, excepto en los tres casos mencionados, en los que se reconoce una sola palabra obviamente quechua: 
ch’uca ([ch"uka]) "saliva", "escupir” ${ }^{56}$. Esta raíz, que se consigna para otros sitios de Ecuador como t'uca ([t"uka]) y ty'uka ([ty"uka]), es, por lo demás significatimavente, la única que guarda correspondencia con /t"'/ cusqueña /t"uqa -/ (Torero, 2002, pp. 106-107).

La asimetría no solo se encuentra al comparar entre el Cuzco y la Sierra centro del Ecuador, sino también al interior de la misma zona ecuatoriana ( $c f$. cap. 5). La situación de la distribución de las aspiradas problematiza su inclusión en la representación escrita estandarizada.

El fenómeno de la presencia de las aspiradas en el Ecuador podría ser explicado teniendo en cuenta la presencia de mitimaes provenientes del Cuzco. El contingente invasor de Túpac Yupanqui habría estado integrado por personas hablantes de quechua y aimara que manejaban las consonantes aspiradas. En dicha ocasión se habría dado una introducción masiva del quechua sureño a los territorios de la Sierra sur y centro del Ecuador. Durante el reinado de Huaina Cápac, estos territorios ya habrían estado bajo el dominio inca y allí habría habido una mayor presencia de gente cuzqueña en la administración y vigilancia de la zona. Entonces, la presencia de aspiradas en el quichua se podría explicar como un efecto de superestrato.

A continuación, presentamos el territorio de la Sierra centro del Ecuador donde están los términos con el fenómeno de aspiración.

56 En otras zonas dialectales del Ecuador 'saliva' se realiza como [thuka, tyuka, tuka]. En el cuzqueño es thoqay (Cusihuaman, 1976, p. 153). Torero manifiesta que su fuente es Cushihuamán (1976), pero en lugar de thoqay lo trascribe como /t"uqa-/. Torero, en este texto, transcribe los sonidos oclusivos aspirados sordos con el símbolo " en lugar de poner h junto a los símbolos de estos. 
Figura 5

Zona con sonidos oclusivos aspirados

REPU⿴LICA DEL ECUADOR

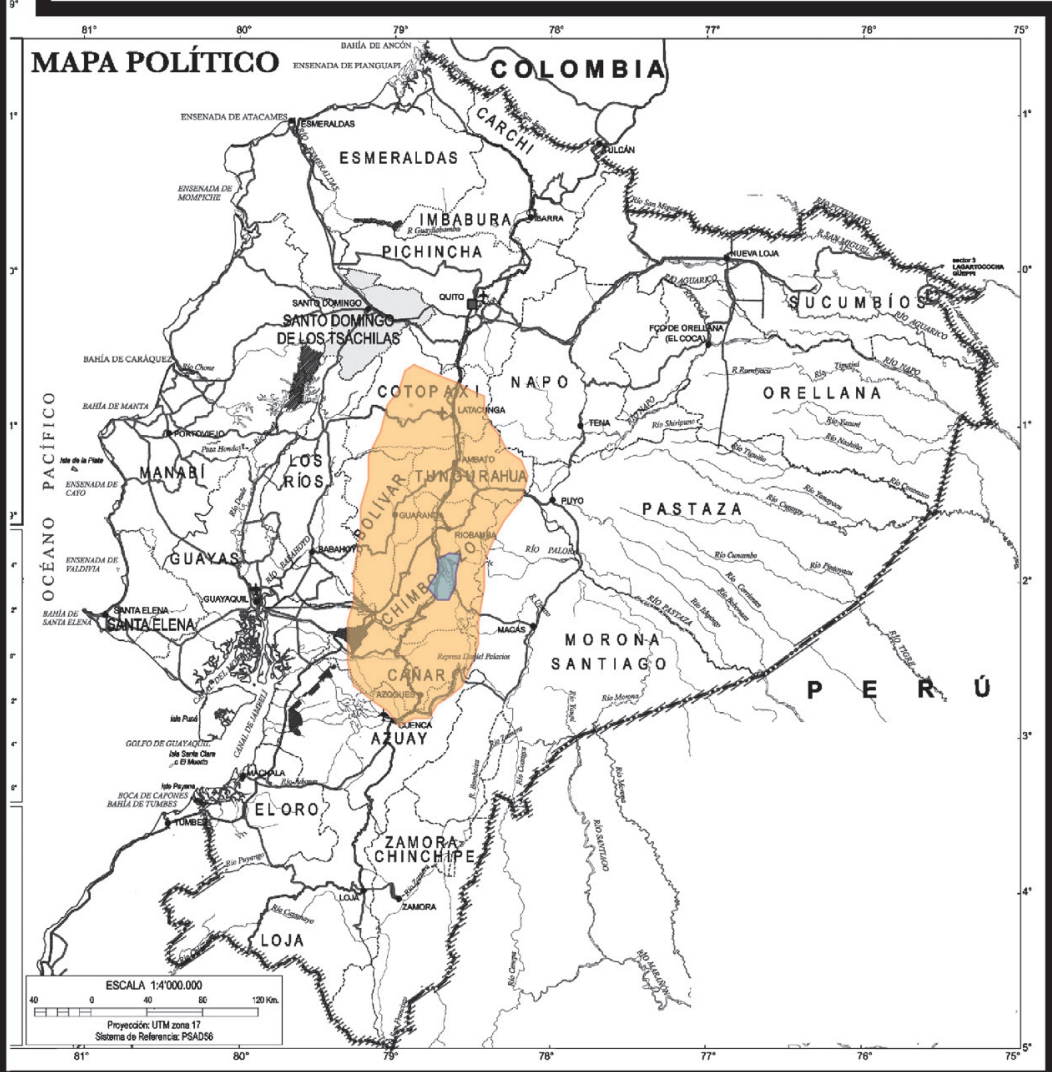

Fuente: el autor 
La complejidad en la fusión de las dos africadas č $/ \hat{c}^{57}$

En el protequechua reconstruido, todos los autores señalan la presencia de dos africadas: /ĉ/ y /č/. En la variedad Junín-Huanca, correspondiente al QI (Cerrón-Palomino, 1976, p. 39) traza la distinción entre /ĉ/ y /č/. Parker (1976, pp. 45-46) apunta que en Siguas-Ancash también se mantienen las dos africadas señaladas. Igual situación se advierte en la variedad Cajamarca-Cañaris del QIIA (Quesada, 1976, p. 35; Taylor, 2000, pp. 48-59) en Chachapoyas, aunque anota que en el habla de los aculturados ya está desapareciendo /ĉ/ y que en Lamas ya ha desaparecido.

En Ecuador estos dos fonemas se han fusionado mayoritariamente en /č/ ${ }^{58}$ Por ejemplo: /ĉaki/ 'pie' y /čaki/ 'seco', han devenido en /čaki/ 'pie', y /čaki-šqa/ en /čakiška/ 'seco'.

Por otra parte, en la variedad Ancash-Huailas del QI, Parker (1976, pp. 45-46) registra en Corongo y Huaraz la distinción entre los

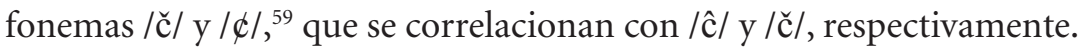

En Ecuador, la distinción entre /č/ y / \/ es más compleja debido a la intromisión del fonema /č'/ del cuzqueño. De los 175 vocablos portadores de /č'/ recopilados por Cusihuamán (1976), solo 42 palabras tienen significado en todas las zonas o al menos en alguna parte de Ecuador. Esto equivale a un $24 \%$ del total. De estas, una decena de palabras se realizan como $[\check{c} \sim \varnothing]$. El resto se realiza como [ $\check{c}]$ en todo el Ecuador. Así, en algunas hablas / $/$ / aparece como variante de /č/. Por ejemplo:

57 Como ya se dijo, en los cuadros fonológicos se ha hecho tradición en la lingüística andina el considerar a las africadas como parte de las oclusivas.

58 Aunque /č/ y / $/$ se han fusionado en el Ecuador en /č/, existen palabras quichuas que en cinco de las seis zonas dialectales se pronuncian con [ $\not$ ]. Por ejemplo: [pacak] 'cien', aunque en el protoquechua de Parker aparezca como "paĉak" y en los diccionarios del siglo XVI se escriba "pachak".

59 En el texto original de Parker (1976) el fonema / $\not /$ se representa con el símbolo /c/ (cf. Cerrón Palomino, 1987, para mayor información sobre la situación actual

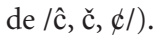




\begin{tabular}{|c|c|c|c|c|}
\hline Variaciones & Unificado & Lugares (Ecu.) & Cuzco & Glosa \\
\hline $\begin{array}{l}\text { [čarki] } \\
{[\text { carki] }}\end{array}$ & /čarki/ & $\begin{array}{l}\text { Sierra centro y sur } \\
\text { Sierra norte }\end{array}$ & /č’arki/ & 'cecina, flaco' \\
\hline $\begin{array}{l}\text { [ačira] } \\
\text { [açira] }\end{array}$ & /ačira/ & $\begin{array}{l}\text { Sierra sur } \\
\text { Sierra norte y centro }\end{array}$ & /ačira/ & 'raíz comestible' \\
\hline $\begin{array}{l}\text { [čawar] } \\
\text { [ çawar] }\end{array}$ & /čawar/ & $\begin{array}{l}\text { Sierra centro y sur } \\
\text { Sierra norte }\end{array}$ & /č’awar/ & 'penco' \\
\hline $\begin{array}{l}{[\text { čini }]} \\
{[\text { ćini }]}\end{array}$ & /čini/ & $\begin{array}{l}\text { Sierra centro y sur } \\
\text { Sierra norte }\end{array}$ & /kisa/ & 'ortiga' \\
\hline $\begin{array}{l}{[\text { cia }]} \\
{[\text { sia }]}\end{array}$ & /ciya/ & Sierra norte y centro & /č’iya/ & $\begin{array}{l}\text { 'liendre' } \\
\text { Sierra sur }\end{array}$ \\
\hline [čaway] & $\begin{array}{l}\text { /čaway/ } \\
\text { /kapina/ }\end{array}$ & $\begin{array}{l}\text { Sierra centro } \\
\text { Sierra norte y sur }\end{array}$ & /č’away/ & 'ordeñar' \\
\hline [čuža] & /ču入a/ & Sierra norte y centro & /ču’入a/ & 'único, impar' \\
\hline 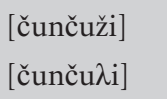 & $\begin{array}{l}\text { /čunču } \mathrm{i} / \\
\text { Sierra sur }\end{array}$ & Sierra norte y centro & /č’unčul/ & 'tripa' \\
\hline $\begin{array}{l}\text { [čukža }] \\
{[\check{c} u g \lambda a]}\end{array}$ & /čuk $\lambda \mathrm{a} /$ & $\begin{array}{l}\text { Sierra norte y centro } \\
\text { Sierra sur }\end{array}$ & /č'uk $\lambda \mathrm{a} /$ & 'choza' \\
\hline
\end{tabular}

Pero en la Sierra norte y centro se pueden encontrar, actualmente, unos pocos ejemplos de pares mínimos entre /č/ y / ф / en palabras de origen quichua. Este fenómeno seguramente se debe a la necesidad de mantener alguna distinción al no existir las aspiradas y glotalizadas como en el Cuzco.

\begin{tabular}{|lll|}
\hline /čanka/ & 'pierna' & \\
/ çanka/ & 'granos machucados' & \\
/čunkana/ & 'agrupar de diez en diez' & [čunkay] (Cuzco) \\
/ çunkana/ & 'chupar' & [č’onqay] (Cuzco) \\
\hline
\end{tabular}

En la Sierra sur, que no tiene / $\not /$ en el sustrato, para diferenciar /č/ y / ф/ este último ha evolucionado a [s]. Así, palabras que en la ma- 
yor parte del Ecuador se pronuncia con / $/$ / como: [pacak] <patsak> 'cien', en esta zona se pronuncia [pasak]. La palabra [micak] <mitsak $>$ 'tacaño' se realiza igualmente como [misak]. En esta última zona se ha dado una evolución ulterior de $|\phi|>/ s /$, por desafricación. Sin embargo, en algunos casos se realiza como [č] en Ecuador, incluida la Sierra sur, por ejemplo: [čug $\lambda \mathrm{a}$ ] /čuk $\lambda \mathrm{a} /$ 'choza', /čunču $\lambda \mathrm{i} /$ 'tripa', /ču $\lambda \mathrm{a} /$ 'único', / čuru/ 'caracol, espiral'. Algunos / $/$ / se correlacionan con /č'/ cuzqueño, pero otros provienen de sustratos prequichuas. Los elementos de sustrato más probables son fitónimos como /yuđu/ 'tipo de planta que crece junto a los ríos' en la Amazonía, /pucu/ 'tipo de hierba silvestre en la provincia de Cotopaxi', etc. Se ha detectado la presencia de un sustrato / $\not$ / en cinco de las seis zonas dialectales que presentarán en el capítulo $5 .{ }^{60}$ La única que no tiene es la Sierra sur.

\section{El uso del fonema /šl}

Como se verá en el capítulo 5, en cinco de las seis zonas dialectales del Ecuador se usa /š/. Esta es una de las diferencias con el ingano de Colombia, en donde este fonema se realiza como [s], de manera similar al cuzqueño. La única zona donde se ha producido este fenómeno es en la Amazonía norte del Ecuador, pero no de manera general en el léxico, como ocurre en el colombiano, sino solo en los morfemas \{-ška\} y \{-špa\}. Esta última característica la comparte con el napeño del Perú, según Mercier (1983).

\section{Nivel morfológico}

Según Parker (1969c/2013), las clases mayores de las raíces del protoquechua son los sustantivos, verbos, ambivalentes y también las

60 De las seis zonas dialectales, en la Sierra sur no se han encontrado sustratos con $\mid \not /$. Las palabras que en las otras cinco zonas se pronuncian con [£], aquí se pronuncian con $[\mathrm{s}]$. 
partículas. ${ }^{61}$ De ellos, los sustantivos son formas libres y flexionan con los morfemas de persona (posesora), ${ }^{62}$ número y caso. Los verbos son formas ligadas que flexionan de acuerdo a la persona, tiempo, aspecto, modo y subordinación. Los ambivalentes comparten rasgos con las categorías nominales y verbales. Las partículas, con excepción de los adverbios, ${ }^{63}$ no flexionan.

Luego de cotejar las diferentes hablas del quechua, Parker reconstruyó 36 morfemas derivadores, 18 flexivos entre verbales y nominales, y 5 enclíticos (independientes) para el protoquechua. Cabe anotar que en el caso de los flexivos verbales Parker tiene algunas vacilaciones, sin embargo, a pesar de estas limitaciones subyacentes a una tarea tan compleja como la de acometer una reconstrucción del protoquechua, la propuesta de Parker sigue siendo útil para continuar con las investigaciones en esta dirección.

Por otra parte, como lo han señalado varios investigadores, entre ellos Muysken (1981), en el quichua ecuatoriano existe una reducción importante en algunos de los sectores de la morfología en comparación con lo que ocurre en los dialectos actuales correspondientes al QI, QIIA y QIIC. La reducción se ha dado principalmente en los sistemas nominal y verbal, no tanto en el de los morfemas independientes. Además de la reducción morfémica, se constatan — como se va verá luego- procesos de resignificación y nuevos desarrollos morfológicos en los dialectos ecuatorianos.

\section{Sistema nominal}

Este sistema está constituido por los morfemas, tanto derivativos como flexivos, que se juntan al nombre.

61 Las partículas comprenden a los negadores, adverbios e interjecciones.

62 En el quichua ecuatoriano la flexión de persona se ha perdido, al parecer, a partir del siglo XVIII.

63 Un ejemplo de flexión del adverbio /achka/ es: /achkata munani/ 'quiero mucho'. 
1. Poco uso de los posesivos de persona. ${ }^{64}$ En cuanto a los morfemas nominales flexivos de persona debe señalarse que en el quichua ecuatoriano hay poco uso de los morfemas posesivos de persona. Para resolver esta situación se recurre al morfema genitivo $\{-\mathrm{pak} / \mathrm{pa}\}$, añadido al nombre o pronombre, que funciona como posesor, por ejemplo: <paypak wasi> 'su casa', < María-pak wasi> 'casa de María'. Además, en el caso de la primera persona, tanto singular como plural, se recurre a la simple yuxtaposición entre el posesor y el poseído. Así, se tiene $<$ ñuka wasi $>$ 'mi casa' y < ñukanchik wasi $>$ 'nuestra casa', en lugar de $<$ wasi-y, wasinchik $>$, respectivamente. Para destacar mejor la diferencia que existe en este punto entre el quichua ecuatoriano y los del Perú (representados por el QIIC), ${ }^{65}$ tenemos:

64 Ha sido común, entre los estudiosos de la morfosintaxis del quichua ecuatoriano, indicar que en el habla contemporánea no existen sufijos de persona que se juntan a los nombres para indicar posesión. Sin embargo, hay un estudioso que muestra su presencia no solamente en los textos de finales de siglos XIX y principios del siglo XX de autores como Grimm, Paris o Guzmán, sino que ha detectado su uso en el quichua oral actual de hablantes de algunas comunidades de Cotopaxi, Pichincha y Azuay (Garcés, 1997, pp. 99-100). Entre los ejemplos trae el siguiente: [turin šamukpi pai kontenta gaxun, turin ižakpi pai žaki gaxun] 'cuando viene su hermano, ella se pone contenta; cuando no está su hermano, ella está triste' (Juan José y Albino Iza, comunicación personal, marzo 1994). Aquí puede observarse la expresión $<$ turin $>$, en la cual el morfema $\{-n\}$ colocado a continuación de $<$ turi $>$, 'hermano de hermana', significaría 'su hermano', en lugar de la expresión genitivodativo < paypak turi shamukpi $>$ que es de esperarse. En este caso se constata que el morfema posesivo de la tercera persona del singular está presente en algunos contextos del habla actual. El autor de este estudio trae otros ejemplos con el posesivo de la segunda persona del singular. Además, subraya el caso de $<$ Apunchik $>$ 'nuestro Señor', que es la unión de $<$ Apu $>$ 'señor' y el morfema posesivo de la primera persona del plural inclusiva $\{$-nchik\}. De confirmar esto las investigaciones, sería plausible plantearse el rescate de esas marcas de persona en el quichua ecuatoriano.

65 Características de estos dialectos pueden consultarse en Cerrón-Palomino (1987, pp. 221-247). 


\section{0}

\begin{tabular}{|lll|}
\hline Variedades ecuatorianas & QIIC (cuzqueño) & Glosa \\
Ñuka-(pak) allku & allqu-y & 'mi perro' \\
Kan-pak allku & allqu-yki & 'tú perro' \\
Pay-pak allku & allqu-n & 'su perro' \\
Ñuka-nchik (pak) allku & allqu-yku & 'nuestro perro' (excl.) \\
Nuka-nchik (pak) allku & allqu-nchik & 'nuestro perro' (incl.) \\
Kankuna-pak allku & allqu-yki-chik & 'vuestro perro' \\
Paykuna-pak allku & allqu-nku & 'su perro' \\
Ñuka mikushka & miku-sqa-y & 'lo que he comido' \\
Kan mikushka & miku-sqa-yki & 'lo que has comido' \\
Pay mikushka & miku-sqa-n & 'lo que ha comido' \\
\hline
\end{tabular}

Esta característica diferencia al ecuatoriano inclusive de la mayor parte de hablas de la Amazonía peruana, aunque ellas también están en el grupo QIIB. Así, según Landerman (1973, pp. 105-106), el quechua del Pastaza peruano sí contiene las marcas personales de posesivo. Consecuentemente, la carencia de los morfemas de marcas posesivas personales solo ocurre en el quichua ecuatoriano, en el peruano de Loreto y en el ingano de Colombia.

2. La fusión de los morfemas de caso: posesivo $\{-p a\}$ y dativo $\{-p a k\} .{ }^{66}$ En las hablas del Ecuador, de Loreto (Perú) y en el ingano, no se hace distinción entre estos dos morfemas. Hubo, pues, una fusión entre ambos morfemas. Por ejemplo:

\begin{tabular}{|lll|}
\hline Ecuatoriano & Cuzqueño & Glosa \\
Mariapak wasi & Mariapa wasi & 'casa de María' \\
Mariapak wasi & Mariapak wasi & 'casa para María' \\
\hline
\end{tabular}

66 Actualmente, algunos quichuistas ecuatorianos están propugnando restablecer la diferencia a nivel escrito entre el posesivo y el dativo, lo cual deberá ser discutido para valorar su conveniencia. Aquí, esta posibilidad la señalamos como un hecho que tendrá algunas repercusiones en la estandarización de la escritura de la lengua. 


\section{1}

3. Ausencia del privativo \{-naq\}. En la nominalización denominativa, en las hablas ecuatorianas, no se usa el morfema privativo \{-naq\}, que de existir se hubiera realizado como [-nak], y que es el correlato del morfema $\{$-yuq\}, que en el ecuatoriano se realiza como [yuk]. La noción de privación se realiza con una circunlocución a base del verbo $<$ illa-y> 'faltar'. Así, lo que en dialectos del Perú sería <wasi-naq>, se corresponde con $<$ wasi illak $>$ en el Ecuador.

4. Uso de diminutivos $\{-k u,-w a,-l l a\}$ en lugar de $\{-c ̌ a\}$. En lugar del morfema diminutivo $\{-c ̌ a\}$, que está presente en varios dialectos del QIIC, en el Ecuador se usan los morfemas $\{-\mathrm{ku}\}$ en la Sierra norte, $\{-w a\}^{67}$ en la Sierra centro y $\{-\lambda \mathrm{a}\}$ en la Sierra sur. ${ }^{68}$ Por ejemplo:

\begin{tabular}{|lll|}
\hline /wasi/ & 'casa' & Todo el país \\
/wasi-ku/ & 'casita' & Sierra norte \\
/wasi-wa/ & 'casita' & Sierra centro y Amazonía \\
/wasi-lla/ & 'casita' & Sierra sur \\
\hline
\end{tabular}

El caso de $\{-\lambda \mathrm{a}\}$ se remonta al protoquechua y constituye un rasgo de preservación.

\section{Sistema verbal}

Este sistema está constituido por los morfemas derivativos y flexivos que se juntan al verbo. En el sistema verbal, particularmente en la verbalización deverbativa, es donde existe mayor reducción e innovación. Así, mientras que varios dialectos del QI y también del QIIC llegan a tener hasta 26 morfemas verbalizadores deverbativos, en el Ecuador solo se emplean siete, que son compartidos con los dialectos antes se-

67 Todo indica que $\{$-wa $\}$ proviene de $<$ wawa $>$ 'niño, niña, tierno', pues se puede también decir $<$ wasi wawa $>$ con el mismo sentido que $<$ wasiwa $>$.

68 En la Sierra sur, en muchas comunidades, se ha generalizado el uso del diminutivo del castellano en lugar del morfema quichua $\{-\lambda a\}$. Así, dicen /ñuka wasizitu/ en lugar de /ñuka wasìa/ 'mi casita'. Lo propio ocurre en los dialectos de Puno (Perú) y Bolivia. 
ñalados y que son: el desiderativo $\{$-naya- $\}$, el repetitivo $\{$-paya $\}$, el continuativo $\{$-raya- $\}$, el cislocativo $\{-\mathrm{mu}-\}$, el causativo $\{-c ̌ i\}$, el recíproco $\{$-naku-\} y el frecuentativo \{-ykača\}. Así pues, según Parker (1976, pp. 115-116) en las provincias de Huaraz, Pomabamba y Antonio Raimondi del dialecto Ankash-Huailas correspondientes al QI, hay 26 morfemas verbalizadores deverbativos. Según Cerrón-Palomino (1976, pp. 181215) en Junín-Huanca del QI hay también 26 verbalizadores deverbativos. En el dialecto cuzqueño, según la lista presentada por Cusihuaman (1976, pp. 193-2236) correspondiente al dialecto QIIC, se señalan más verbalizadores deverbativos que los anteriores del QI.

Aparte de esta situación de reducción del número de verbalizadores deverbativos y del surgimiento de algunos desarrollos propios, existen otras características del sistema morfológico verbal del quichua ecuatoriano que se verán a continuación.

1. Uso de $\{-n a\}$ como infinitivo verbal. En teoría, el infinitivo es un verbo no finito, es decir, se trata de una forma verbal sin tiempo, persona ni número, y ese sentido se parece más a un nombre. Sobre la marca de infinitivo en quechua ha existido una larga discusión. Domingo de Santo Tomás (1560/1995, p. 100) en el "Capítulo nono" no lo define con claridad. Se limita a poner ejemplos de su funcionamiento como nombre. Así, en su gramática trae la expresión "micui allí" traducida como 'comer es bueno', no es una expresión del habla diaria en el quichua ecuatoriano. Esa idea se expresaría con "micuica allimi (can)" 'el comer es bueno'. En este ejemplo y en los otros que señala el autor como infinitivo, la $<\mathrm{i}>$ aparece como marca de nominalización. Mientras que en el capítulo 5 dice lo siguiente sobre el modo infinitivo: "El presente se forma de la primera persona del presente de indicativo quitando la $n$, diciendo coyay" (1560/1995, p. 99). Sin embargo, como lo han sugerido algunos autores, especialmente Cerrón-Palomino en el estudio introductorio a la reedición de la gramática de Domingo de Santo Tomás ( $c f .1560 / 1995$, p. XXXVII), habría otras expresiones del autor de la primera gramática, de donde se podría intuir la marca más aproximada al infinitivo del verbo quichua. Así, en el capí- 
tulo 10 de la obra del dominico se encuentran expresiones como las siguientes: $<$ ñoca cuyangapac xamuni $>$ 'yo vengo a amar' $y<$ ñocanchic coyangapac, xamunchic > 'nosotros venimos a amar' (1560/1995, p. 103). En ellas, quitando la persona, se podría desglosar la forma infinitiva a partir de la expresión <kuya-nqa-ø-paq > 'a amar'. Eliminando \{-paq\}, quedaría $<$ kuyanqa $>$, y esta sería la forma del infinito verbal. En consecuencia, se podría postular como marca de infinitivo originaria el morfema $\{-n q a\}$.

Por otra parte, al menos desde fines del siglo XIX, a nivel escrito, en Ecuador se viene usando el morfema $\{$ na $\}$ como marca de infinitivo, mientras que en hablas de otros países se usa $\{-y\}$. La versión más antigua sobre esta cuestión en el ecuatoriano es el anónimo de 1753, atribuido al jesuita Nieto Polo. En ese texto se señala que el infinitivo es representado por la forma $\{$-nga\}, pues dice que el infinito de 'amar' es < cuianga $>$. Esto se puede observar en el siguiente texto: "Infinitivo. Amar. Cuianga. Efte infinitivo lo ufan los Indios muchas veces, como

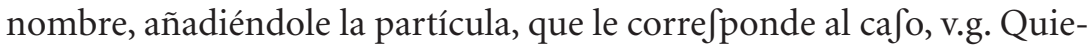
ro comer, Micungata munani” (Anónimo, 1753, folio 12).

Este dato atribuido a Nieto Polo es valioso, pues nos permite confirmar que la marca $\{-$ na $\}$ provendría de ${ }^{*}\{-$ nqa $\},{ }^{69}$ el cual se habría ido simplificando en $\{-$ na $\}$ hacia fines del siglo XVII y comienzos del XVIII.

Posteriormente, el padre Paris (1892/1924), Luis Cordero (1892/1989) y el padre Grimm (1896) emplean la forma infinitiva de los verbos con $\{-n a\}$. Así, 'amar' es <cuyana $>$. Actualmente, si se pregunta a un quichua-hablante bilingüe ¿cómo se dice sembrar?, generalmente responderá [tarpu-na] mas no [tarpu-y], pues este último se asocia más con el imperativo de segunda persona singular: 'siembra tú. Sin embargo,

69 Lo mismo puede decirse del origen del obligatorio $\{-$ na $\}$ que también proviene del $*\{$-nqa $\}$. Esto puede comprobarse con la frase de una canción quichua que se canta en Saraguro: <Ishkay wawa charinkarayku kanllawanmi kawsasha>, cuya interpretación sería: 'Por tener dos hijos solo contigo viviré'. 


\section{4}

cuando la pregunta es a la inversa: ¿Qué significa [tarpu-na]?, le contestan 'está de sembrar', pues se asocia con la forma de obligatoriedad $<$ tarpunami kan $>$. Hubiera sido interesante conocer cómo concebía el infinitivo el padre Lobato, indígena quichua-hablante de la comunidad de Cacha, actual provincia de Chimborazo, de quien se dice que escribió una gramática del quichua ecuatoriano antes de viajar a radicarse en el Perú en 1885.

Como se mencionó, a partir de las obras de fines del siglo XIX, con excepción del padre Guzmán (1920), se hizo costumbre representar en las gramáticas y diccionarios del quichua ecuatoriano el infinitivo con $\{-n a\}$. Así, se escribe < puñu-na, ka-na $>$ 'dormir, ser', respectivamente; mientras en el resto de países escriben $<$ puñu-y, ka-y $>.^{70} \mathrm{El}$ morfema $\{$-na\}, actualmente en Ecuador, en pocos casos se usa para la formación de nombres concretos. Por ejemplo:

\begin{tabular}{|ll|}
\hline miku-na & 'comida' \\
picha-na & 'escoba' \\
purik-na & 'caminata' (en la Amazonía se refiere al paseo familiar por varios días \\
& en la selva)
\end{tabular}

2. No distinción de plural inclusivo y exclusivo. El ecuatoriano no distingue entre el plural inclusivo y el plural exclusivo, tanto a nivel pronominal como verbal de la primera persona. Esta característica del ecuatoriano es compartida con el ingano de Colombia y el amazónico peruano. Por ejemplo:

\begin{tabular}{|lll|}
\hline Ecuatoriano & Peruano & Glosa \\
ñuka-nchik & ñuqa-yku/ñuqa-ykuna & 'nosotros' (exclusivo) \\
ñuka-nchik & ñuqa-nchik & 'nosotros' (inclusivo) \\
miku-nchik & mikuku-yku/miku-ykuna & 'comemos' (nosotros exclusivo) \\
miku-nchik & miku-nchik & 'comemos' (nosotros inclusivo) \\
\hline
\end{tabular}

70 Actualmente, algunos quichuistas indígenas de Ecuador proponen usar el morfema $\{-y\}$ como marca de infinitivo para unificarse con los otros países. Sin embargo, a la luz de estos datos, podría postularse que la marca de infinitivo en $\{$-na\} es un desarrollo ecuatoriano que puede mantenerse en la escritura unificada. 
3. Uso del factitivo $\{-c h i-\}$ en lugar de $\{-c h a-\}$. En lugar del protomorfema factitivo $\{-$ ča $\}$ se usa en todos los dialectos del Ecuador el morfema $\{$-či $\}$. Al parecer, esto implicaría la fusión del factitivo $\{-$ ča $\}$ con el causativo $\{$-či $\}$. Por ejemplo:

\begin{tabular}{|lll|}
\hline Ecuatoriano & Hablas de otros lugares & Glosa \\
wasichini & wasichani & 'hago casa' \\
pampachini & pampachani & 'aplano' \\
\hline
\end{tabular}

4. Uso del reflexivo $\{-r i-\}$ en lugar de $\{-k u\}$. Por ejemplo:

\begin{tabular}{|lll|}
\hline Ecuatoriano & Hablas de otros lugares & 'Glosa' \\
arma-ni & arma-ku-ni & 'baño' \\
arma-ri-ni & arma-ku-ni & 'me baño' \\
\hline
\end{tabular}

5. La no diferenciación de palabras terminadas en vocal o en consonante en el uso del morfema $\{-p a k /-p a\}$. En el QIIA y QIIC, después de vocal, estos morfemas se realizan como [p] y como [b], respectivamente. En tanto que después de consonante se pronunciaría [pa pak paq] fuera de Ecuador, incluido en el ingano de Colombia y el loretano del Perú. Este morfema se pronuncia de la siguiente manera dependiendo de si el nombre termina en vocal o en consonante:

\begin{tabular}{|ll|}
\hline [maria-p wasin $]$ & 'casa de María' \\
{$[$ kuntur-pa wasin $]$} & 'casa del Cóndor' \\
\hline
\end{tabular}

En el ecuatoriano no se aplica esta regla, pues se usa [pa pak] con algunas otras variaciones que constan en el capítulo 5, tanto después de vocal como de consonante. Por ejemplo:

\begin{tabular}{|lll|}
\hline $\begin{array}{l}\text { Maria-pak wasi } \\
\text { Kuntur-pak wasi }\end{array}$ & {$[$ mariapa wasi $\sim$ mariapak wasi $]$} & 'casa de María' \\
& 'casa del Cóndor' \\
\hline
\end{tabular}


Esto prueba que, en verdad, el protomorfema fue ${ }^{\star}\{-$ pa $\}$ y la alomorfía es propia de los dialectos que sincoparon la vocal. Sin embargo, se debe señalar que existen dialectos peruanos que mantienen $\{-\mathrm{pa}\}$ en ambos contextos.

6. Desarrollos morfológicos. Entre los morfemas de innovación que se han desarrollado en el quichua ecuatoriano están: el de cortesía $\{$-pa- $\}$; el durativo $\{$-ku- $\}$ en lugar de ${ }^{\star}\{$-yka $\}$; el reflexivo $\{$-ri $\}$ en lugar $\mathrm{de}^{*}\{-\mathrm{ku}-\}$ (estos dos últimos propuestos para el protoquechua por Parker, 1963-1972/2013, p. 84); el incoativo \{-kri\} en la Sierra; el inceptivo $\left\{\right.$-nka-raku\} en la Amazonía. ${ }^{71}$ Con lo cual los morfemas verbalizadores deverbativos alcanzan a 13. Por ejemplo:

\begin{tabular}{|ll|}
\hline miku-y & 'come' \\
miku-pay & 'come por favor' \\
tarpu-ni & 'siembro' \\
tarpu-ku-ni & 'estoy sembrando' \\
arma-ni & 'baño' \\
arma-ri-ni & 'me baño' \\
miku-ni & 'como' \\
miku-k-ri-ni' & 'voy a comer' \\
miku-ni & 'como' \\
miku-nka-ra-ku-ni & 'estoy yendo a empezar a comer' \\
\hline
\end{tabular}

71 El desarrollo $\{$-nka-ra-ku- $\}$ proviene del ${ }^{*}\{$-nqa $\}$ y de $\{$-ra-ku- $\}$. La explicación es similar a la del morfema $\{-\mathrm{k}-\mathrm{ri}\}$ que se señala más abajo. A esto hay que añadir el elemento lexical <kikin $>$ usado en la Sierra norte y centro con el significado de 'usted', el cual se usa para dirigirse a personas mayores o desconocidas.

72 Sobre $\{$-kri- $\}$ se discute con respecto a la forma de escribir, pues algunos plantean escribir $<$ mikuk rini>, debido a que ese sería el origen de la expresión; sin embargo, otros creen que hay que tomar en consideración que en la mente de los hablantes la secuencia ya se habría internalizado como una unidad. 
Se puede postular que el desarrollo $\{-\mathrm{kri}-\}$ proviene del agentivo $\{-\mathrm{k}\}$ y de $\{$ ri- $\}$ del verbo ir. Igualmente el desarrollo $\{-n k a-r a k u-\}$ provendría de $\{-\mathrm{nka}\}$, de $\{-\mathrm{ra}-\}, \mathrm{y}\{$ rura-y $\}$ 'hacer', y del continuativo $\{-\mathrm{ku}-\}$.

\section{Sufijos independientes}

Los sufijos independientes se juntan tanto al nombre como al verbo. Además, ellos indican si la oración es afirmativa, interrogativa, negativa, etc.

En este sistema de sufijos hay desarrollos como: $\{$-chari $\},\{$-mari $\}$, $\{$-yari $\}$, aunque se conoce que esto no es privativo del quichua ecuatoriano. Se puede postular que estas secuencias son el resultado de ${ }^{\star}\{$ chu-ari $\}$, ${ }^{*}\{$-mi-ari $\}$ y ${ }^{*}\{$-ya-ari $\}$, respectivamente. Los morfemas independientes $\{$-chari\}, \{-mari\} ya se encuentran registrados en el Anónimo de 1753.

Estas construcciones al parecer son bimorfémicas, sobre la base de /ari/, expresión afirmativa. De los morfemas independientes del protoquechua, señalados por Parker, en el ecuatoriano, no se usa $\{-\tilde{n} a\}$. En cuanto a los reportativos, el único usado es en Ecuador $\{-s ̌ i\}$.

\section{Nivel morfosintáctico}

En este nivel no hay muchas diferencias con los otros dialectos, sin embargo, se puede notar el surgimiento de casos de reducción y ensamblaje, en el sentido señalado por Cerrón-Palomino (1997). Uno de ellos es el que se ha dado en la Amazonía sur, en el río Bobonaza (prov. de Pastaza): los hablantes de las comunidades de Sarayacu, Pacayacu, y Teresa Mama suelen ensamblar la palabra que termina en el morfema afirmativo $\{-\mathrm{mi}\}$ con el verbo $\{\mathrm{ka}-\}$, el cual ha sufrido un proceso de reducción y de su forma se ha suprimido /k/, así:

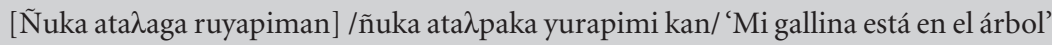


178

\section{Rasgos conservadores del quichua ecuatoriano}

Los morfemas independientes: validador $\{-\mathrm{mi}\}$, interrogativo

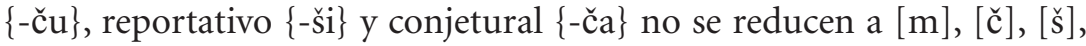
[ᄃ̌], respectivamente, cuando se juntan a palabras que termina en vocal. Así por ejemplo, en el quichua ecuatoriano el sufijo $\{-\mathrm{mi}\}$ se realiza como [mi], tanto después de consonante como después de vocal. No existe la diferenciación como en otros dialectos en los cuales, cuando la palabra a la que se añade termina en consonante, se realiza como [mi] y como $[\mathrm{m}]$ cuando aquella termina en vocal. En este caso, la forma ecuatoriana resulta ser conservadora. Por ejemplo:

\begin{tabular}{|lll|}
\hline Forma ecuatoriana & QIIA-QIIC & Glosa \\
Payka alli yayami kan & Payqa alli yayam kan & 'Él es un buen papá' \\
Payka yachachikmi kan & Payqa yachachikmi kan & 'Él es profesor' \\
Misimi chayta mikurka & Misim chayta mikurqa & 'El gato comió eso' \\
Kunturmi chayta mikurka & Kunturmi chayta mikurqa & 'El cóndor comió eso' \\
\hline
\end{tabular}

El mantenimiento, en todos los contextos, de la vocal en los morfemas posesivo-benefactivo $\{$-pak $\}$, afirmativo $\{-\mathrm{mi}\}$, reportativo $\{$-ši $\}$ y conjeturativo $\{$-ča $\}$ se puede considerar como un signo de conservacionismo frente a las hablas en las cuales, cuando la raíz a la que se adhieren termina en vocal, evolucionaron a formas con caída de la vocal de estos morfemas, dando lugar a las formas [p, m, š, č ], respectivamente, como ocurre en variedades del Perú.

\section{¿El ecuatoriano es una especie de koiné?}

Algunos lingüistas como Muysken, al analizar el léxico y también algunas estructuras del quichua ecuatoriano, llegan a sostener que el quichua ecuatoriano sería una koiné. Muysken argumenta sobre esta posibilidad de la siguiente manera: 
Koines $[s i c]$ se caracterizan lingüísticamente por una reducción morfológica y una nivelación o uniformización dialectal, y socio-históricamente por su origen en la expansión rápida de la lengua madre. Expansión rápida conduce a bilingüismo extenso y a un aprendizaje incompleto por hablantes de otras lenguas (1981, p. 18).

Esta hipótesis tendría cierta plausibilidad debido a los datos de documentos coloniales en los que se apoyan algunos autores para postular que el quichua fue introducido al Ecuador, fundamentalmente por los incas, en distintos momentos y con mitimaes de diferentes lugares del Perú. ${ }^{73}$ Además, en el léxico del quichua ecuatoriano existen términos provenientes tanto del QI como de las variedades del QIIA y QIIC. ${ }^{74}$

Muysken (1981, p. 7), al comparar los morfología del ecuatoriano con el cuzqueño, encuentra que hay coincidencia en varios morfemas: acusativo $\{$-ta $\}$; dativo direccional $\{$-man $\}$; ablativo $\{$-manta $\}$; locativo $\{$-pi\}, 'con' $\{$-wan $\}$, 'entre' $\{$-pura $\}$, 'a causa de' $\{$-rayku\}, 'hasta' $\{$-kama $\}$. Varios de estos son diferentes en el QI. Esta situación apoyaría el argumento de que el quichua ecuatoriano, a pesar de la distancia geográfica que separa a estas dos hablas, comparte con ellos nuestras similitudes.

73 Según Espinoza Soriano (1988), junto con las tropas de Túpac Yupanqui y de Huaina Cápac, vino un gran contingente de mitimaes del pueblo huayacuntu (Cajamarca, norte del Perú). Según este autor, Huaina Cápac dispuso que Carguatanta quedara al frente de los huayacuntu en Quito y luego que fue asesinado por los españoles, un descendiente suyo llamado Caxamarca llegó a ser curaca de los huayacuntu en Quito; este fue bautizado como Diego de Figueroa Caxamarca, aprendió a leer y escribir, a cantar y tañer instrumentos musicales, por lo cual fue escogido para ser preceptor en el colegio de naturales de San Andrés, en Quito. Al igual que este caso, seguramente hubo más mitimaes provenientes de otros lugares del Tahuantinsuyo que debieron haber influido en la conformación de las hablas del quichua ecuatoriano.

74 En el ecuatoriano no existe el fonema / $\hat{c} /$, sin embargo, en varias comunidades de la Sierra centro y norte existe la forma [kaĉa] 'costra', que según Parker (19631972/2013) se registra en Huailas QI y que sería parte del protoquechua. En otras comunidades, en cambio, dicen [karača], que provendría de [ ${ }^{*}$ qara-ča]. 
180

Sin embargo, Muysken no cree que el ecuatoriano esté directamente relacionado con el cusqueño:

Mi conclusión principal va a ser que el quechua ecuatoriano no tiene relación directa con el quechua cuzqueño o incaico, sino más bien ha pasado por un proceso de koinenización a base de variedades chinchay, la lengua general, además de tener influencia superestratal del quechua cuzqueño (1981, p. 1).

Según la hipótesis de Muysken, el quichua ecuatoriano estaría relacionado con el quechua sureño, a partir del cual el cuzqueño, tal como se lo conoce actualmente, se desarrolló con posterioridad a la llegada de los incas al Ecuador. Por esta razón no se puede considerar que el ecuatoriano sea "hijo" del cuzqueño. Una prueba de la relación del ecuatoriano con el sureño se puede observar en los siguientes morfemas:

\begin{tabular}{|c|c|c|c|c|}
\hline Morfema & QI & Sureño & Ecuador & \\
\hline Locativo & & $\{-\hat{c} a w\}$ & $\{-\mathrm{pi}\}$ & $\{-\mathrm{pi}\}$ \\
\hline Ablativo & & $\{$-piqta $\}$ & $\{$-manta $\}$ & $\{$-manta $\}$ \\
\hline Comparativo & $\{$-naw $\}$ & $\{$-hina $\}$ & $\{$-šina $\}$ & \\
\hline $1^{\circ}$ persona verbal presente & $\{-:\}$ & $\{-\mathrm{ni}\}$ & $\{-\mathrm{ni}\}$ & \\
\hline $2^{\circ}$ persona verbal pasado & $\{$-rqa-yki\} & $\{$-rqa-nki $\}$ & $\{-r k a-n k i\}$ & \\
\hline $1^{\circ}$ persona objeto & $\{-\mathrm{ma}\}$ & $\{-$ wa $\}$ & $\{w a\}$ & \\
\hline
\end{tabular}

Por el contrario, en cuanto al léxico — como se señaló en el capítulo 1, al tratar sobre las hipótesis del origen del quechua- se mencionó que existen algunos términos en los que el ecuatoriano coincide con el QI, mas no con el del Cuzco. Por ejemplo:

\begin{tabular}{|llll|}
\hline Léxico & QI & Cuzco & Ecuador \\
Agua & yaku & unu & yaku \\
Lluvia & tamya & para & tamya \\
Cuatro & chusku/trusku & tawa & chusku \\
Flor & wayta/sisa & t'ika & sisa \\
\hline
\end{tabular}


181

La discordancia entre las formas gramaticales y el léxico justificaría la idea de que el ecuatoriano es una especie de koiné. Sin embargo, para extraer conclusiones más plausibles tendrían que realizarse comparaciones con más ejemplos. Por el momento proponemos la ubicación de las hablas del quichua ecuatoriano al interior del grupo QIIB con la siguiente arborización del mismo: ${ }^{75}$

Figura 6

Ubicación del quichua ecuatoriano al interior de la rama QIIB

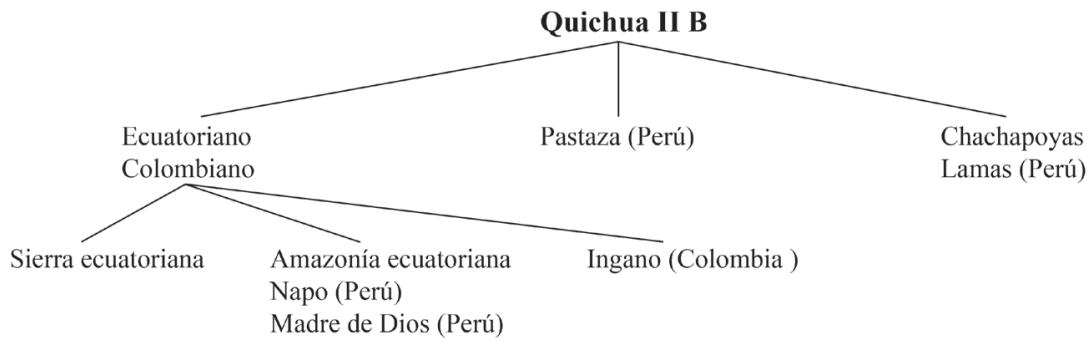

Fuente: el autor

Así, con los datos de Taylor $(1979,2000)$, se puede concluir que Chachapoyas se diferencia del resto por mantener la oposición č/ĉ, mientras el resto de hablas del QIIB no la mantiene. El habla del Pastaza $^{76}$ peruano se caracteriza, según Landerman (1973), por mantener, junto con los anteriores, las marcas posesivas. Ni las hablas ecuatorianas, ni el ingano de Colombia, como tampoco el napeño peruano, mantienen estas características. El ingano de Colombia ha fusionado los fonemas /š/ y /s/ en todos los contextos, según Tandioy (et al., 1978); en tanto que las hablas ecuatorianas y la napeña del Perú, mantienen la diferencia de esos fonemas en el léxico, excepto en los morfemas $\{$-špa $\}$

75 La variedad chincha de la costa centro-sureña del Perú, extinguida a fines del siglo XVI, también formaría parte del grupo QIIB.

76 No se ha conseguido información las características del quichua del río Tigre en el Perú, por lo cual no se lo ha incluido en el diagrama. 
182

y \{-ška\}, según se puede apreciar en Mercier $(1979,1983)$. Así pues, las hablas del Ecuador y el napeño peruano forman un conjunto dialectal. A este grupo habría que añadir, según Mercier (1983, p. 29), el habla de Madre de Dios, en el Perú, pues sus hablantes habrían sido llevados a ese lugar por los caucheros del poblado de Santa Rosa, que se hallaba ubicado en el Napo ecuatoriano. Este hecho habría ocurrido entre fines del siglo XIX y comienzos del XX.

La proximidad de las hablas ecuatorianas amazónicas con las del Napo-Perú y Pastaza-Perú, que se encuentran en el departamento de Loreto, puede deberse a la presencia por doscientos años de las misiones jesuitas de Maynas. Esta realidad se halla representada en un mapa de las misiones jesuíticas de Maynas elaborado por un misionero capuchino, Cabodevilla (1994, 104/2015, p. 146).

Figura 7

Mapa de las misiones jesuitas de Maynas

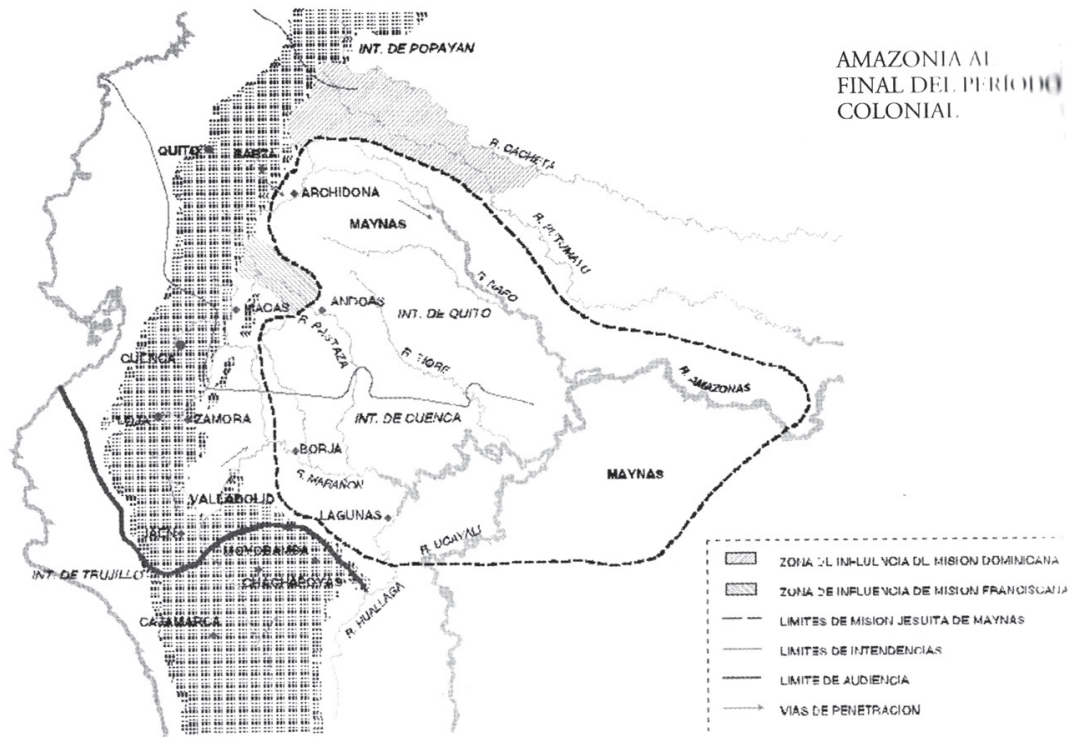

Fuente: Cabodevilla, 1995 
Seguramente por esta razón, en la primera página dedicada "Al lector" de la gramática de 1753, atribuida a Nieto Polo, denominada Breve instrucción o arte para entender la lengua común de los indios según se habla en la provincia de Quito, el autor subrayó lo siguiente:

Me dediqué a componer este Arte de la Lengua comun de los Indios de estas parte de Quito, y Maynas, para cuya composición me informe primero de alguno otro, que avia estado en Maynas, de cosas particulares, y dignas de apuntarse, para los que desean ir por alla, llevados de su zelo y fervor.

Vale anotar que los jesuitas misionaron Maynas desde comienzos del siglo XVII hasta su expulsión en 1767, por parte del rey Carlos III.

De las investigaciones de los autores mencionados se infiere que el ecuatoriano no está muy relacionado con las hablas de la Sierra central peruana (QI), a las cuales, a partir de fines del siglo XVI, las llamaron arbitrariamente chinchaisuyo. Tampoco está directamente relacionado con el cuzqueño actual. El quichua ecuatoriano estaría más relacionado con la variedad extinguida de Chincha, de la costa centro-sureña del Perú, descrita por el dominico Domingo de Santo Tomás. 



\section{Capítulo 4 \\ Estado de la cuestión sobre estudios dialectales del quichua ecuatoriano}

En este capítulo hacemos un recorrido por los trabajos del quichua que de alguna manera aportan datos sobre la variación dialectal del quichua ecuatoriano. Esto permite visualizar el estado de las investigaciones dialectales de la lengua y la complejidad de un proceso de estandarización escrita.

La documentación del quichua ecuatoriano es bastante tardía. De esta variedad no ha llegado hasta nosotros documentos del siglo XVI ni XVII. Se conoce que en Quito y en otros lugares de la Presidencia de Quito, desde fines del siglo XVI, en los medios eclesiásticos se cultivaba el quichua para las campañas de evangelización. Pero los textos para el estudio, al parecer, eran traídos de Lima y seguramente eran los textos “estandarizados” por el Tercer Concilio Limense de 1583. De tal manera que existen vacíos históricos para conocer cómo eran las hablas del quichua del actual Ecuador en esos dos primeros siglos de la Colonia. Solamente unas pocas obras sobre el quichua ecuatoriano del siglo XVIII han llegado hasta nosotros.

Solo en el siglo XIX se imprimió un importante número de obras que contienen las hablas de este quichua. En ellas se visualizan ya las características del quichua ecuatoriano en cuanto a vocabulario y aspectos gramaticales; aunque a nivel de textos catequéticos y de la liturgia se mantuvieron los textos coloniales elaborados en el Perú. Tal es el caso del Padrenuestro, señalado por Ortiz (2001, p. 64). Este autor trae la ver- 
sión de esta oración recogida por el padre Gassó a fines del siglo XIX en la Amazonía ecuatoriana y publicada en 1898. El texto de esta oración es idéntico al del Segundo Concilio Limense de 1567, ratificado por el Tercer Concilio de 1583. En esa versión se mantiene el nosotros exclusivo cuando eso, al parecer, había ya desaparecido en las hablas ecuatorianas, pues en el Pater Noster redactado en Ecuador Runacunapac Rezana Libro del padre Julio Paris (1892/1913, p. 57), ya no aparece el exclusivo $<$ ñucaicu $>$, sino únicamente el inclusivo $<$ ñucanchic $>$, que es el único plural de primera persona que se usa en las hablas ecuatorianas.

Con estos antecedentes, a continuación, revisamos autores y obras que han contribuido al conocimiento de la realidad dialectal de las hablas quichuas del Ecuador.

\section{Época colonial}

Se ha mencionado que fray Jodoco Rique escribió la Doctrina cristiana y sermones en lengua peruana (Rivet y Créqui-Montfort, 1951, p. 25). El padre franciscano Agustín Moreno, historiador, al hablar sobre los documentos que fray Jodoco Rique habría llevado en su traslado de Quito a Pasto en 1570, a la edad de 72 años, después de haber vivido en Quito y haber dirigido el colegio de San Andrés para hijos de caciques indígenas, dice:

Otros manuscritos que seguramente llevó consigo deben ser los también perdidos "catecismo y Oraciones en Lengua Quichua", "De la consolación del varón religioso, que es enviado a predicar a los gentiles", "De las obras de Misericordia y de las prácticas del Evangelio", "Sermones varios en Lengua quichua y castellana", y aún otros manuscritos, de cuya existencia nos habla el sobrino del propio fray Jodoco, Adriano van Marselaer, en una síntesis biográfica de su tío, en la cual afirma que esas noticias las llegó a conocer a través de un franciscano que fue enviado preso al convento de Malina, después de haber vivido en el Perú y certificaba haberlo conocido (Moreno, 1998, p. 364). 
También se dice que el padre Martín de Vitoria escribió un Arte y vocabulario de la lengua del inca (Rivet y Créqui-Montfort, 1951, p. 26). Pero estas obras escritas en el siglo XVI no han llegado a ubicarse. Tampoco se sabe si existieron alguna vez. De encontrarse alguna de estas obras se podría observar la variante dialectal a la que representaban.

A nivel del Perú, hasta el presente, la primera gramática del quichua que se conoce es la del dominico fray Domingo de Santo Tomás. Este autor es consciente de la existencia de variaciones dialectales, pero no realizó ninguna propuesta de clasificación dialectal para las zonas del Perú que recorrió. En su texto se limita a señalar que el quichua era usado en un espacio muy extendido:

Principalmente, si añadiéramos a esto que es lengua que se communicava y de que se usava y se usa por todo el señorío de aquel gran señor llamado Guaynacapa, que se estiende por espacio de más de mil lenguas en largo y más de ciento en ancho. En toda la qual se usava generalmente della de todos los señores y principales de la tierra, y de muy gran parte de la gente común della (1560/1995, p. 9).

Un documento en donde se menciona al quichua relacionado con Quito es la gramática del doctor Alonso de Huerta. Esta obra cataloga al quichua ecuatoriano dentro del grupo Chinchaysuyo, en oposición al imperial cuzqueño, cuando señala:

Aunque la lengua Quichua y General del inga es una, se ha de advertir primero que está dividida en dos modos de usar en ella, que son, el uno muy pulido que se habla en el Cuzco, Charcas y demás partes de la provincia de arriba, que se dice Incasuyo. La otra lengua es corrupta, [que] la llaman Chinchaysuyo, [y] no se habla con la pulicía [el cuidado] y congruidad [congruencia] que los ingas la hablan. Y aunque hasta aquí no se ha enseñado documentos para hablar la lengua Chinchaysuyo, en este arte iré enseñando algunos para que se entienda la diferencia que hay de hablar entre las dos Provincias, que empiezan, la del inga desde Huamanga arriba, y la Chinchaysuyo desde allí abajo hasta Quito (1616/1993, p. 18). 
188

Según este dato, el QI estaría ubicado dentro de la variedad chinchaisuyo. Sin embargo, como se señaló en el capítulo anterior, esto no es exacto.

Juan de Figueredo (1619/1991), en la tercera edición del Arte de la lengua quichua del padre Diego Torres Rubio, trae un vocabulario chinchaisuyo de 135 palabras. De las cuales menos de la mitad son conocidas actualmente en el Ecuador.

Los documentos en donde se puede encontrar información sobre las hablas del quichua ecuatoriano corresponden recién al siglo XVIII. De este siglo se conoce la pastoral y el catecismo de Luis Francisco Romero, $14^{\circ}$ obispo de Quito, redactado en el dialecto del Ecuador, ${ }^{77}$ el 30 de agosto de 1725. Esta carta pastoral del obispo Romero contiene el Catechismo para instruir á los rudos en el misterio de la santissima eucharistia. El catecismo bilingüe quichua-castellano está conformado por 19 preguntas con sus respectivas respuestas.

Aparte de ese documento, del siglo XVIII se conocen otros tratados. Así, se tiene La breve instrucción o arte para entender la lengua común de los indios, según se habla en la provincia de Quito de 1753 atribuida a Tomás Nieto Polo del Águila, oriundo de Popayán quien fue provincial de los jesuitas de Quito al momento de la publicación de este documento.

El padre Grimm, en el "Prólogo" a su Vocabulario español-quichua en 1896, antes de transcribir dicho catecismo realiza un comentario útil para la dialectología del quichua ecuatoriano. Sobre la escritura de los fonemas /s/ y /š/, en la obra del obispo Romero dice:

77 El texto de la pastoral del obispo Romero de 1725 al que se ha tenido acceso es el que reprodujo Grimm en su obra de 1896. Se conoce que este catecismo también fue reproducido en la revista El Oriente Dominicano, publicada en Quito en la década de 1930, y en la Bibliographie des langues aymará et kičua (Rivert y CréquiMontfort, 1951, vol. 1, p. 141). 
189

Al mismo tiempo nos da este Catecismo una idea de la forma que el quichua tuvo en la primera mitad del siglo pasado. No hemos cambiado el modo de escribir las palabras quichuas, aunque muchas veces es diferente la escritura que hemos adoptado en la Gramática. Por lo que hace á la manera de escribir el quichua y á la sustitución de letras entre si, se ha dicho lo necesario en la Introducción á la Lengua Quichua. Tan solo observaremos para mejor inteligencia del Catecismo que los antiguos escribían los sonidos s y sh con el único signo s; así está escrito en nuestro Catecismo sina, etc., en lugar de shina, etc. (Grimm, 1896, pp. XXX-XXXI).

La observación de la escritura hecha por Grimm sobre la representación con la misma grafía $<\mathrm{s}>$ para /s/ y /š/, para el catecismo del obispo Romero, también es válida para el arte atribuido a Nieto Polo.

Otros textos del siglo XVIII son el Vocabulario de la lengua índica, de Juan de Velasco de cerca de 1787. El denominado "Anónimo de Praga", que lleva el título de Breve inst[r] uccion o arte para entender la lengua común de los indios. El Arte de la lengua jeneral de Cuzco llamada quichua que según Dedenbach-Salazar, reposa en el Archivo Nacional de Bogotá. ${ }^{78}$ Estos tres últimos sí emplean la grafía $<$ sh $>$ para representar a /š/.

\section{Época republicana}

A fines del siglo XIX y en las primeras décadas del siglo XX floreció un grupo de autores que escribieron sobre el quichua del Ecuador, los principales fueron: Lobato, Paris, Grimm, Cordero y Guzmán. De

78 El padre Gonzalo Ortiz Arellano, de la Orden de los Redentoristas, en su obra El quichua en el Ecuador: ensayo histórico-lingüistico pone en duda que el Arte de la lengua jeneral publicada por Dedenbach-Salazar sea del siglo XVII ni de ningún otro siglo del quichua ecuatoriano ( $c f$. Ortiz, 2001, pp. 41-43). Su argumentación es que la grafía $<$ sh $>$ solo aparecen en textos del quichua ecuatoriano de mitad del siglo XVIII y contiene un número importante de vocabularios que no son conocidos en los dialectos del Ecuador. 
190

ellos, para la cuestión dialectal, Cordero y Grimm son de mayor interés porque traen algunos datos al respecto. Los trabajos de Paris, Lobato y Guzmán no especificaron a qué dialecto representaban y por eso tienen menos utilidad para estudiar la dialectología. Parece que ellos trataron de hacer obras más generales que sirvan para la evangelización de los indígenas de toda la Sierra, en tanto que Cordero hizo su trabajo por un interés más cultural que religioso. Él era un civil ilustrado.

En la segunda mitad del siglo XX se incrementaron los estudios relacionados con el quichua ecuatoriano, por parte de ecuatorianos y extranjeros. A continuación presentamos los aportes que las diferentes obras han hecho para el estudio de las variaciones dialectales del quichua de Ecuador según el orden cronológico de su publicación.

\section{Luis Cordero}

Este autor elaboró un diccionario tomando como base el dialecto del Azuay (1892/1989). ${ }^{79}$ Aunque Cordero no establece comparaciones dialectales, su diccionario ha servido de referencia para autores como Parker al momento de realizar su clasificación dialectal del quichua ecuatoriano. El autor expresamente señala que su obra contiene el dialecto del Azuay.

En las breves nociones gramaticales concernientes al idioma quichua que pone al inicio de su obra, señala que es necesario emplear las letras $<\mathrm{zh}, \mathrm{z}>$ para los sonidos del quichua que se habla en esa región. En su léxico incluye 26 palabras que comienzan con $<\mathrm{zh}>$ y 14 con $<\mathrm{z}>$. Estas, al parecer, son sustratos del cañari, excepto $<$ zarca $>$ que proviene del hispano-árabe <zarco, zarca > 'persona de ojos azules'.

79 Luis Cordero nació en Déleg (prov. de Cañar) y posteriormente fue a Cuenca (prov. de Azuay), por lo cual su diccionario es representativo de las hablas de la Sierra sur del Ecuador. 


\section{1}

\section{Juan M. Grimm}

El sacerdote alemán Grimm escribió un par de obras sobre el quichua ecuatoriano a fines del siglo XIX (1896) y comienzos del XX (1903). Escribió una gramática que incluye un vocabulario quichua-español y un vocabulario español-quichua. Además, publicó un vademécum para párrocos de indios quichuas. La primera obra es la que nos interesa para la dialectología. Él dice que cuando ya estaba impresa la primera sección —esto es el vocabulario quichua-español— encontró nuevos términos quichuas, particularmente del Oriente, que los incluyó como apéndice antes de la sección español-quichua (La lengua quichua: dialecto de la república del Ecuador, 1896). Mientras los otros autores presentan sus gramáticas y diccionarios sin preocuparse por las variaciones dialectales, Grimm hace mención a algunas diferencias entre las hablas de la Sierra y la Amazonía. Así, en la introducción a su gramática dice:

El dialecto de Quito hablan todavía casi medio millón de indios entre las dos cordilleras de los Andes desde el $4^{\circ}$ grado de latitud meridional hasta $1 / 2$ grado de latitud septentrional y en las llanuras superiores del río Napo; pero con la diferencia de que los indios del Napo hablan el dialecto de Quito en su forma antigua, aunque ya empiezan también a sustituir la $\mathbf{p}$ con la $\mathbf{b}$ y la $\mathbf{t}$ con la $\mathbf{d}$; mientras los de entre las cordilleras lo hablan adulterado. Esta decadencia consiste primero en que el idioma degenera de suyo mismo: si comparamos, por ejemplo, el idioma como lo enseña la "Breve instrucción para entender la lengua común de los indios, según se habla en la provincia de Quito", con el actual, observamos ya perdido en siglo y medio el uso del plural inclusivo y exclusivo y disminuido mucho el uso de la conjugación de complemento personal y de las formas verbales que sirven para expresar los pronombres posesivos. Además los indios han perdido el conocimiento de muchas palabras del dialecto antiguo de Quito. Fuera de esto emplean apócopes, principalmente en el gerundio (Grimm, 1986, p. VI).

En esta obra de Grimm también se encuentra una compilación de algunas piezas literarias en quichua, principalmente las escritas por Luis Cordero, con notas de pie de página, en las cuales señala algunas 
192

especificidades dialectales del habla quichua de la provincia de Azuay, que está en la Sierra sur del Ecuador. Además, incluyó un apéndice con léxico propio de la Amazonía ${ }^{80}$ y alguna información de variación dialectal entre el habla de la Sierra y el dialecto de Tena, en la Amazonía. Así, por ejemplo, nos da a conocer que en el habla de Tena, en el siglo XIX, ya se empleaba la variante [ra] para el morfema del acusativo $\{$-ta $\}$.

\section{Agustín María León}

En la década de 1930, el padre León publicó por entregas sucesivas en la revista El Oriente Dominicano el Compendio de gramática quichua, basado en el quichua de Canelos (río Bobonaza, prov. de Pastaza, Amazonía ecuatoriana). Sobre la dialectología, el autor dice: "Es el mismo dialecto de los pueblos indígenas de la sierra, con algunas excepciones que van anotadas en su lugar" (León, 1937, p. 202). Entre algunas de las notas sobre la variación dialectal señala la fusión del morfema independiente de afirmación $\{-\mathrm{mi}\}$ con el verbo 'ser' $\{\mathrm{kay}\}$, produciéndose un apócope del morfema independiente y una aféresis del verbo, con lo cual, por ejemplo, la expresión <allimi kan> 'está bien' se transforma en [aliman]. También hace notar la síncopa del morfema de pasado $\{-$ rka- $\}$ para transformarse en [ra]. Al respecto, el padre León señala: "En Canelos y pueblos del Bobonaza dicen: mani; mangui; man y usan el carani en lugar de la formula general carcani, y eluden siempre la c después de r" (León, 1937, p. 241).

\section{Ellen Ross}

Esta misionera evangelista había aprendido el quechua en Bolivia, luego vino al Ecuador, donde aprendió el quichua de la provincia de Chimborazo y recorrió algunos lugares de la Sierra ecuatoriana.

80 El léxico de la Amazonía registrado por Grimm dice haberlo tomado de un Vocabulario inga-español, cedido por los padres de la Compañía de Jesús de Quito. Era de esperarse que este texto estuviera en la biblioteca de los jesuitas de Cotocollao, pero hasta el presente no se ha podido localizar. 


\section{3}

Ella escribió dos obras relacionadas con el quichua. Según Richard A. Aschmann, ${ }^{81}$ quien reeditó en versión electrónica la obra de Ross en 2009, vivió solo un año en el Ecuador, en 1958 o 1959.

Ross elaboró un método bilingüe quichua-inglés y también un diccionario quichua-inglés, basándose en el dialecto de la provincia de Chimborazo, para que los religiosos evangélicos pudiesen aprender la lengua indígena.

En su método bilingüe, la autora enumera siete dialectos quichuas de la Sierra ecuatoriana: Colta, Pulucati y Caliata (prov. de Chimborazo), Calderón (prov. de Pichincha), Agato (prov. de Imbabura y asociado con el de Cayambe que está en la prov. de Pichincha), Cuenca (prov. de Azuay) y Saraguro (prov. de Loja). En la presentación de su método señala algunos ejemplos de variaciones dialectales al decir:

The dialect variation which your language helper points out will seem much less confusing if you learn to sort them out into several different categories. Some will be merely a sound level (for example, a certain sound used in CHQ may always be changed into another sound in Imbabura), Others will be on the suffix level, as when a certain suffix is pronounced one way in Colta but another way in Pulucate. Still other changes will be on the level of vocabulary, as when a word that is often used in Colta is substituted by another in Pulucate. Still others will be on the level of grammar, and others in the matter of style. In this lesson only the first two kinds of dialect variations appear.

$\mathbf{L l}$ is in CHQ, Imbabura, Salasaca and Pichincha always pronounced like the $z h$ in "azure".

81 Aschmann realizó la traducción al castellano de la gramática quichua-inglés de Ross en 2009. Esta obra, antes que una gramática, es un método para aprender la lengua por parte de personas de habla inglesa. Sobre la obra dice la autora en su prólogo: "This course has been prepared with a view to providing a concise but comprehensive teaching guide for missionaries wishing to learn Ecuadorian Highland Quichua” (Ross, 1958-1959/2009, p. v). 
194

Imbabura also pronounces it this way. However, in many words that have $\mathbf{l l}$ in $\mathrm{CHQ}$, Imbabura has a simple $\mathbf{l}$. This occurs when the CHQ 11 is followed immediately by the vowel $\mathbf{I}$, or by a consonant. Thus, CHQ alli "good" is ali in Imbabura, and CHQ allcu "dog" is alcu in Imbabura. The $\mathbf{c}$ in cangui and Cana becomes $\mathbf{g}$ in Pichincha and Salasaca.

The suffix -lla occurs in allilla, "Well", (although for the present it is not being studied in detail). In Pulucate, Caliata and Flores (in Chimborazo), and in Pichincha it is pronounced (and spelled) -la (Ross, 1958-1959/2009, pp. 1-2, 1-3).

En su obra, la autora estableció en primer lugar el quichua de la Sierra centro (CHQ) integrado por Colta, Pulucate y Caliata. En segundo lugar señaló el dialecto Calderón y el dialecto Imbabura/Cayambe. ${ }^{82}$ En tercer lugar, el quichua de la Sierra sur (SHQ) integrado por Azuay y Saraguro. Ella no hace referencia a otras hablas de la provincia de Chimborazo ni tampoco a las de las provincias de Cotopaxi, Bolívar y Cañar. De Tungurahua solo menciona a Salasaca, que apenas es una parte de esta provincia. Sin embargo, la clasificación de los dialectos quichuas señalada por Ross fue un antecedente de la clasificación del quichua ecuatoriano en dialectos centrales y dialectos no centrales que posteriormente hicieron algunos lingüistas en la siguiente década.

\section{Gary Parker}

En 1969, Parker presentó un estudio de la evolución de lo que él denomina QA en el cual muestra una clasificación dialectal tentativa del quichua ecuatoriano. Esta clasificación se basó en la información de trabajos anteriores relacionados con el quichua de Ecuador (Cordero, 1892/1955; Orr, 1965; Paris, 1892/1924; Ross, 1958-1959/2009). Sobre los dialectos de Ecuador, Parker dice:

82 La autora no denomina - como podría haberse esperado- NHQ a los dialectos de Calderón, que están en el centro de la provincia de Pichincha, y al de Agato/ Cayambe (Agato está en la provincia de Imbabura y Cayambe al norte de la provincia de Pichincha). 
195

Chart III shows a tentative identification and subgruping of Ecuadorian dialects based mainly on data from Cordero 1955 for southern Highland, Ross 19?? and 196? For Central and Northern Highland, and Orr and Wrisley 1965 for Jungle. So great are both the amount of dialect diversification in Ecuador and the size of the geographical area involved that much systematic dialectological field work must be carried out before a comprehensive statement of the Ecuadorian Quechua situation can emerge (Parker, 1969, p. 154).

A partir de lo que denomina un "proto-ecuatoriano", Parker separa dos ramas de dialectos: Sierra y Amazonía. Luego a los dialectos de la Sierra los clasifica en dos subramas: central-norte y sur. Asimismo, al central-norteño lo divide en norteño y central. Luego, al norteño lo clasifica en Agato y Calderón, y al central en Colta y Pulucate-Caliata. Finalmente, estos últimos son subdivididos en Pulucate y Caliata. Además, el sur es clasificado en Saraguro y Azuay. Por otra parte la rama de la Amazonía se subdivide en Bobonaza-Tena y Limoncocha. Finalmente, Bobonaza-Tena se subdivide en dos.

Figura 8

Clasificación dialectal del quichua ecuatoriano

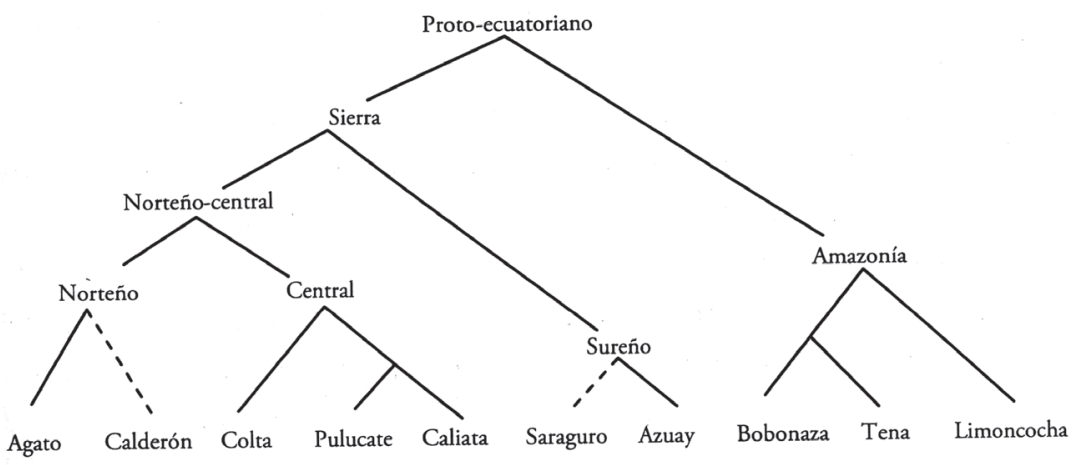

Fuente: Parker, 1969, p. 157; 2013, p. 151 
196

Como se puede apreciar en la figura, en el caso de la Amazonía, Parker se apoyó en la información de Carolyn Orr (1965), en tanto que para la Sierra tomó en consideración los trabajos de Ellen Ross. Lo interesante de la propuesta de Parker es que intenta hacer una clasificación integral, tanto de los dialectos de la Sierra cómo los de la Amazonía, que hasta ese entonces se habían tratado por separado. Sin embargo, por obvias razones de información, en esta propuesta - principalmente en el caso de la Sierra- solo tomó en consideración tres hablas de la provincia de Chimborazo (Colta, Pulucate y Caliata), una de la provincia de Imbabura (Agato), una de la provincia de Pichincha (Calderón), una de Azuay y una de Loja (Saraguro), quedando por ubicar las hablas de las provincias de Cotopaxi, Tungurahua y Bolívar, el sur de la provincia de Chimborazo y la provincia de Cañar.

A pesar de las limitaciones de la época, un aspecto importante a tomar en cuenta es que poco a poco se fue consolidando la idea de clasificar los dialectos de la Sierra en: norteño, central y sureño. Esto será retomado por Peter Cole (1985) y reformulado después por otros autores como Carpenter (1982).

\section{Alfredo Torero}

En su trabajo "Los dialectos quechuas" (1964/2003), con la información bibliográfica de Paris (1892/1924), Grimm (1896), Cordero (1892/1955) y Guzmán (1920), ubicó al quichua (quechua) ecuatoriano, junto con el Ingano de Colombia, en el grupo IIB. Señaló que este dialecto en lo fonológico y lo gramatical estaba a un paso intermedio entre el IIA y IIC. ${ }^{83}$ Observó que una de las características de la variedad ecuatoriana es la sonorización de las oclusivas y africadas orales tras /n/ en el interior de palabra, y señaló otras características como: 
Se habla en los valles interandinos y en el Oriente ecuatorianos. Tiene numerosas variedades cuyas características separadoras no conocemos suficientemente. Ha puesto en desuso los morfemas de persona poseedora que expusimos páginas antes, maneja solo un morfema de plural personal, sin distinción de "inclusivo" y "exclusivo" [...]. Para el "durativo" emplea el morfema /-ku-/. Parecen estar cercanamente emparentadas con los dialectos ecuatorianos las hablas de Colombia (donde el "Ingano" no distingue $* / \mathrm{s} / \mathrm{y} / \mathrm{sh} /, \mathrm{y}$, tal vez, las de la provincia peruana de Maynas (Loreto) utilizadas a lo largo del río Napo (Torero, 1964/2003, p. 55).

De las características del quichua ecuatoriano señaladas por Torero, la sonorización de las oclusivas y africadas después de nasal es parcialmente exacta, pues no se da en todo el léxico de Cañar, Azuay y Loja; pues se mantiene la sordez en términos como [inti] inti 'sol', [yanta] yanta 'leña'. El fonema / $\mathrm{k}$ / es el que más se sonoriza después de $/ \mathrm{n} /$, pero $/ \mathrm{p} / \mathrm{y} / \mathrm{t} / \mathrm{se}$ mantienen como sordas, principalmente en los morfemas. La sonorización de las africadas /č/, y / $\$$ / después de nasal/n/, solo se da en algunos dialectos de las provincias de Imbabura, Cotopaxi, Tungurahua y Chimborazo. En los demás dialectos no se sonorizan las africadas.

En cuanto a la no distinción entre plural inclusivo y exclusivo, la afirmación de Torero es correcta, según ya había sido anotado por autores como Grimm (1896). El uso del morfema \{-ku\} como durativo es igualmente correcta. Por lo demás, el autor menciona que hay varios dialectos, pero no señala cuales son. Textualmente dice:

Ecuador-Colombia. Se presenta con numerosas variedades que no se han deslindado aun suficientemente [...]. Las variedades del oriente ecuatoriano han avanzado al parecer hasta el curso alto y medio del río Napo y quizá hasta otros afluentes septentrionales del río Amazonas (Torero, 2002, pp. 83-84).

En la bibliografía de su obra de 1964 no están las obras de Ellen Ross y en la bibliografía de sus trabajos posteriores, incluida su última obra de 2002, tampoco se menciona las obras de Ross o Carolyn Orr. 
198

Posiblemente debido a que no pudo revisar los trabajos de esas autoras, Torero no propuso una clasificación dialectal interna para el quichua ecuatoriano. A diferencia de Torero, Parker sí conoció los textos de Ross y Orr, y los tomó en cuenta en su propuesta de clasificación dialectal.

Torero ubicó a todas las hablas del quichua ecuatoriano junto con el ingano de Colombia en el grupo IIB. Esto se puede apreciar en la Figura 3 (cf. cap. 3).

\section{Carolyn Orr}

Esta autora publicó en 1965 el Vocabulario quichua del Oriente, en cuya presentación ya mencionaba que existían tres dialectos en la Amazonía ecuatoriana que son: Bobonaza, Tena y Limoncocha. En 1978 publicó un pequeño folleto con los resultados de su investigación sobre dialectos quichuas, elaborado a partir de un borrador de 1973. En este trabajo clasifica al quichua del Ecuador en dialectos de la Amazonía y dialectos de la Sierra. Su estudio dialectal pone énfasis en los tres de la Amazonía ya mencionados (ver cita más abajo). De la Sierra no hace una clasificación dialectal, pero en un glosario de 284 palabras que incluye en su folleto, trae variaciones fonéticas de ese corpus léxico en las provincias de Imbabura, Pichincha, Chimborazo, Cañar y Azuay que están en la Sierra y de las provincias de Pastaza y Napo en la Amazonía. ${ }^{84}$ Sobre los dialectos de la Amazonía dice:

En el Oriente ecuatoriano, hay tres principales dialectos quichuas: uno en la provincia de Pastaza, y los otros dos en la provincia del Napo. Al primero lo llamaremos Pastaza; se localiza alrededor del Puyo, y a lo largo de los ríos Bobonaza, Conambo y Curaray. El segundo lo llamaremos Tena; se ubica alrededor de Tena, Archidona y Arajuno, y por el bajo Napo hasta Yurallpa. Al tercer dialecto lo llamaremos Napo; se extiende

84 Con posterioridad a 1978, fecha de publicación de la obra de Orr, la provincia de Napo fue dividida en dos nuevas provincias: Sucumbíos y años después Orellana. 
desde Loreto y Aquila por los ríos Payamino y Coca, y desde la desembocadura de dichos ríos en el Napo, y hasta Rocafuerte [se refiere a Nuevo Rocafuerte, pues hay un Rocafuerte que está más abajo, en el mismo río Napo, pero en territorio peruano]. Este tercer dialecto se habla también a lo largo de los ríos Putumayo y bajo Aguarico (Orr, 1978, p. 6).

En su trabajo de 1978, Orr sustituyó la nomenclatura de los dialectos de la Amazonía que había propuesto en 1965. En aquella época los había denominado dialectos Bobonaza, Tena y Limoncocha. En este nuevo trabajo ella habla de tres dialectos que son: Pastaza, Tena y Napo. Reemplazó Bobonaza por Pastaza, Limoncocha por Napo y mantuvo el nombre del dialecto de Tena. Estos cambios de denominación de los dialectos muestran una mejora en la precisión de su ubicación. Efectivamente, el nombre de Bobonaza no representaba a las hablas de los ríos Conambo y Curaray que son afines y están también en la provincia de Pastaza. Sin embargo, el nombre de Pastaza tampoco es exacto, pues Arajuno está en la provincia del río Pastaza, pero es un habla más afín con Tena, que está en la provincia de Napo. Igualmente, el cambio de nombre del dialecto de Limoncocha por Napo era necesario, pues sus habitantes tienen el mismo dialecto que los de Tena, por lo tanto, había que buscar un nuevo nombre para la variante que estaba en el río Napo medio. Con todo, el término Napo tampoco representa a las hablas quichuas del río Putumayo. En consecuencia, está pendiente buscar nombres más apropiados para denominar a los dialectos de la Amazonía. En los estudios lingüísticos, con frecuencia, existen problemas entre la jurisdicción política y la realidad dialectal.

Las variaciones morfofonémicas del quichua de la Amazonía ecuatoriana estudiadas por Orr tienen que ver con la conducta de los siguientes sufijos: $\{$-pi\} 'locativo', $\{-\mathrm{ku}$ - $\}$ 'progresivo', $\{$-shka\} 'indicador de acción completa', $\{$-shpa $\}$ 'mismo sujeto', $\{-\mathrm{kppi}\}$ 'cambio de sujeto', $\{$-yuk $\}$ 'posesor', \{-pa\} 'posesivo', \{-kuna\} 'plural', $\{-y\}$ 'imperativo', $\{$-naya- $\}$ 'desiderativo', \{-ta\} 'complemento directo', $\{$-rka- $\}$ 'pretérito', $\{$-nkuna $\}$ 'tercera persona plural', $\{$-naku-\} 'recíproco', $\{$-nkapak\} 'propositivo'. No obstante de dicho avance, quedaba por investigarse las variaciones de la 


\section{0}

mayor parte de los morfemas del quichua amazónico ( $c f$. cap. 5 para las variaciones amazónicas de los morfemas).

\section{Pieter Muysken}

Este autor viene estudiando el quichua de Ecuador desde mediados de la década de 1970. Muysken sugiere que su trabajo es el comienzo de una línea de investigaciones que se podría realizar en el futuro, sobre la morfofonémica; cuando dice:

The following section presents an informal account of the different phonological changes which the suffixes of EcQ have undergone. In most cases, such as voicing and vowel changes, similar but less regular changes also affect the EcQ lexicon. These will not enter into consideration here (Muysken, 1977, p. 10).

Hizo algunas aportaciones al estudio dialectal del quichua de la Sierra ecuatoriana. En su obra presenta las variantes morfofonémicas en el dialecto de la Sierra centro de los morfemas: $\{$-pi $\},\{$-kama $\},\{-k u n a\},\{-$ ta $\}$, $\{$-pak $\},\{$-man $\},\{$-rka $\},\{$-gri $\},{ }^{85}\{$-shpa $\},\{\mathrm{kpi}\}$ y $\{$-pish $\}$. Aparte de ello, señala la variación de 11 vocablos quichuas: "sumak, kunan, yawar, hayak, illakta, yachak, ñan, chay, shamuy, tukuy, ñaubay” (cf. Muysken, 1977, pp. 10-14).

\section{Laurence K. Carpenter}

A partir de la década de 1970 se realizan algunas tesis de lingüística en universidades extranjeras, sobre algunas hablas locales del quichua ecuatoriano. Así, Beukema (1975) realiza una descripción gramatical del quichua de Chimborazo como tesis para la Universidad de Yale. Lombeida-Naranjo (1976) realiza un estudio fonológico de la Sierra como tesis doctoral para la Universidad de Texas. Igualmente, Consuelo Yánez, de la PUCE, realiza en esta década estudios sobre la fonología del quichua en los dialectos de Chimborazo, Imbabura y Loja.

85 Muysken presenta como /-gri/ al morfema $\{-k r i\}$ (1977, p. 14). 
En este contexto, Carpenter llega al Ecuador procedente de Estados Unidos, como integrante del Cuerpo de Paz. Inicia su aproximación al quichua con Louisa Stark a inicios de la década de 1970. Aparece como coautor de El quichua de Imbabura: una gramática pedagógica. Este texto estuvo destinado a la enseñanza del quichua y fue elaborado con Stark (1973).

En el prefacio de dicho texto, los autores señalan que existen cinco subdialectos en la provincia de Imbabura:

Para el desarrollo de este libro nos hemos basado en el dialecto Quichua de la Provincia de Imbabura, ubicada en la Sierra norte del Ecuador. Este dialecto se divide en cinco subdialectos los mismos que se hablan en las siguientes zonas: 1. Desde Cayambe por San Pablo y desde el este de Imbabura a Angla, Zuleta, Angochahua y Rinconada, y desde estas comunidades hasta Mariano Acosta y Pimanpiro; 2. La comunidad de San Rafael; 3. La zona de San Rafael al norte hasta San Roque en el lado oriental del Río Ambi; 4. Al norte de San Roque hasta San Antonio de Ibarra en el lado oriental del Río Ambi; 5 . Al norte de San Rafael y al oeste del Río Ambi por las faldas de Cotacachi. Cada zona se distingue de las otras por diferencias menores en cuanto al habla (pronunciación, gramática y vocabulario) y en la manera de vestir (Stark y Carpenter, 1973, p. I).

Aquí los autores señalan los lugares que integran los subdialectos de Imbabura, pero no especifican en qué consisten las diferencias dialectales, se limitan a decir que su gramática pedagógica se basa en el subdialecto 3, particularmente en el habla de Miguel Andrango Concha y Carlos Conterón Córdova, de Agato e Ilumán, respectivamente, y que hay diferencias de pronunciación, gramática y vocabularios, pero no señalan ni un solo ejemplo concreto de tales variaciones. A pesar de ello, el dato de que al interior de una misma provincia existen varios dialectos plantea la inquietud de investigar el mayor número de ellos para tener un mapa dialectal más completo de la región. 


\section{2}

Figura 9

Los cinco subdialectos del quichua de Imbabura

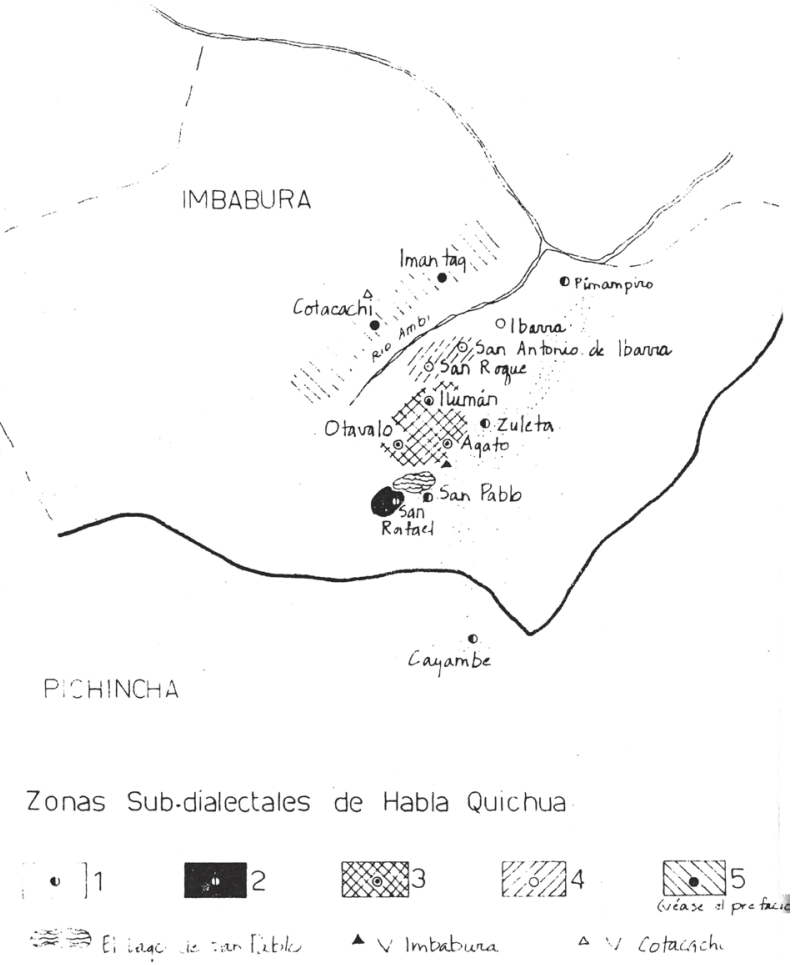

Fuente: Stark y Carpenter, 1973, p. VI

Después de haber trabajado con Louisa Stark, Carpenter visitó otros lugares de habla quichua, principalmente de la Sierra y la Amazonía, para realizar su tesis doctoral. Los lugares recorridos son las provincias de Imbabura, Pichincha, Cotopaxi, Tungurahua, Chimborazo, Bolívar, Cañar, Azuay, Loja, Napo y Pastaza. En su tesis ofrece una síntesis de sus investigaciones bibliográficas, principalmente del período 19501980, luego se centra fundamentalmente en dos aspectos: la descripción de tres niveles de la lengua (fonología, morfología y sintaxis) basándose 


\section{3}

fundamentalmente en el habla de la provincia de Imbabura — que fue su centro de operaciones- y su estudio de las variaciones dialectales.

Sobre los niveles de la lengua, Carpenter repite el trabajo que ya otros autores revisados por él habían hecho. Su cuadro fonológico ( $p h o-$ nemic chart) presenta 33 unidades, pero sin incluir pares mínimos para justificarlos, de las cuales cuatro aparecen entre paréntesis porque considera que provienen del español. Estos son: /b, d, g, ř/. Incluye también un fono fricativo bilabial sordo y una unidad oclusiva palatal sorda distinta de /č/ y de / $\$$ /, sin justificar con pares mínimos. El número elevado de fonemas señalados por él dista del número que realmente tiene el quichua ecuatoriano, pues incluyendo los fonemas aspirados y los de sustrato /z, ž/, apenas llegarían a 24 . De otro lado, en lo relacionado con la morfología, hace una descripción de los morfemas de la lengua. De cada morfema señala dos o tres ejemplos para mostrar su uso, pero sin preocuparse por las variaciones morfofonémicas. Por último, en lo que corresponde a la sintaxis, presenta los constituyentes de la oración, la expansión del nombre y la expansión del verbo.

En cuanto a la variación dialectal, ${ }^{86}$ afirma que los 14 dialectos del quichua ecuatoriano se puede agrupar en dos: el central y el no central. De estos dos grupos, el dialecto denominado central es el más innovador.

Within Ecuador, Quichua exhibits variation at the phonological, morphological, syntactic, and lexemic levels. There are at least 14 dialects of Ecuadorian QIIB subdivided into two major groups, central and non-central. The central varieties exhibit a substantial amount of innovations and variation and most of these dialects probably have their origin in the varieties of Quechua spread by de Chinchay (Carpenter, 1982, p. 41).

86 En el texto de Carpenter (1982), los capítulos que se refieren a los aspectos dialectales y a la sintaxis son los más cortos de todos. Y a pesar de que en el capítulo sobre la dialectología hay mapas de algunos alófonos de los fonemas, incluye muy pocos ejemplos ilustrativos de tales variaciones dialectales. 


\section{4}

Figura 10

Dialectos ecuatorianos según Carpenter

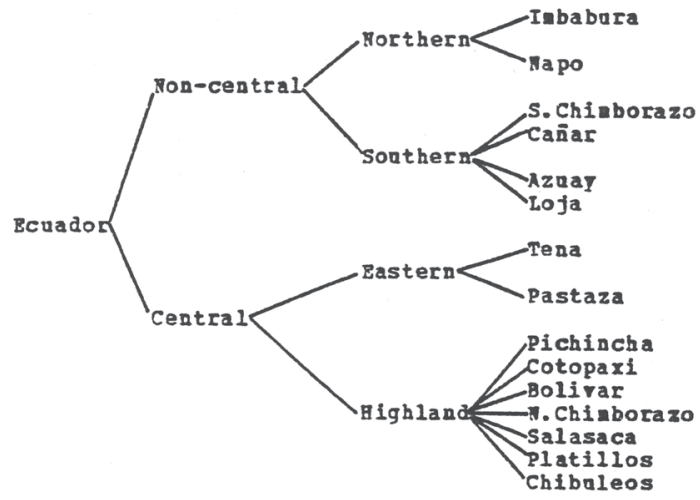

Fuente: Carpenter, 1982, p. 42

Figura 11

Dialectos del quichua ecuatoriano según Carpenter

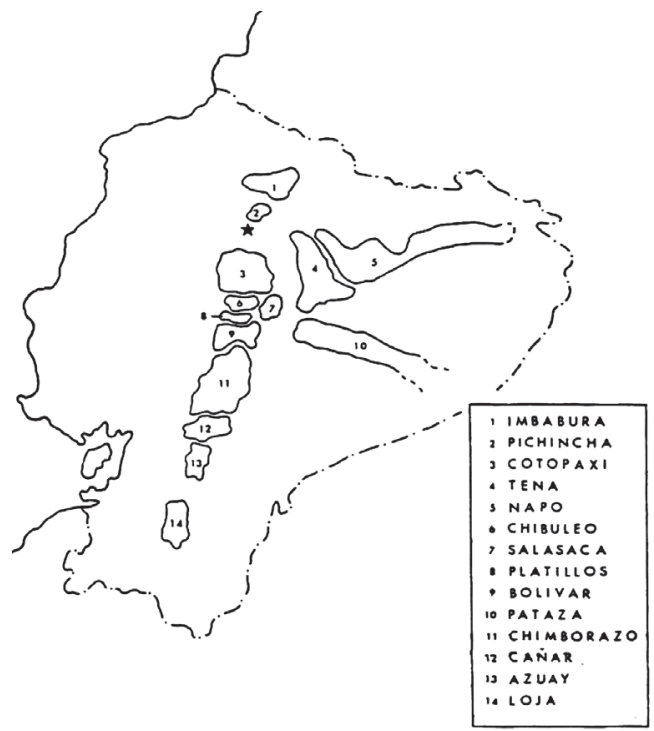

Fuente: Carpenter, 1982, p. 21 


\section{5}

Sobre los "aspectos de dialectología", sostiene que los quichuahablantes de los dos dialectos mayores (central y no central) prefieren comunicarse no en quichua, sino en español.

When Quichua speakers from these two major dialect areas attempt to communicate across the major division boundaries, it is usually carried out in Spanish (or another indigenous language) rather than Quichua. In some cases, the central and the non-central dialects are mutually unintelligible across the major boundary divisions. For example, consider the following utterances, both glossed as 'it is well.'

ali.mi (Imb.)

[alími]

Alli.lladi mi.shka (Tsl.)

[ažižadi míška]

With such variation, bilingual Quichua speakers from these areas consider the other dialects of Quichua to be 'scrambled,' 'mixed.' Or 'not for understanding.' Such bilingual speakers will communicate in Spanish when possible (Carpenter, 1982, pp. 355-356).

La afirmación de Carpenter de que los dos dialectos el central, y el no central son mutuamente ininteligibles no es muy exacta, principalmente a nivel de la Sierra, pues en los cursos de capacitación pedagógica del sistema intercultural bilingüe se ha podido constatar que es posible una intercomprensión, aunque asimétrica. Los hablantes de los dialectos denominados centrales comprenden más a los hablantes de los dialectos no centrales que viceversa. De todas maneras, se ha podido apreciar que luego de unos días de contacto entre los hablantes de estos dos dialectos sí pueden llegar a comprenderse, aunque les resulte bastante extraño el habla del otro interlocutor.

Carpenter presenta 13 mapas en los cuales muestra los lugares de algunas variaciones dialectales a nivel fonético. El autor se limita a presentar los fenómenos de la sonorización de las oclusivas sordas, las reducciones fonéticas, la aspiración y fricativización, la realización de las líquidas, la haplología y la metátesis. A cerca de la variación fonológica dice: 


\section{6}

Phonological variation in the non-central dialects are, for the most part, contemporary reflexes of earlier forms of the language. Thus sound changes are merely allophonic pronunciation differences, and the basic underlying phonemic structure has not been altered. For example, the voicing of occlusives after stops, the realization for the word-final velar $/ \mathrm{k} /$, and the consonantal weakening are manifested in various stages in Ecuador. Regarding voicing of stop consonants after nasals, consider the following examples.

[kamba] [kampa] /kanpa/ 'yours'

[kanda] [kanta] /kanta/ 'to you'

[kanga] [kanka] /kanka/ 'and you' (Carpenter, 1982, p. 357).

Como una ilustración de los mapas de este autor, a continuación presentamos el mapa de variación de lo que él denomina "Realization of liquids" (Carpenter, 1982, p. 368). En ellas están comprendidos los fonemas $/ \lambda / \mathrm{y} / \mathrm{r} / .^{87}$

Figura 12

Realización de los sonidos /I/ y /r/ según Carpenter

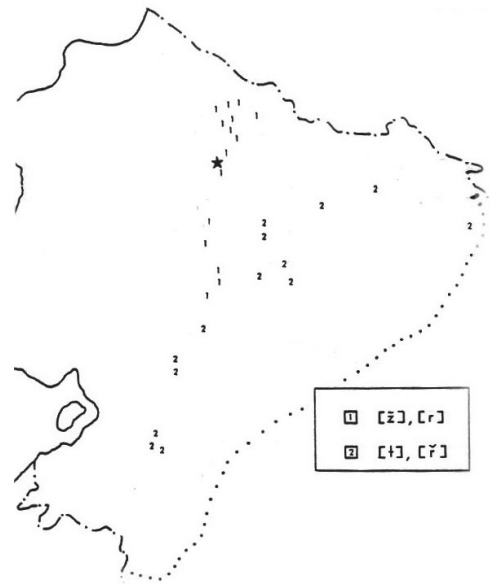

Fuente: Carpenter, 1982

87 Carpenter representa al fonema $/ \lambda /$ con el símbolo $ł$. 


\section{7}

Tales mapas, sin embargo, no resultan muy ilustrativos porque no señalan las provincias en las cuales se manifiestan los fenómenos estudiados. Esto dificulta la ubicación exacta de las variantes en el mapa. Como se verá más adelante, la variación del fonema $/ \lambda /$ se debe estudiar no solamente a nivel del léxico, sino también del morfema $\{-\lambda \mathrm{a}\}$. Esto permitirá una mayor aproximación en la representación objetiva de la variación dialectal.

Sobre los fenómenos fonéticos como reducción, metátesis, etc., presenta los mapas con los lugares donde ocurren, pero sin señalar ejemplos concretos. En cuanto a la morfología, solo estudia las variaciones de los morfemas $\{-$ naku $\},\{$ pak $\},\{$ rka\}. En lo relacionado con las variaciones sintácticas solo menciona el uso de $<$ kikin $>$ y $<$ kan $>$ para la segunda persona. Dice que en la provincia de Imbabura se hace una distinción para la segunda persona, entre $<$ kikin $>$ 'usted' $\mathrm{y}<\mathrm{kan}>$ 'tú', mientras que en los demás dialectos no se conoce dicha diferencia. La afirmación de Carpenter sobre esto es parcial, pues < kikin $>$ también se usa en las provincias de Pichincha, Cotopaxi, Tungurahua, Bolívar y Chimborazo. El uso de $<$ kikin $>$ con el significado de 'usted' se encuentra ya en Yánez y Jara (1975). Sobre las variaciones lexicales, el autor presenta que hay nueve formas distintas de pronunciar la palabra $<$ atallpa $>$ 'gallina', sin embargo, hay que mencionar que en verdad existen más de veinte formas diferentes de pronunciación de esta palabra, por lo que lo manifestado por Carpenter es solo parcial. Finalmente, la limitación más importante de Carpenter es que no hizo diferencia entre las variaciones fonéticas del léxico y las variaciones fonéticas de los morfemas, el estudio diferenciado de estos dos componentes resulta muy importante para el estudio dialectal del quichua. Por lo demás, el autor no presenta criterios explícitos en los que se basó para su clasificación dialectal.

\section{Rodolfo Cerrón-Palomino}

Cerrón-Palomino (1987, cap. VIII) propone la clasificación de los dialectos de la Sierra ecuatoriana en norte, centro y sur. Al referirse al quichua de la Sierra dice: 


\section{8}

En este mismo subgrupo se pueden distinguir, a su vez, tres subramas, correspondientes a las regiones Norte, Centro y Sur. Los dialectos del norte, formados básicamente por los de Imbabura y Pichincha, aunque mantienen la $/ \mathrm{t}^{\mathrm{h}} /$ (de muy escasa ocurrencia), han cambiado la / $\mathrm{p}^{\mathrm{h}} / \mathrm{y} / \mathrm{k}^{\mathrm{h}} /$ en $/ \mathrm{f} / \mathrm{y} / \chi /$, respectivamente [...]; los del centro (hablados en Tungurahua, Chimborazo, Cañar y Azuay) y sur (localizado en Loja) preservan la aspiración para las tres oclusivas. Por su parte la variedad sureña se distingue de las otras dos por mantener la /I//, pronunciada más bien como [1y] (Cerrón-Palomino, 1987, p. 240).

En el dialecto del centro habría que incluir Cotopaxi y excluir Cañar y Azuay, pues estos últimos son más afines con el de Saraguro (Loja). En cuanto a los dialectos de la Amazonía, el autor hace una comparación de 11 morfemas en los tres dialectos señalados por Carolyn Orr.

\section{Willen F. Adelaar con la colaboración de Peter Muysken}

Estos autores, en su libro The Languages of the Andes (2004), dieron importancia a los procesos morfofonémicos en la diversificación dialectal del quichua ecuatoriano, al manifestar que:

The Quechua dialects of Ecuador are morphologically, syntactically and lexically quite similar. The main differences lie in a number of morphophonological processes that affected the affixes in particular. While a southern dialect such as Cañar is rather conservative, Salasaca Quechua has undergone most of the processes involved (Adelaar y Muysken, 2004, p. 237).

Hay una coincidencia de Adelaar y Muysken (2004) con CerrónPalomino (1987) al considerar que las hablas de la Sierra sur son las más conservadoras, en tanto que el habla de Salasaca, que es parte de la Sierra centro, es la más innovadora. 
Figura 13

Realización del fonema $/ \lambda /$ en diferentes lugares

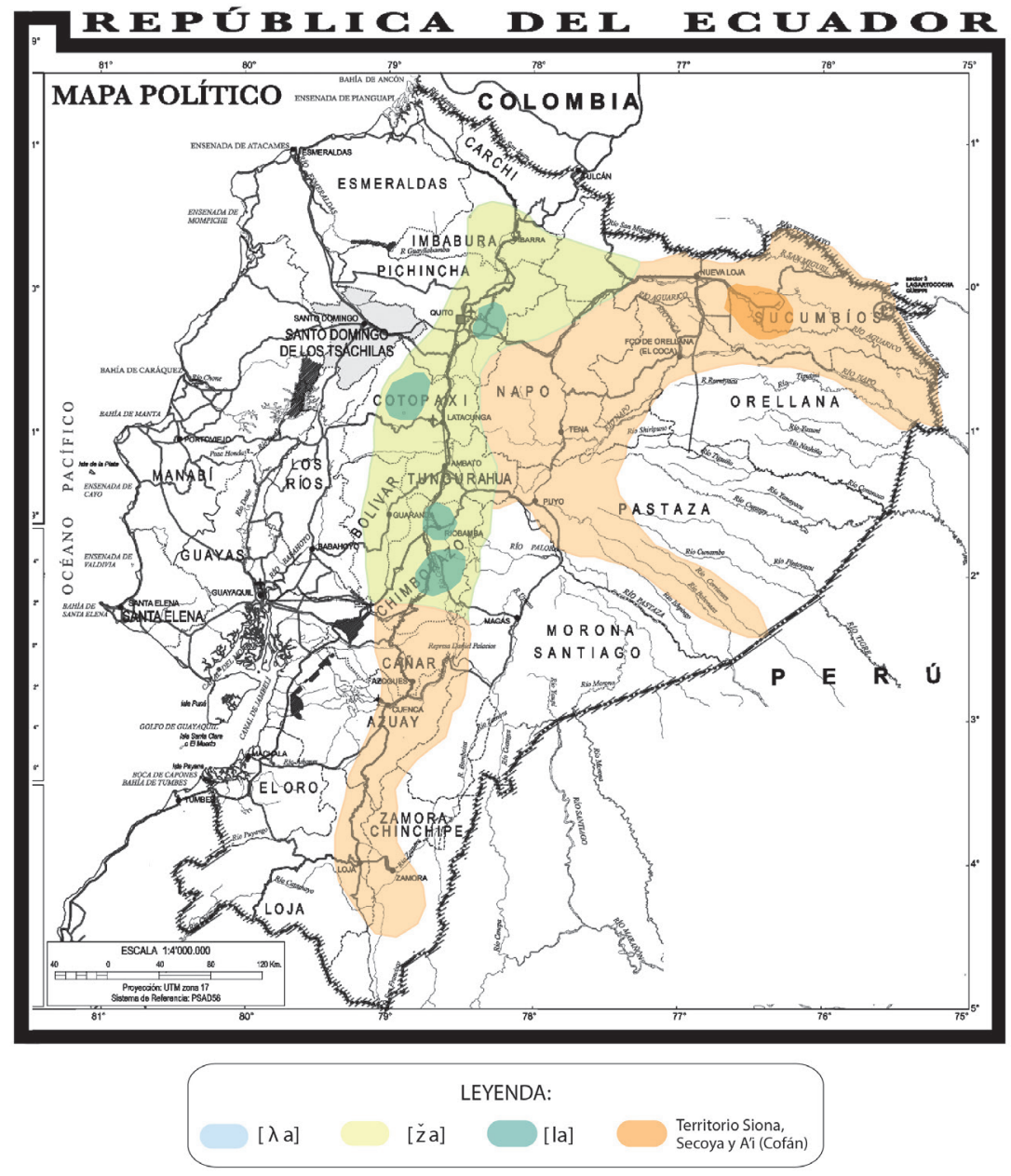

Fuente: el autor 



\section{Capitulo 5 Variaciones dialectales y zonificación dialectal}

Los estudios sobre los dialectos se pueden realizar a nivel diacrónico y/o sincrónico. En ambos casos se enfrentan problemas teóricos y prácticos, como se verá más adelante. Para ilustrar esta situación, al inicio de este capítulo se describen algunos detalles del camino seguido por varios autores en sus intentos por encontrar criterios para estudiar los dialectos y realizar zonificaciones dialectales de una lengua.

La presente investigación parte de un estudio sincrónico de las variaciones fonológicas y morfofonémicas de los dialectos del quichua ecuatoriano, sin embargo, no deja de lado el aspecto histórico, en cuanto toma como referencia la reconstrucción del protoquechua realizado por Parker. Se enmarca, de acuerdo con los fines que persigue, en el ámbito de la lingüística aplicada más que en la general y responde a las necesidades educativas y sociales de la población quichua.

Sobra señalar que las motivaciones para realizar el presente estudio de la diversidad dialectal del quichua son distintas de las que plantean autores como Heggarty (2005), que hacen estudios filogenéticos sobre los dialectos del quechua. Sin desmerecer tales cometidos, todos ellos absolutamente necesarios e importantes, en el presente caso se investiga para tratar de establecer zonas dialectales del quichua ecuatoriano actual con el fin de proponer algunas estrategias tendientes a superar las dificultades suscitadas en el proceso de EIB en el Ecuador. Por ello subrayamos que las investigaciones diacrónicas realizadas por dichos 
autores solo se mencionan como una referencia, a partir de las cuales buscamos entender la diversidad lingüística actual.

El habla de una lengua está conformada por un conjunto de variaciones dialectales, que a su vez se manifiestan a través de sociolectos e idiolectos. Cada persona concretiza la lengua con algunas particularidades. Por otra parte, entre los dialectos no existe un límite discreto y las isoglosas que las definen suelen estar imbricadas por los distintos rasgos dialectales. Frente a esa gran diversidad de realizaciones de la lengua en los hablantes, es necesario buscar formas de generalizar y esto implica hacer idealizaciones. Al respecto, Theodora Bynon comenta:

El primer factor que oscurece el proceso del cambio histórico lo constituye el hecho de que el análisis sincrónico de una lengua exige siempre un cierto grado de idealización de los datos, ya que no debería olvidarse que, cuando un lingüista realiza una formulación sobre "lengua" sea en relación con su estructura sincrónica o con su desarrollo histórico, esta es una abstracción de la realidad observable, que jamás puede ser otra que la de los individuos que emplean la lengua como vehículo de comunicación. Y esta realidad, tal como se observa realmente, no es nunca de una homogeneidad completa. Siempre se hallará que, entre hablantes, existen diferencias que dependen de su situación geográfica y de su clase social, y siempre hay variaciones en el habla de un hablante particular, según la ceremonia de la ocasión (1977/1981, p. 15).

La búsqueda de criterios para una zonificación dialectal y la conciencia de su problemática en las lenguas, vienen desde el siglo XIX. Georg Wenker, en 1881 (cf. Candau, 1985, pp. 5-7), cuando publicó los primeros mapas de los dos dialectos del alemán, ya se refería al problema de la falta de límites discretos para las isoglosas. Se dio cuenta de que los rasgos dialectales de una lengua podían tener su propio alcance territorial y que las isoglosas no correspondían a las fronteras administrativas o políticas de los países.

La búsqueda de criterios empíricos para realizar clasificaciones dialectales continuó en el siglo XX. En el caso del castellano de América, 
diversos autores han ensayado algunos parámetros en sus intentos de realizar una zonificación dialectal. Así, Pedro Henríquez Ureña, en su artículo "Observaciones sobre el español de América", ${ }^{88}$ propuso una zonificación dialectal del castellano tomando como criterio factores externos a la lengua, entre ellos algunos geográficos, históricos y el sustrato de lenguas indígenas. Su propuesta fue la siguiente:

Provisionalmente me arriesgo a distinguir en la América española cinco zonas principales: primera, la que comprende las regiones bilingües del Sur y Sudoeste de los Estados Unidos, México y las Repúblicas de la América Central; segunda, las tres Antillas españolas (Cuba, Puerto Rico y la República Dominicana, la antigua parte española de Santo Domingo), la costa y los llanos de Venezuela y probablemente la porción septentrional de Colombia; tercera, la Región andina de Venezuela, el interior y la costa occidental de Colombia, el Ecuador, el Perú, la mayor parte de Bolivia y tal vez el Norte de Chile; cuarta, la mayor parte de Chile; quinta, la Argentina, el Uruguay, el Paraguay y tal vez parte del Sudeste de Bolivia. El carácter de cada una de las cinco zonas se debe a la proximidad geográfica de las regiones que las componen, los lazos políticos y culturales que las unieron durante la dominación española y el contacto con una lengua indígena principal ( 1 , náhuatl; 2 , lucayo; 3 , quechua; 4, araucano; 5, guaraní). El elemento distintivo entre dichas zonas está, sobre todo, en el vocabulario; en el aspecto fonético, ninguna zona me parece completamente uniforme (Henríquez Ureña, 1921/1993, p. 41).

Unos cuarenta años después de la propuesta de Henríquez, Pedro Jorge Rona hizo una nueva propuesta de zonificación dialectal en su artículo "El problema de la división del español americano en zonas dialectales" (1964/1993, pp. 70-73). Propuso la clasificación del castellano americano basándose en la combinación de cuatro rasgos bastante conocidos:

88 En la presente investigación se usa generalmente el término "castellano" para designar al idioma de Cervantes, pero existen autores que prefieren denominarlo "español". Por esta razón en las referencias se empleará también "español" cuando los autores citados así lo hagan. 
žeísmo, yeísmo, voseo y formas verbales que acompañan al pronombre $<$ vos $>$. Con estos paradigmas distinguió 23 zonas. A pesar de que Rona no respaldó su clasificación en datos empíricos, sí contribuyó con algunas observaciones y avances en la búsqueda de criterios para la zonificación dialectal. A partir de datos bibliográficos planteó su clasificación basándose en factores lingüísticos internos. ${ }^{89}$ Por otra parte, su propuesta de clasificación abrió nuevos caminos, tanto por su insistencia en la definición de "dialecto" como convergencia dinámica de isoglosas como por el uso de variables fonéticas, fonológicas y morfológicas (Lipski, 1994/2009).

Por otra parte, Melvyn Resnick (1976/1993, pp. 85-86), en su propuesta de clasificación del castellano, tomó en consideración ocho oposiciones fonológicas:

- Las pronunciaciones oclusivas /b, d, g/ tras consonante y en posición intervocálica.

- $\quad$ El uso de $[\check{s}]$ por $/ \check{c} /$.

- La distinción entre [ịe] por [ŷe] o [že] en hielo-yema.

- La mezcla entre yeísmo y lleísmo.

- La preponderancia de nasales velares tras fricativas y oclusivas alveolares y dentales.

- La pronunciación velar, glotal y uvular de erre y la jota.

- La presencia de consonantes dobles por asimilación de /r/ y /1/ a la consonante que sigue: [masso] por /marso/.

- La sonorización de /s/ en posición intervocálica, tanto dentro de palabra como al final de la palabra, ante vocal de la palabra siguiente.

Con la combinación binaria de ocho decisiones llegó a presentar 256 zonas dialectales del español en la América hispana.

89 Henríquez anota que la creencia en la "gran homogeneidad" del castellano americano se había dado en personas de "un cierto nivel cultural", debido a que ellas han tenido oportunidad de mantenerse en contacto, pero que esa percepción podía ser muy diferente si acaso eso ocurriera entre personas de "un nivel cultural bajo", pues ellas han permanecido más aisladas. 
En relación con el quechua Cerrón-Palomino, considera que las clasificaciones dialectales no deberían estar sustentadas en consideraciones geográficas ni etnohistóricas, sino que deberían basarse en datos surgidos de la comparación dialectal, proponiéndose una clasificación de base lingüística, es decir, científica.

En efecto, dada la variabilidad interna de todo sistema lingüístico, el cuadro que presentan los dialectos quechuas en el terreno real de los hechos es el de un verdadero mosaico de hablas diferenciadas, en el que pareciera imposible todo intento de clasificación: unas mismas variedades comparten haces comunes de rasgos (=isoglosas) de cierto tipo al tiempo que se diferencian respecto de otros; unas pueden comulgar entre sí en el tratamiento de ciertos aspectos fonológicos mostrando al mismo tiempo, sin embargo, discrepancias en el plano morfológico y léxico. Es esta realidad intricada, pero natural en el desarrollo y evolución de las lenguas (en tanto que estas son usadas por grupos humanos), la que deberá ser "ordenada" por el clasificador (CerrónPalomino, 1987, p. 223).

Cerrón-Palomino además plantea que, aparte del criterio estructural invocado en la clasificación dialectal, existe el de inteligibilidad entre las hablas, pero que este también tiene sus limitaciones debido a que es difícil concebir una medida objetivamente controlable de inteligibilidad y porque también depende del grado de habilidad y experiencias interdialectales previas de los hablantes.

Sobre los problemas teóricos de clasificación, Landerman hizo observaciones a las propuestas clasificatorias del quechua que se habían realizado hasta esa fecha por diferentes autores. Sus críticas tuvieron que ver con la necesidad de usar criterios científicos para sustentar las propuestas de clasificación dialectal, por eso señaló:

This is not to say that the authors are inept or that the solutions are obvious. What is called for, in my opinion, is to take a step back and review the question of just what classification is, and how it can be carried out on a truly scientific basis (Landerman, 1991, p. 142). 
Según Landerman, la clasificación dialectal se debe realizar sobre la base de alguna de las teorías científicas. Entre ellas están las de clasificación categorial, las de clasificación cuantitativa y las de clasificación genética. Las teorías categoriales son útiles para realizar clasificaciones externas e internas de las lenguas. En el primer caso, permite establecer relaciones familiares con otras lenguas y en el segundo caso, subgrupos al interior de las lenguas siguiendo alguna categoría específica seleccionada. Las teorías cuantitativas intentan medir el grado de similitud de unas hablas con otras. Las genéticas permiten agrupar las hablas en función de las evoluciones que han experimentado. Entre estas últimas está la de "innovaciones compartidas".

Para el presente caso, se escogió la teoría de innovaciones compartidas porque permite agrupar las hablas quichua del Ecuador a partir de las regularidades de la evolución interna en relación con los datos del protoquechua reconstruidos por Parker.

Los datos de los dialectos del quichua fueron recogidos de las diferentes partes de la Sierra y la Amazonía donde tradicionalmente se ha hablado esta lengua. La Figura 14 muestra el territorio tradicional del quichua en Ecuador. Como ya se ha señalado, desde hace más de cincuenta años, por el fenómeno de la migración, el quichua se ha extendido a las principales ciudades de la Costa (Guayaquil, Machala, Quevedo) e incluso a las islas Galápagos, donde se encuentran hablantes que provienen de las comunidades Salasaca (prov. de Tungurahua), Saraguro (prov. de Loja) y de la Amazonía. Ellos conservan sus respectivos dialectos y por eso están representados en el mapa del territorio tradicional de la lengua. ${ }^{90}$

90 No se realizó la investigación en los grupos migrantes debido a que en términos generales siguen manteniendo el dialecto de las zonas de origen y por lo tanto no incide directamente en el propósito de este trabajo. 
Figura 14

Distribución del quichua en la Sierra y la Amazonía

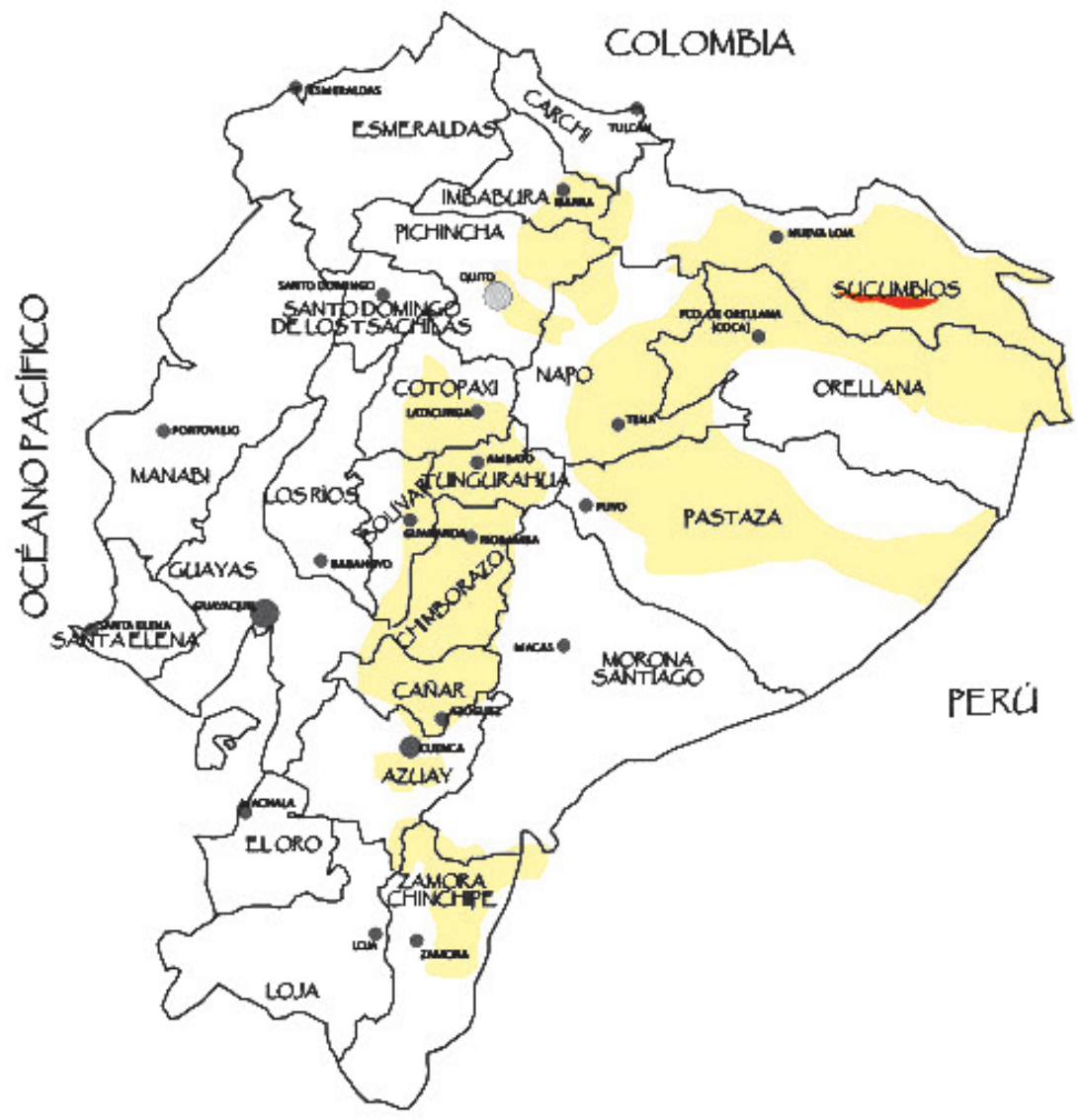

Fuente: el autor 


\section{Metodología}

Para estudiar la diversidad dialectal y luego proponer zonas dialectales del quichua ecuatoriano, se recopiló datos de las hablas concretas debido a que:

La única realidad concreta en la que puede captarse la lengua en su funcionamiento es el acto de habla individual, concreto y situado en un momento y en un punto determinado del espacio y del tiempo. Por eso he sostenido que, en realidad, "no hay hechos de lengua, sino siempre hechos de habla que se integran o no en el sistema de una lengua" (Montes, 1987, p. 23).

Como se sabe, para el establecimiento de las zonas dialectales se toma en consideración las variaciones que presentan las hablas estudiadas en los distintos órdenes de su organización gramatical: fonológica, morfosintáctica y léxico-semántico. Las variaciones morfofonémicas son importantes, pues el nivel fonológico no es suficiente para comprender la diversidad dialectal. Al respecto, Sommerstein dice:

Sobre el nivel fonémico (en la dirección que lleva hacia la gramática) estarán las afirmaciones que conciernan a los casos —ocurren en todas las lenguas- en que una misma forma gramatical es realizada, en diferentes contextos fonológicos o morfológicos, como dos o más formas fonológicas: por ejemplo, el sufijo plural en inglés se pronuncia $[z]$ en una serie de contextos, [s] en otra serie, e [iz] en un tercero. (Que no es una variación alofónica puede probarse observando que las tres formas fonológicas en cuestión contrastan entre sí en loose lose, Suez [/lu: s/ "desatar"; /lu: z/ "perder; /súiz)].) Tales fenómenos, que suponen realizaciones fonémicas alternativas de una misma unidad morfológica, son denominados alternancias morfofonémicas (1977, p. 18).

Con estos antecedentes, a fin de obtener información de los dialectos actuales se realizó una investigación a partir de encuestas estructuradas, complementadas con encuestas libres en comunidades de las diferentes provincias donde se habla quichua. Y así, para el estudio de los fonemas de la lengua se seleccionó palabras que contengan el fone- 
ma en diferentes contextos: posición inicial, posición intermedia, posición final de sílaba, etc. En tanto que para el estudio morfofonémico se consideró la totalidad de los morfemas de la lengua colocados en un contexto oracional. Los datos de la investigación se presentan empleando las escrituras fonética, fonémica y ortográfica, según las necesidades. En el caso de la última, se sigue el alfabeto del Acuerdo Ministerial no 244 de 2004 expedido por la DINEIB, así como las reglas ortográficas que propuestas en el capítulo 7.

\section{Las fuentes bibliográficas}

Además de la investigación de campo, que permitió contrastar y efectuar comparaciones, también se usó como fuente de información los textos escritos en quichua y sobre el quichua ecuatoriano, principalmente los elaborados a partir de la segunda mitad del siglo XX.

A nivel de la familia quechua se tomó como referencia los trabajos históricos y clasificatorios desarrollados por Parker (1963-1972/2013) y Torero (1964, 2002), y discutidos por Adelaar, Manheim y Landerman. En relación con las hablas de la Sierra se usaron los trabajos de Ross (1958-1959/2009), Stark y Carpenter (1973), Yánez y Jara (1975), Naula y Burns (1975), Beukema (1975), Pieter Muysken (1977), Haboud (et al., 1982), Cole (1985/2010) y Cunduri (2008). En cuanto al quichua de la Amazonía se contó con los estudios de Carolyn Orr (y Wrisley, 1965, 1978) y Andi (2012). Adicionalmente, existen algunos materiales educativos en quichua producidos por diferentes proyectos de EIB.

La investigación bibliográfica ha contribuido en tres aspectos:

- Conocer el alcance de las investigaciones que se han realizado sobre el quichua ecuatoriano.

- Seleccionar el corpus y elaborar los instrumentos de investigación para el presente estudio, así por ejemplo, de la obra de Haboud (et al., 1982) se obtuvo parte del corpus y también algunas de las variaciones lexicales entre la Sierra y Amazonía. 


\section{0}

- Complementar la investigación y servir como referencia para contrastarla con los datos obtenidos en la investigación de campo.

\section{El trabajo de campo}

Es innegable la importancia del habla para llegar a la lengua:

La única realidad concreta en la que puede captarse la lengua en su funcionamiento es el acto de habla individual, concreto y situado en un momento y en un punto determinado del espacio y del tiempo. Por eso he sostenido que, en realidad, "no hay hechos de lengua, sino siempre hechos de habla que se integran o no en el sistema de una lengua" (Montes, 1987, p. 23).

Asimismo, Montes transcribe el pensamiento de Rogger, quien sostiene que las investigaciones lingüísticas siempre deben documentarse en los hechos del habla:

Was von de Saussure gänzlich verschwiegen wird ist die Tatsache, Das die Linguistik es immmer nur mit Documenten de Parole zu tun haben kann; siese sind das konkrete Material von dem sämtliche Feststellungen, Untersuchungen, Schlüsse und Spekulationnen auszugehen haben und allein ausgehen könnenn (en Montes, 1987, p. 23).

Finalmente, Montes también cita a Buyssens para enfatizar que el lingüista debe comenzar su estudio a partir del habla: "C'est la raison pour laquelle le linguiste ne peut commencer autrement son étude qu'en se tournant vers la parole" (1987, p. 23).

La investigación de campo se ha realizado en al menos dos comunidades de cada una de las provincias donde se ha hablado tradicionalmente el quichua, como se puede ver en la siguiente tabla: 
Tabla 5

Comunidades donde se realizó las investigaciones lingüísticas

\begin{tabular}{|c|c|c|c|c|c|}
\hline Región & No & Provincia & Cantón & Parroquia & Comunidad \\
\hline \multirow{21}{*}{ 苞 } & \multirow{2}{*}{1} & \multirow{2}{*}{ Imbabura } & Antonio Ante & San Roque & San Roque \\
\hline & & & Ibarra & La Esperanza & San Clemente \\
\hline & \multirow[b]{2}{*}{2} & \multirow[b]{2}{*}{ Pichincha } & Cayambe & Cangahua & El Caucho \\
\hline & & & Quito & Calderón & $\begin{array}{l}\text { San Miguel } \\
\text { del Común }\end{array}$ \\
\hline & \multirow{2}{*}{3} & \multirow{2}{*}{ Cotopaxi } & Saquisilí & Saquisilli & Salacalle \\
\hline & & & Sigchos & Chucchilán & Sarahuasi \\
\hline & \multirow{4}{*}{4} & \multirow{4}{*}{ Tungurahua } & Ambato & Juan Benigno Vela & Chibuleo \\
\hline & & & \multirow{3}{*}{ Pelileo } & Salasaca & Chilcapamba \\
\hline & & & & El Rosario & Churumanga \\
\hline & & & & Salasaca & Rumiñahui \\
\hline & \multirow{3}{*}{5} & \multirow{3}{*}{ Chimborazo } & Riobamba & San Juan & Pisicaz \\
\hline & & & Colta & $\begin{array}{l}\text { Santiago } \\
\text { de Quito }\end{array}$ & $\begin{array}{l}\text { San Antonio de } \\
\text { Rayopamba }\end{array}$ \\
\hline & & & Guamote & Cebadas & San Francisco \\
\hline & \multirow{2}{*}{6} & \multirow{2}{*}{ Bolívar } & \multirow{2}{*}{ Guaranda } & San Simón & Cachisagua \\
\hline & & & & Guanujo & Raro Bajo \\
\hline & \multirow{2}{*}{7} & \multirow{2}{*}{ Cañar } & \multirow{2}{*}{ Cañar } & Cañar & Quilloac \\
\hline & & & & General Morales & Las Cruces \\
\hline & \multirow{2}{*}{8} & \multirow{2}{*}{ Azuay } & Cuenca & Tarqui & Gullanzhapa \\
\hline & & & Nabón & Nabón & Pucallpa \\
\hline & \multirow{2}{*}{9} & \multirow{2}{*}{ Loja } & Saraguro & Tenta & Cañicapac \\
\hline & & & Loja & San Lucas & San Lucas \\
\hline \multirow{12}{*}{ 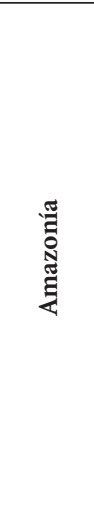 } & \multirow{3}{*}{10} & \multirow{3}{*}{ Sucumbíos } & Putumayo & P. El Carmen & Tase \\
\hline & & & Cascales & El Dorado de Cascales & $\begin{array}{l}\text { San José de } \\
\text { Aguarico }\end{array}$ \\
\hline & & & Shushufindi & Limoncocha & Santa Elena \\
\hline & \multirow{2}{*}{11} & \multirow{2}{*}{ Orellana } & Loreto & San José de Payamino & Payamino \\
\hline & & & Aguarico & Edén & Edén \\
\hline & \multirow{3}{*}{12} & \multirow{3}{*}{ Napo } & Archidona & Rucullacta & Recullacta \\
\hline & & & Tena & Pano & Pano \\
\hline & & & Chaco & Oyacachi & Oyacachi \\
\hline & & & Arajuno & Arajuno & Arajuno \\
\hline & 13 & & & Canelos & Canelos \\
\hline & 13 & Pastaza & Pastaza & Sarayacu & Sarayacu \\
\hline & & & & Montalvo & Atatarkuinjia \\
\hline
\end{tabular}

Fuente: el autor 


\section{2}

Figura 15

Comunidades de la Sierra y la Amazonía

de donde se tomó la información para el presente estudio

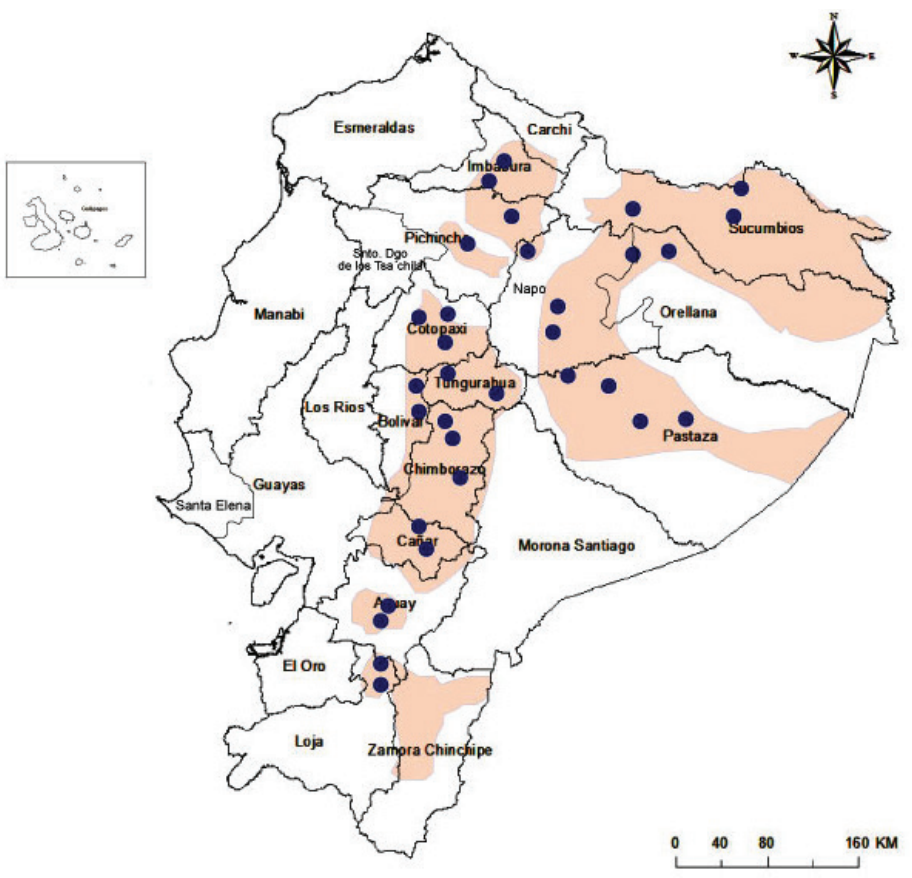

Fuente: el autor

A continuación se presenta los resultados de la investigación del trabajo de campo. Primero se presenta las variaciones a pronunciación a nivel fonético, tanto de los fonemas vocálicos como de los consonánticos y sus fenómenos. En segundo lugar se presenta las variaciones morfofonéticas. En este segmento se presenta primero la clasificación de los morfemas ligados presentes en el quichua ecuatoriano: nominales, verbales e independientes. Se menciona a los morfemas que no tienen variación y luego los morfemas que tienen variación siguiendo el orden antes mencionado. 


\section{3}

\section{Variaciones fonéticas $^{91}$}

En el corpus léxico las variaciones más importantes son el cambio vocálico, la monoptongación, la fricativización de las aspiradas, la sonorización de las sordas, el cambio del punto y el modo de articulación, etc. En cambio, en los morfemas las variaciones consisten, fundamentalmente, en procesos de lenición y supresión de algunos de los fonemas integrantes del morfema. En la Amazonía central también existe alargamiento vocálico en un contexto restringido. En la morfosintaxis se encontró procesos de reducción y ensamblaje..$^{92}$ A continuación se presenta la síntesis de los fenómenos de variación presentes en las hablas quichuas del Ecuador.

\section{Variaciones vocálicas}

Existen dos fenómenos importantes en este nivel, que son el cambio vocálico y la monoptongación. Ellos, sin embargo, no son cambios que se dan a nivel general sino solo a nivel del léxico y morfofonémico en los lugares señalados.

\section{Cambio vocálico}

Este fenómeno, característico de la Sierra centro, consiste en el cambio de /a/ > [i], y de /a/ > [u]; esto significa que la vocal abierta se transforma en cerrada. A nivel de lexemas esto ocurre, fundamentalmente, en la vocal de la segunda sílaba. Ejemplos de cambio vocálico a nivel de lexemas son:

91 Las variaciones dialectales se representan empleando los símbolos del alfabeto fonético internacional AFI adaptado por los investigadores de las lenguas de la Región Andina.

92 El nombre de reducción-ensamblaje ha sido propuesto por Cerrón-Palomino (1997) para designar al fenómeno por el cual dos palabras que normalmente van separadas, en determinados contextos se juntan, dando la impresión de ser una sola entidad. Así por ejemplo: allillami kani > allillamani 'estoy bien'. 


\section{4}

\begin{tabular}{|lll|}
\hline Variación & Forma etimológica & Glosa \\
{$[$ ižikta $]$} & $/$ i $\lambda$ akta/ & 'todos'93 \\
{$[$ žužix] } & $/ \lambda u \lambda a k /$ & 'mentiroso' \\
{$[$ kunun] } & $/$ kunan/ & 'ahora' \\
{$[$ ñukunčix] } & $/$ ñukančik/ & 'nosotros' \\
{$[$ sumux] } & $/$ sumak/ & 'hermoso, bonito' \\
[čušig] & $/$ čushak/ & 'vacío' \\
[yawur] & $/$ yawar/ & 'sangre'94 \\
{$[$ mununa } & $/$ munana/ & 'querer' \\
\hline
\end{tabular}

En las provincias de Cotopaxi, Tungurahua, Bolívar y el norte de Chimborazo, el cambio vocálico, en el contexto señalado, es muy regular; pero en lugares como San Miguel del Común, ubicado hacia el norte (prov. de Pichincha), al igual que en las comunidades de los cantones Colta, Guamote y Alausí, ubicadas hacia el sur (prov. de Chimborazo), el fenómeno ya no es regular.

A nivel de morfemas, el cambio vocálico se encuentra en el ablativo $\{$ manta $\}$, el genitivo-benefactivo $\{$-pak $\}$, el ilativo $\{$-man $\}$, el instrumental-conmitativo $\{-\mathrm{wan}\}$, el oscilativo $\{$-ykača $\}$, el contrastivo $\{$-tak\}, el contrastivo, $\{$-rak $\}$, que devienen en [munta $\sim$ munda $\sim$ mundu], [puk], [mun], [wun], [ykiča yxiča], [tik], [rik], respectivamente. El cambio vocálico de [paš] $>$ [piš] no se considera dentro de este grupo de morfemas debido a que es un fenómeno que también se da en el Perú. El habitual \{-raya\} no sufre propiamente cambio vocálico, sino la supresión de alguno de los fonemas deviniendo en [rya $\sim$ ra].

93 En Cotopaxi, /illakta/ significa 'todos, absolutamente todos'. En otros lugares se entiende como 'el que falta'.

94 Existe también la variación [maykan mayxin] de /maykan/ 'quién', pero se ha constatado que este fenómeno también se da en el Perú, por lo tanto no es exclusivo de esta región del Ecuador, como en el caso del resto de los ejemplos. 


\section{5}

\section{Monoptongación}

La monoptongación consiste en la reducción de los diptongos / ay, uy/ > [i] y del diptongo /aw/ > [u] . Este fenómeno se presenta en las comunidades de la Sierra centro, desde San Miguel del Común (parroquia Calderón, prov. de Pichincha) hasta La Moya (cantón Alausí, prov. de Chimborazo), y se amplía hacia la Amazonía centro, que comprende las comunidades de la parte suroccidental de la provincia de Sucumbíos, la parte occidental de la provincia de Orellana (desde el río Pañacocha hacia el occidente), la provincia de Napo y las comunidades de Arajuno al noroeste de la provincia de Pastaza; y también hacia la Amazonía sur, que comprende las comunidades de los ríos Curaray y Bobonaza (prov. de Pastaza). En la Sierra norte y sur y en la Amazonía norte no ocurre este fenómeno lingüístico. Ejemplos de monoptongación son:

\begin{tabular}{|lll|}
\hline Variación & Forma etimológica & Glosa \\
[šami] & /šamuy/ & 'ven' \\
[šamičix $\sim$ šamiči] & /šamuyčik/ & 'vengan ustedes' \\
{$[$ tuki] } & $/$ tukuy/ & 'todos \\
{$[$ čupi] } & /čawpi/ & 'mitad' \\
[čipi $\sim$ čibi] & /čaypi/ & 'allí' \\
\hline
\end{tabular}

Este fenómeno está bastante esparcido en las diferentes zonas dialectales en algunas palabras, por lo cual, tampoco es de mayor dificultad para la estandarización de la escritura si es que se opta por la forma conservada. Evidentemente, al inicio se constata una compresión asimétrica entre los hablantes de los diversos dialectos, tanto a nivel oral como escrito, pero pronto se familiarizan con el proceso involucrado.

\section{Variaciones consonánticas}

Las variaciones de las consonantes son más complejas que las de las vocales. Existe un diverso grado de evolución aun al interior de las zonas dialectales. Algunas de ellas pueden ser expresadas por reglas más 


\section{6}

generales en tanto que otras son más restringidas. Así, el proceso de sonorización de las oclusivas sordas después de nasales ha alcanzado diversos grados de generalización, como se podrá ver más abajo, donde se presenta una matriz con la realización de los términos involucrados en las comunidades indicadas. A continuación vamos a detallar los principales fenómenos de variación consonántica.

\section{Depalatalización y fricativización de $\lambda$ / en la Sierra centro y norte}

Hay depalatalización de $/ \lambda$ / antes de oclusivas sordas, y de /i/ en la provincia de Imbabura, en Cayambe (prov. de Pichincha) y en la Amazonía. Este fenómeno es apenas percibido por los hablantes que emplean $[\lambda]$, pues se trata solo de un menor contacto de la lengua con el paladar, pero se mantiene el punto y el modo de articulación, así como la sonoridad. Por ejemplo:

\begin{tabular}{|lll|}
\hline Variación & Forma etimológica & Glosa \\
[alpa] & $/ \mathrm{a} \lambda \mathrm{pa} /$ & 'tierra' \\
[tulpa] & $/ \mathrm{tu} \lambda \mathrm{pa} /$ & 'fogón' \\
{$[$ alku] } & $/ \mathrm{a} \lambda \mathrm{ku} /$ & 'perro' \\
{$[$ walka] } & $/ \mathrm{wa} \lambda \mathrm{ka} /$ & 'collar'95 \\
{$[\mathrm{kulki}]$} & $/ \mathrm{ku} \lambda \mathrm{ki} /$ & 'plata' \\
{$[$ ali] } & $/ \mathrm{a} \lambda \mathrm{i} /$ & 'bueno, bien' \\
{$[$ liki] } & $/ \lambda \mathrm{ikiy/}$ & 'rasgar' \\
\hline
\end{tabular}

En la comunidad San Miguel del Común (prov. de Pichincha) hay vacilación: se usa [l] en algunas palabras como [alpa], pero [ž] en otras como [ažku]. Esto indica una frontera dialectal entre la Sierra norte y centro, debido a que en las fronteras dialectales generalmente se dan ciertas superposiciones dialectales.

En las provincias de Cotopaxi, Chimborazo y Bolívar el fonema $/ \lambda /$, en posición intermedia, se fricativiza como $[\check{z}]$, llegando inclusive

95 En la Amazonía < wallka > se refiere al 'collar' y también a las 'cuentas del collar'. 


\section{7}

ensordecerse y realizarse como [̌s]. Estos fenómenos lo perciben más fácilmente los hablantes de la Sierra sur que emplean $[\lambda]$. Los ejemplos que siguen ilustran el fenómeno:

\begin{tabular}{|c|c|c|}
\hline Variaciones & Forma etimológica & Glosa \\
\hline [ažpa ašpa] & $/ \mathrm{a} \lambda \mathrm{pa} /$ & 'tierra' \\
\hline [tužpa $\sim$ tušpa] & $/ \mathrm{tu} \lambda \mathrm{pa} /$ & 'fogón’ \\
\hline [ažku ašku] & $/ \mathrm{a} \lambda \mathrm{ku} /$ & 'perro' \\
\hline [wažka waška] & /waגka & / 'collar' \\
\hline [kužki kuški] & /ku入ki/ & 'plata' \\
\hline
\end{tabular}

En Salasaca (prov. de Tungurahua) $/ \lambda /$ se realiza como $[\check{c}]$ antes de consonante oclusiva sorda, produciéndose un fenómeno de africación, pero en posición intervocálica se mantiene como [ž], como en [žuži] de / $\lambda u \lambda$ ay/ 'mentir'. Otros ejemplos son:

\begin{tabular}{|lll|}
\hline Variación & Forma etimológica & Glosa \\
{$[$ ačpa $]$} & $/ \mathrm{a} \lambda \mathrm{pa} /$ & 'tierra' \\
{$[$ tučpa $]$} & $/ \mathrm{tu} \lambda \mathrm{pa} /$ & 'fogón' \\
{$[$ ačku] } & $\mathrm{a} \lambda \mathrm{ku} /$ & 'perro' \\
{$[$ wačka $]$} & $/ \mathrm{wa} \lambda \mathrm{ka} /$ & 'collar' \\
{$[\mathrm{kučki}]$} & $/ \mathrm{ku} \lambda \mathrm{ki} /$ & 'plata' \\
\hline
\end{tabular}

El fenómeno de fricativización de $/ \lambda /$ es en posición inicial de sílaba y en posición intervocálica es característico de la Sierra centro, en tanto que la fricativización en la Sierra norte solo se da en posición inicial de sílaba. En la Sierra sur, el fenómeno de fricativización solo se da en la comunidad de Pucallpa (prov. de Azuay). La constatación de este hecho fue algo novedoso, pues se esperaba que mantuviera $[\lambda]$ al igual que el resto de comunidades de la zona. Esta comunidad es una especie de isla al interior de otras localidades de la provincia de Azuay que usan $[\lambda]$. Quezada (1976, pp. 38-39) reporta un caso similar en Chetilla (Cajamarca, Perú). Ejemplos en Ecuador son: 


\section{8}

\begin{tabular}{|c|c|c|}
\hline Variación & Forma etimológica & Glosa \\
\hline [žakta] & / $\lambda$ akta/ & 'pueblo, región donde uno vive' \\
\hline [žatan] & / $\lambda$ atan/ & 'desnudo' \\
\hline [žuču] & $/ \lambda \mathrm{uchu} /$ & 'pelado' \\
\hline
\end{tabular}

Queda abierta la investigación del origen de estas islas dialectales al interior de una zona. Investigaciones de orden histórico, social y económico podrían ayudar a entender estos fenómenos.

En general, la realización de $/ \lambda /$ como [1], [̌̌] ó [č] no afecta mayormente la comprensión oral, pero puede acarrear vacilaciones en la escritura, especialmente en personas que han sido alfabetizadas en castellano, debido a la tendencia a escribir el quichua según las normas de ortografía de la RAE.

Presencia de aspiradas en la Sierra centro y su fricativización en la Sierra norte

La aspiración es característica de la Sierra centro, en la Sierra sur es casi nula la existencia de este rasgo. Su presencia es débil en San Miguel del Común (prov. de Pichincha), que es frontera entre la Sierra centro y norte. En la Sierra norte se realiza como fricativas sordas. Así / $\mathrm{p}^{\mathrm{h}} /$ se realiza como $[\varphi]$ y $/ \mathrm{k}^{\mathrm{h}} /$ se manifiesta como $[\mathrm{x}]$.

\begin{tabular}{|c|c|c|c|}
\hline Sierra centro & Sierra norte & Lexema & 'Glosa' \\
\hline [p $\mathrm{p}^{\mathrm{h}}$ anga] & [panga] & /phanka/ & 'hoja' \\
\hline [p $\mathrm{p}^{\mathrm{h}}$ iñay] & [ழiñay] & /phiñay/ & 'enojo' \\
\hline$\left[\mathrm{p}^{\mathrm{h}} \mathrm{uyu}\right]$ & [甲uyu] & /p $\mathrm{p}^{\mathrm{h}} \mathrm{uyu} /$ & 'nube' \\
\hline [p $\mathrm{p}^{\mathrm{h}}$ aki] & [ & / $\mathrm{p}^{\mathrm{h}}$ akiy/ & 'romper' \\
\hline [učup ${ }^{\mathrm{h}} \mathrm{a}$ ] & [uchupa] & /učup ${ }^{\mathrm{h}} \mathrm{a} /$ & 'ceniza \\
\hline [khakuy] & [xakuy] & /knakuy/ & 'frotar' \\
\hline [khiwa] & [xiwa] & /kniwa/ & 'hierba' \\
\hline [k $\mathrm{k}^{\mathrm{h}}$ uyay] & [xuyay] & /kneuyay/ & 'amar' \\
\hline [k katuy] & [xatuy] & /knatuy/ & 'vender' \\
\hline [k'ipa] & [xipa] & /knipa/ & 'después' \\
\hline [k $\left.\mathrm{k}^{\mathrm{h}} \mathrm{upa}\right]$ & [xupa] & / $\mathrm{k}^{\mathrm{h}} \mathrm{upa} /$ & 'basura' \\
\hline
\end{tabular}




\section{9}

El fonema $/ \mathrm{t}^{\mathrm{h}} /$ no sigue regularmente el proceso anterior, pues tiene un mosaico de realizaciones. En el caso de $/ \mathrm{t}^{\mathrm{h}} \mathrm{uka} /$ 'saliva', se realiza como

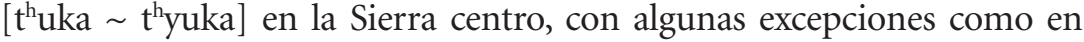
Chibuleo (prov. de Tungurahua) donde se realiza como [ $\left.\check{c}^{\text {h }} u k a\right]$, en San Miguel del Común (prov. de Pichincha) donde ya pierde la aspiración y se realiza como [tuka], en tanto que en la comunidad de Oyacoto (prov. de Pichincha) se realiza como [tutka]. Por otra parte, / $\mathrm{t}^{\mathrm{h}}$ ankay/ 'empujar', que en Pisicaz (prov. de Chimborazo) se realiza como [ $\mathrm{t}^{\mathrm{h}}$ ankay], en Churumanga (prov. de Tungurahua) se transforma en [tangi] y en Chibuleo (prov. de Tungurahua), así como también en la Sierra norte y en la Amazonía, se vuelve [tangay]. En la Sierra norte y el resto del país la pronunciación es [tuka]. En Cañar, que es parte de la Sierra sur, y en algunas comunidades de la provincia de Orellana en la Amazonía, se ha producido otro fenómeno a partir de [tuka], llegándose a pronunciar [čuka]. Así, en San Simón (prov. de Bolívar) de la Sierra centro dicen [šuka].

La fricativización de $/ \mathrm{p}^{\mathrm{h}}, \mathrm{k}^{\mathrm{h}}$ / en la Sierra norte se puede considerar como una evolución ulterior de las oclusivas aspiradas. Siguiendo esa lógica se habría esperado que $/ \mathrm{t}^{\mathrm{h}} /$ evolucionara en la Sierra norte a la fricativa $[\theta]$, pero no es así, pues se realiza como $[\mathrm{t}]$. Los fonemas $/ \mathrm{p}^{\mathrm{h}} /$ $\mathrm{y} / \mathrm{k}^{\mathrm{h}} /$ se manifiestan como oclusivas simples $[\mathrm{p}, \mathrm{k}]$ en las provincias de Cañar, Azuay y Loja y en toda la Amazonía.

Sonorización de las oclusivas sordas tras nasal

Una de las características del quichua ecuatoriano, pero compartida también por el quechua norteño-peruano (Parker, 1963/2013, p. 39), es la sonorización de las oclusivas sordas luego de nasal, así:

\begin{tabular}{|lll|}
\hline [pamba $]$ & $/$ pampa/ & 'planicie' \\
{$[$ tanda $]$} & $/$ tanta/ & 'pan' \\
{$[$ pungu $]$} & $/$ punku/ & 'puerta' \\
[žambi $]$ & $/ \lambda$ ampi/ & 'bronco' \\
{$[$ čunga $]$} & $/$ čunka/ & 'diez' \\
\hline
\end{tabular}


Sin embargo, esto no se cumple por igual a nivel de todas las oclusivas sordas como se hubiera esperado. Pues, a diferencia de la vieja concepción neogramática que sostenía que los cambios eran regulares para todo el sistema de la lengua ( $c f$. Bynon, 1977/1981, pp. 166-167), el fenómeno de propagación léxica ilustrado en la Tabla 6 está más en consonancia con la teoría del cambio gradual. Se puede apreciar que para los fonemas $/ \mathrm{p} / \mathrm{y} / \mathrm{k} /$ la sonorización es general en todo el léxico y no así para los fonemas $/ \mathrm{t} /, / \check{c} / \mathrm{y} / \Phi /$, que presentan diferencias en el proceso de sonorización de las oclusivas sordas en diferentes comunidades. Como se puede notar en la Tabla 6 , es más frecuente la sonorización de /t/ > [d] que la de $/ \check{c} />[\check{z}]$.

Tabla 6

Cuadro de sonorización de las oclusivas sordas $/ \mathrm{t} /,|\mathrm{c} /,| \not \mid$ después de nasal

\begin{tabular}{|c|c|c|c|c|c|c|c|}
\hline Localidad & $\begin{array}{l}\text { /inti/ } \\
\text { 'sol' }\end{array}$ & $\begin{array}{l}\text { /yanta/ } \\
\text { 'leña' }\end{array}$ & $\begin{array}{l}\text { /hanథi/ } \\
\text { 'afrecho- } \\
\text { delgado' }\end{array}$ & $\begin{array}{l}\text { /punča/ } \\
\text { 'día' }\end{array}$ & $\begin{array}{l}\text { /sinči/ } \\
\text { 'fuerte' }\end{array}$ & $\begin{array}{l}\text { / } \$ \text { un } ₫ u / \\
\text { 'andra- } \\
\text { joso' }\end{array}$ & $\begin{array}{l}\text { /minča/ } \\
\text { 'pasado } \\
\text { mañana' }\end{array}$ \\
\hline $\begin{array}{l}\text { La Esperanza, } \\
\text { Imbabura }\end{array}$ & indi & yamda & hamzi & punča & šinži & sunzu & minča \\
\hline Ilumán, Imbabura & indi & yanda & hamzi & punča & šinži & sunzu & minča \\
\hline Pijal, Imbabura & indi & yanta & hanzi & punča & sinči & $\operatorname{sun} \pitchfork u$ & minča \\
\hline $\begin{array}{l}\text { Caucho Alto, } \\
\text { Pichincha }\end{array}$ & inti & yanta & han $₫ i$ & punča & sinči & థun $\$ u$ & minča \\
\hline $\begin{array}{l}\text { San Miguel, } \\
\text { Pichincha }\end{array}$ & inti & yanta & han $₫ i$ & punča & hinči & థun $\pitchfork u$ & minča \\
\hline Salacalle, Cotopaxi & indi & yanta & hanథi & punča & sinči & థunథu & minča \\
\hline Sarahuasi, Cotopaxi & inti & yanta & hanđi & punča & sinči & థunథu & minča \\
\hline Apagua, Cotopaxi & indi & yanta & hanđi & punča & činči & థunণu & minča \\
\hline Salasaca, Tungurahua & indi & yanta & han $₫ i$ & phunča & hinči & థunథu & minča \\
\hline $\begin{array}{l}\text { Chibuleo, } \\
\text { Tungurahua }\end{array}$ & inti & yanta & han $\Phi_{i}$ & phunča & hinči & $\pitchfork u n \$ u$ & minča \\
\hline Pisicaz, Chimborazo & inti & yanta & han $₫ i$ & punča & sinči & \unzu & minča \\
\hline $\begin{array}{l}\text { Rayaloma, } \\
\text { Chimborazo }\end{array}$ & inti & yanta & han $\oplus_{i}$ & punča & sinči & \$unzu & minča \\
\hline $\begin{array}{l}\text { La Providencia, } \\
\text { Chimborazo }\end{array}$ & inti & yanta & hamzi/ & punča & sinči & \$unzu & minča \\
\hline Cachisagua, Bolívar & indi & yanta & hanci & phunča & sinči & sunsu & minča \\
\hline
\end{tabular}


231

\begin{tabular}{|c|c|c|c|c|c|c|c|}
\hline Timburpamba, Cañar & inti & yanta & hamči & punža & sinči & థunథu & minža \\
\hline Gullanzhapa, Azuay & inti & yanta & hamči & punža & sinči & థun $₫ u$ & minča \\
\hline San Lucas, Loja & inti & yanta & han $₫ i$ & punža & sinči & థunథu & minča \\
\hline $\begin{array}{l}\text { Santa Cecilia, } \\
\text { Sucumbíos }\end{array}$ & indi & yanda & anzi & punža & šinži & థunథu & 一 \\
\hline Rucullacta, Napo & indi & yanda & anzi & punža & šinči & థun $\pitchfork u$ & - \\
\hline Chucapi, Napo & indi & yanda & hanzi & punža & šinži & థunzu & minža \\
\hline Arajuno, Pastaza & indi & yanda & anzi & punža & šinži & థun $\pitchfork u$ & minža \\
\hline Canelos, Pastaza & indi & yanda & hanzi & punža & Šinči & \$un\$u & minža \\
\hline
\end{tabular}

Fuente: el autor

Depalatalización de /š/ en la Sierra norte y la Amazonía

El fonema / ̌s se realiza como $[s \sim z]$ en un limitado número de palabras y expresiones con /šina/.

\begin{tabular}{|lll|}
\hline Variación & Forma reconstruida & Glosa \\
{$[$ maskay $] /$ maškay/ } & $*$ maşka- & 'buscar' \\
{$[$ masna $\sim$ mazna $] /$ mašna/ } & $*$ may šina & '¿cuántos? \\
{$[$ kasna $\sim$ kazna $] /$ kašna/ } & $*$ kay šina & 'así, como este' \\
{$[$ časna $\sim$ čazna $] /$ čašna/ } & $*$ chay šina & 'así', como ése' \\
\hline
\end{tabular}

Este fenómeno, aunque notorio para los hablantes, no parece constituir un mayor obstáculo para la estandarización de la escritura.

\section{Variaciones fonéticas atípicas}

En el quichua ecuatoriano existen algunas palabras que tienen realizaciones particulares en diferentes lugares. Este tipo de variaciones si fueran numerosas podrían complicar la estandarización de la escritura, ventajosamente son pocas. La más representativa es el caso de las formas derivadas de /ata $\lambda \mathrm{pa}$, wa $\lambda \mathrm{pa}$ /, las cuales a su vez podrían provenir de la forma /atawa $\lambda \mathrm{pa} /$ para referirse a 'gallina'. 


\section{2}

Tabla 7

Variaciones de pronunciación de los términos <atallpa, wallpa>

\begin{tabular}{|c|c|c|c|}
\hline No & Fonética & Fonología & Ubicación \\
\hline 1 & ata $\lambda \mathrm{pa}$ & 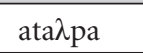 & Chimborazo: Nizag-Alausí. \\
\hline 2 & atalpa & & $\begin{array}{l}\text { Imbabura: Peratán-Imantag-Cotacachi; Colimbuela- } \\
\text { Imantac-Cotacachi; Calera-San Francisco-Cotacachi; } \\
\text { Punge, Quiroga-Cotacachi; San Francisco-El Sagra- } \\
\text { rio-Ibarra; Pinsaqui-San Juan de Ilumán-Otavalo; } \\
\text { Carabuela-San Juan de Iluman-Otavalo; Angla-San } \\
\text { Pablo-Otavalo; Pijal-González Suárez-Otavalo. Pi- } \\
\text { chincha: Otoncito-Otón-Cayambe; Chumillos-Can- } \\
\text { gahua-Cayambe. Sucumbíos: San José de Aguarico-El } \\
\text { Dorado-Cascales. }\end{array}$ \\
\hline 3 & atašpa & & $\begin{array}{l}\text { Imbabura: Peguche-Miguel Egas-Otavalo. Coto- } \\
\text { paxi: Apagua-Zumbagua-Pujilí. Chimborazo: } \\
\text { Llinllín-Columbe-Colta. Bolívar: Bramadero } \\
\text { Grande-Guanujo-Guaranda. }\end{array}$ \\
\hline 4 & atačpa & & Tungurahua: Salasaca-Pelileo. \\
\hline 5 & atažpa & & Bolívar: Pimbalo-Simiatug-Guaranda. \\
\hline 6 & ata $\lambda b a$ & & $\begin{array}{l}\text { Sucumbíos: Rumipamba-Lago Agrio; Río } \\
\text { Jibino-Limoncocha-Shushufindi. }\end{array}$ \\
\hline 7 & atalba & & Bolívar. \\
\hline 8 & ata $\lambda \mathrm{a}$ & & Pastaza: Sarayacu. \\
\hline 9 & ata $\lambda w a$ & & Napo: Tamboyacu-Archidona. \\
\hline 10 & ati $\lambda \mathrm{pa}$ & & \begin{tabular}{|l|} 
Chimborazo. \\
\end{tabular} \\
\hline 11 & atilpa & & $\begin{array}{l}\text { Pichincha: Izacata-Cangahua-Cayambe. Bolívar: Rayo } \\
\text { Bajo-Guanujo-Guaranda. }\end{array}$ \\
\hline 12 & atilba & & Cotopaxi: Zumbagua-Pujilí. \\
\hline 13 & atišpa & & $\begin{array}{l}\text { Chimborazo: Tungurahuilla-Santiago de Quito-Colta; } \\
\text { San Francisco-Cebadas-Guamote. }\end{array}$ \\
\hline 14 & atičpa & & Bolívar. \\
\hline 15 & atilba & & \begin{tabular}{|l} 
Cotopaxi. \\
\end{tabular} \\
\hline 16 & atiža & & $\begin{array}{l}\text { Cotopaxi: San José Ejido-Juan Montalvo-Latacunga. } \\
\text { Bolívar: Queseras, Vintimilla-Guaranda; Casaichi- } \\
\text { Veintimilla-Guaranda; Guantug-Guanujo-Guaranda; } \\
\text { Tagma-San Simón-Guaranda. }\end{array}$ \\
\hline
\end{tabular}




\section{3}

\begin{tabular}{|c|c|c|c|}
\hline 17 & atila & & Cotopaxi: San Miguel-Salcedo. \\
\hline 18 & atil & & Tungurahua: Salasaca-Pelileo. \\
\hline 19 & atulba & & Pichincha: Zámbiza-Quito. Cotopaxi: Zumbahua- Pujilí. \\
\hline 20 & atula & & $\begin{array}{l}\text { Cotopaxi: Chimbacucho-Zumbahua-Pujilí; } \\
\text { Rumipamba-Guangaje-Pujilí. }\end{array}$ \\
\hline 21 & ačilpa & & Chimborazo: El Lirio-Cicalpa-Colta. \\
\hline 22 & wa入pa & waגpa & $\begin{array}{l}\text { Cañar: Chontamarca Chico-Cañar. Azuay: } \\
\text { Gullanzhapa-Tarqui-Cuenca. }\end{array}$ \\
\hline 23 & walpa & & Cañar: Sigsihuaicu-Cañar. \\
\hline 24 & wašpa & & Azuay: Zhiña-Nabón. \\
\hline
\end{tabular}

Fuente: el autor

\section{Variaciones morfofonéticas}

Los morfemas ligados cumplen un papel fundamental en la sintaxis de las oraciones en quichua. Unos morfemas ligados se presentan en un estado simple, pero también existen morfemas que han surgido como producto de un proceso denominado de reducción y ensamblaje de varios morfemas. Esto complica la determinación del número exacto de morfemas existentes en el quichua.

Previo a la presentación de las variaciones morfofonéticas o alomorfos de los diferentes morfemas, a continuación se presenta la clasificación los morfemas ligados presentes en el quichua ecuatoriano. Es ya tradición en la lingüística de agrupar a estos morfemas tomando en consideración si se unen a nombres, a raíces verbales o a los dos indistintamente. De ahí que se los clasifica en morfemas nominales, morfemas verbales, y morfemas independientes:

\section{Morfemas nominales}

Estos morfemas nominales se juntan a los nombres y son de dos clases: derivadores nominales y flexivos nominales. 


\section{4}

1. Derivadores nominales. Los morfemas derivadores son de importancia porque permiten la creación de nuevas palabras para representar nuevos objetos o nuevos conceptos que van surgiendo en la cultura. La derivación, junto con los calcos, los préstamos, los ensamblajes, y los de acuerdo social, sirven para enriquecer el vocabulario. Los morfemas derivadores o derivativos nominales se usan para obtener nuevos nombres o palabras a partir de un nombre o de un verbo.

1.1. Derivadores nominales denominativos. Estos morfemas obtienen nuevos nombres a partir de nombres. Entre ellos están:

- Posesivo $\{$-yuk\}. Así del nombre < wasi > 'casa' se tiene < wasiyuk> 'con casa, dueño de casa'.

- Diminutivos $\{-\mathrm{ku}$, -wa, lla $\}<$ wasiku, wasiwa, wasilla $>$ 'casita'.

- Aumentativo $\{$-sapa $\}<$ makisapa $>$ 'tipo de mono, persona con una mano manaza'.

- Inclusivo $\{$-ntin $\}<$ kusantin warmintin $>$ 'el marido conjuntamente con la mujer'.

- Agentivo $\{$-kamak\} < wasikamak> 'encargado de la casa'.

1.2. Derivadores nominales deverbativos. Con estos morfemas se obtienen nuevos nombres o adjetivos a partir de verbos. Para obtener nombres se toma la raíz verbal y a ella se añade los morfemas. Entre ellos se tiene:

- Agentivo $\{-\mathrm{k}\}$ del verbo puriy/purina 'caminar' se obtiene nombres como /purik/ 'caminante'.

- Instrumental $\{-n a\}$, el denominado infinitivo también puede indicar nombres referidos al objeto con el que se realiza la acción señalada por la raíz verbal, como: <pichana, mikuna, rasuyachina $>$ 'escoba, comida, refrigeradora' respectivamente.

- Infinitivizador $\{-y\}<$ pukllay, kay> 'el jugar, el ser', denominados verbos sustantivados. Aunque en Ecuador la forma infinitiva de los verbos se ha venido representando con la terminación $\{-n a\}$ (cf. "Sistema verbal", cap. 3). 


\section{5}

- Participial \{-shka\} <unkushka, shaykushka, sampayashka> 'enfermo, cansado en la Sierra, cansado en la Amazonía', respectivamente. Indica acción concluida.

- Aumentativo $\{$-ysiki $\}<$ machaysiki $>$ 'borrachoso, borrachin'.

2. Flexivos nominales. Los morfemas flexivos indican las funciones gramaticales del nombre. Sirven de conectores entre las palabras y en algunos casos hasta entre oraciones. De alguna manera equivalen a la función de las preposiciones y conjunciones del español. Unos se juntan al nombre. Estos morfemas nos permiten construir expresiones como frases, oraciones. Por lo tanto, son muy importantes para hablar la lengua.

2.1. Flexivos de persona. En el quichua ecuatoriano se ha considerado que han desaparecido, sin embargo, algunas investigaciones muestran que todavía subsisten los morfemas posesivos de persona como $\{-y\}<$ mamay $>$ 'mi madre' para primera persona, $\{$-yki $\}<$ mamayki $>$ 'tu madre', para segunda persona, $\{-\mathrm{n}\}<$ maman $>$ para tercera persona. Se debe continuar con investigaciones sobre este aspecto, y analizar la posibilidad de rescate de estos morfemas de persona para indicar la persona poseedora.

2.2. Flexivo de número plural. $\{$-kuna $\}<$ wawakuna $>$ 'niños'.

2.3. Flexivos de caso. Entre los casos más importantes están los siguientes:

- Genitivo-benefactivo $\{\text {-pa/pak }\}^{96}<$ Mariapa/Mariapak wasi, allkupa mikuna /allkupak mikuna > 'casa de María/casa para María, comida del perro/comida para el perro'.

- Acusativo $\{$-ta $\}<$ wasita rikuni> 'veo la casa'.

96 En el quichua ecuatoriano, desde el siglo XVIII, se constata que en el habla se han fusionado los casos genitivo con el dativo. Está en debate, hoy día, si se los vuelve a separar o si se los mantiene fusionados, debido a que hay una mínima diferencia en los semas de pertenencia y por el contexto se puede fácilmente diferenciarlos. Si se lo separa $\{$-pa $\}$ sería el caso genitivo y $\{-$ pak $\}$ el caso benefactivo. 


\section{6}

- Ilativo direccional $\{-\operatorname{man}\}<$ wasiman rini> 'voy a la casa, voy hacia la casa'.

- Ablativo originativo $\{$-manta $\}<$ wasimanta shamuni $>$ 'vengo de la casa, vengo desde la casa'. En algunos contextos se usa $\{-n\}$ como en <wasin wasin rin > 'va de casa en casa'.

- Locativo $\{$-pi $<$ wasipi kawsani> 'vivo en la casa'.

- Comitativo instrumental $\{$-wan $\}<$ wasiwan kusilla tiyakuni> 'estoy contento con la casa'.

- Limitativo \{-kama\}<wasikama rini> 'voy hasta la casa'.

- Causal $\{$-rayku $\}<$ kanrayku kushilla tiyakuni $>$ 'estoy feliz por ti'.

- Interactivo \{-pura\} <wawapura pukllakun> 'los niños están jugando entre ellos'.

- Comparativo $\{$-shina $\}$ <allkushina kawsanki> 'vives como perro'.

\section{Morfemas verbales}

Los morfemas verbales se junta a los verbos y son de dos clases: derivadores verbales y flexivos verbales.

1. Derivadores verbales. Estos morfemas obtienen verbos sea a partir de verbos o a partir de nombres.

1.1. Derivadores verbales deverbativos. Estos morfemas hacen que de un verbo se obtiene un nuevo verbo. Entre ellos se tiene los siguientes:

- Desiderativo $\{$-naya- $\}<$ purinayana $>$ 'tener deseos de caminar'.

- Continuativo $\{$-raya- $\}<$ purirayana $>$ 'caminar continuamente'.

- Repetitivo \{-paya- $<$ puripayana $>$ 'caminar como espiando'.

- Frecuentativo $\{$-kacha- $\}<$ purikachana $>$ 'caminar insistentemente'.

- Causativo $\{$-chi- $\}<$ purichina $>$ 'hacer caminar' <wañuchina $>$ 'matar, hacer morir'.

- Durativo $\{-\mathrm{ku}-\}<$ purikuna $>$ 'estar caminando'. Indica acción en proceso.

- Cislocativo $\{-\mathrm{mu}-\}<$ purimuna $>$ 'venir de caminar'. Indica venir de hacer la acción indicada por la raíz verbal. 


\section{7}

- Recíproco $\{$-naku- $<$ < purinakuna > 'caminar el uno hacia el otro'.

- Incoativo $\{-k r i-\}<$ purikrina $>$ 'ir a comenzar a caminar'. Indica inminente comienzo de la acción.

- Futurizador $\{$-nkaraku\} <purinkarakuna> 'estar a punto de comenzar a caminar'.

- Permisivo $\{$-pa- $\}<$ puripana $>$ 'permitirse caminar'.

1.2. Derivadores verbales denominativos. Estos morfemas permiten obtener nuevos verbos a partir de nombres. Entre ellos se tienen los siguientes:

- Transformativo $\{$-ya $\}<$ rumiyana $>$ 'hacerse piedra'.

- Factitivo $\{$-chi $\}<$ wasichina $>$ 'hacer una casa'.

- Desiderativo \{-naya $<$ warminayana > 'tener antojo de mujer'; karinayana 'tener antojo de varón'; yakunayana 'tener antojo de agua', etc. En este último morfema se pueden construir las expresiones de la siguiente manera: < ñukata yakunayanmi> '(a mi) me da antojo de agua'. Obsérvese que el verbo va en tercera persona singular. <Ñukaka yakunayachinimi> 'Tengo antojo de agua'. Obsérvese que en este último caso se tiene que añadir el morfema $\{$-chi- $\}$, luego de $\{$-naya- $\}$ para poder conjugar en primera persona.

1.3. Flexivos verbales. En este caso tenemos los siguientes:

- Tiempo presente, primera persona $\{-n i\}<$ purini $>$ 'camino'.

- Tiempo presente, segunda persona $\{-n k i\}<$ purinki $>$ 'caminas'.

- Tiempo presente, tercera persona singular, $\{-n\}<$ purín $>$ 'camina'.

- De personas 1a $2^{\text {a }}, 3^{\text {a }}$ del plural $\{$-nchik, nkichik, n(kun) $\}<$ mikunchik, mikunkichik, mikun(kuna) > 'comemos, coméis, comen'.

- De persona objeto de $2^{\mathrm{a}}$ o $3^{\mathrm{a}}$ a $1^{\mathrm{a}}\{$-wa- $\}<$ yanapaway, yanapawan> 'ayúdame, él/ella me ayuda'.

- Tiempo pasado $\{-r k a\}<$ purirkani, purirkanki>, etc. 'caminé, caminaste, etc.

- Tiempo futuro, primera persona singular $\{-$ sha $\}<$ purisha $>$ 'caminaré'. 


\section{8}

- Tiempo futuro, segunda persona singular $\{-n k i\}<$ purinki $>$ 'caminarás'.

- Tiempo futuro, tercera persona singular $\{-n k a\}<$ purinka $>$ 'caminará'.

- Tiempo futuro, primera persona plural $\{-\operatorname{shun}\}<$ purishun $>$ 'caminaremos'.

- Tiempo futuro, segunda persona plural $\{$-nkichik $\}<$ purinkichik> 'caminareis'

- Tiempo futuro, tercera persona plural $\{-$ nka(kuna) $\}<$ purinka (kuna)> 'caminarán'.

- Imperativo, segunda persona singular $\{-y\}<$ puriy $>$ 'camina'.

- Imperativo, tercera persona singular $\{$-chun $\}<$ purichun $>$ 'que camine'.

- Imperativo, segunda persona plural $\{$-ychik $\}<$ puriychik $>$ 'caminad, caminen'.

- Imperativo, tercera persona plural $\{$-chun(kuna)\} $<$ purichun(kuna) $>$ 'que caminen'.

- Flexión de subordinación, con diferentes sujetos $\{$-kpi $\}<$ Pay shamukpi, mikusha > 'Cuando él/ella venga, comeré'.

- Flexión de subordinación, con el mismo sujeto hace dos acciones $\{$-shpa $<$ Wasiman chayashpa mikusha $>$ 'Cuando llega a la casa, comeré'.

- Flexión de condicionalidad $\{$-man $\}<$ kullkita charishpaka shuk mushuk wasita rurayman; kullkita charishpaka shuk mushuk wasita rurankiman> 'si tuviera dinero, haría una nueva casa; si tuviera dinero, harías tu nueva casa', respectivamente.

\section{Morfemas independientes}

Estos morfemas pueden juntarse tanto a nombres como con verbos y su ámbito de influencia no solo es la palabra sino toda la oración. En algunos casos resulta difícil traducir el significado de estos morfemas independientes. En las oraciones en el quichua estándar, es obligación que los morfemas independientes, como el de afirmación $\{-\mathrm{mi}\}$, el mor- 


\section{9}

fema reportativo $\{$-shi $\}$, etc., vayan en la oración, aunque no tengan una equivalencia precisa en castellano.

- Topikalizador $\{-\mathrm{ka}\}<$ payka tarpuk runami kan> 'él es agricultor'.

- Afirmativo $\{$-mi $<$ runakunaka yakurayku tantarinchikmi> 'los indígenas nos unimos por el agua'.

- Afirmativo $\{$-mari $<$ runakunaka yakurayku tantarinchikmari> 'los indígenas nos unimos, realmente, por el agua'.

- Negativo $\{$ mana...chu $\}<$ runakunaka mana kullkiwanlla kawsanchikchu> 'los humanos no solo vivimos con dinero'.

- Interrogativo $\{$-chu $<$ kankunaka lumu aswata munankichikchu $>$ ¿ustedes quieren chicha de yuca?

- Dubitativo $\{$-chari\} < paykunaka shamunkachari> ‘será que vienen ellos/ellas?

- Contrastivo $\{$-tak $\}<$ shinallatak ruranami kanchik $>$ 'así debemos hacer'.

- Contrastivo $\{-\mathrm{rak}\}<$ kanka kawsakunkirakchu> 'tú, todavía vives'.

- Aditivo $\{$-pash $\}<$ kanpash, ñukapash kushillami kanchik> 'tú y también yo estamos felices'.

- Limitativo $\{$-lla $\}<$ ñukanchiklla sachaman rinchik> 'solo nosotros vamos a la selva'; <aswata upyaychiklla > 'tomen, no más, la chicha' o 'tomen la chicha sin recelo)'; <arilla ama illachu > 'que no falte el cumplimiento'.

- Deíctico $\{$-karin $<$ paykarin mana rurasha nin> 'él, aún más, dice que no ha de hacer'; <mana rishpakarin, yapata piñarinkami> 'si no se va, más todavía, se ha de enojar ella'.

- Reportativo $\{$-shi $\}<$ kaypi shuk hatun puma tiyashkashi $>$ 'se dice que aquí ha habido un puma grande’. 


\section{0}

De los 68 morfemas ligados del quichua ecuatoriano, ${ }^{97} 31$ son comunes con los protomorfemas señalados por Parker, 12 morfemas de los estudiados no tienen variación, 56 muestran variación, algunos de ellos mínimas, como es el caso del aumentativo \{-ruku\}, que en la Sierra se realiza como [ř uku] y en la Amazonía como [ruku], mientras que otros tienen mayor polimorfismo, como el caso del contrastivo $\{$-rak\}, que tiene ocho alomorfos. Solo tres morfemas diferencian a la Sierra de la Amazonía: el comparativo-clasificador $\{$-sami $\}$ y el propositivo $\{$-nkaraku- $\}$ son desarrollos de la Amazonía, y el propositivo $\{-\mathrm{k}-\mathrm{ri}\}$ es propio de la Sierra. En otros casos, la única diferencia es la existencia de morfemas poco usados en algunas zonas, por ejemplo, el morfema topicalizador $\{-k a\}$ es muy corriente en la Sierra y no así en la Amazonía; otro caso es el morfema honorífico $\{-\mathrm{pa}\},{ }^{98}$ que no es conocido en la Sierra sur, pero muy usado en el resto del país.

Entre los 12 morfemas que tienen pronunciación uniforme en todos los dialectos están los derivadores: el aumentativo \{-sapa $\}$, el concretizador $\{-n a\}$, el comparativo amazónico $\{$-sami $\}$, el reflexivo $\{-$ ri- $\}$, y el causativo $\{-c ̌ i-\}$. Entre los flexivos están el marcador verbal de primera persona singular $\{$-ni $\}$; el marcador verbal de segunda persona singular $\{-n k i\}$; el marcador verbal de tercera persona singular $\{-n\}$; el marcador verbal de primera persona singular de futuro $\{-$ ša $\}$; el marcador verbal de tercera persona singular del futuro $\{-n k a\}$; el marcador verbal de primera persona plural del futuro \{-šun\}; el marcador verbal del imperativo; y el infinitivo $\{-y\}$ (cf. "Sistema verbal", cap. 3). Entre los morfemas independientes que no varían están: el conjetural $\{$-ši $\}$ y la forma gramaticalizada $\{$-čari $\}$, de $\{-c ̌ u+$ ari $\}$. La no variación de estos morfemas constituye un argumento

97 Sin embargo se debe notar que existe un problema para contabilizar los morfemas del quichua ecuatoriano debido a la presencia de algunos morfemas como \{-nkarayku\}, en [mikungaraykuža šamuška] 'ha venido solo por comer', que son el resultado de procesos de reinterpretaciones, en este caso, a partir del morfema $\{-n k a\}$.

98 El morfema $\{$-pa- $\}$ se usa para mostrar una especie de respeto y consideración al interlocutor: [šamuy] 'ven', [šamupay] 'ten la bondad de venir'. 
importante para mostrar la unidad lingüística de los dialectos del Ecuador no solo a nivel de estructura abstracta, sino también en la concreta.

Como se mencionó al inicio de este capítulo, fue necesario realizar una investigación por separado de la pronunciación de los morfemas debido a que, en varios casos, estos tienen una realización geográfica particular. Así, en el morfema limitativo $\{-\lambda \mathrm{a}\}$, el fonema $/ \lambda /$ tiene un comportamiento diferente cuando está en este morfema que cuando aparece en el léxico.

Dicho comportamiento diferencial se puede apreciar en el siguiente fenómeno lingüístico que ocurre en la Sierra centro. Mientras en el léxico el fonema $/ \lambda /$ se realiza como $[z ̌]$ en todas las hablas de la Sierra centro, encambio en el morfema limitativo $\{-\lambda \mathrm{a}\}$, el fonema $/ \lambda /$ tiene tres formas $[\lambda]$, $[\check{z}]$, [1]. Ejemplo: / $\lambda$ aki $\lambda$ a/ 'un poco triste', se realiza como [žaki入a] en Guabug-San Juan-Riobamba, como [žakiža] en San Antonio de Rayaloma-Colta y como [žakila] en Pisicaz-San Juan-Riobamba. Las tres comunidades están a poca distancia entre sí y pertenecen a la misma provincia de Chimborazo.

El morfema $\{-\lambda \mathrm{a}\}$ se realiza como $[\lambda \mathrm{a}]$ en la Sierra sur, en la Amazonía y en Guabug, parroquia San Juan, provincia de Chimborazo que es parte de la Sierra centro. Se realiza como [la] en los siguientes lugares: la provincia de Pichincha, comunidad San Miguel del Común, parroquia Calderón, Cantón Quito; en la provincia de Cotopaxi, en las comunidades de la parroquia Chucchilán, cantón Sigchos, que está al occidente de la provincia; en la provincia de Chimborazo, en parte de las comunidades de la parroquia San Juan, en las comunidades de las parroquias de Cacha y Flores, del cantón Riobamba; y en las comunidades de las parroquias Cajabamba y Columbe, del cantón Colta. En el resto de Sierra centro y en toda la Sierra norte se realiza como [ža]. Por ejemplo, /yaykuyגa/'entra no más' se realiza como: 


\section{2}

[yaykuy $\lambda$ a Sierra sur, Amazonía y en la comunidad de Guabug de la Sierra centro

[yaykuyža] Sierra norte y parte de la Sierra centro

[yaykuyla] Sierra centro (en los sitios mencionados arriba)

\section{Grupos de morfemas que comparten una misma variación}

Existen algunos morfemas que coinciden en tener un mismo tipo de variación. A estos morfemas se los ha agrupado bajo la variación que comparten.

1. Lenición de / $k /$ en morfemas que terminan en este fonema. En los siguientes morfemas el fonema / $\mathrm{k}$ / varía de manera similar en todos ellos. Entre los morfemas involucrados están: nominal denominativo de posesión $\{-y u k\}$; nominal deverbativo agentivo $\{-\mathrm{k}\}$; nominal denominativo de oficio $\{-\operatorname{kamak}\} ;{ }^{99}$ flexivo nominal de caso posesivo-benefactivo $\{$-pak\}; flexivo verbal de primera persona plural $\{-n c ̌ i k] ;$ flexivo verbal de segunda persona plural $\{-n k i c ̌ i k\} ;$ flexivo verbal imperativo plural $\{$-yčik $\}$; independiente contrastivo $\{$-rak $\}$; independiente contrastivo $\{$-tak\}. En estos morfemas se puede observar el fenómeno de mutación fonética conocido como lenición de / $/$ /, consistente en el paso de un sonido fortis a lenis, llegando inclusive a desaparecer. El fonema final $/ \mathrm{k} /$ ha pasado en los lugares señalados por las siguientes etapas [k] $>\mathrm{g}>\mathrm{x}>\emptyset$. El fonema oclusivo se ha sonorizado en algunas regiones, en otras se ha fricativizado, y en otras ha desaparecido. Este fenómeno lingüístico no presenta mayor dificultad para la comprensión entre las diferentes hablas. A continuación detallamos geográficamente las distintas manifestaciones del morfema:

99 En la Sierra ecuatoriana el lexema <kamay $>$ significa 'abundar', mientras que en la Amazonía quiere decir 'probar'. 


\section{3}

Tabla 8

Variaciones del fonema / $\mathrm{k} /$ en el morfema agentivo $\{-\mathrm{k}\}$ y cuando aparece al final de los morfemas $\{$-yuk, -kamak, -tak, -pak, -rak, -nchik, -nkichik, -ychik\}

\begin{tabular}{|c|c|c|}
\hline Variación & Provincia & Comunidad \\
\hline \multirow{2}{*}[\mathbf{k}]{} & Sucumbíos & Santa Cecilia; Orellana: San Luis de Armenia, Loreto \\
\hline & Pastaza & Arajuno \\
\hline \multirow{5}{*}[\mathbf{g}\sim\emptyset]{} & Cotopaxi & Salacalle-Saquisilí, Sarahuasi-Chucchilán-Sigchos \\
\hline & Tungurahua & Chilcapamba-Salasaca-Pelileo \\
\hline & Bolívar & Papaloma-Simiatug-Guaranda \\
\hline & Cañar & Timburpamba-Juncal-Cañar, Quilloac-Cañar \\
\hline & Azuay & Gullanzhapa-Tarqui-Cuenca,Pucallpa-Zhiña-Nabón \\
\hline \multirow[b]{3}{*}[\mathbf{x}\sim\varnothing]{} & Imbabura & Moraleschupa-Cotacachi \\
\hline & Pichincha & Caucho Alto-Olmedo-Cayambe \\
\hline & Chimborazo & $\begin{array}{l}\text { Pisicaz-San Juan-Riobamba, San Antonio de Bashug- } \\
\text { Cacha-Riobamba, San Antonio de Rayaloma-Santia- } \\
\text { go de Quito-Colta, La Providencia-Columbe-Colta }\end{array}$ \\
\hline \multirow{2}{*}[\varnothing]{} & Imbabura & La Esperanza-San Roque-Antonio Ante \\
\hline & Pastaza & Atatarkwinjia, Canelos, Sarayacu, Montalvo \\
\hline
\end{tabular}

Fuente: el autor

2. Morfemas que contienen cambio vocálico. Los flexivos de caso genitivo-benefactivo $\{-\mathrm{pak}\}$, direccional $\{-\operatorname{man}\}$ y originativo $\{-\operatorname{manta}\}$ cambian su vocal /a/ > [u]; los morfemas independientes contrastivos $\{$-rak\} y $\{$-tak $\}$ sufren cambio vocálico /a/ $>$ [i]. Este fenómeno lingüístico ocurre en los lugares de la Sierra centro ya señalados en el capítulo 4 (cf."Willen F. Adelaar...").

\section{Morfemas nominales denominativos}

Estos morfemas permiten derivar nuevos nombres a partir de un nombre. Los que han tenido algún tipo de cambio son: el posesivo $\{-$ yuk $\}$, el inclusivo $\{-$ ntin $\}$ y los diminutivo $\{-\mathrm{ku}\},\{-\mathrm{wa}\}$ y $\{-\lambda \mathrm{a}\}$. 


\section{4}

Los fonemas integrantes de estos morfemas, excepto en $\{-\lambda a\}$, han variado siguiendo los patrones del léxico. Esto permite encontrar regularidades bastante generales entre los dialectos.

1. Posesivo $\{-y u k\}<{ }^{*}\{-y u q\}$. El fenómeno de lenición arriba señalado se observa en las variaciones de este morfema (Parker, 1969c/2013, p. 79). Por ejemplo: /wasiyukmi kani/ 'soy con casa, tengo casa.' ${ }^{100}$

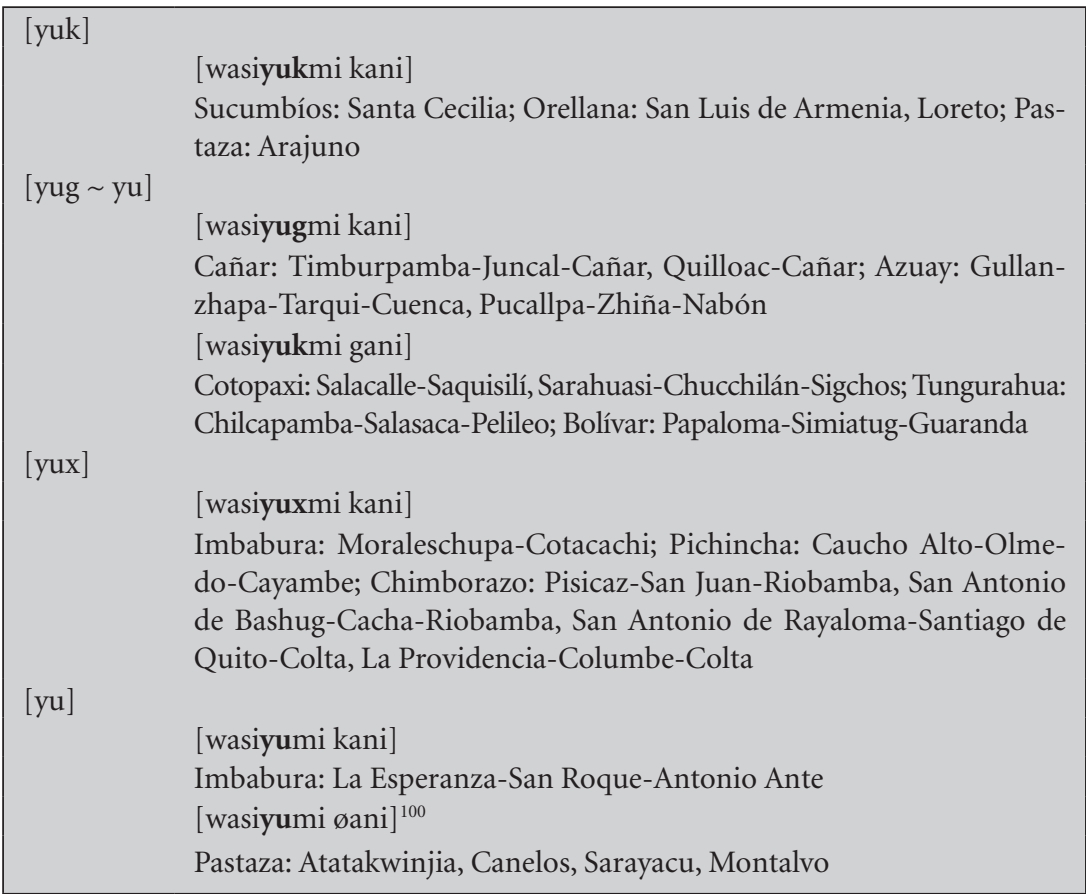

Este morfema es poco usado en Imbabura (Pijal-González-Suárez), Pichincha (San Miguel del Común-Calderón-Quito), y Loja (San

100 En las comunidades del río Bobonaza (prov. de Pastaza) el verbo ka- 'ser, estar' pierde el fonema $/ \mathrm{k} /$. 


\section{5}

Lucas). En estos sitios en lugar de /wasiyukmi kani/ prefieren decir / wasita čarini/, que literalmente sería 'agarro una casa'.

2. Inclusivo $\{-n t i n\}<{ }^{*}\{-$ tin $\}$. Parker postula $\{$-tin $\}$ para el protoquechua, pues considera que la $/ \mathrm{n} /$ precedente constituye un morfema aspectual aparte (Parker, 1969c/2013, p. 79). Su realización puede ofrecerse en dos grupos. El primero formado por las variaciones [ndin $\sim$ ndi], en el segundo de los cuales desaparece la /n/ final. El segundo grupo está formado por las realizaciones [ndig $\sim$ ndix] que provendrían posiblemente de una forma ${ }^{\star}\{-\mathrm{nti}+\mathrm{k}\}$ por analogía. En la conversación se percibe la variación, pero no hay problema para la mutua comprensión. Por ejemplo: /kusantin warmintin rinčik/ 'vamos juntos marido y mujer'.

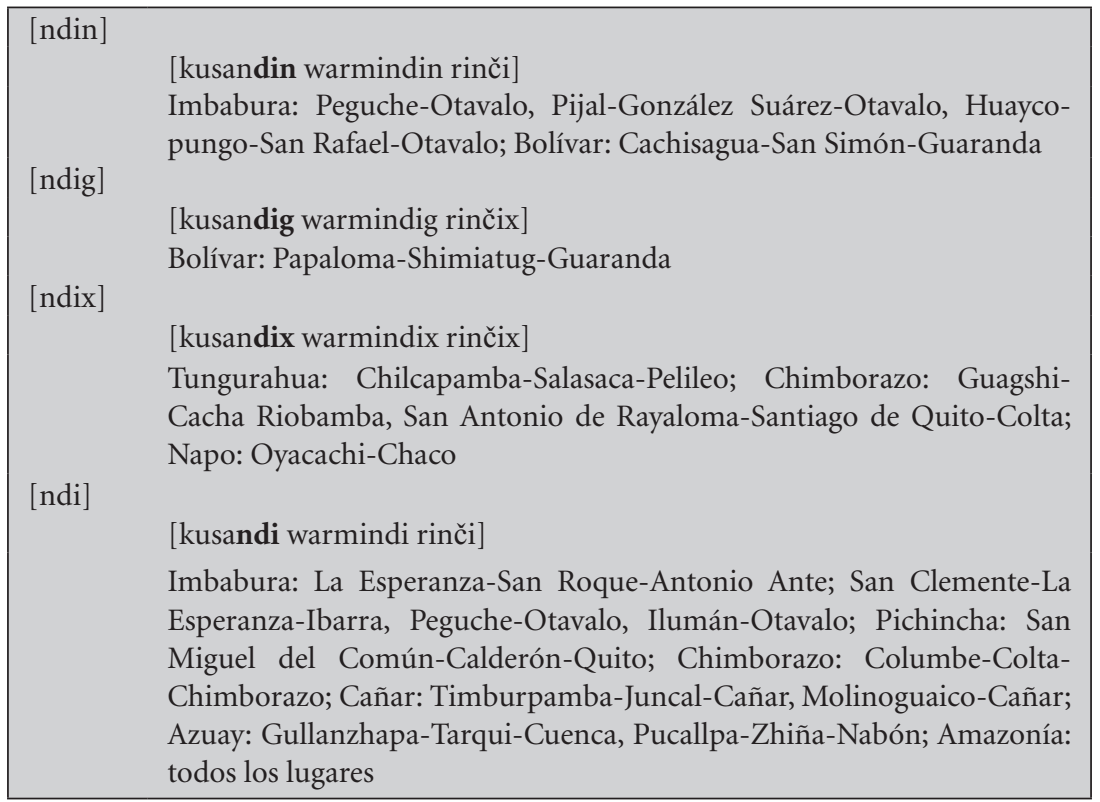

3. Aumentativo $\{-r u k u\}$. Este es un morfema de desarrollo propio de las hablas del Ecuador a partir del lexema /ruku/ 'adulto mayor'. Por 


\section{6}

ejemplo: /šuk hatun wasirukuta ruraškanki/ 'haz hecho una casa muy grande'.

\begin{tabular}{|ll|}
\hline [řku ruku] & [šuk hatun wasiřukuta řuřaškangi] \\
& En las comunidades de la Sierra \\
& \\
& [řuk hatun wasirukuta ruraskangi] \\
& En las comunidades de los ríos Putumayo, San Miguel y Sancudo \\
& (prov. de Sucumbíos), y en las comunidades del río Napo ubicadas \\
& desde el río Coca hacia abajo (prov. de Orellana) \\
& [šu atun wasirukura ruraškanki] \\
& En las comunidades de la provincia de Napo y en las comunidades \\
& ubicadas en el río Arajuno (prov. de Pastaza) \\
& [šuk hatun wasirukuta rurašøangi] \\
& En las comunidades del río Bobonaza \\
\hline
\end{tabular}

4. Diminutivo $\{-k u\}$. En la Sierra norte usan la combinación $\{-k u\}$ $+\{-\lambda \mathrm{a}\}$ para mostrar mayor aprecio. Por ejemplo: /ñuka warmikuta ačkatami $\mathrm{k}^{\mathrm{h}}$ uyani/ 'amo mucho a mi esposita', se manifiesta de la manera que sigue:

\begin{tabular}{|ll|}
\hline$[\mathrm{ku}]$ & \\
& {$[$ ñuka warmikuta aštakami xuyani] } \\
& Imbabura: Huaycopungo-San Rafael-Otavalo \\
& {$[$ ñuka warmikuta aškadami khuyani] } \\
& Cotopaxi: Sarahuasi-Chucchilán-Sigchos (en este lugar, se usa $\{-\mathrm{ku}\}$ cuando \\
& la persona a la que se refiere está presente y $\{$-wa $\}$ cuando está ausente) \\
{$[\mathrm{gu}]$} & \\
& [ñuka warmiguta aštakami xuyani] \\
& Imbabura: La Esperanza-San Roque-Antonio Ante, Pijal-González Suárez- \\
& Otavalo; Pichincha: Caucho Alto-Olmedo Cayambe; Sucumbíos: Santa \\
& Cecilia-Lago Agrio
\end{tabular}

5. Diminutivo $\{-w a\}$. Este es un morfema considerado como de desarrollo propio de la Sierra centro y se extiende hasta la Sierra norte y la Amazonía sur. En la Sierra centro es de uso general, en tanto que en 


\section{7}

la Sierra norte es de uso restringido. Se puede postular que el origen de este morfema está en el lexema /wawa/ 'bebé, pequeño', presente en el léxico del protoquechua de Parker (1969d/2013, p. 139). Por ejemplo: / ñuka warmiwata ačkatami $\mathrm{k}^{\mathrm{h}}$ uyani/ 'yo le quiero mucho a mi esposita'.

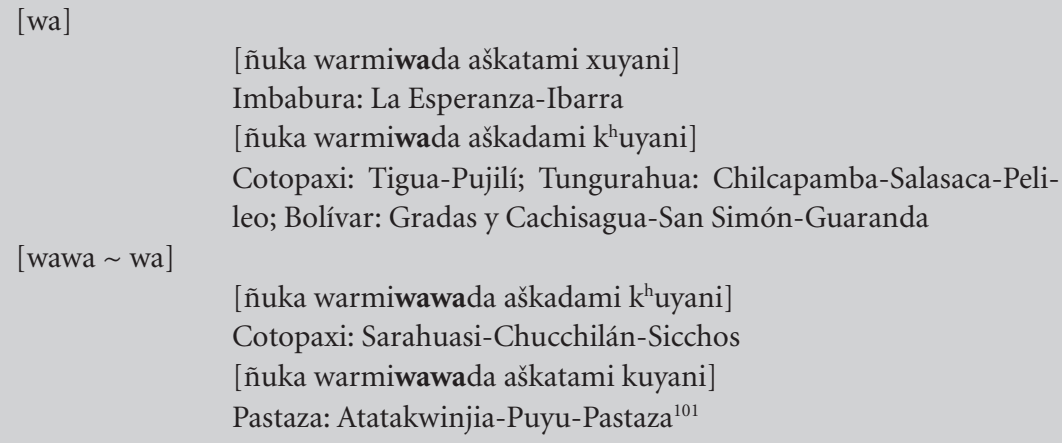

6. Diminutivo $\{-\lambda a\} .{ }^{102}$ Este morfema es usado en pocas comunidades de la Sierra sur y centro, debido a que se ha generalizado el morfema [zitu/a] tomado del diminutivo castellano. Por ejemplo: /ñuka mama入a/ 'mi madrecita'.

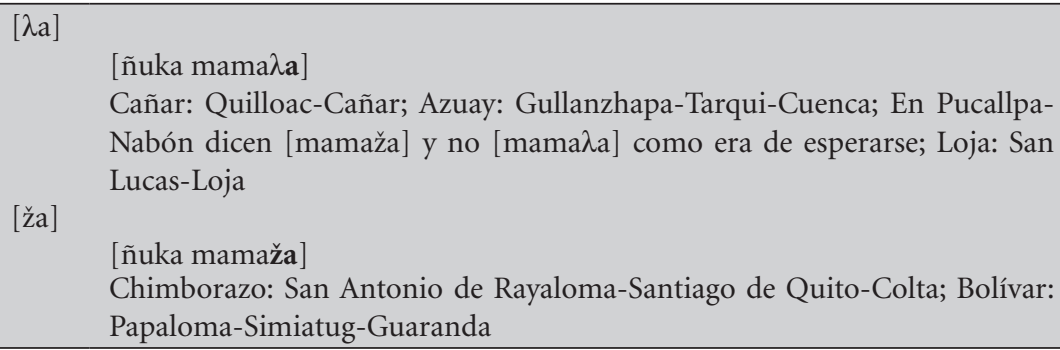

101 Esta ocurrencia demuestra, sin duda, que $\{-$ wa $\}$ sería la contracción de $\{$ wawa $\}$, como se ha señalado.

102 En la Sierra norte se dan expresiones en las que se juntan los dos diminutivos $\{-\mathrm{ku}\}$ y $\{-\lambda \mathrm{a}\}$. Así por ejemplo: [ñuka warmiguža] 'mi mujercita', [mamaguža] 'madrecita'. 


\section{8}

\section{Morfemas nominales deverbativos}

Estos morfemas permiten la creación de nuevos nombres a partir de verbos. Los que tienen variaciones son el agentivo $\{-\mathrm{k}\}$ y el participial $\{-$ ška $\}$

1. Agentivo $/ k /<^{*}\{-q\}$. Este morfema sufre el mencionado proceso de lenición $[\mathrm{k}]>[\mathrm{g}]>[\mathrm{x}]$ (Parker, 1969c/2013, p. 79). El ejemplo es: /payka yačakmi kan/ 'él es un sabio (chamán)’ y se manifiesta como:

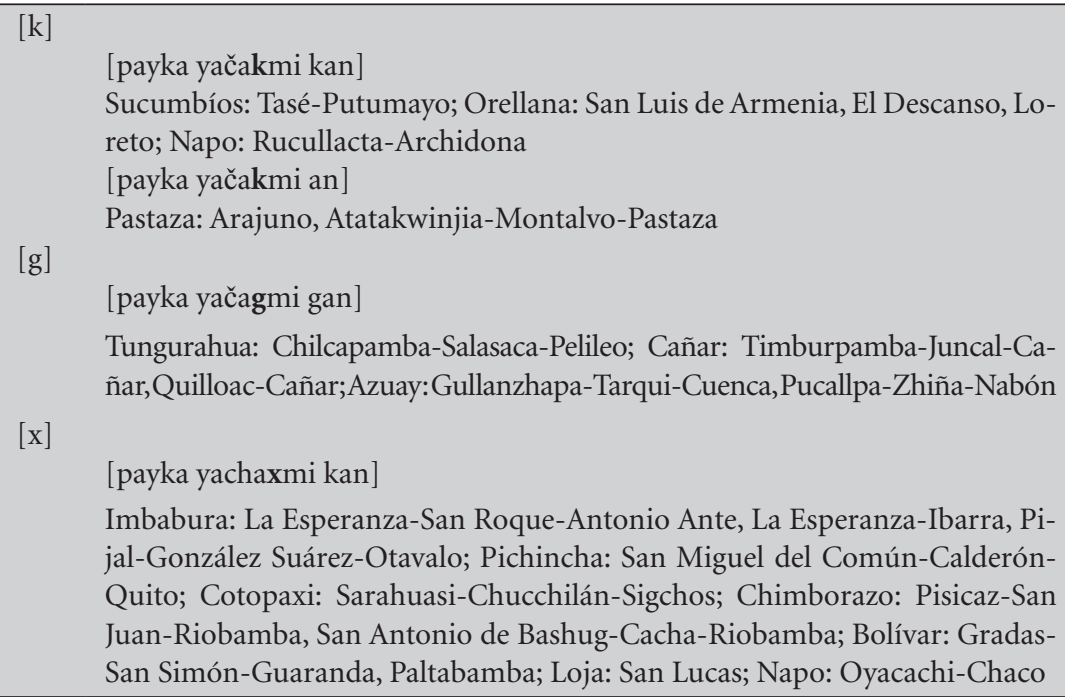

En Timburpamba (prov. de Cañar) también usan $\{$-dor/a $\}$ del español, por ejemplo: /yachachidora/ 'profesora'.

2. Participial $\{-s ̌ k a\}<*\{-\check{q} q a\}$. El ejemplo/unkuškata hampičikuni/ 'estoy haciendo curar al enfermo' se manifiesta como:

[ška]

[unkuškata hambičikuni]

Toda la Sierra

[unkuškara ampičiuni]

Provincia de Napo y comunidades del río Arajuno (prov. de Pastaza) 


\section{9}

\begin{tabular}{|l} 
[unkuškada hampičixuni] \\
Comunidades del río Bobonaza (prov. de Pastaza) \\
[unguskata hampičixuni] \\
Comunidades de los ríos Putumayo, San Miguel, Sancudo (prov. de Sucum- \\
bíos), y en las comunidades del río Napo, desde el río Coca hacia abajo (prov. \\
de Orellana). El cambio de [š] a [s] no se da en el léxico sino solo en este mor- \\
fema participial \{-ška $\}$ y en el subordinador $\{$-špa $\}$ del cual se trata más abajo \\
{$[\mathrm{k}] \quad\left[\right.$ ungukta hambičikuni] ${ }^{103}$} \\
Pucallpa-Zhiña-Nabón (prov. de Azuay); Oyacachi-Chaco (prov. de Napo)
\end{tabular}

Sobre el uso de [k] en Pucallpa y Oyacachi, se puede decir que es una sustitución del participial $\{$-ška\} por el agentivo $\{-\mathrm{k}\}$, debido posiblemente a la proximidad de los campos semánticos. En los demás dialectos se hace una diferenciación entre estos dos morfemas, en los que el participial muestra el resultado de una acción, en tanto que el agentivo muestra la acción en proceso. El ejemplo ilustrativo del uso de $\{-\mathrm{k}\}$ es la misma oración señalada arriba para \{-ška\}, es decir, /unkukta hampičikuni/. Así pues, $[\mathrm{k}]$ no es una variante de pronunciación de $\{$-ška $\}$, sino que se trata de una sustitución de este último por el agentivo $\{-\mathrm{k}\}$.

\section{Morfemas nominales flexivos}

Estos morfemas indican los roles y funciones de los nombres dentro de la oración. El quichua ecuatoriano no tiene los morfemas posesivos de persona, como el resto de dialectos quichuas de Perú y Bolivia. Solo se dan de número y caso. De ellos, los que presentan cambios son: el plural $\{$-kuna\}, los sufijos de caso genitivo-benefactivo $\{$-pak\}, acusativo $\{$-ta $\}$, ilativo $\{\operatorname{man}\}$, ablativo $\{$-manta $\}$, locativo $\{-$ pi $\}$, instru-

103 En este caso, [k] no es un alomorfo del morfema $\{-s k a\}$, sino simplemente otro uso dado al morfema agentivo $\{-\mathrm{k}\}$. 


\section{0}

mental comitativo $\{-$ wan $\}$, limitativo $\{$-kama $\}$, causal $\{$ rayku $\}$, interactivo $\{$-pura $\}$, y el comparativo $\{$-šina $\}$.

Los morfemas $\{$-pak $\},\{$-man $\},\{$-manta $\}$ cambian según las reglas generales que operan en los lexemas. Los otros morfemas presentan una variación compleja.

1. Pluralizador $\{-k u n a\}<*\{-k u n a\}$. Los alomorfos de este morfema son el resultado de lenición del fonema $/ \mathrm{k} /$, el cual se debilita hasta su desaparición (Parker, 1969c/2013, p. 81). El ejemplo /kaypika ačka runakuna kawsanmi/ 'aquí viven muchas personas', se da bajo las formas listadas que siguen:

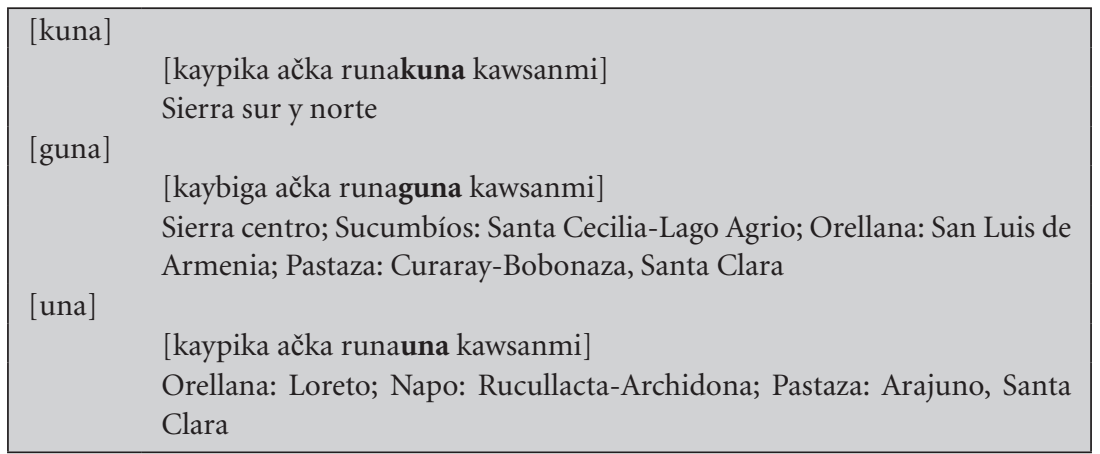

2. Genitivo-benefactivo $\{-p a k\}<{ }^{*}\{-p a\}$ para el genitivo ${ }^{*}\{-p a q\}$ para el benefactivo. ${ }^{104}$ En el Ecuador prácticamente se han fusionado los casos genitivo y benefactivo, tal como estos se manifiestan en el Perú (Parker, 1969c/2013, p. 81). En las variaciones de este morfema han intervenido dos procesos: la lenición del fonema /k/ y el cambio vocálico. En el caso de las hablas que están en algunos ríos de la provincia de Pastaza también existe el cambio de $[\mathrm{p}]>[\mathrm{w}]$. Aquí hay doble desgaste de $[\mathrm{p}]>\mathrm{b}>\mathrm{w}$.

104 De los numerales 2 al 12 pertenecen a la categoría "sufijos de caso". 
En Arajuno y Tena se dan las siguientes realizaciones: /pak/se manifiesta como [k] después de vocal, como [ba] después de consonante nasal y como [wa] en los otros contextos. En los mismo lugares se produce un fenómeno similar con el morfema aditivo $\{$-paš $\}$. Estas innovaciones que se dan en las hablas amazónicas complican su comprensión de parte de los hablantes de la Sierra. Los siguientes ejemplos del morfema \{-pak\} ilustran sus ocurrencias: /paypak kari/ 'tu marido', / kay mikunaka maryapakmi kan/ 'esta comida es para María':105

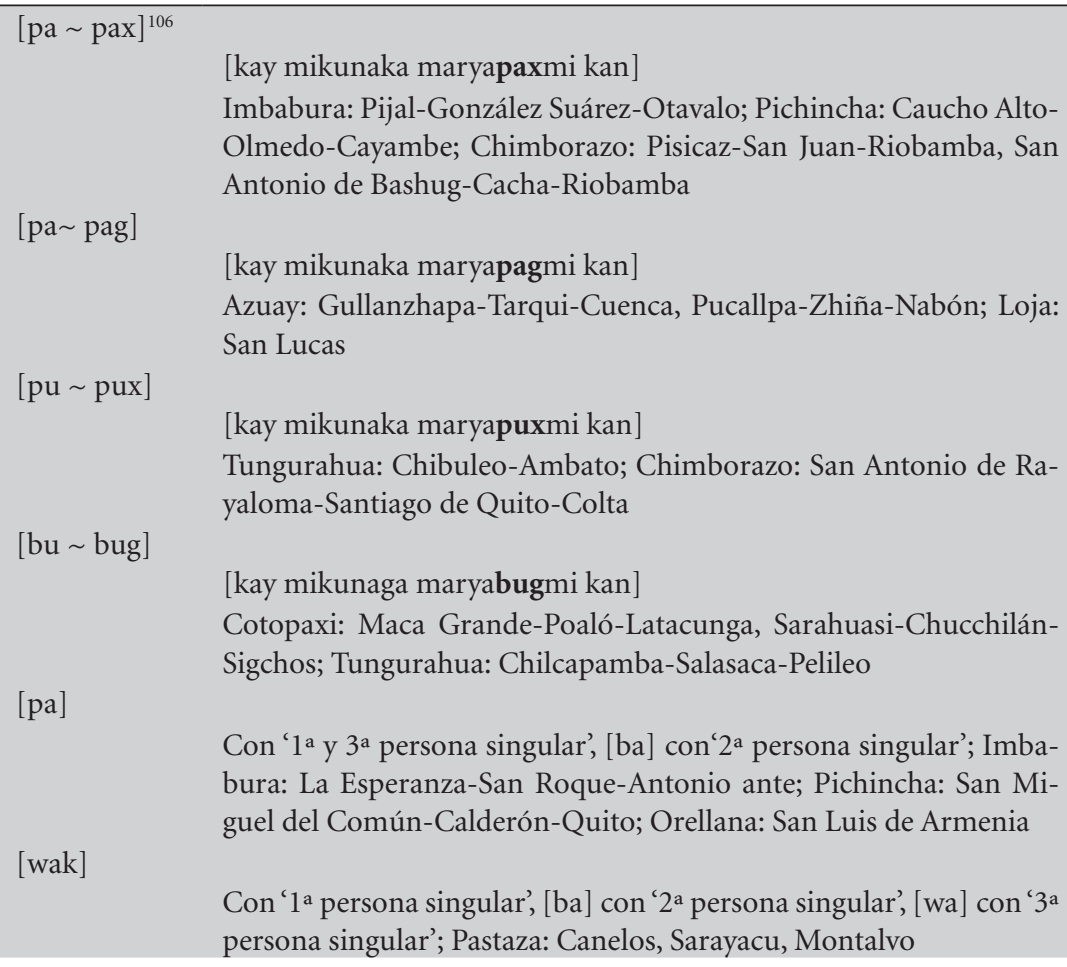

Con ' 1 a y $3^{\text {a }}$ persona singular', [ba] con' $2^{a}$ persona singular'; Imbabura: La Esperanza-San Roque-Antonio ante; Pichincha: San Miguel del Común-Calderón-Quito; Orellana: San Luis de Armenia

Con ' 1 a persona singular', [ba] con ' 2 a persona singular', [wa] con ' 3 a persona singular'; Pastaza: Canelos, Sarayacu, Montalvo

105 En la Sierra 'marido' se dice /kusa/ y en la Amazonía /kari/.

106 Después de nasal /p/ se sonoriza como en [kamba kari], excepto en la Sierra sur, donde no se sonoriza la /p/ después de nasal, manteniéndose como [kampa kari]. 


\section{2}

$[\mathrm{k}]$

Con ' 1 a persona singular', [ba] con ' 2 a persona singular', [wa] con ' 3 a persona singular'; Pastaza: Arajuno

3. Acusativo $\{-t a\}<{ }^{*}\{-k t a\}$. Las variaciones se explican por el proceso de lenición de $[\mathrm{t}]>\mathrm{d}$ y luego de d $>\mathrm{r}$ (Parker, 1969/2013, p. 81). La realización de /t/ como [r] en este morfema, que ocurre en algunas comunidades de la Amazonía, trae problemas de comprensión para los hablantes de la Sierra. El mismo fenómeno ocurre con el morfema independiente contrastivo $\{$-tak\}. Así por ejemplo, en la expresión /šina $\lambda$ atak/ se pronuncia [šina $\lambda$ ara $\chi$ ]. A continuación, las variaciones de /aswata munani/ 'quiero chicha'.

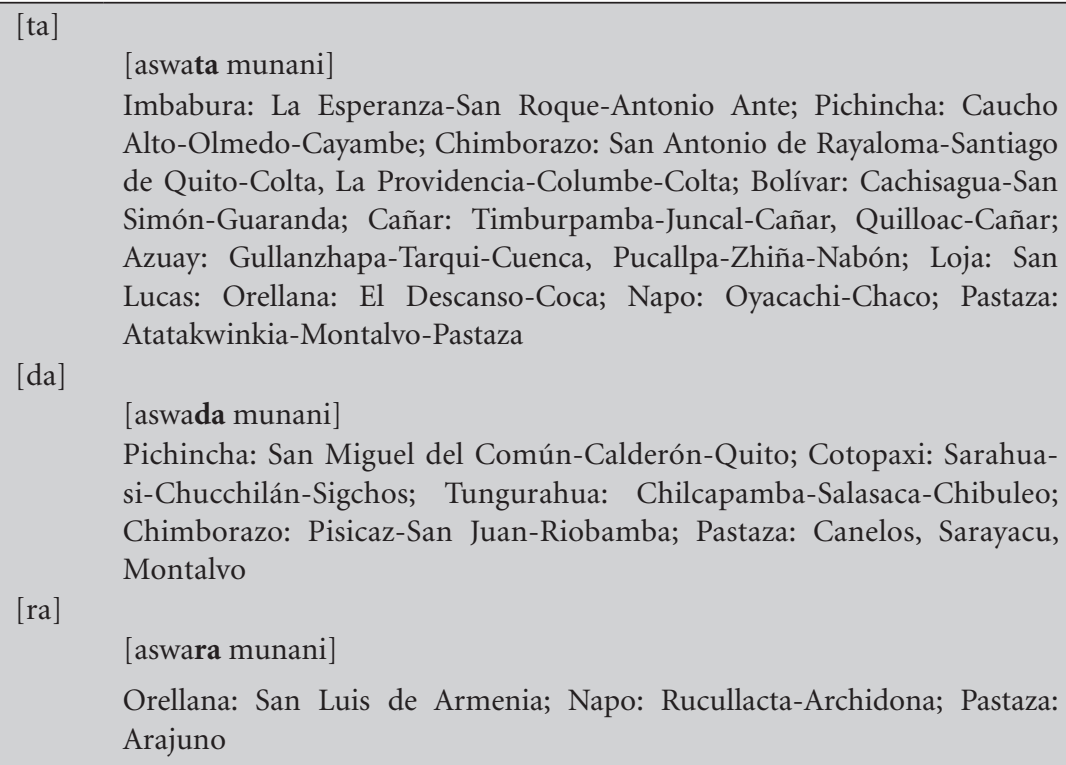
Alto-Olmedo-Cayambe; Chimborazo: San Antonio de Rayaloma-Santiago de Quito-Colta, La Providencia-Columbe-Colta; Bolívar: Cachisagua-San Simón-Guaranda; Cañar: Timburpamba-Juncal-Cañar, Quilloac-Cañar; Azuay: Gullanzhapa-Tarqui-Cuenca, Pucallpa-Zhiña-Nabón; Loja: San Lucas: Orellana: El Descanso-Coca; Napo: Oyacachi-Chaco; Pastaza: Atatakwinkia-Montalvo-Pastaza

[da]

[aswada munani]

Pichincha: San Miguel del Común-Calderón-Quito; Cotopaxi: Sarahuasi-Chucchilán-Sigchos; Tungurahua: Chilcapamba-Salasaca-Chibuleo; Chimborazo: Pisicaz-San Juan-Riobamba; Pastaza: Canelos, Sarayacu, Montalvo

$[\mathrm{ra}]$

[aswara munani]

Orellana: San Luis de Armenia; Napo: Rucullacta-Archidona; Pastaza: Arajuno

4. Ilativo $\{-\operatorname{man}\}<{ }^{*}\{-\operatorname{man}\}$. Este morfema sufre un cambio vocálico y un proceso de desaparición del su fonema final /n/ (Parker, 1969c/2013, p. 81). Por ejemplo: /llaktaman rini/ 'voy a la comunidad'. 


\section{3}

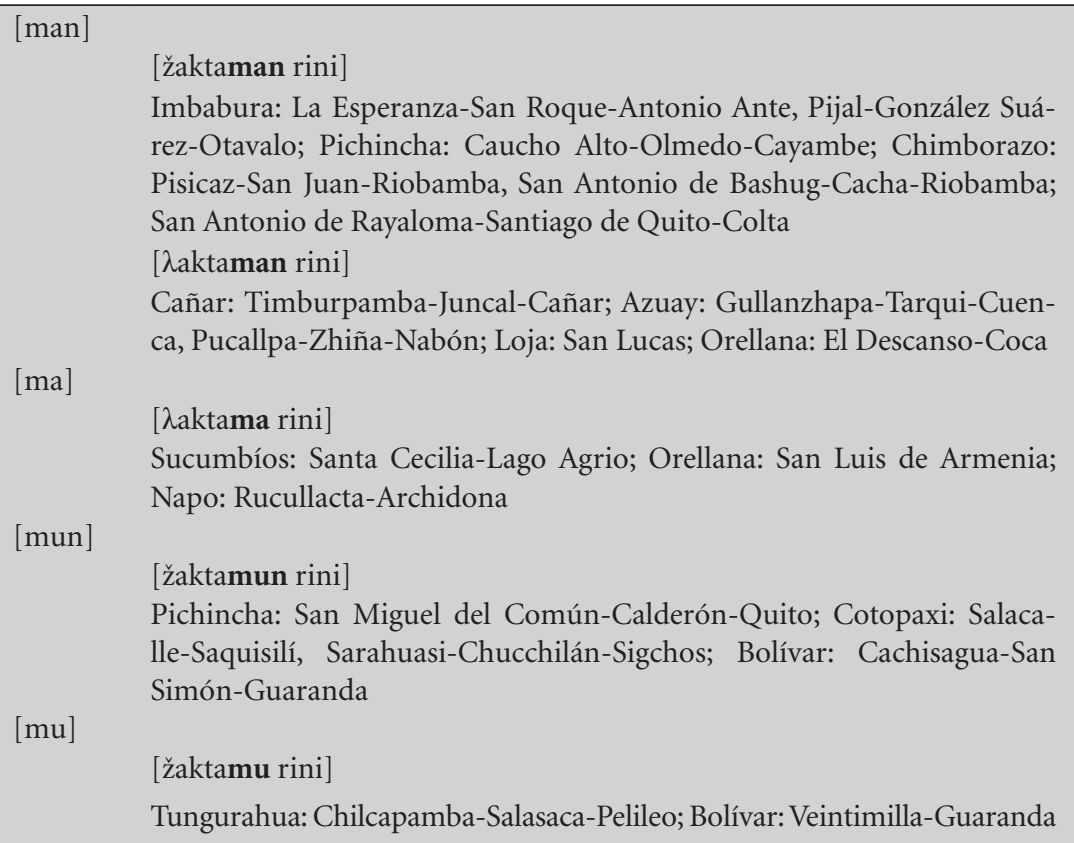

5. Locativo $\{-p i\}<{ }^{*}\{-p i\}$. Este morfema sufre el proceso de lenición de $/ \mathrm{p} /$, pasando de $[\mathrm{p}]>[\mathrm{b}]>[\varnothing]$ (Parker, 1969c/2013, p. 81). En términos de comprensión dialectal, la realización de /p/ como [ø], característica de la Amazonía centro presenta problemas para los hablantes de otras zonas. El ejemplo /wasipi kanka/'e stará en la casa' ilustra la ocurrencia de las variantes:

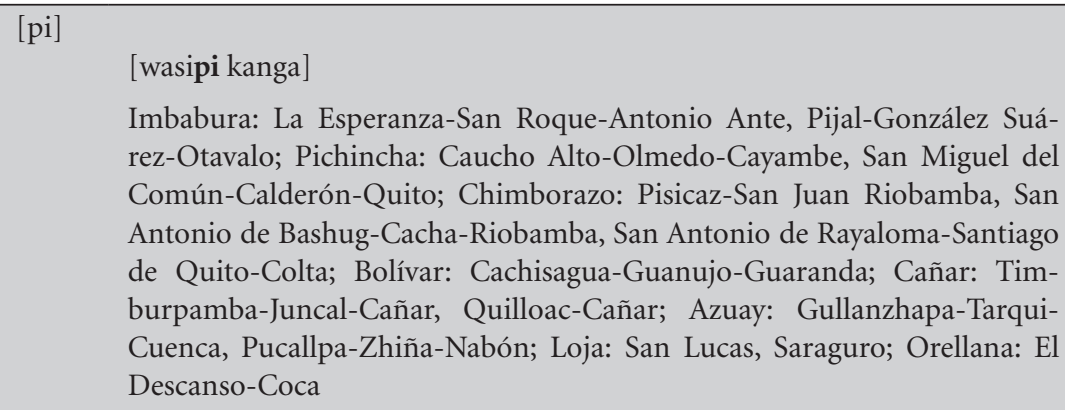




\section{4}

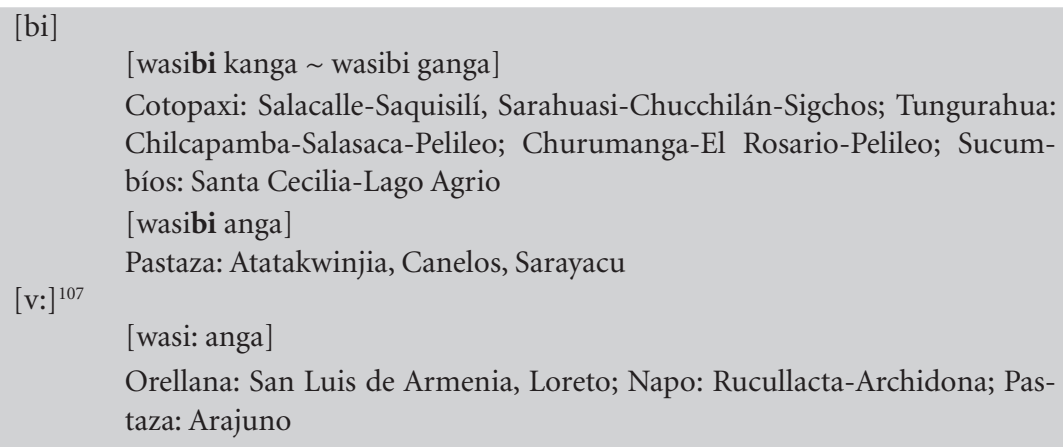

Orellana: San Luis de Armenia, Loreto; Napo: Rucullacta-Archidona; Pastaza: Arajuno

6. Instrumental-conmitativo $\{$-wan $\}<*\{$-wan $\}$. Se puede observar que en unos dialectos hay simplemente una caída del fonema $/ \mathrm{n} /$, en otros se da un cambio vocálico, pero en Salasaca hay elisión de los dos primeros fonemas (Parker, 1969c/2013, p. 81). Por ejemplo: /kusaška ayčata palantawan mikurkančik/ 'cominos la carne asada con plátano'.

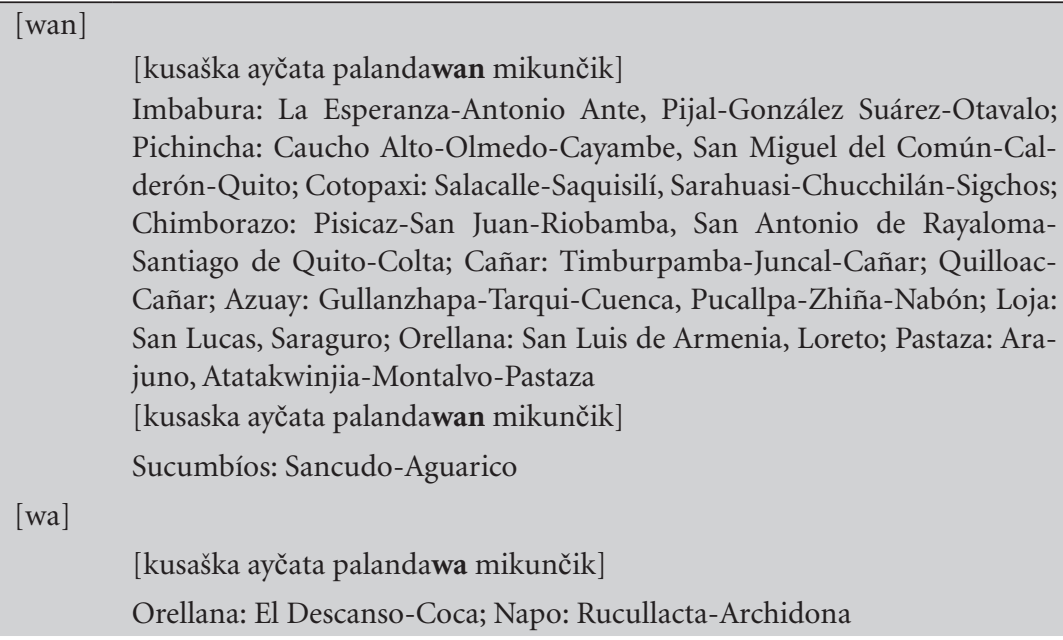

107 En estos lugares, después de un lexema que termina en /i/, el morfema \{-pi\} se manifiesta como un alargamiento vocálico [i:]. 


\section{5}

[wun]

[kusaška ayčata palandawun mikunčix]

Tungurahua: Chibuleo; Bolívar: Cachisagua-San Simón-Guaranda

$[\mathrm{n}]$

[kusaška ayčada palandan mikunči]

Tungurahua: Chilcapamba, Churuloma de Salasaca-Pelileo

En la comunidad Chilcapamba (prov. de Tungurahua), cuando el lexema termina en $/ \mathrm{n} /$ al unirse con la realización de este morfema, se tendría un segmento [nn]; para evitar esto no se añade /n/, que representa al morfema \{-wan\}, sino que este último se realiza como [yun], por ejemplo, [kanyun] 'contigo'. En la comunidad Rumiñahui Chico (prov. de Tungurahua) también dicen [gun], es decir, la expresión se realiza como [kangun].

7. Ablativo $\{$-manta $\}<*\{$-manta $\}$ para el PQA. Parker $(1969 \mathrm{c} / 2013$, p. 81) considera que el caso ablativo es propio de los dialectos modernos, particularmente de la rama sureña, sospecha que por ser bisilábico es una combinación de por lo menos dos morfemas. En el Ecuador, en las variaciones de este morfema se ha dado un proceso de sonorización de $[\mathrm{t}]>[\mathrm{d}]$. En la Sierra centro también sufre cambio vocálico de /a/ en /u/. El ejemplo / $\lambda$ aktamanta karuman rini/ 'me voy lejos de mi tierra' ilustra las diversas realizaciones:

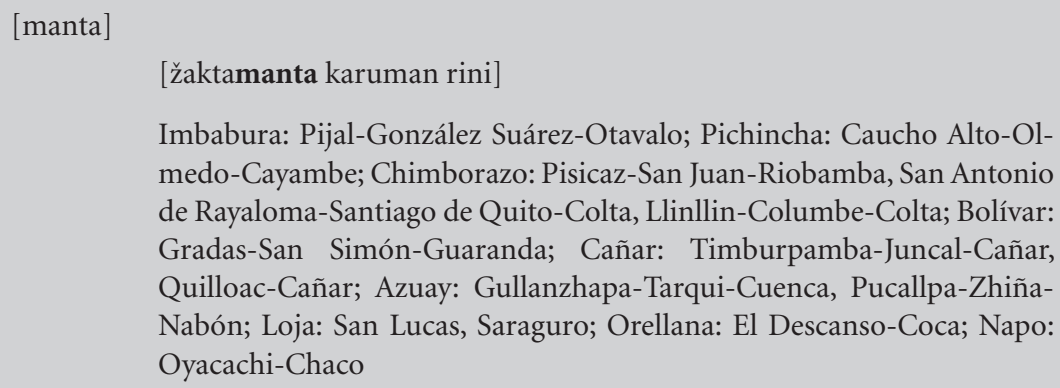




\section{6}

[manda]
[žaktamanda karuman rini]
Imbabura: La Esperanza-San Roque-Antonio Ante; Tungurahua: Chil-
capamba-Salasaca-Pelileo; Bolívar: Papaloma-Simiatug-Guaranda, Qui-
litagua-Guanujo-Guaranda, Vintimilla-Guaranda; Orellana: San Luis de
Armenia, Loreto; Pastaza: Arajuno, Atatakwinjia-Montalvo-Pastaza

8. Limitativo $\{-\mathrm{kama}\}{ }^{*}\{-\mathrm{yaq}\}$. Las variaciones que muestra este sufijo son casi irrelevantes (Parker, 1969c/2013, p. 81). Solo sufre la sonorización de /k/ y, en algunas hablas, el incremento de /n/. Tales cambios son irrelevantes para la intercomprensión. Se tiene el ejemplo de /urkukama purišun/ 'caminamos hasta el cerro' como ilustración de su ocurrencia:

\begin{tabular}{|ll|}
\hline [kama] & [urkukama purišun] \\
& Pichincha: Cauchu Alto-Olmedo-Cayambe; Chimborazo: Pisicaz-San \\
& Juan Riobamba, San Antonio de Rayaloma-Santiago de Quito-Colta; \\
& Bolívar: Gradas-Guaranda, Cachisagua-Guaranda, San Simón-Gua- \\
& randa; Cañar: Timburpamba-Juncal-Cañar, Quilloac-Cañar; Loja: \\
& San Lucas, Saraguro; Sucumbíos: Santa Cecilia; Orellana: San Luis de \\
& Armenia, Lorero; Napo: Oyacachi-Chaco; Pastaza: Atatakwinjia \\
[kaman $]^{108}$ & \\
& [urkukaman purišun]
\end{tabular}

108 Parker considera que el sufijo $\{-\mathrm{n}\}$ es de significado oscuro y que podría ser un aspectual. 


\section{7}

\begin{tabular}{|l} 
Imbabura: La Esperanza-San Roque-Antonio Ante, Peguche-Miguel \\
Egas-Otavalo; Pijal-González-Suárez-Otavalo; Pichincha: San Miguel \\
del Común-Calderón-Quito; Azuay: Gullanzhapa-Tarqui-Cuenca, \\
Pucallpa-Zhiña-Nabón \\
[gama] \\
Cotopaxama purišun] \\
Salasaca-Pelileo
\end{tabular}

9. Causal $\{-r a y k u\}$. Las variaciones de pronunciación de este morfema son casi imperceptibles, como lo ilustra el ejemplo/payrayku $\lambda$ aki kawsani/ 'a causa de ella vivo triste'.

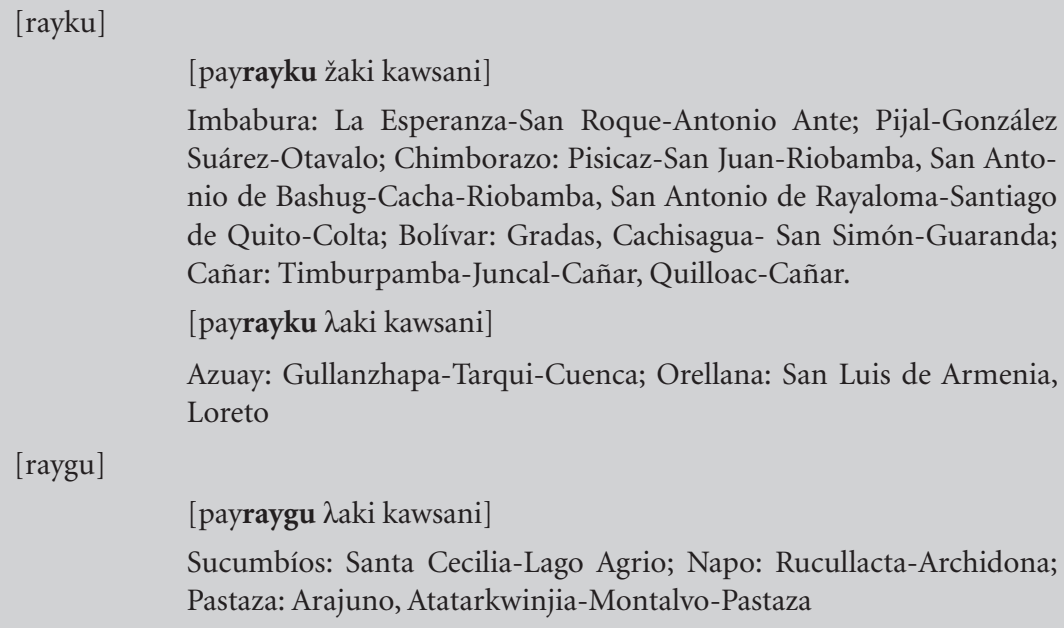

En algunas comunidades de la Sierra este morfema es poco usado, debido a que se lo sustituye por $\{$ manta $\} .{ }^{109}$ Así, se dice /paymanta $\lambda$ aki $\lambda$ a kawsani/ 'por ella estoy triste'. Se usan las variantes del morfe-

109 Esto es extraño desde el momento en que uno de los valores de $\{$-manta $\}$ es el de indicar procedencia (causa). 


\section{8}

ma $\{$-manta $\}$ en Caucho Alto (prov. de Pichincha), Sarahuasi (prov. de Cotopaxi) y Chilcapamba (prov. de Tungurahua).

10. Interactivo $\{-$ pura $\}<\{-$ pura $\}$. En unos lugares este morfema solo indica interacción entre miembros de la misma clase y para indicar la pluralidad coocurre con el morfema \{-kuna\} (Parker, 1976, p. 89), sin embargo, en la mayoría de lugares este morfema indica ambas cosas: interacción y pluralidad. El ejemplo /wawapura puk $\lambda$ akun/ 'están jugando entre niños' ilustra su ocurrencia:

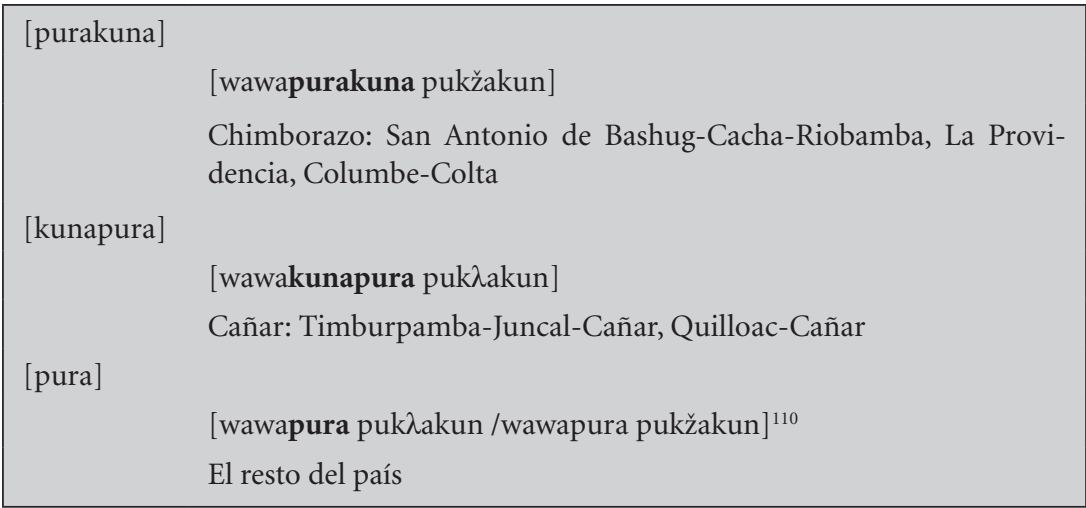

11. Comparativo \{-šina\}. Este morfema tiene su origen en el lexema /šina/ 'así/, habiendo sufrido un proceso de sufijación. Sus variantes presentan una reducción formal. El caso de Salasaca es único debido a que su sibililante fricativa se transforma en africada. El ejemplo / a $\lambda$ kušina kawsanki/ 'vives como perro', muestra sus realizaciones:

110 Para obtener más variaciones dialectales de la expresión, ver realizaciones de los morfemas $\{-\lambda \mathrm{a}\},\{-\mathrm{ku}\}$ y $\{-\mathrm{kuna}\}$. 


\section{9}

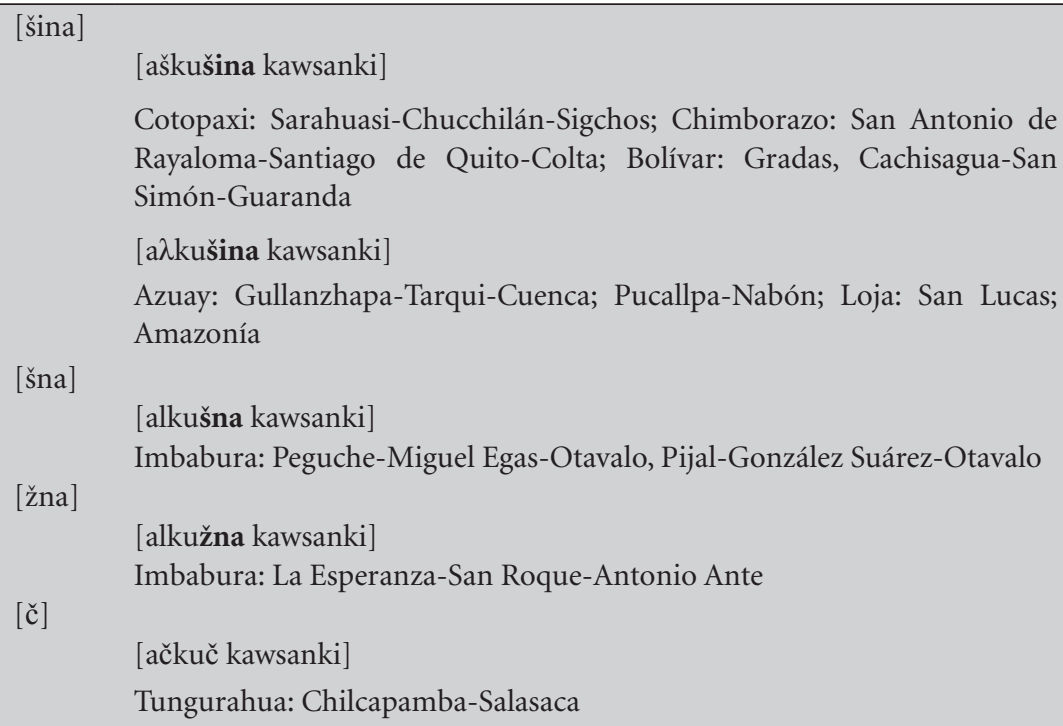

Nótese que en lugar de este morfema se usa \{-laya\}, tomado del castellano, en Pisicaz (prov. de Chimborazo), Gradas (prov. de Bolívar) y Timburpamba (prov. de Cañar). En San Miguel del Común (prov. de Pichincha) usan [yala], que es la variante metatizada de la forma proveniente del castellano.

12. Comparativo $\{$ sami $\}$. Este es un desarrollo propio de la Amazonía, no es posible saberse si \{-sami\} era un lexema para significar 'tipo, clase' antes de transformarse en morfema ligado. El ejemplo es / tukuysami muyuta apamun/ 'Trae toda clase de frutos' y se realiza como [sami] en toda la Amazonía.

\section{Morfemas verbalizadores deverbativos}

Algunos investigadores como Muysken (1977, p. 108) y Carpenter (1982, p. 284) han considerado la existencia del morfema $\{-\mathrm{mu}-\}$ como un cislocativo. En esta investigación, aunque se constata que exis- 
te el verbo <apamu-> 'traer', formado a partir del verbo < apa-> 'llevar', en otros casos parece que este morfema se ha ensamblado con el lexema /ša-/ 'estar de pie. La mayor parte de comunidades prefieren usar el gerundio del verbo seguido del verbo $\{$ šamu- $\}$ donde el morfema $\{-\mathrm{mu}\}$ está soldado, en consecuencia, las expresiones se realizan como [-špa šamu $\sim$ š šamu-]. Así, se tiene [čagrata rikušpa šamuni čagrata rikuš šamuni] en Caucho Alto (prov. de Pichincha) y San Antonio de Rayaloma (prov. de Chimborazo), mientras en otros lugares usan la forma corta y la forma larga [čagrata rikumuni] o también [čagrata rikušpa šamuni čagrata rikuš šamuni] 'vengo de ver la cementera'. En La Esperanza y Pijal (prov. de Imbabura), Sarahuasi (prov. de Cotopaxi), Rumiñahui Chico (prov. de Tungurahua), Pisicaz y San Antonio (prov. de Chimborazo), Cachisagua (prov. de Bolívar), Quilloac (prov. de Cañar), Gullanzhapa (prov. de Azuay) y en la Amazonía, prefieren usar la forma corta [čagrata rikumuni].

Los morfemas verbalizadores deverbativos permiten obtener nuevos verbos a partir de verbos. De ellos, los que han tenido innovaciones en su realización son el desiderativo $\{$-naya- $\}$, el habitual $\{$-raya- $\}$, el intensivo $\{$-paya- $\}$, el durativo $\{-\mathrm{ku}-\}$, el recíproco $\{$-naku- $\}$, el cualificador $\{$-ykača- $\}$, el político $\{-$ pa- $\}$, el prospectivo $\{-k r i-\}$, el prospectivo próximo $\{-n k a r a k u-\}$ y el incorporativo $\{-\lambda \mathrm{i}\}$.

Algunos de ellos no se usan en todas las zonas. Así, el intensivo \{-paya\} no es conocido en Orellana (El Descanso), Napo (Rucullacta) o Pastaza (Atatarkwinjia). El morfema cualificador $\{$-ykača $\}$ no se emplea en Imbabura (Pijal). En otras comunidades también se lo emplea muy poco, como se verá más adelante.

1. Desiderativo $\{$-naya $\}<{ }^{*}\{$-naya $\}$. Este morfema sufre un proceso de reducción de fonemas sin que por eso pierda su significado original: $\{$-naya- $\}>$ nay $>$ [nya] $>$ [ña] (Parker, 1969c/2013, p. 83). El ejemplo /ñukata ñami mikunayan/ 'ya me da ganas de comer' ilustra los casos pertinentes: 


\begin{tabular}{|c|c|}
\hline \multicolumn{2}{|l|}{ [naya] } \\
\hline & [ñami ñukata mikunayan] \\
\hline & $\begin{array}{l}\text { Imbabura: La Esperanza-San Roque-Antonio Ante, Pijal-González Suá- } \\
\text { rez-Otavalo; Cotopaxi: Sarahuasi-Chucchilán-Sigchos; Chimborazo: Pi- } \\
\text { sicaz-San Juan-Riobamba, San Antonio de Bashug-Cacha-Riobamba; Bo- } \\
\text { lívar: Gradas-San Simón-Guaranda; Azuay: Gullanzhapa-Tarqui-Cuenca; } \\
\text { Loja: San Lucas, Saraguro; Pastaza: Atatakwinjia-Montalvo-Pastaza }\end{array}$ \\
\hline \multicolumn{2}{|l|}{ [nay] } \\
\hline & [ñami ñukada mikunayn] \\
\hline & $\begin{array}{l}\text { Tungurahua: Rumiñahui Chico-Salasaca-Pelileo; Sucumbíos: Santa Ceci- } \\
\text { lia-Lago Agrio; Pastaza: Arajuno }\end{array}$ \\
\hline \multicolumn{2}{|r|}{ 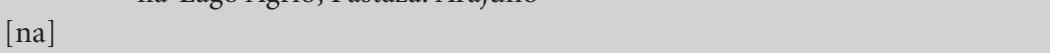 } \\
\hline & [ñami ñukata mikunan] \\
\hline & Pichincha: San Miguel del Común-Calderón-Quito \\
\hline \multicolumn{2}{|l|}{ [ña] } \\
\hline & [ñami ñukata mikuñan] \\
\hline & $\begin{array}{l}\text { Pichincha: Caucho Alto-Olmedo-Cayambe; Orellana: San Luis de Arme- } \\
\text { nia, Loreto; Napo: Oyacachi-Chaco, Rucullacta-Archidona }\end{array}$ \\
\hline
\end{tabular}

2. Continuativo $\{$-raya $\}<^{*}\{-r a-/-$ raya- $\}$. Las variantes muestran el mismo proceso de reducción de fonemas, sin que ello signifique perder el significado de la forma original (Parker, 1969c/2013, p. 83). En las realizaciones del ejemplo /payka purirayašpami kaynarka/ 'él pasó caminando el día’ se pueden apreciar los cambios anunciados.

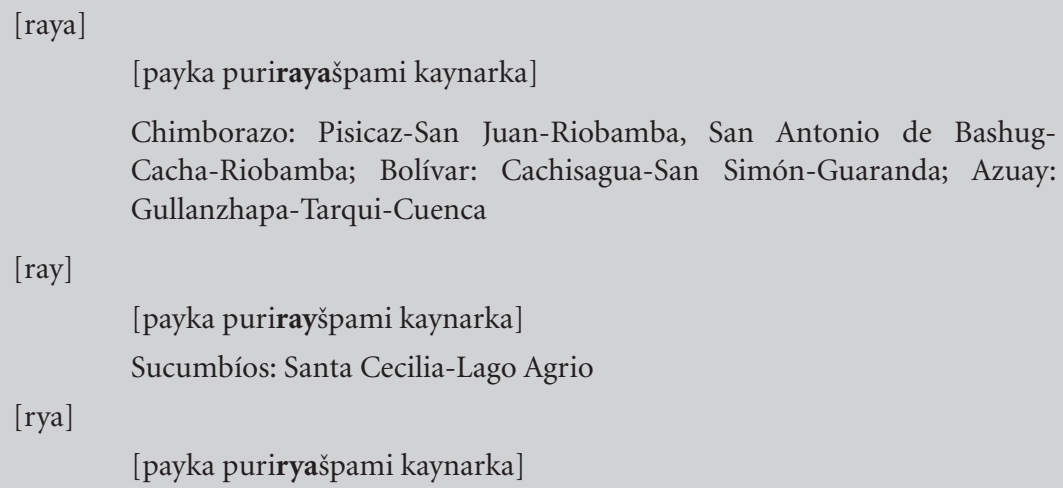

Chimborazo: Pisicaz-San Juan-Riobamba, San Antonio de BashugCacha-Riobamba; Bolívar: Cachisagua-San Simón-Guaranda; Azuay: Gullanzhapa-Tarqui-Cuenca

[ray]

[payka purirayšpami kaynarka]

Sucumbíos: Santa Cecilia-Lago Agrio

[rya]

[payka puriryašpami kaynarka] 


\section{2}

\begin{tabular}{|l} 
Imbabura: La Esperanza-San Roque-Antonio Ante, Pijal-González Suárez- \\
Otavalo; Pichincha: Caucho Alto-Olmedo-Cayambe; Cañar: Quilloac-Cañar \\
[ryu \\
\\
$\quad$ Orellana: San Luis de Armenia, Loreto; Pastaza: Arajuno \\
[ri] \\
[payka puririšpami kaynarka] \\
Cañar: Timburpamba-Juncal-Cañar, Quilloac-Cañar; Azuay: Gullanzha- \\
pa-Tarqui-Cuenca, Pucallpa-Nabón
\end{tabular}

En algunos lugares, las ideas de continuidad y permanencia se expresan a través de otras formas. Así, en Pichincha (San Miguel del Común) dicen [purišala kaynarka] y en Orellana (El Descanso) dicen

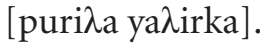

3. Intensivo $\{-$ paya $\}<{ }^{*}\{-$ paya $\}$. Este morfema es usado en pocos lugares (Parker, 1969c/2013, p. 83). Por ejemplo: /paymi ñukata rikupayakun/ 'él me mira intensamente'.

\section{[paya]}

Pichincha: Caucho Alto-Olmedo-Cayambe, San Miguel del Común-Calderón-Quito; Cotopaxi: Sarahuasi-Chucchilán-Sigchos; Bolívar: Gradas, Cachisagua-San Simón-Guaranda; Loja: San Lucas; Sucumbíos: Santa Cecilia-Lago Agrio

No se usa en lugares como Orellana (El Descanso), Napo (Rucullacta) o Pastaza (Atatakwinjia).

4. Durativo $\{-k u\}$. Este es un morfema de desarrollo propio en el Ecuador, pues Parker (1963-1972/2013, p. 84) propone $\star^{\star}$-yka- $\}$ como morfema durativo del protoquechua. Este morfema sufre el proceso de lenición del fonema $/ \mathrm{k} /$, dando como resultado los alomorfos $\mathrm{ku}>\mathrm{gu}$ $>$ u. Evidentemente, el último alomorfo causa dificultades en la comprensión mutua. El ejemplo /kanta maškakurkani/, 'estuve buscándote' ilustra su realización: 


\section{3}

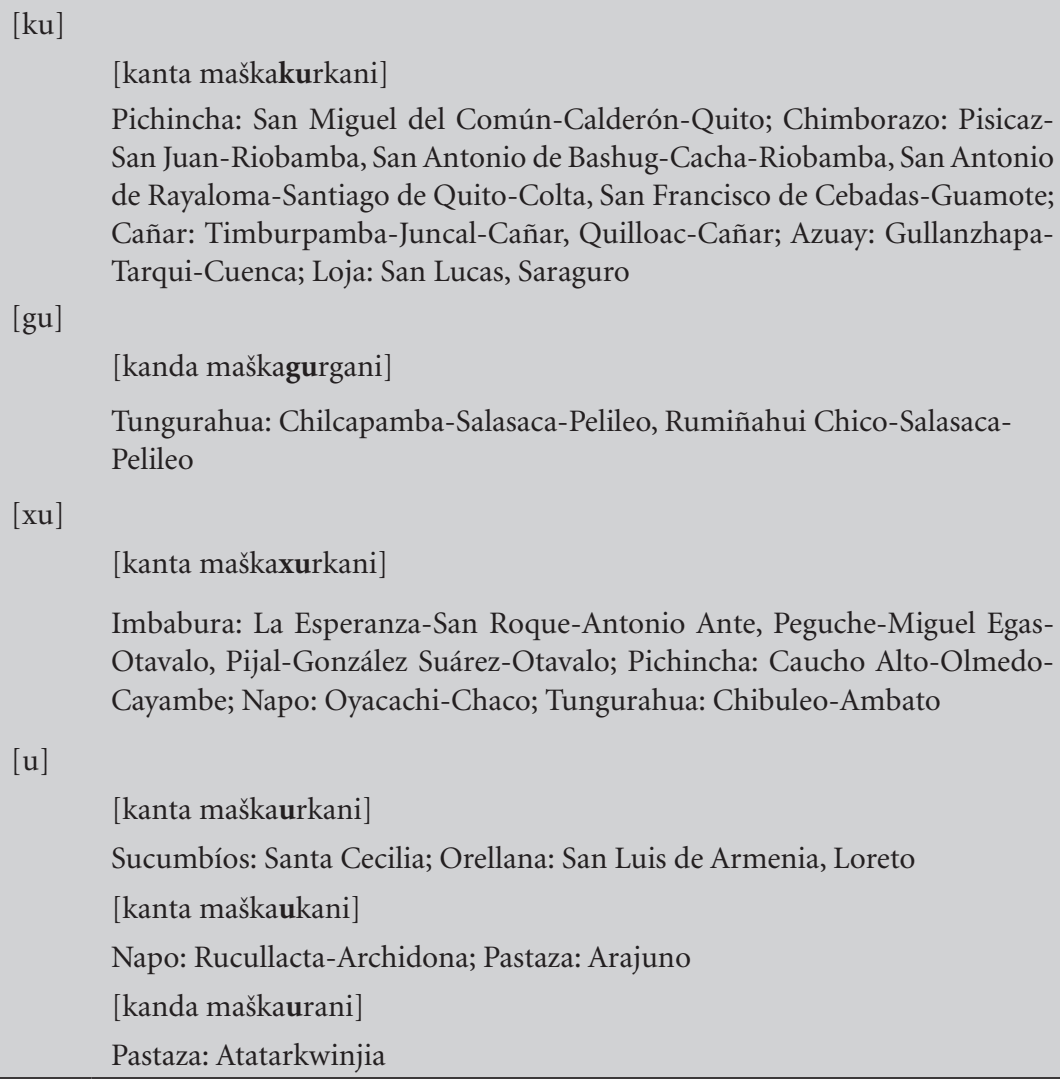

5. Recíproco $\{-n a k u\}<{ }^{*}\{-n a-\}$. Analizando las variaciones se puede observar que hay lenición del primer fonema $/ \mathrm{k} /$ del morfema, produciéndose los siguientes alomorfos [naku $>$ nagu $>$ naxu $>$ nau] (Parker, 1969/2013, p. 83). En Salasaca (2) ${ }^{111}$ también hay cambio vocálico en la primera sílaba, dando como resultado [nuku]. En la Amazonía entera

111 En Salasaca, en la misma comunidad de Chilcapamba, existen dos formas distintas: [nagu] y [nuku], a la primera se la ha identificado con el número 1 y a la segunda con el 2. 


\section{4}

hay supresión de la secuencia de fonemas /ak/. El ejemplo /kaynaka sumakta rimanakurkančik/ 'ayer conversarmos' muestra las realizaciones:

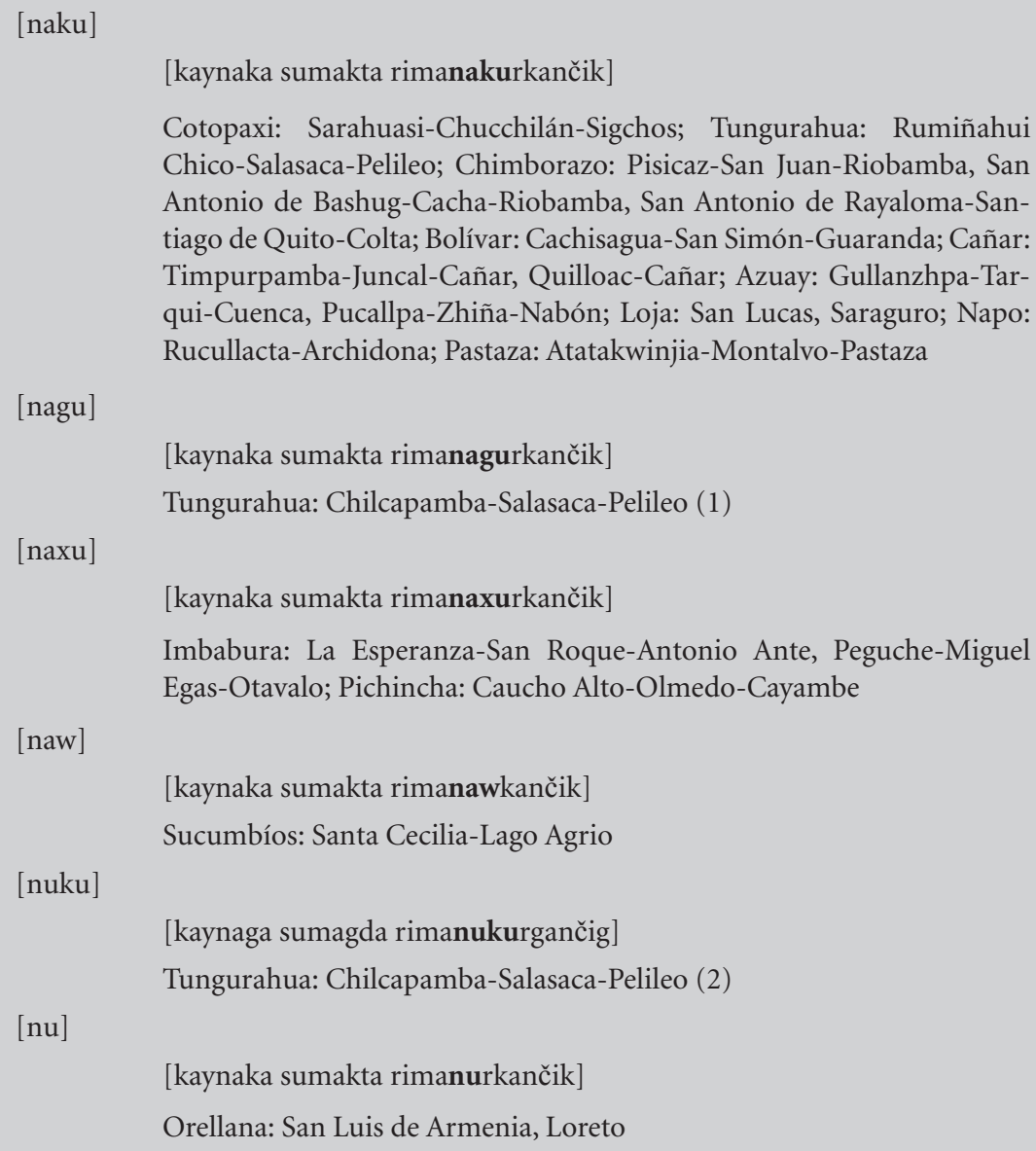

Cotopaxi: Sarahuasi-Chucchilán-Sigchos; Tungurahua: Rumiñahui Chico-Salasaca-Pelileo; Chimborazo: Pisicaz-San Juan-Riobamba, San Antonio de Bashug-Cacha-Riobamba, San Antonio de Rayaloma-Santiago de Quito-Colta; Bolívar: Cachisagua-San Simón-Guaranda; Cañar: Timpurpamba-Juncal-Cañar, Quilloac-Cañar; Azuay: Gullanzhpa-Tarqui-Cuenca, Pucallpa-Zhiña-Nabón; Loja: San Lucas, Saraguro; Napo: Rucullacta-Archidona; Pastaza: Atatakwinjia-Montalvo-Pastaza

[nagu]

[kaynaka sumakta rimanagurkančik]

Tungurahua: Chilcapamba-Salasaca-Pelileo (1)

$[$ naxu $]$

[kaynaka sumakta rimanaxurkančik]

Imbabura: La Esperanza-San Roque-Antonio Ante, Peguche-Miguel Egas-Otavalo; Pichincha: Caucho Alto-Olmedo-Cayambe

$[$ naw $]$

[kaynaka sumakta rimanawkančik]

Sucumbíos: Santa Cecilia-Lago Agrio

[nuku]

[kaynaga sumagda rimanukurgančig]

Tungurahua: Chilcapamba-Salasaca-Pelileo (2)

$[\mathrm{nu}]$

[kaynaka sumakta rimanurkančik]

Orellana: San Luis de Armenia, Loreto

En otros partes, en lugar del morfema $\{-$ naku $\}$ emplean $\{-$ ri $\}$. Ello ocurre en Imbabura (Pijal), Pichincha (San Miguel del Común), Chimborazo (La Providencia) y Orellana (El Descanso). Por ejemplo: /kayna sumakta rimarirkančik/. 


\section{5}

6. Oscilativo $\{-y k a c ̌ a\}<{ }^{*}\{-y k a \hat{c} a\}$. Las variantes se explican por el proceso de lenición del $[\mathrm{k}]>[\mathrm{x}]$ y por el cambio vocálico dando lugar a /ykača/ [ikača > ixača > ixiča] (Parker, 1969/2013, p. 83). Adicionalmente, en una comunidad de la provincia de Chimborazo se produce la sustitución del fonema /y/ inicial por /x/, como se puede apreciar abajo. El ejemplo /imamantatak puriykačankichu/ ‘ipor qué estás caminando de un lado para el otro?' se realiza como sigue:

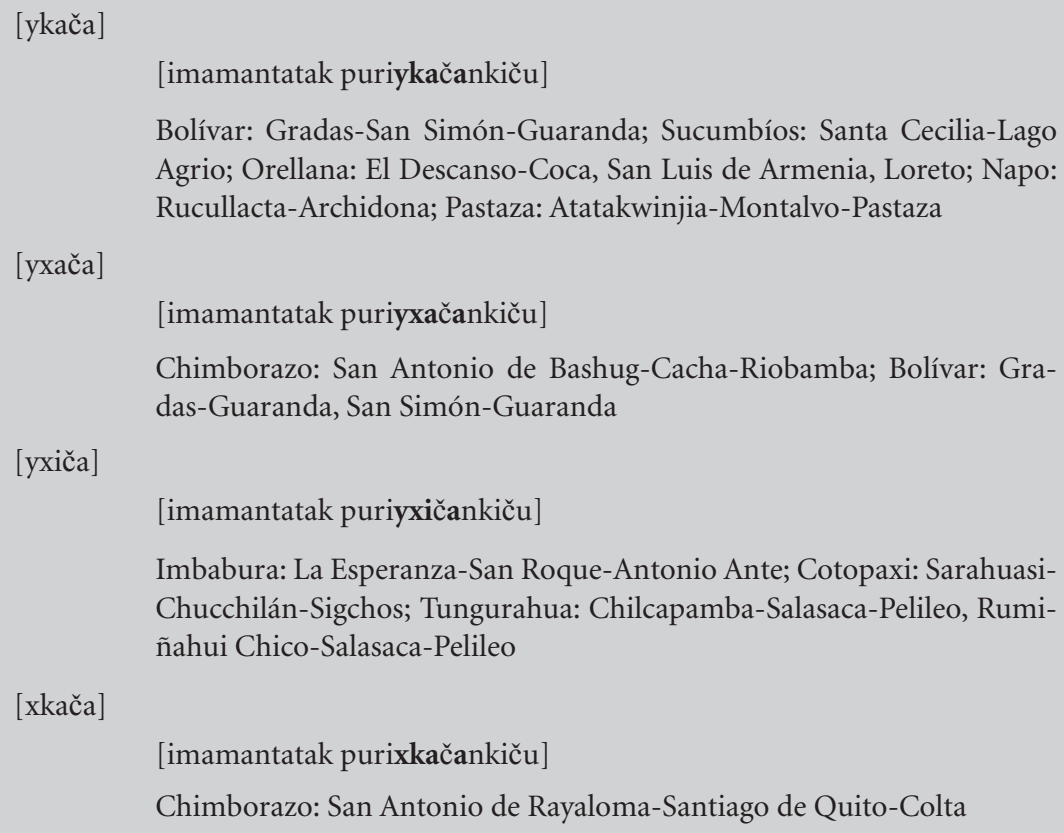

No se usa este morfema en Pijal (prov. de Imbabura).

7. Honorífico $\{-p a\}$. Este es un desarrollo propio de las hablas del Ecuador. Las variantes se explican por el proceso de lenición de /p/ realizándose como pa > ba > wa El ejemplo /wasiman šamupay/ 'ven a la casa por favor' muestra estas realizaciones: 


\section{6}

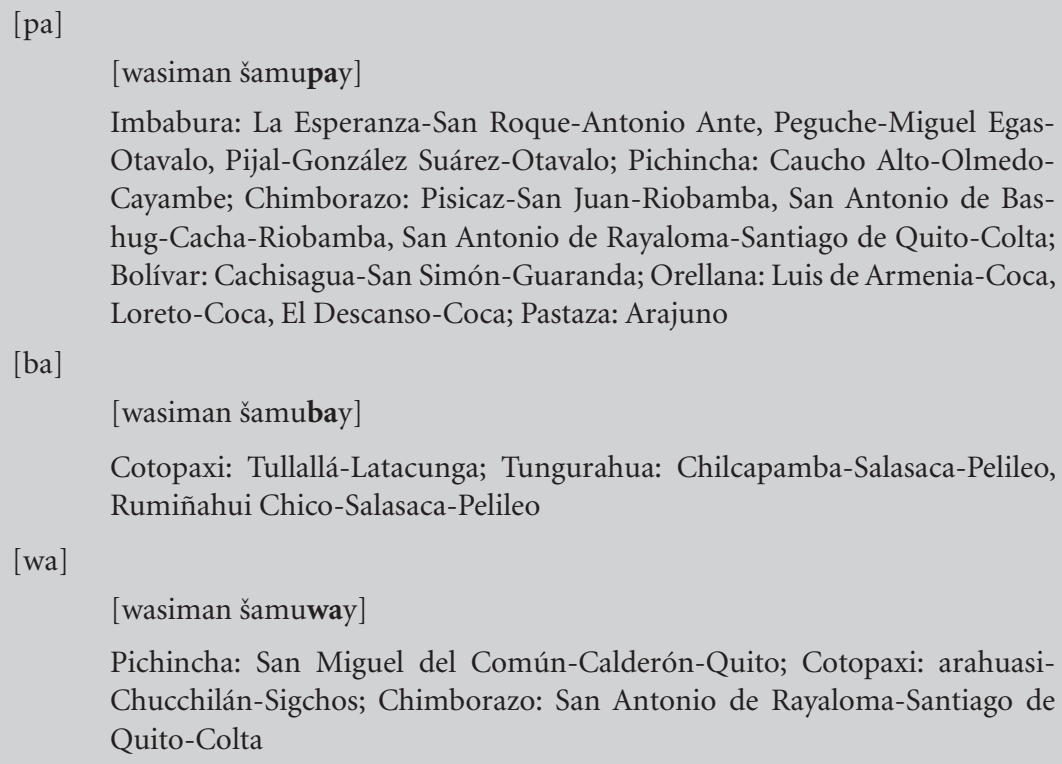

Cotopaxi: Tullallá-Latacunga; Tungurahua: Chilcapamba-Salasaca-Pelileo, Rumiñahui Chico-Salasaca-Pelileo

[wa]

[wasiman šamuway]

Pichincha: San Miguel del Común-Calderón-Quito; Cotopaxi: arahuasiChucchilán-Sigchos; Chimborazo: San Antonio de Rayaloma-Santiago de Quito-Colta

En las provincias de Cañar, Azuay y Loja no hay evidencias de que se utilice este morfema. En Chimborazo (San Antonio de Rayaloma) /pa/ y /wa/ tienen significados diferentes; así, el uso de /wa/ significa menor confianza que el de /pa/ entre los hablantes. La expresión /šamuway/ 'haz el favor de venir' es mucho más familiar que /šamupay/ 'por favor, ven'.

8. Propositivo $\{-k r i-\}$. Este es un desarrollo propio de las hablas de la Sierra ecuatoriana. Es plausible postular que proviene de la fusión del morfema agentivo $\{-\mathrm{k}\}+$ el lexema /ri-/ 'ir', es decir, /mikukrini/ provendría de $<$ mikuk rini $>$ 'voy a comer'. Esto puede ser argumentado con el hecho de que en Breve instrucción aparece la expresión $<$ Puñuc rini $>$ 'Voy a dormir' que el autor de esa obra la relaciona con el supino latino dormitum eo (cf. Anónimo, 1753, p. 12). En las comunidades de la Sierra, donde se lo usa actualmente, tiene un solo alomorfo: [gri], [mikugrini]. En las comunidades de la Amazonía no se lo usa. 


\section{7}

Hay que señalar que en unas comunidades se usa más /mikunkapak rini/ que /mikukrini/. En Salasaca se usa [mikunguri] de /mikunkapak rini/. ¿Se puede postular que su origen está en el ensamblaje-reducción del morfema propositivo \{-nkapak\} y de $\{$ ri- $\}$ del verbo 'ir'? Un equivalente cercano semánticamente en la Amazonía es el morfema \{-nkaraku\} que veremos a continuación.

9. Propositivo próximo \{-nkaraku-\}. ${ }^{112}$ Es un desarrollo propio de la Amazonía ecuatoriana. Es plausible postular que provendría de la fusión de morfema de futuro $\{-n k a\}$ del propositivo $\{$-nkapak $\}+\{-$ ra $\}$ de $<$ ruray $>$ 'hacer' y el continuativo ' $\{-\mathrm{ku}-\}$. El ejemplo es /mikunkarakuni/ > miku-nkapak + rurakuni 'estoy yendo a comer'.

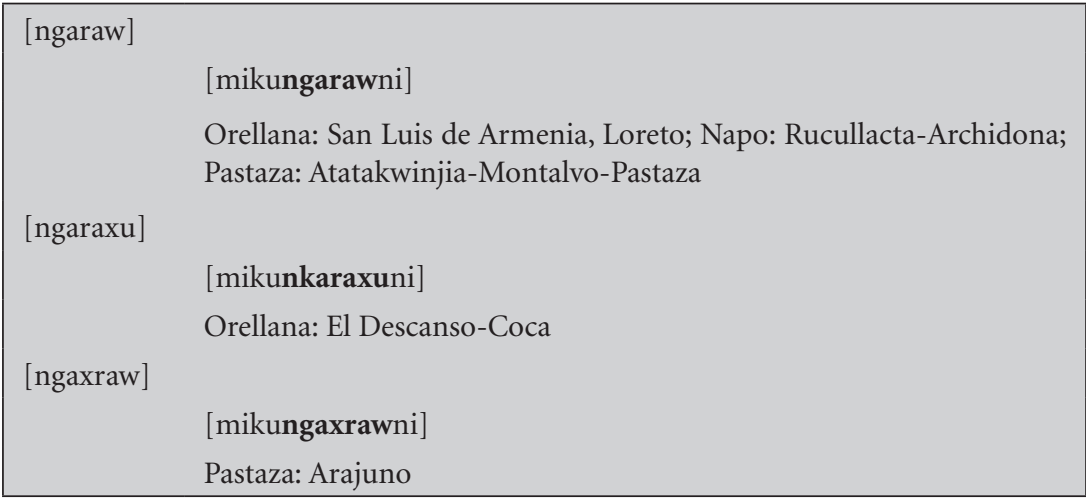

10. Incorporativo $\{-\lambda i\}$. Este morfema es poco productivo y se circunscribe al uso de prendas de vestir. La variación que sufre oscila entre la fricativización de $/ \lambda /$ y la depalatalización del mismo. El ejem-

112 La diferencia entre el propositivo $\{-k r i-\}$ de la Sierra y el $\{$-nkaraku- $\}$ de la Amazonía es que este último indica mayor proximidad temporal en la realización de la acción indicada por el verbo. Por otra parte, cabe anotar que en la Amazonía la estructura /mikuk + ri-/ significa que la persona se va luego de haber realizado la acción. Así, la expresión /mikuk rini/ significa 'voy después de comer'. 


\section{8}

plo /wawata čumpi入inami kan/ 'hay que envolverle al bebé' ilustra las siguientes realizaciones:

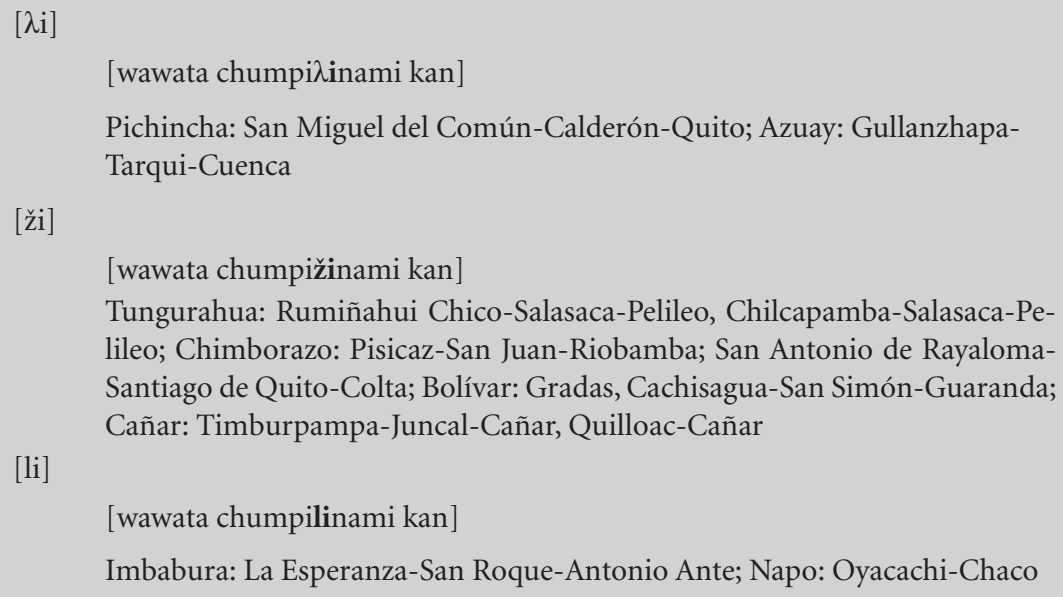

\section{Morfemas flexivos verbales}

Estos morfemas señalan los accidentes del verbo. No tienen variaciones los morfemas de primera persona singular $\{-n i\}$. El de segunda persona singular $\{$-nki $\}$ se pronuncia como [ngi] en todos los dialectos. El de tercera persona singular $\{-n\}$. A continuación presentamos los que sí tienen alguna variación.

1. Primera persona plural $\{-n+\check{c} i k\}<{ }^{*}\{-n+\check{c} i k\}$. Al igual que todos los morfemas terminados en el fonema $/ \mathrm{k} /$, este sufre el proceso de lenición hasta llegar a su desaparición (Parker, 1969c/2013, p. 87). El caso atípico es la sustitución de / $/$ / por /n/ que se presenta en la comunidad de San Miguel del Común (prov. de Pichincha). El ejemplo /sarata tarpunčik/ 'sembramos maíz' ilustra su realización: 


\section{9}

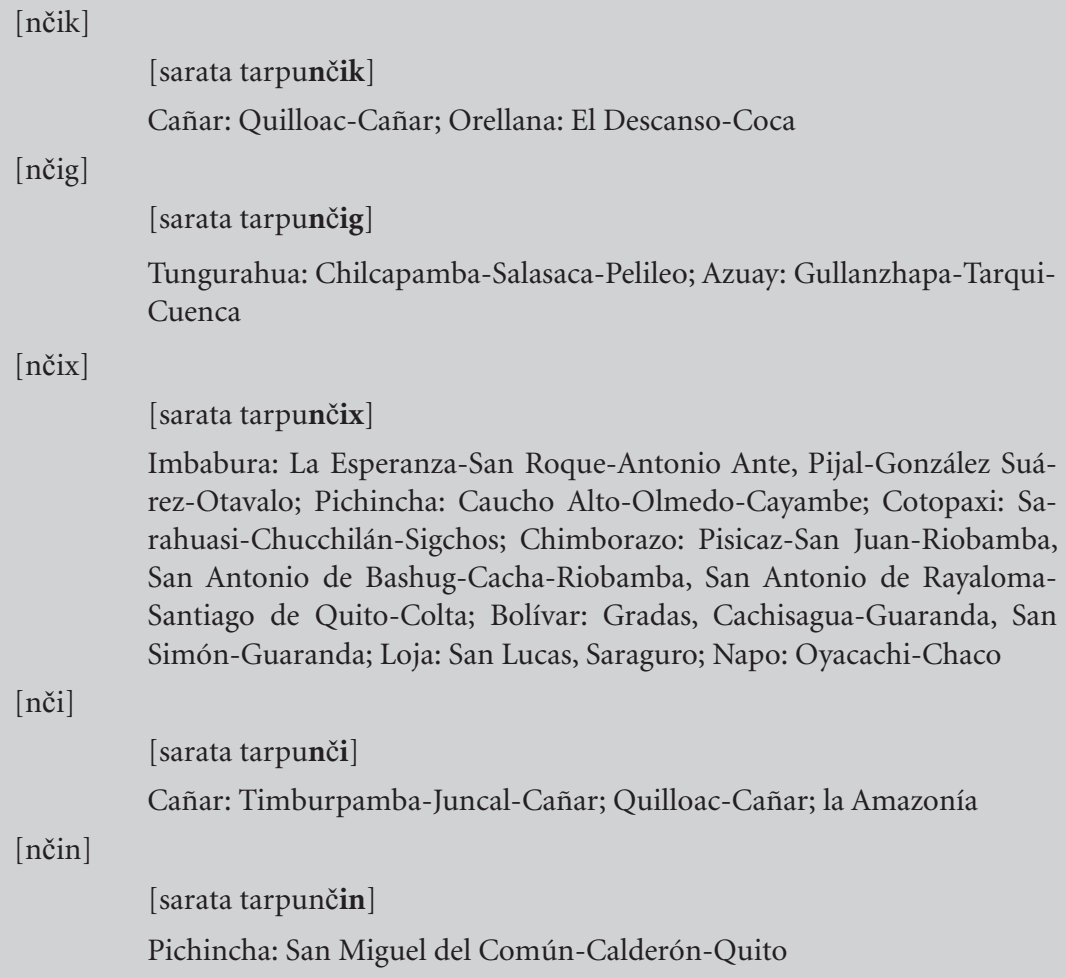
rez-Otavalo; Pichincha: Caucho Alto-Olmedo-Cayambe; Cotopaxi: Sarahuasi-Chucchilán-Sigchos; Chimborazo: Pisicaz-San Juan-Riobamba, San Antonio de Bashug-Cacha-Riobamba, San Antonio de RayalomaSantiago de Quito-Colta; Bolívar: Gradas, Cachisagua-Guaranda, San Simón-Guaranda; Loja: San Lucas, Saraguro; Napo: Oyacachi-Chaco

[nči]

[sarata tarpunči]

Cañar: Timburpamba-Juncal-Cañar; Quilloac-Cañar; la Amazonía [nčin]

[sarata tarpunčin]

Pichincha: San Miguel del Común-Calderón-Quito

La última variación se podría interpretar como un caso de reinterpretación por razones de analogía con las formas verbales que portan $\{-\mathrm{n}\}$. Por ejemplo $\{$-šun $\}$.

2. Segunda persona plural $\{-n k i+\check{c} i k\}<*\{n+k i+\check{c} i k\}$. La variación es similar al caso de \{-nčik\} (Parker, 1969c/2013, p. 87). El ejemplo /sarata tarpunkičik/ 'ustedes siembran maíz' ilustra su realización. 


\section{0}

\begin{tabular}{|c|c|}
\hline \multicolumn{2}{|l|}{ [ngičik] } \\
\hline & Cañar: Quilloac; Orellana: El Descanso \\
\hline \multicolumn{2}{|l|}{ [ngičix] } \\
\hline & [sarata tarpungičix] \\
\hline & $\begin{array}{l}\text { Imbabura: La Esperanza-San Roque-Antonio Ante, Pijal-González } \\
\text { Suárez-Otavalo; Pichincha: Caucho Alto-Olmedo-Cayambe; Coto- } \\
\text { paxi: Sarahuasi-Chucchilán-Sigchos; Chimborazo: Pisicaz-San Juan- } \\
\text { Riobamba, San Antonio de Bashug-Cacha-Riobamba, San Antonio de } \\
\text { Rayaloma-Santiago de Quito-Colta; Bolívar: Gradas-Guaranda, Cachis- } \\
\text { agua-Guaranda, San Simón-Guaranda; Loja: San Lucas, Saraguro; Napo: } \\
\text { Oyacachi-Chaco }\end{array}$ \\
\hline \multicolumn{2}{|l|}{ [ngičig] } \\
\hline & [sarata tarpungičig] \\
\hline & $\begin{array}{l}\text { Tungurahua:Chilcapamba-Salasaca-Pelileo;Azuay:Gullanzhapa-Tarqui- } \\
\text { Cuenca }\end{array}$ \\
\hline \multicolumn{2}{|l|}{ [ngiči] } \\
\hline & [sarata tarpungiči] \\
\hline & Cañar: Timburpamba-Juncal-Cañar; la Amazonía \\
\hline \multicolumn{2}{|l|}{ [ngičin] } \\
\hline & [sarata tarpungičin] \\
\hline & Pichincha: San Miguel del Común-Calderón-Quito \\
\hline
\end{tabular}

3. Tercera persona plural $\{-n+k u n a\}$. Las variaciones muestran el proceso de lenición de $[\mathrm{k}]>$ [g]. En los dialectos de la Amazonía se observa que la tercera persona plural está representada por las formas [nakun $\sim$ naxu $\sim$ nawn $\sim$ nun], que implican una acción continuada y que originariamente marcaban reciprocidad. El ejemplo /paykuna sarata tarpunkuna/ 'ellas siembran maíz' se manifiesta como: 


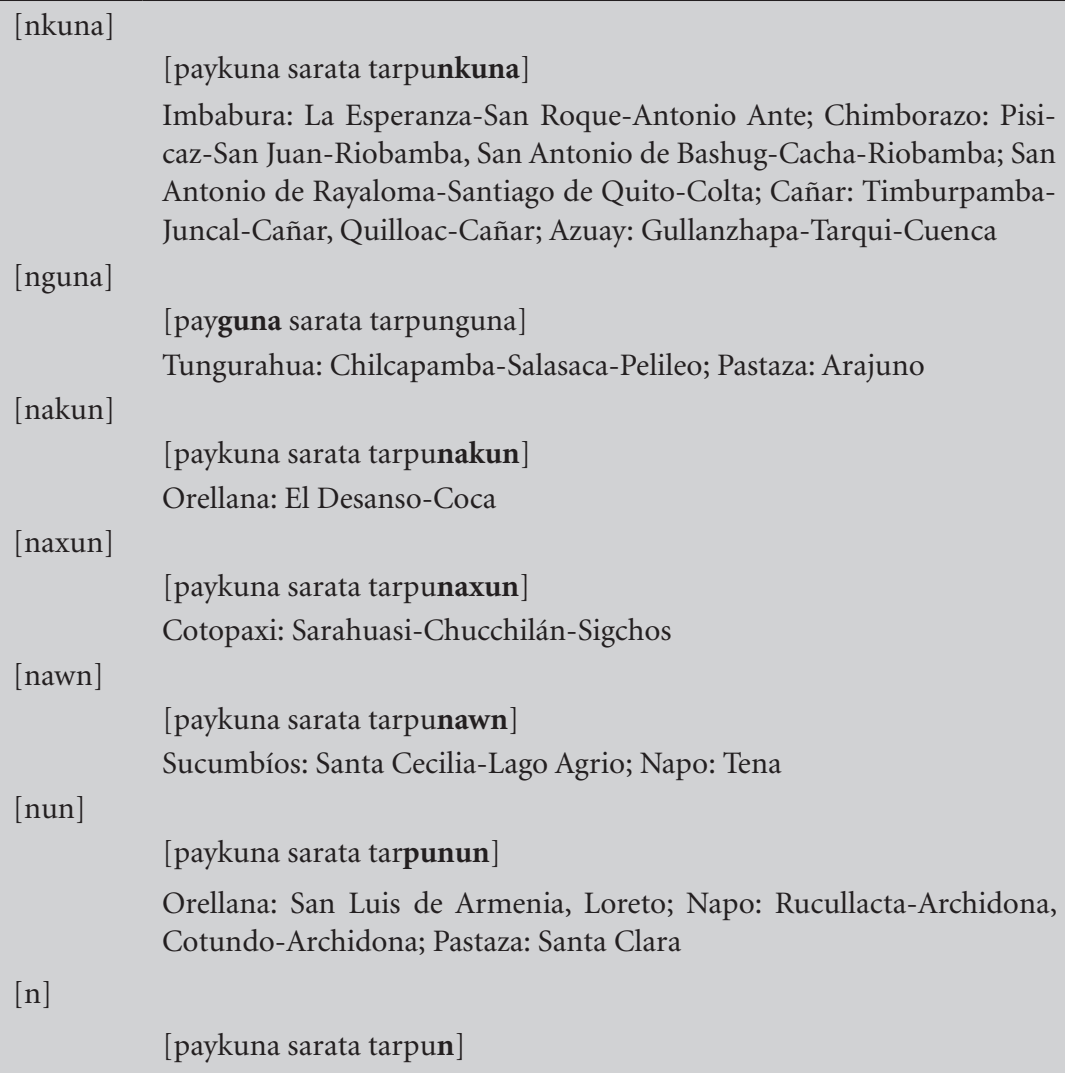

En la Sierra se puede usar la terminación de la tercera persona singular también para la tercera persona del plural. ${ }^{113}$ En la Amazonía no se usa, ni [paykuna sarata tarpun], ni [paykuna sarata tarpunkuna], sino las formas señaladas arriba según los lugares.

4. Flexivo verbal de pasado $\{-r k a-\}{ }^{*}\{-r-\}$. Las variaciones son el resultado de los fenómenos de lenición del fonema $/ \mathrm{k} /$, evolucionando

113 En el uso clásico de la tercera persona la ausencia de marca de plural en el verbo no implicaba singularidad. 


\section{2}

de $[\mathrm{k}]>$ [g], luego la supresión de /k/ o la de /r/ (Parker, 1969c/2013, p. 86). En un sector de Salasaca ocurre lenición de /k/, pero en otro existe simultáneamente lenición de /k/ y supresión de /r/. El ejemplo /kayna papata mikurkani/ 'ayer comí papas' ilustra las siguientes realizaciones:

\begin{tabular}{|c|c|}
\hline \multicolumn{2}{|l|}{ [rka] } \\
\hline & [kayna papata mikurkani] \\
\hline & $\begin{array}{l}\text { Imbabura: La Esperanza-San Roque-Antonio Ante, Peguche-Miguel Egas- } \\
\text { Otavalo, Pijal-González Suárez-Otavalo; Pichincha: Caucho Alto-Olmedo- } \\
\text { Cayambe; Chimborazo: San Antonio de Bashug-Cacha-Riobamba, San } \\
\text { Antonio de Rayaloma-Santiago de Quito-Colta; Bolívar: Cachisagua-Gua- } \\
\text { randa, San Simón-Guaranda; Cañar: Quilloac-Cañar; Azuay: Gullanzhapa- } \\
\text { Tarqui-Cuenca; Orellana: El Descanso-Coca }\end{array}$ \\
\hline \multicolumn{2}{|l|}{$[\mathrm{rga}]$} \\
\hline & [kayna papada mikurgani] \\
\hline & Tungurahua: Chilcapamba (1)-Salasaca-Pelileo \\
\hline \multicolumn{2}{|l|}{ [ra] } \\
\hline & [kayna papada mikurani] \\
\hline & Cotopaxi: Sarahuasi-Chucchilán-Sigchos \\
\hline & [kayna lumuta mikurani] \\
\hline & Pastaza: Atatakwinjia, Canelos, Sarayacu, Curaray \\
\hline \multicolumn{2}{|l|}{$[\mathrm{ka}]$} \\
\hline & [kayna lumura mikukani] \\
\hline & Napo: Rucullacta-Archidona; Pastaza: Arajuno \\
\hline \multicolumn{2}{|l|}{ [ga] } \\
\hline & [kayna papada mikugani] \\
\hline & Tungurahua: Rumiñahui Chico, Chilcapamba (2)-Salasaca-Pelileo \\
\hline \multicolumn{2}{|l|}{ [rki] } \\
\hline & [kayna papada mikurkini] \\
\hline & Tungurahua: Chibuleo-Ambato \\
\hline
\end{tabular}

En Sarayacu (prov. de Pastaza) se da un fenómeno complejo en expresiones donde interviene el verbo \{kay\} 'ser'. En este caso, además de la variación del morfema de pasado \{-rka\} hay la supresión del fonema /k/ del verbo $\{k a y\}$. Allí dicen [šinami ara] </šinami karka/ 'Así era'. 


\section{3}

5. Primera persona plural de futuro $\{-\check{s} u n\}<{ }^{*}\{-\check{s} u n\}$. Este morfema se usa solo o junto a $\{$-čik $\}$ cuando se quiere enfatizar que también el interlocutor es parte de la acción señalada por el verbo (Parker, 1969c/2013, p. 85). Sin embargo, esto último no se da en Azuay (Gullanzhapa), donde solo emplean $\{$-šun $\}$ para ambos casos. En los ríos Putumayo, Zancudo, San Miguel y en el Napo desde el río Pañacocha hacia abajo, hay depalatización de /š/. En el ejemplo /šamušun/ 'vendremos' se presentan las realizaciones:

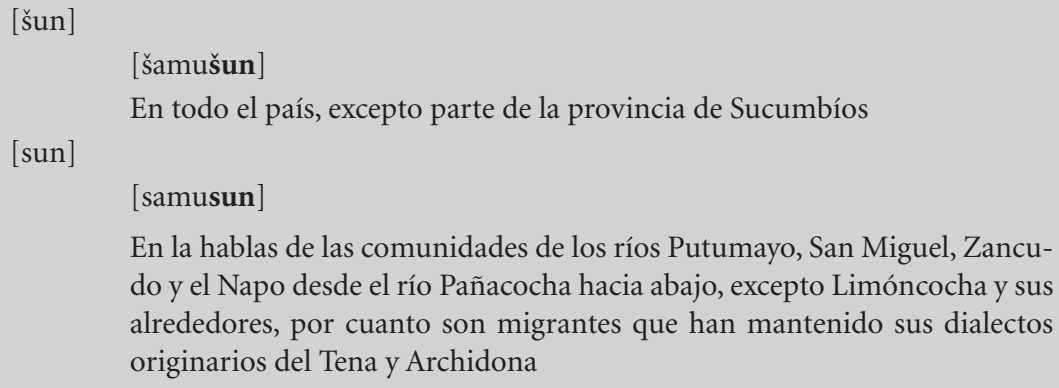

En la hablas de las comunidades de los ríos Putumayo, San Miguel, Zancudo y el Napo desde el río Pañacocha hacia abajo, excepto Limóncocha y sus alrededores, por cuanto son migrantes que han mantenido sus dialectos originarios del Tena y Archidona

6. Primera persona objeto $\{-w a\}{ }^{*}\{-m a-\}$. La única variación se explica por cambio vocálico (Parker, 1968/2013, p. 85). El ejemplo /paymi yanapawan/ 'ella me ayuda' presenta las realizaciones:

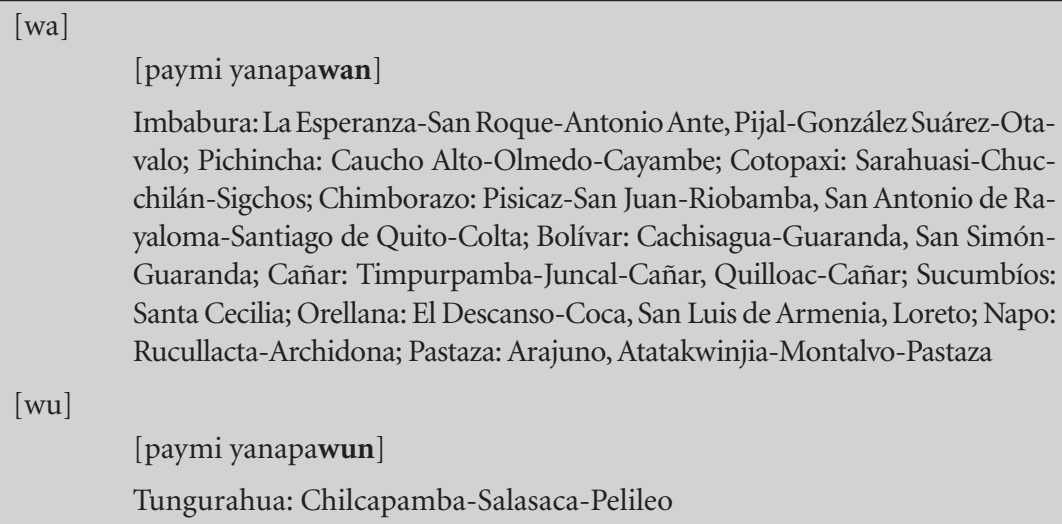




\section{4}

Este morfema no se usa en Pichincha (San Miguel del Común), Chimborazo (San Antonio de Bashug) o Loja (San Lucas), en estos lugares la expresión se transforma en /paymi ñukata yanapan/, donde el objeto es marcado pronominalmente.

7. Imperativo segunda persona plural $\{-y+\check{c} i k\}$. Está conformado por el imperativo singular $\{-y\}$ y el pluralizador $\{-c ̌ i k\}$. Las variaciones ocurren por el tratamiento de $/ \mathrm{k} /$. En el caso de Sarahuasi (prov. de Cotopaxi) hay supresión del fonema inicial /y/. El ejemplo /mikuyčik/ 'coman ustedes' ilustra su ocurrencia:

\begin{tabular}{|c|c|}
\hline \multicolumn{2}{|l|}{ [yčik] } \\
\hline & [mikuyčik] \\
\hline & $\begin{array}{l}\text { Imbabura: La Esperanza-San Roque-Antonio Ante; Chimborazo: Pisicaz- } \\
\text { San Juan-Riobamba; Bolívar: Gradas, Cachisagua-San Simón-Guaranda; } \\
\text { Cañar: Quilloac-Cañar Azuay: Gullanzhapa-Tarqui-Cuenca; Loja: San Lu- } \\
\text { cas, Saraguro; Orellana: El Descanso-Coca }\end{array}$ \\
\hline \multicolumn{2}{|l|}{ [yčig] } \\
\hline & [mikuyčig] \\
\hline & Cañar: Timburpamba-Juncal-Cañar \\
\hline \multicolumn{2}{|l|}{ [yči] } \\
\hline & [mikuyči] \\
\hline & Imbabura: Peguche-Miguel Egas-Otavalo \\
\hline \multicolumn{2}{|l|}{ [čik] } \\
\hline & [mikučik] \\
\hline & Cotopaxi: Sarahuasi-Chucchilán-Sigchos \\
\hline
\end{tabular}

8. Imperativo tercera persona singular $\{$-čun\}. La variación muestra la sonorización y fricativización de /č/, como lo prueba el ejemplo / pay šamučun munani/ 'quiero que venga él':

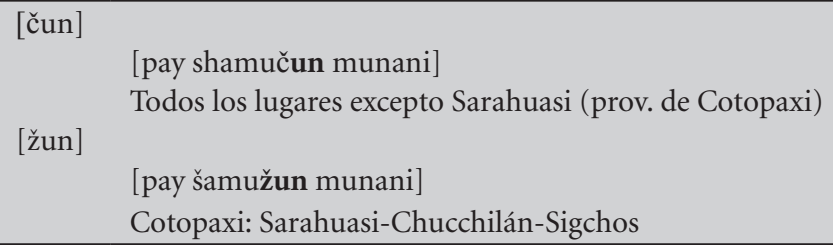




\section{5}

9. Imperativo tercera persona plural \{-čunkuna\}. El morfema está conformado por $\{$-chun $\}+\{$-kuna $\}$. Las variaciones suceden en el siguiente orden: primero se da lenición de $[\mathrm{k}]>[\mathrm{g}]$, luego hay una metátesis de $\{-\mathrm{kuna}\}$ con supresión de /k/, después en la forma con metátesis pierde / $\mathrm{ku} /$, finalmente, desaparece en el morfema \{-kuna\}. El ejemplo /paykuna šamučunkuna munani/ 'quiero que vengan ellas/ ellos' ilustra los cambios señalados:

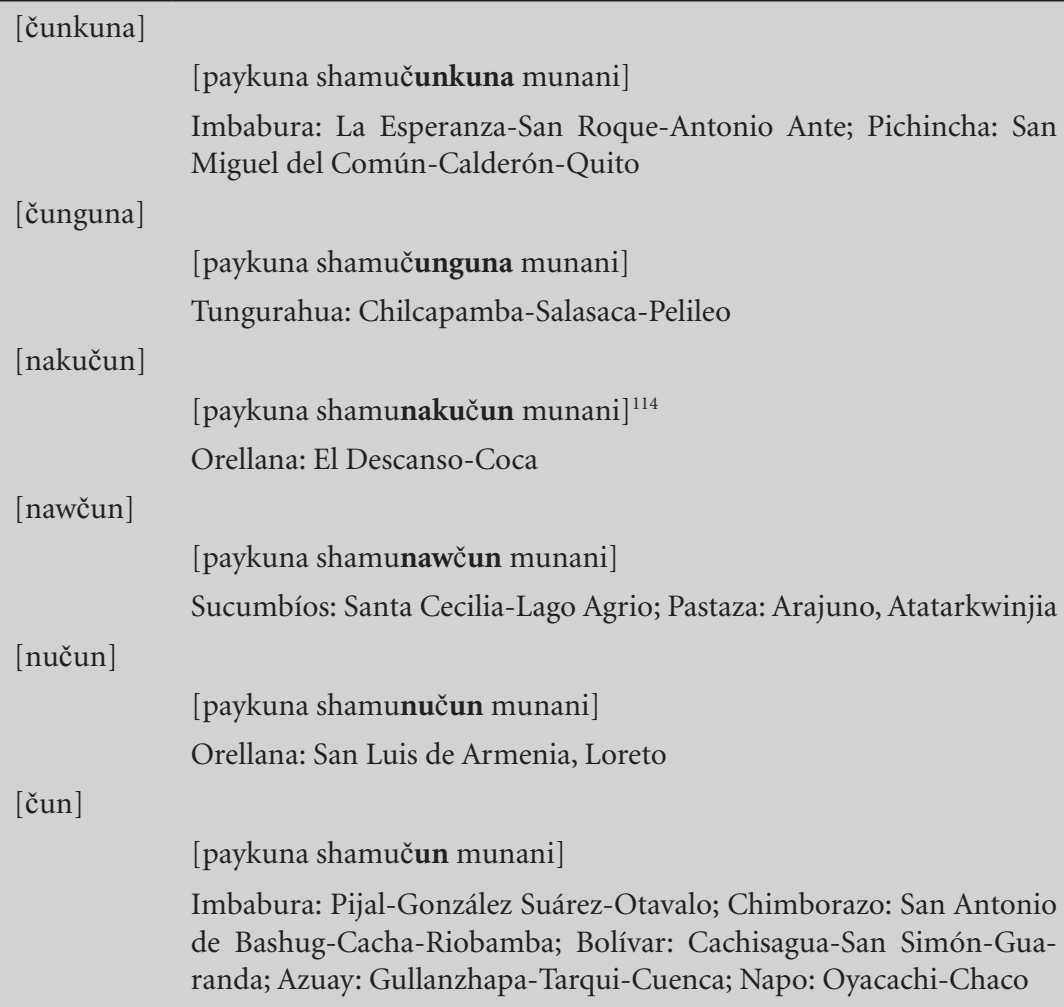

114 Las variantes [nakučun], [nawčun] y [nučun] pueden también ser interpretadas como la fusión del recíproco $\{$-naku- $\}$ y $\{$-čun $\}$. 


\section{6}

10. Flexión de condicionalidad $\{-\operatorname{man}\}{ }^{*}\{-\operatorname{man}\}$. Las variaciones se dan por cambio vocálico y/o por supresión de /n/ (Parker, 1969c/2013, p. 88). El ejemplo /kuגkita čarišpaka mušuk wasita ruraymanmi/ 'si tuviera dinero haría una nueva casa' ilustra el fenómeno de variación.

\begin{tabular}{|c|c|}
\hline \multicolumn{2}{|l|}{ [man] } \\
\hline & [kulkita čarišpaka mušuk wasita ruraymanmi] \\
\hline & $\begin{array}{l}\text { Imbabura: La Esperanza-San Roque-Antonio Ante, Peguche-Miguel } \\
\text { Egas-Otavalo }\end{array}$ \\
\hline & [kuškita čarišpaka mušuk wasita ruraymanmi] \\
\hline & Pichincha, Chimborazo, Bolívar \\
\hline & 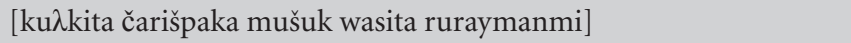 \\
\hline & Cañar; Loja; Sucumbíos, Orellana, Pastaza excepto cantón Arajuno \\
\hline \multicolumn{2}{|l|}{$[\mathrm{mun} \sim \mathrm{mu}]$} \\
\hline & [kuškita čarišpaka mušuk wasida ruraymunmi] \\
\hline & $\begin{array}{l}\text { Cotopaxi; Tungurahua: Chilcapamba-Salasaca-Pelileo, Rumiñahui } \\
\text { Chico-Salasaca-Pelileo; Bolívar: Cachisagua-San Simón-Guaranda }\end{array}$ \\
\hline \multicolumn{2}{|l|}{ [ma] } \\
\hline & [kuגkita čarišaga mušuk wasira ruraymami] \\
\hline & Napo: Rucullacta-Archidona; Pastaza: Arajuno \\
\hline
\end{tabular}

En San Miguel del Común (prov. de Pichincha), la expresión se dice [kulkita čarišaga mušug wasida uřaymanmi], mientras que en Salasaca (prov. de Tungurahua) sería [kučkida čarišaga mušug wasida řuřimumi]. En la comunidad de Angla (prov. de Imbabura), según Bertha Cabrera Quimia, se dice [kulkita čarišpaka mušuk wasita ruraniman]. La forma verbal usada en esta comunidad sería, posiblemente, la forma original de la lengua.

11. Flexión de subordinación distinto sujeto $\{-k p i\}$. Las diferentes realizaciones se explican por lenición de /k/ y por supresión de /p/ y de $/ \mathrm{k} /$, respectivamente. El ejemplo /pay šamukpi mikušami/ 'cuando ella venga comeré ilustra sus manifestaciones: 


\section{7}

[kpi]
[pay shamukpi mikušami]
Imbabura: La Esperanza-San Roque-Antonio Ante, Peguche-Miguel
Egas-Otavalo, Pijal-González Suárez-Otavalo; Pichincha: Caucho Alto-
Olmedo-Cayambe; Loja: San Lucas, Saraguro; Orellana: El Descanso-Co-
ca; Napo: Oyacachi-Chaco; Pastaza: Arajuno
[gpi]
[xpi]
Cañar: Quilloac-Cañar; Azuay: Gullanzhapa-Tarqui-Cuenca
[pay shamuxpi mikušami]
Chimborazo: Pisicaz-San Juan-Riobamba, San Antonio de Bashug-Ca-
cha-Riobamba, San Antonio de Rayaloma-Santiago de Quito-Colta; Pas-
taza: Atatakwinjia-Montalvo-Pastaza
[ki]
[pay shamuki mikušami]
Tungurahua: Chilcapamba-Salasaca-Pelileo, Rumiñahui Chico-Salasaca-
Pelileo, Churumanga-El Rosario-Pelileo

[pay shamupi mikušami]
Orellana: San Luis de Armenia, Loreto; Napo: Rucullacta-Archidona

12. Flexión de subordinación mismo sujeto $\{-s ̌ p a\}<{ }^{*}\{-\check{s}\}+{ }^{*}\{-p a\}$. En las variaciones existe una depalatalización de /š/ y/o supresión de /p/ (Parker, 1969c/2013, p. 87). El ejemplo /ñami mikušpa rini/ 'voy después de comer' o 'ya voy comiendo' nos da las siguientes variaciones:

\section{[špa]}

[ñami mikušpa rini]

Imbabura: La Esperanza-San Roque-Antonio Ante, Peguche-Miguel EgasOtavalo, Pijal-González Suárez-Otavalo; Pichincha: Caucho Alto-Olmedo-Cayambe; Chimborazo: Pisicaz-San Juan-Riobamba, San Antonio de Bashug-Cacha-Riobamba; Cañar: Timburpamba-Juncal-Cañar, QuilloacCañar; Azuay: Gullanzhapa-Tarqui-Cuenca; Loja: San Lucas, Saraguro 


\section{8}

[spa]

[ñami mikuspa rini]

Sucumbíos: Tasé-Putumayo; Orellana: Río Tiputini-Aguarico

$[\check{s} a]$

[ñami mikuša rini]

Pichincha: San Miguel del Común-Calderón-Quito; Cotopaxi: SarahuasiChucchilán-Sigchos; Tungurahua: Rumiñahui Chico-Salasaca-Pelileo, Chilcapamba - Salasaca-Pelileo; Sucumbíos: Santa Cecilia-Lago Agrio; Orellana: San Luis de Armenia, Loreto; Napo: Rucullacta-Archidona; Pastaza: Arajuno, Atatakwinjia-Montalvo-Pastaza

En Orellana (El Descanso) hay lugares donde ya usan [spa], de allí siguiendo el río Napo aguas abajo y en los ríos Putumayo, San Miguel y Aguarico estamos ante un territorio de la variación [spa].

13. Flexión de propósito \{-nkapak\}. Las variaciones son el resultado de los fenómenos de lenición de /p/ y de / $/ \mathrm{k}$, pero también por la supresión de la sílaba /pa/ o por la supresión de la secuencia /pa/ y /k/, además del cambio vocálico de /a/ de la última sílaba. El ejemplo /haku mikunkapak/ 'vamos a comer' ilustra las distintas realizaciones:

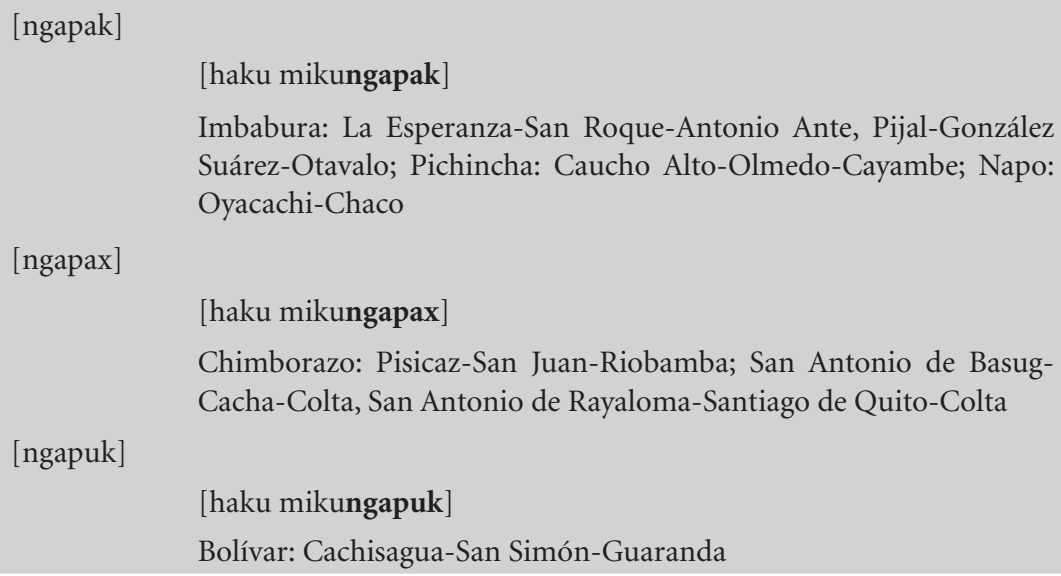




\section{9}

\begin{tabular}{|c|c|}
\hline \multicolumn{2}{|l|}{ [ngabug] } \\
\hline & [haku mikungabug] \\
\hline & Cotopaxi: Sarahuasi-Chucchilán-Sigchos \\
\hline \multicolumn{2}{|l|}{ [ngapa] } \\
\hline & [haku mikungapa] \\
\hline & Azuay: Gullanzhapa-Tarqui-Cuenca; Orellana: El Descanso-Coca \\
\hline \multicolumn{2}{|l|}{ [ngawa] } \\
\hline & [haku mikungawa] \\
\hline & Pastaza: Canelos, Sarayacu \\
\hline & [aku mikungawa] \\
\hline & Pastaza: Atatakwinjia-Montalvo-Pastaza \\
\hline \multicolumn{2}{|l|}{$[$ ngax $]$} \\
\hline & [aku mikungax] \\
\hline & $\begin{array}{l}\text { Pichincha: San Miguel del Común-Calderón-Quito; Napo: Rucullac- } \\
\text { ta-Archidona; Pastaza: Arajuno-Pastaza }\end{array}$ \\
\hline \multicolumn{2}{|l|}{ [ngu] } \\
\hline & [haku mikungu] \\
\hline & $\begin{array}{l}\text { Tungurahua: Chilcapamba-Salasaca-Pelileo, Churumanga-El } \\
\text { Rosario-Pelileo }\end{array}$ \\
\hline
\end{tabular}

\section{Morfemas independientes}

Estos morfemas afectan a toda la oración no solo a la palabra a la cual se hallan ligados. Yánez (2007) los llama “estructurales" debido a que afectan a toda la estructura gramatical de una oración. Los independientes que muestran variación son $\{-$ pash $\},\{\operatorname{rak}\},\{-$ tak $\},\{-c ̌ u\},\{-l l a\}$ y $\{-\mathrm{ka}\}$. Los fonemas de los morfemas $\{-\mathrm{rak}\}$ y $\{-\mathrm{tak}\}$ varían al igual que en

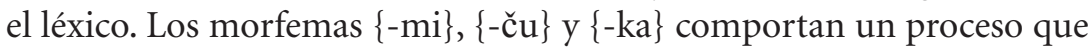
se puede denominar "reducción-ensamblaje", que se analiza más abajo. Así, por ejemplo, el validador $\{-\mathrm{mi}\}$, en Salcedo (prov. de Cotopaxi) y en la Amazonía sur, se fusiona con el verbo $\{\mathrm{ka}-\}$ 'ser'. 


\section{0}

1. Aditivo $\{-p a \check{s}\}<{ }^{*}\{-p a \check{s} \sim p i \check{s}\}$. Las variaciones se explican por el cambio vocálico que también se da en el Perú, la lenición de /p/ y la depalatalización de /š/ (Parker, 1969c/2013, p. 88). La última variación que se da en la Amazonía se da en los contextos fónicos: -s/v_, -bas/nasal_, -was/y_, respectivamente. El ejemplo es: /paypaš šamuškami/ 'ella también ha venido'. En plural emplean [ $s \sim$ was] para todas las personas.

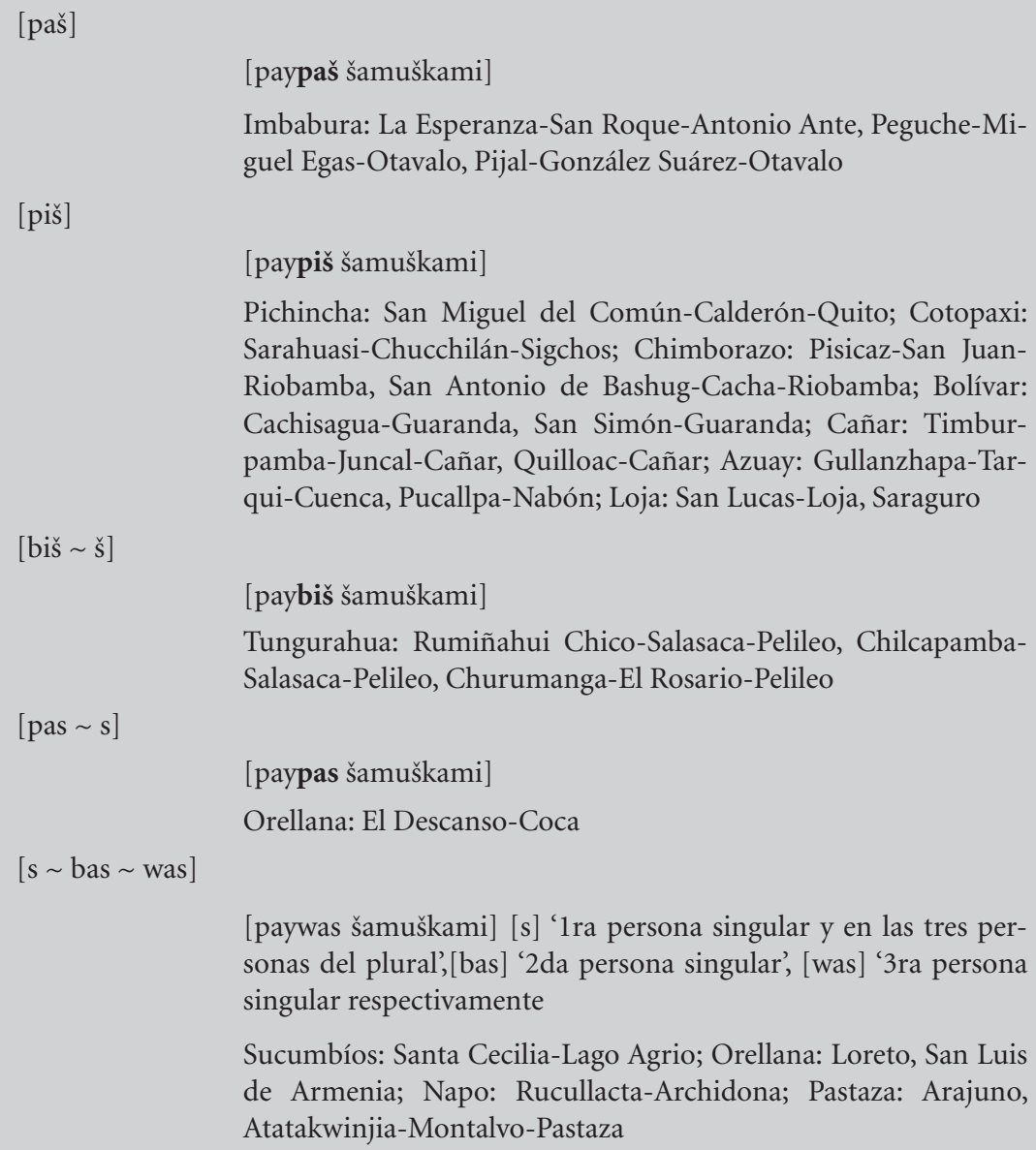

[paywas šamuškami] [s] '1ra persona singular y en las tres personas del plural', [bas] '2da persona singular', [was] '3ra persona singular respectivamente

Sucumbíos: Santa Cecilia-Lago Agrio; Orellana: Loreto, San Luis de Armenia; Napo: Rucullacta-Archidona; Pastaza: Arajuno, Atatakwinjia-Montalvo-Pastaza 
2. Continuativo $\{-r a k\}<{ }^{*}\{$-raq\}. Las variaciones se dan por lenición de /k/ y el cambio vocálico (Parker, 1969c/2013, p. 88). En el ejemplo /manarak riniču/, /čayrak mana/ 'todavía no voy' vemos las siguientes variaciones:

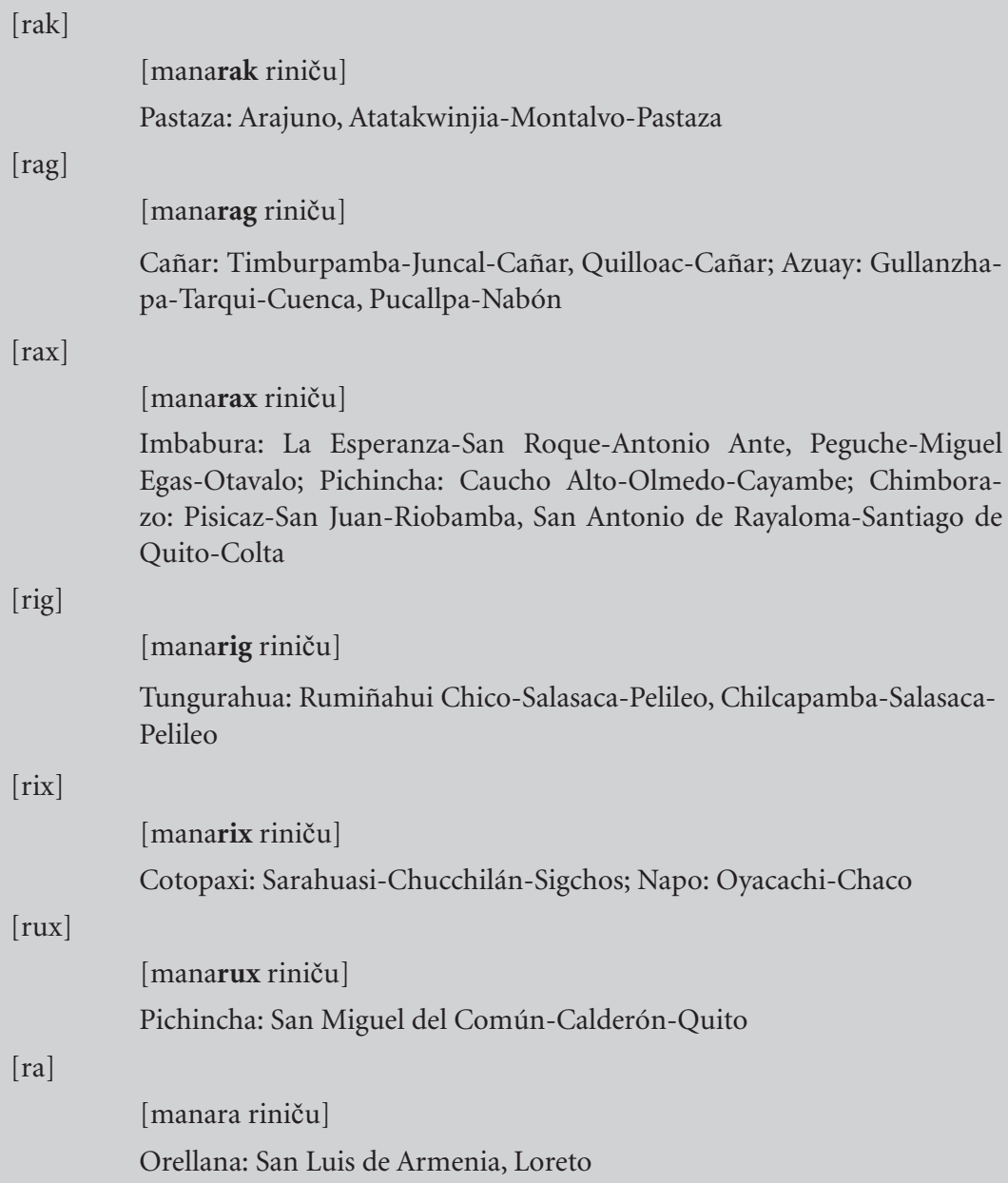
Egas-Otavalo; Pichincha: Caucho Alto-Olmedo-Cayambe; Chimborazo: Pisicaz-San Juan-Riobamba, San Antonio de Rayaloma-Santiago de Quito-Colta

[rig]

[manarig riniču]

Tungurahua: Rumiñahui Chico-Salasaca-Pelileo, Chilcapamba-SalasacaPelileo

$[$ rix $]$

[manarix riniču]

Cotopaxi: Sarahuasi-Chucchilán-Sigchos; Napo: Oyacachi-Chaco

[rux]

[manarux riniču]

Pichincha: San Miguel del Común-Calderón-Quito

$[\mathrm{ra}]$

[manara riniču]

Orellana: San Luis de Armenia, Loreto 


\section{2}

En la Amazonía prefieren usar la expresión /čarak mana riniču/ en lugar de /manarak riniču/. En las hablas de la Sierra centro y norte echan mano de [na], una forma reducida de /mana/. Así, en Salasaca dicen [narig riniču].

3. Contrastivo $\{$-tak $\} *\{$-taq\}. Las variaciones se explican por lenición y cambio vocálico (Parker, 1969c/2013, p. 88). El ejemplo /pitak šamuška/ ‘quién ha venido?' se manifiesta como:

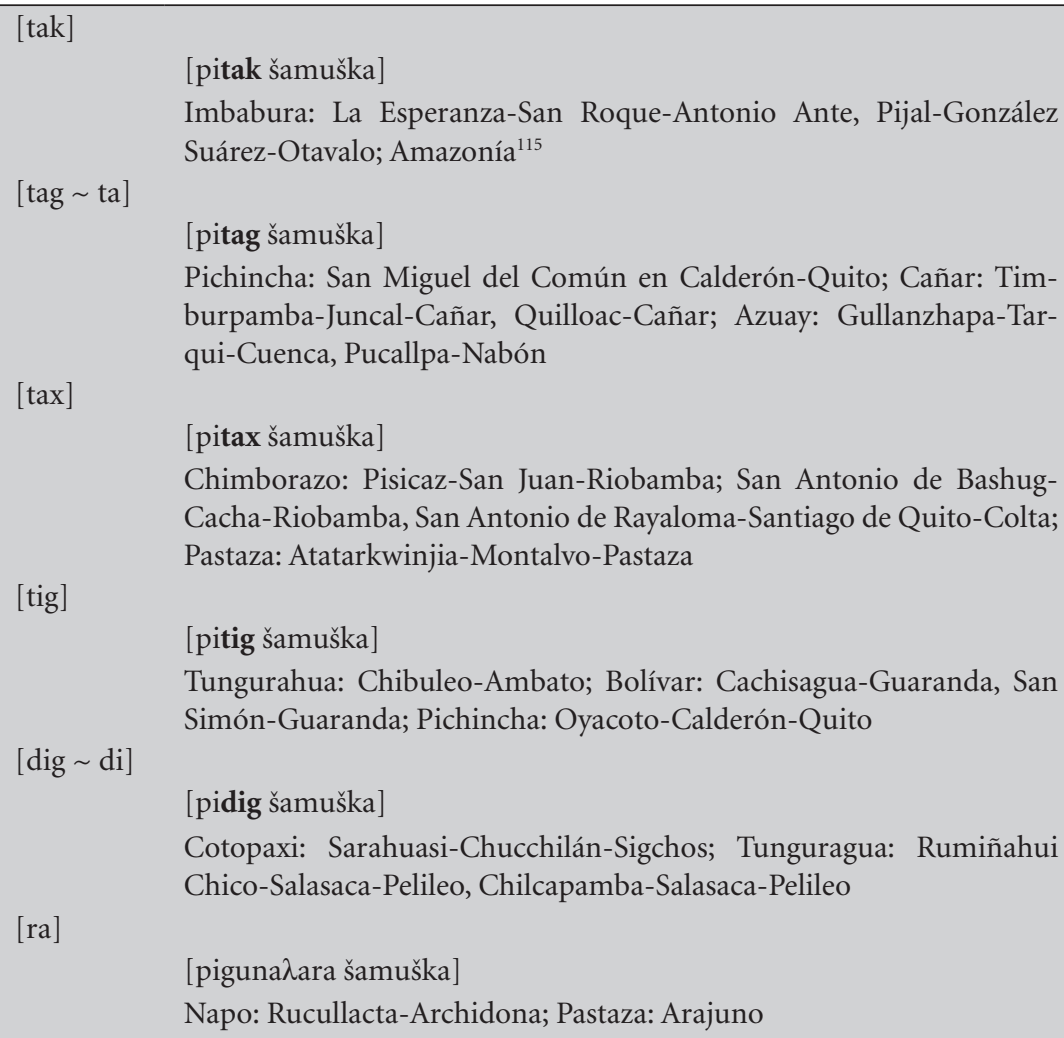

[pitax šamuška]

Chimborazo: Pisicaz-San Juan-Riobamba; San Antonio de BashugCacha-Riobamba, San Antonio de Rayaloma-Santiago de Quito-Colta; Pastaza: Atatarkwinjia-Montalvo-Pastaza

[tig]

[pitig šamuška]

Tungurahua: Chibuleo-Ambato; Bolívar: Cachisagua-Guaranda, San Simón-Guaranda; Pichincha: Oyacoto-Calderón-Quito

$[$ dig $\sim \operatorname{di}]$

[pidig šamuška]

Cotopaxi: Sarahuasi-Chucchilán-Sigchos; Tunguragua: Rumiñahui Chico-Salasaca-Pelileo, Chilcapamba-Salasaca-Pelileo

[ra]

[piguna $\lambda$ ara šamuška]

Napo: Rucullacta-Archidona; Pastaza: Arajuno

115 En Napo y Pastaza (Arajuno) pronuncian [tak] cuando la palabra a la cual se agrega es un monsílabo, pero cuando esta es de dos o más sílabas pronuncian [ra]. 


\section{3}

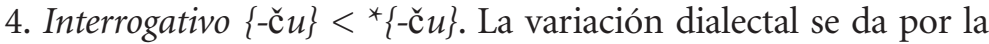
sonorización y fricativización de /č/como se puede apreciar en las realizaciones (Parker, 1969/2013, p. 88). El ejemplo es /munankiču/ ‘ ¿quieres?’.

\begin{tabular}{|c|c|}
\hline \multicolumn{2}{|l|}{$[\check{c} \mathrm{u}]$} \\
\hline & $\begin{array}{l}\text { Imbabura, Pichincha, Tungurahua, Chimborazo, Bolívar, Cañar, Azuay, } \\
\text { Loja y la Amazonía }\end{array}$ \\
\hline & [munungiču] \\
\hline & $\begin{array}{l}\text { Tungurahua: Chilcapamba-Salasaca-Pelileo, Churumanga-El Rosario- } \\
\text { Pelileo }\end{array}$ \\
\hline \multicolumn{2}{|l|}{$[\check{z} \mathrm{u}]$} \\
\hline & [munangižu] \\
\hline & Cotopaxi: Sarahuasi-Chucchilán-Sigchos \\
\hline
\end{tabular}

5. Limitativo $\{-\lambda a\}<{ }^{*}\{-\lambda a\}$. Las variaciones dialectales se dan por fricativización y/o depalatalización de / $\lambda /$ (Parker, 1969/2013, p. 85). El ejemplo /yaykuy $\lambda$ a/ 'entra no más' nos muestra sus manifestaciones:

$[\lambda \mathrm{a}]$

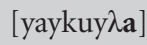

Cañar: Timburpamba-Juncal-Cañar, Quilloac-Cañar; Azuay: GullanzhapaTarqui-Cuenca; Loja: San Lucas; Orellana: El Descanso-Coca

[ikuy $\lambda \mathbf{a}]$

Napo: Tena, Archidona

$[$ Ža $]$

[yaykuyža]

Imbabura: La Esperanza-San Roque-Antonio Ante, Peguche-Miguel Iturrable-Otavalo, Pijal-González Suárez-Otavalo; Tungurahua: ChilcapambaSalasaca-Pelileo; Chimborazo: San Antonio de Bashug-Cacha-Riobamba, Rayaloma-Santiago de Quito-Colta; Azuay: Pucallpa-Nabón [waykuyža]

Cotopaxi: Maca Atápulo-Poaló-Latacunga 


\section{4}

\section{[waygiža]}

Tungurahua: Chilcapamba-Salasaca-Pelileo, Churumanga, Salasaca-Pelileo

[la]

[yaykuyla]

Pichincha: San Miguel del Común-Calderón-Quito; Cotopaxi: Sarahuasi-Chucchilán-Sigchos; Chimborazo: Pisicaz-San Juan-Riobamba, La Providencia-Columbe-Colta

6. Topicalizador $\{-k a\}<{ }^{*}\{-q a\}$. La variación que afecta a este sufijo se debe a la sonorización de /k/ (Parker, 1969/2013, p. 89). En la comunidad de Rucullacta (prov. de Napo) no se lo usa. El ejemplo /payka a $\lambda i ́$ runami kan/ 'él es una buena persona' se da como:

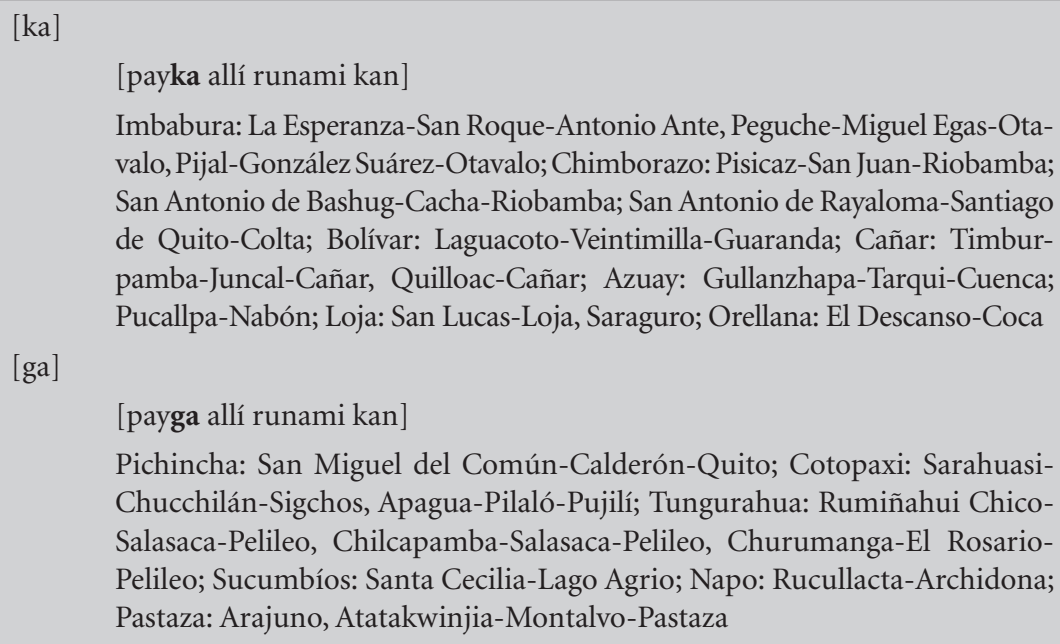
valo, Pijal-González Suárez-Otavalo; Chimborazo: Pisicaz-San Juan-Riobamba; San Antonio de Bashug-Cacha-Riobamba; San Antonio de Rayaloma-Santiago de Quito-Colta; Bolívar: Laguacoto-Veintimilla-Guaranda; Cañar: Timburpamba-Juncal-Cañar, Quilloac-Cañar; Azuay: Gullanzhapa-Tarqui-Cuenca; Pucallpa-Nabón; Loja: San Lucas-Loja, Saraguro; Orellana: El Descanso-Coca

[ga]

[payga allí runami kan]

Pichincha: San Miguel del Común-Calderón-Quito; Cotopaxi: SarahuasiChucchilán-Sigchos, Apagua-Pilaló-Pujilí; Tungurahua: Rumiñahui ChicoSalasaca-Pelileo, Chilcapamba-Salasaca-Pelileo, Churumanga-El RosarioPelileo; Sucumbíos: Santa Cecilia-Lago Agrio; Napo: Rucullacta-Archidona; Pastaza: Arajuno, Atatakwinjia-Montalvo-Pastaza

\section{Procesos de reinterpretación: reducción y ensamblaje}

En el quichua ecuatoriano se presentan algunos casos de morfemas que son el resultado de un proceso de reducción de uno de los morfemas y el ensamblaje con otro morfema (Cerrón-Palomino, 1997), dando como resultado interesantes reinterpretaciones. 


\section{5}

1. Validador $\{-m i\}<{ }^{*}\left\{-m / V_{-} ; m i / C_{-}\right\}$. No hay variaciones excepto en los pocos lugares donde se da el fenómeno de reducción y ensamblaje (Parker, 1969/2013, p. 89). Sea el ejemplo: /kaypimi kawsani/ 'aquí vivo', tenemos:

[mi]

[kaypimi kawsani] [kaybimi kawsani]

Sierra y parte de la Amazonía, desde el Arajuno (prov. de Pastaza) hacia el norte

En la Amazonía (Canelos, Sarayacu y Montalvo, en el río Bobonaza) se da el fenómeno de reducción y ensamblaje. Este proceso consiste en una fusión de este morfema, previo desgaste de /k/, con el verbo ser / $\mathrm{ka}-/$, dando como resultado expresiones como [alimangi] $</$ a $\lambda$ imi kanki/ 'estás bien'. Se da también en la Sierra centro (Salcedo y Salasaca), en donde al juntarse este fenómeno con el del cambio vocálico, producen alternacias como [ažimangi ažimingi] < /a入imi kanki/ 'estás bien'.

2. Validador $\{$-čari $\}<^{*}\{-$ tra $\}$. Proviene de $\{-\check{c} u\}+\{$ ari $\}$ debido al componente de conjetura que está presente en el morfema (Parker, 1969c/2013, p. 89). El ejemplo /payka šamunkačari/ ¿¿vendrá él seguramente?', nos deja: [čari ča], [payka šamunkačari]. Este morfema se usa en todo el país, aunque en la Sierra centro [ča] tiene mayor incertidumbre.

3. Validador $\{$-mari $\}$. Es plausible postular que proviene de $\{-\mathrm{mi}\}$ + ari. Con el ejemplo /payka šamunkamari/ 'él, efectivamente vendrá', tenemos: [mari ma], [payka shamunkamari]. En Salasaca dicen [payga šamuškadimi] 'él realmente ha venido', donde [ma] tiene menor énfasis afirmativo. En el caso de Salasaca, [šamuškadimi] está conformado de $/$ šamu- $/+\{$ ška $\}+\{$-tak $\}+\{-$ mi $\}$.

4. Validador $\{$-yari\}. Aquí solo se da el ensamblaje entre el morfema del imperativo $\{-y\}+$ ari. Con el ejemplo /papata mikuyari/ 'cóme las papas, pues', tenemos: 


\section{6}

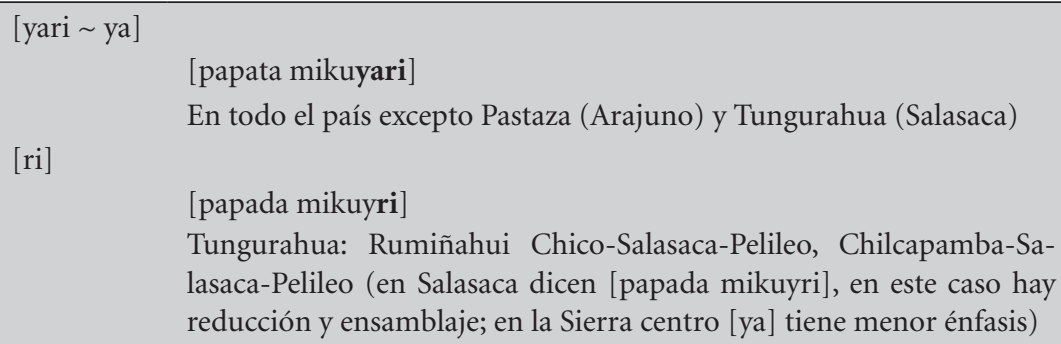

5. Aceptativo $\{$-karin\}. El morfema $\{-k a\}$, unido a /ari(n)/ se ensambló para derivar el morfema aceptativo \{-karin\}. El ejemplo /paykarin mana munankaču/ 'nada que hacer' o 'él no ha de querer', nos deja:

[karin $\sim$ garin]

[paykarin mana munankaču] [paygarin mana munankaču]

Se usa en toda la Sierra

\section{Desarrollos locales}

Luego de procesar las variantes a nivel morfológico, se constata que en el nivel abstracto, la inmensa mayoría de los morfemas de las hablas del quichua ecuatoriano es compartido por todas las zonas dialectales del Ecuador, aunque cada uno con sus distintas realizaciones, como se ha demostrado. Y los pocos morfemas que tienen usos regionales o zonales son:

\section{Tabla 9}

Morfemas que constituyen desarrollos del quichua ecuatoriano

\begin{tabular}{|l|l|}
\hline Morfema & Lugar de uso \\
\hline Comparativo $\{$-sami\} & Amazonía \\
\hline Propositivo $\{$-kri\} & Sierra \\
\hline Propositivo próximo $\{$-nkaraku\} & Amazonía \\
\hline Diminutivo $\{$-wa $\}$ & Sierra centro y Amazonía \\
\hline Diminutivo $\{$-ku\} & Sierra norte \\
\hline
\end{tabular}

Fuente: el autor 


\section{7}

\section{Zonas dialectales}

La zonificación dialectal que se presenta aquí se basa en los resultados de la investigación lingüística sincrónica. ${ }^{116} \mathrm{Al}$ momento de proponer la zonificación dialectal de una lengua se debe dejar en claro que ella, al referirse a un fenómeno social y lingüístico, es dinámica; siempre está más allá de los compartimentos que el lingüista logra establecer. Este procedimiento se parece al de la geometría, que postula abstracciones de las irregularidades de la naturaleza para obtener las figuras regulares, inexistentes en ella. Por lo tanto, las zonificaciones dialectales siempre tendrán sus limitaciones.

Los fenómenos lingüísticos más importantes que se observan en la fragmentación dialectal del Ecuador están relacionados con cambios vocálicos (inflexiones y monoptongación) y consonánticos (lenición y supresión de segmentos). Dentro del fenómeno de lenición están la sonorización y la fricativización de aspiradas.

En el caso del quichua de Ecuador se da una paradoja: existen muchas variaciones a nivel morfofonémico y a nivel de fonemas del léxico, sin embargo, luego del análisis lingüístico, a la luz del "principio de innovaciones compartidas" y de los "diferenciadores dialectales" que caracterizan a cada región, se ha hallado que los dialectos pueden agruparse en pocas zonas dialectales.

Cada una de estas zonas tiene características no compartidas con las otras. Eso permite, entre otras cosas, una fácil identificación de la procedencia del hablante. Así por ejemplo, si se escucha que el hablante usa la variante [ra] del morfema acusativo $\{$-ta $\}$, o la forma [rak] para el validador $\{$-tak\}, automáticamente se sabe que es una persona de la

116 Algunas innovaciones señaladas en el quichua ecuatoriano pueden ocurrir también en hablas quechuas de otros países, pero la presente investigación se limita a lo necesario para establecer la zonificación dialectal de las hablas del Ecuador, en función de su utilidad en las actividades de planificación lingüística aplicada a la EIB. 


\section{8}

Amazonía centro. Igualmente, si una persona registra cambios vocálicos, es un signo de que proviene de la Sierra centro, etc.

A continuación presentamos la propuesta de zonificación y las características que las identifican. Los lugares mencionados tanto en la Sierra como en la Amazonía se señalan siempre de norte a sur.

Figura 16

Las seis zonas dialectales en las que se pueden agrupar las hablas del quichua ecuatoriano

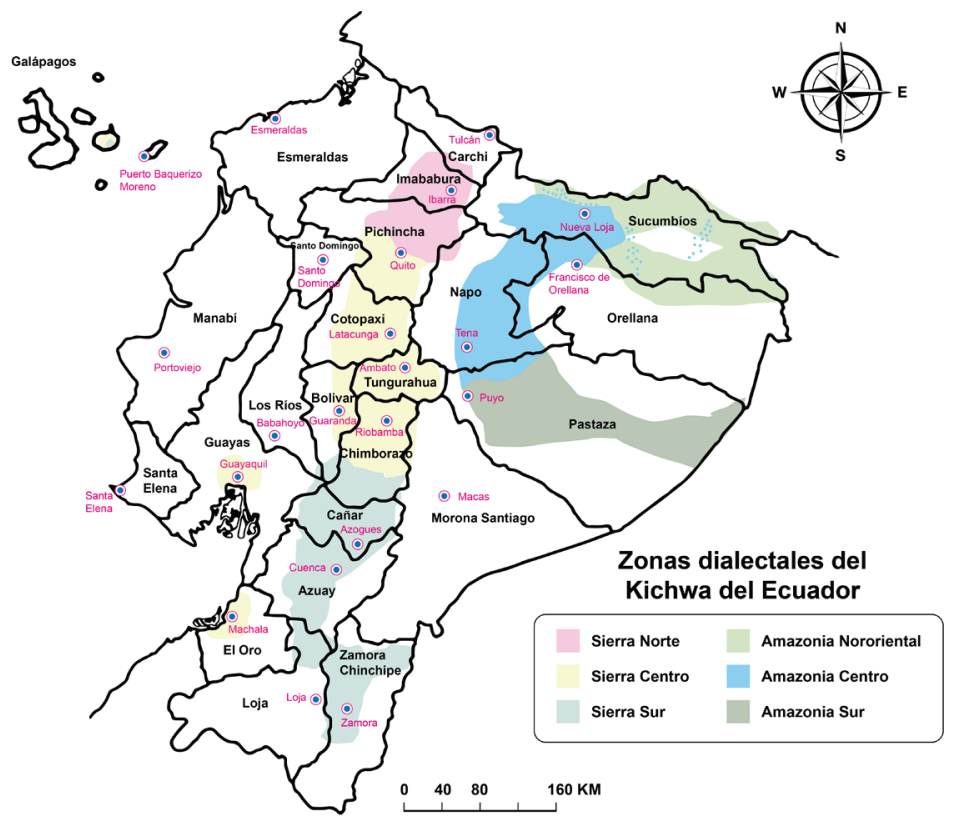

Fuente: el autor

\section{Zona Sierra norte}

Esta zona corresponde a toda la provincia de Imbabura y la parte norte de la provincia de Pichincha, conformada por el norte y el oriente 


\section{9}

del cantón Quito, y los cantones Pedro Moncayo y Cayambe. La frontera norte está constituida por el límite con Colombia. La frontera sur es un accidente natural, el cañón del río Guayllabamba y el río Chiche. $\mathrm{Al}$ este de la frontera está el habla de Oyacachi, ubicada en la cima de la Cordillera oriental, y aunque en la división política actual es parte de la provincia de Napo (región amazónica), lingüísticamente está relacionada con la Sierra norte. Al oeste limita con la Cordillera occidental.

Entre las características de esta zona puede señalarse: primero, la fricativización de las oclusivas aspiradas que se da en la zona de la Sierra centro (cf. supra, "Presencia de aspiradas..."), y segundo, la oclusión de la semiconsonante $[\mathrm{w}] /$ _ $_{\mathrm{i}}>$ [b]. Por ejemplo:

\begin{tabular}{|c|c|c|}
\hline [bira] & /wira/ & 'manteca' \\
\hline [bičay] & /wičay/ & 'subir' \\
\hline [bižay] & /wi入ay/ & 'avisar' \\
\hline [biksa] & /wiksa/ & 'barriga' \\
\hline [biki] & /wiki/ & 'lágrima' \\
\hline
\end{tabular}

\section{Zona Sierra centro}

De norte a sur, comienza en San Miguel del Común (Calderón, Quito), situado en el centro de la provincia de Pichincha, avanza hacia el suroriente de la provincia donde se encuentran los cantones Sangolquí y Mejía (Machachi). Incluye todas las provincias de Cotopaxi, Tungurahua, Bolívar y la parte centro-norte de la provincia de Chimborazo, es decir, los cantones Riobamba, Colta, Guamote, Chambo y la parte centro-norte de Alausí. La frontera sur es un accidente natural: la quebrada de Achupallas.

Entre las características de esta zona están: primero, la presencia de oclusivas aspiradas, posiblemente este sea un fenómeno de retención del quechua del Cuzco, que actuaba como superestrato (cf. supra, "Pre- 


\section{0}

sencia de aspiradas..."), y segundo, la presencia del cambio vocálico de inflexión (cf. supra, "Cambio vocálico").

En esta zona también existe el fenómeno de monoptongación, aunque no es exclusivo de esta, pues también se da en la Amazonía sur. La compartición de la monoptongación con la Amazonía podría ser consecuencia del contacto comercial entre esta y la Sierra centro desde la época colonial. Los ancianos salasaqueños recuerdan que hasta hace unos cincuenta años recibían la mercadería que venía desde Guayaquil en la Costa y se encargaban de llevarla hasta Canelos y otros lugares de la Amazonía. De momento se requiere realizar investigaciones de tipo histórico-económico a este respecto.

Frente a la propuesta morfofonémica reconstruida por Parker, en esta zona y en la Amazonía sur se encuentra la mayor evolución y fragmentación dialectal. Así por ejemplo, al interior del habla de los salasacas, en comunidades muy cercanas, una expresión corta como $<$ Shinallatakmi nisha > 'Así mismo diré', se realiza de la siguiente manera:

[šinažadimi niša] comunidad Manzana Pampa, parroquia Salasaca

[šinažaitimi niša] comunidad Churumanga, parroquia el Rosario

\section{Zona Sierra sur}

Incluye el sur de la provincia de Chimborazo, esto es el cantón Chunchi y continúa hacia el sur con las provincias de Cañar, Azuay, Loja y Zamora. Esta zona se caracteriza por las pocas innovaciones que ha tenido en relación con los fonemas del protoquechua propuesto por Parker (1969/2013) y aparece como el dialecto más conservador en relación a los protofonemas. Otra característica que une a las hablas de esta zona es la presencia de los fonemas / $\check{z} /, / \mathrm{z} / \mathrm{y} / \mathrm{d} /$ en palabras provenientes, posiblemente, de las lenguas de sustrato. Por ejemplo: 


\begin{tabular}{|lll|}
\hline [žiru] & /žiru/ & 'maíz partido' \\
[žaru $]$ & /žaru/ & 'tipo de insecto que canta en el crepúsculo' \\
[žadan] & /žadan/ & 'una variedad de planta' \\
[žima] & /žima/ & 'variedad de maíz blanco para mote' \\
{$[$ žuta $]$} & /žuta/ & 'pájaro' \\
{$[$ hizi $\sim$ hiži] } & /hizi/ & 'risueño/a' \\
{$[$ kiža $]$} & $/$ kisa/ & 'vagina' \\
\hline
\end{tabular}

En esta zona se presentan oposiciones debido al sustrato como:

\begin{tabular}{|ll|}
\hline / 2 atan/ & 'desnudo' \\
/žadan/ & 'una variedad de planta' \\
\hline
\end{tabular}

En este caso particular, si se aplicara el sistema de escritura unificado del quichua ecuatoriano, se tendría que escribir $<$ llatan $>$ para ambos términos, lo cual superaría la diferenciación de las dos realidades.

\begin{tabular}{|ll|}
\hline$/$ kìa/ & 'luna' \\
/kižal & 'vagina' \\
\hline
\end{tabular}

En este último caso, tomado del habla de la comunidad de Quilloac (prov. de Cañar), se tiene un par mínimo que requiere ser diferenciado en la escritura.

\section{Zona Amazonía nororiente}

Comprende la parte nororiental de la provincia de Sucumbíos, los cantones Putumayo, Cuyabeno y parte de Shushufindi. Esto cubre la frontera con Colombia y la frontera oriental con el Perú. También incluye la parte oriental de la provincia de Orellana, comprendiendo el cantón Aguarico y parte de Francisco de Orellana. La frontera norte es el límite con Colombia, el límite sur es el río Napo, al este limita con Perú y la frontera occidental es el río Pañacocha. 


\section{2}

Su característica principal es la depalatalización de /š/ en el subordinador $\{$-šspa y en el participial \{-ška\}. Es la única de las seis zonas dialectales que tiene esta particularidad. El siguiente ejemplo ilustra el cambio de $[$ špa $]>[$ spa]:

\section{[aswataka lumuta takasa mukusa rurančimi] \\ /aswataka lumuta takašpa mukušpa rurančikmi/ \\ 'la chicha hacemos golpeando y aplastando la yuca'}

El fenómeno de depalatalización de /š/ también se ilustra en el ejemplo de cambio de [ška] > [ska]:

[pitruliwmanda $\lambda$ aki tukuska kawsanči]

/petroleomanta $\lambda$ aki tukuška kawsančik/

'debido al petróleo (su explotación) vivimos con problemas'

En el léxico se mantiene el fonema /š/. En esto se diferencia del ingano de Colombia, donde el fonema /š/ se ha fusionado completamente con /s/. La explicación de la realización de /š/ como [s] solo en los morfemas mencionados podría buscarse en un caso especial de evolución interna del quichua; sus hablantes son descendientes de los omaguas, que fueron quichuizados durante la Colonia. Su diferenciación en el tratamiento de la /š/ con el ingano puede verse a continuación:

\begin{tabular}{|lll|}
\hline Zona nororiental & Ingano & Glosa \\
/šamuy/ & /samuy/ & 'venir' \\
/šutuy/ & /sutuy/ & 'gotear' \\
/šitay/ & /sitay/ & 'botar' \\
\hline
\end{tabular}




\section{3}

\section{Zona Amazonía centro}

Comprende desde el río Aguarico al norte y se extiende hasta el río Arajuno en el sur. Incluye los cantones Lago Agrio, Cascales, Sucumbíos y Gonzalo Pizarro en la provincia de Sucumbíos; el cantón Loreto de la provincia de Orellana, desde el río Coca hacia el occidente. Incluye toda la provincia de Napo, excepto la parroquia Oyacachi del cantón Chaco. También le pertenecen la parte norte y occidental de la provincia de Pastaza, constituida por los cantones Arajuno y Santa Clara.

Por otra parte, la razón de la presencia de hablantes del dialecto de la Amazonía centro, como enclaves, en el dialecto de la Amazonía Nororiente, específicamente en parte de la provincia norteña de Sucumbíos se debe a la migración iniciada hace unos sesenta años desde Tena y Archidona (prov. de Napo). Esta movilización se debió a la mano de obra que necesitaba la extracción petrolera y también a que allí pudieron coger nuevas tierras.

En cuanto a sus características dialectales podemos mencionar la caída de /h/ en posición inicial de palabra y de /w/ en inicial de palabra delante de /i/. Como se sabe que el quechua general ya tenía este fenómeno, cabrían dos explicaciones sobre su presencia en esta zona dialectal: una posibilidad sería la retención de este fenómeno del quechua general y la otra sería que se trata de una innovación interna del quichua ecuatoriano. Ejemplos en los que el fonema /h/ > ø son:

\begin{tabular}{|c|c|c|}
\hline [atun] & /hatun/ & 'grande' \\
\hline [awa] & /hawa/ & 'hacia afuera' \\
\hline [ambi] & /hampi/ & 'remedio' \\
\hline [akuyčik] & /hakuyčik/ & 'vámonos' \\
\hline [aytay] & /haytay/ & 'petear' \\
\hline [ičuy] & /hičuy/ & 'abandonar' \\
\hline$[\mathrm{i} \lambda \mathrm{u}]$ & /hi $\lambda \mathrm{u} /$ & 'goloso' \\
\hline [umbi] & /humpi/ & 'sudor' \\
\hline
\end{tabular}




\section{4}

Por otro lado, los ejemplos en los que el fonema /w/ > ø son:

\begin{tabular}{|c|c|c|}
\hline [ira] & /wira/ & 'manteca' \\
\hline [iksa] & /wiksa/ & 'barriga' \\
\hline [iki] & /wiki/ & 'lágrima' \\
\hline [i $\lambda \mathrm{ma}]$ & /mi $\lambda \mathrm{ma} /$ & 'pluma, vello, lana de animales' \\
\hline [ičay] & /wichay/ & 'aguas arriba' \\
\hline [iñay] & /wiñay/ & 'siempre’ \\
\hline [iñari] & /wiñariy/ & 'crecer' \\
\hline
\end{tabular}

Un segundo rasgo de esta zona es la caída del fonema /r/ en el morfema de tiempo pasado $\{$-rka\}, realizándose este como [ka], por ejemplo en [mikukani] /mikurkani/ 'comí. En tercer lugar tenemos la lenición de /t/ en el morfema acusativo $\{$-ta\}, dando como resultado [ra]; este mismo fenómeno se produce en el contrastivo \{-tak\} que se convierte en [rak], así: [tantara munani] /tantata munani/ 'quiero pan'. ${ }^{117}$ Como cuarto está la síncopa del morfema de propósito $\{$-nkapak\}, el cual se realiza como

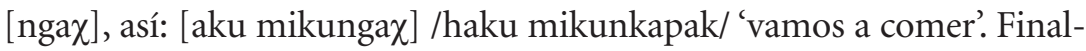
mente, el dialecto de esta zona se caracteriza también por el alargamiento vocálico cuando el morfema \{-pi\} se añade a una raíz que termina en /i/, por ejemplo en [wasi:mi aka] /wasipi karka/ 'estuvo en la casa'.

\section{Zona Amazonía sur}

Está constituida por el centro-sur de la provincia de Pastaza e incluye los cantones Mera y Pastaza. Una de sus primeras características es la realización del morfema de propósito \{-nkapak\} como [ngawa]; el fonema $/ \mathrm{p} /$ de este morfema se realiza como [w], es decir, en forma lenizada; este fenómeno también ocurre en el morfema $\{$-paš $\}$, que se transforme en [was], como en: [haku mikungawa] /haku mikunkapak/

117 Este cambio no se da cuando el elemento léxico es un monosílabo, por ejemplo, [kanta $\lambda$ akini] 'te amo', [payta llakini] 'amo a ella'. En este contexto /t/ no se realiza como [r]. 


\section{5}

'vamos a comer'. Un segundo rasgo de esta zona es el desarrollo de la figura conocida como "reducción y ensamblaje" entre el morfema independiente $\{-\mathrm{mi}\}$ y el lexema $\{\mathrm{ka}-\}$, por ejemplo: [a $\lambda$ iman] que provie-

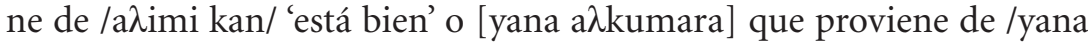
a $\lambda$ kumi karka/ 'era un perro negro'. El dialecto de esta zona también se caracteriza por la caída de / k/ en el verbo \{kay\} 'ser' en todos los tiempos verbales, excepto después de /n/, así: [payka allí yachachik ara] /payka allí yachachikmi karka/ 'él/ella fue un (a) buen profesor(a)'. Otro rasgo es la metátesis en palabras que tienen los fonemas /r/, /y/ en un limitado número de palabras como:

\begin{tabular}{|lll|}
\hline$[$ ruya $]$ & /yura/ & 'árbol' \\
{$[$ raway $]$} & /yawar/ & 'sangre' \\
{$[$ ruyak $]$} & /yurak/ & 'blanco' \\
{$[$ raykay $]$} & /yarikay/ & 'tener hambre' \\
\hline
\end{tabular}

Finalmente, vale mencionar el uso de [inda $\sim$ nda] /inta/ para decir 'sí', en lugar de /ari/, ya que en otros lugares de la Amazonía [inta $\sim$ inda] es el 'tizón', lo cual nada tiene que ver, al parecer, con el adverbio de afirmación 'sí'.

\section{A manera de conclusión}

Tomando en cuenta las diferencias lexicales, se puede hablar de dos bloques únicamente la zona Sierra y la zona Amazónica. Además de las diferencias por fitónimos, zoónimos y del léxico relacionado con actividades propias de cada región, existe también un limitado vocabulario para referirse a actividades que, siendo comunes a las dos regiones, sin embargo, el léxico o su significado es diferente. En algunos casos el léxico diferencial se reduce al empleo de radicales compartidos, pero que conforman derivadas distintas. Por ejemplo: 


\section{6}

\begin{tabular}{|lll|}
\hline Sierra & Amazonía & Glosa \\
/sampayay/ & /šaykuy/ & 'cansarse' \\
/šuyay/ & /čapay/ & 'esperar' \\
/knuyay/ & / akiriy/ & 'amar' \\
/araray/ & /ačačau/ & 'qué calor' \\
/kusa/ & /kari/ & 'marido' \\
/kamačiy/ & /kunay/ & 'aconsejar, amonestar' \\
/ñan/ & /ñanpi/ & 'camino' \\
/kutipay/ & /kutiči/ & 'contestar' \\
/suniyačiy/ & /mantay/ & 'extender' \\
/ñikay, takariy/ & /taktiy/ & 'tropezar' \\
/tuñiy/ & /tulay/ & 'derrumbar' \\
/phunki/ & /pukla/ & 'hinchazón' \\
/tawkashina/ & /tawkasami/ & 'varias clases, tipos' \\
\hline
\end{tabular}

El uso de este léxico ayuda a identificar si una persona es de la Amazonía o de la Sierra. Estas diferencias pueden explicarse como sinónimos con distribución complementaria. Es muy similar a lo que ocurre en castellano, cuando en el norte del Ecuador le dicen < plomero $>$ a la persona que arregla los desagües, en tanto que al sur del Ecuador le dicen $<$ gasfitero $>$.

A nivel de morfofonémica, la diferenciación entre Sierra y Amazonía solo se da en los siguientes desarrollos regionales: $\{-\mathrm{kri}-\}$ y $\{$-nkaraku-\}. El propositivo $\{-\mathrm{kri}\}$ es un desarrollo propio de las hablas de la Sierra ecuatoriana, no hay duda de que esta forma proviene de la fusión de $\{-\mathrm{k}\}+$ el lexema /ri-/, como en /mikukrini/, /mikunkapak rini/ 'voy a comer'. El propositivo próximo \{-nkaraku\} es un desarrollo propio de la Amazonía ecuatoriana, por ejemplo en /mikunkarakuni/ 'estoy yendo a comer', donde: 


\section{7}

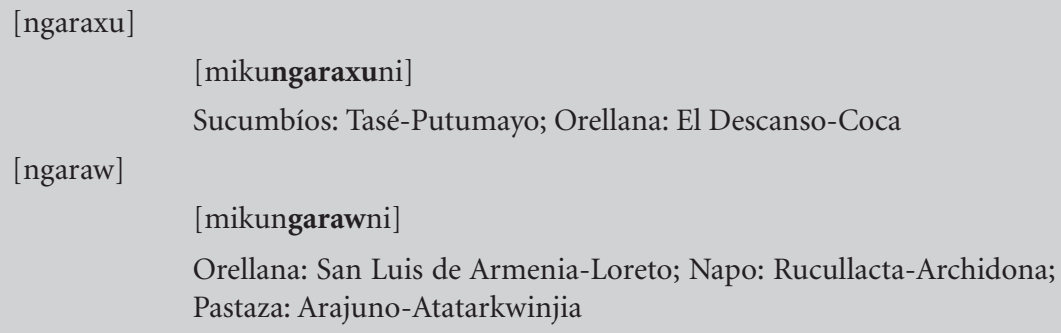

Este estudio es el primero en cubrir con investigaciones empíricas todo el territorio nacional donde tradicionalmente se habla el quichua. Con los datos de esta investigación se concluye que las variaciones del quichua del Ecuador pueden zonificarse en seis áreas dialectales, con lo cual supera las discrepancias que existían entre diversos autores en cuanto a la zonificación dialectal del quichua ecuatoriano. Así, Parker (1963-1972/ 2013, p. 151) había propuesto diez dialectos, siete en la Sierra y tres en la Amazonía; Carpenter (1982, p. 21) había propuesto catorce; en la Amazonía coincidimos con los tres señalados por Orr (1965). Sin embargo, creemos que solo ahora se han precisado, gracias al trabajo de campo efectuado a gran escala, las características dialectales de cada una de las zonas y sus fronteras geográficas.

Así, mientras Parker en el Diagrama IV de su texto ubicó el habla de Calderón en la Sierra norte, con los datos de la investigación ahora se la coloca en la Sierra centro debido al cambio vocálico y a que dicha parroquia desconoce la fricativización de las aspiradas, que es característica de la Sierra norte. En la Sierra centro, Parker solo incluía a las comunidades de Colta, Pulucate y Caliata (prov. de Chimborazo), pero en la zona central debe incluirse también las provincias de Cotopaxi, Tungurahua y Bolívar, juntamente con la parte norte de la provincia de Chimborazo y la parte centro-sur de la provincia de Pichincha. Igualmente, en la Sierra sur, Parker incluía solo a las provincias de Azuay y Loja, pero ahora se incluye dentro de esta zona la provincia de Cañar, 


\section{8}

parte de la provincia de Chimborazo y la provincia de Zamora Chinchipe, que está en la vertiente oriental de la cordillera de los Andes.

En cuanto a las razones por las cuales las hablas ecuatorianas dan la impresión de contener una gran diversidad dialectal, se debe a la imbricación de los diferenciadores dialectales. A esto hay que añadir la presencia ciertas diferencias lexicales locales. Así por ejemplo, en Cotopaxi (Sarahuasi) usan /maytuy/ en lugar de /čumpi iiy/ 'envolver al niño

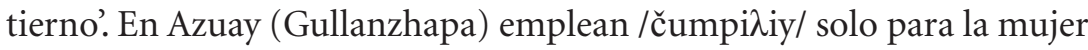
después de dar a luz y para los niños emplean /maytuy/. No emplean / čumpi入iy/ en Imbabura (Pijal), Pichincha (Caucho Alto), Loja (San Lucas) ni Pastaza (Atatarkwinjia).

Igualmente, algunos procesos de reducción y ensamblaje muy locales han contribuido a incrementar la percepción de una amplia variación dialectal. Así por ejemplo, al interior de la Amazonía sur se puede identificar variaciones dialectales a partir de cómo se realiza la expresión /imašina šamuška/ ‘ ¿cómo ha venido?', de manera que en las comunidades de Canelos y Sarayacu dicen [imašina šamuška], mientras que en las comunidades de Montalvo dicen [imina šamuška].

Se ha mostrado que la gran diversidad dialectal del Ecuador se da fundamentalmente a nivel de estructura fonológica superficial y no tanto en otros planos de la gramática. Como se ha visto en los resultados de la investigación, los fenómenos lingüísticos presentes en las hablas del quichua no son muchos, sin embargo, debido a su manifestación en las hablas, da la impresión de estar ante una gran diversidad dialectal. Lo que resulta más complejo es la determinación de las fronteras dialectales debido, posiblemente, a los fenómenos de migraciones libres o forzados del pasado, así como también a las relaciones de intercambio y, en tiempos coloniales, a la evangelización.

Posiblemente por esto Carpenter (1982) optó por considerar como variante dialectal diferente a cada uno de los lugares donde vivió o recogió el material, dividiendo al quichua de Ecuador en 14 dialectos. 


\section{9}

Carpenter, al momento de proponer su clasificación dialectal, no acudió a principios generalmente usados para estos estudios ni dio información precisa de la geografía lingüística.

El establecimiento de las zonas dialectales y su caracterización servirá para algunas acciones prácticas en el proceso de EIB y la implementación de la escritura unificada. Una de ellas en la planificación lingüística que deben hacer los técnicos que elaboran materiales educativos, especialmente para los primeros niveles. En la medida de lo posible se debe emplear al inicio expresiones y formas comunes a todos los dialectos, es decir, que sean entendibles a nivel suprdialectal. Igualmente, entre otras aplicaciones, está su uso en la formación docente; los docentes deben comprender los alcances de la diversidad dialectal de forma sencilla y precisa. Otro uso será para la elaboración de métodos de enseñanza del quichua como segunda lengua. Finalmente, el conocimiento de las características de cada una de las seis zonas dialectales podrá facilitar que muchos quichua-hablantes se vuelvan pluridialectales a nivel oral. 

Capítulo 6

\section{Políticas lingüísticas incaicas, coloniales y republicanas}

En este tema, se pone énfasis no solamente en la lengua como objeto de estudio, sino sobre todo en los sujetos hablantes de ella. La lengua no es solo un instrumento de comunicación, sino que expresa la cosmovisión o weltanschauung ${ }^{118}$ de un pueblo. Por esta razón, ella es un constituyente fundamental de su identidad. Cuando la lengua muere los otros elementos culturales se debilitan y tienden a desaparecer.

La lengua, en cierta manera, es uno de los componentes del poder. Muchos autores se han expresado en este sentido (Mannheim, 1991; Zabaltza, 2006; Howard, 2007; Rodríguez, 2018). Efectivamente, el poder de un pueblo está determinado por lo económico, lo político, lo psicosocial y lo cultural. La lengua se encuentra dentro de lo psicosocial como lo señalaba ya Saussure a comienzos del siglo XX, pero también es parte de la semiósfera de la cultura. En consecuencia, las acciones que se realicen en relación a la valoración de una lengua y actualmente también a ponerla por escrito, están relacionadas con las estructuras de poder de una sociedad.

Para contextualizar la política de estandarización de la escritura del quichua, haremos una revisión de las políticas lingüísticas desde la

118 Weltanschauung es una expresión alemana para referirse a “cosmovisión”, la cual está integrada por los términos welt 'mundo', an 'alrededor de' schau-del verbo schauen 'mirar' y -ung 'sufijo que indica género femenino'. En quichua sería pacharikuy. 
época incaica hasta llegar a la situación actual, atravesando por los diferentes momentos de la vida colonial y republicana. Antes de proseguir en este empeño, vale aclarar que por "política lingüística” se entiende el estatus que un Estado le asigna a una lengua. Generalmente esta situación se cristaliza en algún instrumento legal como una Constitución o alguna otra norma de un país. Al respecto Spolsky dice:

The easiest to recognize are policies that exist in the form o clear-cut labeled statements in official documents. They might, for example, take a form of the clause in a national constitution or a language low, or a cabinet document or an administrative regulation (2004, p. 11).

En el caso del quechua/quichua se trata de ver en qué medida las políticas lingüísticas adoptadas por el poder reinante han modelado el imaginario de las sociedades sobre su valoración y uso en los distintos momentos. Pero además se reivindica la lucha de las nacionalidades indígenas en la generación de estas políticas, principalmente, a partir del siglo XX.

Por otra parte, la estandarización del quichua también tiene relación con las políticas educativas y los proyectos de educación indígena. Una síntesis de estos puede verse con amplitud en Yánez (1995).

\section{Política incaica}

Varios estudiosos han hecho referencia a la política lingüística de los incas en la expansión del quechua. Así, Torero (1970), Hartmann (1979) y Cerrón-Palomino (1987), basándose en textos de los cronistas, han señalado la voluntad de ellos de emplear el quichua como un instrumento de unificación de sus territorios, lo cual se infiere de algunos textos de Cieza de León y de Murúa. Efectivamente, el primero señala que los gobernantes incas dispusieron que todos sus súbditos aprendiesen la lengua del Cuzco desde la edad más temprana posible. En efecto, Cieza de León señala que: 


\section{3}

Y entendido por ellos quan gran trabajo ser caminar por tierra tan larga y adonde a cada lengua y a cada paso avía nueva lengua y que sería gran dificultad el entender a todos por ynterprétes [sic], escojendo lo más seguro ordenaron y mandaron, so graves penas que pusieron, que todos los naturales de su ynperio entendiesen y supiesen la lengua del Cuzco generalmente, así ellos como sus mujeres, de tal manera que aún la criatura no oviese dexado el pecho de su madre quando le comensacen a mostrar la lengua que avía de saber. Y aunque al prençipio fue dificultoso y muchos se pusieron en no querer deprender más lenguas de las suyas propias, los reyes pudieron tanto que salieron con su yntuiçion y tuvieron por bien de conplir su mandato. Y tan de veras se entendió en ello que en tiempo de pocos años se savía y se usava una lengua en más de mil y dozientas lenguas: y aunque esta lengua se usava, todos hablavan las suyas, que son tantas que si lo escribiese no lo creyrían (Cieza de León, 1996, p. 72).

Los funcionarios del imperio, en la práctica, promovían el uso del quechua. La política lingüística sobre el uso de esta lengua en la administración del incario se puede deducir de este otro fragmento de Cieza de León:

Y como saliese un capitán del Cuzco o alguno de los orejones a tomar quenta o residencia o por jues de comiçión entre algunas provinçias o para visitar lo que le hera mandado, no hablaba en otra lengua que la del Cuzco, ni ellos con él. La qual es muy buena, breve y de gran conprehinçión y abastada de muchos vocablos y tan clara que, en pocos días que yo la traté, supe lo que me bastava para preguntar muchas cosas I por donde quiera que andava (Cieza de León, 1996, p. 72).

Otro documento en el cual se hace mención a la política incaica es el relacionado con una supuesta orden impartida por Huaina Cápac, noticia recogida por el mercedario Martín de Murúa, la cual dice:

A este ynga Huayna Cápac se atribuye hauer mandado en toda la tierra se ablase la lengua de Chinchay Suyo, que agora comúnmente se dize la Quichua general, o del Cuzco, por aver sido su madre Yunga, natural de Chincha, aunque lo más cierto es hauer sido su madre mama Occlo, 


\section{4}

muger de Tupa Ynga Yupanqui su padre, y este orden de que la lengua de chinchay Suyo se ablase generalmente hauer sido por tener él una muger muy querida, natural de Chincha (1590/2001, p. 126).

Según los pocos datos relacionados con la política lingüística de los incas, se puede colegir que esta debió ser bastante flexible en relación a las demás lenguas. Propagaron su lengua, pero esto no significó una imposición de un monolingüismo. Como se ha visto en el capítulo 1 y como se verá más adelante, las lenguas prequichuas siguieron vivas durante el incario y solo después de mediados del siglo XVIII, con la generalización del quichua y del castellano, comenzaron a desaparecer.

\section{Política colonial del siglo XVI y XVII}

Las políticas lingüísticas coloniales aplicadas por los españoles en nuestro continente se dieron dentro de un contexto macro que ocurría en la misma España con la publicación de la gramática de Nebrija en 1492. Así pues, una lengua generalizada contribuyó a unificar el poder español. En América, aparte de la pretensión latente de imponer castellano, se usaron las "lenguas generales" que encontraron y emplearon para la difusión ideológica en un contexto de dominación, específicamente para la evangelización. Esta política se aplicó no solamente en el caso del Virreinato del Perú, sino también en otras partes de América como México.

Los colonizadores tempranamente desarrollaron un discurso aparentemente convincente para las sociedades de su tiempo con el objeto de justificar las acciones de sometimiento. La cristianización y la civilización de los indígenas, a través de la castellanización, formaron parte de esta práctica. Así, la cuarta de las siete "causas justas" que los españoles esgrimieron para legitimar la invasión a las culturas de América tenía que ver directamente con el aspecto religioso, pero implícitamente con la lengua. Según ésta, el infiel, el pagano que se negara a admitir la fe cristiana, podía ser obligado por la fuerza, subyugado, esclavizado si fuera necesario. Sobre esta "causa justa", expresada en el documento 


\section{5}

denominado "Requerimiento", redactado y recitado en castellano, señala Montaner:

Pero ¿cómo se le propone al indio la cristianización y la sujeción a la Corona de Castilla? Mediante el Requerimiento, un documento legal redactado en castellano por el jurista Palacios Rubio, en el que se establecía la superioridad del cristianismo comenzó a utilizarse a partir de 1514, generalmente se proclamaba en aldeas vacías, pues los indios habían huido, o se les leía a los estupefactos aborígenes — que no entendían una palabra-, pero si no aceptaban la nueva autoridad, ya existía una coartada jurídico teológica para someterlos por la fuerza de inmediato (2001, pp. 20-21).

Así, mediante una "recitación solemne" en castellano, se impuso esta lengua en los ámbitos jurídicos y académicos. Los investigadores concuerdan en que luego de haber consolidado la invasión a América, la Corona española intentó, primero, castellanizar a la población indígena, y luego, fue por la vía de emplear las lenguas indígenas generales. Así, en su estudio sobre la política de castellanización en México, Tanck de Estrada señala que la Corona usaba dos argumentos: el uno religioso ${ }^{119}$ y el otro relacionado con la "culturización".

A partir de 1550 EL GOBIERNO español comenzó a ordenar que los indios de la Nueva España se les enseñara el idioma castellano. Las

119 Cabe anotar que en el siglo XVI hubo discusión entre los teólogos sobre la traducción/interpretación de algunos conceptos cristianos a las lenguas indígenas. Así por ejemplo, según Estensoro (2003, pp. 94-103), después de ensayar varias posibilidades terminaron cristianizando el nombre de Pachacámac. Se tomó un atributo para representar a Dios. Para otros conceptos, a partir del Tercer Concilio Limense (1582-1583), prefirieron dejar la misma palabra castellana, para evitar las dificultades de traducción. Actualmente, en Ecuador los evangélicos prefieren usar Dios Yaya o simplemente Dios, mientras que los católicos a través de la Conferencia Episcopal Ecuatoriana (1997), en la traducción de la Biblia, retomaron el nombre de Pachacámac para designar a Dios. El título de la Biblia sería Pachacamapac Quillcashca Shimi en una versión estandarizada. 


\section{6}

cédulas reales indicaban que la razón principal para esta medida se debía a la convicción de que las lenguas indígenas no eran suficientemente precisas para "explicar bien y con propiedad los misterios de nuestra Santa Fe Católica” [...]. Además del aspecto religioso, durante el siglo XVI se mencionaba otro motivo para promover la castellanización: ayudaría a los indios asimilar la cultura europea, a tomar "nuestra policía y buenas costumbres” (Tanck de Estrada, 1989, pp. 701-702).

Luego, ante el fracaso de la política de castellanización inmediata y ante la pragmática de los religiosos evangelizadores, se optó por usar de manera transicional las lenguas indígenas mayoritarias para la evangelización. Al respecto, Pottier dice:

El problema de la lengua que debía ser empleada se planteó durante más de tres siglos. Había dos soluciones teóricamente posibles: o los indígenas aprendían el castellano o el portugués, según el caso, o los misioneros estudiaban las lenguas indígenas. Al principio, la Corte española optó por la primera solución. Así podemos comprobarlo en una ordenanza de 1516: "que aya un sacristán... que muestre los niños a leer y escribir hasta que son de edad de nueve años, especialmente a los hijos de los caciques e de los otros principales del pueblo, e así mismo les muestren a hablar romance castellano y ase (ha se) de trabajar con todos los caciques e indios quanto fuera posible que hablen castellano". En 1550 un capítulo de las Leyes de Indias insiste en la necesidad de enseñar el castellano, ante la gran variedad de los idiomas nativos. En 1575 el virrey Toledo ordena que "todos hablen la lengua general del lugar y aprendan la española y usen de ella, de manera que en las dichas lenguas se les pueda enseñar la doctrina cristiana, y ellos la puedan aprender y mejor comunicar con los españoles" (1983, p. 19).

Por su parte, Ortiz, al presentar la historia del quichua, señala que:

Las autoridades españolas en un comienzo trataron de imponer a los indígenas su propia lengua. $Y$ hasta hubo disposiciones oficiales en este sentido, ya desde el año 1540. Pero pronto se percataron que era preferible mantener la estructura administrativa de los Incas, que tenía como 


\section{7}

eje la autoridad de los caciques, y también el idioma quichua como lengua de interrelación y de administración (2001, pp. 32-33).

Las comunidades religiosas fueron las más entusiastas en defender la evangelización en lenguas indígenas. Ellos preferían la existencia de los dos espacios: república de indios y república de españoles. Así, los religiosos se convertían en mediadores entre los indígenas y los castellanos.

En el Ecuador, los mercedarios, los franciscanos, los dominicos, los agustinos y más tarde los jesuitas se dedicaron a la evangelización en quichua; en cuanto a los franciscanos, fray Jodoco Rique llegó a Quito el 6 de diciembre de 1535 (Moreno, 1998) y una de sus primeras labores fue educar a los hijos de los caciques, entre ellos a los hijos de Atahualpa (cf. Ortiz, 2001, pp. 33-34; "La teoría de la introducción...”, cap. 2; “Época colonial", cap. 4).

Se conoce que Jodoco Rique sabía el quichua y que lo usó en el centro educativo franciscano organizado por él para que allí estudien los hijos de los caciques. Sobre el inicio de su trabajo con la población indígena, el padre Moreno, basado en una probanza de 1556 de uno de los hijos de Atahualpa Don Francisco Topatauchi Inga, dice: "Se puede suponer que esto ocurrió dos o tres años después de que los religiosos se aplicaron a aprender el quichua y adecentar unos galpones para recoger a sus discípulos. Su labor educativa se inició hacia 1536” (1998, p. 266).

De los documentos coloniales y de los estudios de algunos historiadores, se infiere que los españoles utilizaron a los caciques indígenas para adquirir ascendencia frente a la población indígena. Desde la lógica del poder y la dominación, al inicio, los españoles se apoyaron en los pueblos contrarios a Atahualpa que tenían otras lenguas, como la cañar; para legitimarse organizaron la administración utilizando a la familia de los incas y a otros caciques que les eran sumisos. Aunque, en el caso de los cañares, luego de utilizarles como "aliados" para invadir los territorios de las lenguas del norte puruhá, panzaleo, cara y pasto, los opri- 
mieron igual que a los demás. Así, se conoce que un tal Pedro de Vergara vivía a costa de los cañares ( $c f$. Oberem, 1974, pp. 269-270) y que pretendió usarlos en su proyectado viaje de conquista a los territorios amazónicos de las actuales provincias de Morona Santiago y Zamora Chinchipe, ante lo cual intervino el Cabildo de Quito para impedírselo. $\mathrm{Al}$ respecto, Moreno señala que: ${ }^{120}$

A fines de mayo de 1540 llegaron a Quito noticias sobre los crímenes y crueldades que cometía, en Tomebamba, Pedro de Vergara capitaneando a un grupo de españoles, con intolerable arbitrariedad. Los Cañaris fueron al principio de la conquista, los mejores aliados de los españoles "ahora nuevamente los ha atado y aprisionado en cadenas y los tiene presos" Vergara se había apoderado de 800 indios cañaris para sacarlos en cadenas y atados con cuerda y otras prisiones. "La provincia de los Cañares es la llave de esta tierra y la que nos ayudó a conquistar esta provincia de Quito y la sustentan y de donde se han conquistado otras provincias que, en nombre de Su Majestad, están pobladas de cristianos" (1998, p. 225).

Sobre la política lingüística hasta 1550 en el Virreinato del Perú, se puede decir que cada orden religiosa se esmeró en la preparación de documentos en quichua para la evangelización y organizó actividades relacionadas con ella. También es importante señalar que en esta primera etapa de evangelización en lenguas indígenas no hubo tanta centralización como ocurrió más tarde, principalmente a partir del III Concilio Limense (1582-1583), el cual tuvo que implementar las disposiciones del Concilio Ecuménico de Trento celebrado entre 1545 y 1563.

Durston considera el año de 1550 como una fecha donde comenzó a organizarse sistemáticamente la pastoral en lenguas indígenas en

120 El padre Moreno no menciona expresamente de dónde tomó las citas, pero por el contexto se entiende que son de los libros del Cabildo de Quito. Al parecer, este cabildo dio algunas disposiciones para tratar de impedir el abuso de los españoles. Según Moreno, fray Jodoco Rique tuvo bastante influencia en el Cabildo de Quito desde su llegada en 1535 hasta 1570. 


\section{9}

los Andes. Él argumenta que la razón de tomar ese dato como referencia es que en ese tiempo surgen varias disposiciones por parte de la jerarquía de la Iglesia colonial:

I use 1550 as a symbolic date for the period when a missionary/pastoral regime first began to develop in a more or less centralized and systematic way after the upheaval that followed on the conquest in 1532. Furthermore, the oldest extant pastoral Quechua texts date to around 1550 (Durston, 2007, p. 17).

Efectivamente, a partir de esta fecha se realizan concilios provinciales y sínodos diocesanos, en cuyos documentos se puede encontrar disposiciones sobre la política lingüística para la evangelización, las cuales con algunos matices se mantendrán por unos doscientos años, es decir hasta los inicios de la administración del rey Carlos III en el siglo XVIII.

A nivel universitario, según Porras Barrenechea (1999, p. 174), el virrey Toledo fue uno de los impulsores de la enseñanza superior del quechua en el Perú. Hasta esa época solo había la cátedra en la iglesia de la Catedral y la que tenían los jesuitas en su propio convento de Lima. Para Toledo, "el verdadero latín para enseñar doctrina a estos indios es saberlo hacer en la lengua de ellos". Este virrey, el 7 de julio de 1579, mediante una ordenanza, inauguró la cátedra de quechua en la Universidad Real y Pontificia del Perú: la Universidad de San Marcos. Su primer catedrático fue el Juan de Balboa. Esta cátedra duró 200 años hasta que el virrey Jáuregui la extinguió el 29 de marzo de 1784.

En la segunda mitad del siglo XVI, la misma Corona española de aquella época, al ver que no prosperaba la castellanización de la población indígena, dio disposiciones para institucionalizar el quechua misionero. De esta manera se podría decir que se oficializó el quechua para la cristianización de los indígenas. Así, el rey Felipe II, mediante cédula dada en Badajoz el 23 de septiembre de 1580 dirigida a los obispos de Lima, Charcas, Cuzco y Quito, dispuso: 
Primeramente os mandamos que en la parte y lugar más cómodo de esa ciudad elijáis el sitio y lugar más dispuesto para leer la dicha cátedra y proveeréis en ella la persona más inteligente de la lengua general de los dichos indios, al cual señalaréis el competente salario [...] que no ordenen de orden sacerdotal, ni den licencia para ello a ninguna persona que no sepan la lengua general de los dichos indios sin que lleve fe y certificación del catedrático que leyere la dicha cátedra de que ha cursado en lo que se debe enseñar en ella, por lo menos un curso entero que se entiende desde el día de San Marcos hasta la cuaresma siguiente que comienzan las vacaciones, aunque el tal ordenante tenga habilidad y suficiencia en la facultad que la iglesia y sacros cánones manda; pues para el enseñamiento y doctrina de los dichos indios lo más importante es saber la dicha lengua (en Hartmann, 1977, p. 20).

En el caso de Quito, la cátedra de quichua, aunque no con rango universitario, fue establecida en 1581. Ella fue inaugurada solemnemente el 17 de septiembre de ese año según una de las actas del Archivo General de Indias. Documentos de este archivo, relacionados con la Real Audiencia de Quito, fueron investigados y compilados en unos 175 tomos por el padre Vacas Galindo, de la orden dominicana, a inicios del siglo XX. Según Hartmann (1977, p. 23), en uno de estos documentos se encuentra una información que fue destacada por el padre Vargas cuando reeditó —en Quito en 1947- la Gramática de quichua del padre Domingo de Santo Thomas de 1560. El texto citado dice:

En Quito a diez y siete días del mes de noviembre de 1581 años, estando en la iglesia de Santa Bárbara de esta ciudad los señores presidente y oidores de la audiencia y cancillería real de su Majestad y otras muchas gentes, el P. Fray Hilario Pacheco, de la Orden de Santo Domingo, subido en una cátedra que allí estaba, hizo una oración en latín, y luego otra en la lengua del inga y asimismo en la lengua castellana y los dichos señores presidente y oidores le dieron la posesión de la dicha cátedra de la lengua de los indios y el dicho fray Hilario Pacheco lo pidió por testimonio y testigos, el señor Francisco de Zúñiga, el tesorero Juan Rodríguez y el contador Miguel de Aguirre y otros muchos clérigos y frailes y legos y yo Diego Suáres de Figueroa escribano de cámara fui presente (en Hartmann, 1977, p. 23). 
Como se señaló en el capítulo 2 ( $c f$. Ortiz, 2001, pp. 33-34), las diversas órdenes religiosas tuvieron su cátedra de quichua dentro de sus conventos a inicios de la Colonia. En el caso de los jesuitas, se dice que la tuvieron durante toda la Colonia en el seminario San Luis. Sin embargo, aparte de estas cátedras particulares de cada congregación, hubo la "cátedra oficial" del quichua en Quito, auspiciada por la Corona española, la cual estuvo a cargo de los dominicos, pero fue largamente disputada por los jesuitas durante fines del siglo XVI y comienzos del XVII, al punto que el rey varias veces debió ratificar el otorgamiento de ella a los dominicos.

\section{La política lingüística de los concilios y sínodos}

Una vez consolidada la dominación española y la pacificación de estos lugares, luego de los enfrentamientos entre Francisco Pizarro y Diego de Almagro, se inició una etapa de planificación lingüística sistemática para la evangelización de los indígenas. Para ello, en los concilios (Burgos, 1995) y los sínodos (Vargas, 1978) se expidieron algunas disposiciones pertinentes al uso de las lenguas en la segunda mitad del siglo XVI. ${ }^{121}$ Los concilios tuvieron su sede en Lima, en tanto que los sínodos relacionados con el Ecuador se realizaron en Quito. En adelante, vamos a revisar los concilios y sínodos realizados durante el siglo XVI.

\section{Primer Concilio Limense}

Este se reunió en la Ciudad de los Reyes (1551-1552) y estuvo presidido por el religioso dominicano arzobispo Gerónimo de Loaiza. Entre las constituciones de los naturales se dice:

121 En lenguaje canónico del siglo XVI, los concilios provinciales equivalían a la reunión de obispos de un Arzobispado, en tanto que los sínodos diocesanos eran los que realizaban un conjunto de delegados a nivel de un Obispado y estaban presididos por el obispo del lugar. 
Constitución 6a. Que a los adultos que han de ser bautizados se les instruya en su propia lengua. Porque a los adultos que se quieren bautizar, pues se obligan a guardar las cosas de nuestra santa fee católica, es justo entiendan lo que en el baptismo reciben y sepan lo que en el catecismo se les pregunta; Mandamos a los sacerdotes que baptizaren a los tales, que los catecismo y preguntas que se les hicieren sean en su lengua que lo entiendan, y los propios respondan a ello (en Burgos, 1995, p. 434).

El resultado de estas políticas dio sus frutos muy pronto. El historiador dominicano, padre Enrique Vacas Galindo (en Moreno, 1998, pp. 278-279), señala que para el año 1564 habían pasado por el colegio franciscano de San Juan Evangelista ${ }^{122} 37$ caciques que fueron el soporte de la administración española. A este dato se añade que los caciques llevaban nombres cristianos y españoles, conservaban sus apellidos indígenas, y se indica el lugar donde ejercían su autoridad. Sobre esto último se puede señalar que los sitios indicados en ese documento corresponden a las actuales provincias de Carchi, Imbabura, Pichincha, Cotopaxi, Tungurahua, Chimborazo, Bolívar y la isla Puná (prov. de Guayas). En este establecimiento de formación indígena no solo se estudiaba lectoescritura, castellano, quichua, canto y música para ser usados en el culto, sino oficios como albañilería, carpintería, barbería, producción de ladrillos, platería, escultura, pintura, etc. Su planta docente, además de los religiosos franciscanos, estaba constituida por ocho profesores indígenas: cuatro maestros y cuatro asistentes.

En un informe de 1568, de la Real Audiencia de Quito al rey, se encuentra la recomendación de una estrategia por la cual se debía enseñar la lengua española y la "lengua del inga" a hablantes de otras lenguas prequichuas. El informe firmado por el doctor Loarte y el licenciado

122 Se conoce que el emperador tomó a su cargo el colegio particular San Juan Evangelista, declarándolo de patronato real mediante cédula del 13 de septiembre de 1555. El posterior cambio de nombre a Colegio Oficial de San Andrés fue, posiblemente, para interesar a favor del plantel al virrey Andrés Hurtado de Mendoza. 
Valverde, al referirse al trabajo del colegio San Andrés de Jodoco Rique, dice:

El fruto que en él se ha hecho hasta ahora ha sido grande porque los naturales han sido enseñados en las cosas pertenecientes a su salvación y de buenas costumbres y habilidades para poder vivir cristiana y católicamente y la república de toda esta ciudad y toda esta provincia ha sido muy aprovechada porque de aquí han salido oficiales de todos los oficios e indios que saben la lengua española, mediante los cuales se puede enseñar a los indios que no saben la doctrina, y en especial sería esto de más utilidad si se tuviese cuidado de traer al Colegio indios de diferentes lenguas, que hay muchas en este distrito, que no se entienden con la lengua general del Inga, que por estos aprenderían la española y la del inga y servirían de intérpretes con los de sus naciones, que de otra manera es imposible poderlos convertir (Moreno, 1998, p. 286). ${ }^{123}$

Finalmente, como ya se mencionó, Jodoco Rique fue enviado por sus superiores, a los 72 años de edad, a Colombia (en esa época Popayán), sin que se conozcan las razones; un viaje en el cual aparentemente se perdieron importantes documentos sobre historia y legua quichua (cf. Moreno, 1998, p. 364; “Época colonial”, cap. 4).

\section{Segundo Concilio Limense}

Se realizó en la Ciudad de los Reyes (1567-1568) y al igual que el primero estuvo presidido por el dominicano arzobispo Gerónimo de Loaiza. En la "Parte de lo que toca a los indios" dice:

Capitulo 3. Que los curas de indios aprendan con cuidado su lengua e para eso sean inducidos por los obispos por amor y también por rrigor [sic]; los que fueren negligentes en ello, al primero año pierdan la tercia

123 En la concepción de aquella época, las lenguas indígenas de estos lugares, diferentes a la quichua, eran consideradas como bárbaras, por lo que la política era la quichuización y/o castellanización de sus hablantes. 


\section{4}

parte de su salario, al segundo y al primero año pierdan la tercia parte de su salario, al segundo y al tercero se acreciente la pena conforme a la culpa la qual a de excutar [sic] los prelados por si o sus visitadores. Capitulo 32. Con precepto, que todos los curas enseñen a los indios varones y mujeres e mochachos no solo en rromanze sino también en su lengua el padre nuestro y el ave maria y credo y los mandamientos de Dios y de la Yglesia, de modo que lo tengan de memoria (en Burgos, 1995, pp. 443-444).

\section{Primer Sínodo Quitense}

Se reunió en Quito en 1570 y estuvo presidido por el dominicano obispo fray Pedro de la Peña.

En la Iglesia de Dios los sacerdotes son guías de las cosas de nuestra santa fee $[$ sic] católica, y porque en estas partes de las Indias fundamos (Fol. 28) Iglesia, muy grande muchedumbre de gentes dispuestas e aprendiendo la ley de Dios para ser cristianos; de parte de los ministros tres cosas son necesarias, que sean sacerdotes doctos, que den buen ejemplo con vida y costumbres, [y] que sepan la lengua de los yngas, ques general en este nuestro obispado (en Vargas, 1978, p. 42). ${ }^{124}$

\section{Tercer Concilio Limense}

Se reunió en la Ciudad de los Reyes (1582-1583) y estuvo presidido por el segundo arzobispo de Lima: Toribio Alfonso Mogrovejo. Inicialmente fue profesor universitario en España y en su país fue nom-

124 Es probable que fray Jodoco Rique, quien estuvo a cargo de la educación de los hijos e hijas de Atahualpa, hubiese escrito un "Catecismo y oraciones en quichua" e influido en el posicionamiento de esta lengua para la evangelización. Rique casó a Francisco Topatauchi Atahualpa con la hermana del cacique de Sarance: Catalina Ango. Este matrimonio con una persona de los Angos de Sarance (actual Otavalo), que eran considerados tan importantes como los Habsburgos en Europa, también debió haber facilitado la sumisión de la población indígena a los españoles (cf. Moreno, 1998, pp. 220-221). 
brado con el cargo de Gran Inquisidor. Luego de la designación para arzobispo de Lima le ordenaron de sacerdote secular, y luego de obispo, por lo tanto, no perteneció a una congregación religiosa. Mogrovejo, conjuntamente con el sexto virrey del Perú, Martín Enríquez, impulsaron la organización del Tercer Concilio Limense. En los decretos de la segunda acción del Concilio se dice:

Cap. 3. Del catecismo que se a de usar y de su traducción. Para que los indios que están aun muy faltos de doctrina christiana, sean en ella mexor instruidos aya una misma forma de doctrina, les parescio necesario, siguiendo los pasos del Concilio General Tridentino, hazer un catecismo para toda esta provincia, por la cual sean enseñados todos los indios conforme a su capacidad. $\mathrm{Y}$ a lo menos los muchachos la tomen de memoria, y los días de Domingo y fiestas lo repitan en la Yglesia...... Por tanto prohíbe y veda que nadie haga y use otra interpretación o traducción en las lenguas del Cuzco y la aymara, assi en la cartilla y doctrina cristiana, como en el catecismo fuera de la traducción que con su autoridad se ha hecho y aprobado [...].

Cap. 6. Que los indios aprendan en su lengua las oraciones y doctrinas. El principal fin del catecismo y doctrina christiana es percibir los misterios de nuestra fee, pues con el espíritu creemos interiormente, para ser justificas, lo que interiormente confesamos con la boca para ser salvos, conforme al Apostol, y asi cada uno ha de ser de tal manera instruido que entienda la doctrina, el español en romance, y el yndio también en su lengua pues de otra suerte, por muy bien que recite las cosas de Dios, con todo eso se quedara sin fruto su entendimiento, como lo dice el mismo Apostol. Por tanto ningún yndio sea de oy mas compelido a aprender en latin las oraciones o cartillas, pues les basta y aun les es muy mejor saberlo y decirlo en su lengua, y si alguno de ellos quisieren podrán también aprenderlo en romance, pues muchos le entienden entre ellos, fuera de esto, no hay para que pedir otra lengua ninguna a los indios [...].

Cap. 11. De los nombres de los indios. Para que se eviten los yerros que en reiterar baptismo y matrimonio indios no conocidos suelen acaecer; totalmente se les quite a los yndios el usar los nombres de su gentilidad e idolatría, y a todos se les ponga nombres en el baptismo cuales se acostumbran entre christianos, y de estos mismos los compelan a usar entre 
si. Mas los sobrenombres [apellidos?], para que entre si se diferencien, procurese que los varones procuren los de sus padres y las mujeres los de sus madres (en Burgos, 1995, pp. 447-449).

Según Durán (2012, p. 205), este tercer concilio, de los cinco que hubo en esta región, fue el que más influyó en la política de evangelización de las poblaciones indígenas no solo durante la época colonial, sino hasta 1899 en que se celebró el Concilio Plenario Latinoamericano, resultado de lo cual surgió una nueva legislación canónico-pastoral para los países "independizados".

Fue a partir del Tercer Concilio Limense que se dejó de usar la variedad centro-costeña recogida por Domingo de Santo Tomás como lengua general para la evangelización y pasó a ser la variedad cuzqueña la nueva lengua general ( $c f$. Cerrón-Palomino, 1987). Igualmente, las políticas lingüísticas de estandarización de la escritura del quechua, adoptadas para la redacción de las tres obras fundamentales para la pastoral quechua (Doctrina christiana y cathecismo para la instrucción de los indios, Confessionario para los cvras de indios ${ }^{125}$ y Tercero catecismo $y$ exposición de la doctrina christiana), se mantuvieron hasta el siglo XIX. La investigadora ecuatoriana Ruth Moya dice al respecto:

Naturalmente la realización de las obras en cuestión no solo exigía el que se asegurara la inteligibilidad de la lengua indígena, sino el que los términos y giros quichuas allí empleados no dieran pie a ninguna confusión de orden teológico. En este sentido, como se puede colegir, se hizo una monumental obra filológica de acuñamientos y de normatización lingüística, tarea sin paralelo en los siglos venideros y solamente equiparable al interés actual de la escuela bilingüe por dotar a la lengua quichua de todo su valor expresivo y comunicativo (1993, p. XIX).

125 La existencia de una especie de "confesión” prehispánica es sostenida por Estenssoro (2004, pp. 206-364). Gerald Taylor, en Amarás a Dios sobre todas las cosas (2007) hace un análisis de tres de ellos, correspondientes a los siglos XVI y XVII. 


\section{7}

\section{Cuarto Concilio Limense}

Celebrado en 1591, también estuvo presidido por el arzobispo Toribio Alfonso Mogrovejo, y ratificó lo dispuesto en el anterior de 1583 señalando lo siguiente:

Cap. XIX. Que los religiosos guarden y cumplan lo que toca a tener Constituciones Synodales, y lo demás contenido en el Capitulo, como los demás curas seculares. Los frayles y religiosos que estuvieren en las doctrinas haciendo officio de curas, ternan en su poder los Concilios Provinciales y Synodales que hicieren el Metropolitano y demás sufragáneos, cada uno en su distrito, y el Cathecismo y Confessonario y Sermonario, hechos en la lengua de los naturales por el Concilio pasado del 83, para que cada uno sepa lo que ha de hazer y tiene a su cargo, y obviere obligación de guardar, procediendo los Ordinarios y Visitadores contra los transgresores y que no fueren observantes en tener los dichos concilios y en no los guardar (en Burgos, 1995, pp. 455-456).

\section{Segundo Sínodo Quitense}

Reunido en Quito, en 1594, estuvo presidido por el agustino obispo Luis López de Solís, cuarto obispo de esta ciudad.

La existencia de varias culturas y señoríos no necesariamente sería garantía de que hubo varias lenguas prehispánicas, sin embargo, las fuentes históricas mencionan su presencia, como se ha señalado en el capítulo 1. La política de usar las lenguas indígenas para la evangelización vino dada por el Tercer Concilio Limense (1582-1585) y en concordancia con esta disposición, el Segundo Sínodo Quitense dispuso a los religiosos que elaboren catecismos en lenguas indígenas diferentes al quichua. El capítulo III del Segundo Sínodo Quitense de 1594 dice: ${ }^{126}$

126 El Tercer Sínodo Quitense se realizó en Loja en 1596 y confirmó todas las disposiciones del Sínodo de 1594, excepto unas disposiciones que quedaron derogadas, pero entre las cuales no consta nada relacionado con las lenguas indígenas. 
Por la experiencia Nos consta que en este Obispado hay diversidad de lenguas que no tienen ni hablan la del Cuzco ni la aimará, y que para que no carezca de la doctrina cristiana es necesario hacer traducir el Catecismo y Confisionario en las propias lenguas: por tanto, conformándonos con lo dispuesto en el Concilio Provincial último, habiéndonos informado de las mejores lenguas que podrían hacer esto, Nos ha parecido cometer este trabajo y cuidado á Alonso Núñez de S. Pedro y á Alonso Ruiz para, la lengua de los llanos y tallana; y á Gabriel de Minaya, para la lengua cañar y purguay; y á Fr. Francisco de Jerez y á Fr. Alonso de Jerez, de la Orden de la Merced, para la lengua de los pastos; y á Andrés Moreno de Zúñíga y Diego Bermúdez Presbítero para la lengua quillasinga; á los cuales encargamos lo hagan con todo cuidado y brevedad, pues de ello será Nuestro Señor servido, y de nuestra parte se lo gratificaremos: $y$ hechos los dichos Catecismos los traigan ó envían ante Nos, para que vistos y aprobados, puedan usar de ellos (en Villalba, 1978, p. 92). ${ }^{127}$

Esta disposición muestra que la política inicial de los españoles de quichuizar y/o castellanizar a los hablantes de otras lenguas que se intentó desde los inicios de la Colonia no había dado mucho resultado. Sin embargo, luego de ese intento de usar las lenguas locales, con el transcurso del tiempo se consolidó la evangelización en quichua.

En el siglo XVII y la primera mitad del XVIII se continuó, a nivel religioso, con la política de usar la lengua indígena para la evangelización. Así pues, aunque no se especifica nombre de la lengua indígena, el "Itinerario para párrocos de indios", obra del obispo doctor Alfonso de la Peña Montenegro (1668, 1771/1984, pp. 21-27), da disposiciones relacionadas con el uso de la lengua indígena en la evangelización. Entre ellas se menciona que los párrocos de indios deben saber la lengua de los indios so pena de caer en pecado mortal y de ser nulo su curato aunque lo hubiere adquirido. ${ }^{128}$

127 Nótese que en esta disposición no se menciona la lengua panzaleo, así como tampoco el historiador González Suárez (1891/2007, p. 13) menciona a la nación panzaleo.

128 En esta obra del obispo Peña, las secciones IX-XII del primer libro de los cinco que la conforman, están destinadas a tratar temas relacionados con la lengua indígena y los párrocos de indios. 


\section{Política colonial del siglo XVIII}

La política lingüística misionera impulsada en el siglo XVI, principalmente en el Tercer Concilio de Lima, se mantuvo por casi doscientos años. Aunque, la pretensión de castellanizar a los indígenas, por parte de los reyes, continuó latente durante el siglo XVII. Así, la real cédula del 16 de febrero de 1688 de Carlos II, ordenaba que se enseñe a leer y escribir a los indios jóvenes en la lengua castellana, porque eso facilitaba la inteligencia de la fe católica y la comunicación con los españoles ( $c f$. Tanck de Estrada, 1989, p. 703). ${ }^{129}$

A mediados del siglo XVIII el anhelo real de castellanizar a la población indígena de sus colonias se hizo más evidente. Así, el 4 de octubre de 1749 el rey Fernando VI, mediante cédula, dispuso a los arzobispados de Lima, México y Santa Fe, la "secularización” de las doctrinas. En consecuencia, los sacerdotes regulares de las comunidades religiosas, que eran los que promovían la evangelización en las lenguas indígenas, comenzaron a ser reemplazados por los seculares diocesanos.

Con el rey Carlos III esta política de castellanización se hizo más decisiva. Contó para ello con el apoyo de las autoridades eclesiales. En 1766 llegó a México el nuevo arzobispo Francisco Antonio Lorenzana, cuya política fue la secularización de las doctrinas y la castellanización, y en 1769 expidió una pastoral sobre la enseñanza del castellano, en el contexto de las revueltas ocurridas allí por la expulsión de los jesuitas en 1767 , los cuales eran partidarios de usar las lenguas indígenas en la evangelización. Al respecto, Tanck de Estrada dice:

Carlos III, basándose en la pastoral de Lorenzana, llegó a declarar que, en la cédula del 16 de abril de 1770 para toda América "se extingan los diferentes idiomas que se usa y solo se hable el castellano". Se puede considerar

129 Según el padre Vargas (1965, p. 14), Juan Griego, un comerciante, habría sido el primero en enseñar el catecismo, y a leer y escribir en castellano a españoles, mestizos e indígenas, en la iglesia de la Catedral de Quito. 


\section{0}

esta cédula como el epítome de las ideas autoritarias, eurocéntricas y anticriollas de la política lingüística hacia las colonias españolas (1989, p. 729).

Posteriormente, en 1778, volvió a expedir otra cédula, basada en la de 1770, en la cual se recordaba a los indios la prohibición de "usar de su lengua nativa" en las escuelas y hacía hincapié en el nombramiento de curas de mayor mérito, aunque no sean "lenguaraces".

En la Real Audiencia de Quito, durante el siglo XVII y la primera mitad del XVIII, solo existieron tres facultades universitarias, no propiamente universidades. Ellas fueron: la de Santo Tomás, la de San Gregorio y la de San Fulgencio, a cargo de las congregaciones de los dominicos, jesuitas y agustinos, respectivamente. Estas facultades podían dar títulos académicos, pero no tenían el rango de universidad real. Recién en 1786, luego de la expulsión de los jesuitas, se fundó la Real Universidad de Santo Tomás y ocupó las dependencias que fueron de los jesuitas; funcionó con unas constituciones provisionales y no llegó a tener un estatuto real aprobado. En la compilación de documentos sobre ese aspecto realizada por Paladines (1996, pp. 119-175), se hallan los estatutos provisionales elaborados por el obispo José Calama y por el presidente de la Real Audiencia de Quito, barón de Carondelet, para el funcionamiento de esta universidad real; pero en el pensum de estudio, a tono con la política del rey Carlos III, solo se contemplaba la enseñanza de latín y castellano, mas no del quichua. Esta política de ignorar las lenguas indígenas en la educación de fines del siglo XVIII permite avizorar lo que sería más tarde la política que se aplicó en la educación ecuatoriana con el advenimiento de la República.

\section{Política de comienzos de la República (siglo XIX)}

La Independencia no significó ninguna ventaja para la población indígena ni para sus lenguas. Hasta mediados del siglo XX los terratenien- 
tes criollos, que tomaron el control político del Ecuador, ${ }^{130}$ mantuvieron la misma estructura colonial de dominación. Las haciendas, continuación de las encomiendas españolas, se heredaban o se vendían con indígenas y animales juntos, como se puede apreciar en los anuncios publicitarios que se hacían en los periódicos hasta bien entrado el siglo XX.

En cuanto a lo lingüístico y educativo, se implementó con fuerza la castellanización y la aculturación, respectivamente. Durante el siglo XIX y la primera mitad del siglo XX, los gobiernos del Ecuador impulsaron la política de "civilizar" a la población indígena, lo cual, lingüísticamente, significaba castellanizarla.

Después de la “independencia” de España en 1822, se formó la Gran Colombia, la cual duró hasta 1830. La dominación a la población indígena y afroamericana continuó y hasta se profundizó en el Ecuador. Una muestra de esta injusticia se puede ver en la legislación indigenista del "libertador" Simón Bolívar, decretada el 15 de octubre de 1828, conocido como Decreto estableciendo la contribución personal de los indigenas ( $c f$. Rubio, 1954, pp. 20-25), por el cual se "legitimaba" el tributo indígena. A esto habría que añadir los tributos indirectos de los indígenas, como los que tenían que pagar por el alcohol consumido en las fiestas religiosas que estaban compelidos a realizar.

La política de educar a los indígenas con unas pocas "becas" no pudo ocultar su ideología manipuladora. Así, según Paladines: ${ }^{131}$

Pese a todos los esfuerzos la expansión de la educación en los sectores de mayores recursos era mínima y casi inexistente para los grupos

130 El poder económico ya lo tenían los criollos en la Colonia, pero con la Independencia ellos se adueñaron también del poder político, que fue su gran aspiración.

131 La información sobre los datos de las becas a los indígenas y el aporte del tributo indígena al Estado, Carlos Paladines afirma haberla tomado de la "Exposición del ministro secretario de Estado", presentada al Congreso $1^{\circ}$ Constitucional del Ecuador en 1831. 


\section{2}

indígenas. Por el año de 1824 se gastaron 200 pesos por becas a cuatro colegiales indígenas, en 1827 el egreso fue de 360 pesos, en 1828 de apenas 160, pues en dicho año se dio el enfrentamiento con el Perú y en consecuencia aumentaron los gastos de guerra El siguiente año la asignación subió a 360 pesos. El aporte para la educación indígena resultaba irrisorio dada la contribución que ellos realizaban, en más de 200.000 pesos, al erario nacional cuyo monto global era de 500.000. El tributo indígena alimentaba casi la mitad de los fondos del Estado (1996, p. 61).

\section{Política republicana}

Con el advenimiento de la República, no hubo una mejora en el estatus de la política lingüística para el quichua. Los gobernantes criollos se sintieron libres para dominar a la población indígena, pues esta ya no tenía a quién demandar por las injusticias. En cuanto a la lengua, se inició una etapa de abierta castellanización. Solo a nivel religioso y a nivel literario hubo algunos momentos de cultivo del quichua, desde fines del siglo XIX, por iniciativa de particulares, pero no como política de Estado. Solo cuando la población indígena tomó consciencia - ya en la segunda mitad del siglo XX - y demandó del Estado, este cedió algún espacio para la educación bilingüe en lenguas indígenas. Sin embargo, en este y en los demás campos, la política de elevar el estatus del quichua y las demás lenguas indígenas se la ha usado como un recurso retórico, sin una voluntad sincera de cambio.

\section{Políticas de la primera mitad del siglo XIX}

Cuando inicia la República, las autoridades se consideraron con derecho de representar a la población indígena y de tutelarlos según su conveniencia. Esto se puede inferir del art. 68 de la Constitución de 1830, cuando dice: "Este congreso constituyente nombra a los venerables curas párrocos por tutores y padres naturales de los indígenas, excitando su ministerio de caridad en favor de esta clase inocente, abyecta y miserable". 


\section{3}

Esta idea del tutelaje a los indígenas permaneció en las constituciones hasta la mitad del siglo XX, lo que se cambiaba eran los actantes. Mientras en la primera mitad del siglo XIX fueron los párrocos los "tutores", a fines de ese siglo, con el Estado liberal, pasaron a ser civiles, ya sea de esa tendencia o los llamados "socialistas".

En cuanto a la lengua, aunque no se incluyó una idea expresa en las constituciones de la república que se dictaron en este período, la práctica fue la castellanización.

\section{Políticas de la segunda mitad del siglo XIX}

Ni García Moreno en la segunda mitad del siglo XIX, ni Eloy Alfaro a fines del siglo XIX y comienzos del XX — los grandes impulsores de la educación - hicieron algo por la lengua quichua. Se dice, sin embargo, que el primero creó escuelas rurales y un normal para indígenas y que el segundo planteó la creación de escuelas bilingües para indígenas (cf. González, 2011, pp. 29-30), pero esto no tuvo mayor concreción.

Los gobiernos liberales, a partir de 1924, dispusieron que los hacendados abrieran a su costa escuelas prediales en sus haciendas, pero esto, en la mayoría de los casos, tampoco se concretó. En los pocos casos en que se hicieron realidad, ellas impartían la educación en castellano. La ideología colonial se mantuvo en contra de la población indígena y de sus lenguas.

En cuanto a la evangelización, la Iglesia católica celebró cuatro concilios en el siglo XIX (1863, 1869, 1873, 1885), conocidos como "los cuatro concilios provinciales de la era republicana” (Flores, 2005). Sobre las disposiciones relacionadas al quichua, emanadas de estos concilios, señala Ortiz lo siguiente: ${ }^{132}$

132 El Catecismo elemental parece ser sinónimo del Catecismo breve que se hizo en el Tercer Concilio Limense de 1583, junto al Catecismo mayor. No se ha podido precisar si el Catecismo medio equivale al mayor limense o si hubo otro. 


\section{4}

Con la era garciana nace en la Iglesia la preocupación por retomar la catequización de los indígenas. El II Concilio Quitense, celebrado en enero de 1869, determina que se traduzca al quichua el catecismo elemental y medio. Esta disposición hace suponer que habían dejado de utilizarse los textos tradicionales y que el siglo transcurrido desde la expulsión de los jesuitas ha sido de total inacción. Años más tarde, el IV Concilio Quitense, de mayo de 1885, dispone que se establezcan cátedras de quichua en todos los seminarios, particularmente, en el central (2001, p. 47).

Seguramente las disposiciones señaladas contribuyeron a que en la segunda mitad del siglo XIX y comienzos del siglo XX hubiese una época de florecimiento en la producción de obras en quichua. Hubo producción de parte de religiosos católicos como Paris, Grimm y Guzmán. Ellos produjeron no solamente gramáticas y vocabularios, sino textos bastante voluminosos para la pastoral quichua. Estas obras fueron publicadas fuera del Ecuador, pues posiblemente era más difícil hacerlo dentro del país, en razón de las ideas liberales "radicales" de los gobiernos de los últimos cinco años del XIX y las primeras décadas del siglo XX.

Además de esta producción textual religiosa en quichua, en la segunda mitad del siglo XIX se dio también la producción no religiosa en quichua por parte de intelectuales como Juan León Mera y Luis Cordero. El primero compiló literatura en quichua y el segundo elaboró un diccionario quichua que recoge las hablas de la Sierra sur. Cordero tiene el mérito de haber incluido en su corpus palabras provenientes de la lengua prequichua cañar; en cuanto a lo literario, escribió algunos poemas en quichua como el conocido "Rinimi llacta rinimi" interpretado al castellano como "El adiós del indio".

\section{Políticas del siglo $\mathrm{XX}$}

A nivel de declaración constitucional, ninguna de las constituciones del siglo XIX ni la primera del siglo XX (1906) hicieron mención siquiera a un idioma oficial del Ecuador. Se asumía de facto que el caste- 
llano era el idioma del país. Solo a partir de la Constitución de 1929 se comenzó a señalar al castellano como idioma oficial. Esta Constitución decía: "El estado ecuatoriano reconoce al español como idioma nacional" (art. 6), además, estableció el nombramiento de un "Senador para la tutela y la defensa de la raza indígena” (art. 33 no 4).

La primera Constitución de la república en la que se habló por primera vez del uso del quichua en la educación fue en la de 1945. Este documento se elaboró luego de la insurgencia popular denominada La Gloriosa, que derrocó en 1944 al Gobierno autoritario de Carlos Alberto Arroyo del Río. En este movimiento participó activamente la población indígena de Cayambe, con el liderazgo de Dolores Cacuango, la impulsora de las escuelas indígenas de Cayambe. El art. 143 no 8 de esa Constitución señalaba: "En las escuelas establecidas en las zonas de predominante población india, se usará, además del castellano, el quechua o la lengua aborigen respectiva". En cuanto a la lengua, esta Constitución señalaba: "El castellano es el idioma oficial de la República. Se reconocen el quechua y demás lenguas aborígenes como elementos de la cultura nacional” (art. 5). Pero esta Constitución apenas duró un año, pues en 1946 fue cambiada por otra que suprimió las regulaciones tanto lingüísticas como de la educación indígena.

Aunque la Constitución de 1945 fue considerada de vanguardia para la época, mantuvo la visión colonial de ignorar las demás lenguas indígenas, así como la idea del tutelaje. ${ }^{133}$ En esa misma Constituyente no se incluyó a indígenas, a pesar de que existían personas como Dolores Cacuango, quien con sus discursos hacía vibrar a miles de indígenas en las plazas y a los académicos en el paraninfo universitario. Han quedado testimonios de su amplio conocimiento de las leyes, sin embargo, el justifi-

133 Ricardo Paredes, un militante comunista blanco ocupó en esta Constituyente el cargo de diputado funcional por la "raza indígena". Recuérdese que ya en la Constitución de 1928 se había establecido un asiento de senador funcional indígena, aunque en la práctica ese puesto fue ocupado siempre por no indígenas. 


\section{6}

cativo pudo ser que no era alfabetizada, ya que dicha Constitución siguió manteniendo el requisito de saber leer y escribir para ser ciudadano. ${ }^{134}$

A pesar del retroceso constitucional de 1946, el quichua comenzó a ser usado en algunas escuelas de las misioneras lauritas, quienes publicaron en 1947 un texto para la enseñanza de la lectura y escritura denominado Mi cartilla inga. Con este texto se trabajó en esos mismos años en las cuatro escuelas indígenas fundadas por Dolores Cacuango (Cayambe, prov. de Pichincha). Estas escuelas sufrieron una persecución no solo de los hacendados, sino también de los representantes de la "educación oficial", debido a lo cual fueron cerradas consecutivamente, hasta que la última de ellas fue destruida físicamente por la dictadura militar de 1963, acusándosela de ser un foco comunista (cf. Rodas, 1989/1998, p. 50).

En la segunda mitad del siglo XX, a iniciativa de instituciones privadas nacionales y extranjeras ( $c f$. cap. 7), se comenzó a usar el quichua en un limitado número de centros educativos. En dicho contexto, la Constitución de 1967 retomó la idea del uso de las lenguas indígenas en la educación, sin embargo, como se puede colegir de su contenido, la política subyacente era la de mera transición, como era la postura de la época, patrocinada incluso por la UNESCO. Así:

En la educación se prestará especial atención al campesino. Se propenderá a que los maestros y funcionarios que traten con él, conozcan el idioma quichua y otras lenguas vernáculas. En las escuelas establecidas en las zonas de predominante población indígena se usará de ser necesario además del español, el quichua o la lengua aborigen respectiva, para que el educando conciba en su propio idioma la cultura nacional y practique luego el castellano (art. 34).

La Constitución política aprobada en referéndum el 15 de enero de 1978, al igual que la de 1929, reconoció que el idioma oficial era el

134 Solo la Constitución de 1978 otorgó el derecho al voto a los analfabetos. 
castellano, pero añadió que "el quichua y las demás lenguas aborígenes formaban parte de la cultura nacional", sin embargo, como era de esperarse, sobre su uso en la educación no se mencionó nada.

El 31 de enero 1978, Consuelo Yánez Cossío consiguió que la PUCE firme un convenio de cooperación con el Ministerio de Educación para la implementación de un programa de alfabetización con el carácter experimental en tres comunidades de la provincia de Cotopaxi. Posteriormente, en la PUCE se creó el CIEI y sobre el trabajo realizado en este centro hasta 1986 hablaremos en el siguiente capítulo.

El 10 de agosto de 1979 Ecuador volvió a la democracia y el presidente Roldós pronunció una parte de su discurso en quichua (dicha versión la realizaron Luis Montaluisa y Luis de la Torre), y ese fue el inicio de una etapa de lucha de las nacionalidades indígenas por la EIB.

Asimismo, en 1983, los indígenas que trabajábamos en el CIEI de la PUCE, con el asesoramiento de la directora del Centro, Consuelo Yánez, tramitamos una reforma al art. 27 no 8 de la Constitución política de 1978. En la versión reformada se incluyó el siguiente texto: "En las zonas de predominante población indígena, el quichua o la lengua de la cultura respectiva será la lengua principal de educación y el castellano será la lengua de relación intercultural".

\section{Creación de la CONAIE}

El primer paso se dio en 1980, cuando se conformó la CONFENIAE. Ese mismo año se realizó en Sucúa, territorio shuar amazónico, el I Encuentro de Nacionalidades Indígenas del Ecuador que decidió crear el CONACNIE. Luego, en 1982, se realizó en Quito el II Encuentro del CONACNIE. Hasta que finalmente, en 1986, tras varias deliberaciones, los dirigentes indígenas de las diferentes nacionalidades decidieron realizar el I Congreso de Nacionalidades Indígenas del Ecuador, del 10 al 13 


\section{8}

de noviembre de 1986, en el Campamento Nueva Vida, cerca de Quito y allí se constituyó la CONAIE. ${ }^{135}$

En este Congreso, entre otros asuntos, se discutió los temas de tierras, proceso de organización, salud, situación de la mujer, derechos humanos y educación indígena. El asunto de la educación bilingüe tuvo el amplio respaldo de los integrantes del Congreso, debido a que había que buscar una solución para la continuación de este proceso una vez que el CIEI había cerrado sus puertas y la alfabetización bilingüe había sido desmantelada por el Gobierno. Entre las resoluciones de este congreso se decidió crear la DINEIB dentro del Ministerio de Educación y una universidad propia de las nacionalidades indígenas. ${ }^{136}$

\section{Creación de la DINEIB}

En 1986 el CIEI de la PUCE dejó de funcionar debido a dificultades institucionales tanto con el Ministerio de Educación como con algunos dirigentes de organizaciones indígenas que fueron influenciados por ciertos políticos de "izquierda” y por organismos del exterior. Una

135 La primera directiva estuvo conformada por: Miguel Tankamash (shuar), presidente; José Jacinto Guamán (quichua-cañar), vicepresidente; Blanca Chancoso (quichua-Imbabura), dirigente de organización; Domingo Ankuash (shuar), dirigente de tierras; Luis Montaluisa (quichua-Cotopaxi), dirigente de educación, ciencia y cultura; Isabel Camas (quichua-Cañar), dirigente de la mujer; Ana María Guacho (quichua-Chimborazo), dirigente de derechos humanos; Julio Aguavil (tsa'chi), dirigente de salud; Luis Macas (quichua-Loja), dirigente de prensa y propaganda. La CONAIE funcionó como una organización de hecho hasta septiembre de 1989, cuando gestionó y obtuvo la personería jurídica.

136 El proponente de estas dos resoluciones fue Luis Montaluisa, dirigente del movimiento indígena de Cotopaxi, que había trabajado en el CIEI de la PUCE. Efectivamente, se creó la DINEIB, mas no la universidad. Luego, una ONG dirigida por Luis Macas creó una universidad indígena particular en nombre de los indígenas, pero no era propia de las nacionalidades como fue la decisión del I Congreso de la CONAIE. Todavía está pendiente la creación de una universidad propia de las nacionalidades indígenas. 


\section{9}

gran parte de los centros de alfabetización fueron desmantelados por el Ministerio de Educación al igual que unos 300 centros educativos infantiles, que de manera informal habían comenzado a hacer funcionar los alfabetizadores indígenas. Parecía el fin del proceso de educación bilingüe iniciado en 1978 y de los procesos de educación comunitaria iniciados por otras instituciones y algunas organizaciones indígenas, como las escuelas indígenas de la provincia de Cotopaxi o las de Simiatug (prov. de Bolívar). ${ }^{137}$ Uno de los referentes educativos que sí logró mantenerse fue el SERBISH, que funcionaba desde la década de 1970 con el apoyo de la Misión Salesiana.

Para hacer efectiva la resolución del I Congreso de la CONAIE, el dirigente de educación (1986-1988) realizó reuniones en cada una de las nacionalidades a fin de discutir el proyecto de creación de una instancia estatal, pero con el direccionamiento de las nacionalidades indígenas. Esto era una utopía no solamente por el formalismo estatal, sino por el racismo existente en la sociedad y dentro de los mandos medios del Ministerio de Educación. Era impensable que indígenas, que eran considerados seres sin preparación académica, estuvieran en capacidad de dirigir una institución educativa.

Con todo, luego de dos años de trabajo, se tuvo ya un documento de políticas educativas de la educación indígena y la propuesta de creación de la DINEIIB. ${ }^{138}$ Este fue presentado a las autoridades educativas en la primera semana de agosto de 1988 y luego de varias dificultades se creó la DINEIIB, mediante decreto ejecutivo no 203, firmado el 9 de noviembre de 1988 y publicado en el Registro Oficial no 66 del 15 de

137 En el MOSEIB, tanto en la versión de 1993 como en la de 2013, se encuentra información de las diferentes experiencias de educación indígena.

138 Posteriormente, en 1992, en la ley 150, se eliminó de la DINEIIB la palabra "Indígena" y quedó simplemente como DINEIB, debido a las críticas de los “izquierdosos" que veían en la palabra indígena un "racismo al revés", un gueto. 
noviembre del mismo año ( $c f$. Montaluisa, 2008). ${ }^{139}$ Dicho decreto le concedía autonomía técnica y administrativa a la DINEIIB frente a las demás dependencias del Ministerio de Educación. La razón de esta autonomía se debía a que durante el período de alfabetización y educación bilingüe, desde 1980 hasta 1986, las autoridades y funcionarios habían puesto muchas trabas a los aspectos curriculares y a la administración de la educación bilingüe. Posteriormente, como consecuencia de las atribuciones concedidas a la DINEIIB y a las direcciones provinciales de educación bilingüe, se expidió un acuerdo ministerial mediante el cual se determinó la jurisdicción de la educación bilingüe. El decreto 203 señaló como deberes y atribuciones de la DINEIIB, entre otros, los siguientes:

- Planificar, dirigir y ejecutar la educación indígena.

- Formar y capacitar profesores y demás recursos humanos para la educación indígena en las diferentes lenguas del país.

- Promover la producción y utilización de materiales didácticos de acuerdo con los criterios lingüísticos, pedagógicos y sociales adecuados.

- Velar por la aplicación de una política lingüística que tome en cuenta un sistema de escritura unificada para cada lengua, basado en lo posible en el criterio fonológico.

- Diseñar modalidades educativas acordes con las necesidades de la población indígena.

- Desarrollar un currículo apropiado para cada uno de los subsistemas y modalidades de educación indígena.

- Dirigir, organizar y ejecutar la alfabetización y educación de adultos bilingüe.

139 Para la creación de la DINEIIB, además de la dinámica generada por los dirigentes de la CONAIE, se contó con el apoyo de Ileana Almeida, Consuelo Yánez y Alfonso Calderón. El texto íntegro del decreto 203 de 1988 fue redactado por Luis Montaluisa y firmado por el presidente de la república sin cambio alguno. 
- Dirigir, organizar y orientar la educación de los normales bilingües.

- Elaborar diseños no formales de interaprendizaje.

- Determinar y coordinar con la DINACE y la DINADER la construcción de las infraestructuras escolar y deportiva, respectivamente. ${ }^{140}$

- Organizar conjuntamente con el nivel superior, las direcciones provinciales de educación indígena.

- Coordinar la planificación educativa indígena con el CONADE.

En noviembre de 1988 se reunió en Cañar el II Congreso de la CONAIE, con la presencia de más de mil dirigentes de todas las nacionalidades indígenas. En sus dos primeros años de existencia, la CONAIE había alcanzado una consolidación interna y se preparaba para tener una gran presencia ante la sociedad y ante el Estado en los años siguientes. ${ }^{141}$

\section{La marcha en defensa de la EIB}

Apenas conocida la creación de la DINEIIB surgió una reacción contraria a esta decisión política. La oposición a la creación de la DINEIIB y a la educación bilingüe se dio tanto a nivel interno del Ministerio de Educación como a nivel político. Varios partidos políticos se opusieron, inclusive la mayoría de congresistas del mismo partido de gobierno. Muchos de los profesores hispanohablantes que trabajaban en

140 DINACE, DINADER y CONADE eran los organismos encargados de la planificación del Estado.

141 En el II Congreso se eligió una nueva directiva para el período 1988-1990. Este congreso quiso reelegir a Luis Montaluisa para la dirigencia de Educación, en reconocimiento a su gestión en la creación de la DINEIIB, pero él no aceptó porque era partidario de la alternabilidad en la dirigencia. Así, la nueva directiva fue: Cristóbal Tapuy (quichua-amazónico), presidente; Luis Macas (quichuaSaraguro), vicepresidente; Manuel Castillo (quichua-Cayambe), dirigente de organización; Eduardo Camas (quichua-Cañar), dirigente de tierras; Arturo Muyulema (quichua-waranga), dirigente de educación; Ángel Kuja (shuar) dirigente de comunicación. 


\section{2}

las comunidades indígenas conformaron frentes de defensa del magisterio para oponerse a la creación de la DINEIIB. El objetivo que tenían era conseguir la derogatoria del decreto ejecutivo. Los más agresivos eran ciertos integrantes de partidos de "izquierda", algunos de los cuales seis años antes se habían opuesto al trabajo del CIEI. Desde enero hasta septiembre de 1989 la oposición fue violenta, tanto que el director nacional de la DINEIIB fue secuestrado en Latacunga y se tomaron las oficinas de la educación bilingüe en Chimborazo. Ante esto, las comunidades respondieron, en cada provincia, con marchas masivas de miles de indígenas en respaldo a la educación bilingüe.

A pesar de que el Gobierno había institucionalizado EIB, muchos sectores, inclusive del mismo Gobierno, se oponían agresivamente a su existencia e implementación. No se resignaban a perder espacios de poder ante las comunidades. Entre los argumentos que manejaban los que se oponían a la creación de la DINEIIB estaban que:

- La educación bilingüe iba a dividir el país.

- No había indígenas preparados para dirigir la educación bilingüe.

- Se iba a darse un retroceso a la educación frente al desarrollo tecnológico.

- Se iba a imponer el quichua y el sistema de escritura unificado a los que no querían.

En ese contexto, el director nacional de la DINEIIB convocó y organizó una marcha nacional en Quito, el 12 de octubre de 1989. En este evento, en el que participaron miles de indígenas, se hizo flamear por primera vez la wipala, lo cual llamó la atención de los grandes medios de comunicación y fue el preámbulo del levantamiento indígena de 1990.

\section{El levantamiento indígena de 1990}

En mayo de 1990, las nacionalidades indígenas decidieron hacer visibles sus demandas sobre diferentes aspectos de sus plataformas de lucha, mediante el "Mandato del levantamiento", que contenía 16 puntos. 
Uno de ellos estuvo destinado a respaldar el SEIB frente a la oposición de sectores políticos, tanto de derecha como de izquierda, y de una parte importante del gremio nacional de profesores que no aceptaban que los indígenas ejerzan la docencia y menos que dirijan su propia educación.

El levantamiento fue convocado por los líderes de las nacionalidades y contó con la participación activa de alfabetizadores y educadores indígenas. Con la fuerza adquirida a raíz de este hecho frente al Estado, en 1991, el director de la DINEIIB preparó el texto de un proyecto de ley para presentar al Congreso Nacional con la finalidad de conseguir se autonomía técnica, administrativa y financiera. Este fue finalmente aprobado en 1992 y fue conocido como la ley $150 .{ }^{142}$ Cabe anotar que el Ministro de Educación de ese entonces, Alfredo Vera Arrata, apoyó la presentación de la propuesta de esta ley que concedía la descentralización a la DINEIB. ${ }^{143}$

A partir de esta ley, la DINEIB fue ampliando el campo de su administración. Mediante reglamentos posteriores emitidos por los ministros, podía firmar acuerdos ministeriales para su jurisdicción, celebrar convenios con instituciones nacionales e internacionales, inclusive formar a su personal a nivel de educación superior en convenio con las universidades. Esto permitió formar unos quinientos docentes con títulos universitarios entre 1990 y 1998.

En la Constitución de 1998, con la insurgencia de la CONAIE desde su fundación en 1986, además de mantener el texto sobre el uso de las lenguas señaladas en la reforma de 1983, se incluyó una sección de derechos colectivos de los pueblos indígenas. Así, en el art. 84 no 11

142 Esta ley fue derogada en 2011, al expedirse la denominada LOEI, con lo cual se legalizó el abuso del decreto 1585 del 18 de febrero de 2009, por el cual el presidente de la república Rafael Correa y su ministro de Educación Raúl Vallejo usurparon las atribuciones de las nacionalidades indígenas del Ecuador.

143 Sin embargo, en 2009, Alfredo Vera, ya funcionario del régimen de Rafael Correa, dijo al autor que había sido un error dar autonomía a la EIB. 


\section{4}

se señalaba como un derecho colectivo: "Acceder a una educación de calidad. Contar con el sistema de educación intercultural bilingüe". En cuanto a la lengua, la Constitución decía:

El Estado respeta y estimula el desarrollo de todas las lenguas de los ecuatorianos. El castellano es el idioma oficial. El quichua, el shuar y los demás idiomas ancestrales son de uso oficial para los pueblos indígenas en los términos que fija la ley (art. 1).

Hay que señalar que este avance en política lingüística y en la declaración de los derechos colectivos no provino del Estado ni de los sectores políticos tradicionales, sino de las comunidades. Ellas, a través de sus representantes, propusieron los referidos textos constitucionales.

\section{Situación actual}

Como se sabe, lo que se combatía en la Colonia era la idolatría, en tanto que en la República, hasta casi finales del siglo XX, se pretextaba el asunto del comunismo. En el siglo XXI el poder criollo ya no tiene como argumento la idolatría ni el comunismo, sino la rectoría para garantizar "educación de calidad y calidez" para todos, incluidos los indígenas. Sin embargo, se parte del prejuicio de que la educación bilingüe no reúne esos requisitos mínimos. Si se observan estos argumentos, es fácil colegir que detrás de esta retórica, desde la Colonia hasta el siglo XXI, está presente la dominación a la población indígena.

Desde el inicio, con la Constitución de 2008, hubo la intención del Gobierno y de varios sectores de "izquierda” ya en el poder, de eliminar el derecho colectivo de la educación bilingüe. Prueba de ello es que el Gobierno había solicitado al CONESUP, a inicios de 2008, elaborar un anteproyecto de Constitución para que la Asamblea Constituyente, que se reunió ese mismo año en la ciudad de Montecristi (prov. de Manabí), lo tomara como referencia; en ese anteproyecto se habían incluido 14 de los 15 derechos colectivos señalados en la Constitución de 1998, pues se había eliminado el derecho a contar con el SEIB. Así, este fue un anuncio claro de la intencionalidad del Gobierno de Correa contra la EIB. 


\section{5}

Frente a la amenaza que se cernía sobre la educación bilingüe, las comunidades, con la participación de los niños, se movilizaron varias veces conjuntamente con el director nacional de la DINEIB, ${ }^{144}$ respaldados por los dirigentes indígenas. Ante esos hechos, el Gobierno, disimulando sus intenciones, accedió a incluir la educación bilingüe como un derecho en la Constitución. Así, el texto constitucional declara que el Ecuador es un Estado plurinacional (art. 1) y reconoce el sistema de EIB (art. 57 no 14, art. 347 no 9). En cuanto a la lengua dice:

El castellano es el idioma oficial del Ecuador; el castellano, el kichwa y el shuar son idiomas oficiales de relación intercultural. Los demás idiomas ancestrales son de uso oficial para los pueblos indígenas en las zonas donde habitan y en los términos que fija la ley. El Estado respetará y estimulará su conservación y uso (art. 2 no 2).

Sin embargo, en las leyes secundarias, estas disposiciones han sido ignoradas o se las ha violado explícitamente. Así, en la LOES (2010, art. 124) se reconoce solo a las lenguas extranjeras como válidas para cumplir con el requisito de idiomas para graduarse en las universidades. Esto rige inclusive para los hablantes de lenguas indígenas. ${ }^{145}$ Asimismo, en la LOEI (2011), aunque se mantiene el sistema de EIB, se lo somete a la rectoría de la educación en castellano.

144 Hasta 2009, el director nacional de la DINEIB era nombrado por concurso público, organizado por las nacionalidades indígenas y el ministro de Educación posesionaba al ganador. El último director designado de esta forma fue Mariano Morocho, en 2007, a quien el ministro de Educación Raúl Vallejo cesó de sus funciones el 18 de febrero de 2009 (un año antes que cumpla el periodo para el que fue electo), amparándose en el decreto presidencial 1585 que violaba la ley 150 de 1992.

145 En el año 2016, en la Ley Código de Ingenios, la Asamblea Nacional incluyó una reforma a la LOES según la cual las universidades deben enseñar una lengua distinta a la materna. Esto abriría alguna posibilidad de que el castellano sea considerado como lengua extranjera para los indígenas, pero en la práctica no se ha implementado esta posibilidad en los instrumentos legales de la educación superior. 


\section{6}

El 18 de febrero de 2009, el Gobierno emitió el decreto ejecutivo 1585 por el cual se suprimió la autonomía que por la ley 150 de 1992 tenía el SEIB para aspectos curriculares, administrativos y financieros. Este decreto fue a todas luces ilegal, pues la ley 150 estuvo en vigencia hasta 2011, cuando recién se expidió una nueva LOEI que legitimó el decreto ejecutivo 1585. A partir de esa nueva ley y otras que se han promulgado para los servidores públicos, se ha separado a la mayor parte de técnicos de las diferentes nacionalidades que se habían formado a nivel universitario, por lo cual se ha debido formar de nuevo otros técnicos de las nacionalidades. El despido al personal se hizo bajo una figura denominada "compra de renuncias voluntarias obligatorias".

A esta situación se suma que a partir del mismo año 2009 no se han publicado nuevos materiales en quichua para uso de los estudiantes. Los materiales en quichua que se venían usando hasta esa fecha fueron cuestionados por las autoridades porque contenían información sobre los levantamientos indígenas, hecho que fue considerado como una "politización de la educación". ${ }^{146}$ A partir de ese año, el Ministerio de Educación ha puesto énfasis en la rectoría de la educación de la población indígena con un currículo único y con material en castellano, es más, el Gobierno de Correa cerró varias escuelas bilingües comunitarias para que los niños indígenas vayan a las llamadas Escuelas del Milenio o Escuelas Siglo XXI, ${ }^{147}$ que están ubicadas en los centros poblados. Se ha obligado a los niños indígenas a caminar durante horas para llegar

146 Solo en 2015 se reimprimió por una sola vez el material antiguo en quichua denominado Kukayu pedagógico, que en 2009 habían cuestionado las mismas autoridades.

147 Hasta 2017 se crearon 65 de estas escuelas. De ellas, apenas unas diez están cerca de los territorios indígenas. A partir de 2018, el Gobierno actual suspendió su construcción debido a que no contribuyeron al mejoramiento real de la educación y a los sobreprecios existentes en los proyectos. La retórica del Gobierno de Correa para reemplazar las escuelas bilingües comunitarias fue que en estas nuevas escuelas se promovería el uso de "tecnología de punta" para la educación. Aún así, algunas comunidades han decidido desobedecer las disposiciones oficiales y asumir por su cuenta el funcionamiento de las escuelas cerradas. 
a esas escuelas donde no se usa la lengua indígena. Los profesores no conocen ni la lengua ni la cultura de las nacionalidades y siguen una "ideología diglósica"148 que se remonta a los tiempos de la Colonia. Con las medidas del llamado Nuevo Modelo de Gestión se ha destruido el SEIB, aunque en el organigrama del Ministerio de Educación se lo siga manteniendo. Las comunidades han sido desmovilizadas y esta situación ha incidido en la desarticulación de la organización comunitaria, lo cual dificulta que se retome en el futuro el proceso militante en pro de la educación bilingüe comunitaria.

Por rectoría, las autoridades educativas del Ecuador entienden el control de la EIB de las diferentes nacionalidades indígenas mediante la aplicación de un currículo nacional único, en el cual no consta ni la ciencia ni la sabiduría ancestral de los pueblos indígenas. El argumento es que la educación de los indígenas no debe ser inferior al resto de la sociedad ecuatoriana. El nuevo currículo de educación bilingüe se viene elaborando desde 2011, pero es revisado continuamente por la Dirección Nacional de Currículo de la Subsecretaría de Fundamentos Educativos del Ministerio de Educación, por parte de personas hispanohablantes que no conocen ni las lenguas indígenas ni sus culturas. En 2017, las autoridades del Ministerio de Educación, por estrategia política, publicaron un documento curricular por cada nacionalidad en lengua indígena. Pero dicho documento es una traducción adaptada y forzada del currículo nacional redactado en castellano y con su visión extranjerizante.

No obstante estas decisiones con respecto a la educación, el Gobierno anterior explotó el uso del quichua en la propaganda oficial, ${ }^{149}$ así

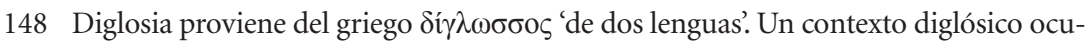
rre cuando en un mismo territorio se da la presencia de dos lenguas, de las cuales una tiene prestigio y la otra no. En tal virtud, una es usada para los actos oficiales (la educación, comunicación, etc.) y la otra queda reducida al ámbito familiar.

149 Esta es una política de usurpación simbólica que se parece a lo señalado por Mannheim (1992, pp. 15-23) cuando menciona que los terratenientes criollos, en 


\section{8}

como en determinadas esferas formales. Documentos como el texto de la Constitución, leyes y sentencias legales, han sido traducidos al quichua sin que nadie los utilice, porque la redacción no es buena. Esta táctica estuvo destinada a fijar en el imaginario, tanto interno como externo, que se ha avanzado en el ejercicio de los derechos de los pueblos indígenas.

El Gobierno que comenzó en mayo de 2017 momentáneamente generó la expectativa de revertir la situación de deterioro de la EIB, inclusive se habló de "restituir la EIB a sus legítimos dueños", pero el decreto 445 firmado en julio de 2018 — supuestamente para restituir la EIB a las nacionalidades — solo ha permitido que, junto al acuerdo ministerial 091 del 4 de octubre de 2018, se cree un aparato burocrático en Quito con un secretario, un subsecretario y ocho direcciones nacionales, es decir, no se estableció la jurisdicción de la EIB en las provincias. Este aparato burocrático reemplazó a la DINEIB, que con una estructura muy sencilla tuvo más poder de decisión y jurisdicción a nivel nacional que el actual aparato burocrático. Tampoco se han restituido las direcciones de educación por nacionalidades, que ya tuvimos desde 2002 hasta 2013.

Finalmente, en la formación docente sigue habiendo dificultades debido a que la UNAE no tiene ni la voluntad ni el personal docente preparado para la EIB. Además, la reapertura de la Universidad Amawtay Wasi y la producción de materiales en lenguas indígenas, son lentos ya que el personal de las nacionalidades que fue formado para estas tareas fue despedido por el anterior Gobierno.

el siglo XVIII, usaron el quichua para legitimar el despojo a los indígenas y apropiarse de los logros de los incas. Algo similar señala César Itier (1992a, pp. 25-49) al referirse a lo ocurrido en el Cuzco, a comienzos del siglo XX, en donde había una tradición antigua de apropiación-expropiación del quechua por las elites locales. En el caso del Ecuador actual, no solamente el poder Ejecutivo realiza esta usurpación simbólica, sino también los otros poderes como la Asamblea Nacional y la Corte Constitucional. Esta última emitió en 2014 una resolución por medio de la cual se afectó a la justicia indígena reconocida en la Constitución y esta resolución contradictoria fue traducida al quichua como una manera de "socializarla". 
Capítulo 7

\section{El quichua y el proceso de estandarización de su escritura}

El proceso de estandarización ${ }^{150}$ de la escritura del quichua ecuatoriano se encuentra en una situación contradictoria, tanto a nivel de estatus como representación del corpus: por una parte están los líderes comunitarios, intelectuales y autoridades de la EIB que se manifiestan a favor de estandarizar la escritura de la lengua. En una encuesta realizada en 2014 a educadores y líderes indígenas sobre aspectos relacionados con la escritura, el $90 \%$ se mostró partidario de la estandarización. Sin embargo, en la práctica existen problemas en la aplicación de la respectiva política. Menos de la mitad de los profesores indígenas que han dado la prueba de bilingüismo desde 2014 hasta 2018 manejan bien la escritura estandarizada. La mayoría escribe con interferencias de la ortografía del castellano o de las hablas locales. ${ }^{151}$

Diferentes autores han señalado que en la escrituración de una lengua no solo intervienen criterios lingüísticos, sino también otros como los de carácter sociolingüístico, político, jurídico, psicológico, religioso, semiótico y pedagógico (Cooper, 1989; Itier, 1992a; Haboud, 1998; King, 2001; Howard, 2007; Ballón, 2009; Luykx, 2013; Zavala et al.,

150 En el Ecuador, en las comunidades, en lugar de la expresión “estandarización del quichua" se habló y aún se sigue hablando de la "escritura unificada del quichua". En términos más amplios, también se habla del "quichua unificado".

151 A esto hay que sumar toda la problemática actual que vive la EIB en el Ecuador y que ya detallamos más arriba (cf. "Situación actual", cap. 6). 
2014). La necesidad de tomar en cuenta el contexto se viene planteando desde hace mucho tiempo. Así, Sebba menciona que Tauli, ya en 1968, al referirse a la planificación lingüística, señalaba lo siguiente:

In new literary languages there may be various social, political, psychological, typographical and economic conditions in conflict with the phonemic principle. Nevertheless, they should not be overestimated. They often depend on prejudices which should be combated, instead of yielding to them [...]. It would be scarcely wise to yield to try to explain to the natives that their orthography is superior to that of French and Spanish (Sebba, 2007, p. 6).

Con estos antecedentes nos preguntamos: ¿Qué problemas existen en la consolidación de la escritura unificada del quichua ecuatoriano? A esta interrogante se añaden otras de orden teórico como: ¿Qué implicaciones surgen, para sus hablantes, al momento de poner por escrito una lengua que se ha mantenido fundamentalmente a nivel oral? ¿Qué componentes intervienen en este proceso?

Para analizar el proceso de estandarización del quichua ecuatoriano, sus avances, limitaciones y dificultades, y para proponer algunas estrategias conducentes a su perfeccionamiento se consideró:

- Contar con referentes teóricos e históricos.

- Presentar un estado del arte de la estandarización de la escritura del quichua.

- Proponer un conjunto de estrategias para la revitalización de la lengua en el contexto de estandarización de su escritura.

- Proponer un conjunto de reglas ortográficas para la escritura del quichua.

\section{Aspectos teóricos e históricos sobre la estandarización de la escritura de lenguas}

Entre los problemas para la consolidación del sistema de escritura del quichua ecuatoriano se encuentran aspectos sociales, pero también 
los que tienen que ver con la comprensión de la complejidad del nuevo código a ser manejado parte de los neoalfabetizados quichuas. Por eso se consideró importante revisar aspectos teóricos relacionados con la escritura, el contexto social y lo ocurrido en procesos de paso de lo oral a lo escrito en otros lugares.

Los educadores, en su trabajo de alfabetización, deben estar conscientes de los diferentes procesos de abstracción seguido por los distintos pueblos hasta llegar a la escritura actual. Esto les permitirá buscar estrategias para enseñar la escritura como un código desarrollado socialmente y hacer que los alumnos recorran conscientemente las etapas escriturarias seguidas por la humanidad. Es necesario que aprendan el código alfabético en un contexto de consciencia semiótica y lingüística.

Históricamente, se conoce que las primeras representaciones escritas fueron pinturas ( $c f$. Moorhouse, 1965; Croato, 1966; Calvet, 1996/2001; Garcés, 2017). Luego surgieron las escrituras ideográficas como una simplificación de los pictogramas que, aun así, requieren de miles de signos. Así, el japonés o nihongo emplea la escritura ideográfica llamada kanji [kanži] que comparte con el chino y utiliza miles de signos. Las culturas indígenas prequichuas de Ecuador también han dejado petroglifos y diseños. Estos pueden ser usados en las escuelas bilingües como un paso previo a la escritura alfabética con pocos signos, la cual por un lado es altamente abstracta, pero cuantitativamente hablando, es bastante simple pues requiere de unas pocas decenas de símbolos (letras).

\section{El paso de lo oral a lo escrito}

La escritura ${ }^{152}$ de una lengua implica el manejo de un nuevo código, un nuevo sistema de signos de representación de la realidad. Desde el

152 En este estudio se entenderá por “escritura” a la representación de los fonemas de la lengua mediante grafemas o letras, sin que ello signifique que se está en contra del enfoque semiótico, que mantiene un concepto más amplio de escritura. Así, 


\section{2}

punto de vista teórico se debe señalar que ningún sistema de escritura, por más localista que sea, es capaz de representar fielmente los rasgos orales de una lengua, ya que siempre existen abstracciones y generalizaciones en diverso grado ( $c f$. Sommerstein, 1977). Sobre los procesos de abstracción y reducción de las culturas orales a una modelización escrita señala Verón:

Todo modelo tiene por objeto, entre otras cosas, simplificar la realidad y la objeción de Goody, llevada a sus últimas consecuencias, implicaría que al material antropológico de las culturas orales no se les puede aplicar ningún modelo abstracto, dado que todo modelo abstracto es tributario del lenguaje escrito, soporte indispensable del observador científico (2013, p. 195).

La humanidad, desde la construcción de los primeros lenguajes siguió un largo proceso de semiosis hasta llegar a la representación escrita actual. Si los signos de la lengua oral implicaban ya una abstracción de la realidad, los signos de la escritura alfabética representan una doble abstracción. En cuanto al signo, este ha sido definido como un algo que representa solo parcialmente la realidad, según lo han teorizado semiólogos como Saussure, Peirce, Eco, Greimas, Barthes, Lotaman, Verón, etc. Peirce definió al signo de la siguiente manera:

Un signo o representamen, es algo que, para alguien, representa o se refiere a algo en algún aspecto o carácter. Se dirige a alguien, esto es, crea en la mente de esa persona un signo equivalente, o tal vez, un signo aún

por ejemplo, se puede considerar escritura la representación del pensamiento y de la lengua mediante diseños en tejidos, cerámica, pinturas, etc. (cf. Calvet, 1996/2001). Por otra parte, asumimos superadas las posiciones que consideraban que la escritura alfabética era superior a la escritura pictográfica y logográfica. Rousseau decía: "Estas tres maneras de escribir responden con bastante exactitud a tres estados diferentes bajo los cuales se pueden considerar las naciones constituidas por los hombres. El dibujo de los objetos corresponde a los pueblos salvajes; los signos de las palabras y de las proposiciones a los pueblos bárbaros; y el alfabeto a los pueblos civilizados" (Rousseau, 1781/1984, p. 24). 


\section{3}

más desarrollado. Este signo creado es o que yo llamo el interpretante del primer signo. El signo está en lugar de algo, su objeto. Está en lugar de ese objeto no en todos los aspectos, sino solo con referencia a una suerte de idea, que a veces he llamado el fundamento del representamen (en Zecchetto, 2000, p. 53). ${ }^{153}$

En cuanto a la presencia de la escritura en una sociedad de tradición oral, unos consideran que no implica un cambio radical en su forma de pensar, mientras otros creen que existe un cambio sustancial, debate que continúa sin resolverse. ¿Qué gana y qué cambia cuando una cultura escritura su lengua? Francis dice que Scribner y Cole realizaron una investigación sobre la influencia de la escritura en comunidades de la etnia Vai (Liberia, África), investigación que fue publicada en 1981; sobre esto señala que:

Durante el curso de la investigación se debatían dos posiciones encontradas: 1) que las invenciones culturales como la escritura no guardan una relación causal con los procesos básicos del desarrollo intelectual. Cambian cómo la sociedad resuelve sus problemas, pero no altera las estructuras de las operaciones mentales, y 2) que cambios tecnológicos en la manera en que manipulamos los símbolos instrumentalizan el desarrollo cognoscitivo e impulsan el surgimiento de nuevas estructuras mentales (Francis, 1997, pp. 48-51).

A pesar de los resultados de esa investigación, ${ }^{154}$ hubo autores que siguieron argumentando a favor de la segunda posición, es decir, "la

153 En varios lugares de sus obras, Peirce da una definición de signo, pero en todas mantiene su pensamiento central sobre el mismo. Así, en el Collected Papers 2.303 dice del signo: "Cualquier cosa que determina alguna otra (su interpretante) para que se refiera a un objeto al cual él mismo se refiere (su objeto); de la misma manera el interpretante se convierte a su vez en un signo, y así ad infinitum".

154 Contrariamente a las expectativas, los resultados de las dos primeras categorías experimentales (la abstracción y la clasificación taxonómica) no mostraron evidencia de que la escritura influenciara en el desarrollo cognoscitivo. En el tercer caso, esto es el efecto de la escritura en el conocimiento reflexivo del lenguaje, se 


\section{4}

escritura reestructura la consciencia”. Así, Francis (1997, pp. 185-186) trae las observaciones de Goody (1987) según la cual la presencia de la escritura trae consigo cambios en la forma de comprender y expresar el significado, afectando a su vez a la organización interna de la cognición y la memoria.

Ong (1987/2012, pp. 20-21), por su parte, señala que la expresión oral está relacionada con un auditorio, una colectividad que oye y participa en acto junto con el orador, en tanto que la escritura y lo impreso lo aíslan; leer y escribir tienden a ser actividades solitarias y conducen a la reflexión interiorizada e individualizada. Esto recuerda a Malinowski (1923 en Ong, 2011, pp. 38-39), quien había comprobado que para los pueblos "primitivos" (orales), la lengua es un modo de acción y no solo una contraseña del pensamiento. Pero, a pesar de que pasar de lo oral a lo escrito implica cambios en la forma de ser de los hablantes, Ong concluye que no hay otro camino para las lenguas orales que avanzar hacia la escritura para poder acceder a los beneficios que ella proporciona.

Olson y Torrance consideran que las culturas escritas tendrían una mayor objetivación de la naturaleza debido a que desarrollarían un grado mayor de distinción entre lo dado y lo interpretado:

La evolución de una tradición escrita, por consiguiente, implica algo más que la acumulación de conocimientos o el desarrollo de una tradición de investigación acumulativa. Implica un nuevo modo de clasificar y organizar el conocimiento. En primer lugar, implica la distinción sistemática entre lo que dice un texto y lo que quiere decir, o sea, entre un texto y su interpretación, y por lo tanto, entre hechos y teorías, entre observaciones e inferencias. Pero en segundo lugar, crea la posibilidad

vio que los hablantes tenían un mayor grado de objetivación del lenguaje; se notó que la escritura propiciaba el desarrollo de una conciencia metalingüística, sin embargo, la investigación mostró que no había diferencias entre letrados y analfabetos en la identificación de frases no gramaticales. 


\section{5}

de recoger los primeros y organizarlos en complejos sistemas de conocimientos (1991/2013, p. 217).

Desde la sociolingüística Calvet, hace énfasis en que en la sociedad occidental no se ha tomado suficiente consciencia de las implicancias de la escritura. Algo similar ocurre con muchos educadores encargados de la alfabetización, pues enseñan a escribir de forma mecánica sin hacer que los alumnos sean conscientes del proceso de abstracción que realizan al representar la lengua y la realidad mediante signos escritos.

La escritura viene a ser, dentro de nuestras sociedades occidentales, algo que se da por descontado y sobre lo que no cabe ni preguntarse: la lengua es considerada bajo dos formas, la oral y la escrita, y eso basta. Simplemente el sentido común ha desarrollado por su cuenta cierto número de ideas aceptadas de las cuales un proverbio latino, citado a menudo, Verba volant, scripta manente, da perfecto testimonio (Calvet, 1996/2001, p. 12).

Entre los aspectos positivos de la escritura, según Joseph, se cuentan: la conciencia de unidades discretas, la conciencia del cambio lingüístico, la contención de la diversidad dialectal, la habilidad en la planificación lingüística y la materialidad de la lengua escrita (1987, pp. 34-37).

\section{La planificación lingüística y la estandarización}

La estandarización de la escritura de una lengua implica un proceso de planificación lingüística. Pero como lo han señalado Cerrón-Palomino (1983), Itier (1992b), Appel y Muysken (1996), Luykx (2013) y Lepe (2014), la planificación lingüística no ocurre in vacuo, sino dentro de un contexto amplio, pues no se puede prescindir de la problemática social, económica y política en la que esta se halla inmersa. En el caso ecuatoriano, la estandarización del quichua está estrechamente vinculada a la EIB y al el ejercicio de los derechos colectivos de las nacionalidades indígenas. 


\section{6}

Desde la reflexión teórica, Haugen, ${ }^{155}$ conjugando los componentes "sociedad" y "lengua" con "norma” y "función", propuso cuatro estadios dentro de un proceso de planificación: selección, codificación, implantación y elaboración, los que en años posteriores pasó a representar un modelo con doble eje: el uno integrado por la sociedad y la lengua, y el otro por forma y función (Moreno, 1998, p. 332; Cerrón-Palomino, 1983, p. 26). La forma es la voluntad de seleccionar una forma lingüística a usarse; luego viene la codificación mediante la estandarización de las grafías, la gramaticalización y la lexicación. La función es la implementación, y esta comprende la difusión educativa y la elaboración modernizada de la terminología. Estos pasos muestran una sucesión lógica, pero también pueden ser simultáneos y cíclicos.

Posteriormente, Heiz Kloss amplió la visión y propuso la diferenciación entre la "planificación de corpus" (aspectos lingüísticos) y la "planificación de estatus" (aspectos sociales), según lo menciona Cooper:

We can discuss these definitions according to their treatment of each of the underlined terms in the following question: Who plans what for whom and how? [...]. The other definitions are more specific, however. These mention imply one or both of the two language-planning foci distinguished by Kloss (1969), corpus planning and status planning (1989, p. 31).

A partir de estas consideraciones, diversos autores elaboraron una serie de ideas sobre el concepto de "planificación del lenguaje". Cooper (1989, pp. 30-31) hizo un resumen de 12 definiciones dadas por diferentes autores entre 1969 y $1986 .{ }^{156}$ Una de ellas, proponía añadir a

155 Haugen (1959) escribió "Planning for a Standard language in Modern Norway" (en Moreno, 1998, pp. 331-332). El modelo propuesto en 1959 fue formulado con más precisión en 1974 y 1979 (en Cerrón-Palomino, 1983).

156 Cooper también analizó las propuestas de planificación del lenguaje de autores como Tauli, Fishman, Rubin, Prator, etc. 


\section{7}

las dos anteriores señaladas por Kloss, la "planificación de la adquisición de la lengua".

En concordancia con la propuesta de reconocer el tercer campo de planificación, King (2001, p. 200), en su estudio sobre la situación del quichua en Saraguro y su posible revitalización, ${ }^{157}$ incluye un esquema de Hornberger (1994) que contempla los tres tipos de planificación con sus respectivas actividades.

En el presente estudio, estas teorías sobre el desglose de los componentes de la planificación se las toma únicamente como un insumo referencial para la diferenciación analítica de los aspectos lingüísticos propiamente dichos de los extralingüísticos, y no como un esquema a seguir de manera sistemática. En el caso ecuatoriano, como se verá más adelante, la gestión de los componentes de la planificación lingüística han estado imbricados con los políticos y sociales.

\section{Los aspectos sociales y la estandarización}

Howard (2007), empleando el análisis crítico del discurso, al estudiar el panorama sociolingüístico andino (Ecuador, Perú y Bolivia), hace notar el vasto campo donde influyen las ideologías lingüísticas. ${ }^{158}$ Las ideologías intervienen en el mantenimiento de imaginarios colonialistas frente a las lenguas indígenas, en la formulación de instrumentos legales, en la justificación de nacionalismos, etc. Sobre el colonialismo

157 En el caso de Saraguro, gran parte de los niños han perdido el quichua y por eso se puede hablar de un proceso de readquisición de la lengua. Esto requerirá de una planificación que incluya la elaboración de un método apropiado para ello. Saraguro no es el único caso, otras regiones del país también sufren el caso de que los niños indígenas han perdido la lengua.

158 "Ideología", en este caso, es entendida como un discurso alienante, aunque podría también en otros contextos tener un sentido más neutro, como un conjunto de ideas o ideario. 


\section{8}

lingüístico, Martín Nakata, ${ }^{159}$ en su obra Disciplinar a los salvajes, violentar las disciplinas (2014, p. 82), señala que los estudios lingüísticos no deben reducirse a la descripción de la lengua como si ellas estuvieran flotando en el vacío. Las ideologías expresadas a través de discursos influyen en los procesos de estandarización de las lenguas. Algunos autores señalan que en la estandarización de las lenguas, además de las ya mencionadas, está la ideología de la modernización ( $c f$. Luykx, 2013).

En el caso del quichua ecuatoriano, autoridades educativas, en 1980, expresaban que la escritura del quichua debía diferenciarse de la del Perú por razones políticas y nacionalistas. A nivel de la población indígena, sin embargo, casi desde el inicio del proceso de alfabetización comenzó a gestarse la idea de llegar a una escritura panandina del quichua/quechua.

Un ejemplo de cómo las ideologías o factores externos a la comunidad influyen en la estandarización de la escritura se puede encontrar en el caso de Haití, donde se presentan problemas de estandarización de la escritura del creole (Schieffelin, 2012) debido a la existencia de dialectos sociales y geográficos. Unos prefieren un dialecto más afrancesado, mientras otros prefieren rescatar los menos interferidos por el francés. En otros casos, como lo señala Pottier, "personas externas a la comunidad intentan determinar un tipo de escritura a una lengua” (1983, p. 23). Para evitar esto es preferible que sean personas de la misma comunidad quienes se involucren directamente en los procesos de estandarización de la escritura, pero hay que estar consciente de que incluso en estos casos puede ideologizarse el proceso.

159 Nakata es un indígena isleño del Estrecho de Torres, entre Australia y Papúa Nueva Guinea, quien hizo investigaciones sobre su lengua y cultura para su tesis doctoral. Esto le permitió realizar una sólida crítica al estilo de investigaciones que llevaron a cabo académicos de universidades europeas. Su libro se inscribe dentro de la serie de pensamiento decolonial. 


\section{9}

A esto hay que añadir las posiciones institucionales. Así por ejemplo, el ILV que trabaja con fines religiosos en diferentes países, ha tenido la política de adecuar la escritura de las lenguas indígenas a la escritura de la lengua dominante del país. En el proceso ecuatoriano ya se mencionó que el ILV tuvo la misma posición, es decir, escribir los dialectos del quichua siguiendo los patrones del castellano, incluyendo libremente préstamos de esta lengua. Detrás de una discusión aparentemente lingüística, estuvieron razones de tipo ideológico. En Ecuador, aunque ya no está presente el ILV, su política de escribir la Biblia o partes de ella con la escritura del castellano adaptada a diferentes dialectos continúa hasta el día de hoy. En décadas pasadas se hicieron traducciones bíblicas en dialectos de Chimborazo, Imbabura y la Amazonía, en ellas se empleó las grafías $<\mathrm{c}, \mathrm{qu}, \mathrm{hu}, \mathrm{j}>$. Estas ediciones continúan siendo usadas en los eventos religiosos.

En 2017, las Sociedades Bíblicas Unidas, publicaron el Nuevo Testamento en el dialecto quichua de Salasaca (prov. de Tungurahua), el cual es uno de los más innovadores en el Ecuador y por lo tanto el que más se aleja de la escritura estandarizada. La obra lleva el título de Diosbuj Shimi: Mushuj Testamento. Lo novedoso de este texto es que lo escriben con las grafías $<\mathrm{k}, \mathrm{w}>$ en lugar de las grafías $<\mathrm{c}, \mathrm{qu}, \mathrm{hu}>$, respectivamente. Con esto, en las grafías se acerca a las del alfabeto unificado, pero con la particularidad de que siguen representando los diptongos. También usan la $<\mathrm{j}>$ en lugar de la $<\mathrm{h}>$ del alfabeto unificado. Pero al haberse representado por escrito la fonética y la morfofonética, así como los fenómenos de reducción y ensamblaje, y los otros fenómenos lingüísticos propios de este dialecto, el texto se aleja de la escritura estandarizada.

Como muchas comunidades indígenas se han pasado del catolicismo al evangelismo, esta política lingüística usada para escribir los textos bíblicos no contribuye a la generalización de la escritura unificada. 


\section{Aspectos lingüísticos en la estandarización de la lengua}

En la planificación de corpus se considera lo relacionado con los estudios propiamente lingüísticos: fonología, morfofonémica, morfosintaxis, lexicología, etc. En el presente caso se pondrá más atención a la fonología y a la morfofonémica, debido a que ellas son las más visibles en el proceso de estandarización de la escritura del quichua.

En el pasado, el modelo del sistema de escritura de las lenguas dominantes fue adaptado para escribir las lenguas indígenas. Esta situación comenzó a cambiar a mediados del siglo XX, cuando algunos círculos de intelectuales comenzaron a utilizar el concepto de fonema, y la representación de las variantes del mismo mediante un solo signo. Sin embargo, la técnica empleada en el establecimiento de los fonemas de una lengua mediante el procedimiento de los pares mínimos fue rebasada al momento de su aplicación, lo que no implica eliminar su uso como procedimiento auxiliar.

La complejidad que se presenta en las lenguas al momento de determinar los fonemas, ha llevado en ocasiones a discusiones "lingüísticas" que impiden llegar a consensos en procesos de estandarización. Así, Weber — de la línea del ILV—, para determinar la existencia de cinco vocales en el quechua del Perú, realiza interpretaciones subjetivas sobre aspectos relacionados con de los pares mínimos. Sostiene que los "pares mínimos" no son necesarios para el establecimiento de fonemas, aunque se esfuerza en encontrarlos para justificar la existencia de las vocales [e], [o] en el quechua: "In some dialects, there are minimal pairs for native words. The pair wira 'a piece of fat or grease' versus wera'fat (person or animal)' is found in much of Huánuco department” (Weber, 2005, p. 12). Y en el mismo texto añade, como nota de pie de página, "some speakers also have the following contrastes: $r \underline{r} k u$ 'old person' versus rok $u$ 'adult" y presenta ejemplos de "impecables" pares mínimos del quechua de Cochabamba tomados de otro autor: "De la Rocha (1987, p. 34) gives the following minimal pairs (among others): chixchi 'hail' versus chexchi 
'pleasant', suxta 'right away' versus soxta 'six', and suxya 'change of appearance' versus 'soxya 'run'” (Weber, 2005, p. 12).

Sin embargo, es fácil notar que se está forzando los hechos. En el caso [wira $\sim$ wera] ambos términos provienen de la misma fuente / wira/ 'manteca, gordo', pues la segunda acepción es solo un sentido figurado de la primera. En el caso de [ruku roku] igualmente ambas expresiones provienen de una misma fuente /ruku/ 'persona mayor'. Así, Weber, en su afán de justificar la existencia de los fonemas /e, o/ en quechua, recurre a pares mínimos cuestionables, y con estos argumentos (Weber, 2005, p. 14) defiende la existencia de cinco vocales en quechua frente a las tres que sostienen la mayoría de lingüistas. ${ }^{160}$

Aparte de los estudios fonológicos para establecer los fonemas y alófonos de la lengua, según los casos, se necesita realizar estudios morfofonémicos, de sintaxis, léxico, etc. Esto permite establecer las características de las zonas dialectales y con esto facilitar la explicación de las implicancias de una escritura estandarizada. En el caso ecuatoriano, como se vio en el capítulo 5, para definir las características de las zonas dialectales se requirió realizar un estudio de las variaciones dialectales a partir del estudio de las variaciones de los fonemas y de los morfemas.

\section{El proceso de estandarización de la escritura del euskera}

En diferentes partes del mundo existen pueblos que están pasando su lengua de lo oral a lo escrito. De ellos el proceso seguido por el pueblo vasco tiene algunas particularidades que son de interés para el estudio del caso ecuatoriano, a pesar de la diferencia de contexto. La lengua euskera es hablada en la frontera de los montes Pirineos entre

160 En el caso de la estandarización del quichua ecuatoriano no hubo problema con las vocales sino con las consonantes, porque en la lengua no hay consonante /q/ que propicie la "apertura" de las vocales /i, u/ como ocurre en la mayor parte de dialectos de Perú. 


\section{2}

España y Francia. Según Elkartea, la preocupación por el euskera estándar surgió casi con el nacimiento de la literatura vasca escrita en el siglo XVI:

El presbítero Joanes Leizarraga, cuando tradujo el Nuevo Testamento al euskara, en el siglo XVI, escribió en el prefacio que en el País Vasco, en Euskal Herria, se hablaba diferente casi de una casa a otra. Por ello, intentó crear una forma de escribir la lengua que fuera entendida por la mayor parte posible de la población (2010, p. 25).

A partir de esa época, varios religiosos comenzaron a buscar formas de escritura que unificaran los diferentes dialectos. En el siglo XIX varios autores del norte de los Pirineos señalaron algunas normas ortográficas básicas. Entre ellas se propuso evitar < gue, gui > y utilizar <ge, gi $>$. También se eliminó la $<\mathrm{v}>$ del alfabeto. Estos detalles demuestran que la normativa para escribir el euskera se apartaba en varios aspectos de la del castellano. Se propuso crear neologismos para sustituir términos provenientes del latín. Algunos de ellos se siguen usando, pero muchos no se usaron porque parecían muy artificiales.

En 1918, un grupo de intelectuales vascos creó la Euscaltzaindia, que es la Academia de la Lengua Vasca. Entre los primeros académicos estuvieron lingüistas, bibliófilos, antropólogos y archiveros. El objetivo principal fue fijar el uso de la lengua escrita, aunque no todos estuvieron satisfechos con el proceso de estandarización de la lengua (Elkartea, 2010, p. 28).

Después de la Guerra Civil Española (1936-1939), todo intento de reivindicar la lengua y la cultura vasca fue acallado. Una generación de intelectuales fue fusilada, detenida o desterrada. Franco prohibió hablar el euskara en público. A partir de 1950 surgió una nueva toma de consciencia por la juventud vasca por recuperar la lengua, en medio de la represión franquista. En ese contexto, la Euskaltzaindia pidió al lingüista Koldo Mitxelena que redactara una propuesta de euskara unificado. Él consideró que había que ir al origen y partió del tronco común de los ocho dialectos. Se basó en el dialecto central debido a que era el más cercano a todos los 


\section{3}

demás y era el más utilizado en las manifestaciones culturales. Pero también, en el caso de que existiera alguna marca en la que coincidían los dialectos periféricos, escogió aquella variante. Su documento contenía cinco propuestas: ortografía, palabras y variantes léxicas antiguas, palabras nuevas, morfología y sintaxis. En octubre de 1968 presentó su propuesta a una asamblea en Arantzazu (cf. Elkartea, 2010, p. 35). ${ }^{161}$

Esta experiencia muestra que los estudios diacrónicos y la etimología pueden contribuir a la estandarización de una lengua. Consecuentemente, trabajos diacrónicos, como los del protoquechua de Parker y otros, pueden ser tomados como referencia para la continuación del proceso de estandarización del quichua.

\section{Estado del arte de la estandarización de la escritura del quichua ecuatoriano}

El proceso de estandarización del quichua ecuatoriano es un caso atípico. No surgió directamente de las políticas estatales. No hubo un libreto de planificación preestablecido. La planificación en los diferentes componentes se fue elaborando sobre la marcha, a propósito de la alfabetización y la EIB promovida por instituciones privadas y por las comunidades. Por esta razón, la narración de las acciones relacionadas con la unificación de la escritura se la realiza en torno a los hechos ocurridos en la educación bilingüe, y también al proceso de organización de las nacionalidades indígenas del Ecuador.

161 Las recomendaciones de la Asamblea de Arantzazu fueron ratificadas y se convirtieron en norma por la Euskaltzaindia, cuando en 1970 fue elegido como director de ella Luis Basante, un sacerdote que había realizado su labor literaria y lingüística en Arantzazu. En 1976 la Euskaltzaindia se transformó en Real Academia de la Lengua Vasca-Euskaltzaindia y continúa hasta ahora promoviendo su estandarización y revitalización. 


\section{4}

Partimos señalando la forma en que se escribió el quichua ecuatoriano en la época colonial y en los inicios de la época republicana. Luego presentamos los cambios que comenzaron a suscitarse en la primera mitad del siglo XX, así como las políticas seguidas por los proyectos de alfabetización y educación bilingüe. Finalmente, describimos la estandarización de 1980 y el ajuste realizado en 1998.

\section{La escritura del quichua ecuatoriano desde la Colonia hasta la mitad del siglo XX}

Las autoridades españolas dieron al quichua el estatus de lengua general para facilitar la evangelización y la administración colonial. En cuanto al corpus, durante la Colonia los textos de la lengua quichua seguían los mismos parámetros del alfabeto castellano. Los manuales para la evangelización y la enseñanza del quichua provenían del Perú. Como señalamos en el capítulo 3, recién a mediados en el siglo XVIII comenzaron a aparecer algunos textos propios del quichua ecuatoriano. $\mathrm{El} \mathrm{Ca}$ techismo incluido por el décimo cuarto obispo de Quito, Luis Francisco Romero, en la pastoral del 30 de agosto de 1725, reproducido literalmente en el Vocabulario español-quichua de la lengua quichua (Grimm, 1896), empleó el siguiente alfabeto para las palabras quichuas: $<\mathrm{a}, \mathrm{c}, \mathrm{ch}, \mathrm{d}, \mathrm{g}, \mathrm{i}, \mathrm{h}$, $1, \mathrm{ll}, \mathrm{m}, \mathrm{n}, \tilde{\mathrm{n}}, \mathrm{p}, \mathrm{qu}, \mathrm{r}, \mathrm{s}, \mathrm{t}, \mathrm{u}, \mathrm{y}>$ (19 letras). Como puede observarse, en el texto del Catechismo de 1725 no se hace distinción entre /š, s/.

Luego de la Independencia, el Estado puso énfasis en el castellano como lengua de educación, pero a partir de mediados del siglo XIX algunos escritores emplearon el quichua para la poesía y la catequesis. En cuanto a la ortografía, los textos del siglo XIX de escritores como Juan León Mera (1892), Luis Cordero (1892/1955), Julio Paris (1892/1961) y Juan Grimm (1896), se encuentran algunos cambios en relación a los escritos del siglo XVIII. Unos son comunes a todos los escritores señalados y otros son particulares de cada uno según su punto de vista. Entre los cambios comunes se encuentra la distinción entre $<\mathrm{s}>\mathrm{y}<\mathrm{sh}>$ para represen- 
tar a los fonemas $/ \mathrm{s} /, / \check{s} /$, respectivamente, el uso de $<\mathrm{j}>$ para representar al fonema /h/ y empleo de $<\mathrm{h}>$ delante de los segmentos $<$ ua, ui $>$.

Entre las particularidades que algunos de los escritores adoptaron se pueden mencionar las siguientes: Cordero y Paris incluyeron el signo $<\mathrm{zh}>$ para representar el fonema de sustrato cañari /ž/; Paris y Grimm adoptaron el signo $<z z>$, para graficar el sonido [ $\not]$; Cordero y Paris incluyeron los signos $<\mathrm{b}, \mathrm{d}, \mathrm{g}>$ en posición inicial de palabra para representar términos de sustratos, principalmente en la escritura de fitónimos y topónimos; Cordero, además, incluyó $<\mathrm{z}>$ para representar el sonido /z/ propio del sur de la Sierra ecuatoriana. Sin embargo de estas diferencias a nivel ortográfico, está subyacente la intención de que sus escritos sean usados a nivel nacional.

Solo en el siglo XX, unos pocos investigadores como Rivet y Jijón y Caamaño usaron el signo $<\mathrm{k}>$ para evitar la multiplicidad de signos en la representación del fonemas $/ \mathrm{k} / \mathrm{y}<\mathrm{w}>$ para evitar uso de la $<\mathrm{h}>$ "muda" o la $<\mathrm{g}>$ delante de las secuencias $<\mathrm{ua}$, ui $>$. Pero las publicaciones de ellos solo fueron conocidas en el reducido círculo intelectual de esa época.

Finalmente, en 1947, un grupo de tres misioneras lauritas elaboró un texto de lectura denominado Mi primera cartilla inca, destinada a la alfabetización infantil en un centro cultural que tenían en Otavalo (prov. de Imbabura). Esta cartilla también fue empleada en las escuelas indígenas de Cayambe de la conocida líder indígena Dolores Cacuango, cartilla que tiene una interesante propuesta pedagógica para la alfabetización. En cuanto a escritura, se usó la del castellano, sin embargo, históricamente es el primer material escrito en quichua para la educación indígena, específicamente para el aprendizaje de lectura y escritura.

\section{La escritura en los programas de alfabetización quichua (segunda mitad del siglo XX)}

El ILV ingresó al Ecuador gracias a un convenio con el Gobierno en 1952 para realizar una labor religiosa y educativa. En sus textos usó la escritura del castellano. Tradujo la Biblia a varios dialectos quichuas 


\section{6}

de la Amazonía y de la Sierra. Su trabajo estuvo centrado fundamentalmente en la Amazonía con alguna injerencia en Colta (prov. de Chimborazo) y otros lugares de la Sierra.

El Instituto Inter Andino de Desarrollo trabajó en las provincias de Cotopaxi, Tungurahua y Chimborazo (Sierra centro) desde la década de 1960 hasta la mitad de la de 1970. Al igual que en el caso anterior, elaboró cartillas por separado, según el habla de algunas comunidades. Por ejemplo, preparó cartillas para alfabetizar con el dialecto de Salasaca (prov. de Tungurahua), otras con el habla de la comunidad La Compañía Grande (prov. de Cotopaxi), etc. Del contenido de las cartillas elaboradas por esta institución, como de las del ILV, se observa que el estatus que se le dio a la lengua quichua era de transición hacia la castellanización. Así, ninguna de las dos instituciones intentó, por ejemplo, enseñar matemáticas en quichua; estaba implícito que una vez que se alfabetizaban los estudiantes, las demás ciencias debían aprenderlas en castellano.

A partir de la década de 1970, en el ILL de la PUCE, Consuelo Yánez (comunicación personal, 2015) realizó estudios de fonología del quichua, planteándose por primera vez la posibilidad de unificar la escritura de la lengua; sin embargo, las investigaciones solo abarcaron las localidades de Colta (prov. de Chimborazo) y Otavalo (prov. de Imbabura), y no se consideraron los dialectos de la Amazonía. Aun así, conjuntamente con Fausto Jara, Yánez elaboró el método Nukanchik Llaktapak Shimi (1973-1975) destinado a la enseñanza del quichua en la universidad a profesores hispanohablantes que trabajaban en comunidades indígenas y al público en general (comunicación personal, 2015). El alfabeto de 21 letras empleado en este método fue el siguiente: <a, ch, i, j, k, k', l, ll, m, n, n, p, p', r, s, sh, t, ts, u, w, y>. Además se usaban las letras $<\mathrm{b}, \mathrm{d}, \mathrm{g}, \mathrm{f}\rangle$ para préstamos del castellano. Sin embargo, las vocales $<$ e, o $>$ de los términos castellanos fueron asimiladas a $<\mathrm{i}, \mathrm{u}>$ del quichua, respectivamente.

Esta escritura también fue empleada en tres promociones de los cursos de formación de lingüistas quichuas que realizó la PUCE a partir de 1975, 


\section{7}

programa diseñado por la directora del ILL (que actualmente es la Facultad de Lingüística, Literatura y Comunicación de la PUCE), Consuelo Yánez.

El 31 de enero de 1978 se firmó un convenio entre la PUCE y el MEC para la realización de un programa experimental de alfabetización quichua en la provincia de Cotopaxi (PUCE, 1980, p. 149). Las comunidades en donde se trabajó fueron: Maca Grande, Yaguartoa y Chami, ubicadas al occidente de Latacunga (prov. de Cotopaxi). En ese mismo año se firmó un convenio entre la PUCE y la Universidad René Descartes (París V), con la participación de personal de esa universidad: el lingüista Alain Bentolila y el sociolingüista Louis-Jean Calvet.

El 22 de octubre de 1979 se creó en la PUCE el CIEI, ${ }^{162}$ aunque informalmente ya venía funcionando desde marzo de ese año, con el fin de ampliar las investigaciones lingüísticas y educativas a otras lenguas indígenas del Ecuador (PUCE, 1980, p. 155). En el CIEI se diseñó el denominado Modelo Maca ${ }^{163}$ según el cual el proceso educativo estaba estructurado con tres componentes:

- Las organizaciones indígenas para la gestión política.

- El Estado, a través del MEC, para la definición de políticas públicas y el aspecto administrativo-financiero.

- $\quad$ El CIEI de la PUCE para el componente científico (Yánez, 1980, pp. 93-119).

162 El CIEI tuvo como finalidad ser un espacio alternativo para la educación indígena. Su documento de constitución fue firmado por el presidente de la Universidad de Paris V y el rector de la PUCE. Este convenio duró dos años. El 4 de noviembre de 1979, Paulo Freire visitó el CIEI y manifestó su acuerdo con el uso de las lenguas indígenas en la educación.

163 Es el nombre que se puso al diseño teórico construido por el CIEI para el Subprograma de Alfabetización Quichua que funcionó entre 1980 y 1986. Este nombre se puso en honor a la comunidad Maca Grande (prov. de Cotopaxi), donde se inició la alfabetización en 1978. El texto íntegro del Modelo Maca está publicado en la revista no 28 de la PUCE de 1980. 


\section{8}

La innovación de esta propuesta fue la participación de las organizaciones indígenas en el proceso educativo. ${ }^{164}$

En el equipo del CIEI se consideró que la única forma de tener una escritura común para todos los dialectos del quichua ecuatoriano era tomar como punto de partida la fonología de la lengua. Al alfabeto del método ya señalado se hicieron ciertos ajustes y se publicó el material experimental de alfabetización. El alfabeto empleado fue el siguiente: <a, ch, i, h, k, kh, l, ll, m, n, n, p, ph, r, s, sh, t, th, ts, u, z> (21 grafías). Con estos signos se elaboraron las tres primeras cartillas de lecto-escritura de alfabetización denominadas: $\tilde{N} u k a n c h i k$ shimi, y las tres cartillas de matemáticas denominadas: Ñukanchik iupai. Se discutió también sobre las consonantes aspiradas y se decidió representarlas por escrito. Como se puede apreciar, se hizo algunos cambios al alfabeto empleado en el método de enseñanza del quichua Ñukanchik Llaktapak Shimi, así:

- No se representaron las semiconsonantes $<\mathrm{w}, \mathrm{y}\rangle$ debido a que se las asimiló con los signos de las vocales $<\mathrm{u}, \mathrm{i}>$, respectivamente. ${ }^{165}$

- Se añadió el signo $<$ ts $>$ para representar algunos términos que tenían el sonido [ $\not \subset$ en algunos dialectos quichuas.

- Las aspiradas se representaron con los signos $<\mathrm{ph}$, th, kh, $>$.

- Los términos de origen sustratístico se los asimiló a la escritura del quichua.

164 Una de las principales causas de la desaparición del CIEI en 1986 fue el deterioro de la relación entre la dirigencia de las organizaciones indígenas y las autoridades del CIEI por la manipulación de personas de "izquierda” que pretendían apropiarse de la institución.

165 Se disminuyeron esas dos grafías con la idea de simplificar la alfabetización. Esta propuesta fue ideada por un asesor francés en 1979, Gabriel Tarlé, quien había trabajado en un programa de alfabetización en Haití, pero no fue bien vista por los líderes indígenas. La eliminación de las grafías $<y, w>$ fue una medida desacertada que influyó negativamente en la credibilidad de la propuesta ortográfica de la PUCE, a pesar las bondades que tenía. Esta escritura solo duró hasta abril de 1980, cuando dejaron de utilizarse estas seis cartillas experimentales. 


\section{9}

Simultáneamente, en la provincia de Chimborazo, mediante un acuerdo entre el MEC y la FIA, a fines de la década de 1970, comenzó a funcionar un programa de alfabetización local denominado Chimborazoca Caipimi. El alfabeto que emplearon comprendía las siguientes fueron las letras: <a, b, c, c' ch, ch', d, g, h, i, j, j' l, ll, m, n, n, p, p', qu, q'u, $r, s, s h, t, t$ ', ts, u, y, z> (30 letras). Este programa, además del aval oficial, tenía el apoyo de la Misión Evangélica, que facilitaba la difusión a través de sus emisoras.

\section{El proceso de estandarización de la escritura del quichua}

Antes de describir los principales pasos que se dieron en favor del objetivo anunciado, creemos necesario presentar el sistema fonológico del quichua actual. En esta variedad ecuatoriana existen los siguientes fonemas: en los dialectos de las zonas Sierra centro y parte de la Sierra sur existe un reducido número de palabras aspiradas: /ph, th, chh, kh/; adicionalmente, hay la presencia de / $\notin, \mathrm{z}, \mathrm{z}, \mathrm{b}, \mathrm{d}, \mathrm{g} /$ en el léxico proveniente de lenguas prequichuas; fuera de ello, están los fonemas presentes de préstamos del castellano y que no figuran en el cuadro.

\section{Las reuniones para la estandarización del quichua}

El 10 de agosto de 1979, el presidente Jaime Roldós Aguilera, al retornar la democracia y tomar posesión de su cargo, pronunció una parte de su discurso en quichua. A raíz de este acontecimiento, ${ }^{166}$ se presentó la coyuntura para la ampliación de la alfabetización en quichua que ve-

166 Según el testimonio de Consuelo Yánez (comunicación personal, 2015), la idea del discurso en quichua surgió del vicepresidente de la republica Osvaldo Hurtado, que fue profesor de la PUCE, quien lo canalizó a través del CIEI. La motivación fue las cartas escritas totalmente en quichua que alfabetizadores y personal del CIEI enviaron a los futuros gobernantes unos quince días antes de su posesión. Los primeros integrantes del CIEI en 1979 fueron: Consuelo Yánez, Luis Macas, Rosa Vacacela, Luis de la Torre, Luis Montaluisa y Ana Yánez. 


\section{0}

nía funcionando por iniciativa de personal de la PUCE. Efectivamente, el Gobierno decidió realizar una campaña de alfabetización y dentro de esta campaña nacional se estableció el Subprograma de Alfabetización Quichua a nivel nacional, con excepción de la provincia de Chimborazo, pero inmediatamente se presentó el problema de la escritura. ¿Con qué escritura y metodología se iba a realizar la alfabetización en idioma quichua?

Con el afán de resolver estos asuntos, a inicios de 1980, se realizaron algunas reuniones para llegar a un alfabeto único y consensuar una metodología para la campaña de alfabetización. Estos acercamientos se realizaron en el MEC, donde participaron algunos líderes indígenas y delegados del CIEI, pero sin llegar a ningún acuerdo. Entonces se pensó en una reunión más amplia con dirigentes indígenas a nivel nacional, patrocinada por el mismo ministerio, reunión que se realizó en un centro de capacitación de trabajadores: el INEFOS, los días 12 y 13 de marzo de 1980. El único acuerdo fue el de volverse a reunir un mes más tarde para seguir discutiendo los temas tratados, sin embargo, en las discusiones se perfilaron claramente dos tendencias:

- Un grupo, influenciado por el ILV, sostenía que ya existían libros escritos en varios dialectos con el sistema ortográfico castellano en los cuales se había invertido mucho esfuerzo (la Biblia). Ellos sostenían que la unificación debía ser cercana al habla de la localidad y afirmaban, entre otras cosas, que "no hay que aceptar imposiciones. Hay que respetar el derecho de cada comuna indígena tenga su propia escritura y método de alfabetización de acuerdo a sus problemas y necesidades. Los indígenas somos completamente diferentes entre unos grupos de otros. Las grafías $<\mathrm{k}, \mathrm{w}>$ son letras gringas", etc.

- El otro grupo consideraba que los indígenas del país tenían una problemática común y que era menester la unificación de todos para hacer frente a los problemas, por lo que propuso la unificación de la escritura y el método de alfabetización. Esto suponía que cada dialecto tenía que hacer concesiones lingüísticas, aspectos que no fueron discutidos. 
Por esa época las organizaciones de las nacionalidades indígenas recién estaban en un proceso de conformación. La FEI, ${ }^{167}$ fundada por Dolores Cacuango bajo el criterio de un sindicato obrero campesino, con los auspicios del Partido Comunista Ecuatoriano, obtuvo su personería jurídica el 29 de enero de 1945, pero para la década de 1980 ya había perdido su vigencia. En la Sierra, la ECUARUNARI, fundada en 1973, no tenía personería jurídica. En la Amazonía recién se estaba organizando la CONFENIAE que en un momento se llamó GONAE. La CONAIE estaba en proceso de gestación a través del CONACNIE. Las organizaciones indígenas evangélicas estaban organizadas en cada provincia con personería jurídica, por lo que el MEC pudo convocarles más fácilmente. En consecuencia, en los encuentros hubo una alta representación evangélica con posición contraria a la estandarización de la escritura.

Un mes después del encuentro en INEFOS, el MEC convocó a una nueva reunión a la que acudieron alrededor de cien personas, con el consenso previo de que podían ingresar solo delegados indígenas. En consecuencia, solo fue autorizado el ingreso de un delegado indígena del CIEI de la PUCE. Esta reunión se efectuó entre el 14 y el 18 de abril de 1980, en medio de una gran tensión en la que se designó como director de la reunión a Ampam Karakras, vicepresidente shuar del CONACNIE, para discutir la escritura del quichua.

En la reunión, se optó porque todas las personas e instituciones que tuvieran propuestas de alfabetos hicieran su exposición. Se presentaron nueve propuestas de alfabetos. De ellas, cuatro fueron institucionales: del CIEI de la PUCE con 21 grafías, de las Escuelas Indígenas de Cotopaxi con 19, del Centro de Capacitación Bilingüe de Chimborazo con 30, de la Dirección Provincial de Educación de Imbabura con 25.

167 La FEI, como membrete, existe hasta el día de hoy dentro de una organización sindical. Desde hace más de cuarenta años ya no tiene comunidades de base y su presidente lleva en funciones por más de treinta años, poniéndose al servicio de cada Gobierno de turno. 


\section{2}

Hubo cinco propuestas a nivel personal: una de la Amazonía con 25 grafías, una de Imbabura con 28, una de Cañar con 30, una de Saraguro con 23 y una de Calderón con 26 grafías.

Al final del encuentro se emitieron varias resoluciones, cuyo cuarto punto del documento de relatoría (Seminario Nacional de Alfabetización Quichua-La Merced "Nueva Vida", Participación, Grafía, y Metodología: Resoluciones Generales) propone el alfabeto quichua unificado del Ecuador:

A-B-C-CH-D-F-G-H-I-J-L-LL-M-N-Ñ-P-Q-R-S-T-U-Y-Z-ZH-SH-TS (26 letras). Para aprobar el alfabeto quichua se analizó exhaustivamente: cada cual expuso serios argumentos lingüísticos y experiencias vividas como las de la PUCE, Centro Bilingüe de Chimborazo y otras provincias de la Sierra y Oriente; luego de una acalorada discusión se procedió a la consideración y aprobación de las letras del alfabeto quichua; esta fecha histórica para la nacionalidad quichua y la patria ecuatoriana fue el jueves 17 de abril 1980, a las 4 p.m. en la sala de sesiones de la plenaria (en Montaluisa, 1980, pp. 133-134).

La aprobación de este alfabeto, letra por letra, a mano alzada, parecía ahogar la posibilidad de unificación. La presencia de las letras $<$ b, d, g, f, j> propiciaba la proliferación de muchas formas de escribir, por ejemplo, /michik/ 'pastor' podía escribirse como < michic, michig, michij, michi >; / panka/ 'hoja' podía graficarse como <panga, fanga >; /inti/ 'sol', como $<$ inti, indi $>$, etc.

En la misma reunión se nombró a cinco representantes indígenas, profesores y líderes comunitarios, que pasaron a ser parte del personal de planta del MEC como promotores nacionales en el Subprograma Nacional de Alfabetización Quichua.

Con estos antecedentes, el mes de mayo siguiente se constituyó una mesa de trabajo con un representante del MEC, los promotores qui- 


\section{3}

chuas seleccionados y tres representantes del CIEI de la PUCE, ${ }^{168}$ con el objeto de analizar la escritura del quichua, la metodología de la lectoescritura y la enseñanza de matemáticas. Con ellos se llegó a un acuerdo en usar las grafías $<\mathrm{b}, \mathrm{d}, \mathrm{g}, \mathrm{f}>$ solo para préstamos del castellano. $\mathrm{La}<\mathrm{j}>$ solo se debía usar al inicio de la palabra. No se incluyó la $<$ zh $>$ para representar el fonema /ž/, porque no se pensó en el sustrato cañar, solo se lo consideró como un alófono de los fonemas $/ \lambda$, č/ de palabras quichuas como [žakta, munagižu] <llakta, munankichu> 'pueblo, ¿Quieres?'. De esta manera, el alfabeto propuesto esta vez constaba de 21 letras: <a, c, ch, h, i, j, l, ll, m, n, ñ, p, qu, r, s, sh, t, ts, u, y, z>. La comisión conformada señalaba que dicho sistema ortográfico era la base para la alfabetización de ese momento y que luego de un período de experimentación podría ser revisado con la participación de los neoalfabetizados.

Consuelo Yánez, al hacer memoria de las pugnas existentes por el asunto de la escritura, señala:

La lucha por la imposición de los distintos dialectos había comenzado años antes con la escritura diferenciada que practicaba el ILV. Cada grupo quería que se escribiera en lo que creía era su dialecto aunque no hubiera diferencias, y quienes más peleaban por ello eran los indígenas que pertenecían a iglesias o sectas evangélicas (Yánez, 1991, p. 90).

Como ya se dijo, en el caso ecuatoriano las discrepancias giraban en torno a las consonantes y no a las vocales, como en Perú, pero los argumentos ideológicos de los que se oponían eran bastante similares a los de la Academia Mayor de la Lengua Quechua del Qosqo y del ILV ( $c f$. Godenzzi, 1992). En Ecuador, la discrepancia gira en torno a la representación de los sonidos [b, d, g, f, x] y al uso de las letras $<\mathrm{k}, \mathrm{w}>$ para representar a los fonemas $/ \mathrm{k} / \mathrm{y} / \mathrm{w} /$, respectivamente.

168 La comisión del CIEI estuvo presidida por Consuelo Yánez y los técnicos indígenas Luis de la Torre y Luis Montaluisa. 


\section{4}

El ILV siguió publicando sus textos según la ortografía del castellano. En su bibliografía de publicaciones (1985) señala que durante el período 1981 a 1985 se publicaron 23 textos de lectura empleando escrituras distintas para los diferentes dialectos del quichua, con el fin de fijar un sistema de escritura para cada uno.

Por su parte, el equipo del CIEI de la PUCE publicó durante el período 1980-1986, 65 títulos entre cartillas, mapas, guías e inclusive textos para educación infantil quichua empleando la escritura estandarizada de 1980. Entre estos materiales se publicó el primer diccionario quichua-quichua: Caimi Nucanchic Shimiyuc-panca (Haboud, et al., 1982). En este diccionario, las definiciones, las oraciones contextuales, los ejemplos, las notas sobre sinónimos, mapas, etc., se realizaron en quichua; incluso los nombres de lenguas prequichuas fueron escritos con la ortografía estandarizada del quichua. Esto dio ocasión a que algunos autores como Salomon hicieran algunos reparos a la escritura unificada del quichua de ese entonces:

La desventaja es la misma que se nota en todas las publicaciones del grupo asociado con la Universidad Católica, a saber, la insistencia en una representación grafofonémica que no refleja la realidad de ningún dialecto ecuatoriano, sino una lengua franca imaginaria e idealizada. Las convenciones arbitrarias utilizadas falsifican de una forma rara la pronunciación normal; por ejemplo nadie en ningún sitio denomina la provincia de Imbabura "Inpapura", pero esta es la forma reconocida por los autores como correcta (Salomon, 1983, p. 400).

La crítica de Salomon tenía razón en lo relacionado con la escritura de los términos provenientes de las lenguas de sustrato, pero no en cuanto a que la escritura unificada no refleja la realidad de ningún dialecto. Efectivamente, como se ha visto desde el punto de vista semiolingüístico, la escritura siempre implica abstracción, más todavía en el caso de una escritura estandarizada. Unificar la escritura a partir de reflejar un dialecto significaría generalizar ese dialecto dejando de lado los 


\section{5}

elementos de planificación lingüística que se deben tener en consideración en estos casos.

El Subprograma de Alfabetización Quichua, en el marco del convenio MEC-PUCE, se ejecutó entre 1980 y 1986 en 924 centros de alfabetización, con la participación de unos mil alfabetizadores en todas las provincias con población quichua, con excepción de Chimborazo, que seguía su propia política.

El CIEI cerró sus puertas el 30 de septiembre de $1986,{ }^{169}$ pero durante su existencia, además del aporte científico a la educación indígena, gestionó la reforma del art. 27 de la Constitución en 1983, para que se incluya un inciso que disponía que en las zonas de predominante población indígena la lengua principal de educación fuera el quichua o la lengua de la cultura respectiva. Esta reforma contribuyó al posicionamiento de la educación bilingüe en la estructura legal, sin embargo, en el MEC se continuó con una actitud racista hacia este sistema. Una de esas manifestaciones fue la negativa a operativizar un convenio firmado con la PUCE para titularizar a los cerca de mil educadores indígenas que habían acumulado las 4000 horas de capacitación que se requería para obtener el título de Bachiller en Ciencias de la Educación. Igualmente, el MEC obstaculizó la publicación de materiales educativos en lenguas indígenas

169 De 1978 a 1980 trabajaron en el CIEI doce personas: diez de ellas quichua-hablantes. De 1980 a 1986, cuando dejó de funcionar, laboraron unas sesenta personas, la mayor parte quichuas de diferentes comunidades del país, y también hablantes de otras lenguas indígenas. El CIEI fue dirigido por Consuelo Yánez desde su creación en 1979 hasta septiembre de 1985, en que renunció ante la oposición del nuevo director del ILL, Fernando Miño Garcés, y la manipulación a algunos dirigentes indígenas por parte de políticos de "izquierda", que pretendían dirigir el proceso de alfabetización indígena del Ecuador. Entonces la dirección del CIEI fue encargada a Luis Montaluisa, pero la situación de esta institución se complicó debido a que a los problemas anteriores se sumó la cada vez más tensa relación con las autoridades del MEC, por lo que la PUCE decidió cerrarlo. 


\section{6}

con el argumento de que, al estar escritos en lenguas indígenas, ellos no podían estar seguros de que estén acordes con el currículo oficial.

Volviendo al tema de la escritura, después de la aprobación del alfabeto unificado del quichua en 1980, poco a poco los proyectos de educación bilingüe infantil, que habían comenzado a funcionar localmente a partir de $1976,{ }^{170}$ por iniciativa de algunas organizaciones comunitarias, fueron adoptando la escritura unificada elaborada en el Subprograma de Alfabetización Quichua del convenio MEC-PUCE. Los programas locales que aceptaron rápidamente la escritura unificada fueron las Escuelas Indígenas de Cotopaxi, que venían funcionando desde 1979, las Escuelas de la Ribera del Río Napo, actual provincia de Orellana, que venían funcionando desde 1980 y las escuelas de Simiatug (prov. de Bolívar) que venían funcionando desde 1979. Estos programas habían solicitado al equipo del CIEI-PUCE que capacitara a los profesores indígenas y en algunos casos hasta pidieron el material de alfabetización para adultos del CIEI, para el trabajo educativo con niños. Igualmente, adoptaron esta escritura estandarizada el Proyecto de Educación Bilingüe de la CONFENIAE y el Proyecto de Educación Bilingüe de la GTZ, que comenzaron a funcionar en 1986.

En el campo político uno de los factores contribuyó al posicionamiento de la escritura unificada, fue el proceso organizativo que culminó en la conformación de la CONAIE en 1986. Luego de conformada sus directivos apoyaron este proceso, y eso hizo este sueño de contar con un solo sistema de escritura para los dialectos del quichua ecuatoriano vaya madurando poco a poco.

En el campo técnico, los temas lingüísticos y sociolingüísticos que se incluyó en el proceso de alfabetización a partir de 1979 contribuyeron significativamente a que los alfabetizadores, profesores y líderes apoyen a

170 Más información sobre estas experiencias locales se encuentran en el MOSEIB (DINEIB-Ministerio de Educación, 1993/2013; Montaluisa, 2008). 


\section{7}

la estandarización. En los cursos de capacitación se incluía más cien horas para cada uno de los siguientes temas: fonología, morfosintaxis, dialectología, sociolingüística, historia de la escritura, etc. En estos cursos las discusiones eran acaloradas y agrias, pues había posiciones localistas. Pero al final se veía que no había otra alternativa para contar con un proceso educativo como nacionalidad que unificar la escritura. Sin embargo, el Programa de Alfabetización Chimborazoca Caipimi, que venía funcionando en la provincia de Chimborazo desde antes de 1980, no aceptó la reglamentación de la escritura que se hizo en Quito en los meses siguientes a la unificación del alfabeto realizado en abril 1980, y particularmente los ajustes realizados en mayo de ese mismo año, lo que dificultaba la generalización de la escritura unificada, debido a que la provincia de Chimborazo tenía y tiene una alta densidad de población indígena. Efectivamente, la cartilla Chimborazoca caipimi, aparecida en 1983 se publicó con el siguiente alfabeto: <a, b, c, c', ch, d, f, g, h, i, j, l, ll, m, n, n, p, qu, r, s, sh, t, ts, u, y> (25 letras). Dicho programa funcionó hasta 1988.

Únicamente después de la creación de la DINEIB en 1988 y más concretamente después del levantamiento indígena de $1990,{ }^{171}$ la provincia de Chimborazo fue paulatinamente aceptando el alfabeto de 21 letras.

El alfabeto de 1998 y el acuerdo 244 de 2004

Durante la década de 1980 se capacitaron alrededor de mil alfabetizadores quichuas, como ya se mencionó. Todos ellos eran ya o llegaron a ser líderes de las comunidades. Varios de ellos, por las tardes o

171 Varias comunidades indígenas evangélicas se sumaron al levantamiento de 1990, por encima de su dirigencia local y de la FEINE, que en ese momento estuvo del lado del Gobierno. Los comuneros se tomaron directamente las radios evangélicas que existían en la provincia de Chimborazo. Igual cosa ocurrió con comunidades afiliadas a la FENOC (actual FENOCIN), cuyos dirigentes suelen ser afines a los gobiernos de turno. 


\section{8}

noches, alfabetizaban a los adultos, y durante el día enseñaban a leer y escribir a los niños que no iban a las escuelas oficiales. Así surgieron unas 300 escuelas bilingües informales. ${ }^{172}$ En los cursos de capacitación que duraban entre uno y tres meses se incluyeron materias lingüísticas, como ya se mencionó. De tal suerte que hasta 1988, en que se creó la DINEIB, se había hecho un avance importante en el tema de posicionar la escritura unificada.

Esto continuó ya con en 1991 se firmó un convenio entre la Universidad de Cuenca, la DINEIB y la GTZ de Alemania. Este programa, dirigido por inicialmente Ruth Moya y Alejandro Mendoza, dotó de formación lingüística a muchos profesores indígenas. Después, en la misma Universidad de Cuenca y en otras como la UTPL y en la UPS, se formaron profesores indígenas en educación bilingüe, con un importante componente de materias sobre lingüística, aparte de las pedagógicas, en el plan curricular. Sin embargo, el número de personas que han sido formadas con este perfil es pequeño todavía frente a las necesidades de personal. ${ }^{173}$

Los hechos señalados contribuyeron a crear consciencia en los líderes indígenas de la necesidad de contar con un sistema de escritura unificado. Se publicaron materiales en diversos proyectos con la escritura unificada de la que se habló anteriormente. Varios indígenas evangélicos asistieron a los cursos de alfabetización, a los cursos de formación de profesores e inclusive a los programas de licenciatura que incluían temas de lingüística. Pero aunque el número de personal con formación lingüística a nivel universitario es pequeño, la actitud de los alfabeti-

172 A estas instituciones se las denominaba centro-escuelas, debido a que el mismo alfabetizador trabajaba por las noches o los fines de semana con los adultos y entre semana con los niños. Ellos recibían una bonificación mensual del Estado de unos 80 dólares por trabajar con los adultos. El trabajo con los niños era voluntario y no autorizado oficialmente.

173 Actualmente, la mayoría de estas personas han sido desvinculadas de la EIB por el Gobierno. 


\section{9}

zadores y educadores bilingües que recibieron cursos de historia de la escritura y del alfabeto influyó en la consciencia de las comunidades en favor de la adopción de las grafías $<\mathrm{k}, \mathrm{w}>$ en el alfabeto.

Diez años después de su creación, el 29 de julio de 1998, la DINEIB organizó un encuentro de profesionales indígenas para reconsiderar el uso de las grafías $<\mathrm{k}, \mathrm{w}>$ para representar a los fonemas $/ \mathrm{k}$, w/, respectivamente. En esta reunión, que tuvo lugar en Tabacundo (prov. de Pichincha), participaron veinte delegados. Allí establecieron el siguiente alfabeto: <a, ch, i, j, k, l, ll, m, n, ñ, p, r, s, sh, t, u, w, y> (18 grafías). No se normativizó la escritura de los elementos de sustrato ni de los préstamos. Luego, en 2004, la DINEIB emitió un acuerdo ministerial para oficializar el alfabeto de la mencionada reunión.

En la reunión de 1998 también decidieron conformar la ALKI, la cual venía funcionando a medias, pero actualmente ha quedado en suspenso debido a que el Gobierno de Correa, en 2011, a través de la LOEI, creó el IICSAE. ${ }^{174}$

\section{Problemas en la consolidación de la estandarización del quichua ecuatoriano}

Desde 1988 hasta 1995 la CONAIE no tenía vinculación directa con los partidos políticos. Esto la colocó entre las tres instituciones más creíbles del Ecuador, junto con la Iglesia católica y las Fuerzas Armadas. Esta situación permitió posicionar la EIB y por lo tanto las lenguas indígenas. Sin embargo, a partir de 1995, debido a la manipulación de

174 El IICSAE estuvo en fase de organización desde hace unos tres años, pero sin integrar en su seno personal especializado en lingüística ni investigación. El concurso para elegir a su director no fue transparente y no fue concebido como un instituto de los indígenas, sino para indígenas, dirigido por el ministro de Educación. El 19 de abril de 2018, el presidente de la república, mediante el decreto 373, dispuso que este instituto sea absorbido por el actual Ministerio de Educación. 
políticos de "izquierda" que se infiltraron paulatinamente, la situación de autonomía de la CONAIE comenzó a debilitarse frente al Estado y a los gobiernos. Cuando no ha existido sincronización entre estos dos componentes, el proceso se ha estancado o debilitado.

Por otra parte, algunos padres de familia no están convencidos de que el uso de la lengua quichua sea una alternativa para la educación de los niños. Se piensa que el quichua no está equipado como una lengua de educación en las comunidades indígenas. Los efectos de la diglosia están latentes, como puede verse.

Otro problema serio es que a raíz del cierre de las direcciones provinciales de EIB y de las direcciones de educación que cada nacionalidad tuvo hasta 2012, se despidió a casi la totalidad de los técnicos indígenas formados a nivel universitario. Este personal era el encargado de elaborar material educativo, capacitar a los docentes, etc.

Igualmente se limitó el trabajo de los seis institutos superiores pedagógicos interculturales bilingües que venía formando a los docentes indígenas. En la universidad pedagógica creada para formar docentes a nivel nacional no tienen apertura ni capacidad científica para formar docentes indígenas.

No se ha renovado el convenio con la Universidad de Cuenca que trabajó en investigación lingüística y en la formación de profesionales indígenas en pedagogía y otros aspectos relacionados con la EIB. Por otra parte, la Universidad de Cuenca ya no cuenta con el personal especializado en lingüística y educación bilingüe que tuvo anteriormente.

A nivel de corpus, el alfabeto quichua establecido en 1998 en Tabacundo, oficializado en 2004, carece de reglas ortográficas o directrices para explicar a las variaciones dialectales. Como se sabe, tales reglas de uso son importantes ya que el alfabeto por sí solo es insuficiente para implementar una escritura auténtica. Tampoco se ha previsto la forma de escritura de los sustratos ni los préstamos. Por otra parte, subsisten 
algunas discrepancias sobre la representación del fonema /h/. Si bien en la Sierra han aceptado el uso la grafía $<\mathrm{h}>$, en la Amazonía existen sectores que prefieren la $<j>$. Sin embargo, este caso no es complicado pues solo se trata de escoger una de las dos grafías.

De otro lado, tampoco se había investigado de manera sistemática las variaciones fonéticas y morfofonémicas señaladas en el capítulo 5. La falta de estos estudios no ha permitido explicar de manera sistemática a los docentes y a los productores de materiales educativos sobre las características de las seis zonas dialectales para que lo tomen en consideración en la planificación del corpus.

Una de las causas por las que los textos redactados en quichua unificado son difíciles de leer y poco atractivos obedece a la introducción caótica de neologismos. Muchos de ellos han sido creados sin recurrir a la ayuda de los morfemas derivadores. Esto genera problemas al momento de leer los textos estandarizados. Sin embargo, estos problemas de metodología y estrategia no significan que la estandarización sea inviable; lo que hay que cambiar son las estrategias de creación de neologismos, el estilo de redacción de los textos y la metodología de su implementación.

También hay severos problemas de redacción no solo en textos como la Constitución y las leyes, sino también en los textos que se venían elaborando para la educación de los niños. Los textos están escritos con oraciones demasiado largas, sin el uso apropiado de signos de puntuación y con estilo oral. Esto ha traído como consecuencia que sean materiales escritos oscuros y difíciles.

Con todos estos antecedentes, a continuación proponemos algunas estrategias para superar la diglosia, consolidar el bilingüismo y facilitar la implementación de la escritura unificada. 


\section{Propuesta de estrategias para la revitalización del quichua en el contexto de estandarización de su escritura}

En los procesos educativos descritos anteriormente se ha evidenciado que las comunidades a través de sus instancias organizativas influyeron en el posicionamiento de las lenguas indígenas, y en el reconocimiento de la educación bilingüe por parte de los gobiernos. Mientras que personal técnico, tanto indígena como no indígena, en muchos casos vinculados a universidades, se encargó de organizar los aspectos de la planificación del corpus.

\section{Acciones relacionadas con el estatus}

Hoy estamos en una nueva etapa. Existe la voluntad de las comunidades de estandarizar la escritura, como se señaló al inicio. El asunto es buscar los mecanismos para superar las dificultades que se han presentado. Igualmente, se está generando consciencia de recuperar la educación propia. Para ello se tiene que fortalecer algunas acciones.

\section{El reposicionamiento de las nacionalidades indígenas en torno a las lenguas y culturas y territorios}

Como ya se ha señalado, a partir de 1995 la dirigencia indígena se dedicó más a la política electoral antes que a la consolidación de la EIB y otros componentes de la cultura. Esto trajo como consecuencia un debilitamiento en el proceso. A esto se añadió las acciones gubernamentales en contra de los procesos organizativos de las nacionalidades indígenas, y la cooptación de varios dirigentes indígenas por parte del Gobierno. Parecía que el modelo extractivista ${ }^{175}$ ahogaba para siempre

175 Por modelo extractivista se entiende la planificación del desarrollo del país mediante la explotación del petróleo, la minería, las extensas plantaciones de palma africana que esteriliza los suelos, etc. Los minerales están en territorios indígenas y por esta razón el Gobierno consideró que la educación bilingüe era una amenaza para su modelo económico. 
la EIB y que el movimiento indígena se dispersaba. Sin embargo, han surgido grupos de jóvenes que han comenzado a organizar centros culturales para realizar acciones en favor de la lengua y la cultura, haciendo uso de lo dispuesto en el art. 1 de la Constitución, de que el quichua y el shuar son idiomas oficiales. Igualmente, muchos jóvenes en las redes sociales están haciendo uso del quichua y algunos de ellos han asumido ya la dirigencia de organizaciones locales.

Por otra parte, las comunidades han comenzado un proceso de defensa de la educación bilingüe comunitaria. Varias escuelas han sido cerradas oficialmente para dar paso a las Escuelas del Milenio, pero las comunidades están haciéndolas funcionar por su cuenta. ${ }^{176}$ En las reuniones de las organizaciones, uno de los puntos de discusión es el de la recuperación de la EIB. En el "mandato" para las autoridades está la implementación de los derechos colectivos. La experiencia ha demostrado que es la lucha de los pueblos indígenas la que permite posicionar las lenguas y la educación bilingüe en la sociedad ( $c f$. Rodas, 1998). Las comunidades han comenzado a juntarse a nivel local y están exigiendo a la dirigencia nacional que asuma la defensa de la educación bilingüe. ${ }^{177}$

El sistema educativo ecuatoriano debe promover las lenguas y las ciencias ancestrales en la sociedad

Varias instituciones han comenzado a tratar el tema de las lenguas y ciencias ancestrales. Así, en la UCE, en el pensum de estudios de la Carrera de Matemáticas, se han incluido las cátedras Etnomatemáticas I y Etnomatemáticas II. Como punto de partida, han organi-

176 Hay comunidades en las provincias de Cotopaxi, Imbabura y Loja donde siguen haciendo funcionar las escuelas comunitarias bilingües, a pesar que el Gobierno dispuso su cierre.

177 En la primera semana de junio de 2015, se realizó una reunión nacional con la participación de unos cien líderes para asumir la defensa de la EIB. A este evento asistieron también dirigentes de la CONAIE y la ECUARUNARI. 


\section{4}

zado el I Simposio de Ciencias Ancestrales y el I Congreso de Etnomatemáticas. La UNL está organizando una reunión académica sobre este mismo tema. La UPS tiene en perspectiva la creación de la cátedra Ciencias Ancestrales.

Estas acciones van a presionar el cambio de actitud de las autoridades y de la población cuando se trabaje un aspecto relegado: la cuestión epistemológica. Actualmente, la educación del país está pensada con mentalidad urbana y europeizante. Se presenta como prototipo de educación de calidad al uso de las TIC, el BI, la aplicación de las pruebas PISA, ${ }^{178}$ etc. El currículo único está elaborado con criterio externo. Pero ya surgen voces en la sociedad ecuatoriana que están cuestionando este tipo de educación, y proponiendo la inclusión en el currículo de aspectos culturales y lingüísticos relacionados con las lenguas indígenas. Se tiene que apoyar estos procesos.

\section{En relación con el corpus}

Las comunidades, en general, tienen consciencia de la distinción entre una variedad formal y otra informal. En ese contexto se propone las siguientes acciones:

\section{Conocimiento y tratamiento de las variaciones dialectales}

Ya se ha mencionado que toda representación escrita implica abstracciones de la realidad fónica. Además, la variación dialectal del Ecuador, una vez sistematizada en zonas dialectales, no es tan caótica como parecería a simple vista. Esto tiene que explicarse en un manual sobre escritura. Con estos antecedentes, en la estandarización de la escritura

178 Es un proyecto de la OCDE que pretende evaluar a los estudiantes de diferentes países con parámetros internacionales. Esto podría ser útil para migrantes, pero no debe ser el único referente para la EIB. 


\section{5}

del quichua es necesario conocer y dar un tratamiento en la ortografía a los fenómenos lingüísticos que se señalan a continuación:

1. La presencia de variaciones vocálicas $[a>i],[a>u]$. Esta característica de la Sierra centro se evidencia aquí: [yuyag yuyig] /yuyak/ 'pensante, el que piensa', [yawar yawur] /yawar/ 'sangre'.

Este fenómeno, aunque es percibido por los hablantes de las otras zonas dialectales, no es un obstáculo para la comprensión oral. A nivel formal se usa la forma estandarizada pero en el nivel informal se sigue mantiene las variaciones vocálicas. Cuando en los textos aparece escrito $<$ yuyay, yawar>, los estudiantes de la zona que tiene esta variación, tanto de los procesos de alfabetización de adultos como de los niños, no han tenido problemas de comprensión. Estos fenómenos ocurren en todas las lenguas y no son obstáculo para la unificación escrita. Así, en el español rural existen las variaciones [ $\lambda$ obió $\sim \lambda$ ubió] y eso no es obstáculo para que todos escriban <llovió $>$. En consecuencia, en el fenómeno de cambio vocálico la normativa es la de escribir según la forma anterior a la innovación esto es con $<\mathrm{a}>$.

2. La presencia de sonidos aspirados /ph, th, $\mathrm{kh} /$. La no representación escrita de estos sonidos afecta a la Sierra centro. Como ejemplos tenemos: [phuyu, thyuka, khipa] < puyu, tyuka, kipa> 'nube, saliva, después'. Ventajosamente, para la estandarización, el léxico que contienen estos sonidos es escaso y tampoco existen pares mínimos con los sonidos simples /p, t, k/. Con todo, se debe dejar abierto a que en el futuro, luego de realizar un inventario del léxico existente con estos sonidos y si hubiera un consenso nacional, podrían tener su propia representación.

3. Los sonidos fricativizados $[\varphi, x]$. En la Sierra norte se presenta este caso, proveniente de los fonemas /ph, kh/. Como ejemplos tenemos: [ $\varphi$ uyu, xipa] <puyu, kipa > 'nube, después'. El corpus que contiene este fenómeno es pequeño, por lo cual se puede hacer el inventario y presentar a los estudiantes como parte del conocimiento de la realidad socio-geográfica quichua. 


\section{6}

4. Las variaciones sonorizadas de los fonemas $/ p, t, k /$ que son $[b$, $d, g]$. La sonorización de estos fonemas, generalmente, está limitada al contexto después de nasal o en posición intervocálica. En la alfabetización de 1980 ya se optó por no representarlos y no hubo dificultad. Como ejemplos tenemos: [pamba, tanda, šungu] <pampa, tanta, shunku> 'planicie, pan, corazón'. La supresión de los fonemas /p, k/ como en [pambay, puriuni] < pampapi, purikuni> 'planicie, estoy caminando' no impide la comprensión, pues se parece al fenómeno de castellano de la Costa donde oralmente dicen [kansao, komio] en <cansado, comido $>$. En este caso, se escribirá la forma larga que, generalmente, es la más antigua.

5. La variación $[\check{s} \sim s]$. Está presente en la Amazonía norte. Esto solo ocurre en los morfemas \{-ška, špa $\}$, lo cual facilita la explicación a sus hablantes y tampoco encierra dificultad, debido a que existe algún parecido ortográfico entre $<\mathrm{sh}, \mathrm{s}>\mathrm{y}$ también a la proximidad en la articulación fonética.

6. Las variaciones del fonema $\lambda /[\lambda \sim \check{c} \sim \check{s} \sim 1]$ en algunos vocablos

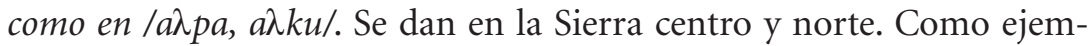

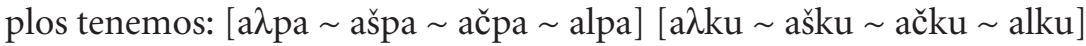
$<$ allpa, allku> para 'tierra, perro'. Este fenómeno es algo parecido a lo que ocurre en castellano con $/ \lambda /$ que se realiza como $[\check{z}, \lambda, y]$ en la Sierra sur, norte y en la Costa, respectivamente. Un ejemplo en castellano que ilustra esto es / $\lambda$ egar/ que se realiza como [žegar, $\lambda$ egar, yegar] <llegar $>$. Estas variaciones pueden acarrear alguna dificultad para la estandarización de la escritura, pero no son un obstáculo insalvable.

7. Las variaciones del fonema $/ w /[w \sim b \sim \emptyset]$. Estas variaciones, que se dan en la Sierra norte y en la Amazonía centro, respectivamente, están limitadas al contexto en que /w/ va antes de /i/. Como ejemplos tenemos: [wira $\sim$ bira $\sim$ ira] [wiksa $\sim$ biksa $\sim$ iksa] [wiki $\sim$ biki $\sim$ iki] $<$ wira, wiksa, wiki> para 'manteca, barriga, lágrima'. Es apenas una docena de palabras las que están en este caso. 


\section{7}

8. Las variaciones del fonema /č/ [ $\check{c} \sim \varnothing \sim s]$. Están presentes en inicial de palabra en la Sierra. Como ejemplos tenemos: [čawar $\sim \not$ awar $\sim$ sawar] <chawar> 'penco, cabuya'. Las tres formas mencionadas pertenecen a la Sierra centro, norte y sur, respectivamente. Son muy escasas las palabras donde ocurre este fenómeno.

9. Las variantes de $/ x /[x \sim \emptyset]$. Están presentes en posición inicial de palabra en la Amazonía centro. Como ejemplos tenemos: [hambi ambi] 'remedio'. El léxico está identificado y es escaso.

10. Palabras de las lenguas de sustrato que contienen /ts, zh, z/. Como ejemplos tenemos: /yucu, žadán, zipi/ <yutsu, zhadan, zipi> para 'un tipo de planta amazónica, un tipo de planta en Cañar, escamoso en la Sierra sur', respectivamente. Estas palabras deben escribirse con los signos apropiados para las lenguas de sustrato y se tienen que introducir en los textos escritos cuando los estudiantes ya manejen bien la lectura y escritura.

11. Palabras del castellano y otras lenguas de adstrato y superestrato. Estas palabras se deben escribir tal como se usan en las lenguas de origen.

\section{Socialización de las diferencias dialectales}

En las capacitaciones a los docentes se tiene que ilustrar de manera sistemática las diferencias dialectales que se encuentran en las seis zonas establecidas para el Ecuador. La difusión debe alcanzar también a los centros que espontáneamente se han creado en varias ciudades para enseñar quichua. Esto puede ser apoyado por las radios comunitarias que se han instalado últimamente. Esto permitirá la formación de hablantes polidialectales. 


\section{8}

Introducción progresiva y sistemática de expresiones que contengan variantes morfofonémicas y lexicales que no sean comunes a todas las zonas dialectales en los materiales educativos

En la etapa de alfabetización, los estudiantes deben sentir que los textos que usan son cercanos al habla cotidiana de ellos. Por ejemplo, para enseñar las vocales, tenemos las palabras $<$ mama, sisa, uma $>$ 'mamá, flor, cabeza' que son apropiadas pues se las puede dibujar y en todas las zonas dialectales se las pronuncia de la misma manera y tienen el mismo significado. Para enseñar las consonantes se pueden emplear palabras como: <papa, tuta, puma, kuri, wawa, sisa, lumu, yaya, nina, shunku, rumi, llama, ñuñu, churu, hampi> 'papa, noche, puma, oro, niño, flor, yuca, papá, fuego, corazón, piedra, llama (el animal), espiral, remedio'. Estas palabras, excepto <llama $>$, todas son pronunciadas de igual manera y reconocidas en todas las zonas dialectales. En el caso de $<$ llama $>$ hay dos formas de pronunciar: [ $\lambda$ ama $\sim$ žama], debido a las variantes del fonema $/ \lambda /[\lambda \sim \check{z}]$, pero igual cosa ocurre en castellano, por lo cual no presenta dificultad para unificar por escrito estas diferencias orales.

Luego ya se pueden construir oraciones sencillas, que tengan algunas mínimas variaciones dialectales como $<$ Mamaka mikunata yanunmi> 'Mamá cocina la comida', que es comprensible en todas las zonas dialectales sin mayor dificultad. Las imágenes en los textos son un buen complemento para hacer que las expresiones sean cercanas a los niños.

\section{Elaboración de un diccionario etimológico} y pluridialectal quichua-quichua

Este trabajo será importante para que los educadores y quizá toda la población quichua-hablante tenga una información polidialectal a nivel oral, para conservar la diversidad dialectal. La propuesta es que 


\section{9}

cada entrada lexical de este diccionario etimológico y polidialectal contenga la siguiente información:

- El término con escritura estandarizada.

- Las variantes de pronunciación indicando la zona dialectal o la comunidad donde se pronuncia.

- La etimología.

- Los posibles sinónimos.

- La descripción en quichua.

- Un ejemplo que ilustre su empleo contextualizado.

- Los sinónimos, en caso de existir.

- Glosa en castellano.

En el caso de plantas, animales y algunos otros términos que lo requieran, debería incluirse una imagen ilustrativa. En este diccionario también tienen que constar los sufijos y sus variantes morfofonémicas. ${ }^{179}$

Creación cuidadosa e introducción progresiva de neologismos

Se propone su introducción planificada desde el primer nivel. La creación de neologismos se debe hacer a partir de los morfemas derivadores antes que de frases o circunlocuciones. Por ejemplo: a partir del verbo <chiriyachiy > 'enfriar', añadiendo el morfema derivador instrumental $\{-n a\}$, se puede obtener < chiriyachina $>$ para 'refrigeradora'. Sin embargo, por el momento no se descarta la introducción de préstamos de otras lenguas.

179 La necesidad de elaborar un diccionario etimológico surgió del Rodolfo CerrónPalomino en conversación personal (2015). Esta obra emplearía un modelo más completo que el diseñado por el autor para el diccionario Caimi Ñucanchic Shimiyuc-Panca (Haboud et al., 1982), pues se incluiría la información etimológica. Para la etimología se podría tomar como referencia los trabajos de Parker y de Cerrón-Palomino. Un equipo de especialistas de los países andinos podría realizar esta obra. 


\section{0}

Realización de eventos lingüísticos

Es necesario realizar eventos para discutir los problemas pendientes y diseñar estrategias para consolidar la estandarización de la escritura.

\section{Estrategia para la recuperación del quichua}

El descenso de la población quichua hablante en las últimas décadas ha sido drástico. Esto pone a la lengua en situación de vulnerabilidad. Según el censo de 2010, la población que se identifica como quichua bordea los 776077 individuos. Esto equivale a un 5,5\% del total de 14 millones de habitantes del país, en tanto que hace veinte años la población de habla quichua llegaba a los dos millones de personas.

Desde el año 2014, algunos estudiantes de la UPS han venido realizado, como requisito para su graduación, estudios sobre la realidad vital del quichua en la zona de Cayambe (prov. de Pichincha), donde hace apenas cincuenta años el quichua parecía vigoroso y fue el escenario de lucha de la líder Dolores Cacuango. Actualmente, el quichua casi ha desaparecido en toda esa extensa zona. Solo los ancianos lo hablan, los jóvenes y los niños ya no. Algo similar ocurre en otras zonas como Saraguro (prov. de Loja) ( $c f$. King, 2001). En varias de estas comunidades existe el interés por recuperar la lengua y ante esta situación es necesaria la reintroducción del quichua mediante un método por inmersión. Este método ya se ha comenzado a elaborar.

\section{Propuesta de inclusión de reglas ortográficas para la implementación del alfabeto quichua ya establecido en 1998 y ratificado en 2004}

Con los antecedentes expuestos y luego del estudio de las variaciones dialectales, la discusión del paso de lo oral a lo escrito, y las experiencias de la escrituración del quichua que han sido expuestas en los capítulos anteriores, se plantea la necesidad de establecer un conjunto 
de reglas ortográficas para la unificación escrita de la lengua. Un alfabeto por sí solo no es garantía de unificación de la escritura, pues con el mismo alfabeto se puede escribir de muchas maneras.

El principal criterio que se elige para decidir sobre las variantes fonológicas y gramaticales de la lengua, en función de su unificación, es el etimológico, es decir, aquel que se basa en el conocimiento histórico de la evolución de la lengua. Esto significa que las variantes más antiguas permiten unificar la escritura de la lengua, en tanto que las innovaciones lingüísticas responsables de la fragmentación dialectal apuntan a la dispersión antes que a la estandarización. Con estos antecedentes, a la luz del criterio etimológico mencionado, sin desatender la presencia de lenguas de sustrato prequichua, se proponen las siguientes reglas para la unificación de la escritura de la lengua: ${ }^{180}$

1. Las variantes del fonema vocálico /a/ que se realizan como [a i] $[\mathrm{a} \sim \mathrm{u}$ ] se escriben con $<\mathrm{a}>$. Ejemplo: las variantes de /pitak/ [pitak pitik], de /ñukanchik/ [ñukanchik ñukunchik], se escriben: <pitak> '¿quién?', <ñukunchik> 'nosotros'.

2. Las variantes de los fonemas /p, t, k/ [p b], [t $\sim \mathrm{d} \sim \mathrm{r}],[\mathrm{k} \sim \mathrm{g}]$ se escriben con $<\mathrm{p}, \mathrm{t}, \mathrm{k}>$. Ejemplo: /kanpak/ [kanpak $\sim$ kanbak] se escribe <kanpak> 'tuyo'; [inti indi] se escribe <inti > 'sol', [shinallatak, shinalladak, shinallarak] se escribe <shinallatak> 'así mismo'; [kankuna $\sim$ kanguna] se escribe $<$ kankuna $>$ 'ustedes'.

3. Las variantes de $/ \mathrm{k} /[\mathrm{k} \sim \mathrm{h} \sim \emptyset]$, se escriben con $<\mathrm{k}>$. Ejemplo: [purikuni $\sim$ purihuni $\sim$ puriuni] se escribe <purikuni $>$ 'estoy caminando': [kipa $\sim$ hipa] se escribe $<$ kipa $>$ 'después'.

180 En estas reglas ortográficas para facilitar la comprensión de los signos a la mayor parte de lectores, se establece el siguiente correlato ortográfico usado en estas reglas con los símbolos del AFI: $<\mathrm{ll}\rangle=|\lambda /,<\mathrm{sh}\rangle=|\check{\mathrm{s}} /\langle\mathrm{ch}\rangle=| \check{\mathrm{c}} /,\langle\mathrm{zh}\rangle=\mid \check{\mathrm{z}} /,\langle\mathrm{ts}\rangle$ $=/ \mathbb{\$} /$. Igualmente, en el presente caso los símbolos del alfabeto ortográfico se usan para representar las variantes fonéticas dialectales de sus respectivos fonemas. 


\section{2}

4. Las variantes de $/ 1 \mathrm{l} /[1 \sim \mathrm{ll} \sim \mathrm{sh} \sim \mathrm{ch} \sim \mathrm{zh}]$ se escriben con $<\mathrm{ll}>$. Ejemplo: [alpa $\sim$ allpa $\sim$ ashpa $\sim$ achpa $\sim$ azhpa] se escribe $<$ allpa $>$ 'tierra'; [milma $\sim$ millma $\sim$ mishma $\sim$ mizhma] se escribe $<$ millma> 'lana, vello'.

5. Las variantes de /ch/ [ch $\sim \mathrm{zh}]$ se escriben $\operatorname{con}<\mathrm{ch}>$. Ejemplo: / kanchu/ [kanchu kanzhu] '¿tú?', se escribe 'kanchu' ‘tú?'.

6. Las variantes de $/ \mathrm{h} /$, en posición inicial de palabra $[\mathrm{h} \sim \emptyset]$ se escribe con h>. Ejemplo: [hambi $\sim$ ambi] se escribe <hampi> 'remedio, medicina'.

7. Las variantes de /ch/ [ch $\sim$ ts $\sim$ s] se escriben $\operatorname{con}<\mathrm{ch}>$. Ejemplo: [chawar $\sim$ tsawar $\sim$ sawar] se escribe $<$ chawar $>$ 'penco'.

8. Las variants de /sh/ [sh $\sim \mathrm{s}]$ se escriben con $<\mathrm{sh}>$. Ejemplo: [mashkana $\sim$ maskana] 'investigar', se escribe $<$ mashkana $>$.

9. Las variantes de /p/ [p $\sim \mathrm{f}]$ se escriben con $<\mathrm{p}>$. Ejemplo: [pichana $\sim$ fichana] se escribe $<$ pichana $>$ 'escoba'.

10. Las variantes de $/ \mathrm{y} /[\mathrm{y} \sim \tilde{\mathrm{n}}]$ se escribe con $<\mathrm{y}>$. Ejemplo: [manña $\sim$ manya $\sim$ mayan] se escribe manya 'orilla'.

11. Las palabras que tengan aspiradas /ph, th, chh, kh/ podrán escribirse con las grafías $<\mathrm{ph}$, th, chh, $\mathrm{kh}>$, pero también podrán escribirse con sus correlatos $<\mathrm{p}, \mathrm{t}, \mathrm{ch}, \mathrm{k}>$. Ejemplo: $<$ phukuna $>$ 'soplar' (pronunciado con aspiración en la Sierra centro) o también <pukuna $>$. Este punto debe ser analizado cuidadosamente, pues para estandarizar la escritura a nivel del Ecuador, bastaría emplear $<\mathrm{p}, \mathrm{t}, \mathrm{ch}, \mathrm{k}\rangle$, sin embargo, si a futuro se pretende estandarizar con hablas de otros lugares como Cuzco o Bolivia, sería más conveniente usar los símbolos específicos de las correspondientes aspiradas que han subsistido en el habla de la Sierra centro.

12. En los casos de la presencia de expresiones donde existen fenómenos lingüísticos de reducción y ensamblaje, se escribe las formas originales. Ejemplo de reducción: [haku mikungu] usado en Salasaca-Tungurahua, /haku mikunkapak/ <haku mikunkapak $>$. Ejemplo de reducción y ensamblaje: [allimani] usado en el río 


\section{3}

Bobonaza (prov. de Pastaza) y también en Salcedo y Salasaca (Sierra centro), /allimi kani/ se escribirá < allimi kani> 'estoy bien'. 13. Las palabras provenientes de lenguas diferentes al quichua se las escribirá de la misma manera que se lo hace en su lengua de origen. Esto es válido también para los términos provenientes de las lenguas de sustrato prequichua. Esto implica que para estos términos se puede usar las grafías $<e, o, t s, z h, z, b, d, g, f>$.

14. No es necesario usar signos de interrogación, pues en quichua esto se lo hace con morfemas: $\{$-chu, -tak\}. Ejemplo: $<$ Munankichu $>$ ‘Quieres?', < Pitak shamurka> ‘Quién vino?'. 



\section{Conclusiones}

A continuación, formulamos las conclusiones por capítulos y en función del objetivo lingüístico y el sociolingüístico.

\section{Capítulo 1}

La alta presencia de topónimos de lenguas de sustrato en la Sierra ecuatoriana es un argumento a tenerse en cuenta en las investigaciones sobre el origen y presencia del quichua en el Ecuador. Los nombres prequichuas de los lugares, en gran parte, parecen ser compuestos de dos morfemas libres antes que de un morfema libre y un sufijo ligado. Se requiere continuar con las investigaciones sobre los sustratos prequichuas, tanto a nivel filológico como archivístico y bibliográfico. La investigación en los archivos permitirá recuperar las formas más antiguas. Los resultados contribuirán a determinar la forma de escritura de los términos pertenecientes a ellas, por lo cual es necesario:

- Realizar un inventario nacional de los topónimos, antropónimos, fitónimos y zoónimos prehispánicos. En el caso de los topónimos se debe constatar in situ si ellos son ríos, lomas, laderas, quebradas, lagunas, valles, mesetas, etc.

- Averiguar sobre la pronunciación. En los casos en que el nombre responde a varios elementos al mismo tiempo, es necesario buscar cuál de ellos es el más antiguo. Así por ejemplo, en la lengua panzaleo, el término <Laipo $>$ es al mismo tiempo una quebrada y el nombre de la localidad que está junto a ella en las estribaciones de la Cordillera oriental. ¿Cuál es el más antiguo? Además 


\section{6}

$<$ po $>$ es espino en lengua tsa'fiki. ¿Existe alguna relación con el topónimo?

- Identificar los términos de filiación quichua y aimara para diferenciar los términos de las lenguas preincaicas. A partir de esta nómina y con apoyo de la etnohistoria, la arqueología y otras ciencias, se podrá lingüísticamente establecer los términos de las lenguas ecuatorianas de sustrato. La presencia de topónimos de filiación aimara como: <Huanacauri, Guamaní, Collas, Cuzcun, Cuzhcun, Quinde>, así como también los antropónimos, al parecer, aimaras: <Pilatuña, Quisintuña, Pastuña $>$ en la Sierra ecuatoriana, se explicaría por la política incaica de los mitimaes. A esto posiblemente se sumó la presencia de personal aimara en los ejércitos incas, así como a la movilidad durante la época colonial. Hay que considerar que incluso podría haber elementos de la lengua puquina en algunos topónimos combinados con $<$ cachi> 'fortaleza' y no necesariamente serían del quichua 'sal', como podría pensarse inicialmente.

- Identificar términos híbridos en los que se conoce el significado de una parte del término, por ejemplo, $<$ mollebuela $>$ en territorio de la antigua lengua cara, donde $<$ molle $>$ viene del quichua $<$ mulli $>$ 'una planta' y $<$ buela $>$ en lengua cara, al parecer, tendría el significado de $<$ pampa $>$ en quichua 'planicie'. En territorio de la lengua panzaleo, existe el híbrido $<$ mulliquindil $>$. Actualmente es el nombre de un lugar en Salcedo (prov. de Cotopaxi). En este caso $<$ mulli $>$ provendría del quichua y <quindil $>$ podría ser el equivalente de $<$ pampa $>$. Efectivamente en Salasaca existe el compuesto $<$ mollepamba $>$.

- En la investigación de los sustratos es importante considerar el criterio de que el léxico cultural es más vulnerable que el social. El cultural, en este caso, corresponde al lenguaje relacionado con el poder, lo ritual, la cosmovisión, las ciencias, las artes, etc., en tanto que el social está relacionado con los aspectos de la vida cotidiana. Esto implica un gran desafío para la sostenibilidad de 


\section{7}

la EIB, pues se tiene que contar con investigaciones serias sobre el léxico cultural y no solo el social.

- Los nombres provenientes de las lenguas de sustrato no deben escribirse bajo los criterios de estandarización del quichua, sino que deben mantenerse como lo eran en sus lenguas originales.

\section{Capítulo 2}

Sobre el origen del quichua ecuatoriano, la hipótesis de que sea autóctono, no tiene sustento histórico. Las hipótesis que señalan que el quichua en el Ecuador es preincaico o que su presencia se debe a los incas, requieren de más estudios de archivo y de etnohistoria para determinar la influencia de las relaciones comerciales y la presencia de mitimaes en la expansión del quichua.

\section{Capítulo 3}

El quichua ecuatoriano tiene muchos aspectos en común con la variedad descrita por Domingo de Santo Tomás en 1560, entre ellos, como lo ha señalado (Cerrón-Palomino, 1995), tenemos:

- Sonorización de las oclusivas sordas después de nasal.

- La tendencia a la lenición de las oclusivas en posición implosiva.

- Registro de una sola africada, la palatal.

- La ausencia de laringalizadas, exceptuando una mínima presencia en la zona de la Sierra centro del Ecuador, que tiene poca correspondencia con sus correlatos del Cuzco.

Por otra parte, se concluye que el ecuatoriano, tiene algo de koiné como lo señalado por Muysken (1981). Una evidencia de ello sería la reducción experimentada en la morfología si se compara con el protoquechua y las variantes del quechua de la rama central peruana. Además, en cada localidad fue evolucionando y llegó a tener desarrollos propios en la morfología. El léxico se enriqueció con términos prequichuas. 


\section{8}

\section{Capítulo 4}

Se constata que son pocos los estudios que expresamente tienen relación con el tema de la variación dialectal. Entre ellos se pueden mencionar a Ross, Stark y Carpenter. Existen otros que, aunque no tuvieron la prioridad de un estudio dialectal, de todas maneras proporcionan alguna información al respecto. Sin embargo, no se llegó a establecer una zonificación dialectal con criterios de lingüística interna, como es el caso de las "innovaciones compartidas".

\section{Capítulo 5}

Se constata que en Ecuador existe una gran diversidad dialectal. La presencia de numerosos grupos de mitimaes parece haber sido una de las causas de la fragmentación dialectal del quichua ecuatoriano. Otra causa sería los propios procesos de la evolución en cada localidad debido al poco contacto que tuvieron las comunidades quichuas durante la Colonia y en los primeros tiempos de la República. La incidencia de estos fenómenos ha sido fundamentalmente a nivel de la fonética y del léxico, pero no tanto en el sintáctico; por lo cual, con un poco de atención y contacto, en pocos días es posible lograr un buen nivel de comprensión mutua a nivel oral entre hablantes de las diferentes zonas dialectales del Ecuador. Sin embargo, en algunos casos esta comprensión es asimétrica. Las personas que registran las formas más conservadoras se hacen entender con mayor facilidad por parte de las personas que hablan formas más innovadoras, pero lo contrario es más difícil; por ejemplo, una persona de Cañar (Sierra sur) puede hacerse entender fácilmente por una persona de Salasaca (Sierra centro), pero no a la inversa. En consecuencia, el conocimiento de las características de las zonas dialectales facilitará el proceso de estandarización de la escritura del quichua.

Si se toma como punto de referencia el protoquechua, el grado de innovación de mayor a menor sería el siguiente: Sierra centro, Amazonía sur, Amazonía centro, Amazonía norte, Sierra norte y Sierra sur. 
$\mathrm{Al}$ interior de la Sierra centro, el habla de Salasaca es la más innovadora debido a la presencia simultánea de los fenómenos de cambio vocálico, reducción-ensamblaje y sonorización casi total de las oclusivas sordas.

\section{Capítulo 6}

Las políticas lingüísticas aplicadas por el Estado desde la Colonia han sido, en general, negativas, y en particular, podemos concluir que:

- En la Colonia el uso del quichua estuvo al servicio de la dominación. No se pensó en términos de valorar la lengua y la cultura. Detrás del uso del quichua en la evangelización de la población indígena por doscientos años, estuvo latente la política de castellanizarla, por parte de los reyes de España y de sus ministros religiosos o eclesiásticos, aunque el III Concilio Limense establecía el uso de las lenguas generales para la tarea misional.

- La política de usar el quichua en la evangelización hizo que esta lengua se consolide y que muchas lenguas prequichuas desaparezcan para siempre. Aunque esto ayudó a la preservación del quichua, pues caso contrario se hubiera producido una castellanización total y tampoco se tendría esta lengua indígena.

- La política de la Corona española de la segunda mitad del siglo XVIII de castellanizar a la población indígena, fue asumida por los Estados criollos que se conformaron luego de la Independencia. Esto ha generado la diglosia que persiste hasta el día de hoy.

- En el siglo XXI, el Gobierno de la llamada "revolución ciudadana" ha enredado y confundido el valor de las lenguas indígenas con fines de consolidar su poder, pues no hubo acciones concretas para promover su avance. Más grave aún es el discurso retórico de la Constitución de 2008, donde se encuentra una sutil usurpación simbólica del discurso de las comunidades indígenas sobre su lengua y cultura, como puede deducirse del art. 2. Hasta el momento, la disposición de la LOEI de que se enseñe el quichua en todos los colegios del país solo está en el papel, no se ha tomado ninguna 
medida para implementarla. Los centros educativos bilingües no cuentan con textos en sus lenguas, solo se les entrega textos en castellano con la normativa de aplicarlos obligatoriamente. Las evaluaciones se hacen bajo los parámetros de la educación occidental, lo cual impide que algunos educadores intenten por su cuenta hacer una educación con contenidos y metodologías adecuados a la lengua y la cultura de sus estudiantes.

- Los gobiernos denominados de "izquierda" se han caracterizado por centralizar y rectorar, tanto los aspectos científicos como los administrativos de la EIB. Esta política es perjudicial, pues los funcionarios encargados de esto no cuentan ni con el conocimiento lingüístico ni con el pedagógico.

Se debe decir que el quichua ha sobrevivido a pesar de las políticas lingüísticas coloniales y republicanas. Su vida futura dependerá de lo que hagan las mismas comunidades en el siglo XXI. Si las comunidades indígenas retoman la EIB, esta será un complemento importante en la práctica cotidiana de las familias.

\section{Capítulo 7}

En el Ecuador, la mayoría de los líderes y docentes de la población quichua-hablante es partidaria de la estandarización de la lengua a nivel escrito, sin embargo, la mayor dificultad para conseguir la consolidación de este objetivo es la presencia de la diversidad dialectal. Adicionalmente hay que considerar también la presencia de sustratos de lenguas prequichuas. Por otra parte, se requiere diseñar e implementar un plan de capacitación sostenido a los docentes sobre las variaciones dialectales y las reglas ortográficas — propuestas en este trabajo_-, para implementar el alfabeto determinado para la escritura de la lengua. Esto implica incluir un curso de lingüística general y un curso de lingüística quichua, tanto en el currículo de formación docente como en la capacitación de los que ya están en servicio. Al momento, la mayoría de los docentes no está manejando apropiadamente la estandarización, como 
se ha podido comprobar en las pruebas escritas de suficiencia en el conocimiento del idioma, que realizan para ingresar al magisterio y para la recategorización.

La consolidación del proceso de estandarización de la escritura dependerá de las estrategias que se implementen en la formación de docentes y en la elaboración de materiales educativos, así como del fortalecimiento técnico y psicosocial del SEIB y su posicionamiento en la sociedad ecuatoriana.

Finalmente cabe señalar que las principales contribuciones de este estudio al proceso de estandarización de la escritura del quichua son: la sistematización, con investigación de campo y bibliográfica, de las variantes lingüísticas; la zonificación dialectal empleando el criterio de innovaciones compartidas; las reglas ortográficas propuestas a partir de la etimología, así como la propuesta de representar en la escritura los términos de sustrato. Esto último es necesario porque son elementos que contribuyen a la identidad histórica y sociocultural de los pueblos que hablan quichua el día de hoy en el Ecuador, en el contexto de la EIB generado por las nacionalidades indígenas y ojalá llegue el día de que sea también regida por ellas mismas. 



\section{Referencias bibliográficas}

Adelaar, W. (1977). Tarma Quechua, Grammar, Texts, Dictionary. Lisse: Peter de Ridder Press.

Adelaar, W. (1982a). Léxico quechua de Pacaraos. Documento de Trabajo no 45. Lima: Universidad Mayor de San Marcos.

Adelaar, W. (1982b). Características del quechua de Pacaraos. En R. CerrónPalomino (comp.), (pp. 19-34). Lima: Signo.

Adelaar, W. (julio, 2013). Quechua I y Quechua II: En defense de una distinción establecida. Revista Brasileira de Lingüística Aplicada, 5(1).

Adelaar, W. y Muysken, P. (2004). The Languages of the Andes. Cambridge University Press.

Almeida, I. (1991). Por la oficialización de la lengua kechwa en el Ecuador. Pueblos Indígenas y Educación, 18, 121-39. Quito: Abya-Yala.

Álvarez, C. (ed.). (2011). Diccionario achuar por campos semánticos. Quito: UPS.

Álvarez, C. y Montaluisa, L. (2017). Perfiles de las lenguas y saberes del Ecuador. Quito: IICSAE.

Andi, B. (2012). Desviaciones de la norma estándar del habla kichwa de las comunidades indígenas del cantón Tena. Cuenca: Universidad de Cuenca; DINEIB; UNICEF.

Anónimo. (1753). Breve instrucción o arte para entender la lengua común de los indios según se habla en la provincia de Quito. Lima: Imprenta de la Plazuela de San Chriftoval (texto atribuido al padre Nieto Polo).

Anónimo. (circa 1571). Relación de la tierra de Jaén. En M. Jiménez de la Espada, (1887/1965), Relaciones geográficas de indias Perú (vol. IV, tomo CLXXXV, pp. 143-146). Biblioteca de Autores Españoles. Madrid: Atlas.

Anónimo. (circa 1582). Relación de la doctrina e beneficio de Nambija y Yaguarsongo. En M. Jiménez de la Espada, (1881-1887/1965), Relaciones geográficas de indias Perú (vol. IV, tomo CLXXXV, pp. 139-142). Biblioteca de Autores Españoles. Madrid: Atlas. 


\section{4}

Appel, R. y Muysken, P. (1987/1998). Bilingüismo y contacto de lenguas. Barcelona: Ariel.

Asamblea Nacional Constituyente. (1944-1945). Constitución Política de la República del Ecuador. Quito: Talleres Gráficos Nacionales.

Asamblea Nacional Constituyente. (1998). Constitución Politica del Ecuador.

Asamblea Nacional del Ecuador. (12 de octubre de 2010). Ley Orgánica de Educación Superior. Registro Oficial no 298, año I. Quito: Asamblea Nacional.

Asamblea Nacional del Ecuador. (2008). Constitución de la República del Ecuador. Quito: Asamblea Nacional.

Asamblea Nacional del Ecuador. (31 de marzo de 2011). Ley Orgánica de Educación Intercultural Bilingüe. Registro Oficial no 417. Quito: Asamblea Nacional.

Ballón, E. (2009). La dentera multilingüe e intercultural en las sociedades andinas (conflictos de lengua, habla y escritura). Revista Andina, 49.

Beresford-Jones, D. y Heggarty, P. (2010). Broadening Our Horizons: Towards an Interdisciplinarry Prehistory of the Andes. Boletín de Arqueología PUCP, 14, 61-84. Lima: PUCP.

Betanzos, J. (1551/2015). Suma y narración de los incas. En F. Hernández y R. Cerrón-Palomino (eds.). Lima: PUCP.

Beukema, R. (1975). A Gramatical Sketch of Chimborazo Quichua (Tesis). Universidad de Yale.

Borchart de Moreno, Ch. (2007). El corregimiento de Otavalo: territorio, población y producción textil (1535-1808). Quito: Studio 21.

Borja, A. (circa 1591). Relación en suma de la doctrina e beneficio de Pimampiro $y$ de las cosas notables que en ella hay, de la cual es beneficiado el P. Antonio Borja. En M. Jiménez de la Espada, (1881-1887/1965), Relaciones geográficas de indias Perú (vol. III, tomo 184, pp. 248-253). Biblioteca de Autores Españoles. Madrid: Atlas.

Borja, A. (circa 1591). Relación en suma de la doctrina e beneficio de Pimampiro $y$ de las cosas notables que en ella hay, de la cual es beneficiado el padre Antonio Borja. En P. Ponce Leiva, (1992), Relaciones histórico-geográficas de la Audiencia de Quito (siglo XVI-XIX) (pp.480-488). Quito: Instituto de Historia y Antropología Andina; Abya-Yala.

Bravomalo de Espinosa, A. (2006). Ecuador ancestral. Quito: Quik Print.

Bray, T. (2003). Los efectos del imperialismo incaico en la frontera norte: una investigación arqueológica de la Sierra septentrional del Ecuador. Quito: Abya-Yala. 


\section{5}

Buchwald, O. (1919/2007). El Sebondoy vocabulario y notas. En G. Costa von Buchwald, Contribuciones para el conocimiento y estudio del colorado, quechua, aymara, totoró, páez y otras lenguas de los pueblos antiguos del Pacífico sur. Guayaquil: Impresión Polígrafa.

Burgos, H. (1995). Primeras doctrinas en la Real Audiencia de Quito 1570-1640. Quito: Abya-Yala.

Büttner, Th. (1993). Uso del quichua y el castellano en la Sierra ecuatoriana. Quito: PEBI; MEC; GTZ; Abya-Yala.

Bynon, T. (1977/1981). Lingüistica histórica. Madrid: Gredos.

Caillavet, Ch. (1983). Toponimia histórica, arqueología y formas prehispánicas de agricultura en la región de Otavalo-Ecuador. Boletín del Instituto Francés de Estudios Andinos, XII(3-4), 1-21.

Caillavet, Ch. (2000). Etnias del norte: etnohistoria e historia del Ecuador. Quito: Abya-Yala.

Calvet, L. (1974). Linguistique et colonialisme: petit traité de glottophagie. París: Petit Bibliothèque Payot.

Calvet, L. (1996/2001). Historia de la escritura: de Mesopotamia hasta nuestros días. Buenos Aires: Paidós.

Carpenter, L. (1982). Ecuadorian Quichua: Descriptive Sketch and Variation (Tesis doctoral). Universidad de Florida.

Carpenter, L. (1984). Andean Studies Occasional Papers: Aspects of Quichua Dialectology. Bloomington: Jatari Foundation; Universidad de Indiana.

Casevitz, F., Renard, T., Saignes, H. y Taylor, A. (1988/1986). Al este de los Andes (tomo II). Quito: Abya-Yala.

Černý, J. (1999). Algunas observaciones sobre el español hablado en América. Philologica 74. Olomouc, Rep. Checa: Acta Universitatis Palackianae Olomucensis Facultas Philosophica.

Cerrón-Palomino, R. (1976). Gramática quechua Junín-Huanca. Lima: Ministerio de Educación; Instituto de Estudios Peruanos.

Cerrón-Palomino, R. (1983). Multilingüismo y defensa idiomática. Documento de trabajo no 46. Lima: CILA; Universidad Nacional Mayor de San Marcos.

Cerrón-Palomino, R. (1987). Lingüística quechua. Cuzco: Centro de Estudios Rurales Andinos Bartolomé de las Casas.

Cerrón-Palomino, R. (1988). Unidad y diferenciación lingüística en el mundo andino. Pesquisas en Lingüística Andina. Puno: GTZ; Universidad Nacional del Altiplano. 


\section{6}

Cerrón-Palomino, R. (1992). El uso del alfabeto oficial. En C. Godenzzi (ed.), El quechua en debate. Cuzco: Centro de Estudios Rurales Andinos Bartolomé de las Casas.

Cerrón-Palomino, R. (1997). Reducción y ensamblaje en la formación de sufijos del quechua. Revista de Lingüística y Literatura Lexis, XXI(2).

Cerrón-Palomino, R. (2013a). Las lenguas de los incas: el puquina, el aimara y el quechua. Frankfurt y Main: Peter Lang.

Cerrón-Palomino, R. (2013b). Tras las huellas del Inca Garcilaso: el lenguaje como hermenéutica en la comprensión del pasado. Boston: Latinoamericana.

Cerrón-Palomino, R. (2015a). Toponimia andina: problemas y métodos. Revista de Lingüística y Literatura Lexis, XXXIX(1). Lima: PUCP.

Cerrón-Palomino, R. (2015b). Betanzos como quechuista. En F. Hernández y R. Cerrón-Palomino (eds.), Juan de Betanzos y el Tahuantinsuyo (pp. 29-39). Lima: PUCP.

Cerrón-Palomino, R. (2017). El quchua "Del Ynga" según testimonio de los primeros cronistas. En J. Godenzzi y C. Garatea (coords.), Historia de las literaturas del Perú (tomo 1). Lima.

Chávez, E. (2014). El alfabeto hñähñu: notas para una primera aproximación a la historia de la normalización de la escritura. En L. Lepe y N. Rebolledo (eds.), Educación bilingüe y políticas de revitalización de lenguas indígenas. Quito: Abya-Yala.

Cieza de León, P. (1553/1973). La crónica del Perú (tomo 1). Lima: Promoción Editorial Inca.

Cieza de León, P. (1996). Crónica del Perú (tomo 2). Lima: PUCP; Academia Nacional de Historia.

Cohen, M. y SAINTE, J. (1963/1971). La escritura y la psicología de los pueblos. México: Siglo XXI.

Cole, P. (1985/2010). Imbabura quechua. Australia: Croom Helm.

Cooper, R. (1989). Language Planning and Social Change. Cambridge University Press.

Cordero, L. (1892/1955). Diccionario quichua-español, español-quichua. Quito: CCE.

Cordero, O. (1923/1981). El quechua y el cañari. Cuenca: Universidad de Cuenca. Costa von Buchwald, G. (2007). Contribuciones para el conocimiento y estudio del colorado, quechua, aymara, totoró, páez y otras lenguas de los pueblos antiguos del Pacífico sur. Guayaquil: Impresión Polígrafa.

Costa von Buchwald, G. (2010). Otto von Buchwald: sabio alemán en tierras ecuatorianas y peruanas (siglos XIX-XX). s/e. 


\section{7}

Costales, A. (1956). Los chimbus. Quito: CCE.

Costales, A. y Costales, D. (2001). El legendario general indio Alejo Sáez. Quito: Abya-Yala.

Costales, A. y Costales, D. (2002). Etnografía, lingüística e historia antigua de los caras o yumbos colorados 1534-1978. Quito: Abya-Yala.

Cunduri, M. (2008). Uso de los morfemas en el habla kichwa de Columbe. Quito: DINEIB; Universidad de Cuenca; UNICEF.

Cusihuaman, A. (1976). Gramática quechua Cuzco-Collao. Lima: Ministerio de Educación; Instituto de Estudios Peruanos.

Dávalos y Figueroa, D. (1602). Primera parte de la miscelánea austral [...] en varios coloquios. Lima: Antonio de Ricardo.

De Aguilar, G. (1582/1897). Relación por mi Fray Gerónimo de Aguilar de la Orden de Nuestra Señora de la Merced Redention de Cautivos de la Doctrina y Pueblo de Caguasqui y Quilca [...]. En M. Jiménez de la Espada, (1897/1965), (pp. 245-247). Biblioteca de Autores Españoles. Madrid: Atlas.

De la Peña, A. (1668, 1771/1984). Itinerario para párrocos de indios. Guayaquil: José Reig Satorres.

De los Ángeles, fray D. (circa 1582/1965). San Francisco de Pacha y San Bartolomé de arocxapa. En M. Jiménez de la Espada, (1897/1965), (p. 271). Biblioteca de Autores Españoles. Madrid: Atlas.

De Torres, G. (s/f). Memorial de lo que los dichos Padre fray Gaspar de Torres y don Alonso Gualapianguo, cacique y gobernador an hecho. En J. Monroy, El convento máximo de la Merced de Quito de 1534 a 1617. Quito: Labor.

Dedenbach-Salazar, S. (1993). Una gramática colonial del quichua del Ecuador: arte de la lengua general del Cusco llamada quichua. Bonn: Bonner Amerikanische Studien.

Defares, J. (1982). "Enkele problemen rond de lexicale besschrijving van het Sranan (Some problems concerning the lexical description of Sranan). Oso, 1(1), 47-52.

Deler, J. P. (1981). Genese de l'espace équatorien: essai dur le territoire et la formation de l'etat national. Paris: Institut Français de Études Andines.

Deler, J. P. (2008). Ecuador: del espacio al Estado nacional. Quito: UASB; IFEA; Corporación Editora Nacional.

Deler, J. P., Gómez, N. y Portais, M. (1983). El manejo del espacio en el Ecuador (tomo 1, geografía histórica). Quito: Abya-Yala. 


\section{8}

DINEIB-Ministerio de Educación. (1993/2013). Modelo del Sistema de Educación Intercultural Bilingüe. Quito: DINEIB.

Durston, A. (2007). Pastoral quechua: The history of Christian tranlation in colonial Peru (1550-1650). Indiana: Notre Dame University Press.

Elkartea, G. (2010). La estandarización de la lengua: la recuperación del euskara II. Gipuzkoa: Gertu.

Elson, B. (ed.). (1962). Ecuadorian Indian languages: I. México DF: ILV.

Espinosa, J. y Jácome, G. (1988). Las toponimias de Cajas y Girón. Cuenca: PUCE-Cuenca.

Espinoza, W. (1988). Etnohistoria ecuatoriana. Quito: Abya-Yala.

Estenssoro, J. (2003). Del paganismo a la santidad: la incorporación de los indios del Perú al catolicismo 1532-1750. Lima: IFEA.

Figueredo, J. (1619/1991). Arte de la lengua quichua. Quito: Proyecto EBI; GTZ.

Fishman, J. (1967). Bilingualism with and without Diglossia; Diglossia with and without Bilingualism. Journal of Social Issues, XXIII(2), 29-39.

Francis, N. (1997). Malintzin: bilingüismo y alfabetización e la Sierra de Tlaxcala-México (tomo 1.) Quito: Abya-Yala.

Gallegos, fray G. (circa 1582/1965). Sant Francisco de Pueleusi de Azogue. En M. Jiménez de la Espada, (1897/1965), (p. 274). Biblioteca de Autores Españoles. Madrid: Atlas.

Garcés, F. (1997). Sufijos nominales de persona en el quichua ecuatoriano. Revista de Lingüística y Literatura Lexis, XXXIX(1), 85-106. Lima: PUCP.

Garcés, F. (1999). Cuatro textos coloniales del quichua de la provincia de Quito. Quito: PEBI.

Garcés, F. (2004). De la voz al papel: la escritura quechua del periódico Conosur Nawpaqman. Cochabamba, Bolivia: Centro de Comunicación y Desarrollo Andino.

Garcés, F. (2017). Escrituras andinas de ayer y hoy. Cochabamba: INIAM; UMSS. García, C. y Placencia, M. (2011). Estudios de variación pragmática en español. Buenos Aires: Dunken.

García, J. (2013). Toponimias de la provincia de Loja. Loja: Graficplus.

Godenzzi, J. (comp.) (1992). El quechua en debate: ideología, normalización y enseñanza. Cuzco: Centro de Estudios Rurales Andinos Bartolomé de las Casas.

González Holguín, D. (1608/1993). Vocabulario de lengua quichua (tomos 1 y 2). Quito: Corporación Editora Nacional; Proyecto de Educación Bilingüe Intercultural. 
González Saá, H. (1938). Relación de Hernán González Saá, exponiendo sus trabajos en la conversión de los indios. Quito: Labor.

González Suárez, F. (1891/2007). Historia general de la república del Ecuador. Guayaquil: Publicaciones Educativas Ariel.

González, M. (2011). Movimiento indígena y educación intercultural en el Ecuador. México: UNAM; CLACSO.

González, M. (ed.). (1987). Diccionario y gramática del chibcha. Bogotá: Instituto Caro y Cuervo.

Goody, J. (1987). The Interface of Written and Oral. En N. Francis, Malintzin: bilingüismo y alfabetización en la Sierra de Tlaxcala-México (tomo 1, p. 53). Quito: Abya-Yala.

Grijalva, C. (1923/1988). Cuestiones previas al estudio filológico-etnográfico de las provincias de Imbabura y Carchi. Quito: BCE.

Grijalva, C. (enero-abril, 1921). Nombres y pueblos de la antigua provincia de Imbabura. Academia Nacional de Historia, II(3-4), 33-70.

Grimm, J. (1896). La lengua quichua: dialecto de la república del Ecuador. Friburgo: Frisgovia.

Guerrero, A. (2014). La escrituración del chichimeca jonaz. En L. Lepe y N. Rebolledo (eds.), Educación bilingüe y políticas de revitalización de lenguas indígenas. Quito: Abya-Yala.

Guzmán, M. (1920/1989). Gramática de la lengua quichua: dialecto de la república del Ecuador. Quito: Proyecto de Educación Bilingüe Intercultural; Convenio MEC-GTZ.

Haboud, M. (1998). Quichua y castellano en los Andes ecuatorianos: los efectos de un contacto prolongado. Quito: Abya-Yala.

Haboud, M., Montaluisa, L. Muenala, F. y Viteri, F. (1982). Caimi Nucanchic Shimiyuc-Panca. Quito: PUCE; MEC.

Hartmann, R. (1977) Apuntes históricos sobre la cátedra del quechua en Quito: siglos XVI-XVII. Boletín de la Academia Nacional de Historia, LIX, 127-128. Quito.

Hartmann, R. (1979). ¿"Quechuismo Preincaico” en el Ecuador? Ibero-Amerikanisches Archiv, 5(3), 267-299. Berlín.

Hartmann, R. (1997). Fuentes quechuas de la época colonial con referencia al Ecuador. Anuario de Historia de América (jbLA), 34, 53-72.

Hartmann, R. (julio-diciembre, 1975). Aportes de estudiosos alemanes al conocimiento del quechua. Boletín de la Academia Nacional de Historia, LVII(124), 301-316. Quito. 
Hartmann, R. (octubre-diciembre, 1994). El papel de los mitimaes en el proceso de quechuización: el caso del Ecuador y la problemática de las fuentes. América Indígena, 54(4), 61-98. México DF: Instituto Indigenista Interamericano.

Hartmann, R. y Oberem, U. (1987). Textos quichuas del Oriente ecuatoriano. Boletín de los Museos del Banco Central del Ecuador, 7. Guayaquil.

Heggarty, P. (2005). Enigmas en el origen de las lenguas andinas: aplicando nuevas técnicas a las incógnitas por resolver. Revista Andina, 40, 9-80. Cuzco: Centro de Estudios Rurales Andinos Bartolomé de las Casas.

Heggarty, P. y Beresford-Jones, D. (2010). Archaeology, Language, and the Andean Past: Principle, Methods, and the New 'State of the Arte'. Boletin de Arqueología, 14, 29-60. Lima: PUCP.

Henríquez Ureña, P. (1921/1993). Observaciones sobre el español de América. En F. Moreno (ed.), La división dialectal del español de América (pp. 39-62). Universidad de Alcalá de Henares.

Hocquenghem, A. (2012). How did Quechua Reach Ecuador? En P. Heggarty y D. Beresford-Jones (eds.), Archaeology and Language in the Andes: A Cross-Disciplinary exploration of Prehistory. Oxford: British Academy by Oxford University Press.

Hornberger, N. (1994). Literacy and language planning. Language and Education, 8(1-2), 75-86.

Howard, R. (2007). Por los linderos de la lengua: ideologías lingüísticas en los Andes. Lima: PUCP; IFEA; IEP.

Howard, R. (2010). "Why do they steal our phonemes?" Inventing the survival of the Cañari language (Ecuador). En B. Carlin y S. van de Kerke (eds.), Linguistics and Archaeology in the Americas (pp. 123-146). Leiden: Brill.

Huerta, A. (1616/1993). Arte breve de la lengua quechua. Quito: Proyecto EBI; Corporación Editora Nacional.

Humboldt, W. (1972). Sobre el origen de las formas gramaticales y sobre su influencia en el desarrollo de las ideas. Barcelona: Anagrama.

Itier, C. (1992a). Lenguas, ideología y poder. En C. Godenzzi (ed.), El quechua en debate. Cuzco: Centro de Estudios Rurales Andinos Bartolomé de las Casas.

Itier, C. (1992b). "Cuzqueñistas" y "foráneos": las resistencias a la normalización de la escritura del quechua. En C. Godenzzi (ed.), El quechua en debate. Cuzco: Centro de Estudios Rurales Andinos Bartolomé de las Casas. 


\section{1}

Itier, C. (2013). Las bases geográficas de la lengua vehicular del imperio inca. Bulletin de l'Institut Francais d'Études Andines, 42(2), 237-260.

Jijón y Caamaño, J. (1940). El Ecuador interandino y occidental antes de la Conquista castellana (tomo 1). Quito: Editorial Ecuatoriana.

Jijón y Caamaño, J. (1941). El Ecuador interandino y occidental antes de la Conquista castellana (tomo 2). Quito: Editorial Ecuatoriana.

Jijón y Caamaño, J. (1952/1997). Antropología prehispánica del Ecuador. Quito: Abya-Yala.

Jiménez de la Espada, M. (1897/1965). Relaciones geográficas de las indias (3 tomos). Biblioteca de Autores Españoles. Madrid: Atlas.

Joseph, J. (1989). The Rise of Language Standards and Standard Languages. Londres: Newcastle University Library.

Jouanen, J. (1941). Historia de la Compañía de Jesús en la antigua provincia de Quito 1570-1774 (tomo 1). Quito: Editorial Ecuatoriana Plaza de San Francisco.

Junyent, M., Comellas, P., Barrieras, M., Cortés, M., Monrós, E. y Fidalgo, M. (2014). La diversidad lingüística: una invitación a reconocerla, comprenderla e incorporarla. Cuadernos para el Análisis, 41. Barcelona: Horsori.

King, K. (2001). Language Revitalización Processes and Prospects: Quichua in the Ecuadorian Andes. Clevedon: Multilingual Matters.

Kloss, Heinz. (1969). Research Possibilities on Group Bilingualism: a report. Quebec: Internacional Center for Research on Bilingualism.

Landerman, P. (1973). Vocabulario quechua de Pastaza. Yarinacocha, Perú: ILV.

Landerman, P. (1991). Quechua dialects and their classification (Tesis doctoral). Los Ángeles: Universidad de California.

León, A. (1937). Compendio de gramática quichua. Revista El Oriente Dominicano. Quito.

Lepe, L. y Rebolledo, N. (2014). Educación bilingüe y políticas de revitalización de lenguas indígenas. Quito: Abya-Yala.

Lipski, J. (1994/2009). El español de América. Madrid: Cátedra.

Lombeida-Naranjo, E. (1976). Ecuadorian Highlands Quechua Phonology (Tesis de grado). Universidad de Texas.

López de Solís, L. (1978). Constituciones sinodales de 1594. Instituto de Historia Eclesiástica Ecuatoriana. Quito: Instituto de Historia Eclesiástica Ecuatoriana.

López, L., Abraham, M. y Moya, R. (eds.). (2015). Pueblos Indígenas y Educación, 64. Quito: Abya-Yala. 


\section{2}

Lozano, A. (2018). Caranqui-Ibarra. Quito: UCE.

Luykx, A. (2013). La estandarización como un proceso global: políticas importadas, armonización y el derecho a la disciplina. En M. Haboud y N. Ostier (eds.), Voces e imágenes de las lenguas en peligro. Quito: Abya-Yala.

Mannheim, B. (1991). The Language of the Inka since the European Invasion. Austin: Unversity of Texas Press.

Mannheim, B. (1992). El renaciomiento del quechua del siglo XVIII. En C. Godenzzi (ed.), El quechua en debate. Cuzco: Centro de Estudios Rurales Andinos Bartolomé de las Casas.

Martínez, E. (1977). Etnohistoria de los pastos. Quito: Editorial Ecuador.

Melvyn, R. (1976/1993). Algunos aspectos históricos-geográficos de la dialectorlogía hispanoamericana. En F. Moreno (ed.), La división dialectal del español de América. Universidad de Alcalá de Henares.

Mercier, J. (1979). Nosotros los Napu-Runas/Napu Runapa Rimay: mitos e historia. Iquitos, Perú: CETA; Ministerio de Educación del Perú.

Mercier, J. (1983). El kichwa del Napo. En Á. Corbera (comp.), Educación y lingüística en la Amazonía peruana. Lima: Centro Amazónico de Antropología y Aplicación Práctica.

Middendorf,E.(1890).Das Runa Simioder die Kesua Sprache.Leipzig: Brockhaus.

Monroy, J. (1937/1938). El convento de la Merced de Quito de 1534-1617. Quito: Labor.

Montaluisa, L. (febrero, 1980a). El vocabulario general del quichua. Revista de la Universidad Católica, VIII(25). Quito: PUCE.

Montaluisa, L. (noviembre, 1980b). Historia de la escritura del quichua. Revista de la Universidad Católica, VIII(28). Quito: PUCE.

Montaluisa, L. (1981). Mu-Cri-Ria-Cu-Naya-Pa-Chi-Naku-Ri-Cacha Yuyaita Yapachic Shimimanta Yachai (Tesis de grado). Quito: PUCE.

Montaluisa, L. (1991). Runa Shimi: contribuciones para su estudio. Quito: CONAIE.

Montaluisa, L. (1992). Fonología del awapit: hacia la estandarización de su escritura. Pueblos Indígenas y Educación, 22. Quito: Abya-Yala.

Montaluisa, L. (2008). Trayectoria histórica de la educación intercultural bilingüe del Ecuador. En C. Vélez (ed.), Educación intercultural bilingüe y participación social. Quito: CARE; Contrato Social por la Educación.

Montaluisa, L. (2011). Diversidad cultural. En VV. AA., Estado del país: informe cero Ecuador 1950-2010. Quito. 


\section{3}

Montaner, C. (2001). Las raíces torcidas de América Latina. Barcelona: Plaza \& Janés.

Montes, J. (1987). Dialectología general e hispanoamericana: orientación teórica, metodológica y bibliográfica. Bogotá: Instituto Caro y Cuervo.

Moorhouse, A. (1965). Historia del alfabeto. México DF: FCE.

Moreno, A. (1998). Fray Jodoco Rique y Fray Pedro Gocial. Quito: Abya-Yala.

Moreno, F. (ed.). (1993). La división dialectal del español de América. Universidad de Alcalá de Henares.

Moscoso, L. (13 de noviembre de 2007). La ruta escondida. Revista Patrimonio. Moya, R. (1993). Estudio introductorio a la edición facsimilar del "Arte Breve de la Lengua Quechua” de Alonso de Huerta de 1616. Quito: Proyecto EBI; Corporación Editora Nacional.

Murúa, M. (1590/2001). Historia general del Perú. Madrid: Dastin.

Muysken, P. (1977). Syntactic Developments in the Verb of Ecuadorian Quechua. Oruro: The Peter de Ridder Press.

Muysken, P. (1981). El quechua de Perú y de Ecuador: una visión comparativa. Ámsterdam: Universidad de Ámsterdam.

Nakata, M. (2014). Disciplinar a los salvajes, violentar las disciplinas. Quito: Abya-Yala.

Naula, J. y Burns, D. (1975). Bosquejo gramatical del quichua de Chimborazo. Quito: s/e.

Núñez, J. (1999/2009). Historias de un país llamado Quito (tomo 1). Quito: Electra.

Oberem, U. (1974). Los cañaris y la Conquista española de la Sierra ecuatoriana: otro capítulo de las relaciones interétnicas en el siglo XVI. Journal de la Société des Americanistes, 63, 263-274.

Oberem, U. (enero-diciembre, 1978). El acceso a recursos naturales de las diferentes ecologías en la sierra ecuatoriana (siglo XVI). Boletín de la Academia Nacional de Historia, LVI(131-132), 191-208. Quito.

Oberem, U. (s/f). Los quijos. Instituto Otavaleño de Antropología.

Olson, D. y TORRANCE, N. (comps.) (1991/2013). Cultura escrita y oralidad. Barcelona: Gedisa.

Ong, W. (1987/2012). Oralidad y escritura. Buenos Aires: FCE.

OREALC/UNESCO. (2019). Conocimientos ancestrales y politicas educativas en América Latina: hacia un diálogo de saberes. Segundo Informe. Chile: Maval.

Orr, C. (1978). Dialectos quichuas del Ecuador. Cuadernos Etnolingüísticos, 2, Quito: ILV. 


\section{4}

Orr, C. (1991). Estudios gramaticales en Napo: quichua y huaorani. Cuadernos Etnolingüísticos, 16. Quito: ILV.

Orr, C. (1991). Vamos a aprender quichua de Pastaza. Cuadernos Etnolingüísticos, 17. Quito: ILV.

Orr, C. (1991). Vamos a aprender quichua de Tena. Cuadernos Etnolingüísticos, 18. Quito: ILV.

Orr, C. y Wrisley, B. (1965/1981). Vocabulario quichua del Oriente del Ecuador. Quito: ILV.

Ortiz, G. (2001). El quichua en el Ecuador: un ensayo histórico lingüístico. Quito: Abya-Yala.

Pablos, Hernando (1582/1965). Relaciones geográficas que enbio a mandar su magestad se hiziese desta ciudad de Cuenca y de toda su provincia. En M. Jiménez de la Espada, (1897/1965). Biblioteca de Autores Españoles. Madrid: Atlas.

Palacio, J. (1989). Los omaguas en el río Napo ecuatoriano. Napo: CICAME; Vicariato Apostólico de Aguarico.

Paladines, C. (ed.). (1996). El pensamiento pedagógico ilustrado. Quito: IMQ; Abya-Yala.

Paris, J. (1892/1913). Ecuador runacunapac rizana libro. Turnhout, Bélgica: Brepols.

Paris, J. (1892/1924). Gramática de la lengua quichua del Ecuador. Cuenca: s/e. Parker, G. (1963/2013). La clasificación genética de los dialectos quechuas. En R. Cerrón-Palomino (ed.), (2013), Trabajos de lingüística quechua. Trabajo I. Lima: PUCP.

Parker, G. (1963-1972/2013). Trabajos de lingüística histórica quechua. En R. Cerrón-Palomino (ed.). Lima: PUCP.

Parker, G. (1969). Comparative quechua phonology and grammar IV: The evolution of quechua A. Working Papers in Lingüistics, 1, 149-204. Honolulu: Departament of Lingüistics University of Hawaii.

Parker, G. (1970). Huaylas quechua phonology: a Preliminary Generative Statement Using Markedness Theory. Working Papers in Lingüistics, 2(4), 143-176. Honolulu: Departament of Lingüistics University of Hawaii. Parker, G. (1976). Gramática del ancash. Lima: Instituto de Estudios Peruanos. Paz Maldonado, fray J. (circa 1583/1965). Relación del pueblo de Sant-Andrés de Xunxi para el muy ilustre señor licenciado Francisco de Auncibay, del Consejo de su Majestad y su Oydor en la Real Audiencia de Quito. En M. Jiménez de la Espada, (1897/1965), (p. 261). Biblioteca de Autores Españoles. Madrid: Atlas. 


\section{5}

Paz y Miño, L. (enero-junio, 1937). Contribución a las lenguas indígenas del Ecuador. Boletín de la Academia Nacional de Historia, XV(42-45). Quito: Litografía e Imprenta Romero.

Paz y Miño, L. (julio-diciembre, 1940). Lenguas indígenas del Ecuador I: la lengua pasto. Boletín de la Academia Nacional de Historia, XX(56). Quito: Litografía e Imprenta Romero.

Paz y Miño, L. (enero-junio, 1941a). Lenguas indígenas del Ecuador II: la lengua kara. Boletín de la Academia Nacional de Historia, XXI(57). Quito: Litografía e Imprenta Romero.

Paz y Miño, L. (julio-diciembre, 1941b). Lenguas indígenas del Ecuador III: la kito o panzaleo. Boletín de la Academia Nacional de Historia, XXI(58). Quito: Litografía e Imprenta Romero.

Paz y Miño, L. (enero-junio, 1942). Lenguas indígenas del Ecuador: la lengua Puruguay. Boletín de la Academia Nacional de Historia, XXI(59). Quito: Litografía e Imprenta Romero.

Paz y Miño, L. (enero-junio, 1946a y b). Lenguas indígenas del Ecuador: diccionario toponímico. Boletín de la Academia Nacional de Historia, XXVI(67). Quito: Litografía e Imprenta Romero.

Paz y Miño, L. (enero-junio, 1947). Lenguas indígenas del Ecuador: diccionario toponímico (continuación). Boletín de la Academia Nacional de Historia, XXVII(69). Quito: Litografía e Imprenta Romero.

Paz y Miño, L. (enero-junio, 1948a). Lenguas indígenas del Ecuador: diccionario toponímico (continuación). Boletín de la Academia Nacional de Historia, XXVIII(71). Quito: Litografía e Imprenta Romero.

Paz y Miño, L. (julio-diciembre, 1948b). Lenguas indígenas del Ecuador: diccionario toponímico (continuación). Boletín de la Academia Nacional de Historia, XXVIII(72). Quito: Litografía e Imprenta Romero.

Paz y Miño, L. (enero-junio, 1949a). Lenguas indígenas del Ecuador: diccionario toponímico (continuación). Boletín de la Academia Nacional de Historia, XXIX(73). Quito: Litografía e Imprenta Romero.

Paz y Miño, L. (julio-diciembre, 1949b). Lenguas indígenas del Ecuador: diccionario toponímico (continuación). Boletín de la Academia Nacional de Historia, XXIX(74). Quito: Litografía e Imprenta Romero.

Paz y Miño, L. (enero-junio, 1950a). Lenguas indígenas del Ecuador: diccionario toponímico (continuación). Boletín de la Academia Nacional de Historia, $X X X(75)$. Quito: La Prensa Católica. 


\section{6}

Paz y Miño, L. (julio-diciembre, 1950b). Lenguas indígenas del Ecuador: diccionario toponímico (continuación). Boletín de la Academia Nacional de Historia, XXX(76). Quito: La Prensa Católica.

Paz y Miño, L. (julio-diciembre, 1952a). Lenguas indígenas del Ecuador: diccionario toponímico (continuación). Boletín de la Academia Nacional de Historia, XXXI(78). Quito: La Prensa Católica.

Paz y Miño, L. (enero-junio, 1952b). Lenguas indígenas del Ecuador: diccionario toponímico (continuación). Boletín de la Academia Nacional de Historia, XXXI(79). Quito: La Prensa Católica.

Paz y Miño, L. (julio-diciembre, 1952c). Lenguas indígenas del Ecuador: diccionario toponímico (continuación). Boletín de la Academia Nacional de Historia, XXXII(80). Quito: La Prensa Católica.

Paz y Miño, L. (enero-junio, 1961a). Las agrupaciones y lenguas indígenas del Ecuador, entre 1500 y 1959. Boletín de la Academia Nacional de Historia, XLIII(97). Quito: La Prensa Católica.

Paz y Miño, L. (julio-diciembre, 1961b). Lenguas indígenas del Ecuador: la lengua kañar. Boletín de la Academia Nacional de Historia, XLIII(93). Quito: La Prensa Católica.

Peirce, Ch. (1987). Collected papers: obra lógico-semiótica. Madrid: Taurus.

Pérez, A. (1960). Quitus y caras. Quito: Instituto Ecuatoriano de Antropología y Geografía Llacta.

Pérez, A. (1962). Los seudo-pantsaleos. Quito: Instituto Ecuatoriano de Antropología y Geografía Llacta.

Pérez, A. (1978). Los cañaris. Quito: CCE.

Pérez, A. (1979). Los puruhuayes. Quito: CCE.

Pérez, A. (1980a). El idioma cuayker. Quito: CCE.

Pérez, A. (1980b). Los paltas. Quito: CCE.

Pérez, A. (1982). Los chimbus. Quito: CCE.

Ponce, P. (1992). Relaciones histórico-geográficas de la Audiencia de Quito (siglo XVI-XIX). Quito: Marka; Abya-Yala.

Porras Barrenechea, R. (1999). Indagaciones peruanas: el legado del quechua. Lima: Universidad Mayor de San Marcos.

Porras, P. (1980). Arqueología del Ecuador. Quito y Otavalo: Gallo Capitán.

Pottier, B. (1983). América Latina en sus lenguas indígenas. Caracas: UNESCO.

Pozzi-Escot, I. (1998). El multilingüismo en el Perú. Cuzco: Centro de Estudios Rurales Andinos Bartolomé de las Casas.

PUCE. (1980). Documentos. Revista de la Universidad Católica, 25. Quito. 
Quesada, F. (1976). Gramática quechua Cajamarca-Cañaris. Lima: Ministerio de Educación; Instituto de Estudios Peruanos.

Reino, P. (1988). Los panzaleos: una visión histórico-lingüística. Ediciones Universidad y Sociedad.

Rivet, P. y Créqui-Montefort, G. (1951). Bibliographie des Langues Aymará et Kičua (4 tomos). París: Institut D’ethnologie.

Rodas, R. (1989/1998). Dolores Cacuango Mama Wiñay Kausay Yuyashkami: kichwa wawakunapak churashka yachanawasikuna Cayambemanta ayllu llaktapi, castellano shimipi, kichwa shimipi imashina yachachishkamanta willachiy. 'Crónica de un sueño: las escuelas indígenas de Dolores Cacuango, Una experiencia de educación bilingüe en Cayam$b e$ '. Edición bilingüe. Quito: Ministerio de Educación; DINEIB; GTZ; Proyecto de Educación Bilingüe Intercultural.

Rodas, R. (1998). Dolores Cacuango. Quito: GTZ; Proyecto de Educación Intercultural Bilingüe.

Rodas, R. (2007). Dolores Cacuango, pionera en la lucha por los derechos indígenas. Quito: Crear Gráfica.

Rodríguez, A. (1892/1965). Relación hecho por el Muy Reverendo padre Fray Andrés Rodríguez de la Orden de Nuestra Señora Santa maría de las Mercedes, Redención de Captivos, de lo que en este Pueblo de Lita Hay. En M. Jiménez de la Espada, (1897/1965). Biblioteca de Autores Españoles. Madrid: Atlas.

Rodríguez, M. (2018). Educación intercultural bilingüe, interculturalidad y plurinacionalidad en el Ecuador: luchas y experiencias del movimiento indígena: desde Dolores Cacuango hasta la Revolución Ciudadana (tomo 1). Quito: Abya-Yala.

Rona, P. (1964/1993). El problema de la división de español americano en zonas dialectales: presente y futuro de la lengua española. Madrid: Ofines.

Rostworowski, M. (1970). Mercaderes del Valle de Chincha en la época prehispánica: un documento y unos comentarios. Madrid: Revista Española de Antropología Americana, vol. 5.

Rousseau, J. (1781/1984). Ensayo sobre el origen de las lenguas. Buenos Aires: FCE.

Rubio, A. (1954). Legislación indigenista del Ecuador. México: Instituto Indigenista Interamericano.

Salazar de Villasante. (circa 1562-1572). Relación general de las poblaciones españolas del Perú hecha por el licenciado Salazar de Villasante. En M. Jiménez de la Espada, (1881/1965), Relaciones geográficas de indias 


\section{8}

Perú (vol. CLXXXIII, pp. 121-143). Biblioteca de Autores Españoles. Madrid: Atlas. [La primera parte de este documento también se encuentra en Ponce, 1992].

Salinas, J. (circa 1573). Relación y descripción de la ciudad de Loxa. En M. Jiménez de la Espada, (1881-1887/1965), Relaciones geográficas de indias Perú (vol. III, tomo, 184, pp. 301-302). Biblioteca de Autores Españoles. Madrid: Atlas.

Salomon, F. (1980/2011). Los señoríos étnicos de Quito en la época de los incas. Quito: Biblioteca Básica de Quito.

Salomon, F. (1983). El quichua de los Andes ecuatoriales: algunos aportes reciente. Revista Andina, 2, 393-405. Cuzco.

Salomon, F. (1997). Los yumbos, niguas y tsatchila o "colorados" durante la Colonia. Quito: Abya-Yala.

Santo Tomás, D. (1560/1995). Grammatica o arte de la lengua general de los indios de los reynos del Peru. Cuzco: Centro de Estudios Rurales Andinos Bartolomé de las Casas.

Saussure, F. (1915/1978). Curso de lingüística general. Buenos Aires: Losada.

Schieffelin, B. (2012). El criollo haitiano "real": ideología, metalingüística y opción ortográfica. En K. Woolard y P. Kroskrit (eds.), Ideologías lingüísticas: práctica y teoría. Madrid: Catarata.

Sebba, M. (2007). Spelling and Society. Nueva York: Cambridge University Press. Sommerstein, A. (1977). Fonología moderna. Madrid: Cátedra.

Spolsky, B. (2004). Language Policy: Key topics in sociolingüístics. Cambridge University Press.

Stark, L. (1985). Ecuadorian Highland Quechua: History and Current Status. En H. Manelis y L. Stark (eds.), South american indian laguages, Retrospects and Prospects (pp. 443-480). Austin: University of Texas Press.

Stark, L. y Carpenter, L. (1973). El quichua de Imbabura: una gramática pedagógica. Otavalo: Instituto Interamericano de Desarrollo.

Stark, L. y Muysken, P. (1977). Diccionario español-quichua quichua-español. Quito: BCE.

Tanck de Estrada, D. (abril-junio, 1989). Castellanización, política y escuelas de indios en el arzobispado de México a mediados del siglo XVIII. Historia Mexicana, 38(4), 701-741.

Tandioy, F., Levinshon, S. y Maflla, A. (1978). Apuntes sobre gramática inga. Villavicencio, Colombia: ILV.

Taylor, A. (1988). Las vertientes orientales de los andes septentrionales: de los bracamoros a los Quijos. En Casevitz, F.M. Th Saignes y A.C. Taylor: 


\section{9}

$\mathrm{Al}$ este de los andes: Relaciones entre las sociedades amazónicas y andinas entre los siglos XV y XVII, tomo II. Quito: Ediciones Abya-Yala e Instituto Francés de Estudios Andinos (IFEA).

Taylor, G. (1984a). Yauyos, un microcosmo dialectal quechua. Revista Andina, 3, 121-146. Cuzco.

Taylor, G. (1984b). Estudio de dialectología quechua (Chachapoyas, Ferreñafe, Yauyos). Lima: Universidad Nacional de Educación Enrique Guzmán.

Taylor, G. (2000). Estudios lingüisticos sobre Chachapoyas. Lima: Universidad Mayor de San Marcos; IFEA.

Taylor, G. (2007). Amarás a Dios sobre todas las cosas. Lima: IFEA; Lluvia Editores.

Torero, A. (1964/2003). Los dialectos quechuas. Fabla, II(2). Lima: INVEL; Universidad Nacional Mayor de San Marcos.

Torero, A. (1970). Lingüística e historia de la sociedad andina. Anales Científicos de la Universidad Nacional Agraria, VIII, 231-264. Lima: Universidad Nacional Agraria.

Torero, A. (1974/2007). El quechua y la historia social andina. Lima: Pedagógico San Marcos.

Torero, A. (1984/2011). Cuestiones de lingüística e historia andinas, compilación (tomo 1). Huacho, Perú: Filomeno Zubieta Núñez.

Torero, A. (2002). Idiomas de los Andes: lingüística e historia. Lima: IFEA.

Vacas, O. y Yánez, C. (2012). Diccionario de plantas. Quito: PUCE; DINEIB.

Vargas, J. (1965). Historia de la cultura ecuatoriana. Quito: CCE.

Vargas, J. (1978). Los sínodos de Quito del siglo XVI. Revista del Instituto de Historia Eclesiástica Ecuatoriana, (3-4). Quito: PUCE.

Velasco, padre J. (1789/1978). Historia del Reino de Quito en la América Meridional (3 tomos). Quito: CCE.

Velasco, padre J. (1964). Vocabulario de lengua indica. Quito: Instituto Ecuatoriano de Antropología y Geografía; Biblioteca Ecuatoriana Aurelio Espinosa Pólit; Llacta.

Verón, E. (2013). La semiosis social 2: ideas, momentos, interpretantes. Buenos Aires: Paidós.

Villalba, J. (1978). Los sínodos quitenses del obispo Luis López de Solís: 1594 y 1596. Revista del Instituto de Historia Eclesiástica Ecuatoriana, (3-4). Quito: PUCE.

VV. AA. (1975). Ñucunchimunda. Quito: Instituto Interandino de Desarrollo. Weber, D. (2005). Writing Quechua: The Case for a Hispanic Orthography. Los Ángeles: Universidad de California. 
Yánez, C. (1974). Fonología y escritura del quichua ecuatoriano. Suplemento Científico del ILV, 5. Quito: PUCE.

Yánez, C. (1980). Modelo Maca. Revista de la Pontificia Universidad Católica del Ecuador, 28. Quito: PUCE.

Yánez, C. (1991). Macac: teoría y práctica de la educación indígena. Cali: CELATER.

Yánez, C. (1995). La educación indígena en el Ecuador. Quito: ICAM; UPS.

Yánez, C. (2007). Lengua y cultura quichua. Quito: Abya-Yala.

Yánez, C. y Jara, F. (1975). Nukanchik Llaktapak Shimi. Quito: PUCE.

Zavala, V., Mujica, L., Córdova, G. y Ardito, W. (2014). Quichwasimirayku: batallas por el quechwa. Lima: PUCP.

Zecchetto, V. (ed.). (2000). Seis semiólogos en busca del lector (tomo 1). Quito: Abya-Yala.

\section{Referencias electrónicas}

Candau, M. (1985). Historia de la lengua española. Scripta Humanistica, 13. Recuperado de https://bit.ly/2KO9A7D/

De Estrada, D. (s/f). Castellanización, politica y escuelas de indios en el Arzobispado de México a mediados del siglo XVIII. Recuperado de https://bit. ly/2KNDklh/

Durán, J. (2012). Los concilios hispanoamericanos y las comunidades indígenas (siglo XVI): el método de socialización: aplicaciones y denuncias de agravios. Anuario Argentino de Derecho Canónico, 18. Recuperado de https://bit.ly/2KMMYoe/

Haugen, E. (1959). Planning for a Standard Language in Modern Norway. Anthropological Linguistics, 1(3), pp. 8-21. Wiscosin University Press. Recuperado de https://bit.ly/2ziD3A4/

Maldonado, L. (2012). ¿Cómo estamos los pueblos indígenas según el censo 2010? Recuperado de https://bit.ly/2L6lBEs/

Pijal, L. (s/f). ¿Cómo estamos las nacionalidades y pueblos indígenas según el censo de población y vivienda 2010? Recuperado de https://bit.ly/31XadS6/

Ross, E. (¿1958-1959?/2009). Introduction to Central Highland Quichua of Ecuador or Quichua in Ten Easy Lessons (the other 40 are harder). Recuperado de https://bit.ly/2L1g1TN/ 


\section{Sobre el autor}

Luis Octavio Montaluisa Chasiquiza es profesor de semiótica y lingüística en la UPS sede Quito. Ha sido profesor en la PUCE y en la Universidad de Cuenca. Fue el primer director de Educación, Ciencia y Cultura de la CONAIE (1986-1988), director-fundador de la DINEIB (1988-1991 y 1998-2002), creador de la Taptana Montaluisa para la explicación-comprensión de los sistemas de numeración posicionales (1982). Es PhD. en Lingüística Andina con mención en Estudios Andinos por la Pontificia Universidad Católica del Perú (2018), máster en Tecnologías para el Aprovechamientos de los Recursos Naturales no Tradicionales por la UPS, máster en Seguridad y Desarrollo por el IAEN, doctor en Ciencias de la Educación y licenciado en Lingüística Aplicada a la Enseñanza del Quichua por la PUCE. Es conferencista nacional e internacional y autor de textos sobre lingüística y pedagogía, así como miembro de número de la Sección Educación de la CCE. La presente investigación fue su tesis doctoral para la Pontificia Universidad Católica del Perú y estuvo dirigida por el PhD. Rodolfo Cerrón-Palomino. 



\section{Carrera de Educación Intercultural Bilingüe}

— ste libro arranca con un estudio de términos, principalmente topónimos, de las lenguas pasto, cara, panzaleo, puruhá, cañar, y palta que son sustratos de la lengua quichua. Propone la discusión acerca de las teorías sobre el origen de la familia quechua/quichua. Muestra el mosaico de las variaciones dialectales actuales, a nivel fonético-fonológico y morfológico, en tanto que en los niveles sintáctico y semántico las diferentes hablas son más regulares.

El autor clasifica seis zonas dialectales apoyándose en la teoría de "innovaciones compartidas". Esto permite que los educadores interculturales bilingües e interesados en la lengua y cultura puedan convertirse en polidialectales por una parte, y por otra, que puedan manejar la escritura unificada. Revisa, además, investigaciones relacionadas con aspectos dialectológicos de la lengua y discute la evolución de la escritura del quichua ecuatoriano y de las políticas lingüísticas: la escritura de una lengua puede servir para unir a sus hablantes o para contribuir a su dispersión. A partir del estudio de las variaciones dialectales y usando la "etimología", propone reglas ortográficas para respaldar la estandarización de la escritura. Si bien la academia se había preocupado de elaborar un alfabeto unificado, no había reparado en las reglas ortográficas para su aplicación. En la presente publicación, el autor ha convenido escribir quichua cuando el texto está redactado en castellano, y kichwa cuando el texto está en esta lengua.
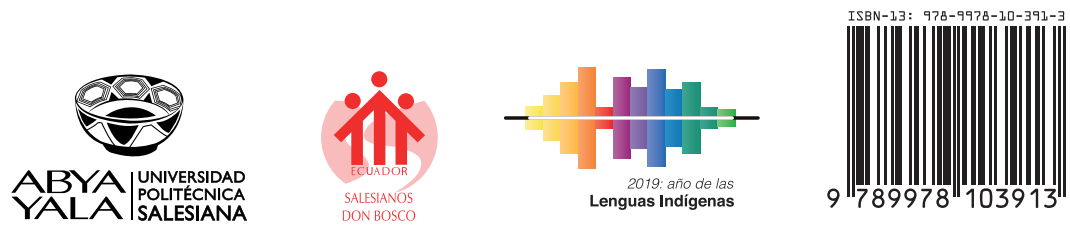